\title{
A Study of Smoke Movement in Multi-storey Buildings Using \\ Experiments and Computer Modelling
}

\author{
By \\ Yan Wang \\ B. Sc, Bishop's University, Canada \\ B. Eng, Tianjin University, P.R. China
}

\begin{abstract}
A thesis submitted to
The Faculty of Graduate Studies and Research Office in partial fulfilment of the requirements for the degree of

Master of Applied Science
\end{abstract}
Department of Civil and Environmental Engineering
Carleton University
Ottawa, Ontario, Canada

January 2008

Copyright $\subset$
2008 - Yan Wang 


$\begin{array}{ll}\begin{array}{l}\text { Library and } \\ \text { Archives Canada }\end{array} & \begin{array}{l}\text { Bibliothèque et } \\ \text { Archives Canada }\end{array} \\ \begin{array}{l}\text { Published Heritage } \\ \text { Branch }\end{array} & \begin{array}{l}\text { Direction du } \\ \text { Patrimoine de l'édition }\end{array} \\ \begin{array}{l}\text { 395 Wellington Street } \\ \text { Ottawa ON K1A 0N4 } \\ \text { Canada }\end{array} & \begin{array}{l}\text { 395, rue Wellington } \\ \text { Ottawa ON K1A 0N4 } \\ \text { Canada }\end{array}\end{array}$

Your file Votre référence ISBN: 978-0-494-40645-8 Our file Notre référence ISBN: 978-0-494-40645-8

NOTICE:

The author has granted a nonexclusive license allowing Library and Archives Canada to reproduce, publish, archive, preserve, conserve, communicate to the public by telecommunication or on the Internet, loan, distribute and sell theses worldwide, for commercial or noncommercial purposes, in microform, paper, electronic and/or any other formats.

The author retains copyright ownership and moral rights in this thesis. Neither the thesis nor substantial extracts from it may be printed or otherwise reproduced without the author's permission.
AVIS:

L'auteur a accordé une licence non exclusive permettant à la Bibliothèque et Archives Canada de reproduire, publier, archiver, sauvegarder, conserver, transmettre au public par télécommunication ou par l'Internet, prêter, distribuer et vendre des thèses partout dans le monde, à des fins commerciales ou autres, sur support microforme, papier, électronique et/ou autres formats.

L'auteur conserve la propriété du droit d'auteur et des droits moraux qui protège cette thèse. $\mathrm{Ni}$ la thèse ni des extraits substantiels de celle-ci ne doivent être imprimés ou autrement reproduits sans son autorisation.
In compliance with the Canadian Privacy Act some supporting forms may have been removed from this thesis.

While these forms may be included in the document page count, their removal does not represent any loss of content from the thesis.
Conformément à la loi canadienne sur la protection de la vie privée, quelques formulaires secondaires ont été enlevés de cette thèse.

Bien que ces formulaires aient inclus dans la pagination, il n'y aura aucun contenu manquant.

\section{Canada}




\begin{abstract}
In multi-storey building fires, smoke is the main threat to occupants, therefore it is necessary for performance-based fire safety design to be based on accurate predictions of smoke movement in multi-storey buildings using computer models. However, these computer models need to be validated against experimental data.
\end{abstract}

Ten full-scale experiments including four fuel-package fires and six propane fires were conducted in the National Research Council Canada (NRCC)'s 10-storey tower to generate realistic smoke movement data for model validation.

In this study, an approach is developed using propane as a fuel to reproduce the temperature distribution of various fuel-package tests in order to estimate the heat release rate of fuel-package fires when the oxygen consumption method cannot be used.

A two-zone model CUsmoke is used to simulate fires with steady or linear growth heat release rates in a single-compartment and in a two-compartment building, as well as fires with non-linear heat release rates in a multi-compartment multi-storey building. The comparisons between the CUsmoke predictions and the experimental data demonstrate that the model is capable of predicting smoke movement in single and multi-compartment multi-storey buildings. 


\section{Acknowledgements}

I would like to thank my supervisors, Dr. George Hadjisophocleous and Dr. Ehab Zalok for all their time, guidance, advice and effort spent on my thesis.

I would like to thank Dr. Jim R. Mehaffey, for his inspiration, advice and assistance.

I would like to thank the technical staff of NRCC's fire lab and Carleton University's fire program, Donald Carpenter, Eric Gibbs, Bruce Taber, and Ba Lamthien for their technical support on my experiments. Also, I would like to thank Lei Peng and Ravinder Virk for their help.

I would like to thank my husband $\mathrm{Ge} \mathrm{Wu}$ and my son Yuhe Wu for their limitless love and understanding to me. Especially my son, he accompanies me during my studying years and understands my time is limited with him. He shows strong interest in learning fire protection knowledge, and obtained praise in a competition of evacuation plan design of elementary schools in Quebec in 2006.

I would like to thank my parents for their encouragement to improve myself.

Last but not least, I would like to thank all those people who show their friendly cares during my thesis work. 


\section{Table of Contents}

1. Introduction ...................................................................................................................1

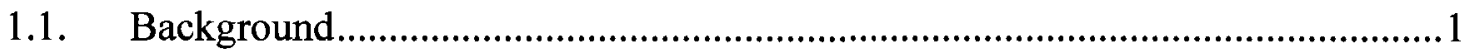

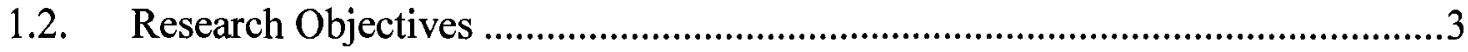

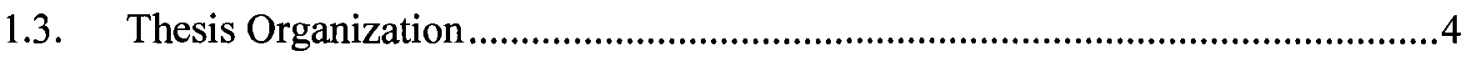

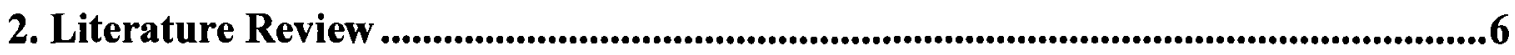

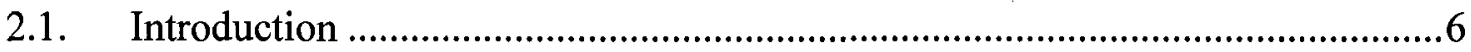

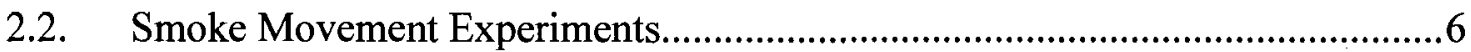

2.3. Computer Models for Smoke Movement .......................................................10

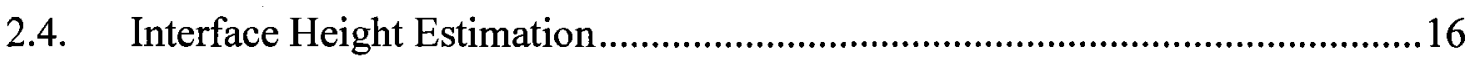

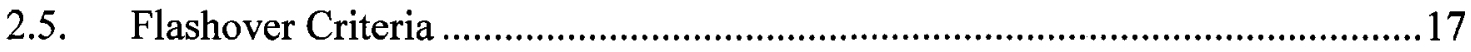

2.6. Heat Release Rate Measurement of Room Fires ...........................................17

3. Description of Experiments and Experimental Facility .........................................22

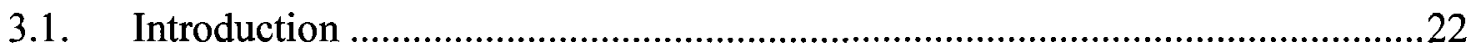

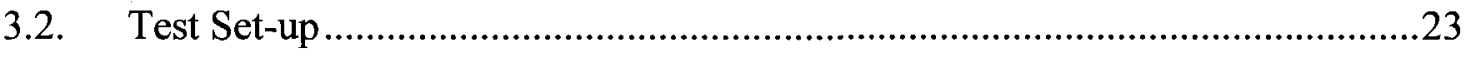

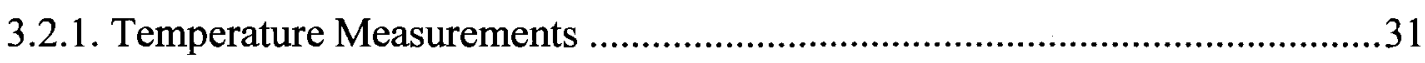

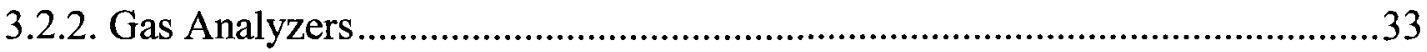

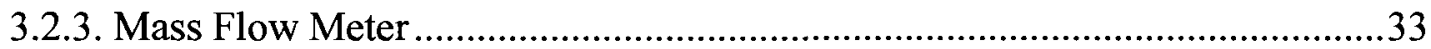

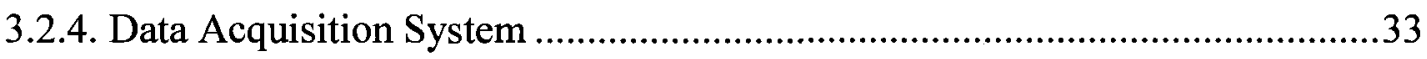

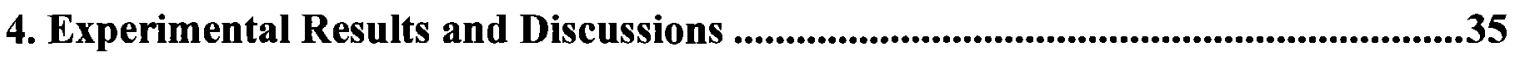

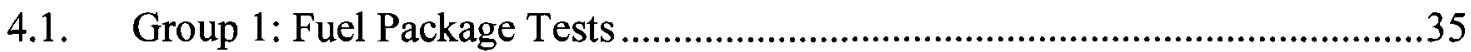

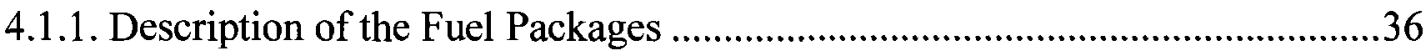

4.1.2. Low fire load clothing fuel package test (Test CLC-I) .............................38

4.1.3. High fire load clothing fuel package test (Test CLC-II) ................................46

4.1.4. Computer showroom fuel package test (Test CMP) ..................................56

4.1.5. Bookstore fuel package test (Test BK) ..................................................66

4.1.6. Summary of Group 1: Fuel Package Tests ...................................................75 
4.2. Group 2: Propane Tests for HRR Estimation of Fuel Package Tests ..................80

4.2.1. Propane test for HRR estimation of Test CLC-I (Test CLC-I-R) ....................84

4.2.2. Propane test for HRR estimation of Test CLC-II (Test CLC-II-R).................92

4.2.3. Propane test for HRR estimation of Test CMP (Test CMP-R) ......................100

4.2.4. Propane test for HRR estimation of Test BK (Test BK-R) .............................108

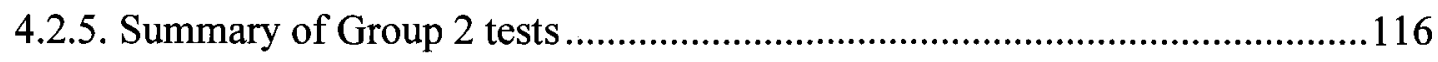

4.3. Group 3: Propane Group Tests .................................................................118

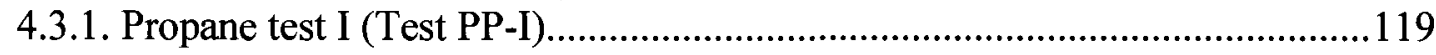

4.3.2. Propane test II (Test PP-II) ......................................................................128

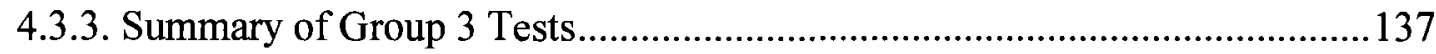

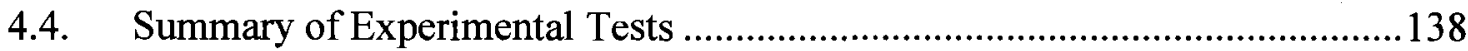

5. Modelling...................................................................................................................................141

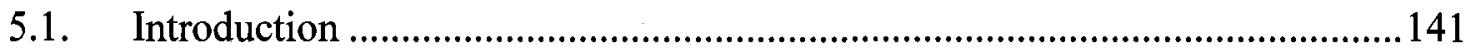

5.2. Modelling the 10-Storey Smoke Tower ........................................................142

5.2.1. Structure of 10-Storey Smoke Tower System: Floor plan, and vertical-vent

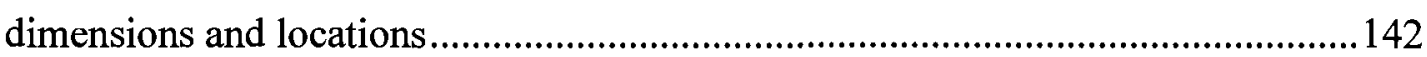

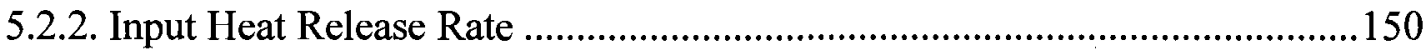

5.2.3. Fuel Properties and Fire Source Location ....................................................... 150

5.2.4. Thermal Properties of the Compartment Boundaries ......................................150

5.3. Comparison of Model Predictions and Experimental Data ..............................151

5.3.1. Single Compartment Tests...............................................................................151

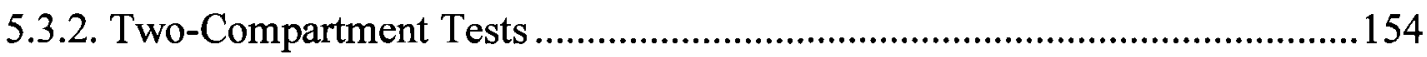

5.3.3. Multi-storey Building Tests....................................................................... 158

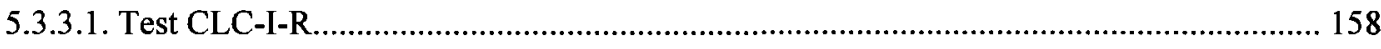

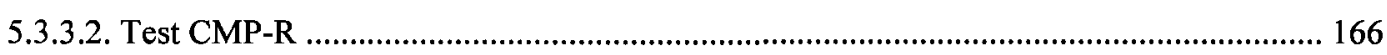

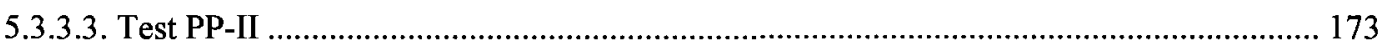

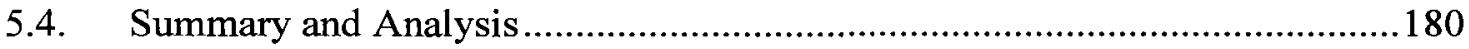

6. Conclusions and Recommendations.......................................................................181

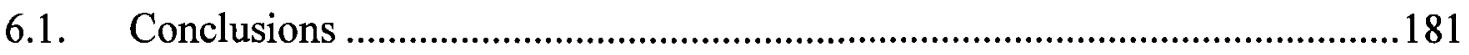

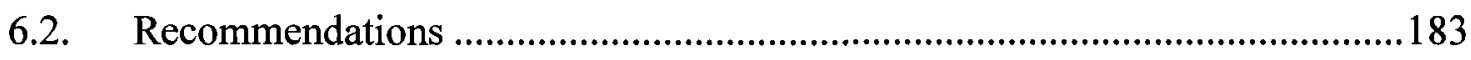


Appendix A: Calculation method of conductivity and specific heat for ceramic fiber .189

Appendix B: Input and output files of CUsmoke (two-compartment single-storey

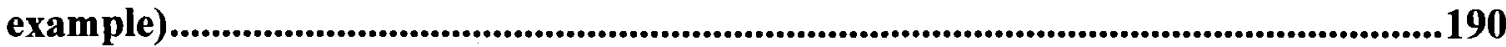




\section{List of Tables}

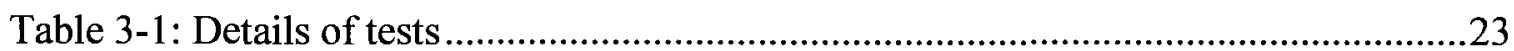

Table 3-2: The open/closed conditions of the doors at first floor ..............................26

Table 4-1: Fuel components and fire loads of Group 1: Fuel package tests ....................37

Table 4-2: The maximum gas temperatures in the stair shaft of different floors for Test CLC-I

Table 4-3: The maximum gas temperatures in the vestibules of the floors with open doors for Test CLC-I .

Table 4-4: The maximum gas temperatures in the main compartments of the floors of the $4^{\text {th }}, 8^{\text {th }}$ and $10^{\text {th }}$ for Test CLC-I

Table 4-5: The maximum gas temperatures in the stair shaft of different floors for Test CLC-II.

Table 4-6: The maximum gas temperatures in the vestibules of the floors with open doors for Test CLC-II

Table 4-7: The maximum gas temperatures in the main compartments of the floors of the $4^{\text {th }}, 8^{\text {th }}$ and $10^{\text {th }}$ for Test CLC-II

Table 4-8: The maximum gas temperatures in the stair shaft of different floors for Test CMP

Table 4-9: The maximum gas temperatures in the vestibules of the floors with open doors for Test CMP

Table 4-10: The maximum gas temperatures in the main compartments of the floors of the $4^{\text {th }}, 8^{\text {th }}$ and $10^{\text {th }}$ for Test CMP.

Table 4-11: The maximum gas temperatures in the stair shaft of different floors for

Test BK

Table 4-12: The maximum gas temperatures in the vestibules of the floors with open doors for Test BK

Table 4-13: The maximum gas temperatures in the main compartments of the floors of the $4^{\text {th }}, 8^{\text {th }}$ and $10^{\text {th }}$ for Test BK 75

Table 4-14: The concentration of $\mathrm{O}_{2}, \mathrm{CO}_{2}$ and $\mathrm{CO}$ in the stair shaft at the fire floor for Group 1 tests 
Table 4-15: A summary of the maximum temperatures and the lowest interface heights in the fire compartment for Group 1 tests 78

Table 4-16: Upper layer gas temperature difference between peak value and initial value at various locations for Group 1 tests .79

Table 4-17: The maximum gas temperatures in the stair shaft of different floors for Test CLC-I-R

Table 4-18: The maximum gas temperatures in the vestibules of the floors with open doors for Test CLC-I-R .90

Table 4-19: The maximum gas temperatures in the main compartments of the floors of the $4^{\text {th }}, 8^{\text {th }}$ and $10^{\text {th }}$ for Test CLC-I-R

Table 4-20: The maximum gas temperatures in the stair shaft of different floors for Test CLC-II-R

Table 4-21: The maximum gas temperatures in the vestibules of the floors with open doors for Test CLC-II-R 98

Table 4-22: The maximum gas temperatures in the main compartments of the floors of the $4^{\text {th }}, 8^{\text {th }}$ and $10^{\text {th }}$ for Test CLC-II-R

Table 4-23: The maximum gas temperatures in the stair shaft of different floors for Test CMP-R

Table 4-24: The maximum gas temperatures in the vestibules of the floors with open doors for Test CMP-R

Table 4-25: The maximum gas temperatures in the main compartments of the floors of the $4^{\text {th }}, 8^{\text {th }}$ and $10^{\text {th }}$ for Test CMP-R

Table 4-26: The maximum gas temperatures in the stair shaft of different floors for Test BK-R

Table 4-27: The maximum gas temperatures in the vestibules of the floors with open doors for Test BK-R

Table 4-28: The maximum gas temperatures in the main compartments of the floors of the $4^{\text {th }}, 8^{\text {th }}$ and $10^{\text {th }}$ for Test BK-R 116

Table 4-29: A summary of the maximum temperatures and the lowest interface heights in the fire compartment for Group 2 tests. 
Table 4-30: The concentration of $\mathrm{O}_{2}$ and $\mathrm{CO}_{2}$ in stair shaft at the fire floor for Group 2 tests

Table 4-31: Upper layer gas temperature difference between peak value and initial value at various locations for Group 2 tests, and Group 1 tests

Table 4-32: The maximum gas temperatures in the stair shaft of different floors for Test PP-I

Table 4-33: The maximum gas temperatures in the vestibules of the floors with open doors for Test PP-I.

Table 4-34: The maximum gas temperatures in the main compartments of the floors of the $4^{\text {th }}, 8^{\text {th }}$ and $10^{\text {th }}$ for Test PP-I.....

Table 4-35: The maximum gas temperatures in the stair shaft of different floors for Test PP-II

Table 4-36: The maximum gas temperatures in the vestibules of the floors with open doors for Test PP-II .

Table 4-37: The maximum gas temperatures in the main compartments of the floors of the $4^{\text {th }}, 8^{\text {th }}$ and $10^{\text {th }}$ for Test PP-II

Table 4-38: A summary of the maximum temperatures and the lowest interface heights in the fire compartment for Group 3 tests.

Table 4-39: The concentration of $\mathrm{O}_{2}$ and $\mathrm{CO}_{2}$ in the stair shaft at the fire floor for Group 3 tests 138

Table 4-40: Upper layer gas temperature difference between peak value and initial value at various locations for the tests of Group 3 138

Table 5-1: Dimensions, locations and status of the vertical-vents of the 10-storey tower

Table 5-2: Material properties of 10-storey tower boundaries

Table 5-3: Material properties of single compartment boundaries [31]

Table 5-4: Comparison of upper layer temperature and interface height between model predictions and experimental results

Table 5-5: Material properties of two-compartment boundaries [34]

Table 5-6: Comparison of predicted and experimental peak temperatures in the stair shaft and corresponding times during Test CLC-I-R 
Table 5-7: Comparison of predicted and experimental upper layer peak temperatures in the vestibules of even floors and corresponding times during Test CLC-I-R ......... 165

Table 5-8: Comparison of predicted and experimental upper layer peak temperatures in the main compartments and corresponding times of the $4^{\text {th }}, 8^{\text {th }}$ and $10^{\text {th }}$ floors during Test CLC-I-R

Table 5-9: Comparison of predicted and experimental peak temperatures in the stair shaft and corresponding times during Test CMP-R

Table 5-10: Comparison of predicted and experimental upper layer peak temperatures in the vestibules of even floors and corresponding times during Test CMP-R.

Table 5-11: Comparison of predicted and experimental upper layer peak temperatures in the main compartments and corresponding times of the $4^{\text {th }}, 8^{\text {th }}$ and $10^{\text {th }}$ floors during Test CMP-R

Table 5-12: Comparison of predicted and experimental peak temperatures in the stair shaft and corresponding times during Test PP-II 178

Table 5-13: Comparison of predicted and experimental upper layer peak temperatures in the vestibules of even floors and corresponding times during Test PP-II 179

Table 5-14: Comparison of predicted and experimental upper layer peak temperatures in the main compartments and corresponding times of the $4^{\text {th }}, 8^{\text {th }}$ and $10^{\text {th }}$ floors during Test PP-II 


\section{List of Figures}

Figure 3-1: Typical floor plan of the 10-storey smoke tower......................................24

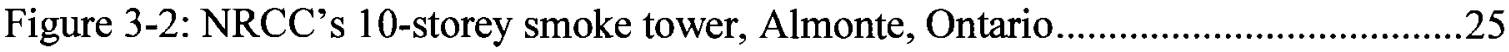

Figure 3-3: Locations of fuel packages and propane burner in fire compartment ...........25

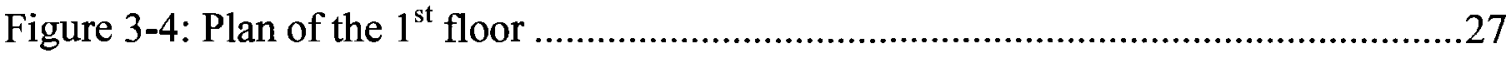

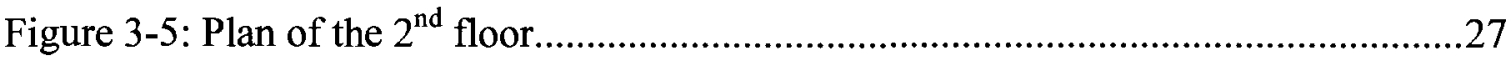

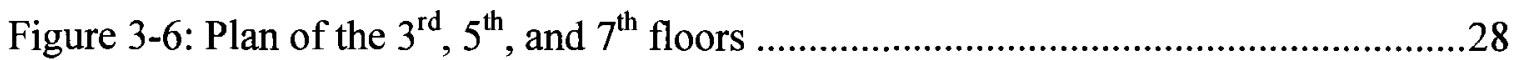

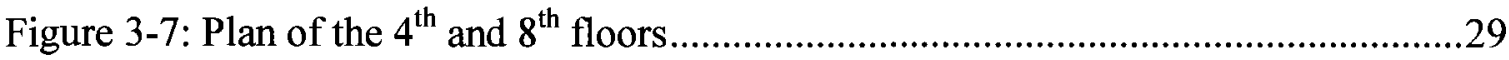

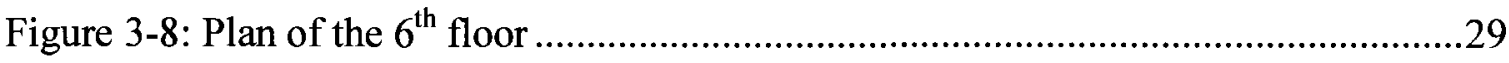

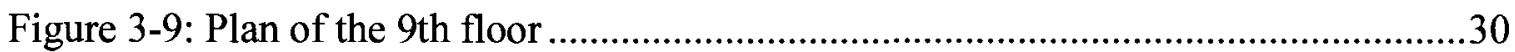

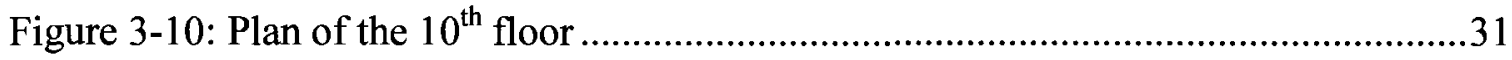

Figure 3-11: Expected smoke movement flow in the 10-storey tower........................31

Figure 3-12: Thermocouples and gas analyzer's probe layout......................................32

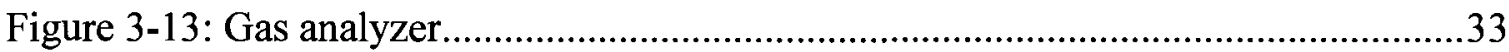

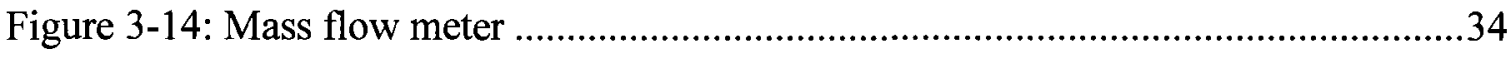

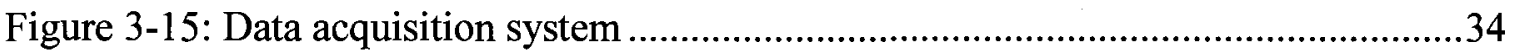

Figure 4-1: Photographs depicting the clothing II fuel package (CLC-II) and ignition....36

Figure 4-2: Photographs depicting the computer fuel package (CMP) and ignition.........37

Figure 4-3: Photographs depicting the bookstore fuel package (BK) and ignition ...........37

Figure 4-4: Concentration of $\mathrm{O}_{2}$ and $\mathrm{CO}_{2}$ in the stair shaft at the fire floor (Test CLC-I) 38

Figure 4-5: Concentration of CO in the stair shaft at the fire floor (Test CLC-I) .............39

Figure 4-6: Gas temperature histories at different heights in the corner of the fire

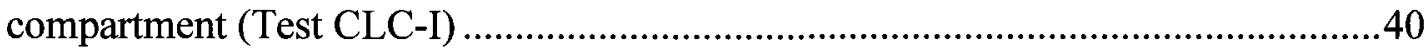

Figure 4-7: Gas temperature profiles in the fire compartment at different times

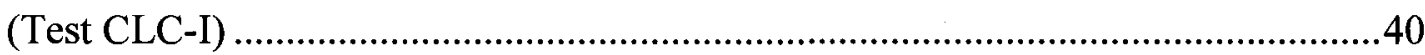

Figure 4-8: Gas temperature histories at different heights at the doorway (Test CLC-I) .41

Figure 4-9: Gas temperature profiles at the doorway at different times (Test CLC-I).....42

Figure 4-10: Gas temperature histories in the stair shaft (Test CLC-I) .........................43

Figure 4-11: Gas temperature histories in the vestibules of the floors with open doors

(Test CLC-I) 
Figure 4-12: Gas temperature histories in the vestibules of the floors with closed doors (Test CLC-I)

Figure 4-13: Gas temperature histories in the main compartments of the floors of the $4^{\text {th }}$, $8^{\text {th }}$ and $10^{\text {th }}$ (Test CLC-I) 46

Figure 4-14: Concentration of $\mathrm{O}_{2}$ and $\mathrm{CO}_{2}$ in stair shaft at the fire floor (Test CLC-II) ..47

Figure 4-15: Concentration of $\mathrm{CO}$ in the stair shaft at the fire floor (Test CLC-II)

Figure 4-16: Gas temperature histories at different heights in the corner of the fire compartment (Test CLC-II)

Figure 4-17: Gas temperature profiles in the fire compartment at different times

(Test CLC-II)

Figure 4-18: Gas temperature histories at different heights at the doorway (Test CLC-II)

Figure 4-19: Gas temperature profiles at the doorway at different times (Test CLC-II) ..51

Figure 4-20: Gas temperature histories in the stair shaft (Test CLC-II) 52

Figure 4-21: Gas temperature histories in the vestibules of the floors with open doors

(Test CLC-II)

Figure 4-22: Gas temperature histories in the vestibules of the floors with closed doors

(Test CLC-II)

Figure 4-23: Gas temperature histories in the main compartments of the floors of the $4^{\text {th }}, 8^{\text {th }}$ and $10^{\text {th }}$ (Test CLC-II)

Figure 4-24: Concentration of $\mathrm{O}_{2}$ and $\mathrm{CO}_{2}$ in the stair shaft at the fire floor (Test CMP) 57

Figure 4-25: Concentration of $\mathrm{CO}$ in the stair shaft at the fire floor (Test CMP).... 57

Figure 4-26: Gas temperature histories at different heights in the corner of the fire compartment (Test CMP)

Figure 4-27: Gas temperature profiles in the fire compartment at different times

(Test CMP)

Figure 4-28: Gas temperature histories at different heights at the doorway (Test CMP) .61

Figure 4-29: Gas temperature profiles at the doorway at different times (Test CMP).....61

Figure 4-30: Gas temperature histories in the stair shaft (Test CMP)

Figure 4-31: Gas temperature histories in the vestibules of the floors with open doors

(Test CMP) 
Figure 4-32: Gas temperature histories in the vestibules of the floors with closed doors

(Test CMP)

Figure 4-33: Gas temperature histories in the main compartments of the floors of the $4^{\text {th }}, 8^{\text {th }}$ and $10^{\text {th }}$ (Test CMP) .65

Figure 4-34: Concentration of $\mathrm{O}_{2}$ and $\mathrm{CO}_{2}$ in the stair shaft at the fire floor (Test BK)...66

Figure 4-35: Concentration of $\mathrm{CO}$ in stair shaft at the fire floor (Test BK).

Figure 4-36: Gas temperature histories at different heights in the corner of the fire compartment (Test BK)

Figure 4-37: Gas temperature profiles in the fire compartment at different times

(Test BK)

Figure 4-38: Gas temperature histories at different heights at the doorway (Test BK) ....70

Figure 4-39: Gas temperature profiles at the doorway at different times (Test BK).........70

Figure 4-40: Gas temperature histories in the stair shaft (Test BK) ...............................72

Figure 4-41: Gas temperature histories in the vestibules of the floors with open doors

(Test BK)

Figure 4-42: Gas temperature histories in the vestibules of the floors with closed doors

(Test BK)

Figure 4-43: Gas temperature histories in the main compartments of the floors of the $4^{\text {th }}, 8^{\text {th }}$ and $10^{\text {th }}$ (Test BK).

Figure 4-44: Gas temperature histories in the fire compartment, at the doorway on the fire

floor and in the stair shaft at the fire floor for Test CLC-I and Test CLC-II .76

Figure 4-45: Gas temperature histories at different heights in the corner of the

fire compartment (Test CLC-I-R).

Figure 4-46: Heat release rate (Test CLC-I-R).

Figure 4-47: Concentration of $\mathrm{O}_{2}$ and $\mathrm{CO}_{2}$ in the stair shaft at the fire floor

(Test CLC-I-R)

Figure 4-48: Gas temperature histories at different heights at the doorway (Test CLC-I-R)

Figure 4-49: Gas temperature histories in the stair shaft (Test CLC-I-R)

Figure 4-50: Gas temperature histories in the vestibules of the floors with open doors

(Test CLC-I-R) 
Figure 4-51: Gas temperature histories in the vestibules of the floors with closed doors

(Test CLC-I-R)

Figure 4-52: Gas temperature histories in the main compartments of the floors of the $4^{\text {th }}, 8^{\text {th }}$ and $10^{\text {th }}$ (Test CLC-I-R) .92

Figure 4-53: Gas temperature histories at different heights in the corner of fire compartment (Test CLC-II-R)

Figure 4-54: Heat release rate (Test CLC-II-R)

Figure 4-55: Concentration of $\mathrm{O}_{2}$ and $\mathrm{CO}_{2}$ in the stair shaft at the fire floor

(Test CLC-II-R)

Figure 4-56: Gas temperature histories at different heights at the doorway

(Test CLC-II-R)

Figure 4-57: Gas temperature histories in the stair shaft (Test CLC-II-R)

Figure 4-58: Gas temperature histories in the vestibules of the floors with open doors

(Test CLC-II-R) .98

Figure 4-59: Gas temperature histories in the vestibules of the floors with closed doors

(Test CLC-II-R)

Figure 4-60: Gas temperature histories in the main compartments of the floors of the $4^{\text {th }}, 8^{\text {th }}$ and $10^{\text {th }}$ (Test CLC-II-R).

Figure 4-61: Gas temperature histories at different heights in the corner of the fire compartment (Test CMP-R)

Figure 4-62: Heat release rate (Test CMP-R).

Figure 4-63: Concentration of $\mathrm{O}_{2}$ and $\mathrm{CO}_{2}$ in the stair shaft at the fire floor (Test CMP-R)

Figure 4-64: Gas temperature histories at different heights at the doorway (Test CMP-R)

Figure 4-65: Gas temperature histories in the stair shaft (Test CMP-R)

Figure 4-66: Gas temperature histories in the vestibules of the floors with open doors

(Test CMP-R) 106

Figure 4-67: Gas temperature histories in the vestibules of the floors with closed doors

(Test CMP-R) 
Figure 4-68: Gas temperature histories in the main compartments of the floors of the $4^{\text {th }}, 8^{\text {th }}$ and $10^{\text {th }}$ (Test CMP-R)

Figure 4-69: Gas temperature histories at different heights in the corner of the fire compartment (Test BK-R)

Figure 4-70: Heat release rate (Test BK-R).

Figure 4-71: Concentration of $\mathrm{O}_{2}$ and $\mathrm{CO}_{2}$ in the stair shaft at the fire floor (Test BK-R)

Figure 4-72: Gas temperature histories at different heights at the doorway (Test BK-R)

Figure 4-73: Gas temperature histories in the stair shaft (Test BK-R).

Figure 4-74: Gas temperature histories in the vestibules of the floors with open doors

(Test BK-R)

Figure 4-75: Gas temperature histories in the vestibules of the floors with closed doors

(Test BK-R)

Figure 4-76: Gas temperature histories in the main compartments of the floors of the $4^{\text {th }}, 8^{\text {th }}$ and $10^{\text {th }}$ (Test BK-R).

Figure 4-77: Heat release rate (Test PP-I)

Figure 4-78: Concentration of $\mathrm{O}_{2}$ and $\mathrm{CO}_{2}$ in the stair shaft at the fire floor (Test PP-I)

Figure 4-79: Concentration of $\mathrm{CO}$ in the stair shaft at the fire floor (Test PP-I)

Figure 4-80: Gas temperature histories at different heights in the corner of the fire compartment (Test PP-I)

Figure 4-81: Gas temperature profiles in the fire compartment at different times (Test PP-I).

Figure 4-82: Gas temperature histories at different heights at the doorway (Test PP-I) 123

Figure 4-83: Gas temperature profiles at the doorway at different times (Test PP-I) .....124

Figure 4-84: Gas temperature histories in the stair shaft (Test PP-I) .............................124

Figure 4-85: Gas temperature histories in the vestibules of the floors with open doors (Test PP-I).

Figure 4-86: Gas temperature histories in the vestibules of the floors with closed doors

(Test PP-I). 
Figure 4-87: Gas temperature histories in the main compartments of the floors of

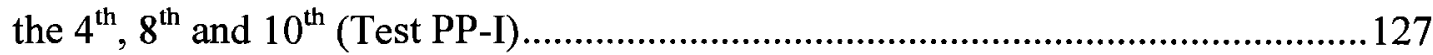

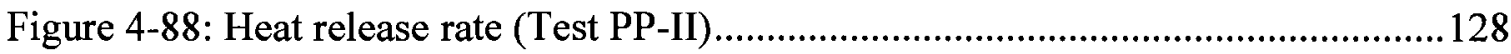

Figure 4-89: Concentration of $\mathrm{O}_{2}$ and $\mathrm{CO}_{2}$ in the stair shaft at the fire floor (Test PP-II)

Figure 4-90: Concentration of $\mathrm{CO}$ in the stair shaft at the fire floor (Test PP-II)

Figure 4-91: Gas temperature histories at different heights in the corner of the fire compartment (PP test-II)

Figure 4-92: Gas temperature profiles in the fire compartment at different times

(Test PP-II)

Figure 4-93: Gas temperature histories at different heights at the doorway (Test PP-II) 132

Figure 4-94: Gas temperature profiles at the doorway at different times (Test PP-II).... 133

Figure 4-95: Gas temperature histories in the stair shaft (Test PP-II)

Figure 4-96: Gas temperature histories in the vestibules of the floors with open doors

(Test PP-II)

Figure 4-97: Gas temperature histories in the vestibules of the floors with closed doors

(Test PP-II)

Figure 4-98: Gas temperature histories in the main compartments of the floors of the $4^{\text {th }}, 8^{\text {th }}$ and $10^{\text {th }}$ (Test PP-II) 136

Figure 5-1: Plan of the $1^{\text {st }}$ floor used in the model

Figure 5-2: Plan of the $2^{\text {nd }}$ floor used in the model 143

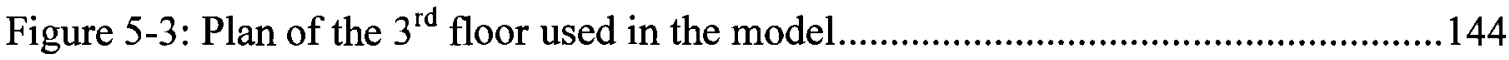

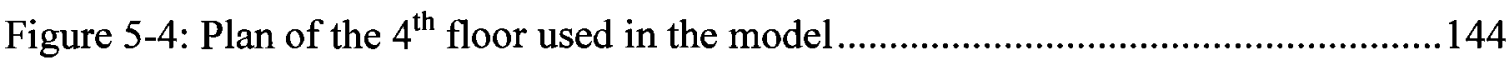

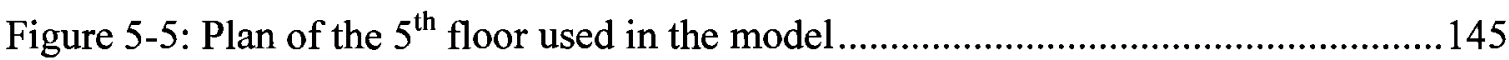

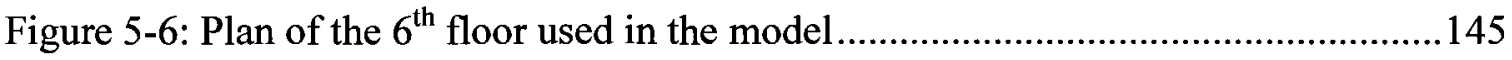

Figure 5-7: Plan of the $7^{\text {th }}$ floor used in the model ....................................................146

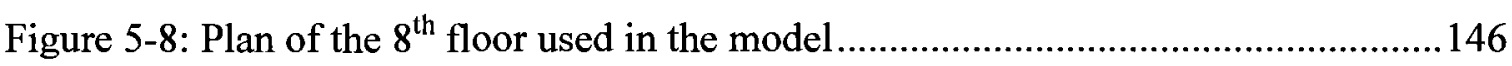

Figure 5-9: Plan of the $9^{\text {th }}$ floor used in the model ..................................................... 147

Figure 5-10: Plan of the $10^{\text {th }}$ floor used in the model ................................................ 147

Figure 5-11: Upper layer temperature in the fire compartment (single-compartment example) 
xviii

Figure 5-12: Comparison of predicted and experimental upper layer temperatures in the fire compartment and the corridor (linear HRR test) 155

Figure 5-13: Comparison of predicted and experimental interface heights in the fire compartment and the corridor (linear HRR test)..... .156

Figure 5-14: Comparison of predicted and experimental upper layer temperature in the fire compartment and the corridor (steady HRR test) 156

Figure 5-15: Comparison of predicted and experimental interface heights in the fire compartment and the corridor (steady HRR test) 157

Figure 5-16: Nominal input HRR and model output HRR (Test CLC-I-R). 158

Figure 5-17: Comparison of predicted and experimental upper layer concentration of $\mathrm{O}_{2}$ and $\mathrm{CO}_{2}$ in the stair shaft at the fire floor (Test CLC-I-R). 159

Figure 5-18: Comparison of predicted and experimental upper layer temperatures in the fire compartment and doorway (Test CLC-I-R) 161

Figure 5-19: predicted interface height in the fire compartment and the vestibule on the fire floor (Test CLC-I-R)

Figure 5-20: schematic upper and lower zones of the fire compartment and the vestibule on the fire floor 162

Figure 5-21: Comparison of predicted and experimental upper layer temperatures in the stair shaft at the $2^{\text {nd }}$ to $5^{\text {th }}$ floors (Test CLC-I-R). 163

Figure 5-22: Comparison of predicted and experimental temperatures in the stair shaft at the $6^{\text {th }}$ to $10^{\text {th }}$ floors (Test CLC-I-R). 163

Figure 5-23: Comparison of predicted and experimental upper layer temperatures in the vestibules of even floors (Test CLC-I-R). 164

Figure 5-24: Comparison of predicted and experimental upper layer temperatures in the main compartments of the floors of the $4^{\text {th }}, 8^{\text {th }}$ and $10^{\text {th }}$ (Test CLC-I-R). 165

Figure 5-25: Nominal input HRR and model output HRR (Test CMP-R). 166

Figure 5-26: Comparison of predicted and experimental upper layer concentration of $\mathrm{O}_{2}$ and $\mathrm{CO}_{2}$ in the stair shaft at the fire floor (Test CMP-R). 168

Figure 5-27: Comparison of predicted and experimental upper layer temperatures in the fire compartment and doorway (Test CMP-R). 
Figure 5-28: Comparison of predicted and experimental upper layer temperatures in the stair shaft at the $2^{\text {nd }}$ to $5^{\text {th }}$ floors (Test CMP-R).

Figure 5-29: Comparison of predicted and experimental temperatures in the stair shaft at the $6^{\text {th }}$ to $10^{\text {th }}$ floors (Test CMP-R).

Figure 5-30: Comparison of predicted and experimental upper layer temperatures in the vestibules of even floors (Test CMP-R)

Figure 5-31: Comparison of predicted and experimental upper layer temperatures in the main compartments of the floors of the $4^{\text {th }}, 8^{\text {th }}$ and $10^{\text {th }}$ (Test CMP-R)..................173

Figure 5-32: Nominal input HRR and model output HRR (Test PP-II) ..........................174

Figure 5-33: Comparison of predicted and experimental upper layer concentration of $\mathrm{O}_{2}$ and $\mathrm{CO}_{2}$ in the stair shaft at the fire floor (Test PP-II) 175

Figure 5-34: Comparison of predicted and experimental upper layer temperatures in the fire compartment and doorway (Test PP-II) 176

Figure 5-35: Comparison of predicted and experimental upper layer temperatures in the stair shaft at the $2^{\text {nd }}$ to $5^{\text {th }}$ floors (Test PP-II)

Figure 5-36: Comparison of predicted and experimental temperatures in the stair shaft at the $6^{\text {th }}$ to $10^{\text {th }}$ floors (Test PP-II). 177

Figure 5-37: Comparison of predicted and experimental upper layer temperature in the vestibules of even floors (Test PP-II)

Figure 5-38: Comparison of predicted and experimental upper layer temperature in the main compartments of the floors of the $4^{\text {th }}, 8^{\text {th }}$ and $10^{\text {th }}$ (Test PP-II). 


\section{Introduction}

\subsection{Background}

In multi-storey building fires, smoke is known to be a more significant threat to life than heat. This is because smoke contains toxic products of combustion and reduces visibility. For example, irritant smoke products, such as hydrogen chloride $(\mathrm{HCl})$, hydrogen bromide $(\mathrm{HBr})$ and sulphur dioxide $\left(\mathrm{SO}_{2}\right)$, as well as soot impair vision. Asphyxiant gases such as carbon monoxide (CO) and hydrogen cyanide $(\mathrm{HCN})$ cause intoxication and loss of consciousness in a fire, whereas gases like carbon dioxide $\left(\mathrm{CO}_{2}\right)$ cause hyperventilation. It is therefore important to predict the smoke conditions in a building during a fire.

Assessment of smoke movement is a basic and important part of a fire risk analysis. In a multi-storey building, stair shafts are the main egress routes for occupants, but also one of the means of smoke spread between floors. There are many fire incidents where occupants have died in the stair shafts or corridors above the fire floor. This is mainly due to smoke inhalation while attempting to evacuate [1]. It is therefore crucial to accurately predict smoke movement in a multi-storey building with corridors, stair shafts, and compartments, in order to undertake performance-based fire safety design or a fire risk analysis. 
Many countries have already supplemented their prescriptive fire and building codes with performance-based codes. The advantage of performance-based codes is that they provide more flexibility in design, as well as, promote innovation. Computer models are widely used in performance-based fire safety design and fire risk analysis. In order to predict fire growth and smoke movement in the compartment of fire origin and in other compartments in the building, corridors and stair shafts for various typical fire scenarios, a number of computational tools can be used. There are mainly three different types of computer models which are used to predict smoke movement in buildings: (1) network models; (2) zone models; and (3) computational fluid dynamic (CFD) models [2].

CUsmoke is a two-zone model developed at Carleton University to predict fire growth and smoke movement in multi-compartment buildings. CUsmoke can also consider the effect of sprinkler suppression and fire department actions on the heat release rate (HRR) of the fire. This model can simulate as many as 100 compartments with volumes ranging from $0.125 \mathrm{~m}^{3}$ to $1,000,000 \mathrm{~m}^{3}$ [3]. CUsmoke is a sub-model of the fire risk analysis model CUrisk [3]. CUrisk is a computer model for fire risk analysis of commercial buildings that can be used to evaluate safety levels in these buildings. CUrisk consists of a number of sub-models dealing with various aspects of fire, such as fire development and spread; CUsmoke for smoke movement calculations; occupant evacuation; economic impact of fires and life safety.

Despite all this, CUsmoke lacks validation, which is mainly due to lack of realistic data on smoke movement in multi-storey buildings. Therefore, this research is an attempt to enhance the predictive capabilities of smoke movement in multi-storey buildings through acquisition of experimental data. The 10-storey smoke tower facility of the National 
Research Council Canada (NRCC) located in Almonte, Ontario, Canada was used to conduct different tests for investigation of smoke movement from various fires, and to develop realistic experimental data for model validation. The details including the structure, test set-up and instrumentation used are explained in Chapter 3.

The facility is designed to simulate the centre core of a high-rise building with different size compartments, corridors and stair shaft. The compartment of fire origin $(3.78 \mathrm{~m} \mathrm{x}$ $8.9 \mathrm{~m} \times 3.3 \mathrm{~m}$ height) was located on the second floor. Ten large-scale fire tests categorized in three groups were designed and conducted in the facility. The concentration of $\mathrm{O}_{2}, \mathrm{CO}$ and $\mathrm{CO}_{2}$ in the stair shaft at the fire floor, and the temperature distribution of the upper hot layer and the lower cold layer in the fire compartment were recorded. The temperatures of the stair shaft at each floor and the temperatures of some typical locations on each floor were recorded as well. The experimental data are then compared to the results predicted by CUsmoke.

\subsection{Research Objectives}

The research has four objectives. The primary objective of this research is to compare the smoke movement characteristics of four fuel package fires: two representing fuels in clothing stores (CLC-I and CLC-II), one fuels in computer showrooms (CMP-I) and one fuels in bookstores (BK). To accomplish this, tests using the above-mentioned fuel packages will be conducted. The data on temperature distribution and concentration of oxygen $\left(\mathrm{O}_{2}\right)$, carbon monoxide $(\mathrm{CO})$ and carbon dioxide $\left(\mathrm{CO}_{2}\right)$ will be used for comparison. 
The second objective is to compare the smoke movement characteristics between these four fuel packages and the propane fires. To accomplish this, the data from both fuel package tests and propane fire tests will be used, as explained later in the thesis.

The third objective is to estimate the heat release rate (HRR) in the fire compartment of these fuel packages using a propane burner. The 10-storey smoke tower in Almonte is not equipped with the capability to measure the heat release rate of fires directly using the oxygen consumption method [4], which is stated in section 2.6. Therefore, to estimate the HRR in the fire compartment during the fuel-package fires, an approach developed in this study will be used, whereby propane is used as a fuel to reproduce the temperature distribution of the different fuel package tests.

The final objective is to validate the CUsmoke model by comparing its predictions with the experimental results. This objective will be accomplished by simulating the fires in the 10-storey tower facility at Almonte. The model predictions will then be compared to the experimental data to see how well the model works for the multi-storey buildings.

\subsection{Thesis Organization}

The thesis is organized into six chapters. Chapter 1 provides a brief introduction to the context of the problem and why this research is needed; followed by the main research objectives and organization of the thesis. Chapter 2 comprises literature reviews on smoke movement; computer models for fire growth and smoke movement; interface height estimation; flashover criteria, and heat release rate measurements of fuel package fires. This chapter also provides the justification for the research based on the cited literature and what it will contribute. In Chapter 3 the description of the experiments and 
experimental facility explaining the structure of the 10-storey test tower, test set-up and instrumentation used for the tests is discussed. This is followed by the experimental results and discussion in Chapter 4. Discussion of CUsmoke model parameters and comparison of modelling and experimental results for all the tests are given in Chapter 5. The final chapter, Chapter 6 , gives the conclusions and recommendations for further work. 


\section{Literature Review}

\subsection{Introduction}

This chapter presents a literature review on smoke movement. It reviews multicompartment enclosure fires, existing computer models for fire growth and smoke movement, and examples of validation of some zone models. It also addresses the interface height estimation, the criteria for flashover, and the methods used to estimate the heat release rate of fuel package fires.

\subsection{Smoke Movement Experiments}

Due to the threat of smoke to life in fires, an in-depth understanding of smoke movement is important for fire risk analysis and fire safety design. As a fire burns, it generates heat and smoke. The hot products rise as a plume and large quantities of cold air are entrained from the atmosphere into the plume.

There are many definitions of smoke [5] - [8]. In general, smoke is a mixture of hot vapours and gases produced by combustion or pyrolysis along with particulate matter of unburned or partially burned fuel and the quantity of entrained air.

In the room of fire origin and adjacent rooms or corridors, the temperature of the smoke is high enough so that the smoke movement is driven by buoyant forces produced by the fire. However, for multi-room and multi-storey buildings, when smoke reaches rooms or corridors which are far away from the area of the fire origin or enters a stair shaft, there 
will be a significant temperature drop due to air mixing and probably heat loss through the walls [9]. Forces, such as the stairwell stack effect, wind effect, mechanical heating and ventilation or air-conditioning systems, primarily control smoke movement.

Numerous experimental studies have been conducted to understand the principles of smoke movement in compartments, atriums, tunnels, and shaft [10] - [18]. For example, Cooper et al. [19] reported a set of multi-compartment fire experiments. The test space involved two compartments: a burn room with floor area of $14 \mathrm{~m}^{2}$ and a corridor of various areas. The heat release rates (HRR) used were steady values of $25 \mathrm{~kW}, 100 \mathrm{~kW}$, or $225 \mathrm{~kW}$; as well as a linearly growing fire with $\mathrm{Q}=\mathrm{Ct}, \mathrm{C}=30 \mathrm{~kW} / \mathrm{min}$, where $\mathrm{Q}$ is the heat release rate in $\mathrm{kW}$, and $\mathrm{t}$ is the time in minutes. In this study, the temperatures and pressure difference between the two compartments near the ceiling were measured. The development of the stratified hot layers was monitored by a vertical thermocouple tree and photometer. A layer interface was identified and the interface height was determined.

Luo et al. [10] reported on experiments performed in a single-storey multi-compartment building at the Victoria University of Technology, Australia. A propane burner was placed in the fire room to simulate a fire under both steady-state and transient-state conditions. There were four rooms used for the experiment with the fire room connected to the other three rooms. Temperatures, radiation heat fluxes and flow velocities were measured in the building and the experimental results were used to validate a Computational Fluid Dynamics (CFD) model.

An experimental study on smoke movement and mixing/entrainment in a multi-storey shaft was conducted by Marshall [17], using a 1/5 scale prototype of a 5-storey open 
shaft. 17 sets of experiments were conducted for different sizes of fire, door opening and the height of the shaft. The plume rising alongside the wall was modeled. A theory for predicting the quantity of smoke entering the ceiling reservoir of an open multi-storey shaft was established based on a theory for predicting the mixing of smoke and air in enclosed multi-level shopping center. A simpler empirical straight-line relationship was also provided for predicting smoke movement in multi-compartment buildings.

Mercier et al. [18] performed experimental tests to study flow and heat transfer in an open vertical enclosure, which represented elevator shaft, warehouses and atriums, due to a building fire. Tests were conducted using a 1/3 scale prototype. Smoke and hot gases were injected into the enclosure at a low level opening. Temperatures and flow rates in the shaft were measured. It was observed that a wall plume and a re-circulating flow existed in the shaft, and horizontal uniform conditions could not be established. Therefore, wall plumes should consider these features.

Although ample experimental data exist in the literature for smoke movement in atria, tunnels, and multi-compartment buildings, experiments involving both horizontal and vertical smoke spread in residential buildings that produce data suitable for comparison with computer models are scarce. Three fire experiments within multi-compartment and multi-storey buildings reported in the literature are discussed below.

Hokugo et al. [9] conducted full-scale smoke movement experiments in the 10-storey experimental smoke tower of the National Fire Laboratory, NRCC. The building has apartments, corridors, stairwells and elevator shaft. Two propane burners were placed on the second floor. Three types of fires were designed to represent different fire scenarios. 
Temperatures, pressure differences and carbon dioxide concentrations were recorded at various locations. The results were used to compare with predictions of the NRCC smoke movement model. Good agreement between the experimental data and the model was reported in the paper.

He et al. [21] conducted a series of full-scale fire experiments at the Center for Environment Safety and Risk Engineering (CESARE)'s Experimental Building-Fire Facility (EBFF), Victoria University of Technology, which consists of a four-storey fullscale building. The experiments varied in burning rates and ventilation conditions. Temperatures, pressures, flow velocities, smoke densities and species concentrations were measured in various parts of the building. The chimney effect and mixing/entrainment were detected in a large vertical shaft with multiple openings. In remote areas of the room of fire origin, the layering effect was found not to be dominant for fires of moderate strength. The experimental results were used to make comparisons with the CFAST model [20] and also applied to validate the network model CESARE-SMOKE [21].

Zhong et al. [22] conducted smoke movement tests in a five-storey building at the State Key Laboratory of Fire Science at the University of Science and Technology, China. The five-storey building is a $1 / 2$ scale model with two stairwells. Timber and kerosene were used as fuel. Tests were conducted with the fire starting in different rooms and under a number of ventilation conditions. Parameters of fire smoke, such as flow velocity, temperature, air pressure difference, smoke ingredients and concentrations of species in the multi-storey building were measured in the tests. It was reported that the smoke 
spread around the passageways in the building and the concentrations of toxic gases such as $\mathrm{CO}, \mathrm{CO}_{2}, \mathrm{SO}_{2}$, $\mathrm{NO}$ and $\mathrm{NO}_{2}$ exceeded the tenability limit for humans.

\subsection{Computer Models for Smoke Movement}

During the past 20 years, advancement in computer technology has led to the development of computer models for simulating fire and smoke movement. In 1989, Friedman [23] reported on an international survey of computer models for fire and smoke. The survey found 36 fire computer models. In 1991, the 2 nd edition of this report included 62 models from 10 countries and in 1992, 74 models from 13 countries were surveyed and reported. The tendency to replace prescriptive fire and building codes with performance-based codes also promoted the development of computer fire models. Performance-based codes provide more flexibility in design and promote innovation. Canada published the new objective-based codes in October 2005. Many other countries and regions such as UK, New Zealand, Australia and Hong Kong have either made similar changes or are in the process of doing that. More and more improved models have been developed. In 2003, Olenick and Carpenter [24] published an updated international survey of computer models for fire and smoke, which updated the work completed by Friedman [23]. The survey identified and categorized 168 computer-modelling programs. The models were categorized as zone models for compartment fires; field models for compartment fires; detector response models; egress models; fire endurance models; and miscellaneous models.

Zone models (usually two-zone models for pre-flashover fires) divide each compartment into two zones: the hot upper smoke layer and the cool lower layer. Within each zone, the properties are assumed to be uniform. Energy and mass conservation are applied to each 
zone. Modelling relevant fire processes, for example plume entrainment, vent flow, and heat transfer, provides necessary source terms for the conservation equations. Zone models can be developed for single-compartment and multi-compartment configurations, for pre-flashover and post-flashover fires [24]. For example, BRI-2 [25] is a two-zone model for multi-storey, multi-compartment smoke transport; COMPF2 [26] is a postflashover model; FFM [27] is a pre-flashover zone model; CFAST [20] is a two-zone model multi-compartment model that is used to calculate the evolving distribution of smoke, fire gases and temperature throughout compartments. For all these models, the range of individual spaces varies from as small as $1 \mathrm{~m}^{3}$ to as large as $1000 \mathrm{~m}^{3}$.

Field models such as the Fire Dynamics Simulator (FDS) [28] divide the computational space into very small control volumes and solve the fundamental equations for mass, momentum, energy and species concentration for each control volume. Furthermore, field models can to simulate smoke movement in a multi-storey building theoretically.

Detector response models typically use zone models to calculate smoke and heat transfer, and use submodels to predict the response time of a device such as a smoke detector, or sprinklers [24]. Egress models predict the evacuation time of occupants [24], whereas fire endurance models simulate the behaviour of structural building elements subjected to fire [24].

Miscellaneous models are not suitable for the previously mentioned simulations. For example, CONTAMW [29] is a network model. Network models treat compartments as single zones (nodes); each node has its specific temperature and pressure. The building is represented as a network of nodes. Vertical shaft such as stair shaft are treated as a series 
of nodes, one for each floor. Network models are not adequate to model buoyancy induced flows, thus, two distinct layers cannot be modelled.

Zone models, field models, and some miscellaneous models can all be used to simulate smoke movement in a multi-storey building. However, field models are expensive and require high computational resources to simulate fires in a multi-storey building with corridors, stair shaft, elevator shaft, and a large number of various size compartments. Network models cannot model the two distinct layers. Currently, zone models may be a good compromise for modelling smoke movement in a multi-storey multi-compartment building with results that are good enough for engineering applications.

Comparisons between predictions of various zone models and experimental results are reported in the literature. A few zone models and relevant comparisons involving several fires with steady, linear or non-linear HRR in a single-compartment or a multicompartment building are discussed below.

Remesh and Tan [30] compared the results measured in twenty full-scale experiments in a single compartment conducted by Dembsey et al. [31] with fire sizes (steady HRR) ranging from $330 \mathrm{~kW}$ to $980 \mathrm{~kW}$, and various fire locations at the center or at the sidewall of the fire compartment with the predictions of three two-zone models: CFAST, OZone [32], and CFMFAN [30]. CFAST does not account for the switchover from a preflashover to a post-flashover fire. However, OZone and CFMFAN can predict preflashover and post-flashover fires by switching over from a two-zone model to a onezone model after flashover. The direct experimental measurements such as the temperatures of the upper and lower layers, and derived quantities such as the interface 
height were compared with the prediction results of the three models. CFAST overestimated the upper layer temperature by about $20^{\circ} \mathrm{C}$, whereas, OZone and CFMFAN underestimated the upper layer temperature by about $120^{\circ} \mathrm{C}$ and $100^{\circ} \mathrm{C}$ respectively. All three models underestimated significantly the lower layer temperature.

Matsuyama et al. [33] conducted a series of full-scale experiments using $\mathrm{t}^{2}$ fires in a fire room and a linked corridor. There was a doorway of $1.0 \mathrm{~m} \times 2.0 \mathrm{~m}$ (height) between the fire room and the corridor. A triangular shaped polyurethane mattress was used to generate $\mathrm{t}^{2}$ fires for the tests. The temperatures of the fire room and the corridor were measured. During the experiments, Matsuyama et al. [33] observed a quick mixing of smoke and air during the decay phase. The experimental results were compared with the predictions of the zone models BRI2 and CFAST. The temperature predictions of the upper layer of both models were higher than the maximum experimental temperature.

Fu and Hadjisophocleous [34], described the theory behind the smoke movement twozone model in FIERAsmoke. The model is based on ordinary differential equations (ODEs) governing the conservation principles of mass and energy for two zones in each compartment with fire or smoke. The four independent variables selected are pressure, enthalpy of upper layer, and mass of upper layer and lower layer. The implemented fire models are introduced including combustion, fluid flow and heat transfer models. For each compartment without fire or smoke, a non-linear algebraic equation based on mass conservation is used instead of the ODEs.

Full-scale experiments in a single-compartment conducted by Dembsey et al. [31] with steady HRRs of $330 \mathrm{~kW}, 630 \mathrm{~kW}$ and $980 \mathrm{~kW}$ and the fire source located at the center of 
the compartment were simulated using CFAST [20], FIRST [35], and FIERAsmoke models. A two-compartment experiment conducted by Cooper et al. [19] with linear HRR was modeled using FIERAsmoke model. The predictions, such as upper layer temperature and lower layer temperature, were compared with the experimental data. In the single-compartment for example, CFAST over-predicted the upper layer temperature, whereas FIRST under-predicted the upper layer temperature. The prediction results for upper layer temperatures using FIERAsmoke model were close to experimental data. All the three zone models under-predicted the lower layer temperature significantly, but among the three models, the smallest difference between the model prediction and the experimental data was from FIERAsmoke. For the two-compartment with linear HRR example, FIERAsmoke showed favourable upper layer temperature predictions in the fire compartment and the corridor when compared with the experimental results.

Using FIERAsmoke, Hadjisophocleous and Fu [2] simulated two experiments, a case in summer and a case in winter conducted in the NRCC's 10-storey tower, and compared the model predictions for smoke temperature and concentration of $\mathrm{CO}_{2}$ in the stair shaft with experimental data. The measured heat release rate of a sofa in the open was used as input HRR. The FIERAsmoke model predictions showed that the combustion was not as complete as in the open for both the summer and winter cases during the peak period of heat release. This model predicted well the fire condition on the fire floor, but on floors above the fire floor, temperatures and concentrations of $\mathrm{CO}_{2}$ lower than the experimental data were predicted. This paper indicated that the FIERAsmoke predictions followed the trends observed during the experiments and that the model was capable of predicting smoke movement through stair shaft in a multi-storey building. 
Some zone models such as OZone and FIRST cannot simulate fires in a multicompartment building as these models are designed for simulating fires in single compartments. Zone models such as CFAST can simulate fires in a multi-compartment multi-storey building, however CFAST has a limitation of modelling a maximum of 30 compartments.

In this study, a two-zone model for multi-storey multi-compartment buildings called CUsmoke developed at Carleton University was used to simulate fires and smoke movement in different buildings: in a single-compartment; in a single-storey multicompartment building; and in a multi-storey multi-compartment building. CUsmoke was developed based on the two-zone model FIERAsmoke, and the basic theory behind the CUsmoke can be found in reference [3]. In CUsmoke, the stair shaft uses the model reported by Achakji and Tamura [36]. The stair shaft of each floor is treated as a separate compartment, and mass flow between neighbouring floors through the stair shaft is treated as a flow through an equivalent circular ceiling vent. Furthermore, in this model two plume models, McCaffrey's model [37] and Heskestad's model [38] are employed. Heskestad's plume model is widely used [3] to simulate fire and smoke movements in atria or warehouses. For this study, McCaffrey's plume model was used to simulate the enclosure fire examples.

CUsmoke provides two methods to input the HRR of the fire: using an equation or using a series of discrete HRR points with corresponding times. Using discrete points one can define any type of HRR theoretically. The method of using discrete points to describe HRR was used in the 10-storey tower simulation of this study. The model also has the capacity to model as many as 100 compartments with space ranging between $0.125 \mathrm{~m}^{3}$ to 
$1,000,000 \mathrm{~m}^{3}$. In this study, the 10 -storey tower system is modelled using 62 compartments including the fire compartment, the vestibules, the stair shaft, and the corridors and upper compartments.

\subsection{Interface Height Estimation}

Cooper et al. [19] developed a method known as N-percent method to estimate the interface height between the hot smoke zone and the cool lower zone in a compartment based on experimentally determined temperature measurements over the height of the compartment. A thermocouple tree with a series of thermocouples recorded the temperatures at different elevations. The interface height estimated in this method is at the height where the temperature $T_{i}$ is given by:

$T_{i}=C n\left(T_{\max }-T_{\min }\right)+T_{\min }$

Eqn (2-1)

where, $T_{i}$ is the gas temperature at the interface height; $T_{\max }$ is the maximum gas temperature recorded in the compartment; $T_{\min }$ is the minimum gas temperature recorded near the bottom of the compartment; and $\mathrm{Cn}$ is an interpolation constant in the range of $0.15 \sim 0.2$.

Lougheed et al. [39], [40] indicated that the value of $C n=0.2$ gives an interface height near the bottom of the transition zone, while the value of $C n=0.8$ gives an interface height near the top of the transition zone.

Hadjisophocleous et al. [41] suggested that a value of $C n=0.5 \sim 0.6$ be adopted in CFD modelling. In this study, $C n=0.6$ [42] was used to estimate the interface height in the fire compartment for the experiments conducted in the 10-storey tower. 


\subsection{Flashover Criteria}

"Flashover is generally defined as the transition from a growing fire to a fully developed fire in which all combustible items in the compartment are involved in fire" [43]. Chou [44] points out that unlike a fire burning in an open space; flashover is one of the most important phenomena in enclosure fires. Criteria used for identifying flashover are the following:

(1) An upper gas layer temperature of $600^{\circ} \mathrm{C}[45]$;

(2) A radiant heat flux level on the floor of $20 \mathrm{~kW} / \mathrm{m}^{2}$ [45];

(3) Flames coming out of the fire compartment openings [44].

In this study, the radiant flux was not measured in the experiments and flame coming out of the opening could not be observed, as no video equipment was installed. Therefore, the criterion of an upper gas layer temperature of $600^{\circ} \mathrm{C}$ is used to determine flashover.

\subsection{Heat Release Rate Measurement of Room Fires}

A room fire is quite different than an unconfined fire. A room fire grows depending on not only the nature of its combustible components, but also the type of the fuel, and the construction, geometry and the condition of the openings of the room [4]. For fires in the open, heat release rate can be calculated by knowing the burning rate of the fuel and its heat of combustion. The typical range of net heat of combustion of cellulosic materials is $17-20 \mathrm{~kJ} / \mathrm{g}[46]$.

For a room experiment, it is not practical to calculate the heat release rate using a method based on the measurement of the sensible heat losses by the system and the development 
of an energy balance. In 1917, Thornton [47] indicated that for a large number of organic liquids and gases, a more or less constant net amount of heat is released per unit mass of oxygen consumed for complete combustion. Based on the principle that the heat released per unit of oxygen consumed is approximately the same for a wide range of organic fuels commonly encountered in fires, a technique of oxygen consumption calorimetry has been developed and commonly used [48]. Huggett [48] states that heat release rate can be estimated based on only two simple measurements, the volumetric flow of air and the combustion products through the fire system, and the concentration of oxygen in the exhaust duct. The heat release rate calculation is based on the assumption of complete burning. However, in actual fires, incomplete burning always exists. If large quantities of products of incomplete combustion, such as $\mathrm{CO}, \mathrm{HCN}$ and soot, are collected in the exhaust system, corrections must be adopted to account for the effect of incomplete burning on heat release rate. The paper indicates that the heat release from a fire involving conventional organic fuels is $13.1 \mathrm{~kJ}$ per gram of oxygen consumed, with an accuracy of $\pm 5 \%$ or less.

Compared to Huggett's method [48] of using the volumetric flow, Janssens [4] provided a set of equations to calculate the heat release rate in large-scale fire experiments based on the oxygen consumption principle. The common feature of the equations in this paper is that the volumetric flow rate is not used in calculating the heat release rate. Four options are provided to estimate the heat release rate by measuring the concentration of (1) oxygen only; (2) oxygen and carbon dioxide; (3) oxygen, carbon dioxide and carbon monoxide; (4) oxygen, carbon dioxide, carbon monoxide and water vapour. The 
concentration of oxygen must be measured for any of the options. A solution to determine the net rate of heat release of the test specimens is also stated in the paper.

The technique of oxygen consumption calorimetry is widely used in bench-scale and fullscale fire tests all over the world. This technique was applied early to the ASTM E-84 tunnel test by Parker [49]. Subsequently twenty-one enclosure fire tests and eight free burn tests conducted by Quintiere and McCaffrey [50] to study the burning of wood and plastic cribs in an enclosure were conducted. They applied a variation of the oxygen consumption method reported by Sensenig [51] to obtain the heat release rate for their tests.

Bwalya et al. [52] conducted medium-scale and room-scale tests using wood crib, mockup sofa and used sofa as fuel to simulate fires in a residential basement room. It was not possible to use oxygen consumption calorimetry for the room-scale tests to obtain the heat release rate. So medium-scale experiments were conducted using an open calorimeter for measuring the heat release rate and the production of light-obscuring smoke under well-ventilated conditions. Janssens [4] method was used to estimate the heat release rate.

In 1983, Babrauskas [53] published a paper about upholstered furniture heat release rate measurement and estimation. Furniture fires account for a large proportion of all accidental fires. Furniture fires are primarily divided into upholstered furniture fires and bed fires. An oxygen-consumption based furniture calorimeter was used to measure furniture heat release rates. This instrument avoids capturing all the sensible heat, instead, measures oxygen concentration changes to easily determine heat release rate according to 
the equation developed by Parker [54]. Regarding the heat release rate, two primary variables - the peak rate of heat release and the time to reach the peak are important to be considered. The peak intensity values are needed to determine the worst room fire behaviour, and the time to reach the peak is also important because in many fires, detection may be feasible at or very shortly after ignition [53].

The arrangements of the fuel package components affect heat release rate. Chow [55] conducted experiments using a cone calorimeter to measure the heat release rate of individual component materials of a typical furniture foam sofa and combination of the materials. In the tests, all materials were consumed under a high radiative heat flux of $50 \mathrm{~kW} / \mathrm{m}^{2}$. Observation of tests indicate that the transient heat release rate curves cannot be simply added together if the component materials are stacked up as a 'sandwich' panel. Thermal radiation at the burning surface would be different. However the total heat released for the component materials can be added together to give the total heat released of the furniture arrangement with a deviation of less than $15.8 \%$.

Mowrer et al. [56] pointed out that in building fires, the heat release rate is probably the single most important parameter from the early stage to the likelihood of flashover and through the post-flashover conditions. Heat release rate of many fuel arrays have been derived from fire experiments based on mass loss rate or oxygen consumption. Heat release rate experimental data are typically acquired at discrete intervals and stored digitally. If recording the heat release rate at $5 \mathrm{~s}$ intervals, a 15 -min fire experiment will include 180 time-heat release rate pairs. Mowrer et al. [56] provide an algorithm to characterize experimentally measured heat release rate histories. Two general representations, exponential and $t$-squared, are discussed in detail. The characterizations 
require the selection of two representative data pairs from experimentally measured heat release rate history and evaluation of the peak heat release rate and the total cumulative heat released. This provides a convenient way to input heat release rates when using computer models to simulate fires if the model accepts exponential and t-squared equations to describe heat release rate curves.

Since a system to measure mass flow rate to enable the use of the oxygen consumption method to estimate the heat release rate is not available in the NRCC's 10-storey tower, in this study, an approach is developed using propane as a fuel to reproduce the temperature distribution of the different fuel package tests run in the same facility. The propane flow rate is then used to estimate the heat release rate of the fuel package fires. Details of this method are described in Chapter 4. 


\section{Description of Experiments and Experimental Facility}

\subsection{Introduction}

Ten full-scale fire tests were designed and conducted to obtain data on smoke movement from four different fuel packages and propane fires in a multi-storey building. The data were generated for comparison purposes with the predictions of the two-zone model CUsmoke. The fuel package group (Group 1) tests included two clothing store packages (Test CLC-I and Test CLC-II) to observe the effects of different fire loads with the same fuel components; a computer showroom package (Test CMP) and a bookstore package (Test BK). Group 2 tests (CLC-I-R, CLC-II-R, CMP-R and BK-R) were conducted using propane gas to estimate the heat release rates of the Group 1 tests, whereas Group 3 included the tests, PP-I and PP-II, which were conducted to generate more experimental data for the validation of CUsmoke. Details of the three groups are shown in Table 3-1. 
Table 3-1: Details of tests

\begin{tabular}{|c|c|c|c|c|c|c|}
\hline \multirow{2}{*}{$\begin{array}{c}\text { Group } \\
\text { number } \\
\text { and name }\end{array}$} & Test ID & $\begin{array}{c}\text { Textiles } \\
(\mathrm{kg})\end{array}$ & $\begin{array}{c}\text { Plastics } \\
(\mathrm{kg})\end{array}$ & $\begin{array}{c}\text { Wood/Paper } \\
(\mathrm{kg})\end{array}$ & $\begin{array}{c}\text { Total } \\
\text { mass }(\mathrm{kg})\end{array}$ & $\begin{array}{c}\text { Total Fire } \\
\text { Load } \\
(\mathrm{MJ})\end{array}$ \\
\hline \multirow{3}{*}{ Group 1 } & CLC-I & 30.73 & 0.304 & 4.407 & 35.44 & 661 \\
\cline { 2 - 7 } & CLC-II & 61.46 & 0.608 & 8.814 & 70.88 & 1322 \\
\cline { 2 - 7 } & CMP & 2.70 & 18.88 & 41.80 & 63.38 & 1624 \\
\cline { 2 - 7 } & BK & 2.294 & 0 & 603.6 & 606.9 & 10610 \\
\hline \multirow{3}{*}{ Group 2 } & CLC-I-R & \multicolumn{5}{|c|}{ Propane gas to reproduce Test CLC-I } \\
\cline { 2 - 7 } & CLC-II-R & \multicolumn{5}{|c|}{ Propane gas to reproduce Test CLC-II } \\
\cline { 2 - 7 } & CMP-R & \multicolumn{5}{|c|}{ Propane gas to reproduce Test CMP } \\
\cline { 2 - 6 } & BK-R & \multicolumn{5}{|c|}{ Propane Test BK } \\
\hline \multirow{2}{*}{ Group 3 } & PP -1 & \multicolumn{5}{|c|}{ Propane } \\
\cline { 2 - 6 } & PP -2 & \multicolumn{5}{|c|}{} \\
\hline
\end{tabular}

\subsection{Test Set-up}

The test facility used to conduct all the tests is a 10-storey tower located in the fire research laboratory of the National Research Council Canada (NRCC). A typical floor plan of the tower is shown in Figure 3-1. Figure 3-2 is a photograph of the facility.

The ceiling height of the $1^{\text {st }}$ and $2^{\text {nd }}$ floor is $3.3 \mathrm{~m}$, while the ceiling height of all other floors is $2.4 \mathrm{~m}$. The facility is constructed using reinforced normal weight concrete. There is one stair shaft from the $1^{\text {st }}$ to the $10^{\text {th }}$ floor. As shown in Figure 3-1, on each floor, between the stair shaft and the main compartment, there is a vestibule. The floor area of the main compartment on all floors is $8.9 \times 3.78 \mathrm{~m}$. The fire compartment was located on the $2^{\text {nd }}$ floor. The dimensions of the fire compartment were $8.9 \times 3.78 \times 3.3 \mathrm{~m}$ high. The six sides of the fire compartment were totally covered by $25.4 \mathrm{~mm}$ thick ceramic fibre. The vestibule between the fire compartment and the stair shaft at the $2^{\text {nd }}$ floor was also covered by $25.4 \mathrm{~mm}$ thick ceramic fibre. Elsewhere the concrete surfaces (including the 
stair shaft and the corridor of the $2^{\text {nd }}$ floor, and all structural surfaces of the non-fire floors) were not insulated.

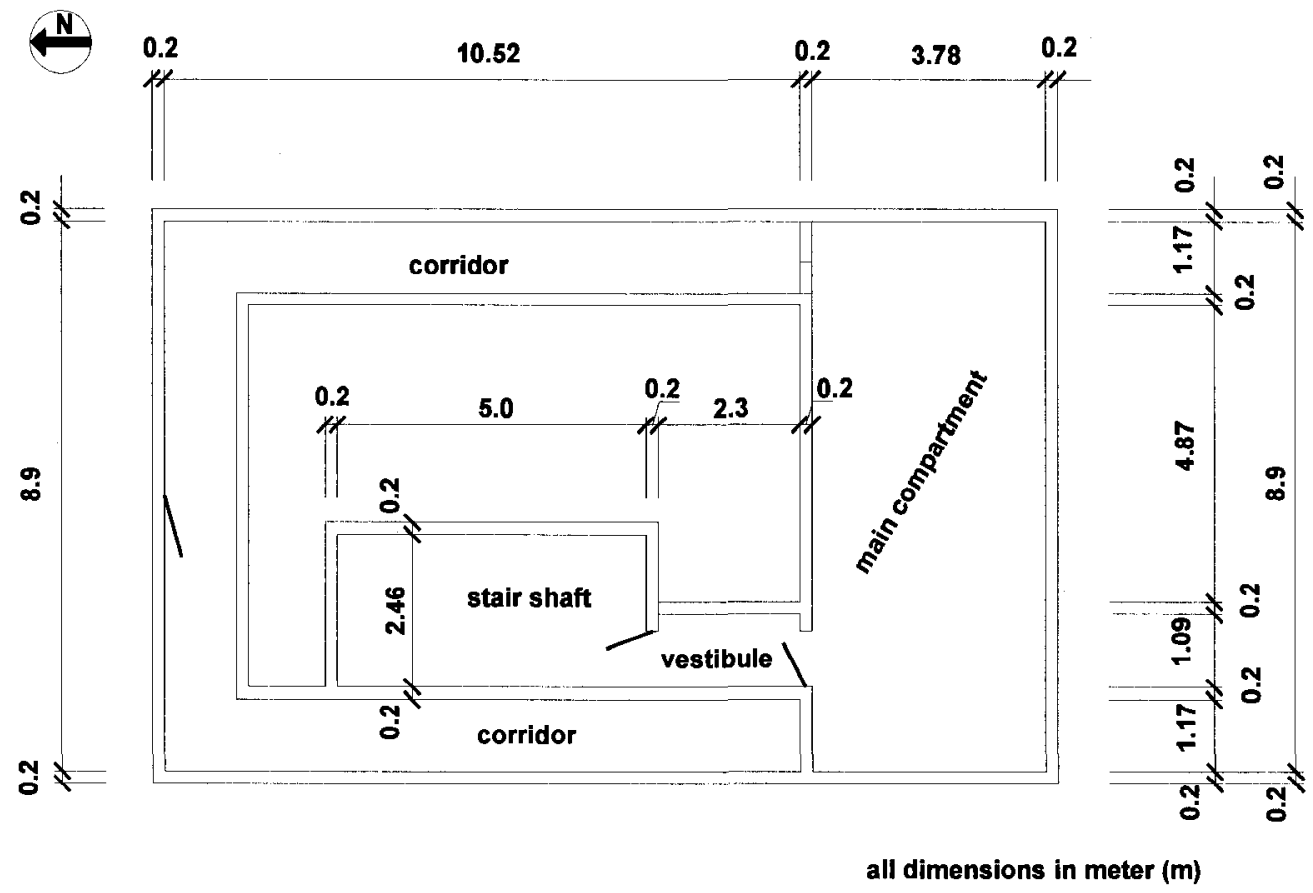

Figure 3-1: Typical floor plan of the 10-storey smoke tower

The locations of the fuel packages CLC-I, CLC-II, CMP and BK and the location of the propane burner used in the tests are shown in Figure 3-3. The propane burner has a height of $0.85 \mathrm{~m}$ above floor and can produce a maximum HRR of $3 \mathrm{MW}$.

Thermocouples and gas analyzers were used to record gas temperatures and concentrations of $\mathrm{O}_{2}, \mathrm{CO}$ and $\mathrm{CO}_{2}$. A standard mass flow meter was used to measure the mass flow of propane in the Group 2 and 3 tests. 


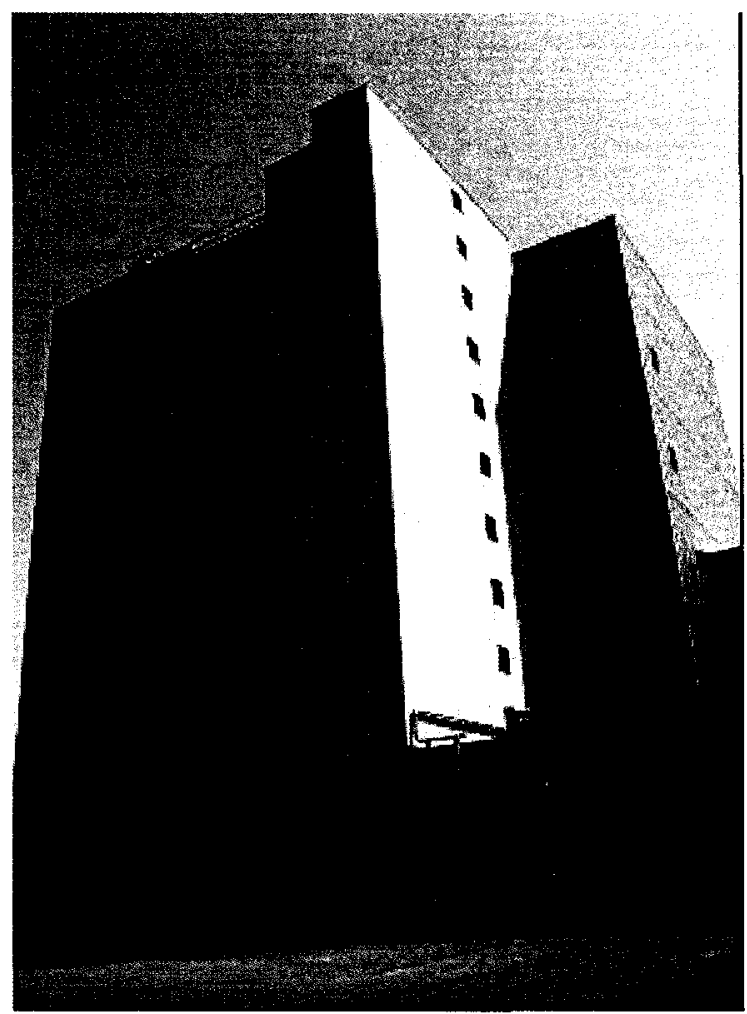

Figure 3-2: NRCC's 10-storey smoke tower, Almonte, Ontario
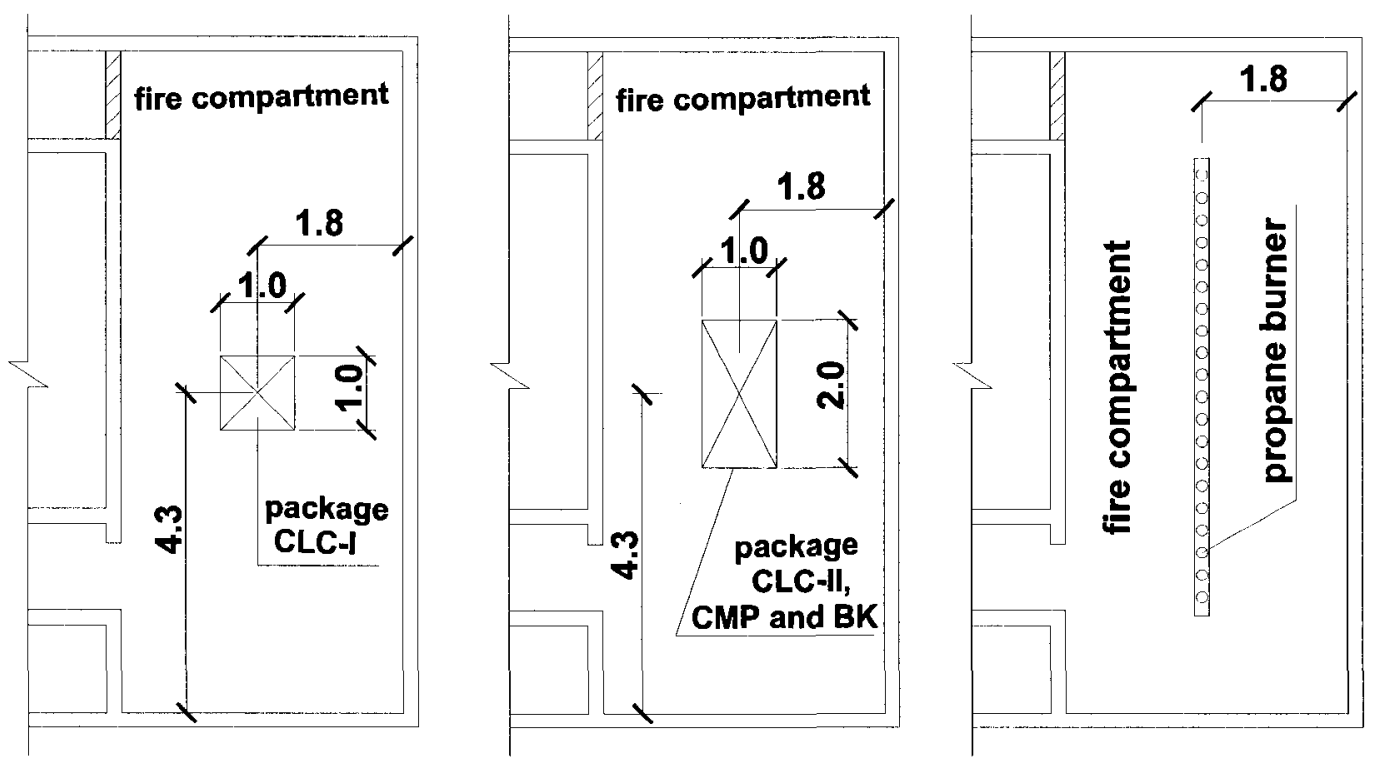

Figure 3-3: Locations of fuel packages and propane burner in fire compartment 
The condition of the doors on different floors is described in the following sections. There were six doors on the $1^{\text {st }}$ floor (Figure 3-4). The condition of these doors during the tests is shown in Table 3-2. For tests CLC-I, CLC-II and PP-I, door 'DR-3' was kept open during the tests. This door connects the tower to a corridor of the office area of the lab. Because some smoke entered the corridor during these tests, for tests CLC-I-R and CLC-II-R, the door 'DR-3' was closed, but door 'DR-1' was open instead. For all other tests, door 'DR-3' and 'DR-4' were closed. Door 'DR-6' opened directly to the outside resulting in flow of fresh air entering through stair shaft at the $1^{\text {st }}$ floor.

The conditions of the doors on all other floors were similar for all tests. Figure 3-5 shows the fire floor plan (Floor 2) in the test tower. The doors between the fire compartment and the vestibule, as well as between the vestibule and the stair shaft were kept open. Between the fire compartment and the corridor, there was an opening $1.2 \mathrm{~m}$ wide and $0.85 \mathrm{~m}$ high located at the bottom of the wall to supply additional fresh air from the corridor of the $2^{\text {nd }}$ floor into the fire compartment.

Table 3-2: The open/closed conditions of the doors at first floor

\begin{tabular}{|c|c|c|c|c|c|c|c|}
\hline GROUP & TEST ID & DR-1 & DR-2 & DR-3 & DR-4 & DR-5 & DR-6 \\
\hline \multirow{4}{*}{$1^{\text {st }}$} & CLC-I & Closed* & Open & Open* & Open & Open & Closed \\
\cline { 2 - 8 } & CLC-II & Closed* & Open & Open* & Open & Open & Closed \\
\cline { 2 - 8 } & CMP & Closed & Closed & Closed & Closed & Closed & Open \\
\cline { 2 - 8 } & BK & Closed & Closed & Closed & Closed & Closed & Open \\
\hline \multirow{4}{*}{$2^{\text {nd }}$} & CLC-I-R & Open* & Open & Closed* & Open & Open & Closed \\
\cline { 2 - 8 } & CLC-II-R & Open* & Open & Closed* & Open & Open & Closed \\
\cline { 2 - 8 } & CMP-R & Closed & Closed & Closed & Closed & Closed & Open \\
\cline { 2 - 8 } & BK-R & Closed & Closed & Closed & Closed & Closed & Open \\
\hline \multirow{2}{*}{$3^{\text {rd }}$} & PP -1 & Closed & Open & Open & Open & Open & Closed \\
\cline { 2 - 8 } & PP -2 & Open & Open & Closed & Open & Open & Closed \\
\hline
\end{tabular}

Note: the door condition with * means that the door condition was changed to avoid the entry of smoke into the office space, however it had no effect on the experiments because DR-1 and DR-3 are of similar size and they both lead to a large space. 


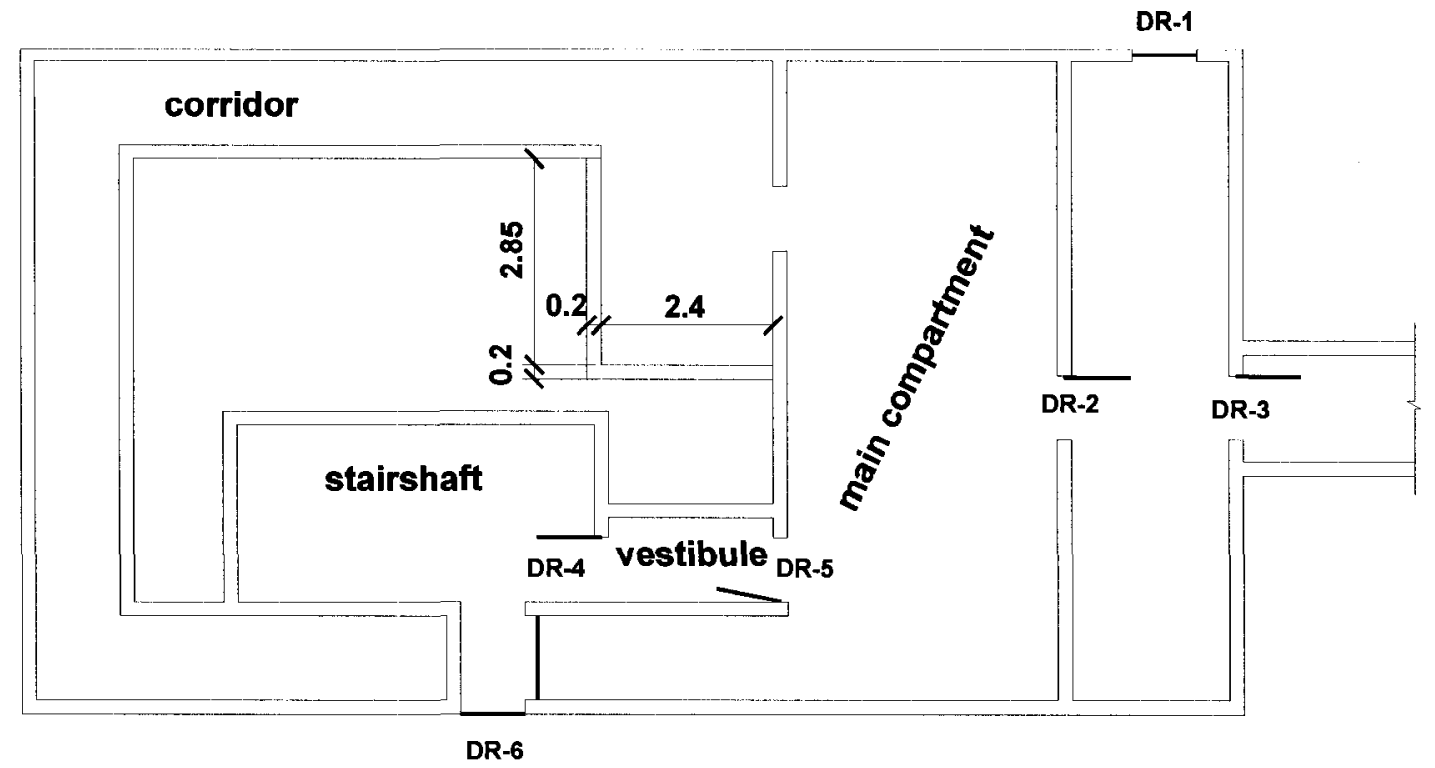

Figure 3-4: Plan of the $1^{\text {st }}$ floor

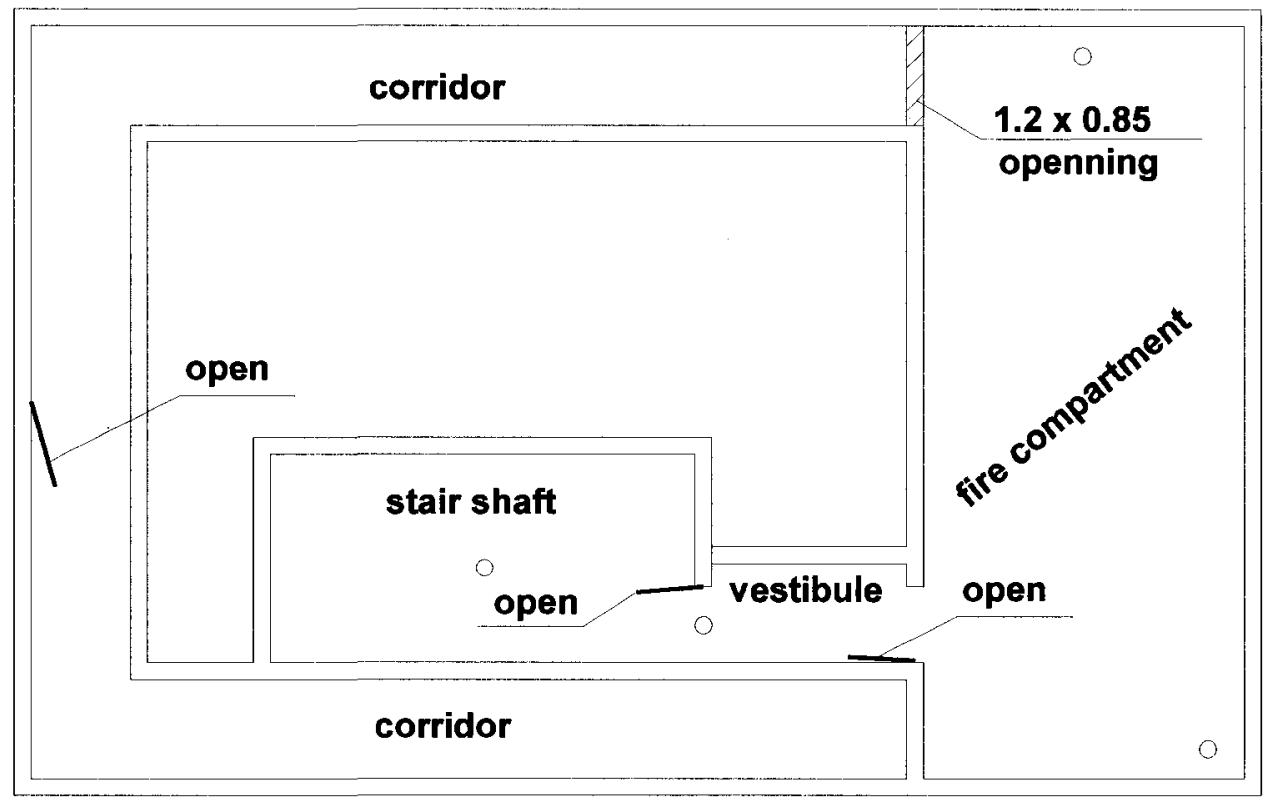

Figure 3-5: Plan of the $2^{\text {nd }}$ floor 
The plans for the $3^{\text {rd }}, 5^{\text {th }}$, and $7^{\text {th }}$ floors are shown in Figure 3-6. The doors between the stair shaft and the vestibule were fully closed. A $1.9 \times 1.85 \mathrm{~m}$ opening on the wall connected the vestibule and the corridor.

The plans of the $4^{\text {th }}$ and $8^{\text {th }}$ floors are shown in Figure 3-7. The doors between the stair shaft and the vestibule were fully opened on these floors, whereas the door between the vestibule and the main compartment was held partially opened. A small leakage from the corridor to outside existed on these two floors.

On the $6^{\text {th }}$ floor (Figure 3-8), the door between the stair shaft and the vestibule was fully open, and the door between the vestibule and the main compartment was held partially open. However, inside the main compartment of this floor, an inner wooden compartment was constructed for other NRCC committed tests independent of this study. No thermocouples were installed inside the main compartment of this floor.

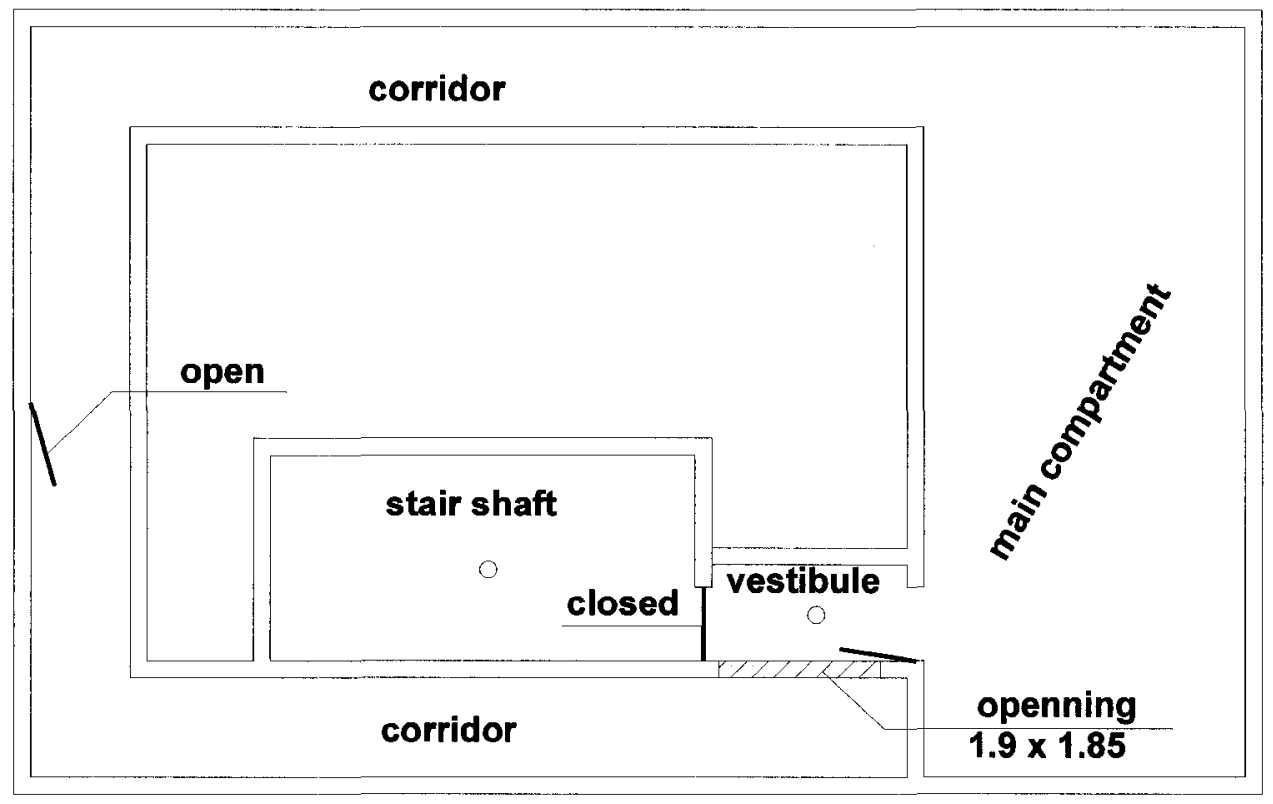

Figure 3-6: Plan of the $3^{\text {rd }}, 5^{\text {th }}$, and $7^{\text {th }}$ floors 


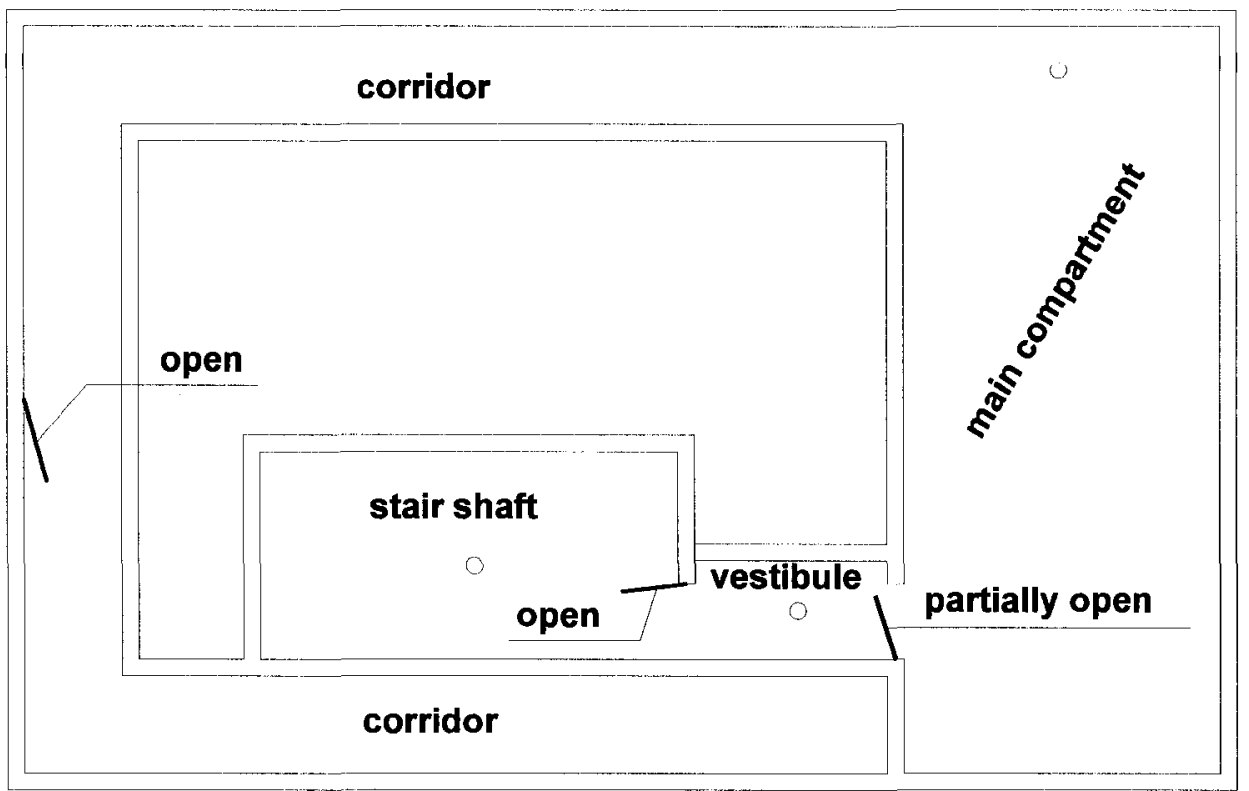

Figure 3-7: Plan of the $4^{\text {th }}$ and $8^{\text {th }}$ floors

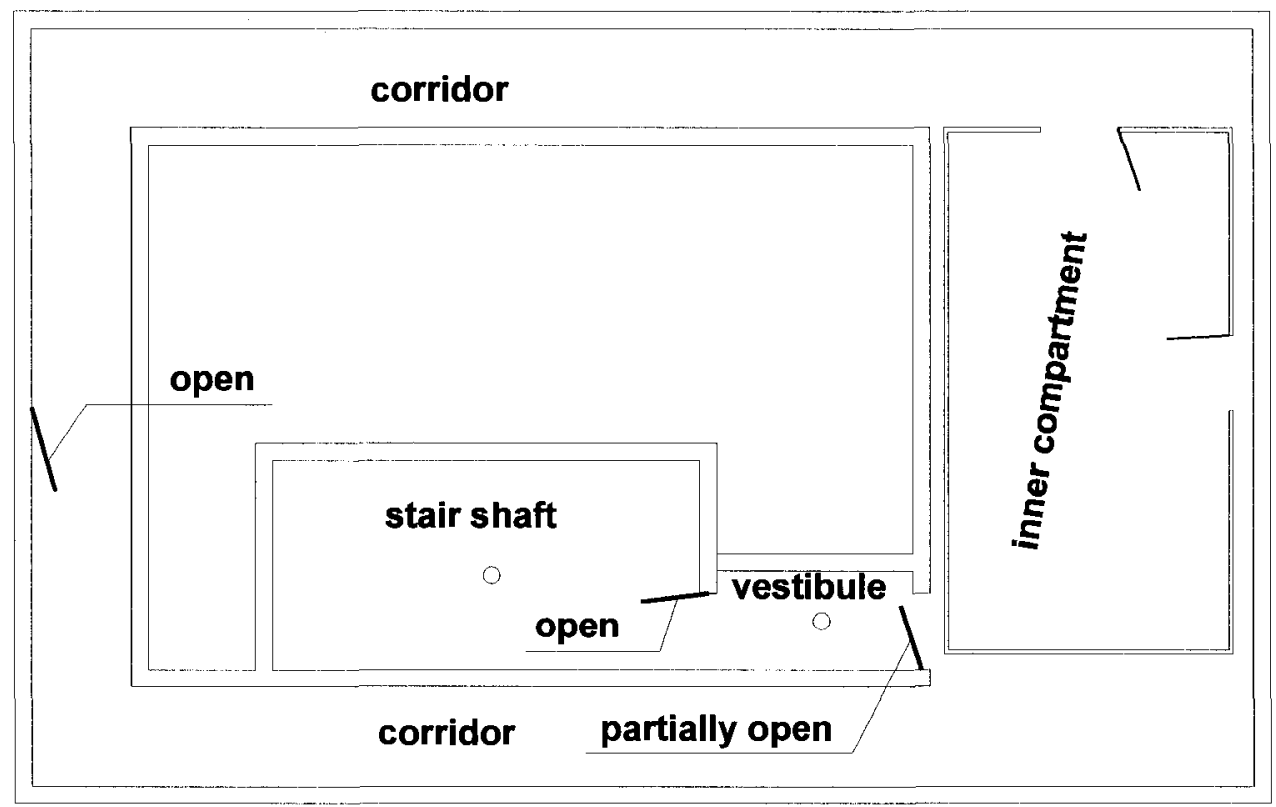

Figure 3-8: Plan of the $6^{\text {th }}$ floor

Figure 3-9 shows the plan of the $9^{\text {th }}$ floor. The door between the stair shaft and the vestibule was closed. The difference between the $9^{\text {th }}$ floor and the other floors with a 
closed door is that on this floor, there was a small compartment connected to the main compartment.

Figure 3-10 shows the plan for the $10^{\text {th }}$ floor. The door between the stair shaft and the vestibule was fully open. The difference between the $10^{\text {th }}$ floor and the other floors with open door is that on this floor a small compartment was connected to the main compartment.

The expected smoke movement in the 10-storey tower during the tests is shown in Figure 3-11. Smoke is expected to flow from the compartment of fire origin on the $2^{\text {nd }}$ floor to the vestibule and then to the stair shaft. In the stair shaft smoke moves upwards due to buoyancy and enters the vestibules and compartments of the upper floors.

Instrumentation and the data acquisition system used for the tests are described in the following sections. These systems were calibrated and provided by NRCC for these tests.

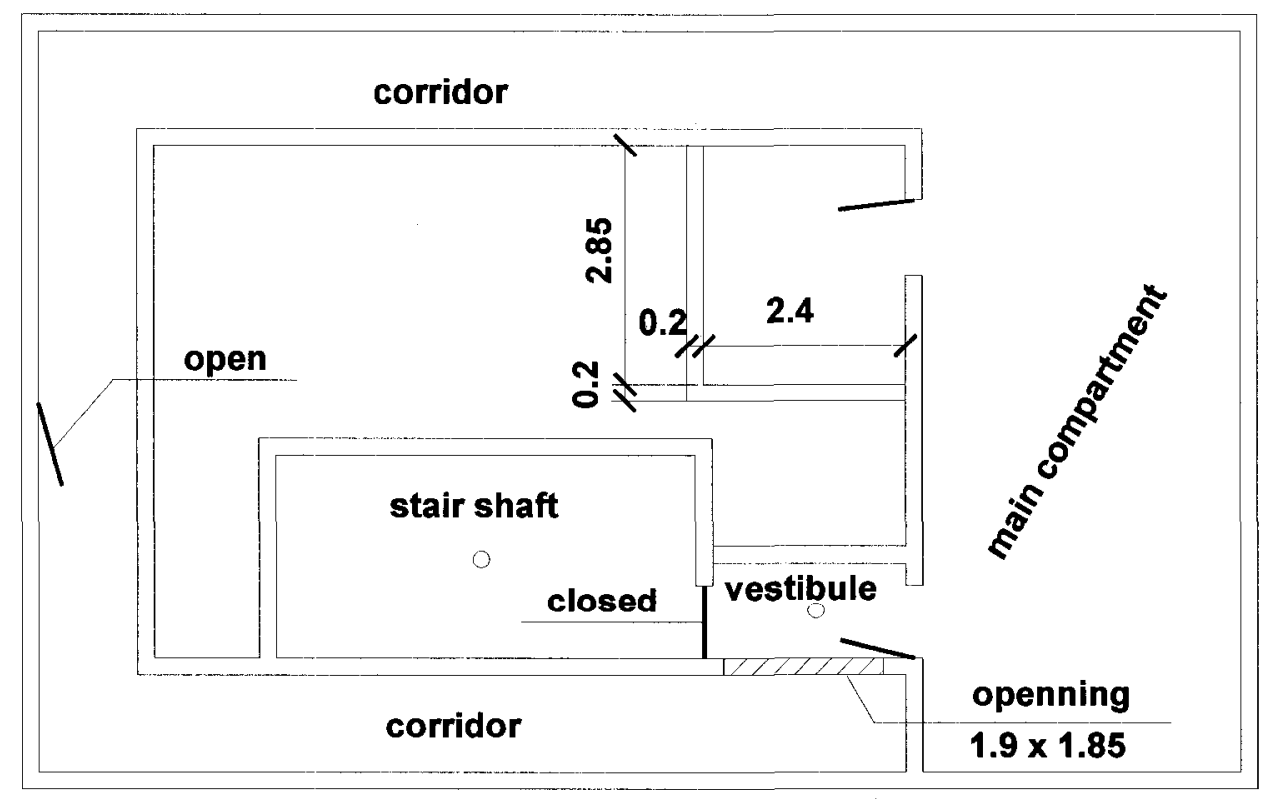

Figure 3-9: Plan of the 9th floor 


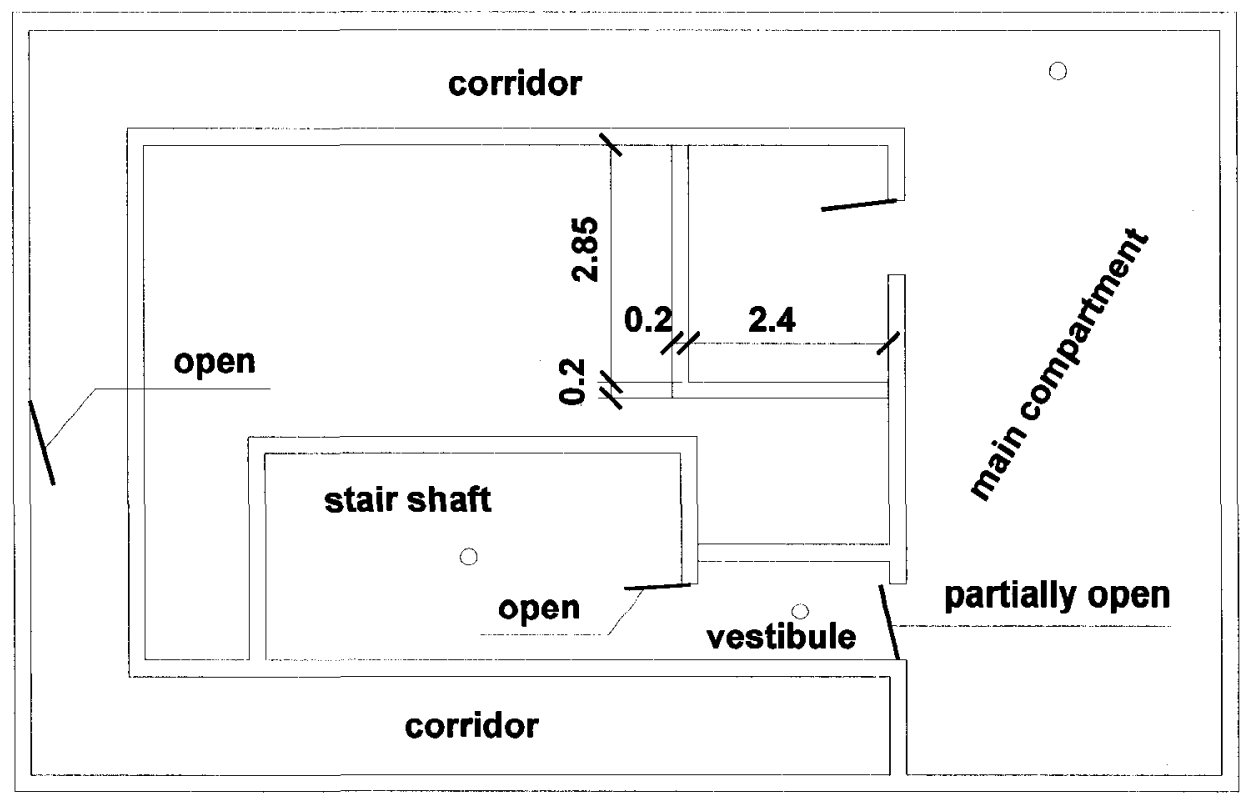

Figure 3-10: Plan of the $10^{\text {th }}$ floor

\begin{tabular}{|c|c|c|c|}
\hline floor \# & stair shaft & vestibule & main compartment \\
\hline$\# 10$ & $\uparrow$ & $\Rightarrow$ & $\rightarrow$ \\
\hline \#9 & 个 & & \\
\hline$\# 8$ & F & $\Rightarrow$ & $\rightarrow$ \\
\hline$\# 7$ & 个 & & \\
\hline \# 6 & 卡 & $\Rightarrow$ & $\rightarrow$ \\
\hline$\# 5$ & 个 & & \\
\hline$\# 4$ & 凡 & & $\rightarrow$ \\
\hline \# 3 & 个 & & \\
\hline \# 2 & 4 & $\leftarrow$ & fire compartment \\
\hline
\end{tabular}

Figure 3-11: Expected smoke movement flow in the 10-storey tower

\subsubsection{Temperature Measurements}

'OMEGA - K Type' thermocouples (thermocouples made by OMEGA) were installed to measure the gas temperatures. In the southwest corner of the fire compartment, a 
thermocouple (TC) tree was set to record the temperature profile along the height of the compartment, and also to help in determining the height of the interface between the upper and lower layers. The TC tree consisted of thirteen TCs that were installed at the following heights: $0.62,0.92,1.22,1.37,1.52,1.67,1.82,1.97,2.12,2.27,2.42,2.57$ and $2.95 \mathrm{~m}$. A thermocouple was also installed under the ceiling and close to the east wall in the fire compartment. Another short TC tree was installed in the doorway between the vestibule and the stair shaft of the $2^{\text {nd }}$ floor (fire floor) with five TCs at elevations of 0.35 , $0.75,1.15,1.65$ and $2.05 \mathrm{~m}$. A TC was also placed in the middle of the stair shaft at each floor from the $1^{\text {st }}$ to the $10^{\text {th }}$ at a height of $0.6 \mathrm{~m}$ below the ceiling.

On floors of the $4^{\text {th }}, 8^{\text {th }}$ and $10^{\text {th }}$, a TC was installed $0.3 \mathrm{~m}$ below the ceiling, close to the east wall of the main compartment. A TC was also located at the centre of the vestibule of each floor from the $3^{\text {rd }}$ to the $10^{\text {th }}$ at a height of $0.15 \mathrm{~m}$ below the ceiling. Figure $3-12$ shows the layout for all thermocouples.

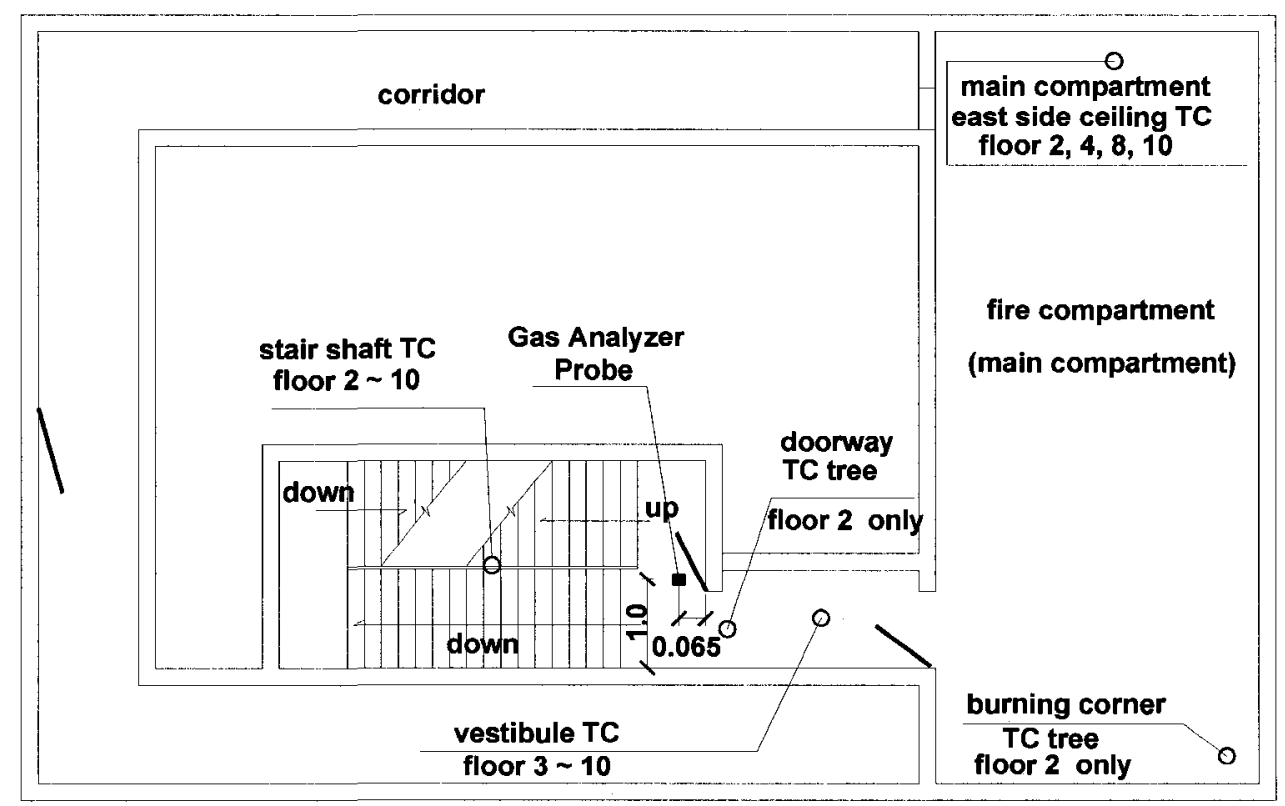

Figure 3-12: Thermocouples and gas analyzer's probe layout 


\subsubsection{Gas Analyzers}

An 'ABB - EL3020' gas analyzer shown in Figure 3-13 was used to measure the concentration of $\mathrm{CO}, \mathrm{CO}_{2}$ and $\mathrm{O}_{2}$ in the stair shaft at the fire floor. The probe location of the gas analyzer is shown in Figure 3-12. The height of the gas analyzer probe is $0.15 \mathrm{~m}$ below the ceiling.

\subsubsection{Mass Flow Meter}

A 'SIERRA - 780S Flat-Trak ${ }^{\mathrm{TM}}$, standard mass flow meter shown in Figure 3-14 was used to record the mass flow rate of propane consumed during the propane tests. Based on the mass flow, the heat release rate of the fire was calculated.

\subsubsection{Data Acquisition System}

The data measured by the thermocouples, gas analyser and mass flow meter were recorded using a 'SCHLUMBERGER - SI 35951C' data acquisition system, which is shown in Figure 3-15.

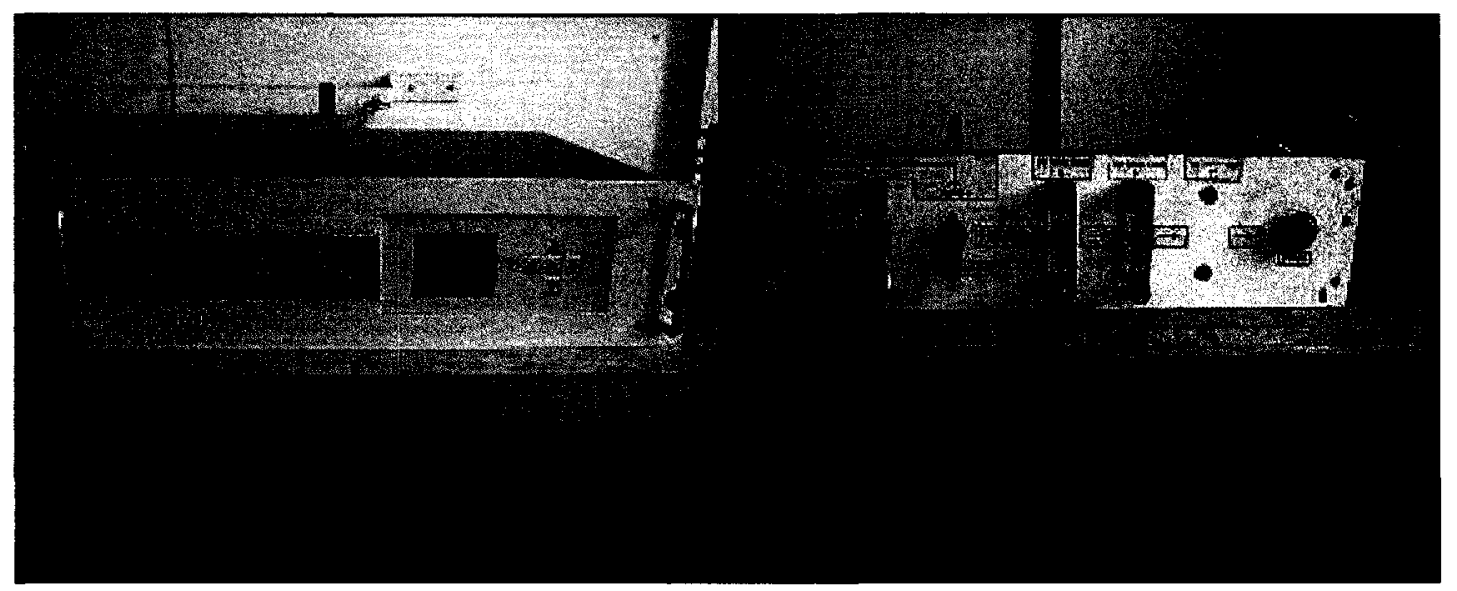

Figure 3-13: Gas analyzer 


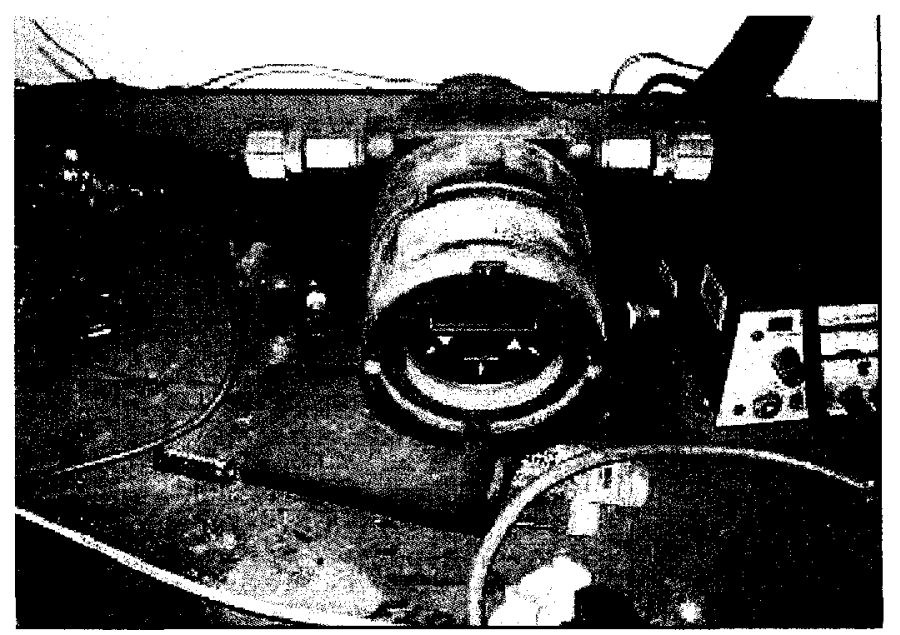

Figure 3-14: Mass flow meter

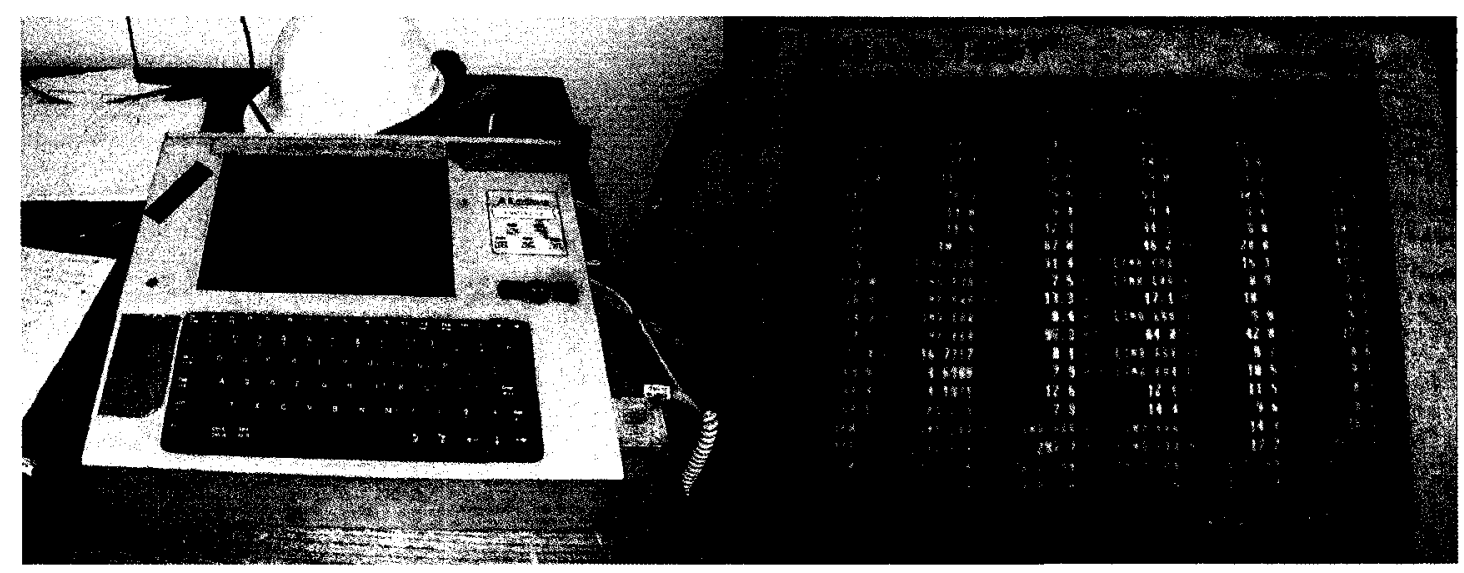

Figure 3-15: Data acquisition system 


\section{Experimental Results and Discussions}

This chapter provides detailed descriptions of the test results, such as the temperature history, the interface height, and the concentrations of $\mathrm{CO}, \mathrm{CO}_{2}$ and $\mathrm{O}_{2}$ in the stair shaft at the fire floor. Descriptions for the temperature distribution in the stair shaft and the vestibule, as well the temperature of the main compartments on the $4^{\text {th }}, 8^{\text {th }}$, and $10^{\text {th }}$ floors are given in the following sections.

The interface height in the compartment of fire origin was estimated using the temperature in the compartment and Eqn (4-1).

$T_{i}=0.6\left(T_{\max }-T_{\min }\right)+T_{\min }$

where, $T_{i}$ is the gas temperature at the interface height; $T_{\max }$ is the maximum gas temperature recorded in the compartment and $T_{\min }$ is the minimum gas temperature recorded near the bottom of the compartment.

\subsection{Group 1: Fuel Package Tests}

In this Group, four fuel package tests were conducted to simulate different fuel package fires representing combustibles and fire load densities of commercial buildings [57]. The fuel packages included two clothing fuel packages, clothing I (CLC-I) and clothing II (CLC-II), that simulated fires in clothing stores with same fuel components but containing different fire loads; a computer showroom (CMP) package that simulated a 
fire in a computer showroom and a bookstore (BK) package that simulated a fire in a bookstore. A propane T-burner with $\mathrm{HRR}$ of $75 \mathrm{~kW}$ to simulate an ignition source from a large wastepaper basket [57] was used to ignite the fuel packages for the tests in this Group. This T-burner operated for 3 minutes following ignition, and then was turned off.

\subsubsection{Description of the Fuel Packages}

The CLC-I and CLC-II packages consisted mainly of textiles. The CMP package consisted mainly of wood and plastics, and the BK package consisted of wood and paper [57]. The total fire load of CLC-II package was double the total fire load of CLC-I package. The fire load density of Test CLC-II was therefore double the density of Test CLC-I. Table 4-1 shows the mass of the different fuel packages along with their total fire loads contained in the packages used in the tests of Group 1, and the fire load densities of the fuel package tests. Figure 4-1, Figure 4-2 and Figure 4-3 show the clothing, computer and bookstore packages respectively.

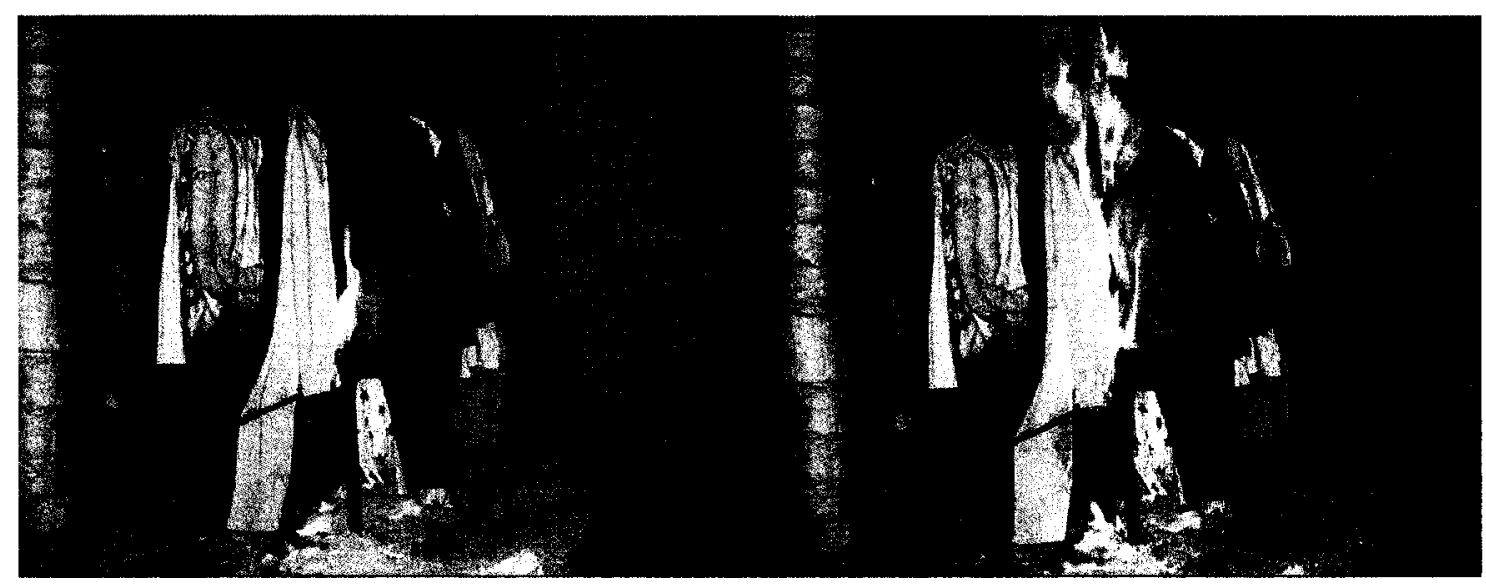

Figure 4-1: Photographs depicting the clothing II fuel package (CLC-II) and ignition 


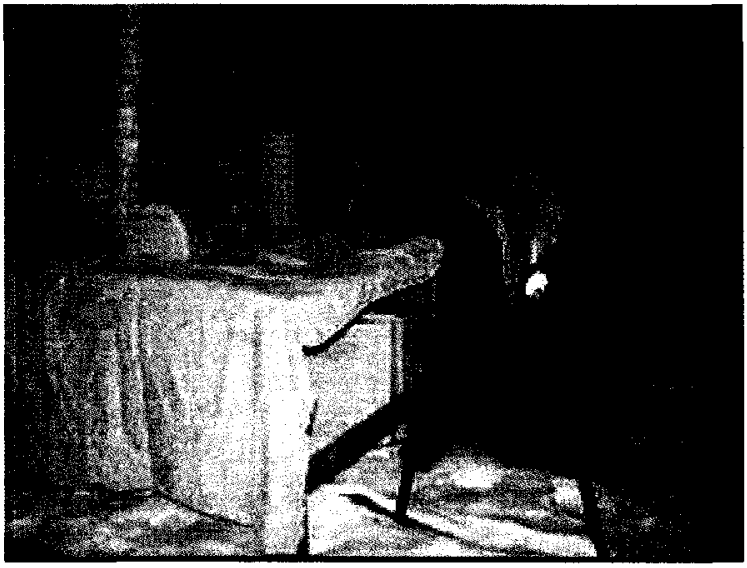

Figure 4-2: Photographs depicting the computer fuel package (CMP) and ignition

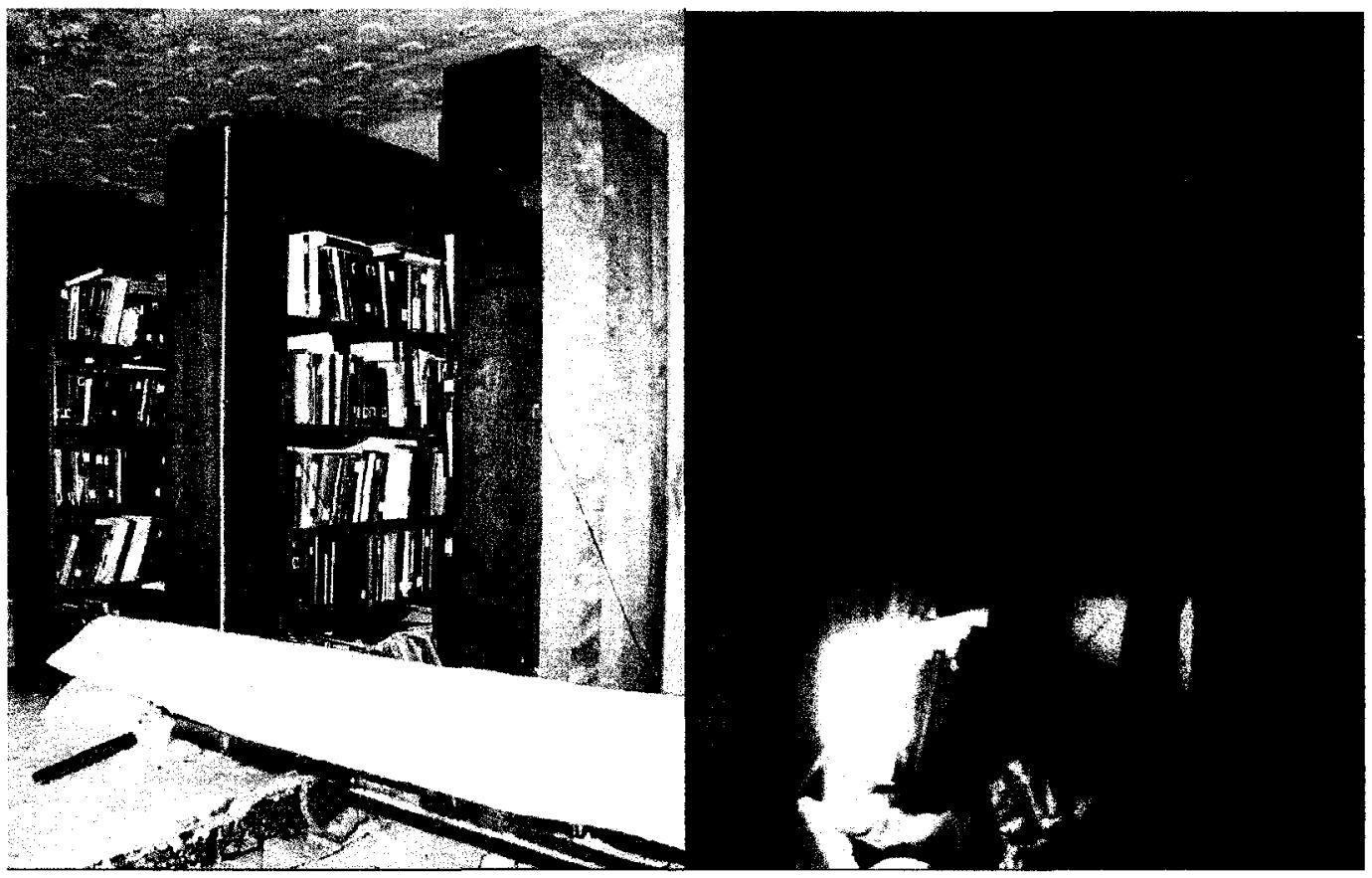

Figure 4-3: Photographs depicting the bookstore fuel package (BK) and ignition

Table 4-1: Fuel components and fire loads of Group 1: Fuel package tests

\begin{tabular}{|c|c|c|c|c|c|}
\hline \multirow{2}{*}{ Test ID } & \multicolumn{5}{|c|}{ Fuel Component } \\
\cline { 2 - 6 } & $\begin{array}{c}\text { Textiles } \\
(\mathrm{kg})\end{array}$ & $\begin{array}{c}\text { Plastics } \\
(\mathrm{kg})\end{array}$ & $\begin{array}{c}\text { Wood/Paper } \\
(\mathrm{kg})\end{array}$ & $\begin{array}{c}\text { Total } \\
(\mathrm{kg})\end{array}$ & $\begin{array}{c}\text { Total Fire } \\
\text { Load } \\
(\mathrm{MJ})\end{array}$ \\
\hline CLC-I & 30.73 & 0.304 & 4.407 & 35.44 & 661 \\
\hline CLC-II & 61.46 & 0.608 & 8.814 & 70.88 & 1322 \\
\hline CMP & 2.70 & 18.88 & 41.80 & 63.38 & 1624 \\
\hline BK & 2.294 & 0 & 603.6 & 606.9 & 10610 \\
\hline
\end{tabular}




\subsubsection{Low fire load clothing fuel package test (Test CLC-I)}

The low fire load clothing fuel package (CLC-I) was used to simulate a clothing store fire (Test CLC-I).

Figure 4-4 shows the concentration of $\mathrm{O}_{2}$ and $\mathrm{CO}_{2}$ in the stair shaft at the fire floor. The figure indicates that the lowest concentration of $\mathrm{O}_{2}$ was $6.71 \%$ at $250 \mathrm{~s}$, and the highest concentration of $\mathrm{CO}_{2}$ was $10.62 \%$ at $270 \mathrm{~s}$.

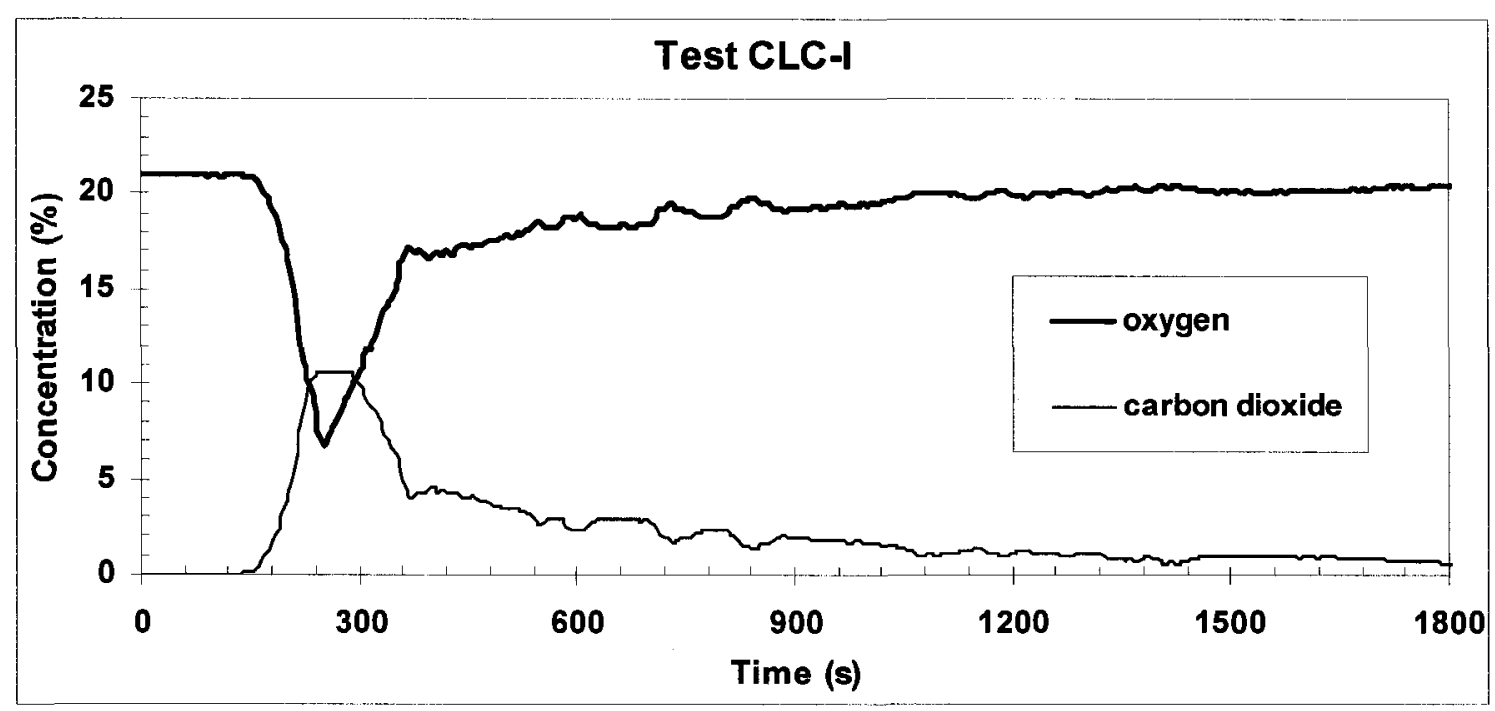

Figure 4-4: Concentration of $\mathrm{O}_{2}$ and $\mathrm{CO}_{2}$ in the stair shaft at the fire floor (Test CLC-I)

Figure 4-5 shows the concentration of $\mathrm{CO}$ in the stair shaft at the fire floor. The highest concentration of $\mathrm{CO}$ peaked at $4,811 \mathrm{ppm}$ at $250 \mathrm{~s}$. This occurred right after reaching flashover condition when the fire became ventilation controlled and it burned under oxygen vitiated conditions. Following a sharp peak the $\mathrm{CO}$ concentration dropped to about $550 \mathrm{ppm}$ and remained at that level for the duration of the fire. 


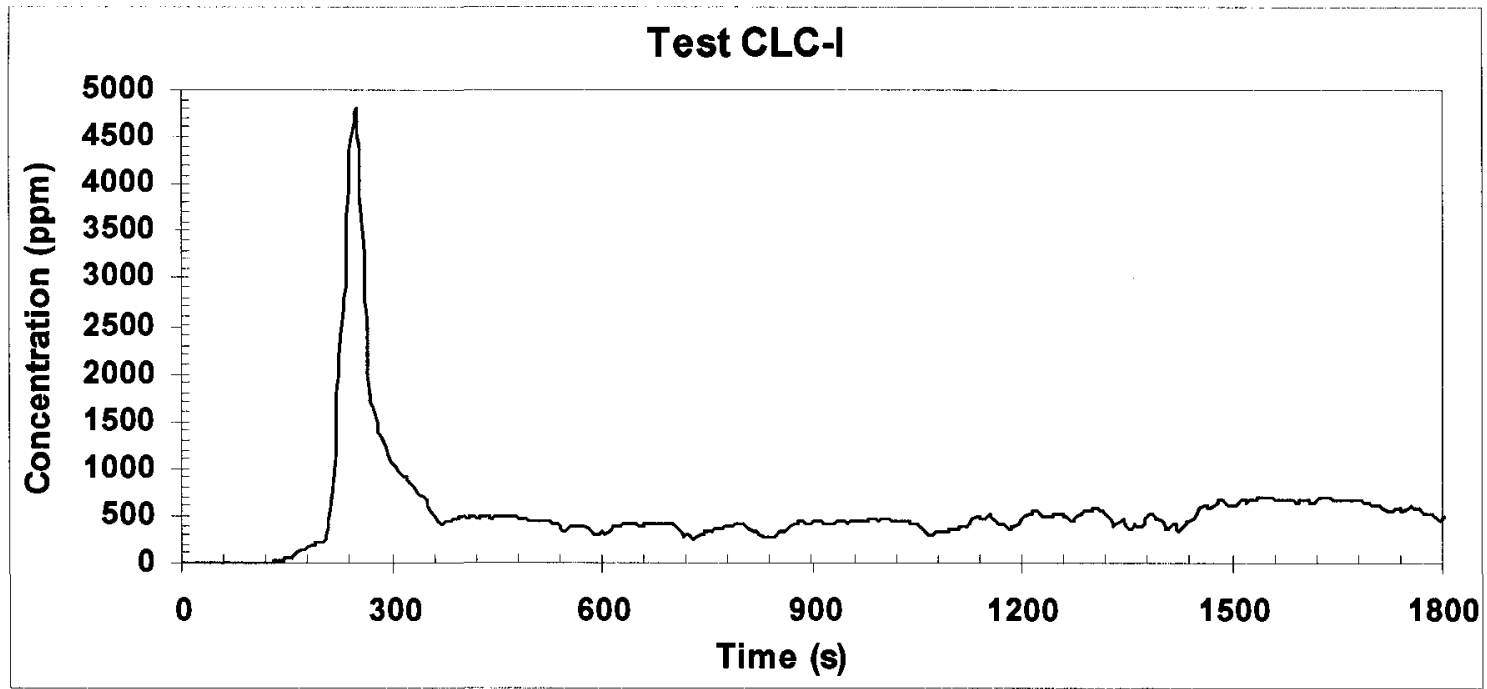

Figure 4-5: Concentration of $\mathrm{CO}$ in the stair shaft at the fire floor (Test CLC-I)

The temperatures measured by the thermocouple tree located in the corner of the fire compartment are shown in Figure 4-6. It can be noted from the figure that the temperature in the fire compartment increased to a maximum value of $684^{\circ} \mathrm{C}$ at $235 \mathrm{~s}$ after ignition. The fire reached the flashover condition at $220 \mathrm{~s}$ using the upper layer average temperature of $600^{\circ} \mathrm{C}$ as the flashover criterion. Once it reached a peak temperature, the temperature in the fire compartment started to decrease steadily until the end of the test at $1800 \mathrm{~s}$.

Figure 4-7 shows gas temperature profiles in the fire compartment at different times. The figure also shows the interface heights estimated using Eqn (4-1), which are indicated by arrows in the figure. At $180 \mathrm{~s}$, the interface height was at $1.7 \mathrm{~m}$, however at the time of reaching the flashover condition it dropped to $1.07 \mathrm{~m}$. It then dropped further to $0.92 \mathrm{~m}$ at $235 \mathrm{~s}$ and after that it increased to $1.11 \mathrm{~m}$ at $415 \mathrm{~s}$. 


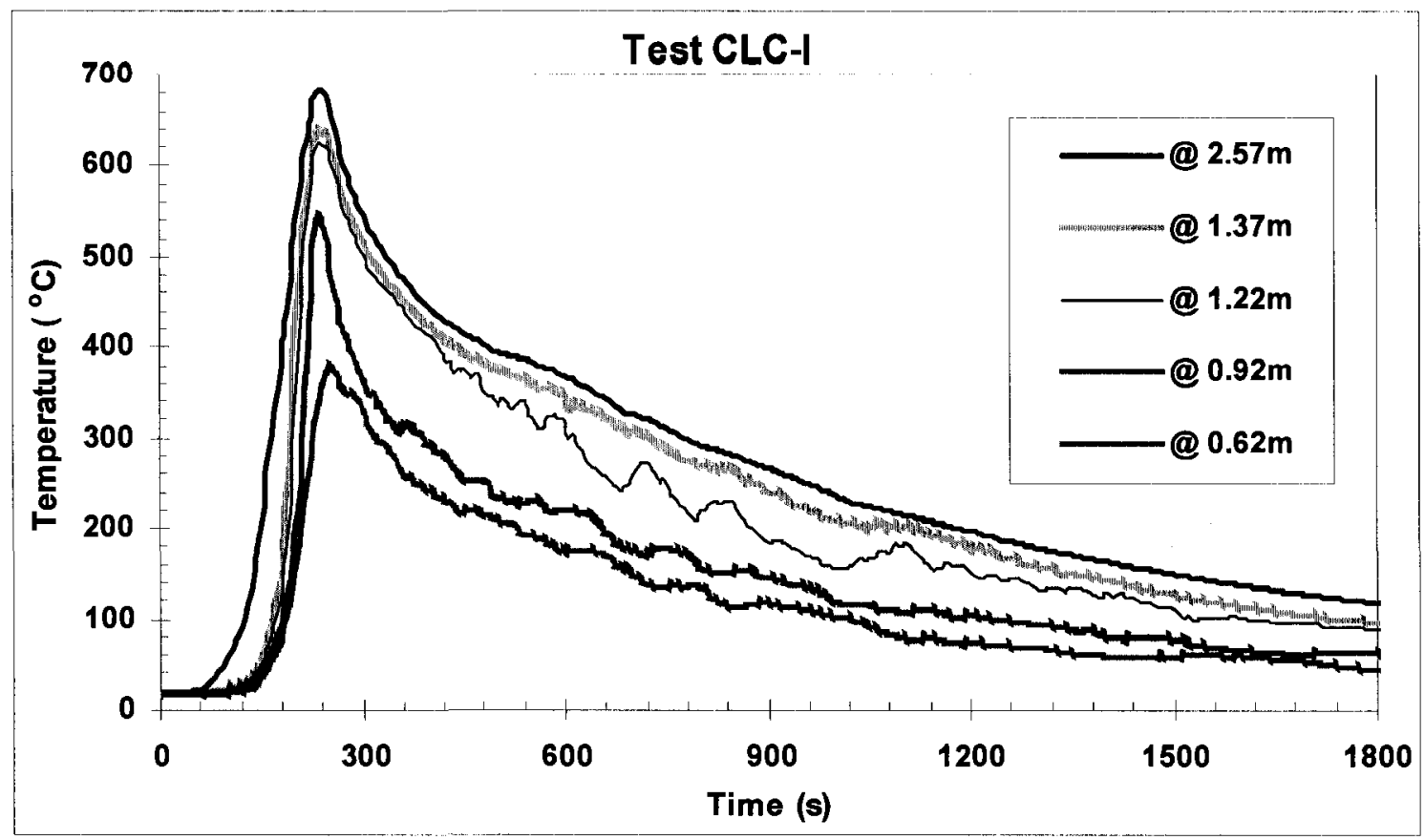

Figure 4-6: Gas temperature histories at different heights in the corner of the fire compartment (Test CLC-I)

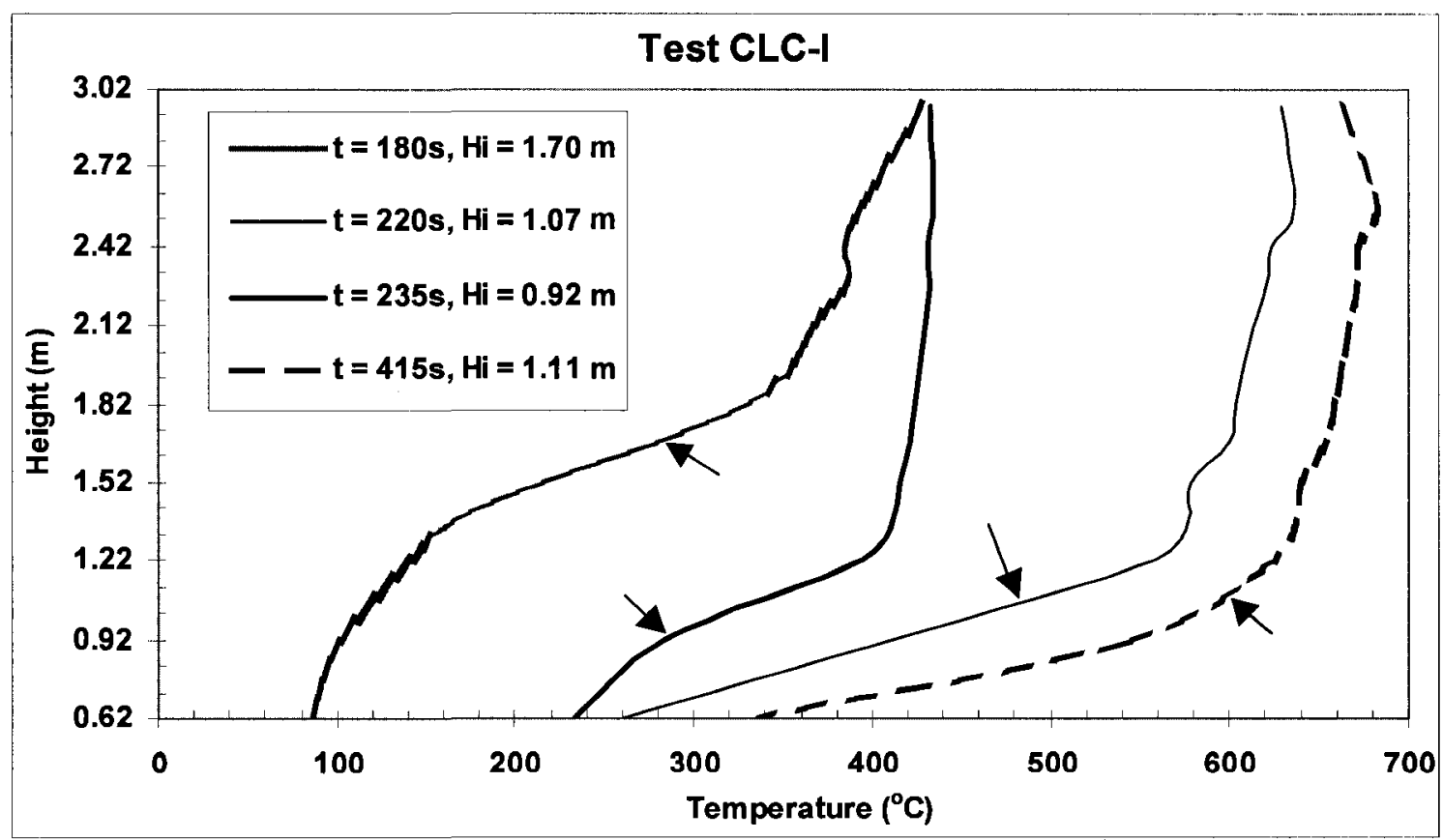

Note: Arrows indicate the locations of interface heights.

Figure 4-7: Gas temperature profiles in the fire compartment at different times (Test CLC-I) 
A short thermocouple tree with 5 TCs was installed at the doorway between the stair shaft and the vestibule of the $2^{\text {nd }}$ floor. Smoke moved into the stair shaft at the fire floor from the fire compartment via this vestibule. Figure 4-8 shows the temperature histories at different heights at the doorway recorded by the thermocouples of this TC tree. A maximum temperature of $478^{\circ} \mathrm{C}$ at $250 \mathrm{~s}$ was recorded by the thermocouple at $2.05 \mathrm{~m}$ height. The gas temperature profiles at the doorway at different times, before and after reaching the maximum temperature at $220 \mathrm{~s}$ and $430 \mathrm{~s}$, and at the time of reaching the maximum temperature at $250 \mathrm{~s}$ are shown in Figure 4-9.

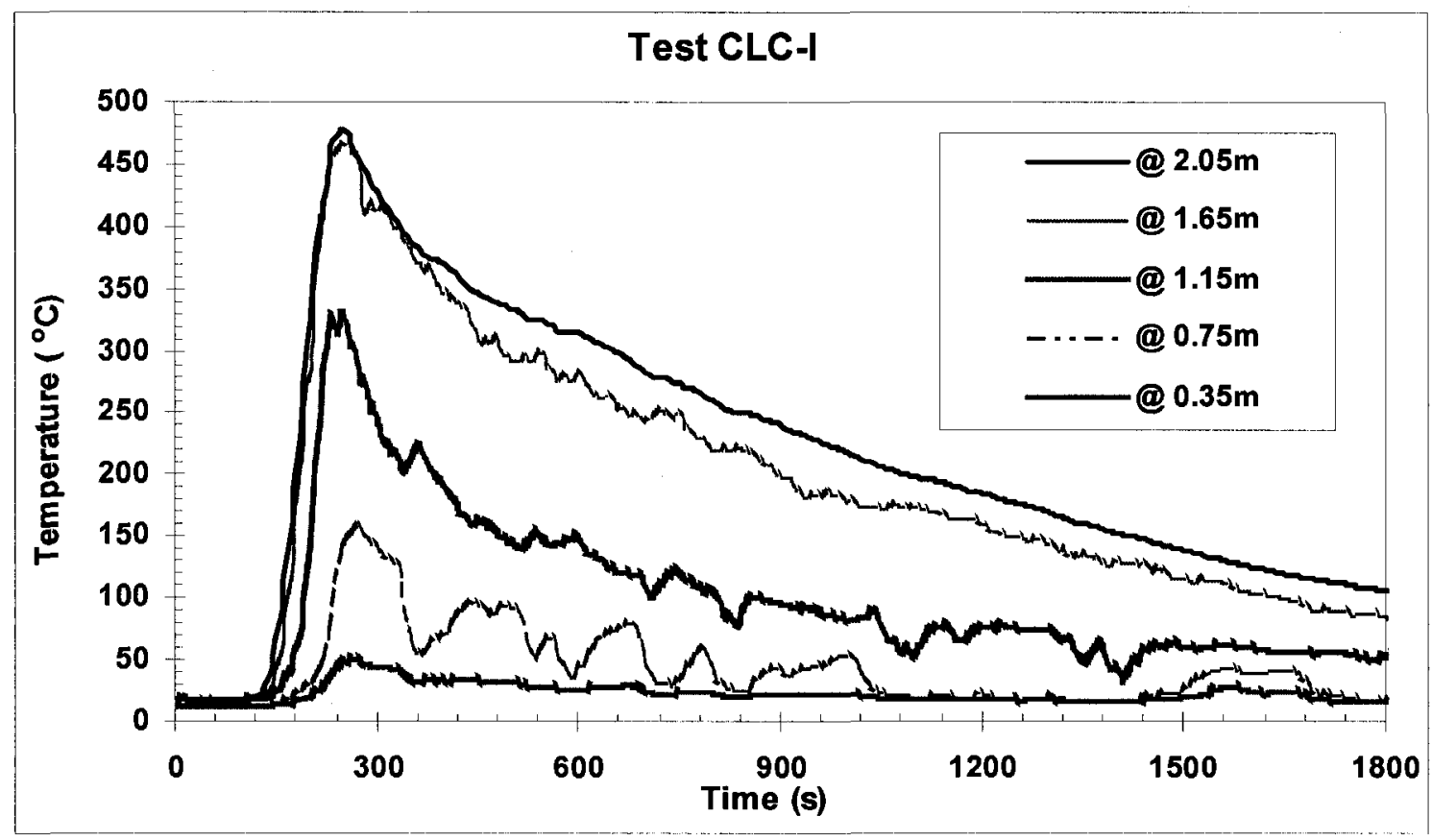

Figure 4-8: Gas temperature histories at different heights at the doorway (Test CLC-I) 


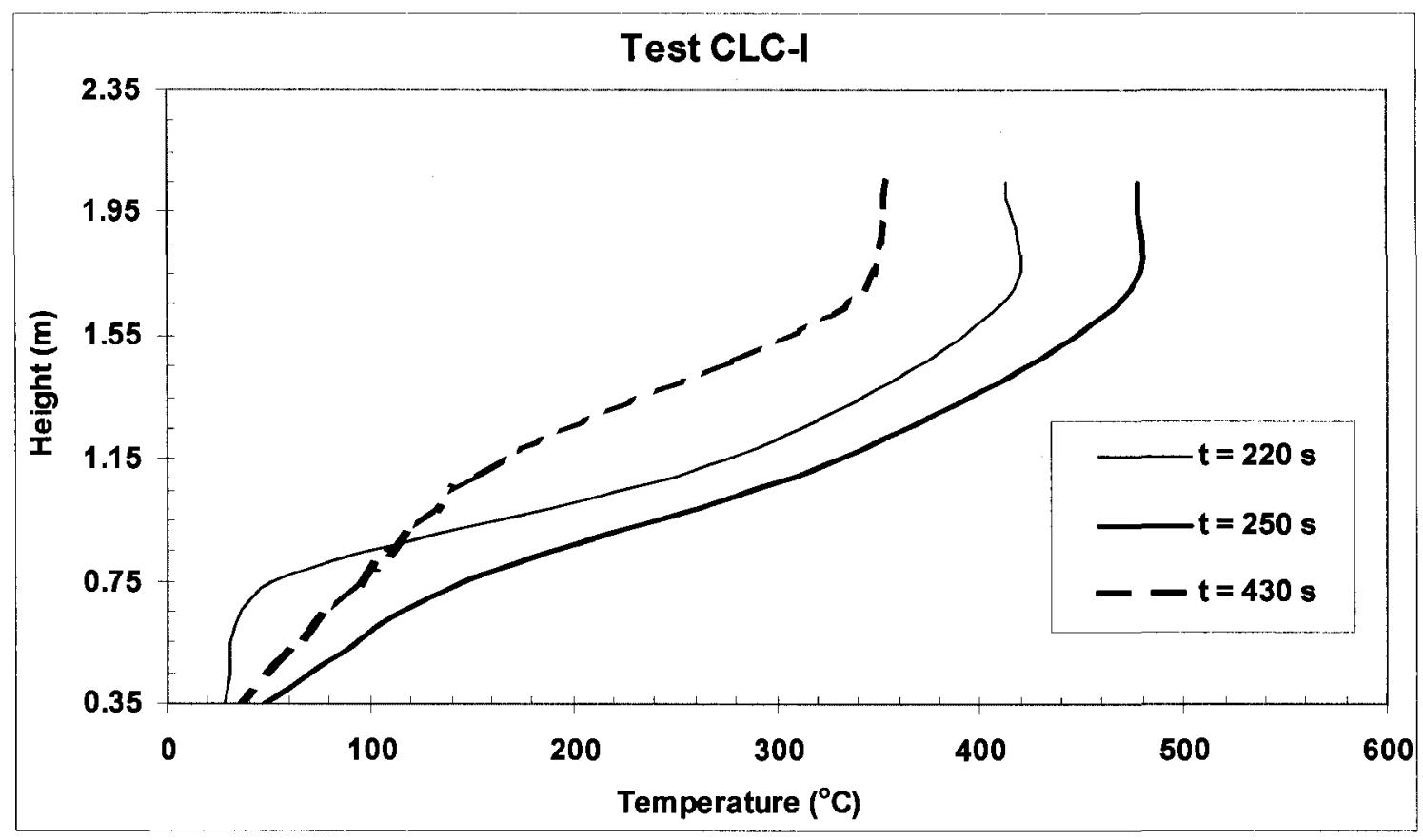

Figure 4-9: Gas temperature profiles at the doorway at different times (Test CLC-I)

The gas temperature histories in the stair shaft for Test CLC-I as recorded by the thermocouples installed in the stair shaft at each floor from the $2^{\text {nd }}$ to $10^{\text {th }}$ are shown in Figure 4-10. The figure shows that the maximum gas temperature in the stair shaft of the fire floor was $288^{\circ} \mathrm{C}$ at $265 \mathrm{~s}$. As stated before, the maximum gas temperature was $684^{\circ} \mathrm{C}$ at $235 \mathrm{~s}$ in the compartment of fire origin and $478^{\circ} \mathrm{C}$ at $250 \mathrm{~s}$ at the doorway of the fire floor. Table 4-2 lists the maximum values of the gas temperatures and their corresponding times. The table indicates that the maximum gas temperatures in the stair shaft decrease with height, due to heat losses to the boundaries and mixing with cold air. 


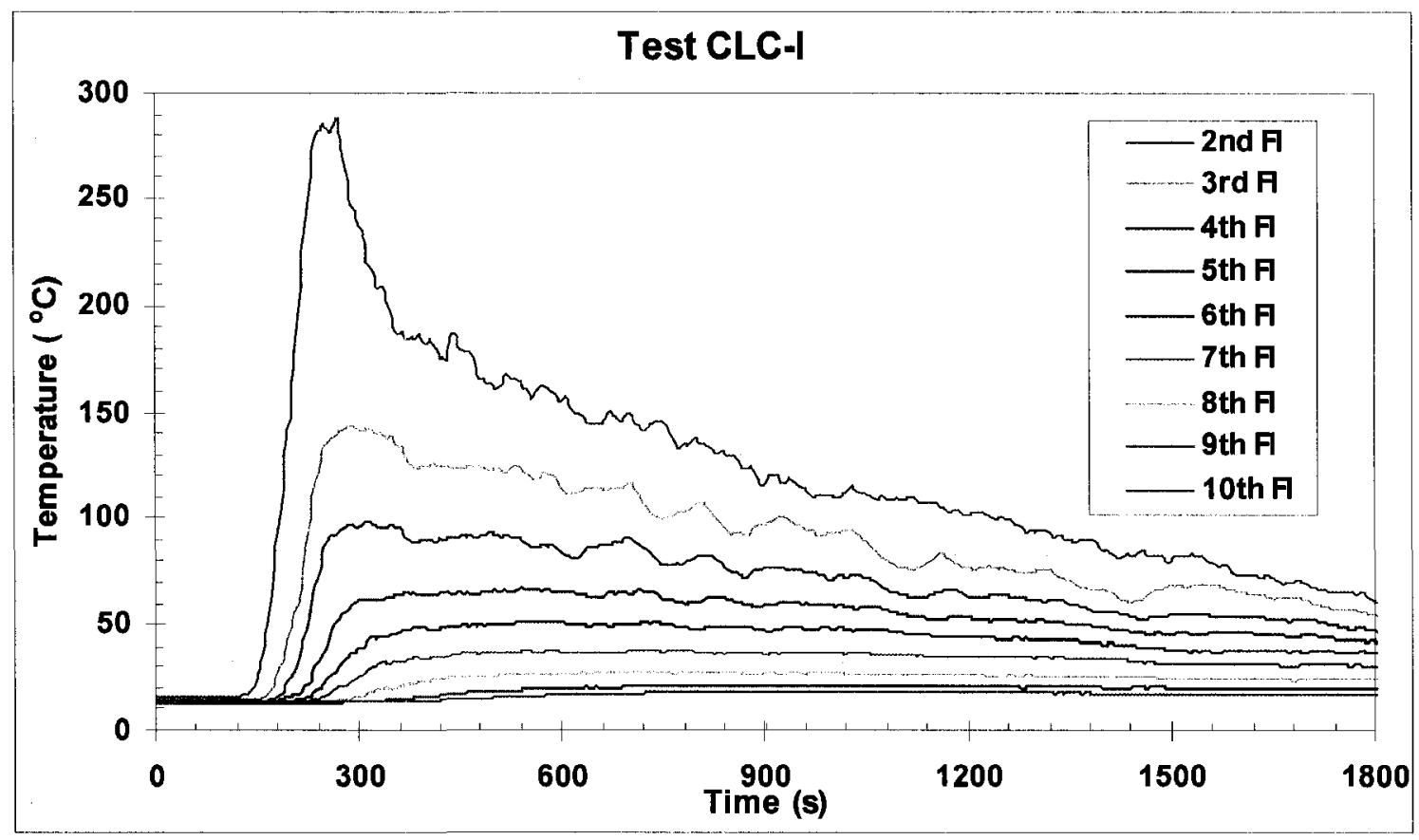

Figure 4-10: Gas temperature histories in the stair shaft (Test CLC-I)

Table 4-2: The maximum gas temperatures in the stair shaft of different floors for Test CLC-I

\begin{tabular}{|c|c|c|c|c|c|c|c|c|c|c|}
\hline $\begin{array}{c}\text { Test } \\
\text { ID }\end{array}$ & Floor \# & $\begin{array}{c}2^{\text {nd }} \\
\text { floor }\end{array}$ & $\begin{array}{c}3^{\text {rd }} \\
\text { floor }\end{array}$ & $\begin{array}{c}4^{\text {th }} \\
\text { floor }\end{array}$ & $\begin{array}{c}5^{\text {th }} \\
\text { floor }\end{array}$ & $\begin{array}{c}6^{\text {th }} \\
\text { floor }\end{array}$ & $\begin{array}{c}7^{\text {th }} \\
\text { floor }\end{array}$ & $\begin{array}{c}8^{\text {th }} \\
\text { floor }\end{array}$ & $\begin{array}{c}9^{\text {th }} \\
\text { floor }\end{array}$ & $\begin{array}{c}10^{\text {th }} \\
\text { floor }\end{array}$ \\
\hline \multirow{4}{*}{ CLC-I } & $\mathrm{T}_{\mathrm{i}}\left({ }^{\circ} \mathrm{C}\right)$ & 15.9 & 15.0 & 14.4 & 14.0 & 13.6 & 13.3 & 13.0 & 13.0 & 13.9 \\
\cline { 2 - 11 } & $\mathrm{T}_{\mathrm{p}}\left({ }^{\circ} \mathrm{C}\right)$ & 288.2 & 143.6 & 97.9 & 67.3 & 51.7 & 38.7 & 18.0 & 21.1 & 18.5 \\
\cline { 2 - 11 } & $\Delta \mathrm{T}\left({ }^{\circ} \mathrm{C}\right)$ & 272.3 & 128.6 & 83.5 & 53.3 & 38.1 & 25.4 & 15.0 & 8.1 & 4.6 \\
\cline { 2 - 10 } & $\mathrm{t}_{\mathrm{p}}(\mathrm{s})$ & 265 & 285 & 315 & 540 & 555 & 760 & 795 & 835 & 1025 \\
\hline
\end{tabular}

Note: $T_{i}$ is the initial gas temperature; $T_{p}$ is the peak gas temperature; $\Delta T$ is the gas temperature difference between $T_{p}$ and $T_{i}$; and $t_{p}$ is the time when the gas reached the peak temperature

The doors between the stair shaft and the vestibules of the $3^{\text {rd }}, 5^{\text {th }}, 7^{\text {th }}$ and $9^{\text {th }}$ (odd floors) were fully closed, while the doors of the $4^{\text {th }}, 6^{\text {th }}, 8^{\text {th }}$ and $10^{\text {th }}$ (even floors) were fully open. In the vestibules of each floor, a TC was installed to measure the gas temperature history. Figure 4-11 shows the gas temperature histories recorded by the thermocouples in the vestibules of the floors with open doors. The maximum values of the gas 
temperature and their corresponding times in the vestibules of the floors with open doors are listed in Table 4-3. The data show that the maximum gas temperatures in the vestibules of the floors with open doors decrease with height.

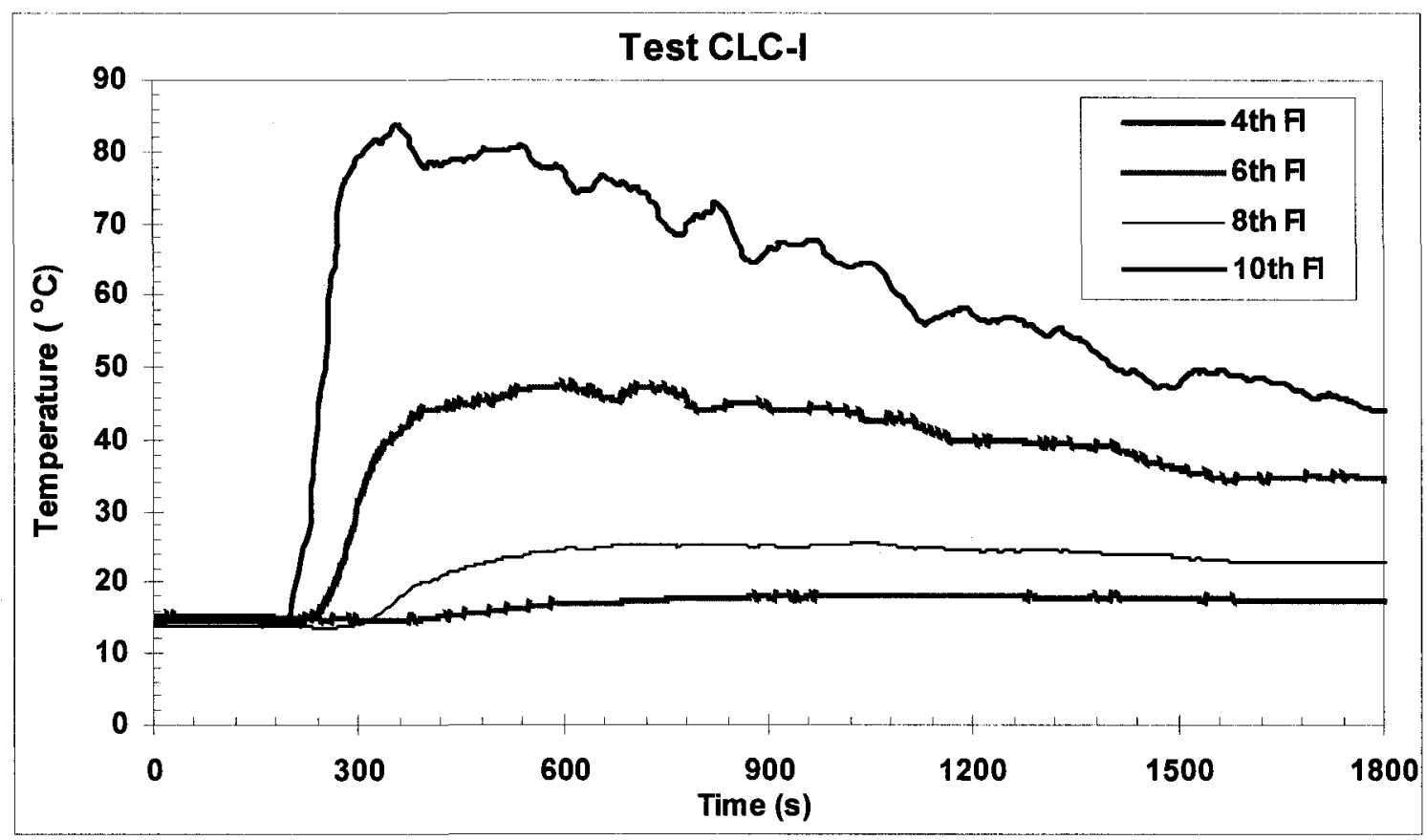

Figure 4-11: Gas temperature histories in the vestibules of the floors with open doors (Test CLC-I)

Table 4-3: The maximum gas temperatures in the vestibules of the floors with open doors for Test CLC-I

\begin{tabular}{|c|c|c|c|c|c|}
\hline Test ID & Floor \# & $4^{\text {th }}$ floor & $6^{\text {th }}$ floor & $8^{\text {th }}$ floor & $10^{\text {th }}$ floor \\
\hline \multirow{4}{*}{ CLC-I } & $\mathrm{T}_{\mathrm{i}}\left({ }^{\circ} \mathrm{C}\right)$ & 14.8 & 14.4 & 13.9 & 15.2 \\
\cline { 2 - 6 } & $\mathrm{T}_{\mathrm{p}}\left({ }^{\circ} \mathrm{C}\right)$ & 83.9 & 47.5 & 25.7 & 18.1 \\
\cline { 2 - 6 } & $\Delta \mathrm{T}\left({ }^{\circ} \mathrm{C}\right)$ & 69.1 & 33.1 & 11.8 & 2.9 \\
\cline { 2 - 6 } & $\mathrm{t}_{\mathrm{p}}(\mathrm{s})$ & 355 & 615 & 1040 & 1050 \\
\hline
\end{tabular}

Note: $T_{i}$ is the initial gas temperature; $T_{p}$ is the peak gas temperature; $\Delta T$ is the gas temperature difference between $\mathrm{Tp}$ and $\mathrm{Ti}$; and tp is the time when the gas reached the peak temperature

Figure 4-12 shows the gas temperature histories in the vestibules of the floors with closed doors. The figure indicates that the gas temperatures in the vestibules of the floors with 
closed doors increased by a few degrees especially for the lower floors demonstrating that the doors were not completely sealed. Slight leakages existed between the stair shaft and the vestibules at the odd floors but they were insignificant.

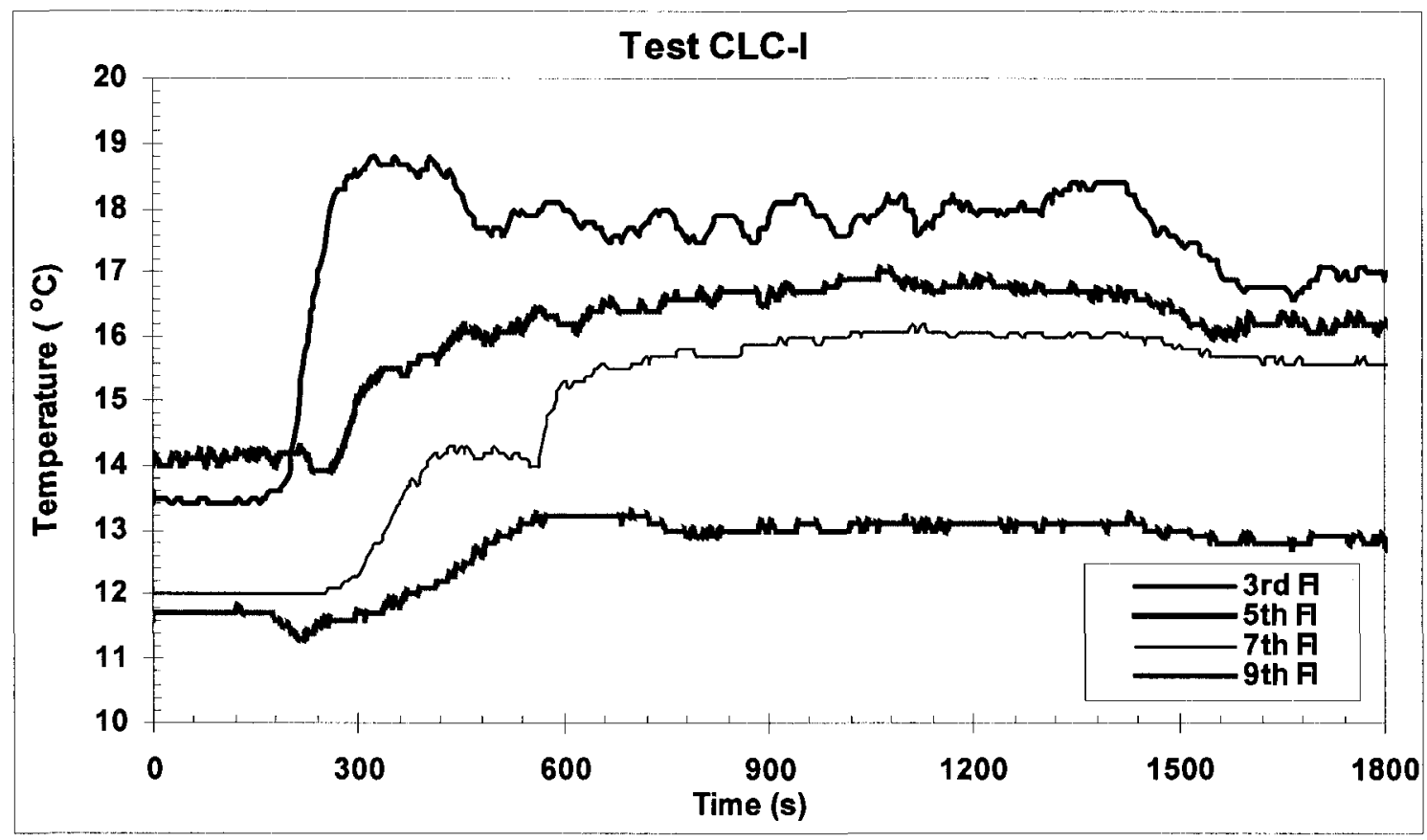

Figure 4-12: Gas temperature histories in the vestibules of the floors with closed doors (Test CLC-I)

On the even floors, the doors between the stair shaft and the vestibules were kept fully open, and the doors between the vestibules and the main compartments were partially open. Smoke from the stair shaft entered the main compartments through the vestibules. The gas temperature histories recorded by the thermocouples located in the main compartments of the $4^{\text {th }}, 8^{\text {th }}$ and $10^{\text {th }}$ floors are shown in Figure $4-13$. The maximum values of the gas temperature and their corresponding times are listed in Table 4-4. 


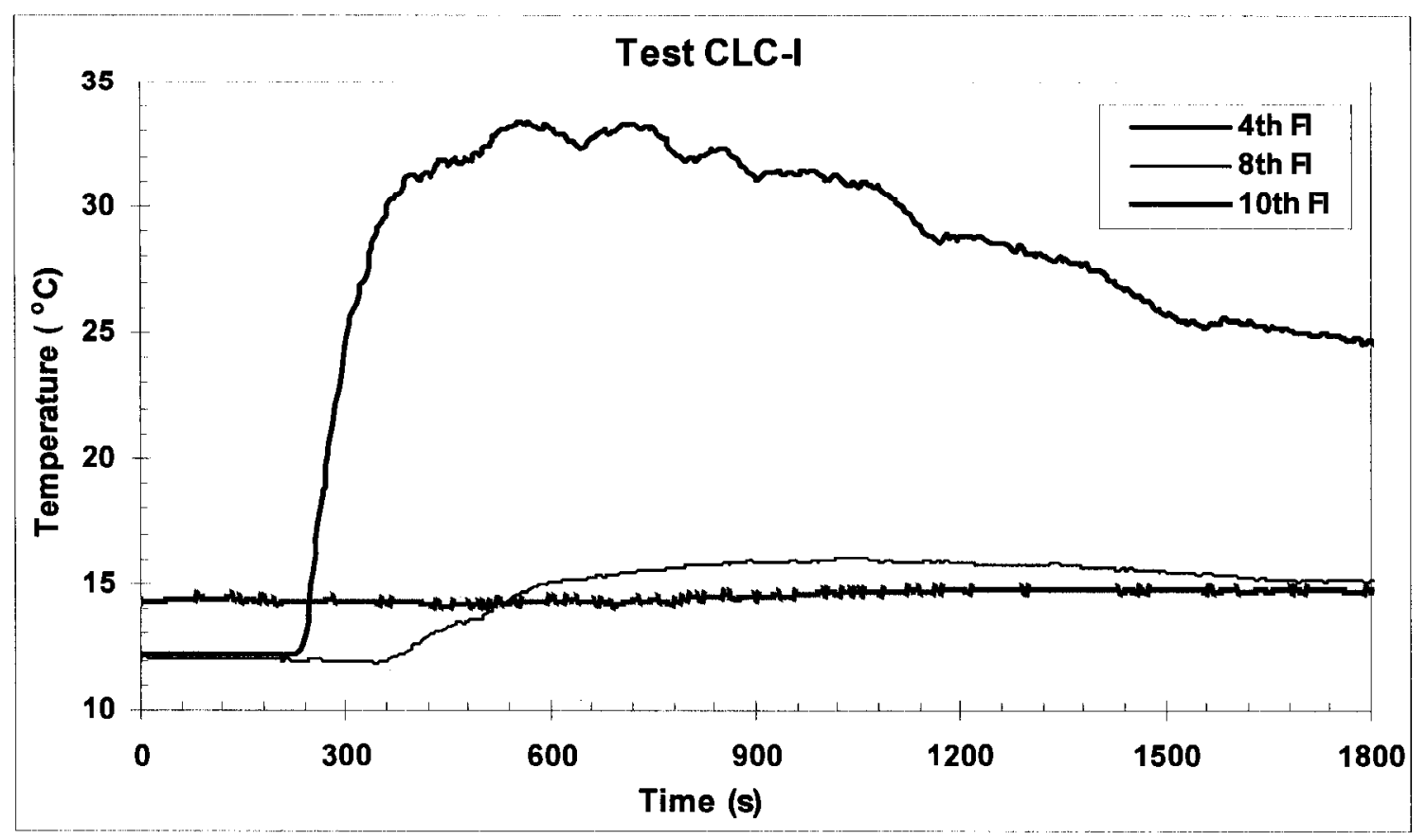

Figure 4-13: Gas temperature histories in the main compartments of the floors of the $4^{\text {th }}, 8^{\text {th }}$ and $10^{\text {th }}$ (Test CLC-I)

Table 4-4: The maximum gas temperatures in the main compartments of the floors of the $4^{\text {th }}, 8^{\text {th }}$ and $10^{\text {th }}$ for Test CLC-I

\begin{tabular}{|c|c|c|c|c|}
\hline Test ID & Floor \# & $4^{\text {th }}$ floor & $8^{\text {th }}$ floor & $10^{\text {th }}$ floor \\
\hline \multirow{3}{*}{ CLC-I } & $\mathrm{T}_{\mathrm{i}}\left({ }^{\circ} \mathrm{C}\right)$ & 12.3 & 12.1 & 14.3 \\
\cline { 2 - 5 } & $\mathrm{T}_{\mathrm{p}}\left({ }^{\circ} \mathrm{C}\right)$ & 33.4 & 16.1 & 14.9 \\
\cline { 2 - 5 } & $\Delta \mathrm{T}\left({ }^{\circ} \mathrm{C}\right)$ & 21.1 & 4.0 & 0.6 \\
\cline { 2 - 5 } & $\mathrm{t}_{\mathrm{p}}(\mathrm{s})$ & 555 & 1060 & 1985 \\
\hline
\end{tabular}

Note: $T_{i}$ is the initial gas temperature; $T_{p}$ is the peak gas temperature; $\Delta T$ is the gas temperature difference between $T_{p}$ and $T_{i} ;$ and $t_{p}$ is the time when the gas reached the peak temperature

\subsubsection{High fire load clothing fuel package test (Test CLC-II)}

The high fire load clothing fuel package (CLC-II) was used to conduct Test CLC-II. The fire load density of this fuel package was twice the fire load density of package CLC-I and contained the same fuel components. 
Figure 4-14 shows the concentration of $\mathrm{O}_{2}$ and $\mathrm{CO}_{2}$ in the stair shaft at the fire floor of Test CLC-II. The figure indicates that the lowest concentration of $\mathrm{O}_{2}$ was $4.62 \%$ at $255 \mathrm{~s}$, which was lower than the value of $6.71 \%$ at $250 \mathrm{~s}$ for Test CLC-I. The highest concentration of $\mathrm{CO}_{2}$ was $14.74 \%$ at $255 \mathrm{~s}$, compared to the value of $10.62 \%$ at $270 \mathrm{~s}$ for Test CLC-I.

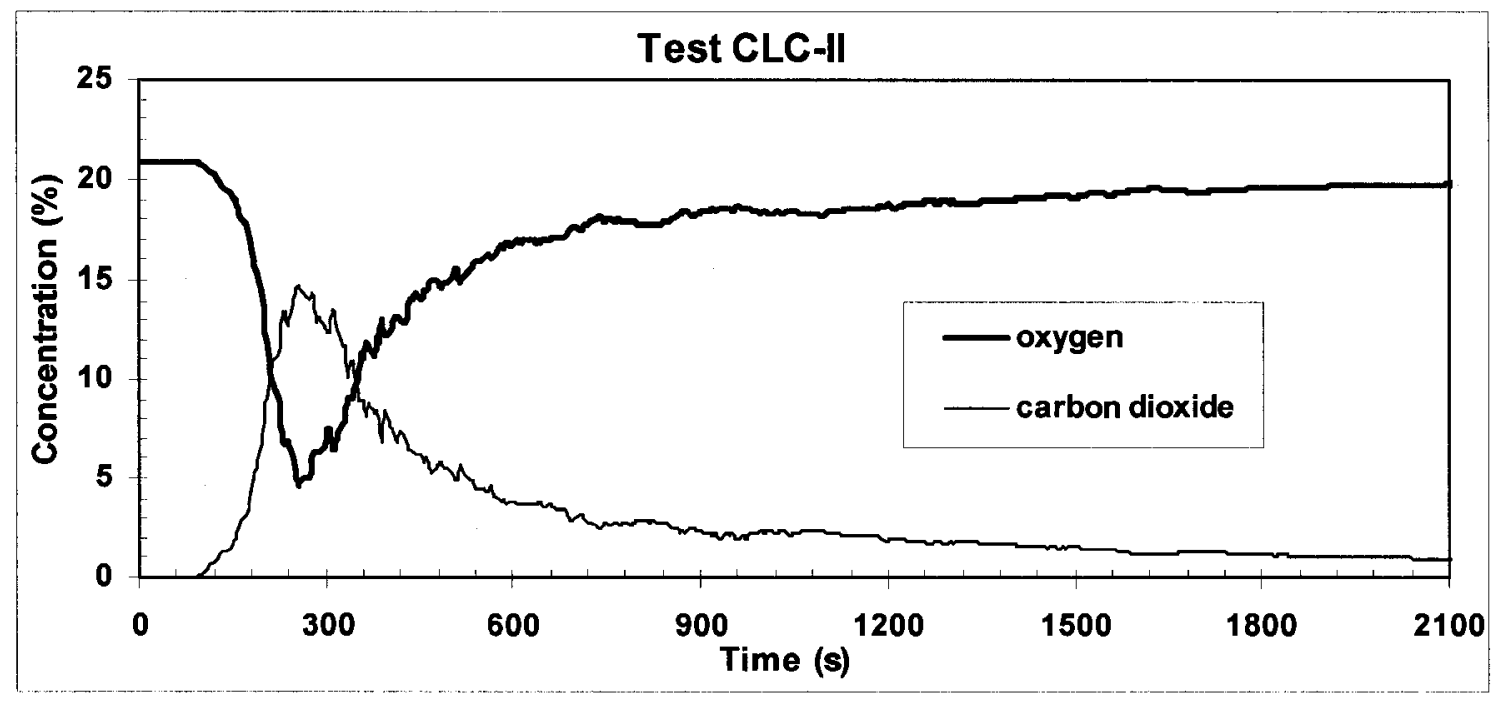

Figure 4-14: Concentration of $\mathrm{O}_{2}$ and $\mathrm{CO}_{2}$ in stair shaft at the fire floor (Test CLC-II)

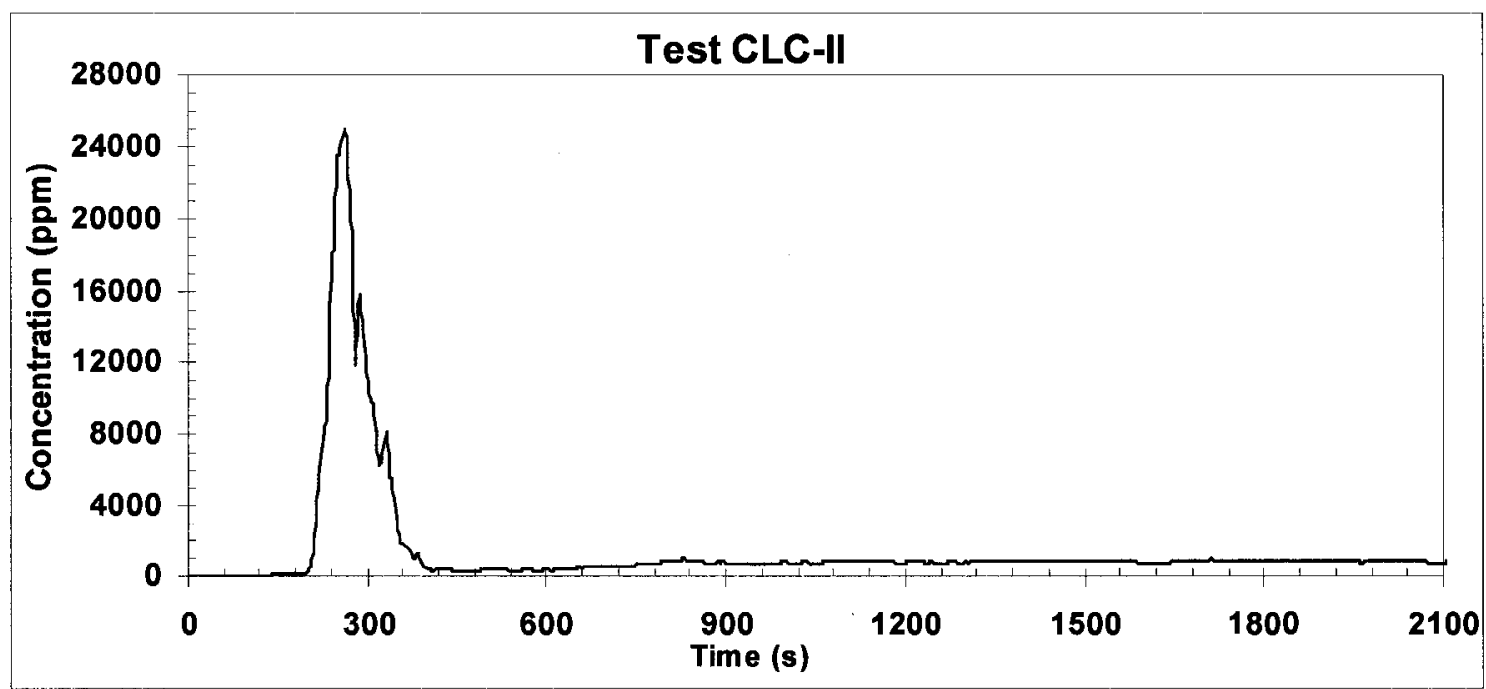

Figure 4-15: Concentration of $\mathrm{CO}$ in the stair shaft at the fire floor (Test CLC-II) 
The concentration of $\mathrm{CO}$ in the stair shaft at the fire floor is shown in Figure 4-15. It can be noted from the figure that the concentration of $\mathrm{CO}$ is quite large, $24,917 \mathrm{ppm}$ at $260 \mathrm{~s}$.

The temperatures measured by the thermocouple tree located in the corner of the fire compartment are shown in Figure 4-16. The fire reached the flashover condition of $600^{\circ} \mathrm{C}$ in the upper layer at $210 \mathrm{~s}$. The time of reaching this condition was close to that of Test CLC-I, indicating that the two clothing fuel packages had similar fire growth rates. This was expected as both packages contained the same fuel components. It can be seen from Figure 4-16 that the temperature in the fire compartment increased quickly until about $250 \mathrm{~s}$. After this time, the temperatures increased at a slower rate reaching a maximum value of $827^{\circ} \mathrm{C}$ at $335 \mathrm{~s}$. All the temperatures in the fire compartment for Test CLC-II were higher than those during Test CLC-I, thereby indicating that the fire was more intense in this test. The fire entered the decay phase at about $400 \mathrm{~s}$, and the temperature started to decrease steadily until the end of the test at $2100 \mathrm{~s}$.

Figure 4-17 shows gas temperature profiles and interface heights in the fire compartment at different times. The figure indicates higher temperatures for the CLC-II test fire compared to Test CLC-I. For example, at $335 \mathrm{~s}$, the temperature was very high even at $0.62 \mathrm{~m}$ height. Before reaching the flashover condition, the interface height was $1.49 \mathrm{~m}$ at $180 \mathrm{~s}$, however once the flashover condition was reached, the interface height dropped to $1.11 \mathrm{~m}$ at $335 \mathrm{~s}$. During the decay phase of the fire, the interface height slightly increased to $1.21 \mathrm{~m}$ at $480 \mathrm{~s}$. 


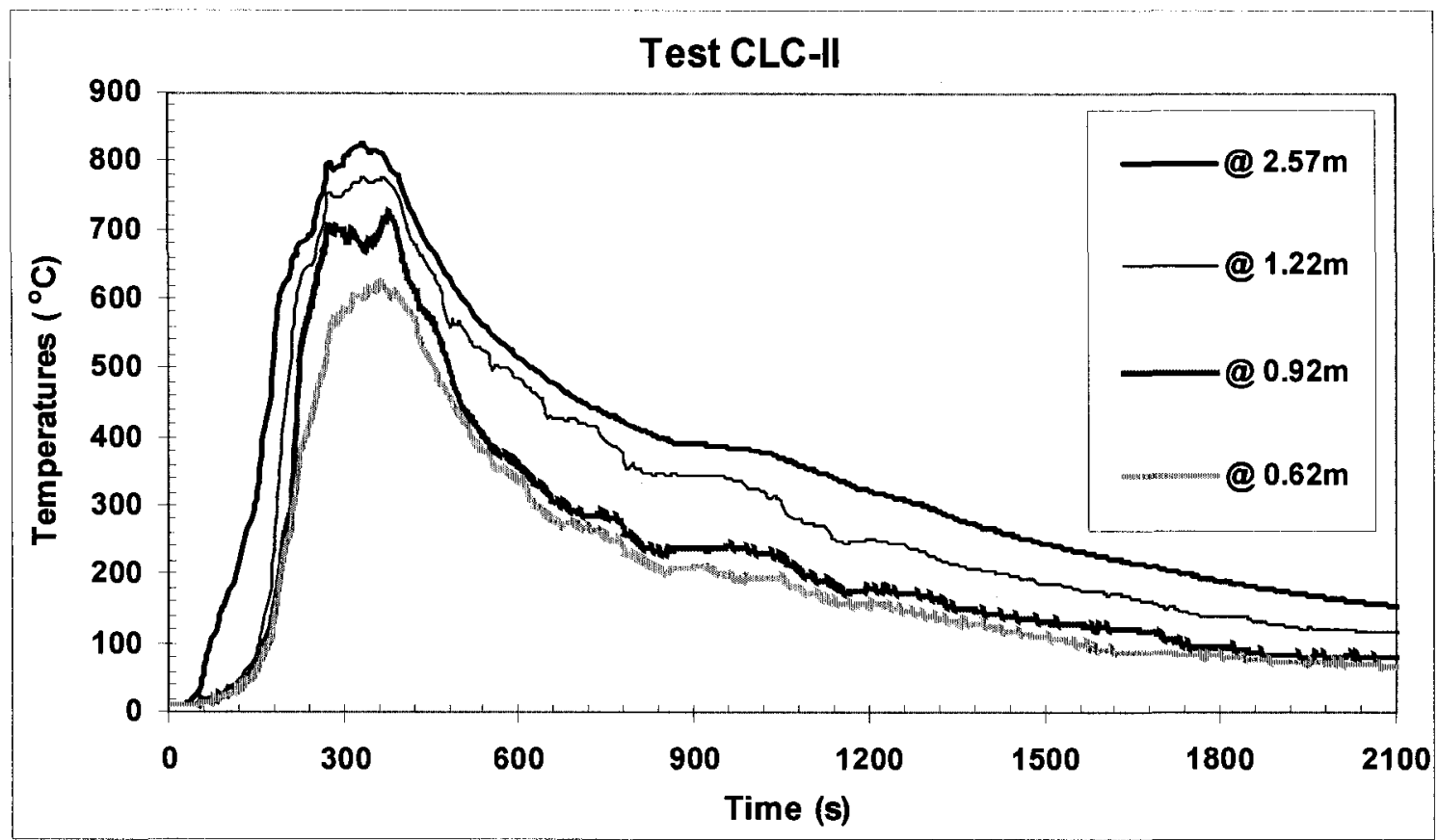

Figure 4-16: Gas temperature histories at different heights in the corner of the fire compartment (Test CLC-II)

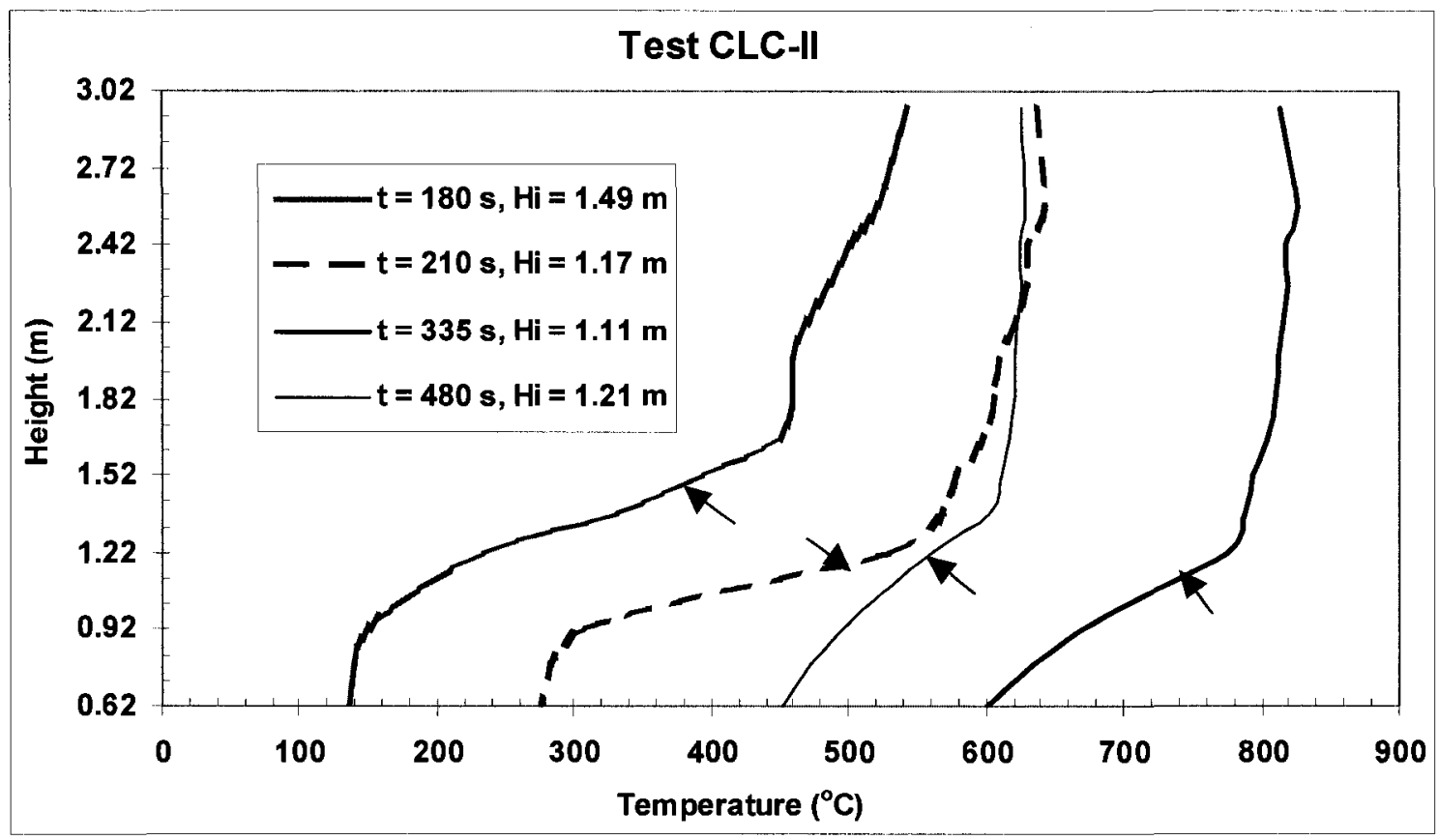

Note: Arrows indicate the locations of interface heights

Figure 4-17: Gas temperature profiles in the fire compartment at different times (Test CLC-II) 
Figure 4-18 shows the gas temperature histories at different heights at the doorway during Test CLC-II as recorded by the thermocouples placed at the doorway. A maximum temperature of $816^{\circ} \mathrm{C}$ at $315 \mathrm{~s}$ was recorded by the thermocouple at $2.05 \mathrm{~m}$ height. This temperature was almost as high as the peak temperature, $827^{\circ} \mathrm{C}$ at $335 \mathrm{~s}$, in the fire compartment, and its corresponding time was earlier compared to the peak temperature time in the fire compartment. The concentration of $\mathrm{O}_{2}$ was as low as $4.62 \%$ at $255 \mathrm{~s}$ in the stair shaft at the fire floor (Figure 4-14). Due to the movement of air from the stair shaft to the fire compartment, fresh air entering the fire compartment through the stair shaft and the vestibule of the $2^{\text {nd }}$ floor, the concentration of oxygen increased in the stair shaft, the vestibule of the $2^{\text {nd }}$ floor and the fire compartment, and further in the stair shaft compared to the fire compartment. Despite the oxygen supply to the fire compartment, the oxygen was insufficient to support the complete burning of the decomposed fuel in the fire compartment. With the movement of smoke from the fire compartment to the stair shaft via the vestibule, some of the hot unburned fuel carried by the smoke entered the doorway and the stair shaft area where it burned, once oxygen supply was met.

Figure 4-19 shows four gas temperature profiles at the doorway at different times for Test CLC-II, which are as follows: (a) before reaching the flashover condition in the fire compartment (at $210 \mathrm{~s}$ ), (b) $315 \mathrm{~s}$ at which time the maximum temperature was reached in the doorway, (c) at $335 \mathrm{~s}$, when the maximum temperature was reached in the compartment of fire, and (d) at $480 \mathrm{~s}$ at a time after reaching the maximum temperature in the fire compartment. 


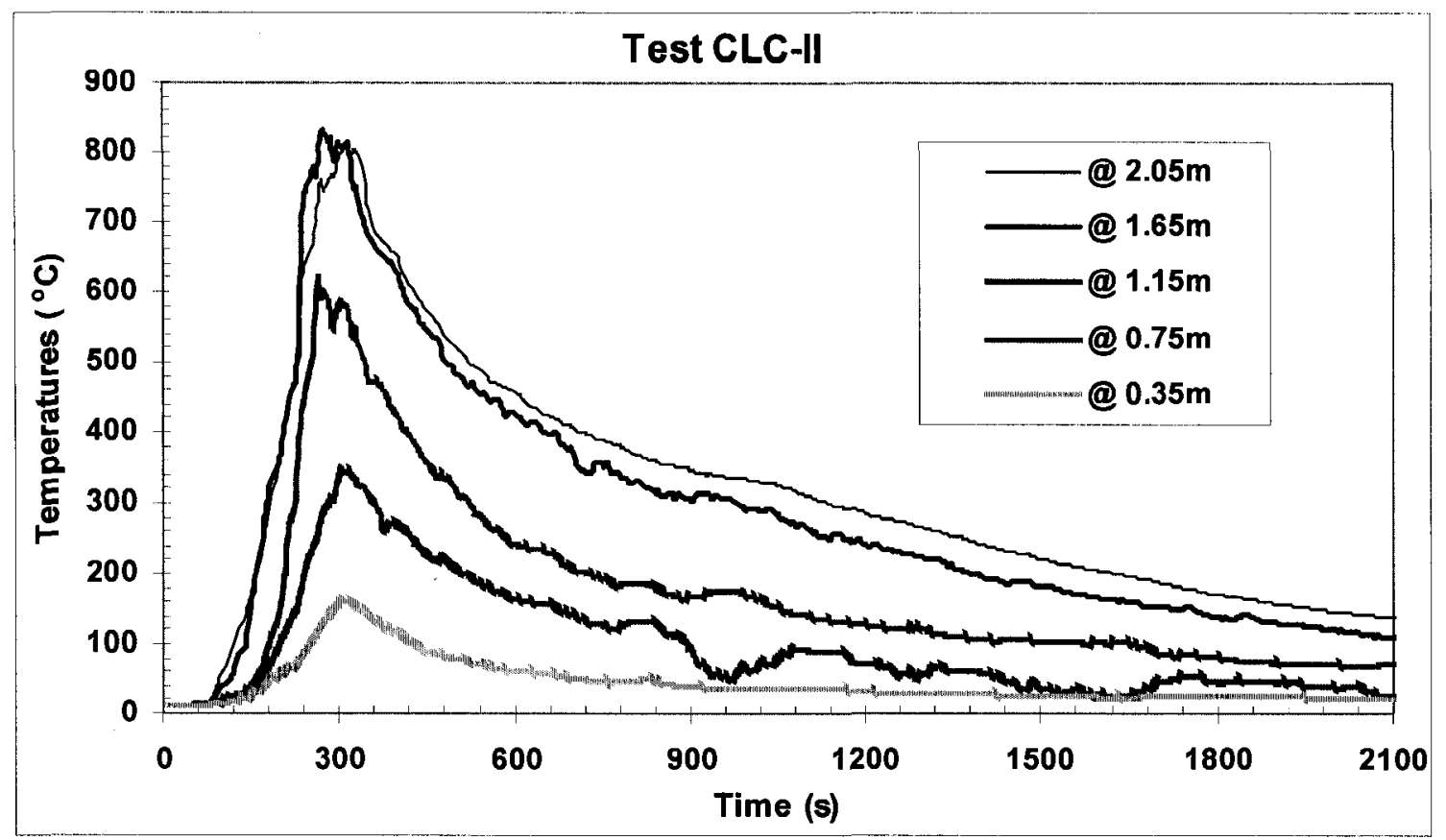

Figure 4-18: Gas temperature histories at different heights at the doorway (Test CLC-II)

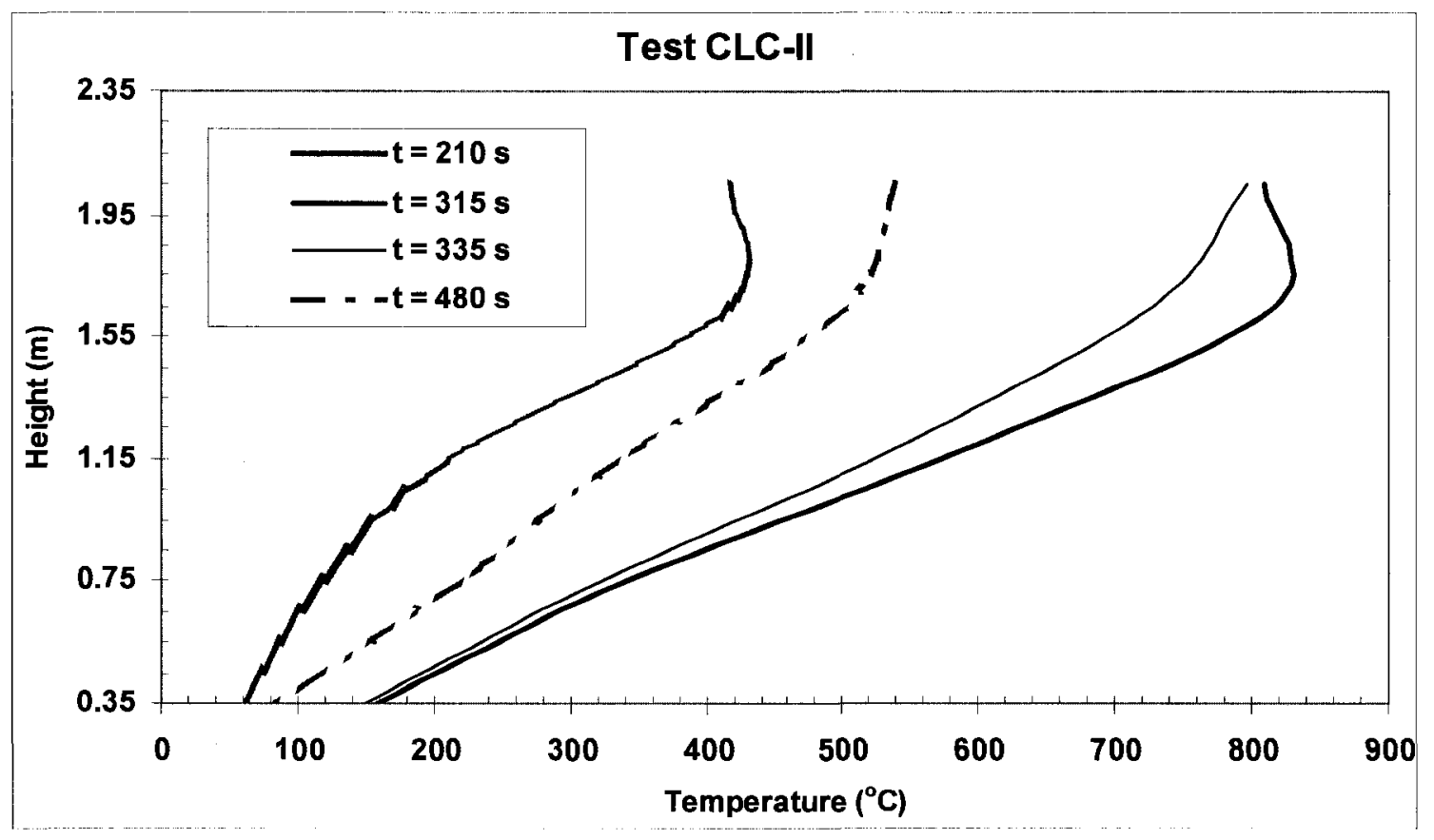

Figure 4-19: Gas temperature profiles at the doorway at different times (Test CLC-II) 
The gas temperature histories in the stair shaft for Test CLC-II recorded by the thermocouples installed in the stair shaft at each floor from the $2^{\text {nd }}$ to $10^{\text {th }}$ are shown in Figure 4-20. The maximum gas temperature in the stair shaft at the fire floor was $393^{\circ} \mathrm{C}$ at $275 \mathrm{~s}$. As mentioned earlier, the maximum gas temperature was $827^{\circ} \mathrm{C}$ at $335 \mathrm{~s}$ in the fire compartment, and $816^{\circ} \mathrm{C}$ at $315 \mathrm{~s}$ at the doorway of the fire floor. The temperature peaked early in the stair shaft at the fire floor compared to the peak temperatures in the fire compartment or the doorway because some unburned hydrocarbon burned in the stair shaft at the fire floor when meeting sufficient fresh air there. The maximum values of the gas temperature and their corresponding times at the stair shaft for floors $2^{\text {nd }}$ to $10^{\text {th }}$ are listed in Table 4-5.

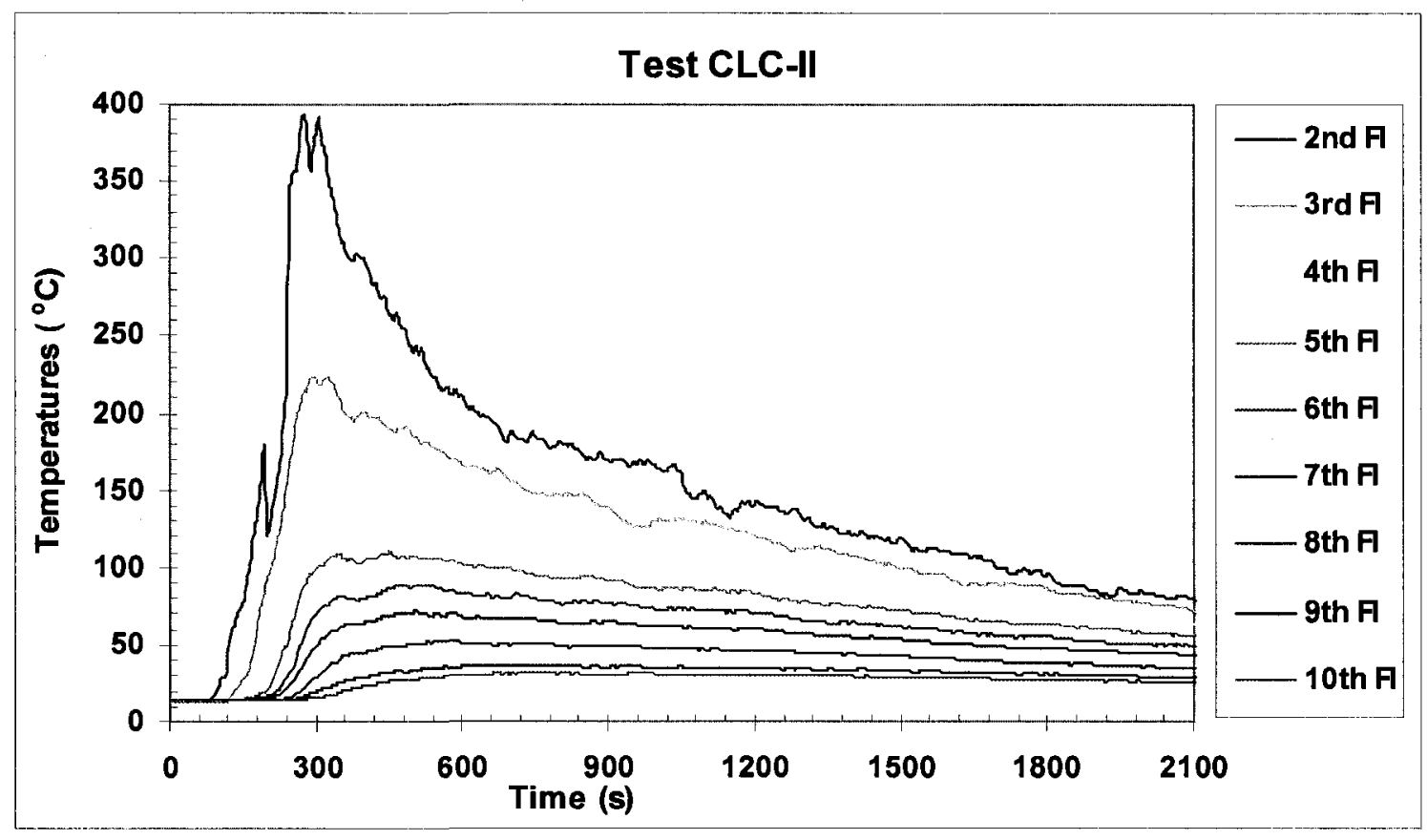

Figure 4-20: Gas temperature histories in the stair shaft (Test CLC-II) 
Table 4-5: The maximum gas temperatures in the stair shaft of different floors for Test CLC-II

\begin{tabular}{|c|c|c|c|c|c|c|c|c|c|c|}
\hline \multicolumn{2}{|c|}{ Test ID } & $\begin{array}{l}2^{\text {nd }} \\
\text { floor }\end{array}$ & $\begin{array}{c}3^{\text {rd }} \\
\text { floor }\end{array}$ & $\begin{array}{c}4^{\text {th }} \\
\text { floor }\end{array}$ & $\begin{array}{c}5^{\text {th }} \\
\text { floor }\end{array}$ & $\begin{array}{l}6^{\text {th }} \\
\text { floor }\end{array}$ & $\begin{array}{c}7^{\text {th }} \\
\text { floor } \\
\end{array}$ & $\begin{array}{c}8^{\text {th }} \\
\text { floor }\end{array}$ & $\begin{array}{c}9^{\text {th }} \\
\text { floor }\end{array}$ & $\begin{array}{l}10^{\mathrm{th}} \\
\text { floor }\end{array}$ \\
\hline \multirow{4}{*}{ CLC-II } & $\mathrm{T}_{\mathrm{i}}\left({ }^{\mathrm{o}} \mathrm{C}\right)$ & 13.6 & 13.6 & 13.8 & 13.7 & 14.1 & 14.0 & 13.9 & 14.4 & 15.0 \\
\hline & $\mathrm{T}_{\mathrm{p}}\left({ }^{0} \mathrm{C}\right)$ & 393.3 & 223.3 & 155.3 & 110.3 & 88.5 & 71.5 & 53.6 & 37.4 & 31.9 \\
\hline & & 379.7 & 209.7 & 141.5 & 96.9 & 74.4 & 57.5 & 39.7 & 23.0 & 16.9 \\
\hline & $t_{p}(s)$ & 275 & 290 & 325 & 455 & 480 & 505 & 585 & 795 & 965 \\
\hline
\end{tabular}

The peak temperatures in the stair shaft were higher than those during Test CLC-I. However, the time taken to achieve peak temperatures at the top floor for Test CLC-II was shorter compared to Test CLC-I, because greater buoyancy contained more energy and caused gases to move faster. The table also indicates that the maximum gas temperatures in the stair shaft decreased with height, due to more heat losses to the boundaries and mixing with cold air.

Figure 4-21 shows the gas temperature histories recorded by the thermocouples in the vestibules of the floors with open doors. The maximum values of the gas temperature and their corresponding times in the vestibules of the floors with open doors are listed in Table 4-6. The maximum temperatures were higher than those during Test CLC-I and decreased with height, because of heat losses to the boundaries and mixing with cold air.

Figure 4-22 shows the gas temperature histories in the vestibules of the floors with closed doors. The test results were similar to the Test CLC-I. For example, the gas temperatures in the vestibules of the floors with closed doors still increased a few degrees compared with the initial values. The doors between the stair shaft and the vestibules of the odd floors were fully closed, but not completely sealed. 


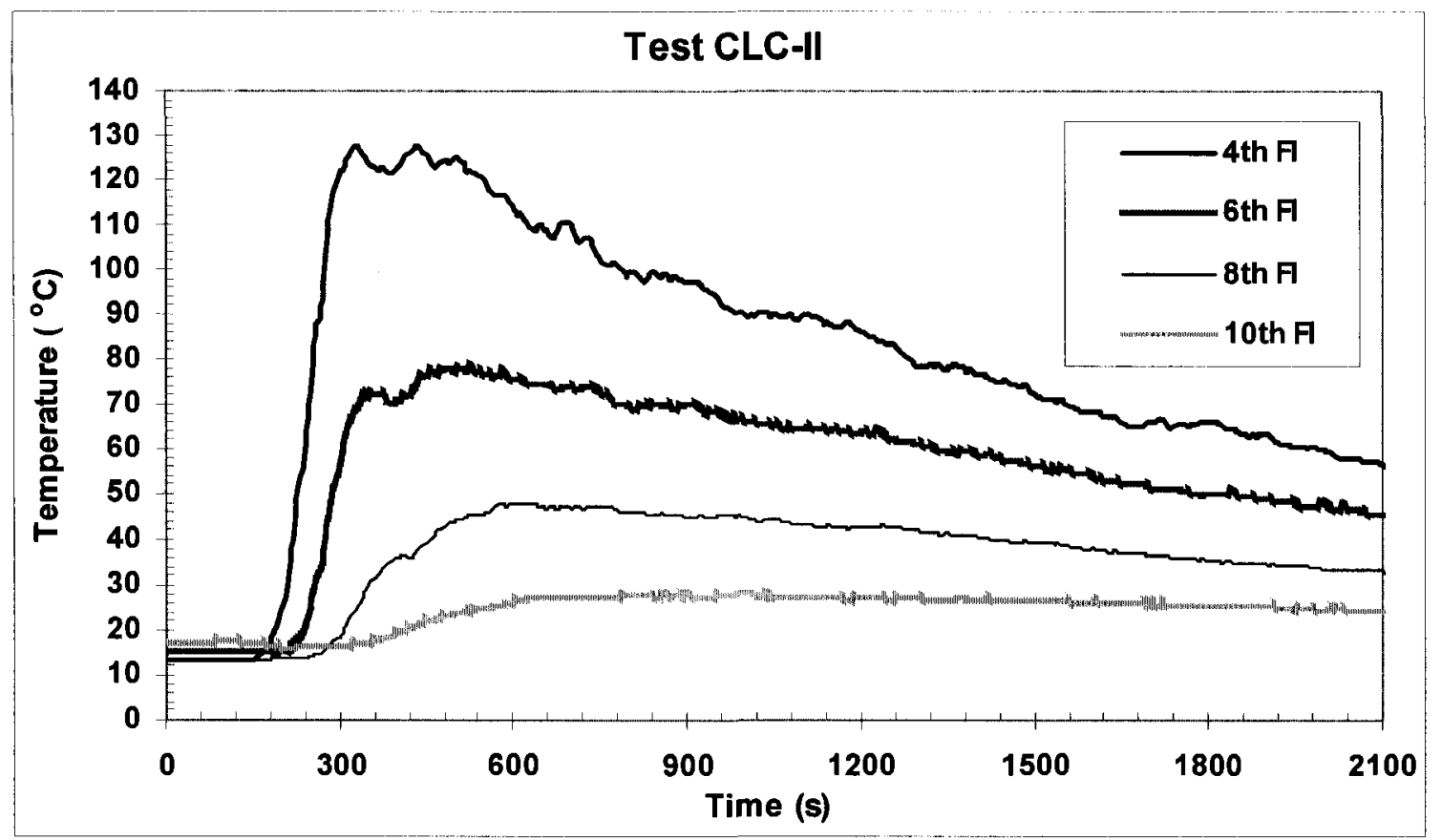

Figure 4-21: Gas temperature histories in the vestibules of the floors with open doors (Test CLC-II)

Table 4-6: The maximum gas temperatures in the vestibules of the floors with open doors for Test CLC-II

\begin{tabular}{|c|c|c|c|c|c|}
\hline \multicolumn{2}{|c|}{ Test ID } & $4^{\text {th }}$ floor & $6^{\text {th }}$ floor & $8^{\text {th }}$ floor & $10^{\text {th }}$ floor \\
\hline \multirow{4}{*}{ CLC-II } & $\mathrm{T}_{\mathrm{i}}\left({ }^{\circ} \mathrm{C}\right)$ & 13.6 & 15.3 & 13.5 & 17.5 \\
\cline { 2 - 6 } & $\mathrm{T}_{\mathrm{p}}\left({ }^{\circ} \mathrm{C}\right)$ & 127.8 & 78.2 & 47.9 & 28.2 \\
\cline { 2 - 6 } & $\Delta \mathrm{T}\left({ }^{\circ} \mathrm{C}\right)$ & 114.2 & 62.9 & 34.4 & 10.7 \\
\cline { 2 - 6 } & $\mathrm{t}_{\mathrm{p}}(\mathrm{s})$ & 325 & 525 & 610 & 995 \\
\hline
\end{tabular}

Figure 4-23 shows the gas temperature histories in the main compartments of $4^{\text {th }}, 8^{\text {th }}$ and $10^{\text {th }}$ floors. The maximum values of the gas temperature and their corresponding times at the main compartments of $4^{\text {th }}, 8^{\text {th }}$ and $10^{\text {th }}$ floors are listed in Table 4-7. The maximum temperatures during Test CLC-II were higher compared to those during Test CLC-I. The maximum gas temperatures at the main compartments decreased with the height. These results are similar to the CLC-I test results. 


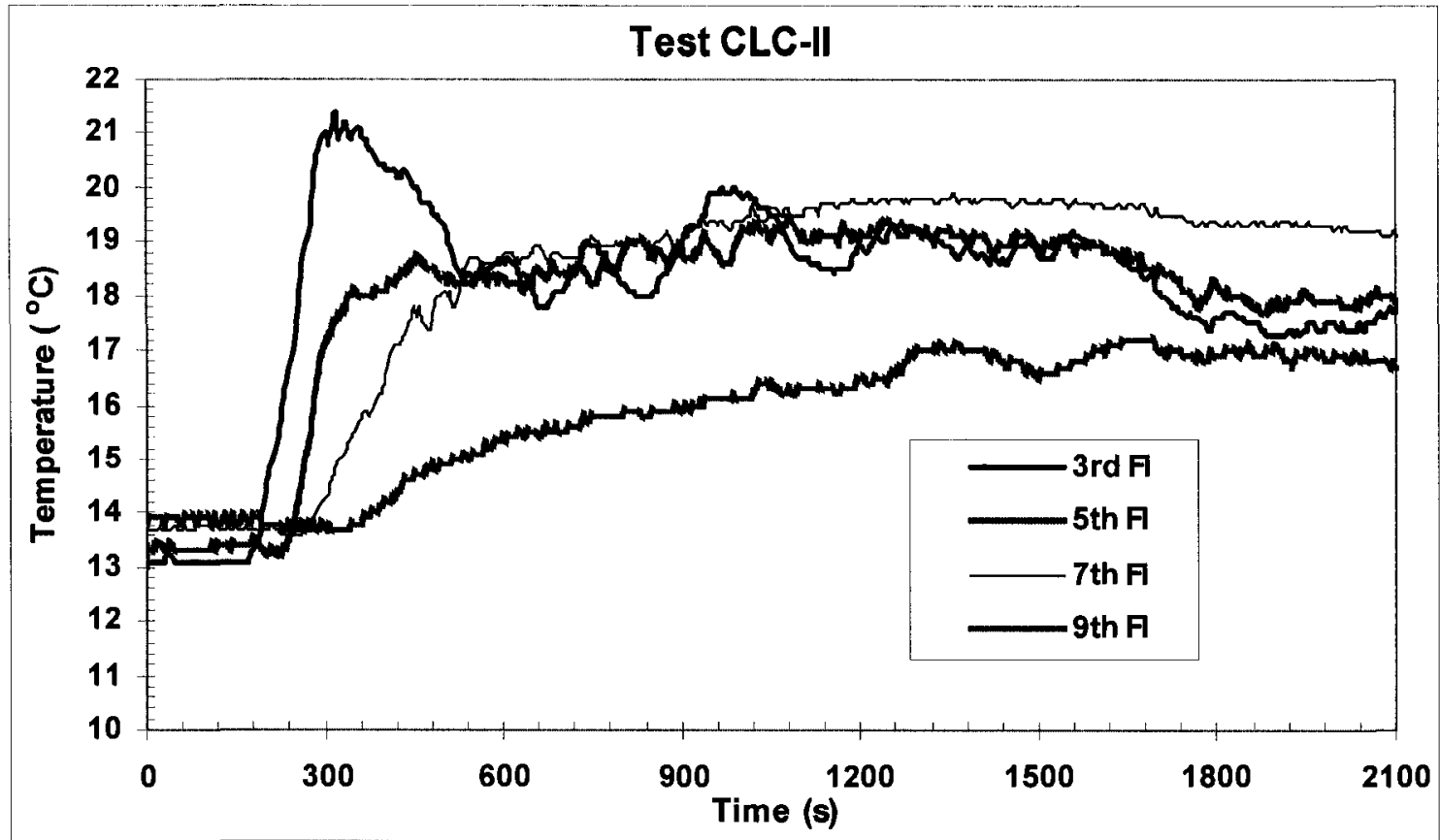

Figure 4-22: Gas temperature histories in the vestibules of the floors with closed doors (Test CLC-II)

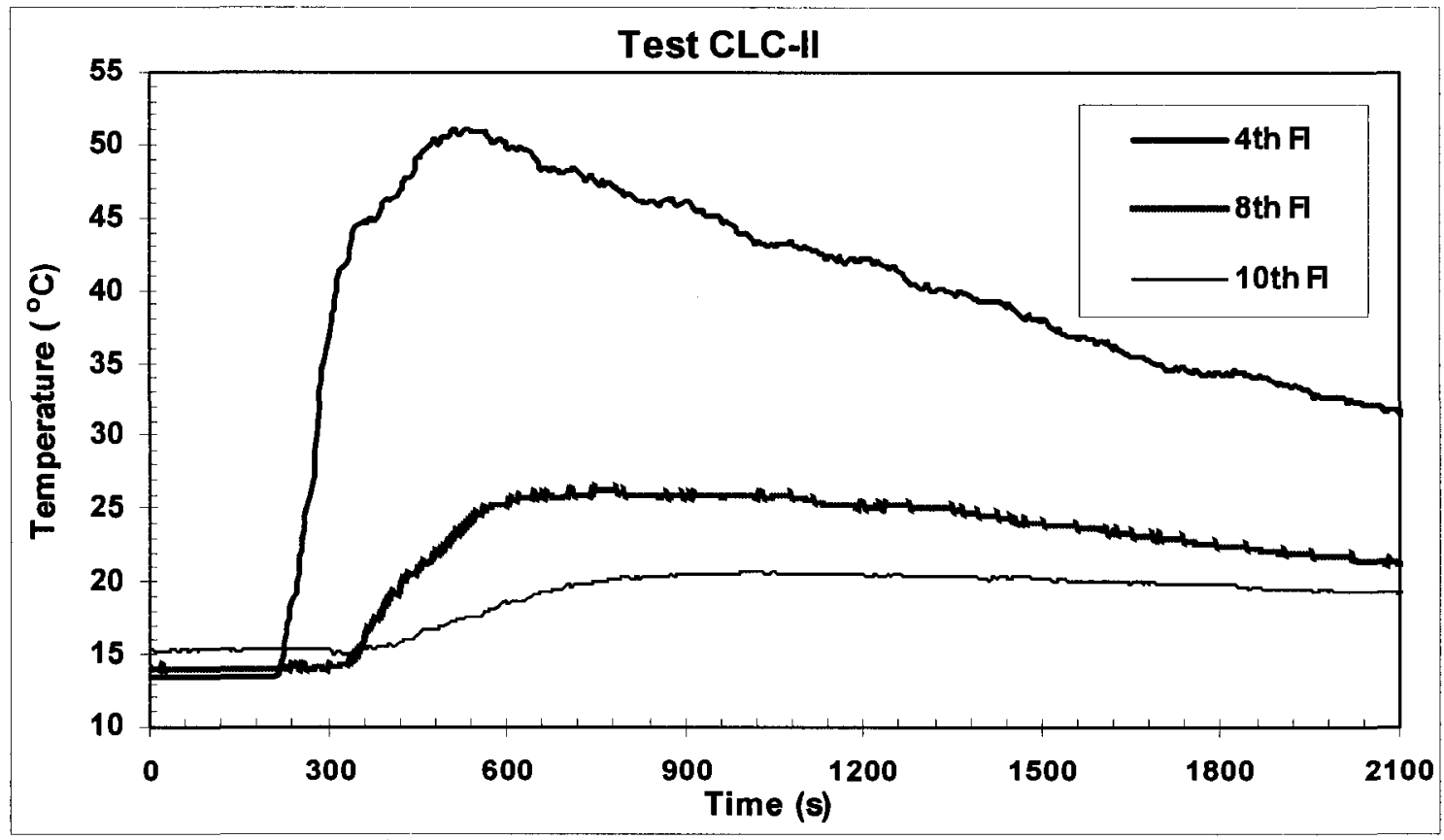

Figure 4-23: Gas temperature histories in the main compartments of the floors of the $4^{\text {th }}, 8^{\text {th }}$ and $10^{\text {th }}$ (Test CLC-II) 
Table 4-7: The maximum gas temperatures in the main compartments of the floors of the $4^{\text {th }}, 8^{\text {th }}$ and $10^{\text {th }}$ for Test CLC-II

\begin{tabular}{|c|c|c|c|c|}
\hline \multicolumn{2}{|c|}{ Test ID } & $4^{\text {th }}$ floor & $8^{\text {th }}$ floor & $10^{\text {th }}$ floor \\
\hline \multirow{4}{*}{ CLC-II } & $\mathrm{T}_{i}\left({ }^{\circ} \mathrm{C}\right)$ & 13.5 & 14.0 & 15.3 \\
\cline { 2 - 5 } & $\mathrm{T}_{\mathrm{p}}\left({ }^{\circ} \mathrm{C}\right)$ & 51.1 & 26.3 & 20.8 \\
\cline { 2 - 5 } & $\left.\Delta \mathrm{T}^{\circ} \mathrm{C}\right)$ & 37.6 & 12.3 & 5.5 \\
\cline { 2 - 6 } & $\mathrm{t}_{\mathrm{p}}(\mathrm{s})$ & 535 & 760 & 1000 \\
\hline
\end{tabular}

\subsubsection{Computer showroom fuel package test (Test CMP)}

The computer showroom (CMP) fuel package was used to conduct Test CMP, which simulated a computer showroom. The total fire load contained in this fuel package was $1624 \mathrm{MJ}$ containing mainly wood and plastics. For comparison, the total fire load contained in package CLC-II was $1322 \mathrm{MJ}$ containing mainly textiles.

Figure 4-24 shows the concentration of $\mathrm{O}_{2}$ and $\mathrm{CO}_{2}$ in the stair shaft at the fire floor during Test CMP. The figure indicates that the lowest concentration of $\mathrm{O}_{2}$ was $11.32 \%$ at $570 \mathrm{~s}$, which was much higher than the value of $4.62 \%$ at $255 \mathrm{~s}$ for Test CLC-II. The highest concentration of $\mathrm{CO}_{2}$ was $7.93 \%$ at $570 \mathrm{~s}$, which is much lower than the value of $14.74 \%$ at $255 \mathrm{~s}$ for Test CLC-II. Due to insufficient oxygen supplied in the fire compartment during Test CLC-II, this test experienced ventilation-controlled conditions. Some of the unburned fuel carried by the smoke entered the doorway area and the stair shaft at the $2^{\text {nd }}$ floor where it burned. This resulted in a higher concentration of $\mathrm{CO}_{2}$ in the stair shaft at the fire floor than that measured during Test CMP. 


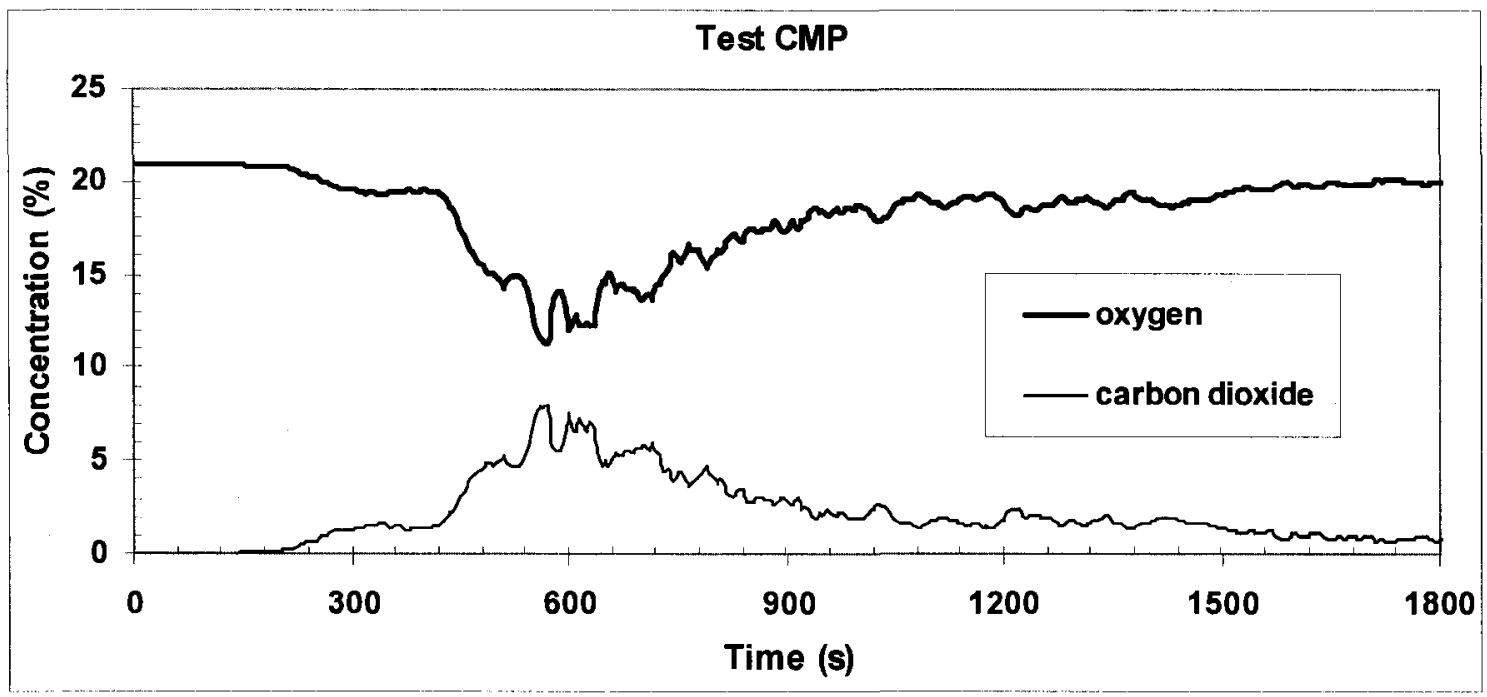

Figure 4-24: Concentration of $\mathrm{O}_{2}$ and $\mathrm{CO}_{2}$ in the stair shaft at the fire floor (Test CMP)

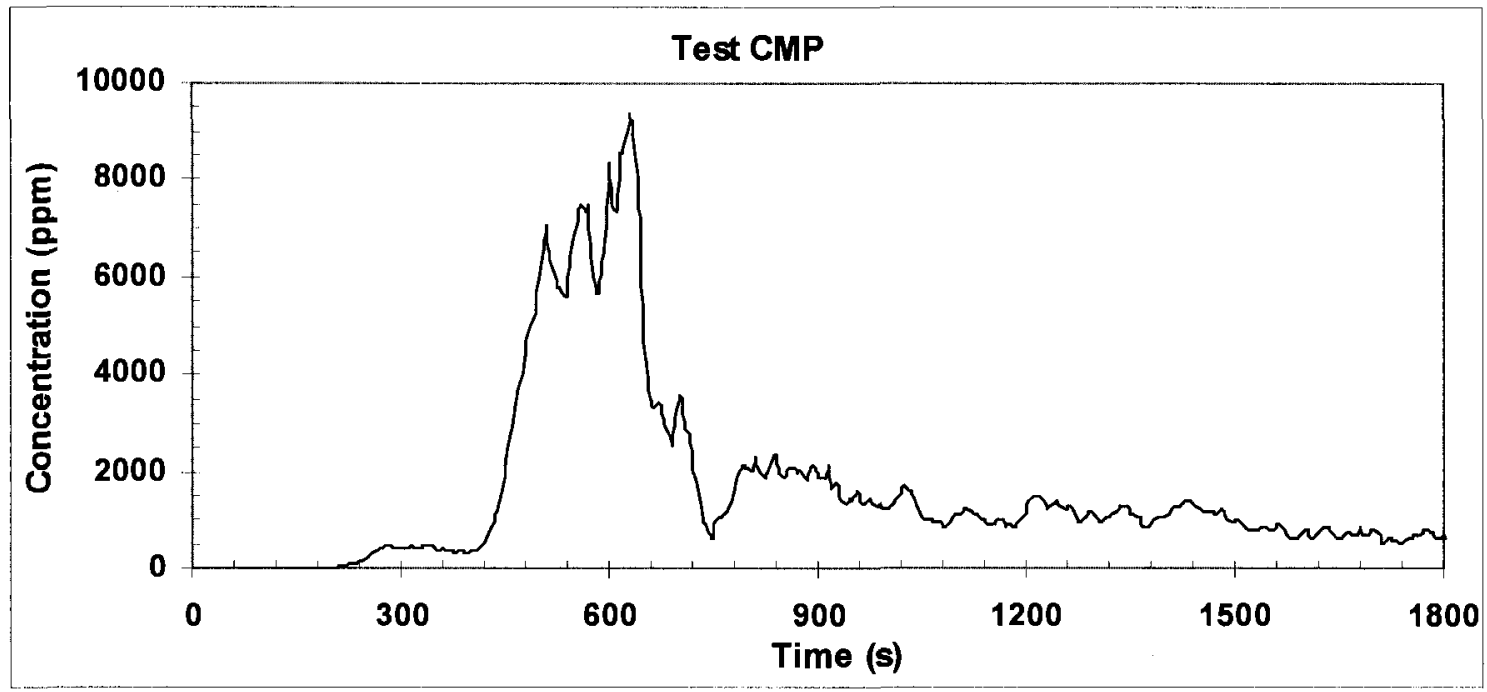

Figure 4-25: Concentration of $\mathrm{CO}$ in the stair shaft at the fire floor (Test CMP)

The concentration of $\mathrm{CO}$ in the stair shaft at the fire floor is shown in Figure 4-25. It can be seen from the figure that the concentration of $\mathrm{CO}$ is $9,366 \mathrm{ppm}$ at $630 \mathrm{~s}$, which is not as large as the value of $24,917 \mathrm{ppm}$ at $260 \mathrm{~s}$ for Test CLC-II (Figure 4-15). As described previously, the lowest concentration of $\mathrm{O}_{2}$ was $11.32 \%$ at $570 \mathrm{~s}$ for Test CMP, whereas the lowest concentration of $\mathrm{O}_{2}$ was $4.62 \%$ at $255 \mathrm{~s}$ in the stair shaft at the fire floor for 
Test CLC-II shown in Figure 4-14, which was relatively higher compared to the lowest concentration of $\mathrm{O}_{2}$ in the fire compartment. Due to insufficient oxygen supplied in the fire compartment in Test CLC-II, there was more incomplete combustion in Test CLC-II which resulted the higher concentration of CO for Test CLC-II compared to Test CMP.

The temperatures measured by the thermocouple tree located in the corner of the fire compartment are shown in Figure 4-26. Using the upper layer average temperature of $600^{\circ} \mathrm{C}$ as the flashover criterion, the fire reached the flashover condition at $550 \mathrm{~s}$ after ignition. The flashover time was at $210 \mathrm{~s}$ during Test CLC-II, indicating that the fire growth rate during Test CMP is slower than during Test CLC-II. It can be seen from Figure 4-26 that the temperature in the fire compartment increased continuously and reached a maximum value of $861^{\circ} \mathrm{C}$ at $680 \mathrm{~s}$. The temperature in the fire compartment at $2.57 \mathrm{~m}$ height for Test CLC-II was $827^{\circ} \mathrm{C}$ at $335 \mathrm{~s}$ (Figure 4-16). About $20 \mathrm{~s}$ after ignition, heavy smoke was observed filling the fire compartment. The temperature in the fire compartment at $0.62 \mathrm{~m}$ height for Test CMP was lower than that during Test CLC-II, although the temperature in the fire compartment at $2.57 \mathrm{~m}$ height for Test CLC-II was a little higher than that for Test CLC-II. This is because more soot was produced in Test CMP than Test CLC-II, which increased heat loss by radiation. The fire entered the decay phase after reaching a peak temperature, and the temperature started to decrease steadily until the end of the test at $1800 \mathrm{~s}$. 


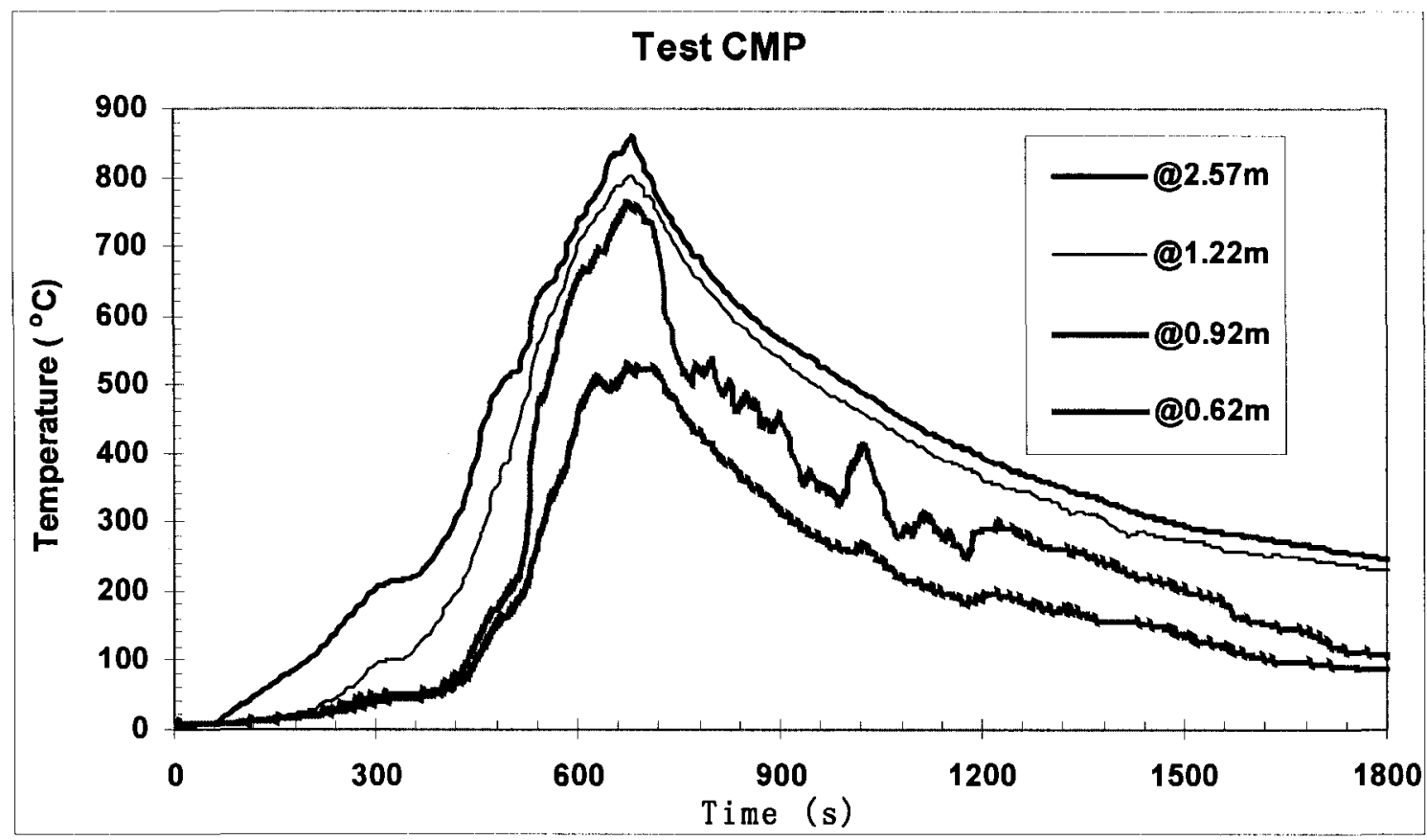

Figure 4-26: Gas temperature histories at different heights in the corner of the fire compartment (Test CMP)

Figure 4-27 shows gas temperature profiles and interface heights in the fire compartment at different times. The temperature was very high even at $0.62 \mathrm{~m}$ height. Before reaching the flashover condition, the interface height was $1.05 \mathrm{~m}$ at $480 \mathrm{~s}$, however once this condition was reached, the interface height dropped to $0.99 \mathrm{~m}$ at $550 \mathrm{~s}$. The interface height dropped to $0.88 \mathrm{~m}$ at $680 \mathrm{~s}$ when the peak temperature was reached. During the decay phase of the fire, the interface height increased to $1.01 \mathrm{~m}$ at $860 \mathrm{~s}$.

Figure 4-28 shows the gas temperature histories at different heights at the doorway during Test CMP as recorded by the thermocouples placed at the doorway. A maximum temperature of $635^{\circ} \mathrm{C}$ at $690 \mathrm{~s}$ was recorded by the thermocouple at $2.05 \mathrm{~m}$ height. This temperature was much lower than the peak temperature of $816^{\circ} \mathrm{C}$ at $315 \mathrm{~s}$ at the same height for Test CLC-II shown in Figure 4-18. As stated before, the lowest concentration of $\mathrm{O}_{2}$ in the stair shaft at the fire floor was $11.32 \%$ at $570 \mathrm{~s}$ for Test CMP, which was much higher than the value of 
4.62\% at $255 \mathrm{~s}$ for Test CLC-II shown in Figure 4-14. The peak temperature in the fire compartment was reached at $680 \mathrm{~s}$, while the peak temperature at the doorway was reached at $690 \mathrm{~s}$; smoke moved into the stair shaft through the vestibule on the fire floor. These values indicate that no combustion was taking place in the stair shaft or the doorway area, which is the reason why the maximum temperature at the doorway for Test CMP is lower than that during Test CLC-II.

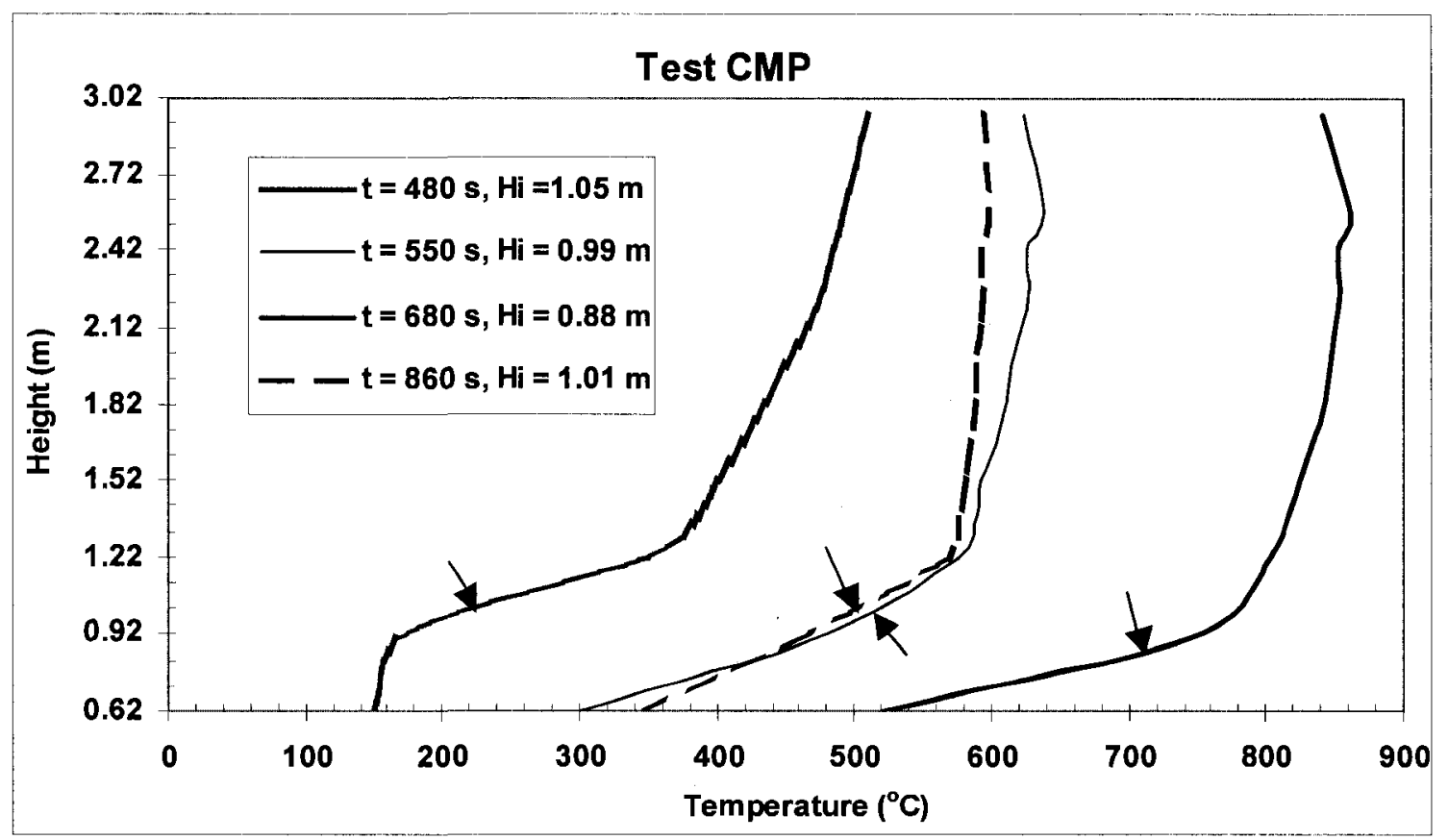

Note: Arrows indicate the locations of interface heights.

Figure 4-27: Gas temperature profiles in the fire compartment at different times (Test CMP)

Figure 4-29 shows three gas temperature profiles at the doorway at different times for Test CMP: (a) before reaching the flashover condition in the fire compartment (at $480 \mathrm{~s}$ ), (b) at $690 \mathrm{~s}$ at which time the maximum temperature reached the doorway, (c) at $920 \mathrm{~s}$, time after reaching the maximum temperature. 


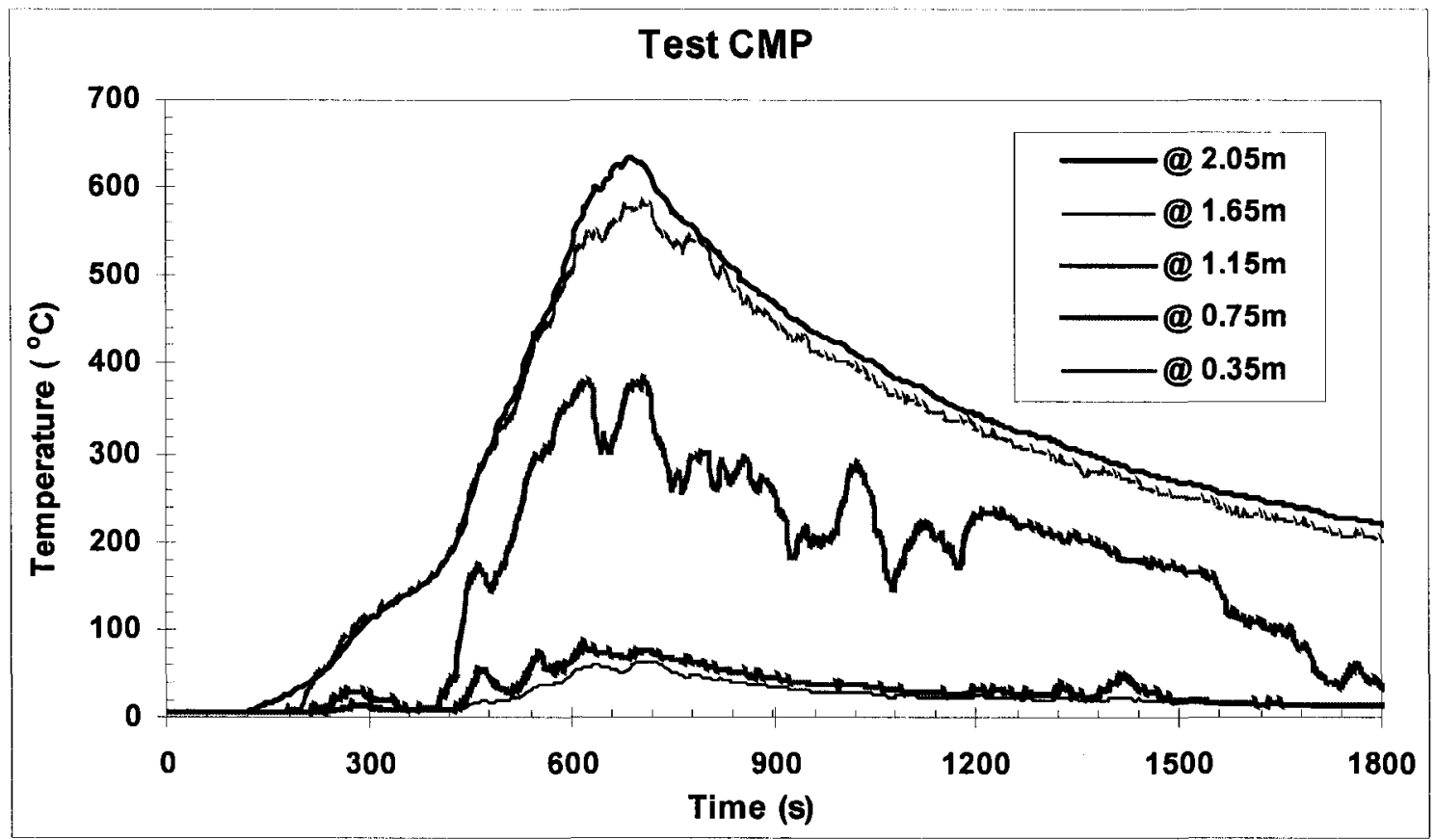

Figure 4-28: Gas temperature histories at different heights at the doorway (Test CMP)

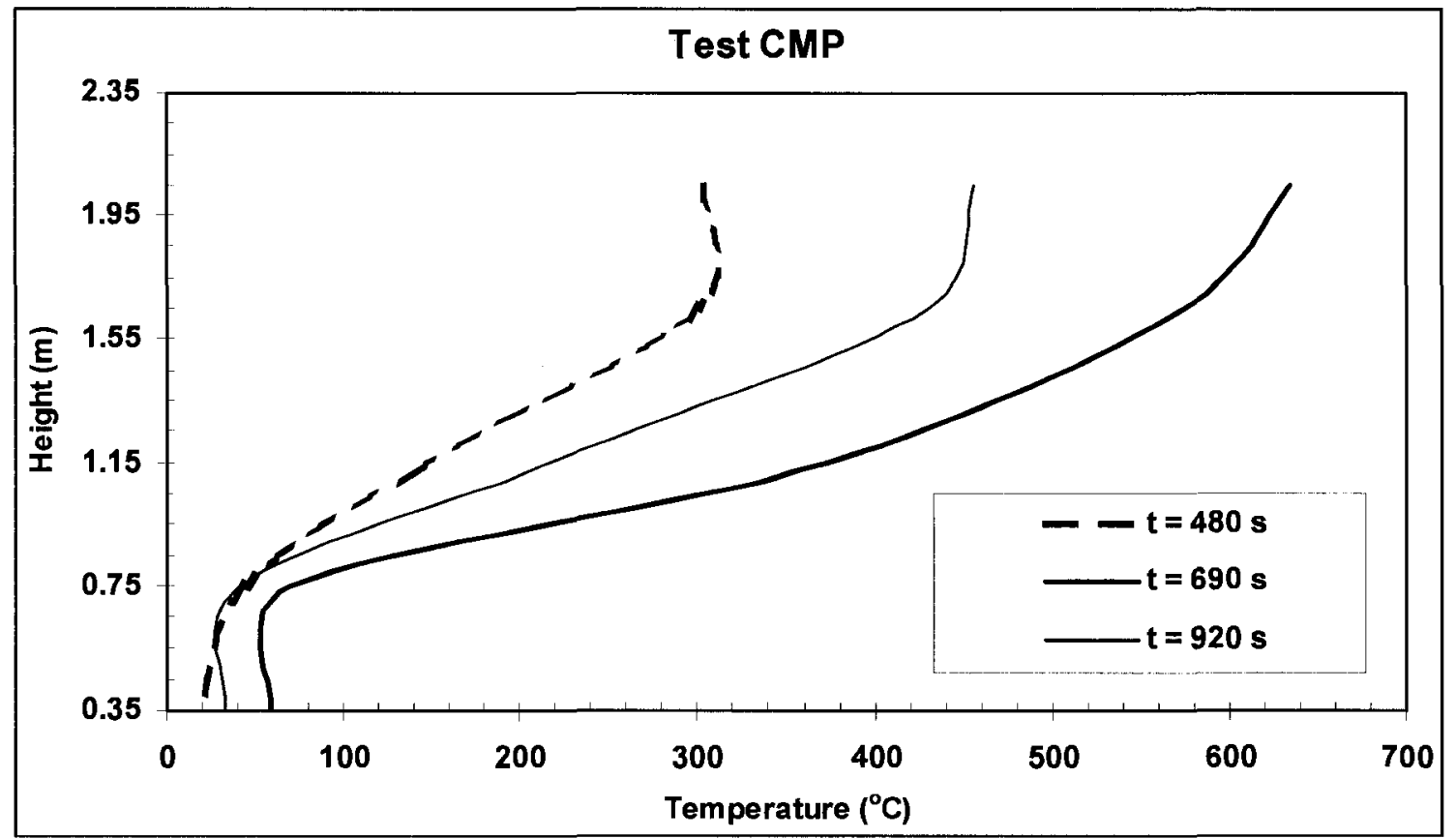

Figure 4-29: Gas temperature profiles at the doorway at different times (Test CMP)

The gas temperature histories in the stair shaft for Test CMP recorded by the thermocouples installed in the stair shaft at each floor from the $2^{\text {nd }}$ to $10^{\text {th }}$ are shown in 
Figure 4-30. The maximum gas temperature in the stair shaft at the fire floor was $246^{\circ} \mathrm{C}$ at $715 \mathrm{~s}$ for Test CMP, compared to $393^{\circ} \mathrm{C}$ at $275 \mathrm{~s}$ shown in Figure 4-20 for Test CLCII. As mentioned earlier, the maximum gas temperature was $861^{\circ} \mathrm{C}$ at $680 \mathrm{~s}$ in the fire compartment and $635^{\circ} \mathrm{C}$ at $690 \mathrm{~s}$ at the doorway of the fire floor. The maximum values of the gas temperature and their corresponding times in the stair shaft for floors $2^{\text {nd }}$ to $10^{\text {th }}$ are listed in Table 4-8.

The temperatures in the stair shaft for Test CMP were lower than that at the same locations for Test CLC-II shown in Figure 4-20. The table also indicates that the maximum gas temperatures in the stair shaft decreased with height, due to more heat losses to the boundaries and mixing with cold air.

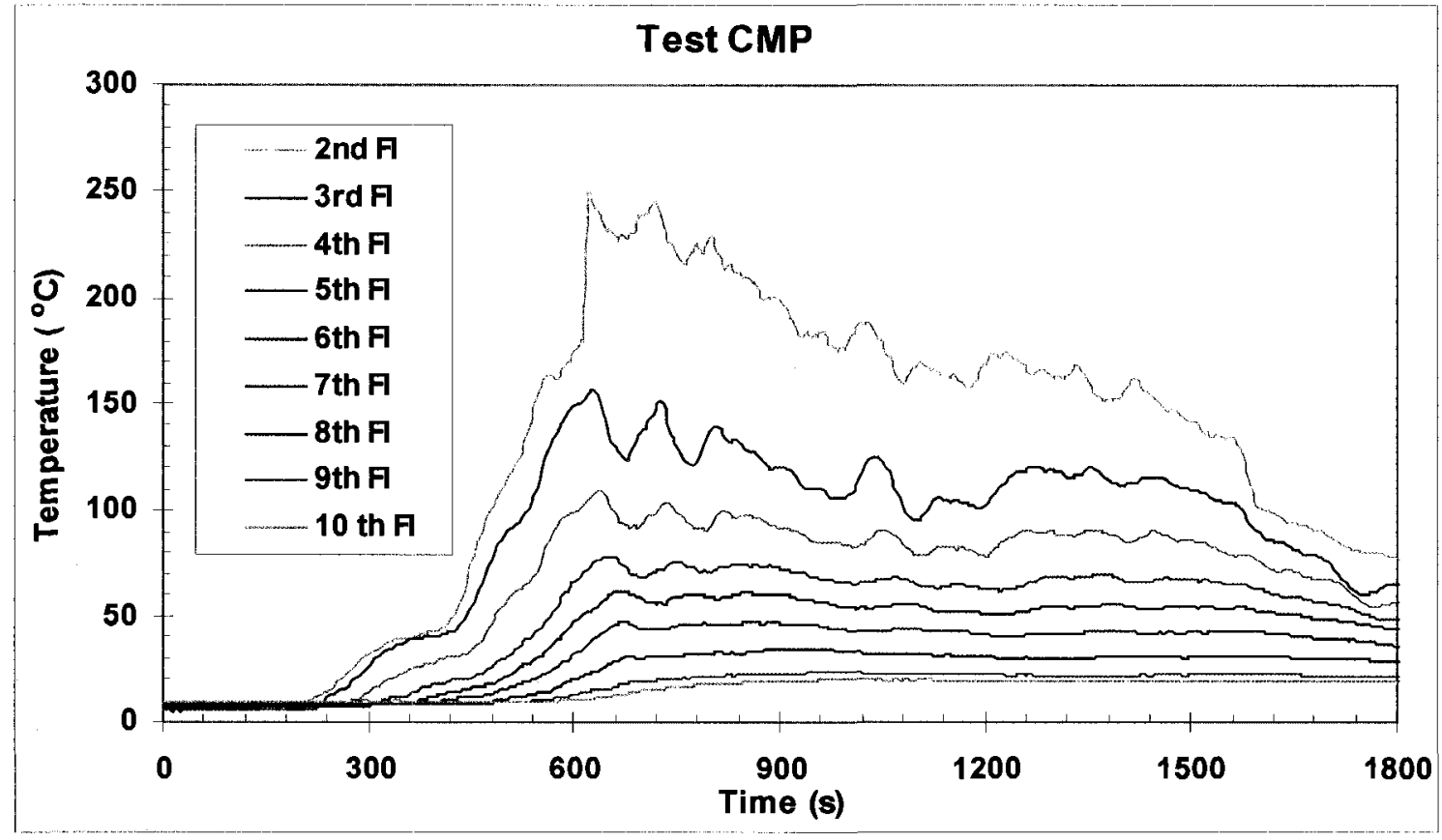

Figure 4-30: Gas temperature histories in the stair shaft (Test CMP) 
Table 4-8: The maximum gas temperatures in the stair shaft of different floors for Test CMP

\begin{tabular}{|c|c|c|c|c|c|c|c|c|c|c|}
\hline \multicolumn{2}{|c|}{ Test ID } & $\begin{array}{c}2^{\text {nd }} \\
\text { floor }\end{array}$ & $\begin{array}{c}3^{\text {rd }} \\
\text { floor }\end{array}$ & $\begin{array}{c}4^{\text {th }} \\
\text { floor }\end{array}$ & $\begin{array}{c}5^{\text {th }} \\
\text { floor }\end{array}$ & $\begin{array}{c}6^{\text {th }} \\
\text { floor }\end{array}$ & $\begin{array}{c}7^{\text {th }} \\
\text { floor }\end{array}$ & $\begin{array}{c}8^{\text {th }} \\
\text { floor }\end{array}$ & $\begin{array}{c}9^{\text {th }} \\
\text { floor }\end{array}$ & $\begin{array}{c}10^{\text {th }} \\
\text { floor }\end{array}$ \\
\hline \multirow{4}{*}{$\mathrm{CMP}$} & $\mathrm{T}_{\mathrm{i}}\left({ }^{\circ} \mathrm{C}\right)$ & 6.5 & 5.4 & 5.8 & 6.2 & 6.7 & 7.3 & 7.5 & 8.1 & 9.8 \\
\cline { 2 - 12 } & $\mathrm{T}_{\mathrm{p}}\left({ }^{\circ} \mathrm{C}\right)$ & 246.2 & 151.0 & 104.4 & 75.4 & 60.5 & 47.2 & 34.1 & 23.5 & 19.6 \\
\cline { 2 - 11 } & $\Delta \mathrm{T}\left({ }^{\circ} \mathrm{C}\right)$ & 239.7 & 145.6 & 98.6 & 69.2 & 53.8 & 39.9 & 26.6 & 15.4 & 9.8 \\
\cline { 2 - 11 } & $\mathrm{t}_{\mathrm{p}}(\mathrm{s})$ & 715 & 725 & 735 & 755 & 775 & 895 & 925 & 980 & 990 \\
\hline
\end{tabular}

Figure 4-31 shows the gas temperature histories for Test CMP recorded by the thermocouples in the vestibules of the floors with open doors. The maximum values of the gas temperature and their corresponding times in the vestibules of the floors with open doors are listed in Table 4-9. The maximum temperatures were lower than those during Test CLC-II shown in Figure 4-21 and decreased with height, because of heat losses to the boundaries and mixing with cold air.

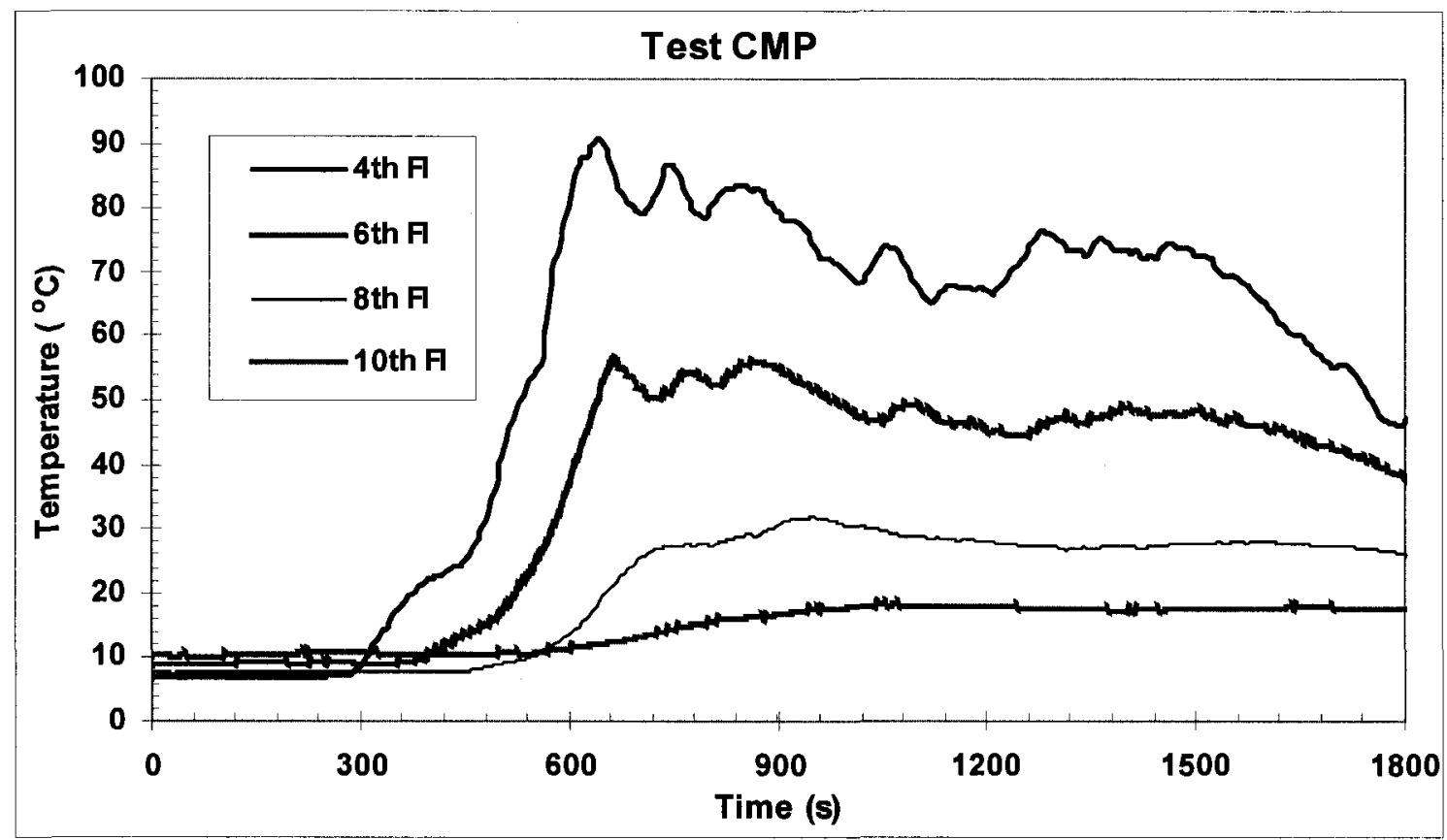

Figure 4-31: Gas temperature histories in the vestibules of the floors with open doors (Test CMP) 
Table 4-9: The maximum gas temperatures in the vestibules of the floors with open doors for Test CMP

\begin{tabular}{|c|c|c|c|c|c|}
\hline \multicolumn{2}{|c|}{ Test ID } & $4^{\text {th }}$ floor & $6^{\text {th }}$ floor & $8^{\text {th }}$ floor & $10^{\text {th }}$ floor \\
\hline \multirow{4}{*}{ CMP } & $\mathrm{T}_{\mathrm{i}}\left({ }^{\circ} \mathrm{C}\right)$ & 6.9 & 8.9 & 7.7 & 10.3 \\
\cline { 2 - 6 } & $\mathrm{T}_{\mathrm{p}}\left({ }^{\circ} \mathrm{C}\right)$ & 87.0 & 56.0 & 31.9 & 18.2 \\
\cline { 2 - 6 } & $\Delta \mathrm{T}\left({ }^{\circ} \mathrm{C}\right)$ & 80.1 & 47.1 & 24.2 & 7.9 \\
\cline { 2 - 6 } & $\mathrm{t}_{\mathrm{p}}(\mathrm{s})$ & 745 & 865 & 950 & 1050 \\
\hline
\end{tabular}

Figure 4-32 shows the gas temperature histories for Test CMP in the vestibules of the floors with closed doors. The test results were similar to the Test CLC-I (Figure 4-12) and CLC-II (Figure 4-22). For example, the gas temperatures in the vestibules of the floors with closed doors still increased a few degrees compared with the initial values. As with the other two tests, the doors between the stair shaft and the vestibules of the odd floors were fully closed, but not completely sealed.

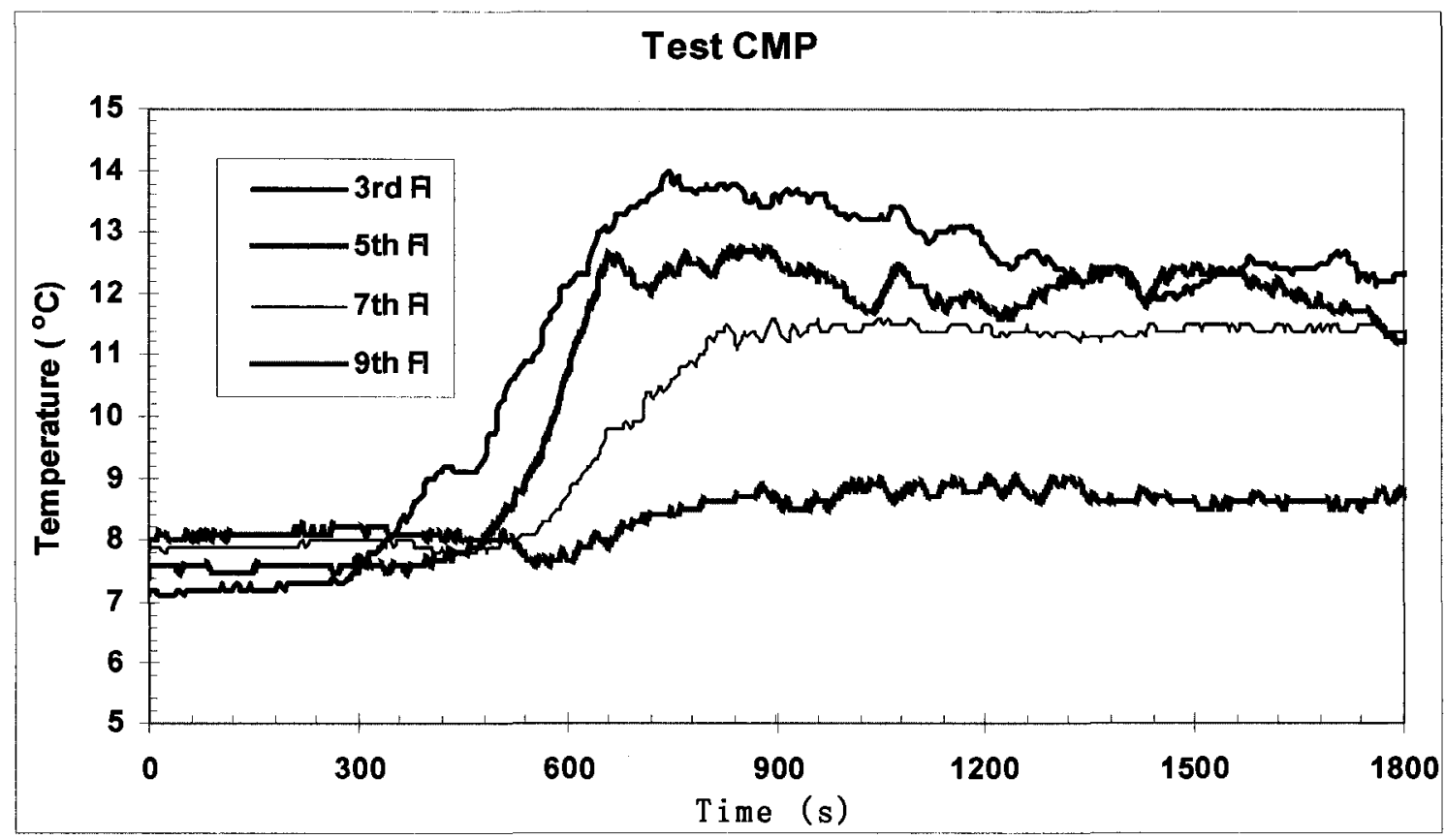

Figure 4-32: Gas temperature histories in the vestibules of the floors with closed doors (Test CMP) 
Figure 4-33 shows the gas temperature histories in the main compartments of the $4^{\text {th }}, 8^{\text {th }}$ and $10^{\text {th }}$ floors for Test CMP. The maximum values of the gas temperature and their corresponding times at the main compartments of the $4^{\text {th }}, 8^{\text {th }}$ and $10^{\text {th }}$ floors are listed in Table 4-10. The maximum temperatures during Test CMP were lower than those during Test CLC-II shown in Figure 4-23. The maximum gas temperatures in the main compartments decreased with height. These results are similar to the CLC-I and CLC-II test results.

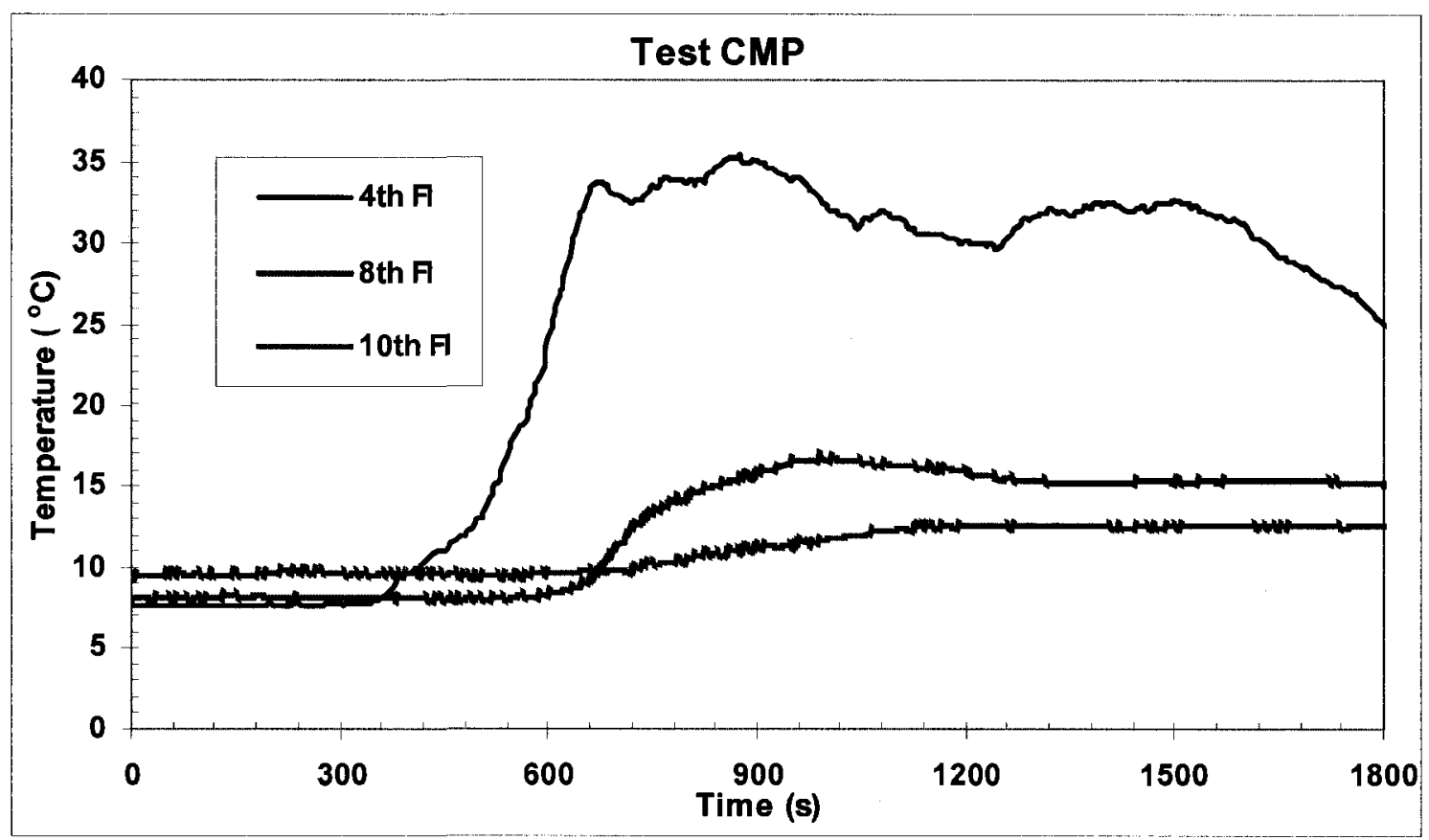

Figure 4-33: Gas temperature histories in the main compartments of the floors of the $4^{\text {th }}, 8^{\text {th }}$ and $10^{\text {th }}$ (Test CMP)

Table 4-10: The maximum gas temperatures in the main compartments of the floors of the $4^{\text {th }}, 8^{\text {th }}$ and $10^{\text {th }}$ for Test CMP

\begin{tabular}{|c|c|c|c|c|}
\hline \multicolumn{2}{|c|}{ Test ID } & $4^{\text {th }}$ floor & $8^{\text {th }}$ floor & $10^{\text {th }}$ floor \\
\hline \multirow{4}{*}{ CMP } & $\mathrm{T}_{\mathrm{i}}\left({ }^{\circ} \mathrm{C}\right)$ & 7.6 & 8.0 & 9.4 \\
\cline { 2 - 5 } & $\mathrm{T}_{\mathrm{p}}\left({ }^{\circ} \mathrm{C}\right)$ & 35.4 & 16.8 & 12.6 \\
\cline { 2 - 5 } & $\Delta \mathrm{T}\left({ }^{\circ} \mathrm{C}\right)$ & 27.8 & 8.8 & 3.2 \\
\cline { 2 - 6 } & $\mathrm{t}_{\mathrm{p}}(\mathrm{s})$ & 875 & 990 & 1200 \\
\hline
\end{tabular}




\subsubsection{Bookstore fuel package test (Test BK)}

The bookstore fuel package (BK) was used to conduct Test BK. This package had a total fire load of 10,610 MJ. Fuel components were mostly wood/paper. The fire load density used in Test BK was the largest among the four fuel package tests.

Figure 4-34 shows the concentration of $\mathrm{O}_{2}$ and $\mathrm{CO}_{2}$ in the stair shaft at the fire floor of Test BK. The figure indicates that the lowest concentration of $\mathrm{O}_{2}$ was $3.72 \%$ at $1255 \mathrm{~s}$, which was the lowest recorded value of all Group 1 tests. The highest concentration of $\mathrm{CO}_{2}$ was $16.55 \%$ at $1255 \mathrm{~s}$; which was the highest one among this group.

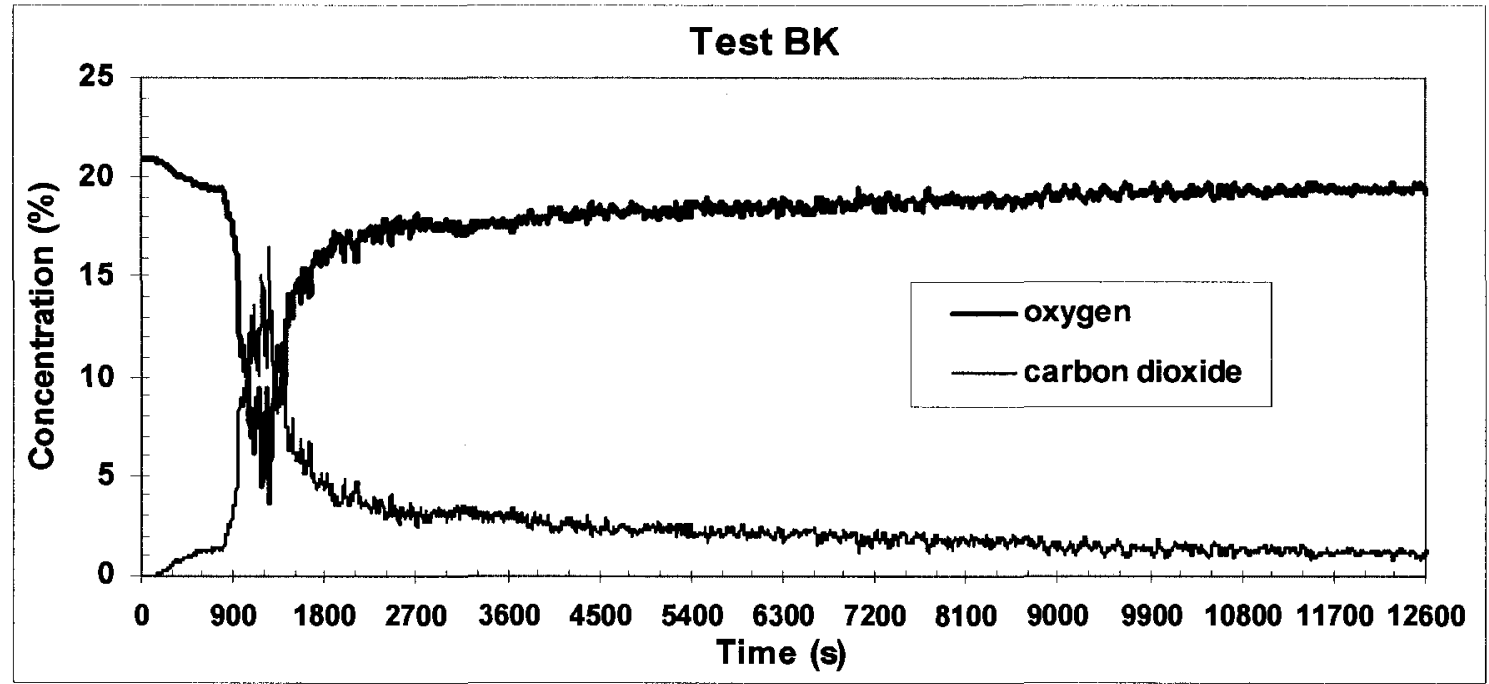

Figure 4-34: Concentration of $\mathrm{O}_{2}$ and $\mathrm{CO}_{2}$ in the stair shaft at the fire floor (Test BK)

The concentration of $\mathrm{CO}$ in the stair shaft at the fire floor is shown in Figure 4-35. It can be seen from the figure that the concentration of $\mathrm{CO}$ is very large. The value of $28,251 \mathrm{ppm}$ at $1085 \mathrm{~s}$ for Test BK is the highest among the four tests of Group 1. 


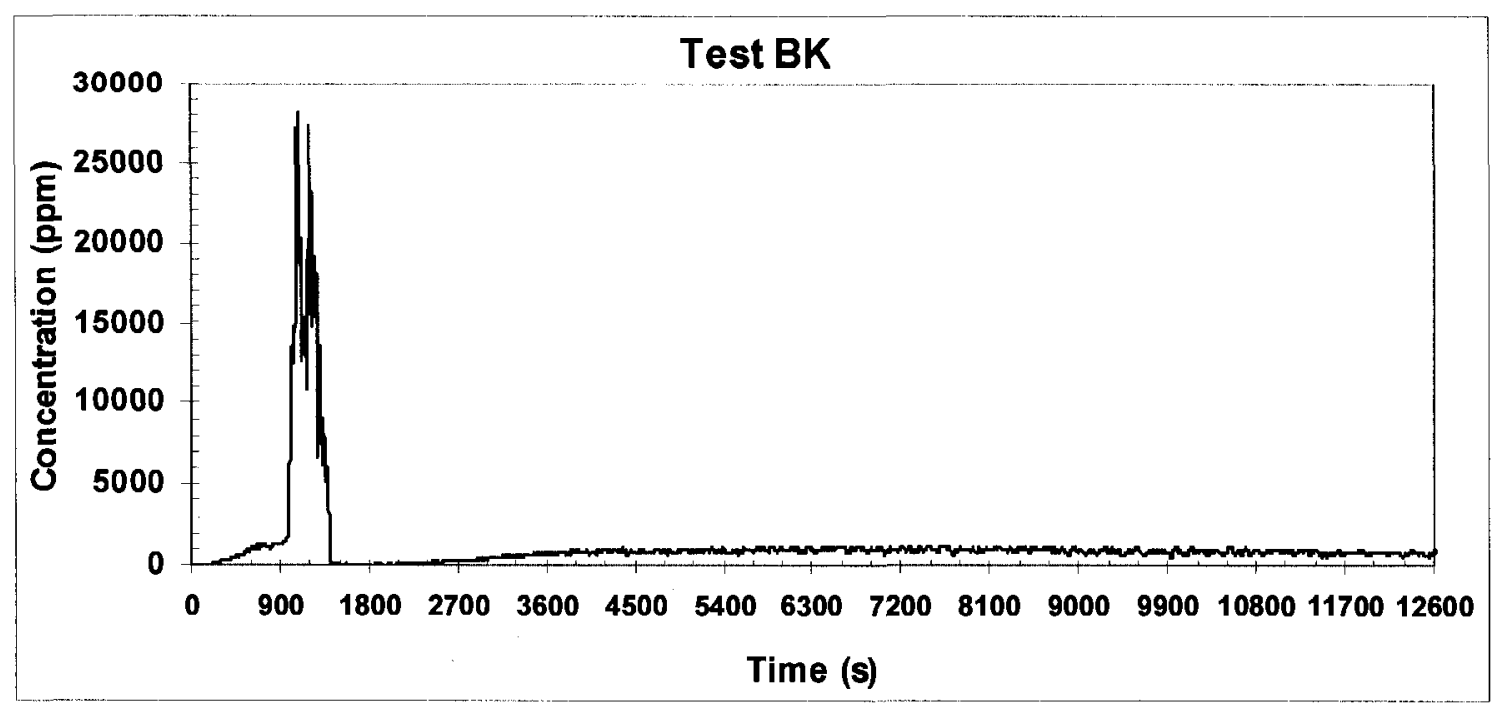

Figure 4-35: Concentration of $\mathrm{CO}$ in stair shaft at the fire floor (Test BK)

The temperatures measured by the thermocouple tree located in the corner of the fire compartment are shown in Figure 4-36. Using the upper layer average temperature of $600^{\circ} \mathrm{C}$ as the flashover criterion, the fire reached the flashover condition at $1040 \mathrm{~s}$. Compared to Test CLC-I (220 s), Test CLC-II (210 s), and Test CMP (550 s), Test BK took longer time to reach the flashover condition. The fire growth rate of Test BK was the lowest among the four tests of Group 1. It can be seen from Figure 4-36 that the temperature in the fire compartment increased and reached a maximum value of $952^{\circ} \mathrm{C}$ at $1390 \mathrm{~s}$. All the temperatures in the fire compartment for Test BK were higher than those of other tests in Group 1. Even at $12,600 \mathrm{~s}$, the temperature at $2.27 \mathrm{~m}$ height was still as high at $200^{\circ} \mathrm{C}$, thereby indicating that the fire was the most intense and with the longest duration among the four package fires. The fire entered the decay phase after reaching the peak temperature, and the temperature started to decrease steadily until the end of the test at $12,600 \mathrm{~s}$. 


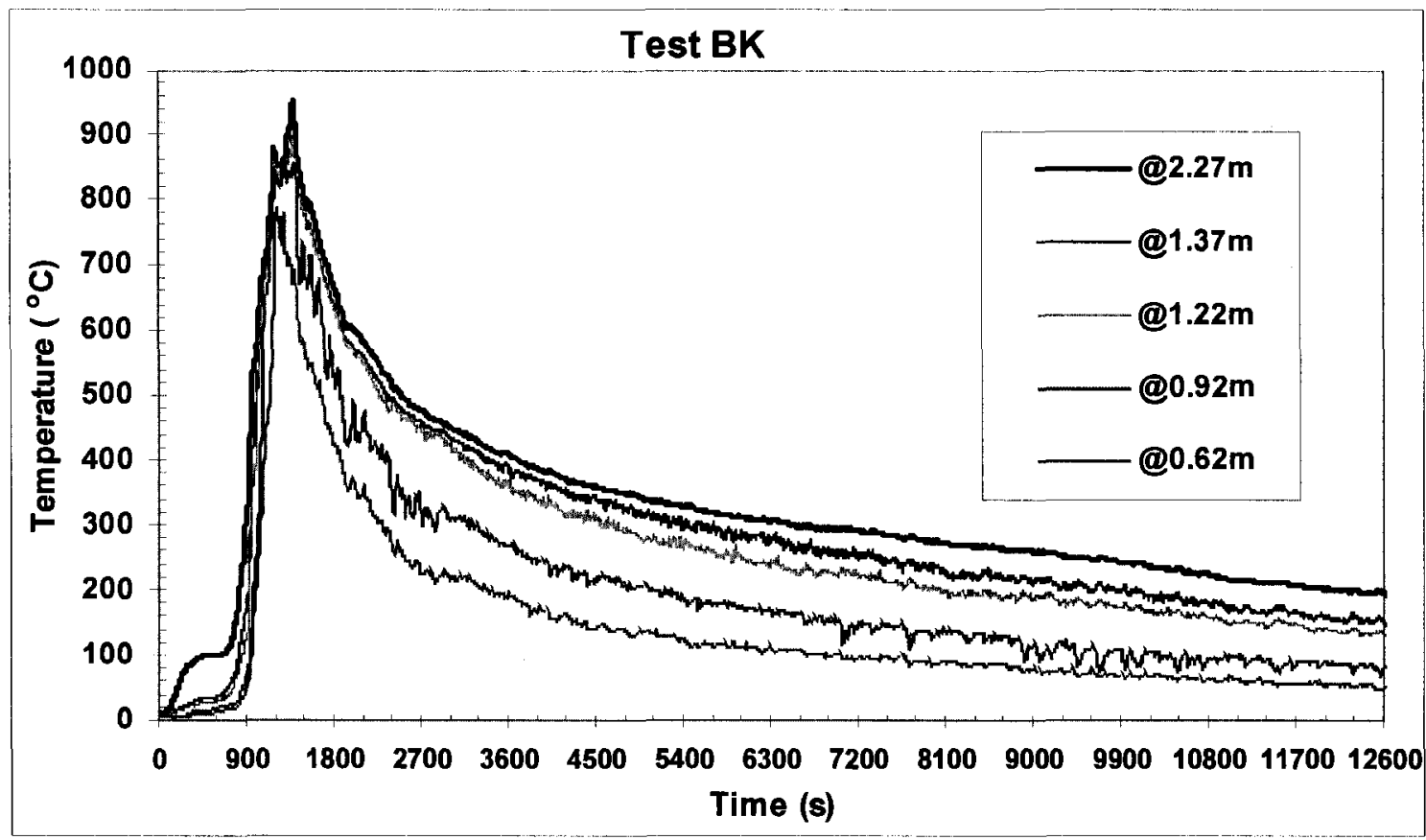

Figure 4-36: Gas temperature histories at different heights in the corner of the fire compartment (Test BK)

Figure 4-37 shows gas temperature profiles and interface heights in the fire compartment at different times. The figure indicates higher temperatures for the BK test fire compared to other tests of Group 1. For example, at $1390 \mathrm{~s}$, the temperature was very high even at $0.62 \mathrm{~m}$ height. Before reaching the flashover condition, the interface height was $1.38 \mathrm{~m}$ at $960 \mathrm{~s}$, however once the flashover condition was reached, the interface height dropped to $1.10 \mathrm{~m}$ at $1040 \mathrm{~s}$. The interface height dropped down to $0.91 \mathrm{~m}$ at $1390 \mathrm{~s}$, the time at which the maximum temperature in the fire compartment was reached. During the decay phase of the fire, the interface height slightly increased to $1.00 \mathrm{~m}$ at $1690 \mathrm{~s}$. 


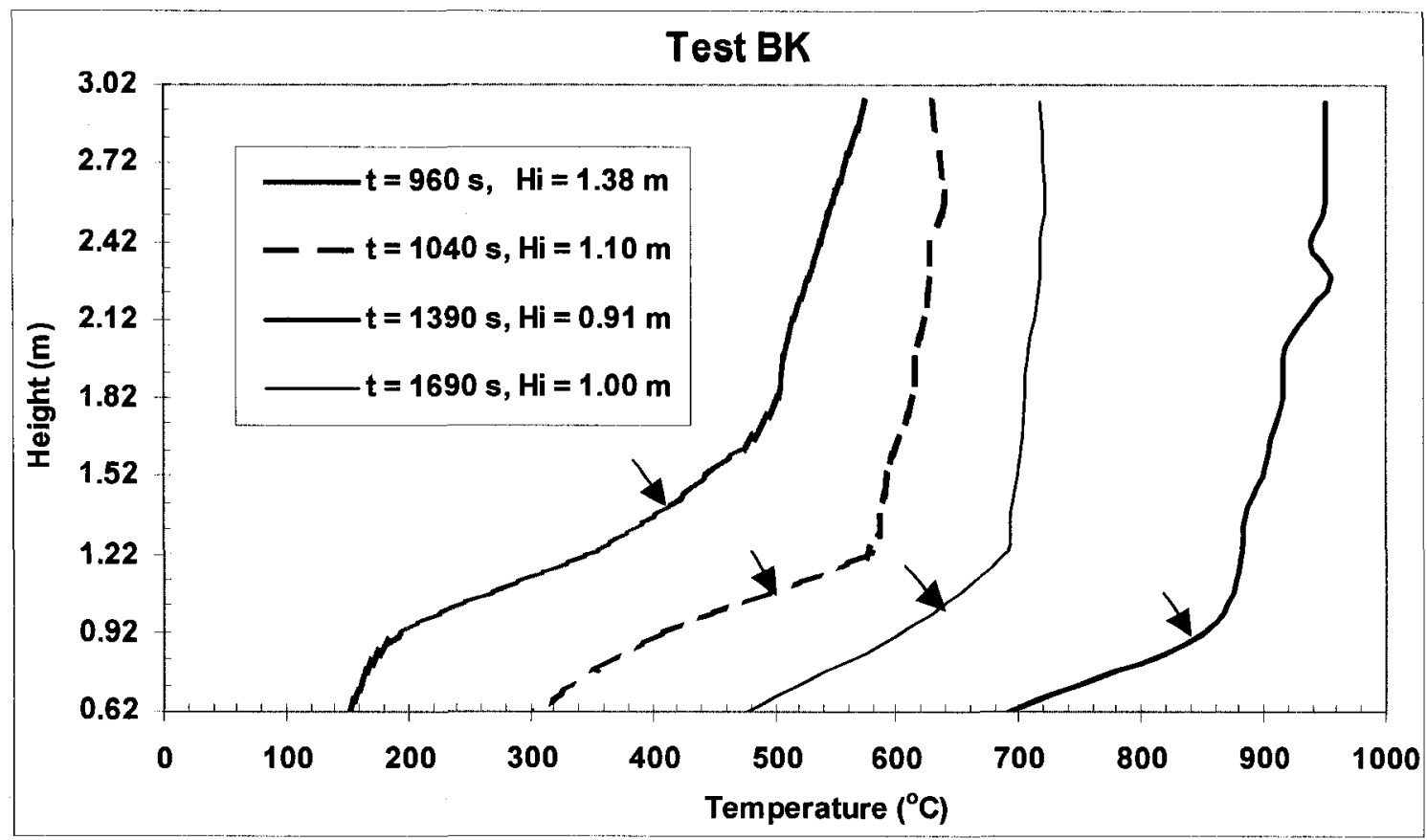

Note: Arrows indicate the locations of interface heights.

Figure 4-37: Gas temperature profiles in the fire compartment at different times (Test BK)

Figure 4-38 shows gas temperature histories at different heights at the doorway of Test BK as recorded by the thermocouples placed at the doorway. A maximum temperature of $887^{\circ} \mathrm{C}$ at $1260 \mathrm{~s}$ was recorded by the thermocouple at $1.65 \mathrm{~m}$ height. This temperature is higher than the maximum temperature in the compartment at that time indicating that combustion was taking place in the vestibule as a result of unburned hydrocarbons leaving the fire compartment.

Figure 4-39 shows four gas temperature profiles at the doorway at different times for Test BK: (a) at $960 \mathrm{~s}$, before reaching the flashover condition in the fire compartment, (b) at $1260 \mathrm{~s}$ the time at which the maximum temperature was reached in the doorway, (c) at $1390 \mathrm{~s}$, when the maximum temperature was reached in the compartment of fire, and (d) at $1690 \mathrm{~s}, 300 \mathrm{~s}$ after reaching the maximum temperature. 


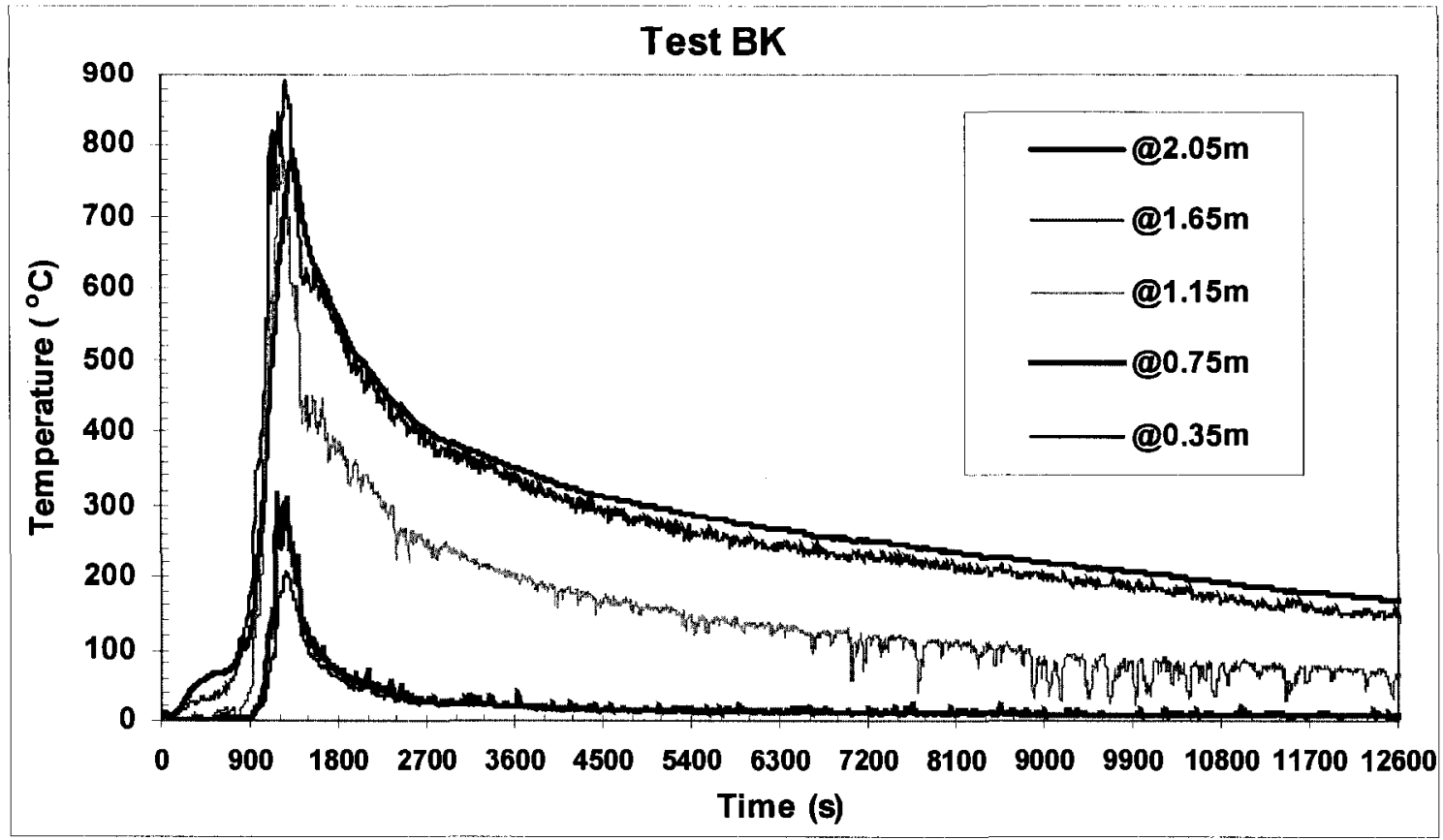

Figure 4-38: Gas temperature histories at different heights at the doorway (Test BK)

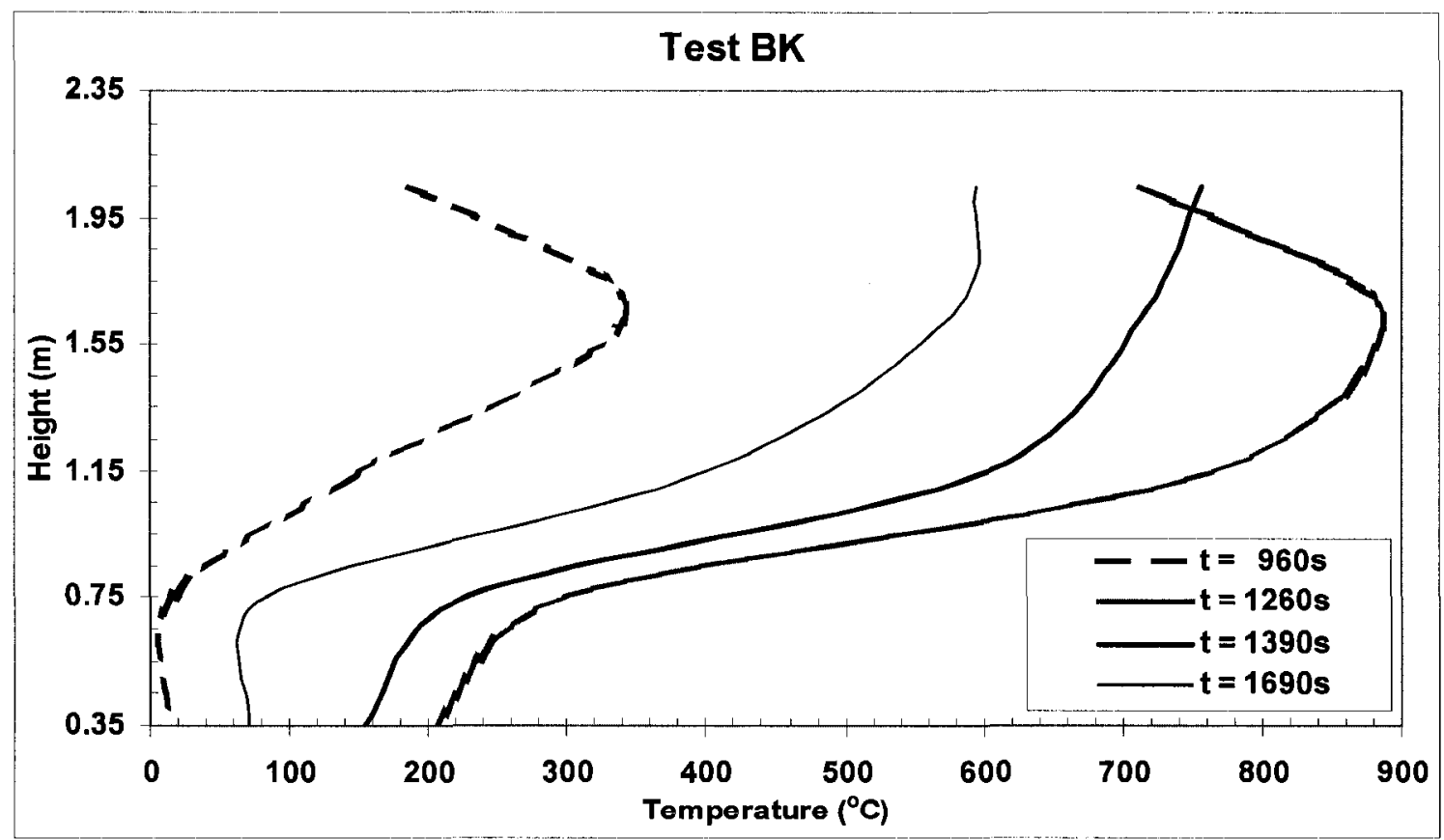

Figure 4-39: Gas temperature profiles at the doorway at different times (Test BK) 
The gas temperature histories in the stair shaft for Test BK recorded by the thermocouples installed in the stair shaft at each floor from the $2^{\text {nd }}$ to $10^{\text {th }}$ are shown in Figure 4-40. The maximum gas temperature in the stair shaft of the fire floor was $642^{\circ} \mathrm{C}$ at $1250 \mathrm{~s}$. As mentioned earlier, the maximum gas temperature was $952^{\circ} \mathrm{C}$ at $1390 \mathrm{~s}$ in the fire compartment shown in Figure $4-36$ and $887^{\circ} \mathrm{C}$ at $1260 \mathrm{~s}$ at the doorway of the fire floor shown in Figure 4-38. The temperature peaked early in the stair shaft at the fire floor compared to the peak temperatures at the fire compartment or the doorway because of combustion taking place in the stair shaft due to unburned hydrocarbons. The maximum values of the gas temperature and their corresponding times in the stair shaft at the floors 2 to 10 are listed in Table 4-11. Temperatures in the stair shaft for Test BK were higher than the other tests of Group 1. The temperature differences between the peak temperatures and the initial temperatures in the stair shaft for Test BK were higher than those of other tests of this group. The table also indicates that, as with the other tests, the maximum gas temperatures in the stair shaft decreased with the height, due to heat losses to the boundaries and mixing with cold air.

Figure 4-41 shows the gas temperature histories recorded by the thermocouples in the vestibules of the floors with open doors. The maximum values of the gas temperature and their corresponding times in the vestibules of the floors with open doors are listed in Table 4-12. The temperature differences between the maximum values and the initial values were higher than those of the other fuel package tests. 


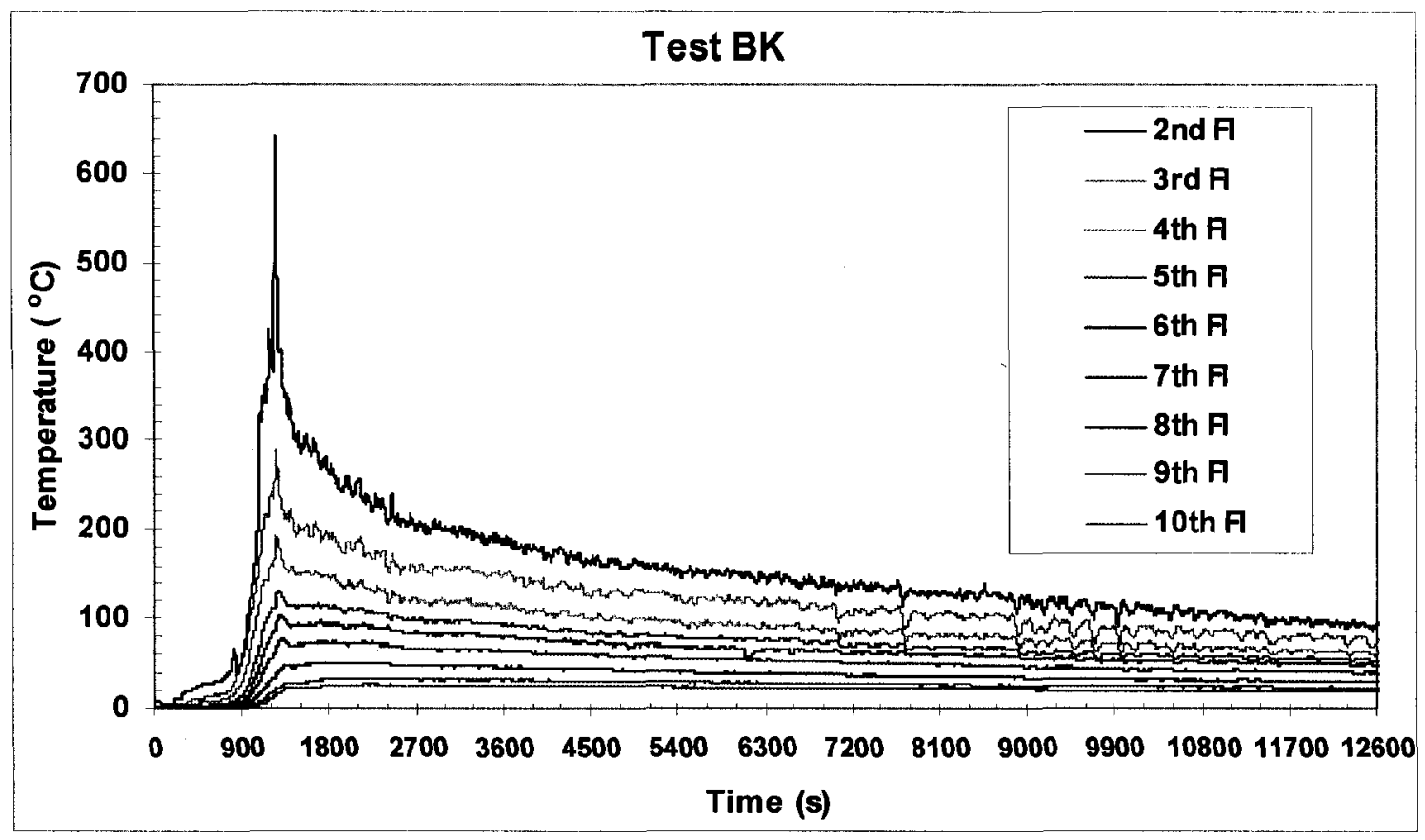

Figure 4-40: Gas temperature histories in the stair shaft (Test BK)

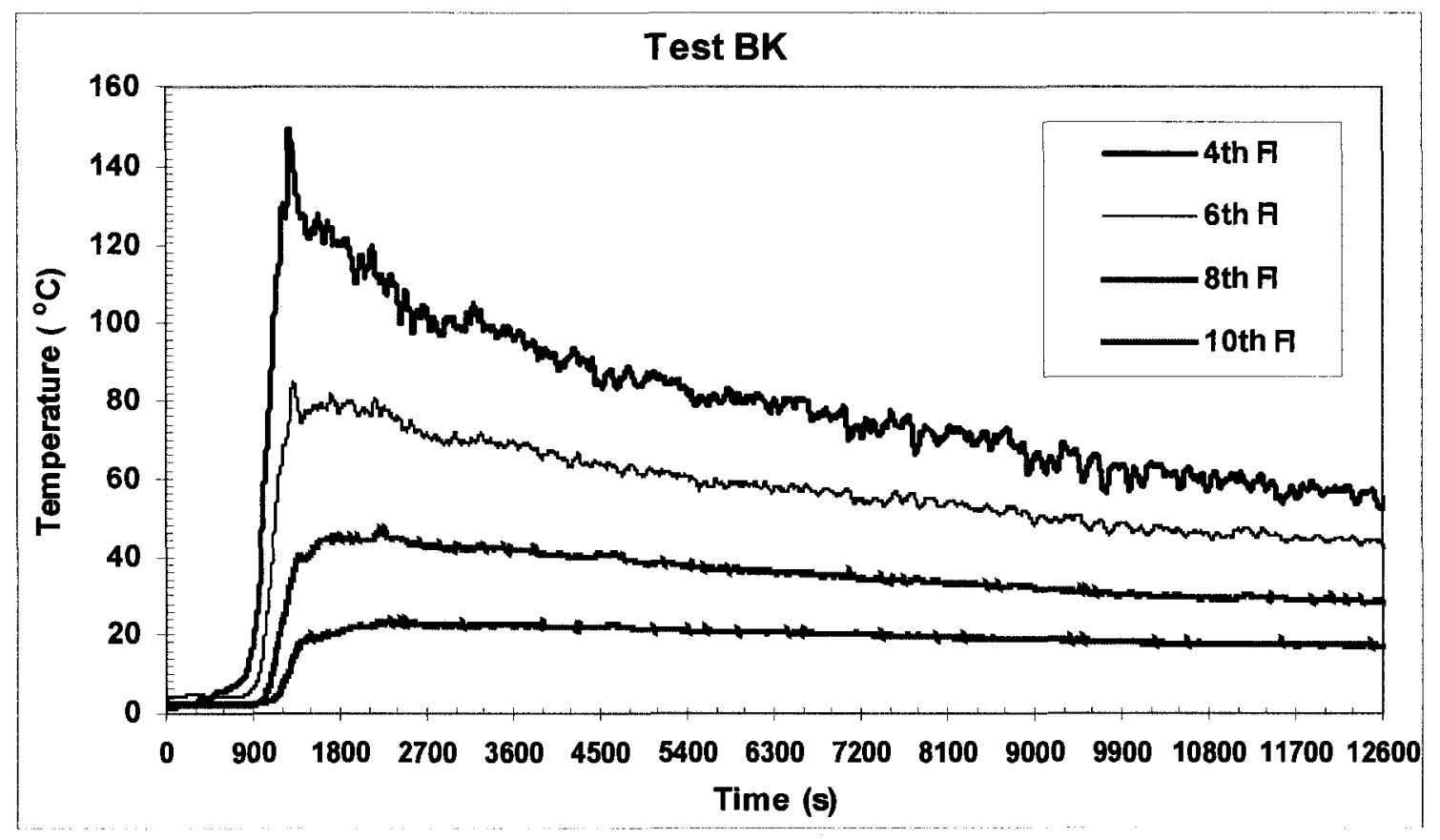

Figure 4-41: Gas temperature histories in the vestibules of the floors with open doors (Test BK) 
Table 4-11: The maximum gas temperatures in the stair shaft of different floors for Test BK

\begin{tabular}{|c|c|c|c|c|c|c|c|c|c|c|}
\hline \multicolumn{2}{|c|}{ Test ID } & $\begin{array}{c}2^{\text {nd }} \\
\text { floor }\end{array}$ & $\begin{array}{c}3^{\text {rd }} \\
\text { floor }\end{array}$ & $\begin{array}{c}4^{\text {th }} \\
\text { floor }\end{array}$ & $\begin{array}{c}5^{\text {th }} \\
\text { floor }\end{array}$ & $\begin{array}{c}6^{\text {th }} \\
\text { floor }\end{array}$ & $\begin{array}{c}7^{\text {th }} \\
\text { floor }\end{array}$ & $\begin{array}{c}8^{\text {th }} \\
\text { floor }\end{array}$ & $\begin{array}{c}9^{\text {th }} \\
\text { floor }\end{array}$ & $\begin{array}{c}10^{\text {th }} \\
\text { floor }\end{array}$ \\
\hline \multirow{4}{*}{ BK } & $\mathrm{T}_{\mathrm{i}}\left({ }^{\circ} \mathrm{C}\right)$ & 6.7 & 2.9 & 1.5 & 1.2 & 2.1 & 2.6 & 2.0 & 2.0 & 2.7 \\
\cline { 2 - 12 } & $\mathrm{T}_{\mathrm{p}}\left({ }^{\circ} \mathrm{C}\right)$ & 642.3 & 289.3 & 193.8 & 130.4 & 103.4 & 77.8 & 51.4 & 34.1 & 26.8 \\
\cline { 2 - 12 } & $\Delta \mathrm{T}\left({ }^{\circ} \mathrm{C}\right)$ & 635.6 & 286.4 & 192.3 & 129.2 & 101.3 & 75.2 & 49.4 & 32.1 & 24.1 \\
\cline { 2 - 11 } & $\mathrm{t}_{\mathrm{p}}(\mathrm{s})$ & 1250 & 1255 & 1265 & 1280 & 1290 & 1310 & 2210 & 2235 & 2240 \\
\hline
\end{tabular}

Table 4-12: The maximum gas temperatures in the vestibules of the floors with open doors for Test BK

\begin{tabular}{|c|c|c|c|c|c|}
\hline \multicolumn{2}{|c|}{ Test ID } & $4^{\text {th }}$ floor & $6^{\text {th }}$ floor & $8^{\text {th }}$ floor & $10^{\text {th }}$ floor \\
\hline \multirow{4}{*}{ BK } & $\left.\mathrm{T}_{\mathrm{i}}{ }^{\circ} \mathrm{C}\right)$ & 1.0 & 4.3 & 2.1 & 2.8 \\
\cline { 2 - 6 } & $\mathrm{T}_{\mathrm{p}}\left({ }^{\circ} \mathrm{C}\right)$ & 149.3 & 84.8 & 46.5 & 23.4 \\
\cline { 2 - 7 } & $\Delta \mathrm{T}\left({ }^{\circ} \mathrm{C}\right)$ & 148.3 & 80.5 & 44.4 & 20.6 \\
\cline { 2 - 7 } & $\mathrm{t}_{\mathrm{p}}(\mathrm{s})$ & 1275 & 1315 & 2265 & 2295 \\
\hline
\end{tabular}

Figure 4-42 shows the gas temperature histories in the vestibules of the floors with closed doors. The test results were similar to the other tests in this group. For example, the gas temperatures in the vestibules of the floors with closed doors increased a few degrees. The doors between the stair shaft and the vestibules of the odd floors were fully closed, but not completely sealed.

Figure 4-43 shows the gas temperature histories in the main compartments of the $4^{\text {th }}, 8^{\text {th }}$ and $10^{\text {th }}$ floors. The maximum values of the gas temperature and their corresponding times at the main compartments of the $4^{\text {th }}, 8^{\text {th }}$ and $10^{\text {th }}$ floors are listed in Table $4-13$. The temperature differences between the maximum temperatures and the initial temperatures of Test BK were higher compared to other tests. The maximum gas temperatures of the main compartments decreased with height. 


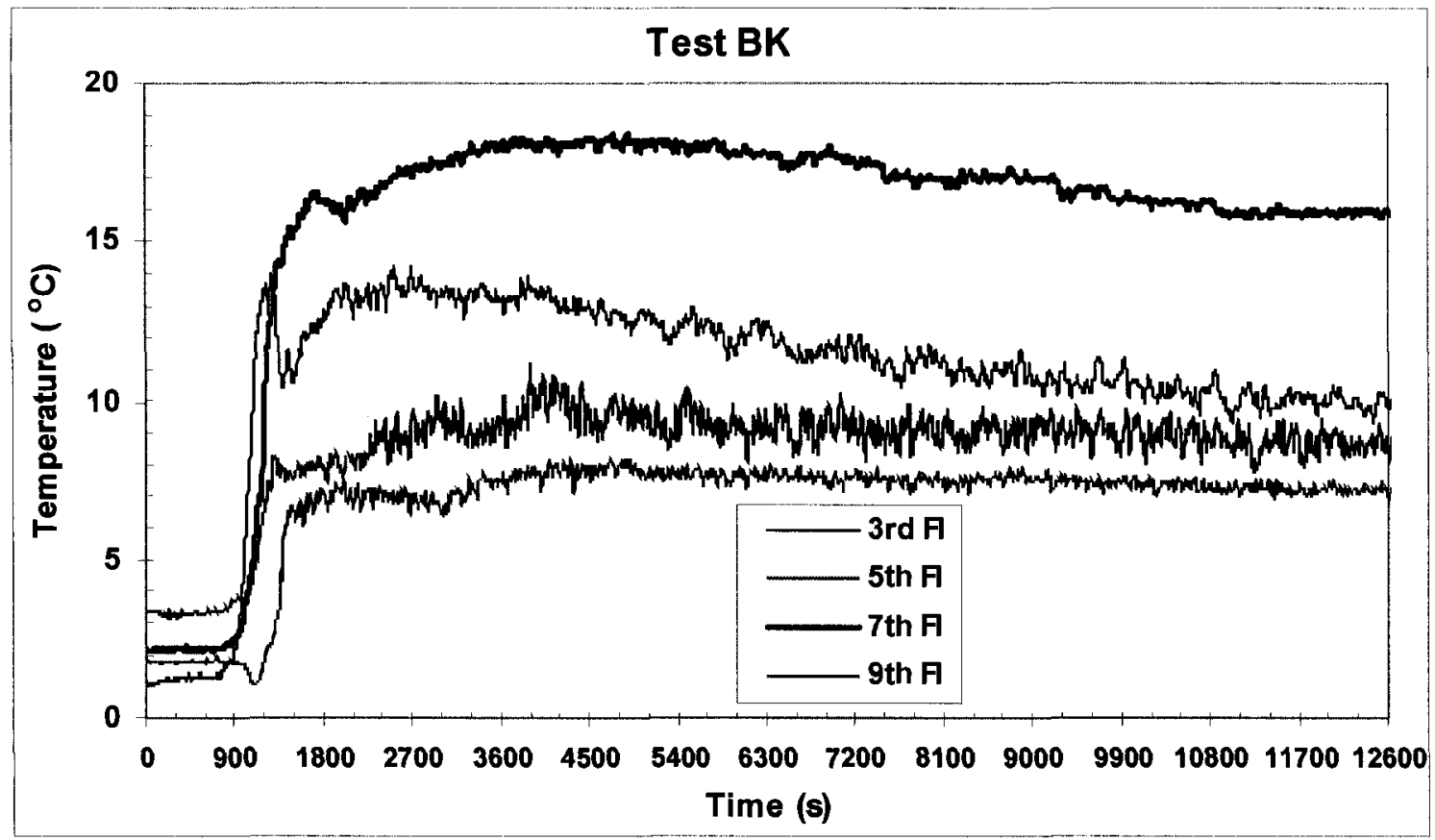

Figure 4-42: Gas temperature histories in the vestibules of the floors with closed doors (Test BK)

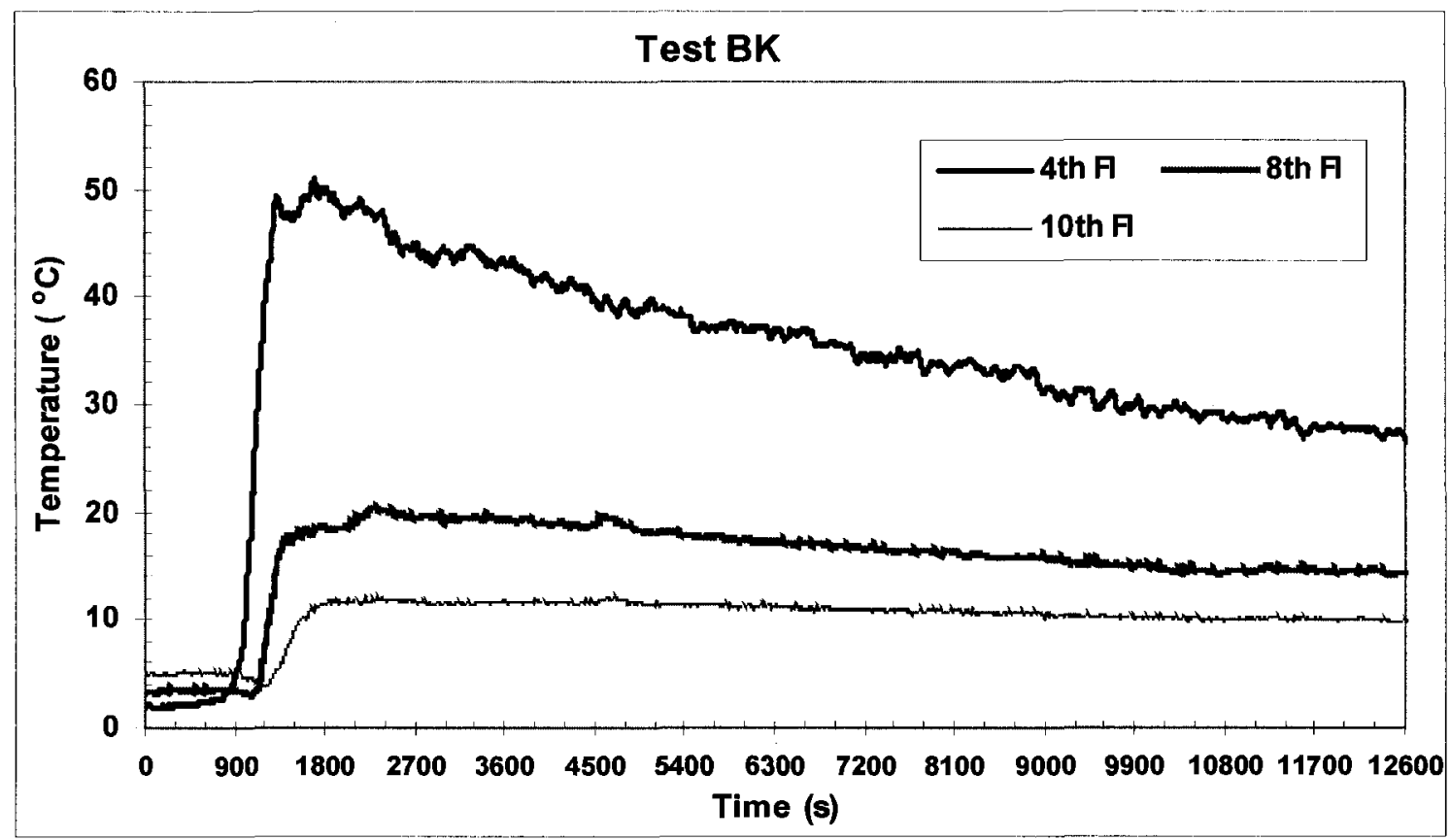

Figure 4-43: Gas temperature histories in the main compartments of the floors of the $4^{\text {th }}, 8^{\text {th }}$ and $10^{\text {th }}$ (Test BK) 
Table 4-13: The maximum gas temperatures in the main compartments of the floors of the $4^{\text {th }}, 8^{\text {th }}$ and $10^{\text {th }}$ for Test BK

\begin{tabular}{|c|c|c|c|c|}
\hline \multicolumn{2}{|c|}{ Test ID } & $4^{\text {th }}$ floor & $8^{\text {th }}$ floor & $10^{\text {th }}$ floor \\
\hline \multirow{4}{*}{ BK } & $\mathrm{T}_{\mathrm{i}}\left({ }^{\circ} \mathrm{C}\right)$ & 2.0 & 3.1 & 5.0 \\
\cline { 2 - 5 } & $\mathrm{T}_{\mathrm{p}}\left({ }^{\circ} \mathrm{C}\right)$ & 51.0 & 20.5 & 12.1 \\
\cline { 2 - 5 } & $\Delta \mathrm{T}\left({ }^{\circ} \mathrm{C}\right)$ & 49.0 & 17.4 & 7.1 \\
\cline { 2 - 5 } & $\mathrm{t}_{\mathrm{p}}(\mathrm{s})$ & 1700 & 2270 & 2355 \\
\hline
\end{tabular}

\subsubsection{Summary of Group 1: Fuel Package Tests}

Comparison of the results for the Group 1, fuel package tests, CLC-I, CLC-II, CMP and BK, can be summarized as follows:

CLC-I vs. CLC-II

Tests CLC-I and CLC-II had the same fuel components but different fire load densities. The fire load density of Test CLC-II was twice than that of Test CLC-I. As a result, the fire growth rates of these tests were similar. These rates are higher than those of the two other fuel package tests because clothing has more surface area contacting air when burning than computers and books.

As shown in Figure 4-44, which depicts gas temperature histories in the fire compartment, at the doorway on the fire floor and in the stair shaft at the fire floor for Test CLC-I and Test CLC-II, the peak temperature of the fire compartment during Test CLC-I, was the lowest of Test CLC-II, due to the lower fire load density. Test CLC-I reached the flashover condition at $220 \mathrm{~s}$ and experienced a peak temperature of $684^{\circ} \mathrm{C}$ at $235 \mathrm{~s}$, after at which time the temperature started to decrease. The peak temperatures were $684^{\circ} \mathrm{C}$ at $235 \mathrm{~s}$ in the fire compartment, $478^{\circ} \mathrm{C}$ at $250 \mathrm{~s}$ at the doorway area and $272^{\circ} \mathrm{C}$ at $265 \mathrm{~s}$ in the stair shaft at the fire floor. Whether some unburned hydrocarbons 
burned in the stair shaft at the fire floor cannot be indicated from the temperature distributions. However the low value of the concentration of $\mathrm{O}_{2}$ of $6.71 \%$ and the high value of the concentration of $\mathrm{CO}_{2}$ of $10.62 \%$ in the stair shaft at the fire floor denotes that some unburned hydrocarbons burned in the stair shaft at the fire floor.

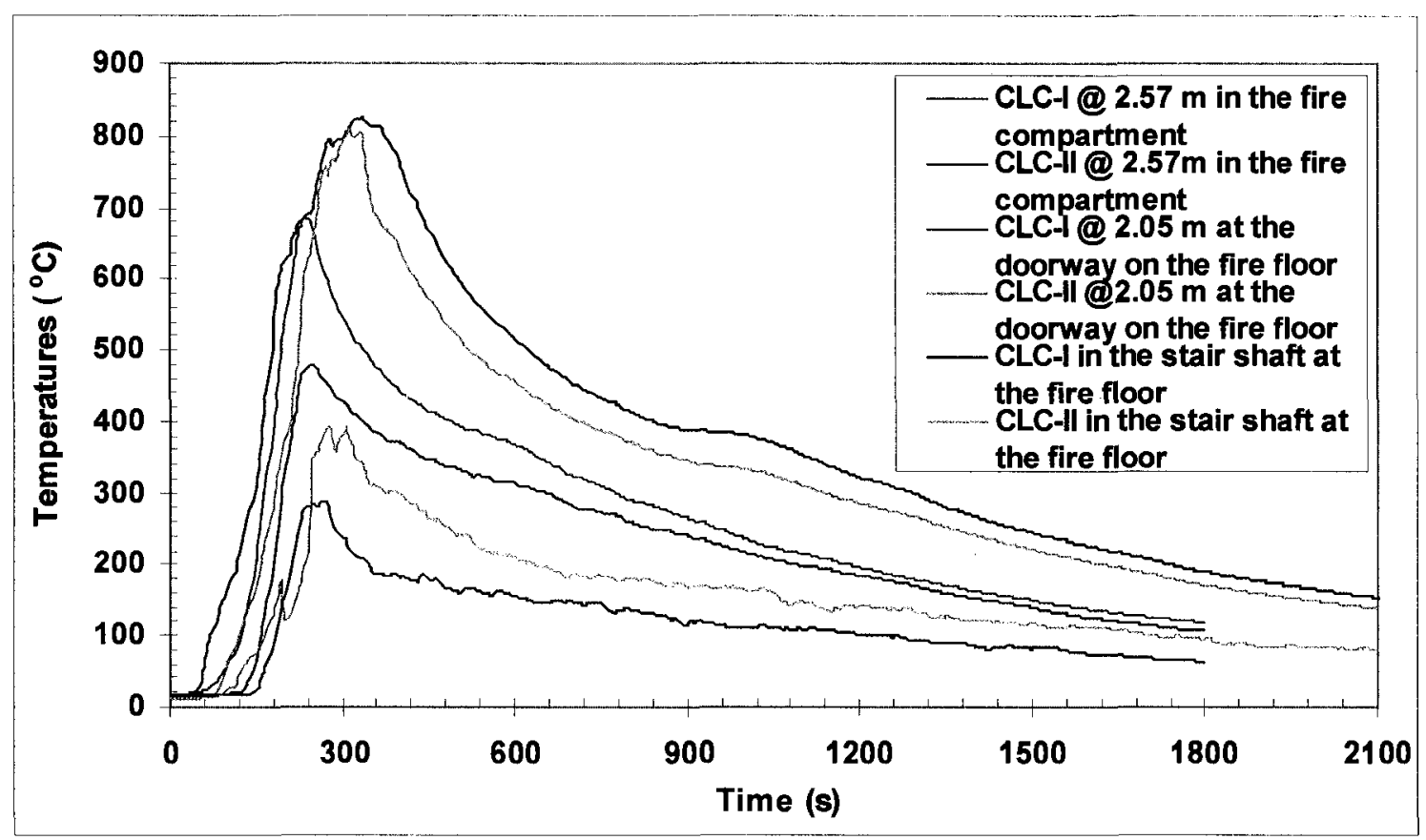

Figure 4-44: Gas temperature histories in the fire compartment, at the doorway on the fire floor and in the stair shaft at the fire floor for Test CLC-I and Test CLC-II

The concentration of $\mathrm{O}_{2}$ in the stair shaft at the fire floor during Test CLC-II decreased to $4.62 \%$ just after the time of reaching the flashover condition. As a result, there was not sufficient oxygen in the fire compartment to support complete burning of all the released hydrocarbons. Therefore, some unburned hydrocarbons entered into the stair shaft of the $2^{\text {nd }}$ floor where they burned resulting in higher temperatures in the stair shaft and doorway area. The concentration of $\mathrm{CO}$ and $\mathrm{CO}_{2}$ was also high in Test CLC-II compared to Test CLC-I. For example, the concentration of $\mathrm{CO}$ was as high as $24,920 \mathrm{ppm}$ (about 
$2.5 \%$ ) for Test CLC-II. The peak temperatures were $827^{\circ} \mathrm{C}$ at $335 \mathrm{~s}$ in the fire compartment, $816^{\circ} \mathrm{C}$ at $315 \mathrm{~s}$ at the doorway area and $380^{\circ} \mathrm{C}$ at $275 \mathrm{~s}$ in the stair shaft at the fire floor. These peak temperature distributions also indicated that some unburned hydrocarbons entered into the stair shaft and burned there.

CMP vs. CLC-II

Test CMP and CLC-II had similar fire load densities but different fuel components. The CMP fuel package had wood and plastics, whereas the CLC-II package had textiles. Temperatures in the fire compartment were similar for these tests, however Test CMP had lower temperatures in the stair shaft and the doorway areas compared to Test CLC-II. This is because in Test CMP, everything burned in the fire compartment, compared to Test CLC-II where unburned hydrocarbons burned in the stair shaft and the doorway area on the fire floor.

For Test CMP, 20 to 30 seconds after ignition, heavy dark smoke caused by plastics filled the fire compartment. This resulted in lower visibility in the fire compartment. The concentration of $\mathrm{O}_{2}$ in the stair shaft at the fire floor was $11.32 \%$, which was higher compared to other tests. The concentration of $\mathrm{CO}_{2}$ and $\mathrm{CO}$ was lower compared to Test CLC-II.

$B K$ vs. CMP, CLC-I and CLC-II

Test BK had the largest fire load density compared to the other tests in this group. Due to the large fire load density, the temperatures were the highest in the fire compartment, the stair shaft and the doorway area. Test BK had also the lowest concentration of $\mathrm{O}_{2}$ and the 
highest concentrations of $\mathrm{CO}_{2}$ and $\mathrm{CO}$. Due to insufficient availability of $\mathrm{O}_{2}$ in the fire compartment, some unburned hydrocarbons burned in the stair shaft and the doorway area, where sufficient fresh air was entrained from the stair shaft.

Table 4-14 summarizes the concentration of $\mathrm{O}_{2}, \mathrm{CO}_{2}$ and $\mathrm{CO}$ in the stair shaft at the fire floor for Group 1 tests.

Table 4-14: The concentration of $\mathrm{O}_{2}, \mathrm{CO}_{2}$ and $\mathrm{CO}$ in the stair shaft at the fire floor for Group 1 tests

\begin{tabular}{|c|c|c|c|c|}
\hline Test ID & CLC-I & CLC-II & CMP & BK \\
\hline \multirow{2}{*}{ Lowest concentration of $\mathrm{O}_{2}(\%)$} & 6.71 & 4.62 & 11.32 & 3.72 \\
& $@ 250 \mathrm{~s}$ & $@ 255 \mathrm{~s}$ & $@, 570 \mathrm{~s}$ & $@, 1255 \mathrm{~s}$ \\
\hline \multirow{2}{*}{ Highest concentration of $\mathrm{CO}_{2}(\%)$} & 10.62 & 14.74 & 7.93 & 16.55 \\
& $@ 270 \mathrm{~s}$ & $@, 255 \mathrm{~s}$ & $@, 570 \mathrm{~s}$ & $@, 1255 \mathrm{~s}$ \\
\hline Highest concentration of $\mathrm{CO}(\mathrm{ppm})$ & 4,811 & 24,917 & 9,366 & 28,251 \\
& $@ 250 \mathrm{~s}$ & $@ 260 \mathrm{~s}$ & $@ 630 \mathrm{~s}$ & $@, 1085 \mathrm{~s}$ \\
\hline
\end{tabular}

Table 4-15 lists the maximum temperatures and the lowest interface heights in the fire compartment along with the estimated flashover times for the Group 1 tests.

Table 4-15: A summary of the maximum temperatures and the lowest interface heights in the fire compartment for Group 1 tests

\begin{tabular}{|c|c|c|c|c|}
\hline Test ID & CLC-I & CLC-II & CMP & BK \\
\hline Peak Temp. ( $\left.{ }^{\circ} \mathrm{C}\right)$ & 684 & 827 & 861 & 952 \\
\hline Time of Peak (s) & 235 & 335 & 680 & 1390 \\
\hline $\begin{array}{c}\text { Time of } \\
\text { Flashover (s) }\end{array}$ & 220 & 210 & 550 & 1040 \\
\hline $\begin{array}{c}\text { The Lowest } \\
\text { Interface Height }\end{array}$ & $0.92 \mathrm{~m} @ 235 \mathrm{~s}$ & $1.11 \mathrm{~m} @ 335 \mathrm{~s}$ & $0.88 \mathrm{~m} @ 680 \mathrm{~s}$ & $0.91 \mathrm{~m} @ 1390 \mathrm{~s}$ \\
\hline
\end{tabular}

Table 4-16 provides a detailed summary of the temperature distributions at various locations of the fuel package tests for Group 1 tests. 
Table 4-16: Upper layer gas temperature difference between peak value and initial value at various locations for Group 1 tests

\begin{tabular}{|c|c|c|c|c|c|c|c|c|c|c|c|c|c|}
\hline \multirow{2}{*}{\multicolumn{2}{|c|}{ Floor \# }} & \multicolumn{4}{|c|}{ Stair Shaft } & \multicolumn{4}{|c|}{ Vestibule } & \multicolumn{4}{|c|}{\begin{tabular}{|} 
Main Compartment \\
(fire compartment \\
at $2^{\text {nd }}$ floor)
\end{tabular}} \\
\hline & & \multirow{2}{*}{$\begin{array}{c}\text { CLC-I } \\
4.6 \\
\end{array}$} & \multirow{2}{*}{\begin{tabular}{|c|} 
CLC-II \\
16.9 \\
\end{tabular}} & \multirow{2}{*}{$\begin{array}{c}\text { CMP } \\
9.8\end{array}$} & \multirow{2}{*}{$\frac{\text { BK }}{24.1}$} & \multirow{2}{*}{\begin{tabular}{|c|} 
CLC-I \\
2.9
\end{tabular}} & \multirow{2}{*}{$\begin{array}{c}\begin{array}{c}\text { CLC- } \\
\text { II }\end{array} \\
10.7\end{array}$} & \multirow{2}{*}{$\begin{array}{c}\text { CMP } \\
7.9\end{array}$} & \multirow{2}{*}{$\frac{\text { BK }}{20.6}$} & \multirow{2}{*}{\begin{tabular}{|c|} 
CLC-I \\
0.6 \\
\end{tabular}} & \multirow{2}{*}{$\begin{array}{c}\begin{array}{c}\text { CLC- } \\
\text { II }\end{array} \\
5.5\end{array}$} & \multirow{2}{*}{$\frac{\text { CMP }}{3.2}$} & \multirow{2}{*}{$\frac{\text { BK }}{7.1}$} \\
\hline $10^{\text {th }}$ & $\begin{array}{l}\Delta \mathrm{T} \\
\left({ }^{\circ} \mathrm{C}\right)\end{array}$ & & & & & & & & & & & & \\
\hline 10 & $\begin{array}{c}\mathbf{t}_{\mathbf{p}} \\
(\mathbf{s})\end{array}$ & 1025 & 965 & 990 & 2240 & 1050 & 995 & 1050 & 2295 & 1985 & 1000 & 1200 & 2355 \\
\hline \multirow{2}{*}{$9^{\text {th }}$} & $\begin{array}{c}\Delta \mathrm{T} \\
\left({ }^{0} \mathrm{C}\right)\end{array}$ & 8.1 & 23.0 & 15.4 & 32.1 & - & - & - & - & - & - & - & - \\
\hline & $\begin{array}{c}\mathbf{t}_{\mathbf{p}} \\
(\mathbf{s})\end{array}$ & 835 & 795 & 980 & 2235 & - & - & - & - & - & - & - & - \\
\hline \multirow{2}{*}{$8^{\text {th }}$} & $\begin{array}{c}\Delta \mathrm{T} \\
\left({ }^{\circ} \mathrm{C}\right)\end{array}$ & 15.0 & 39.7 & 26.6 & 49.4 & 11.8 & 34.4 & 24.2 & 44.4 & 4.0 & 12.3 & 8.8 & 17.4 \\
\hline & $\begin{array}{c}\mathbf{t}_{\mathbf{p}} \\
(\mathbf{s})\end{array}$ & 795 & 585 & 925 & 2210 & 1040 & 610 & 950 & 2265 & 1060 & 760 & 990 & 2355 \\
\hline \multirow{2}{*}{$7^{\text {th }}$} & $\begin{array}{c}\Delta \mathrm{T} \\
\left({ }^{\mathbf{0}} \mathrm{C}\right)\end{array}$ & 25.4 & 57.5 & 39.9 & 75.2 & - & - & - & - & - & - & - & - \\
\hline & $\begin{array}{c}\mathbf{t}_{\mathrm{p}} \\
(\mathbf{s})\end{array}$ & 760 & 505 & 895 & 1310 & - & - & - & - & - & - & - & - \\
\hline \multirow{2}{*}{$6^{\text {th }}$} & $\begin{array}{c}\Delta \mathrm{TT} \\
\left({ }^{\mathrm{O}} \mathrm{C}\right)\end{array}$ & 38.1 & 74.4 & 53.8 & 101.3 & 33.1 & 62.9 & 47.2 & 80.5 & - & - & - & - \\
\hline & $\begin{array}{c}\mathbf{t}_{\mathbf{p}} \\
(\mathbf{s})\end{array}$ & 555 & 480 & 775 & 1290 & 615 & 525 & 865 & 1315 & - & - & - & - \\
\hline \multirow{2}{*}{$5^{\text {th }}$} & $\begin{array}{c}\Delta \mathrm{T} \\
\left({ }^{\circ} \mathrm{C}\right)\end{array}$ & 53.3 & 96.6 & 69.2 & 129.2 & - & - & - & - & - & - & - & - \\
\hline & $\begin{array}{c}\mathbf{t}_{\mathbf{p}} \\
(\mathrm{s})\end{array}$ & 540 & 455 & 755 & 1280 & - & - & - & - & - & - & - & - \\
\hline \multirow{2}{*}{$4^{\text {th }}$} & $\begin{array}{c}\Delta \mathrm{TT} \\
\left({ }^{\mathbf{C}} \mathbf{C}\right)\end{array}$ & 83.5 & 141.5 & 98.6 & 192.3 & 69.1 & 114.2 & 83.9 & 148.3 & 21.1 & 37.6 & 27.8 & 49.0 \\
\hline & $\begin{array}{c}\mathbf{t}_{\mathrm{p}} \\
(\mathrm{s})\end{array}$ & 315 & 325 & 735 & 1265 & 355 & 325 & 745 & 1275 & 555 & 535 & 875 & 1700 \\
\hline \multirow{2}{*}{$3^{\text {rd }}$} & $\begin{array}{c}\Delta \mathrm{T} \\
\left({ }^{\mathbf{0}} \mathbf{C}\right) \\
\end{array}$ & 128.6 & 209.7 & 145.6 & 286.4 & - & - & - & - & - & - & - & - \\
\hline & $\begin{array}{c}\mathbf{t}_{\mathbf{p}} \\
(\mathbf{s})\end{array}$ & 285 & 290 & 725 & 1255 & - & - & - & - & - & - & - & - \\
\hline \multirow{2}{*}{$2^{\text {nd }}$} & $\begin{array}{c}\Delta \mathrm{TT} \\
\left({ }^{\mathrm{C}} \mathrm{C}\right)\end{array}$ & 272.3 & 379.7 & 239.7 & 635.6 & 478.0 & 815.9 & 635.0 & 887.2 & 684.0 & 826.8 & 861.2 & 951.9 \\
\hline & $\begin{array}{c}\mathbf{t}_{\mathrm{p}} \\
(\mathbf{s})\end{array}$ & 265 & 275 & 715 & 1250 & 250 & 315 & 690 & 1260 & 235 & 335 & 680 & 1390 \\
\hline
\end{tabular}




\subsection{Group 2: Propane Tests for HRR Estimation of Fuel Package Tests}

To simulate fire experiments using computer models, it is necessary to know the heat release rate of the fire. As discussed earlier, for the fuel package fires, the HRR could not be calculated using the oxygen consumption method, because the facility was not equipped with a system for measuring the flow rate and properties of the combustion products required by the oxygen consumption method. So, an alternative method was developed using a parallel set of tests with propane as the fuel.

The main assumption for this method is that if the propane test reproduces the temperature in the compartment during a fuel package test, then the heat release rate of the propane test must be similar to that of the fuel package test. For propane fires, the HRR can be computed by measuring the mass flow rate of the propane consumed. Knowing this rate and the heat of combustion of propane a theoretical heat release rate can be computed using:

$\dot{Q}=\dot{m} \Delta H_{c h}$ Eqn (4-2) where, $\dot{Q}$ is Heat Release Rate $(\mathrm{kW}) ; \dot{m}$ is the propane mass flow rate $(\mathrm{g} / \mathrm{s}) ; \Delta \mathrm{H}_{\mathrm{ch}}$ is chemical heat of combustion, which is $43.7 \mathrm{~kJ} / \mathrm{g}$ [58].

To determine the validity of the assumption consider a pre-flashover enclosure fire in which there exist two distinct layers: an upper hot layer and lower cold layer. $T_{h}$ is the uniform temperature in hot upper layer, and $T_{a}$ is the uniform temperature of the lower 
layer. The equation describing the conservation of energy of the upper layer can be written as:

$\dot{Q}=\dot{Q}_{C O N V}^{V}+\dot{Q}_{C O N V}^{U}+\dot{Q}_{R A D}^{U}+\dot{Q}_{R A D}^{L}+\dot{Q}_{R A D}^{V}$

where, $\dot{Q}$ is heat release rate of the fire $(\mathrm{kW})$

$\dot{Q}_{C O N V}^{V}$ is rate of heat loss by convection through vent $(\mathrm{kW})$

$\dot{Q}_{C O N V}^{U}=$ rate of convective heat transfer to upper walls and ceiling (kW)

$\dot{Q}_{R A D}^{U}=$ rate of radiative heat transfer to upper walls and ceiling $(\mathrm{kW})$

$\dot{Q}_{R A D}^{L}=$ rate of radiative heat transfer to lower walls and floor $(\mathrm{kW})$, and

$\dot{Q}_{R A D}^{V}=$ rate of radiative heat transfer through vent $(\mathrm{kW})$

The convective and radiative terms can be computed as follows:

$\dot{Q}_{C O N V}^{V}=\dot{m}_{h} c_{p}\left(T_{h}-T_{a}\right)$

Eqn (4-4)

where, $\dot{m}_{h}=$ mass flow rate of hot gas through vent $(\mathrm{kg} / \mathrm{s}) ; c_{p}=$ specific heat of hot gas $(\mathrm{kJ} / \mathrm{kgK}) ; T_{h}=$ temperature of hot gas $(\mathrm{K}) ; T_{a}=$ temperature of ambient air $(\mathrm{K})$ and

$\dot{Q}_{C O N V}^{U}=h_{c} A^{U}\left(T_{h}-T_{s, u}\right)$

Eqn (4-5)

where, $h_{c}=$ convective heat transfer coefficient $\left(\mathrm{kW} / \mathrm{m}^{2} \mathrm{~K}\right) ; A^{U}=$ area (walls + ceiling) contacting hot layer $\left(\mathrm{m}^{2}\right) ; T_{s, u}=$ surface temperature upper walls and ceiling $(\mathrm{K})$.

$\dot{Q}_{R A D}^{U}=\varepsilon \sigma A^{U}\left(T_{h}^{4}-T_{s, u}^{4}\right)$

Eqn (4-6) 
where, $\sigma=$ Stefan Boltzmann constant $=5.67 \times 10^{-11}\left(\mathrm{~kW} / \mathrm{m}^{2} \mathrm{~K}^{4}\right) ; \varepsilon=$ effective emissivity between gas and surfaces.

$\dot{Q}_{R A D}^{L}=\varepsilon \sigma A^{F}\left(T_{h}^{4}-T_{s, L}^{4}\right)$

Eqn (4-7)

where, $A^{F}=$ area of bottom layer $=$ area of floor $\left(\mathrm{m}^{2}\right) ; T_{s, L}=$ surface temperature of lower walls, floor and fuel $(\mathrm{K}) ; \varepsilon=$ effective emissivity between gas and surfaces

$\varepsilon=1-\exp \left\{-K_{m}\left(H-z_{I}\right)\right\}$

Eqn (4-8)

where, $H=$ Height of enclosure $\left(\mathrm{m}^{2}\right) ; z_{I}=$ height of interface $\left(\mathrm{m}^{2}\right) ; K_{m}=$ mean extinction (absorption) coefficient $\left(\mathrm{m}^{-1}\right)$; for different fires, this value may be different.

$\dot{Q}_{R A D}^{V}=\varepsilon \sigma A^{V, U}\left(T_{h}^{4}-T_{a}^{4}\right)$

Eqn (4-9)

where, $A^{V, U}=$ upper area of vent $\left(\mathrm{m}^{2}\right) ; \varepsilon=$ emissivity of hot gas, $\varepsilon \approx 1$.

For post-flashover fires it is assumed that the gas in the fire compartment is well stirred with a uniform temperature $T_{h}$. The conservation of energy of the hot gas is:

$\dot{Q}=\dot{Q}_{C O N V}^{V}+\dot{Q}_{C O N V}^{B}+\dot{Q}_{R A D}^{B}+\dot{Q}_{R A D}^{V}$

where,

$\dot{Q}=$ Heat Release Rate $(\mathrm{kW})$

$\dot{Q}_{C O N V}^{V}=$ rate of heat loss by convection through vent $(\mathrm{kW})$

$\dot{Q}_{\text {CONV }}^{B}=$ rate of convective heat transfer to boundaries and fuel $(\mathrm{kW})$

$\dot{Q}_{R A D}^{B}=$ rate of radiative heat transfer to boundaries and fuel $(\mathrm{kW})$ 
$\dot{Q}_{R A D}^{V}=$ rate of radiative heat transfer through vent $(\mathrm{kW})$

As before the convective and radiative components can be calculated using:

$\dot{Q}_{C O N V}^{V}=\dot{m}_{h} c_{p}\left(T_{h}-T_{a}\right)$

Eqn (4-11)

where, $\dot{m}_{h}=$ mass flow rate of hot gas through vent $(\mathrm{kg} / \mathrm{s}) ; c_{p}=$ specific heat of hot gas $(\mathrm{kJ} / \mathrm{kgK}) ; T_{h}=$ temperature of hot gas $(\mathrm{K}) ; T_{a}=$ temperature of ambient air $(\mathrm{K})$.

$\dot{Q}_{C O N V}^{B}=h_{c} A^{B}\left(T_{h}-T_{s, B}\right)$

where, $h_{c}=$ convective heat transfer coefficient $; A^{B}=$ area (walls + ceiling + floor $)\left(\mathrm{m}^{2}\right)$; $T_{h}=$ temperature of hot gas $(\mathrm{K}) ; T_{s, B}=$ surface temperature walls, ceiling and floor $(\mathrm{K})$; and

$\dot{Q}_{R A D}^{B}=\varepsilon \sigma A^{B}\left(T_{h}^{4}-T_{s, B}^{4}\right)$

Eqn (4-13)

where, $\varepsilon=$ effective emissivity between gas and surfaces; $A^{B}=$ area of boundary surfaces (walls + ceiling + floor - vents $)\left(\mathrm{m}^{2}\right) ; T_{h}=$ temperature of hot gas $(\mathrm{K}) ; T_{s, B}=$ surface temperature of boundaries $(\mathrm{K})$ and

$\dot{Q}_{R A D}^{V}=\varepsilon \sigma A^{V}\left(T_{h}^{4}-T_{a}^{4}\right)$

Eqn (4-14)

where, $A^{V}=$ area of vent $\left(\mathrm{m}^{2}\right)$ and $\varepsilon=$ emissivity of hot gas, $\varepsilon \approx 1$ in this direction

Both the fuel package fires and the corresponding propane fires were conducted in the same test facility with the same set-up, boundary properties and vent areas. Analyzing Eqn (4-3) to Eqn (4-14), the only heat transfer components that may give rise to different values between the fuel package fires and the corresponding propane fires are the radiative components. This is due to the difference in the rates of generation of soot that 
is possible between the fuel package fires and the propane fires, which affects the mean extinction (absorption) coefficient $\mathrm{K}_{\mathrm{m}}$. This, however will result in relatively small differences in heat transfer in the compartment relative to the convective heat transfer components because the fire compartment surfaces were insulated. The convective components of both fires are expected to produce similar values.

Another cause of discrepancies in the heat release rate between the fuel package and the propane tests is combustion that takes place outside the room for some of the tests due to the availability of unburned hydrocarbons in the gases leaving the compartment. These discrepancies are easily identified and will be discussed later.

\subsubsection{Propane test for HRR estimation of Test CLC-I (Test CLC-I-R)}

In Test CLC-I-R propane was used as fuel to reproduce the temperature-time curve in the fire compartment of fuel package Test CLC-I.

The temperatures measured by the thermocouple tree (TC) located in the corner of the fire compartment are shown in Figure 4-45. During the first $175 \mathrm{~s}$ the temperature in the fire compartment increased at a faster rate for Test CLC-I-R compared to Test CLC-I. At $175 \mathrm{~s}$, the temperature of Test CLC-I-R was very close to the temperature of Test CLC-I. After this time period, the temperature increased and reached a maximum value of $671^{\circ} \mathrm{C}$ at $260 \mathrm{~s}\left(2.57 \mathrm{~m}\right.$ height), compared to the maximum value of $684^{\circ} \mathrm{C}$ at $235 \mathrm{~s}(2.57 \mathrm{~m}$ height) obtained in Test CLC-I.

Using the upper layer average temperature of $600^{\circ} \mathrm{C}$ as the flashover criterion, the fire reached the flashover condition at $250 \mathrm{~s}$ for Test CLC-I-R while for Test CLC-I the flashover condition reached at $220 \mathrm{~s}$. The fire entered the decay phase after reaching the 
peak resulting in a steady decrease in temperatures until the end of the test at $1500 \mathrm{~s}$. The interface height in the fire compartment determined using Eqn (4-1) was $1.13 \mathrm{~m}$ at $260 \mathrm{~s}$ for Test CLC-I-R, whereas it was $0.92 \mathrm{~m}$ at $235 \mathrm{~s}$ for package Test CLC-I, with temperatures reaching maximum in the fire compartment.

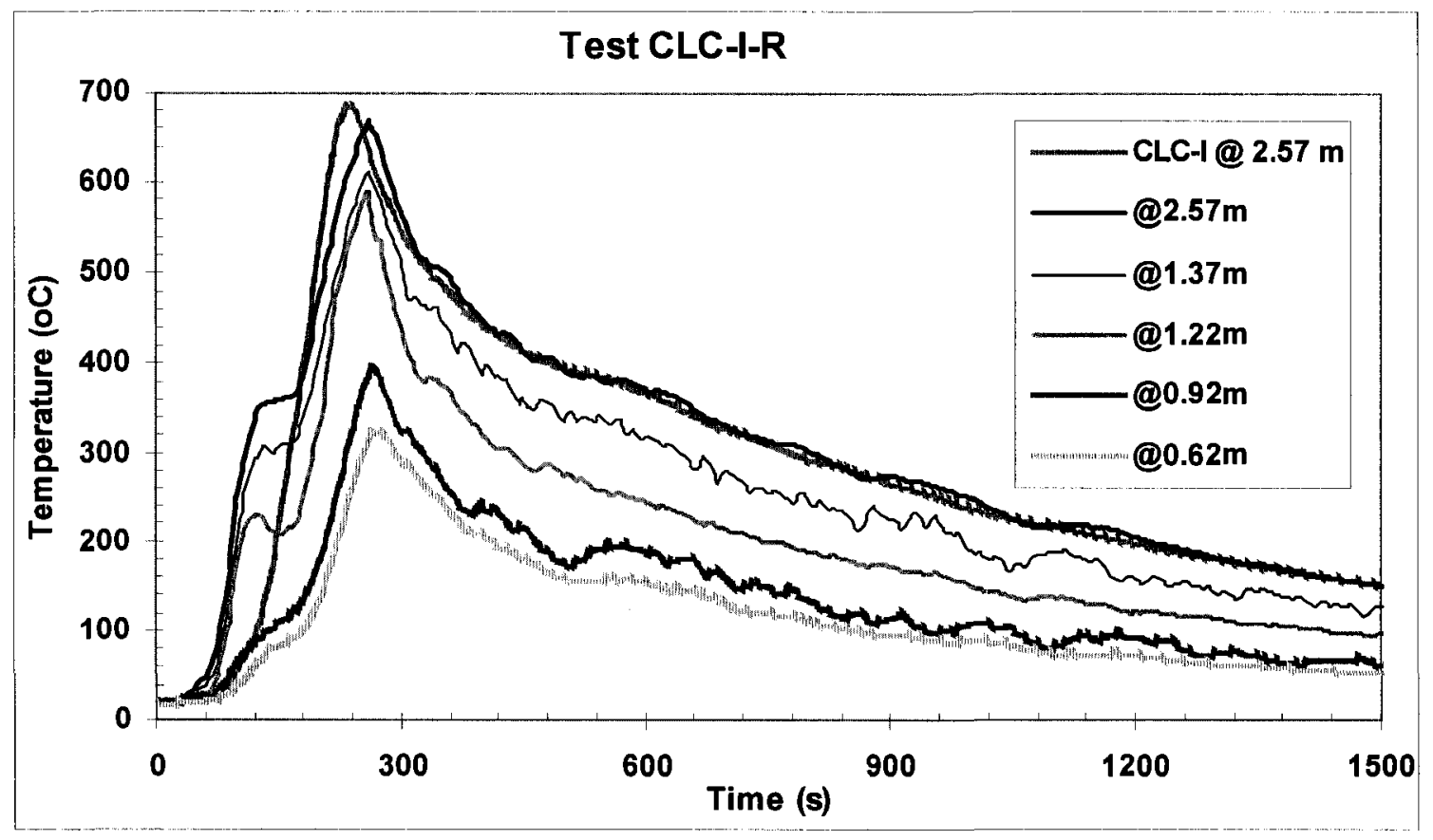

Figure 4-45: Gas temperature histories at different heights in the corner of the fire compartment (Test CLC-I-R)

The heat release rate during Test CLC-I-R is shown in Figure 4-46. The HRR increased to $960 \mathrm{~kW}$ at $80 \mathrm{~s}$, which caused the temperature in the fire compartment to increase faster than the temperature of Test CLC-I. To slow down the temperature rise, the propane flow rate was reduced causing a reduction of the HRR. At $130 \mathrm{~s}$, the HRR increased steadily until it reached a peak value of $2565 \mathrm{~kW}$ at $240 \mathrm{~s}$. Once the peak was reached, there was a relatively steep and fast drop of HRR until $300 \mathrm{~s}$, followed by a slower rate until the end of the test at $1500 \mathrm{~s}$. 


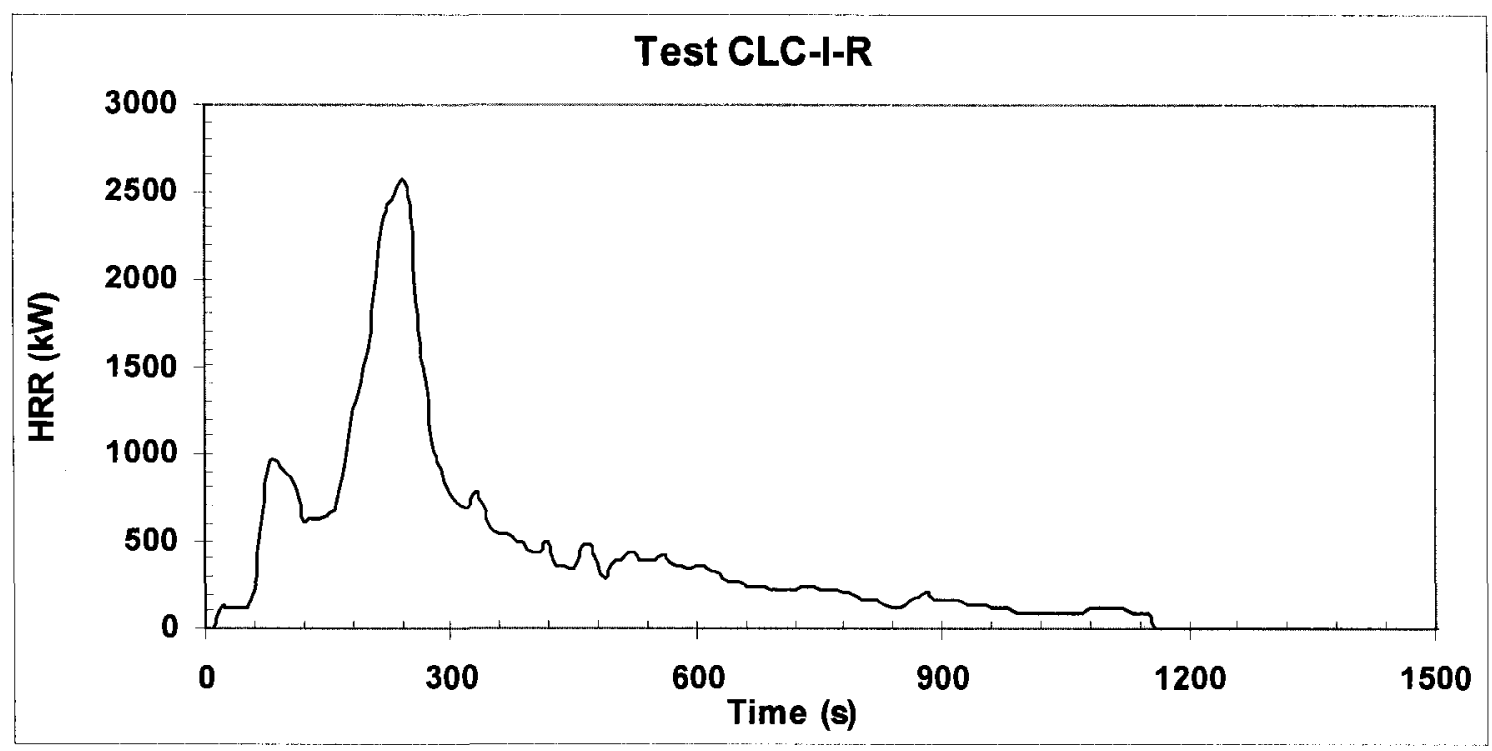

Figure 4-46: Heat release rate (Test CLC-I-R)

Figure 4-47 shows the concentration of $\mathrm{O}_{2}$ and $\mathrm{CO}_{2}$ in the stair shaft at the fire floor during Test CLC-I-R. The figure indicates that the lowest concentration of $\mathrm{O}_{2}$ was $12.39 \%$ at $280 \mathrm{~s}$, which is higher than the value of $6.71 \%$ at $250 \mathrm{~s}$ for Test CLC-I shown in Figure 4-4. The highest concentration of $\mathrm{CO}_{2}$ was $5.30 \%$ at $270 \mathrm{~s}$, which is lower than the value of $10.62 \%$ at $270 \mathrm{~s}$ for Test CLC-I shown in Figure 4-4. Due to insufficient oxygen supplied in the fire compartment, during Test CLC-I some unburned hydrocarbons entered into the stair shaft at the $2^{\text {nd }}$ floor carried by smoke and burned there, consuming $\mathrm{O}_{2}$ and generating $\mathrm{CO}_{2}$. This resulted in the lower value of the concentration of $\mathrm{O}_{2}$ and higher value of the concentration of $\mathrm{CO}_{2}$ for Test CLC-I than Test CLC-I-R. The concentration of $\mathrm{CO}$ in the stair shaft at the fire floor for Test CLC-I-R was very low, not shown in the figure. However, the concentration of $\mathrm{CO}$ in the stair shaft at the fire floor for Test CLC-I was 4,811 ppm at $250 \mathrm{~s}$ (Figure 4-5). The propane fire during Test CLC-I-R produced less $\mathrm{CO}$ than the fuel package fire during Test CLC-I. The reason is that the well-ventilated combustion of propane does not 
produce significant amounts of $\mathrm{CO}$. Since the propane burner was located in the lower layer there was enough oxygen for an efficient combustion producing less $\mathrm{CO}$. In fuel package fire, the fuel package obstructed the oxygen so there was not good mixing with the pyrolysis products producing more $\mathrm{CO}$.

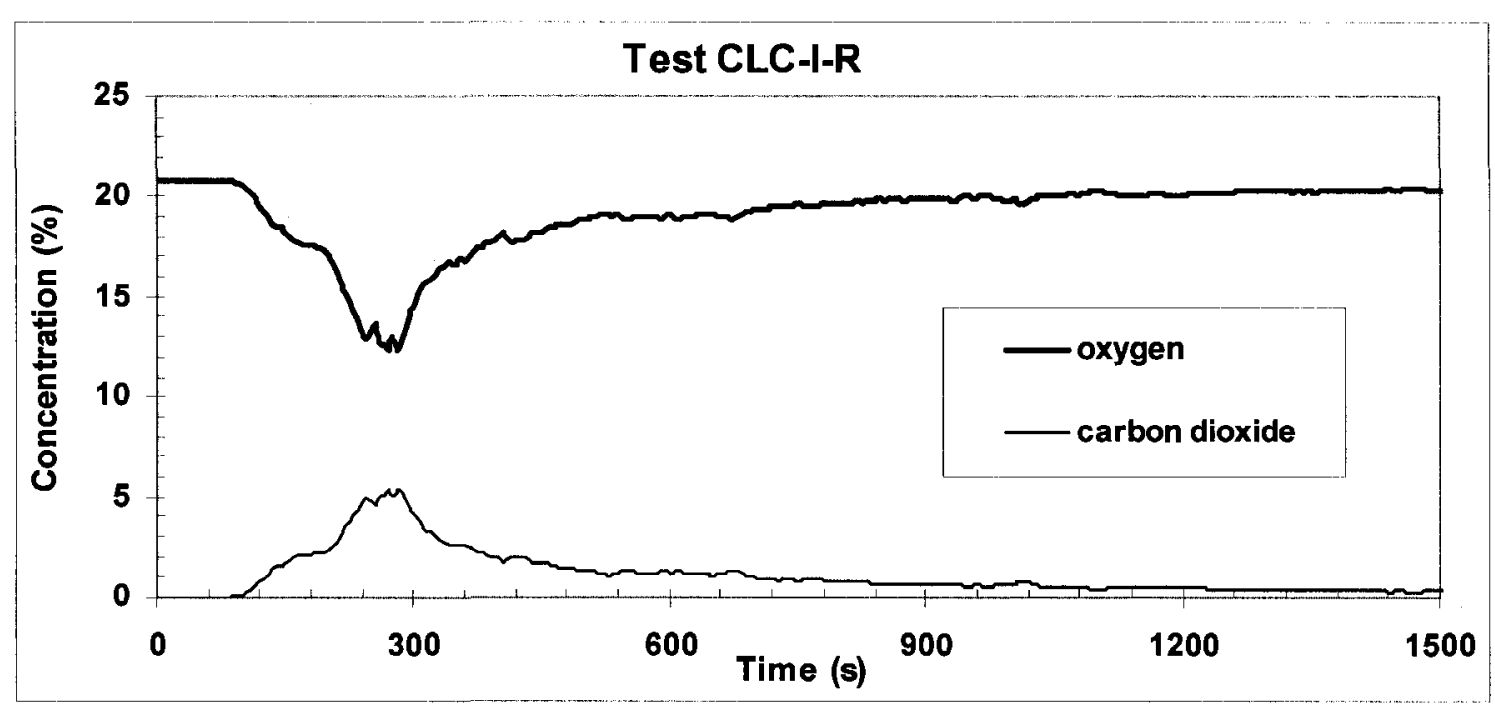

Figure 4-47: Concentration of $\mathrm{O}_{2}$ and $\mathrm{CO}_{2}$ in the stair shaft at the fire floor (Test CLC-I-R)

Figure 4-48 shows the gas temperature histories at different heights at the doorway during Test CLC-I-R as recorded by the thermocouples placed at the doorway. A maximum temperature of $522^{\circ} \mathrm{C}$ at $260 \mathrm{~s}$ was recorded by the thermocouples at $1.65 \mathrm{~m}$ height, which was higher compared to $468^{\circ} \mathrm{C}$ at $250 \mathrm{~s}$ (1.65 m height) shown in Figure 4-8 for Test CLC-I. The peak temperature in the fire compartment during Test CLC-I-R was $671^{\circ} \mathrm{C}$, while $684^{\circ} \mathrm{C}$ for Test CLC-I shown in Figure 4-6. Since the propane Test CLC-I-R produced less soot than the fuel package Test CLC-I, there was less radiative heat loss resulting in higher temperatures at the doorway for Test CLC-I-R than Test CLC-I. 


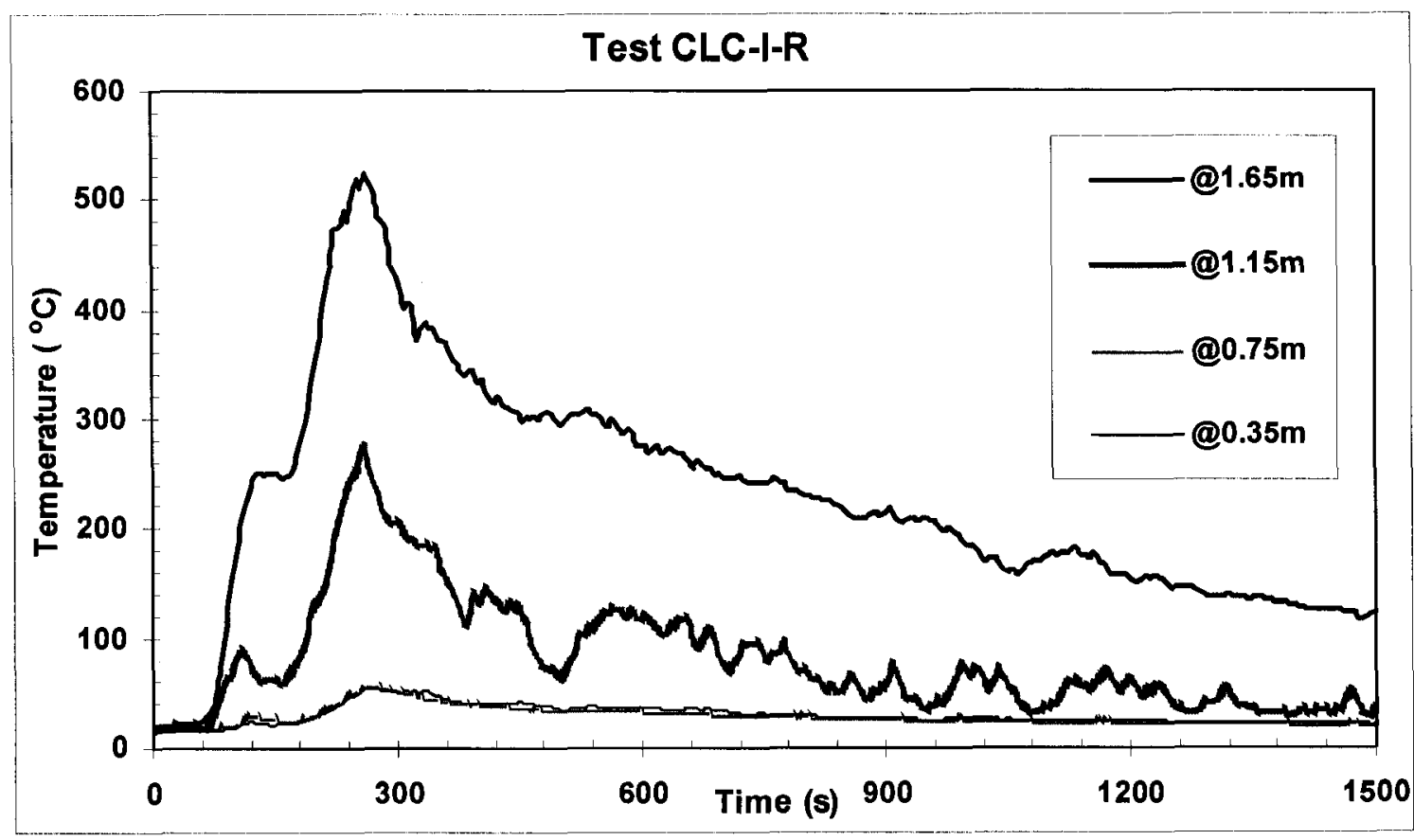

Figure 4-48: Gas temperature histories at different heights at the doorway (Test CLC-I-R)

The gas temperature histories in the stair shaft during Test CLC-I-R recorded by the thermocouples installed in the stair shaft at each floor from the $2^{\text {nd }}$ to $10^{\text {th }}$ are shown in Figure 4-49. The maximum gas temperature in the stair shaft of the fire floor was $254^{\circ} \mathrm{C}$ at $265 \mathrm{~s}$. As mentioned earlier, the maximum gas temperature was $671^{\circ} \mathrm{C}$ at $260 \mathrm{~s}$ in the fire compartment, and $522^{\circ} \mathrm{C}$ at $260 \mathrm{~s}$ at the doorway of the fire floor. As listed in Table 4-16, for Test CLC-I, the maximum gas temperatures were $684^{\circ} \mathrm{C}$ at $235 \mathrm{~s}$ in the fire compartment, $478^{\circ} \mathrm{C}$ at $250 \mathrm{~s}$ at the doorway and $272^{\circ} \mathrm{C}$ at $265 \mathrm{~s}$ in the stair shaft at the fire floor. The higher peak temperature in the stair shaft at the $2^{\text {nd }}$ floor of Test CLC-I also indicates that some unburned hydrocarbons burned in the stair shaft at the fire floor during Test CLC-I.

Smoke leaving the fire compartment passed through the vestibule and from there entered the stair shaft. The maximum values of the gas temperature and their corresponding times 
at the stair shaft for floors $2^{\text {nd }}$ to $10^{\text {th }}$ are listed in Table 4-17. The table indicates that the maximum gas temperatures in the stair shaft decreased with height, due to heat losses to the boundaries and mixing with cold air similar to Test CLC-I.

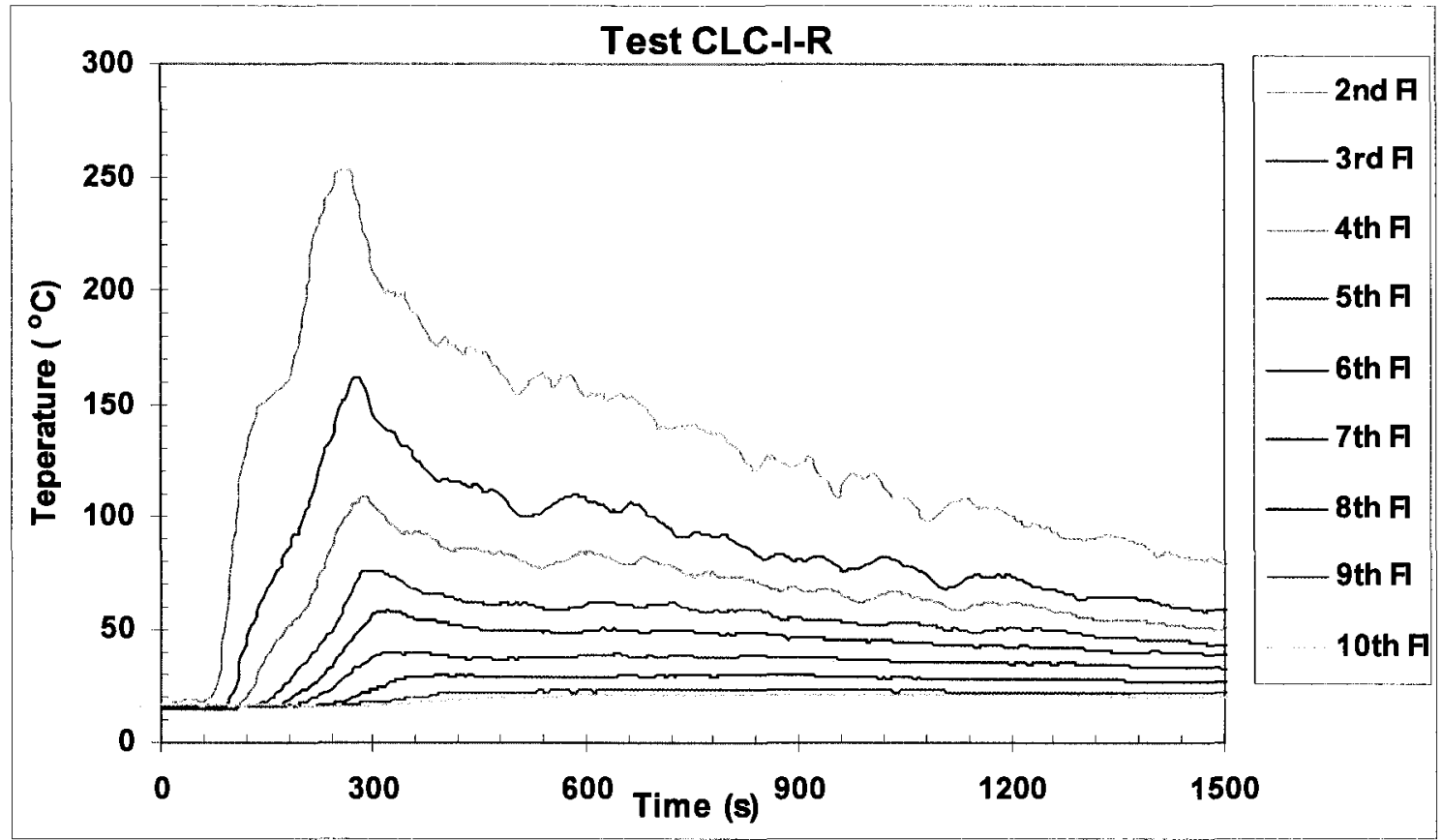

Figure 4-49: Gas temperature histories in the stair shaft (Test CLC-I-R)

Table 4-17: The maximum gas temperatures in the stair shaft of different floors for

Test CLC-I-R

\begin{tabular}{|c|c|c|c|c|c|c|c|c|c|c|}
\hline Test ID & Floor \# & $\begin{array}{c}2^{\text {nd }} \\
\text { floor }\end{array}$ & $\begin{array}{c}3^{\text {rd }} \\
\text { floor }\end{array}$ & $\begin{array}{c}4^{\text {th }} \\
\text { floor }\end{array}$ & $\begin{array}{c}5^{\text {th }} \\
\text { floor }\end{array}$ & $\begin{array}{c}6^{\text {th }} \\
\text { floor }\end{array}$ & $\begin{array}{c}7^{\text {th }} \\
\text { floor }\end{array}$ & $\begin{array}{c}8^{\text {th }} \\
\text { floor }\end{array}$ & $\begin{array}{c}9^{\text {th }} \\
\text { floor }\end{array}$ & $\begin{array}{c}10^{\text {th }} \\
\text { floor }\end{array}$ \\
\hline \multirow{4}{*}{ CLC-I-R } & $\mathrm{T}_{\mathrm{i}}\left({ }^{\circ} \mathrm{C}\right)$ & 16.5 & 14.6 & 14.6 & 14.8 & 15.4 & 15.4 & 15.2 & 15.3 & 16.3 \\
\cline { 2 - 12 } & $\mathrm{T}_{\mathrm{p}}\left({ }^{\circ} \mathrm{C}\right)$ & 253.6 & 161.7 & 109.2 & 76.2 & 58.7 & 40.5 & 30.1 & 23.6 & 21.4 \\
\cline { 2 - 12 } & $\Delta \mathrm{T}\left({ }^{\circ} \mathrm{C}\right)$ & 237.1 & 147.1 & 94.6 & 61.4 & 43.3 & 25.1 & 14.9 & 8.3 & 5.1 \\
\cline { 2 - 11 } & $\mathrm{t}_{\mathrm{p}}(\mathrm{s})$ & 265 & 265 & 285 & 295 & 320 & 325 & 855 & 885 & 960 \\
\hline
\end{tabular}

Note: $T_{i}$ is the initial gas temperature; $T_{p}$ is the peak gas temperature; $\Delta T$ is the gas temperature difference between $T_{p}$ and $T_{i}$ and $t_{p}$ is the time when the gas reached the peak temperature

Figure 4-50 shows the gas temperature histories for Test CLC-I-R recorded by the thermocouples in the vestibules of the floors with open doors. The maximum values of the gas temperature in the vestibules of the floors with open doors and their 
corresponding times are listed in Table 4-18. The maximum temperatures decreased with height, because of heat losses to the boundaries and mixing with cold air.

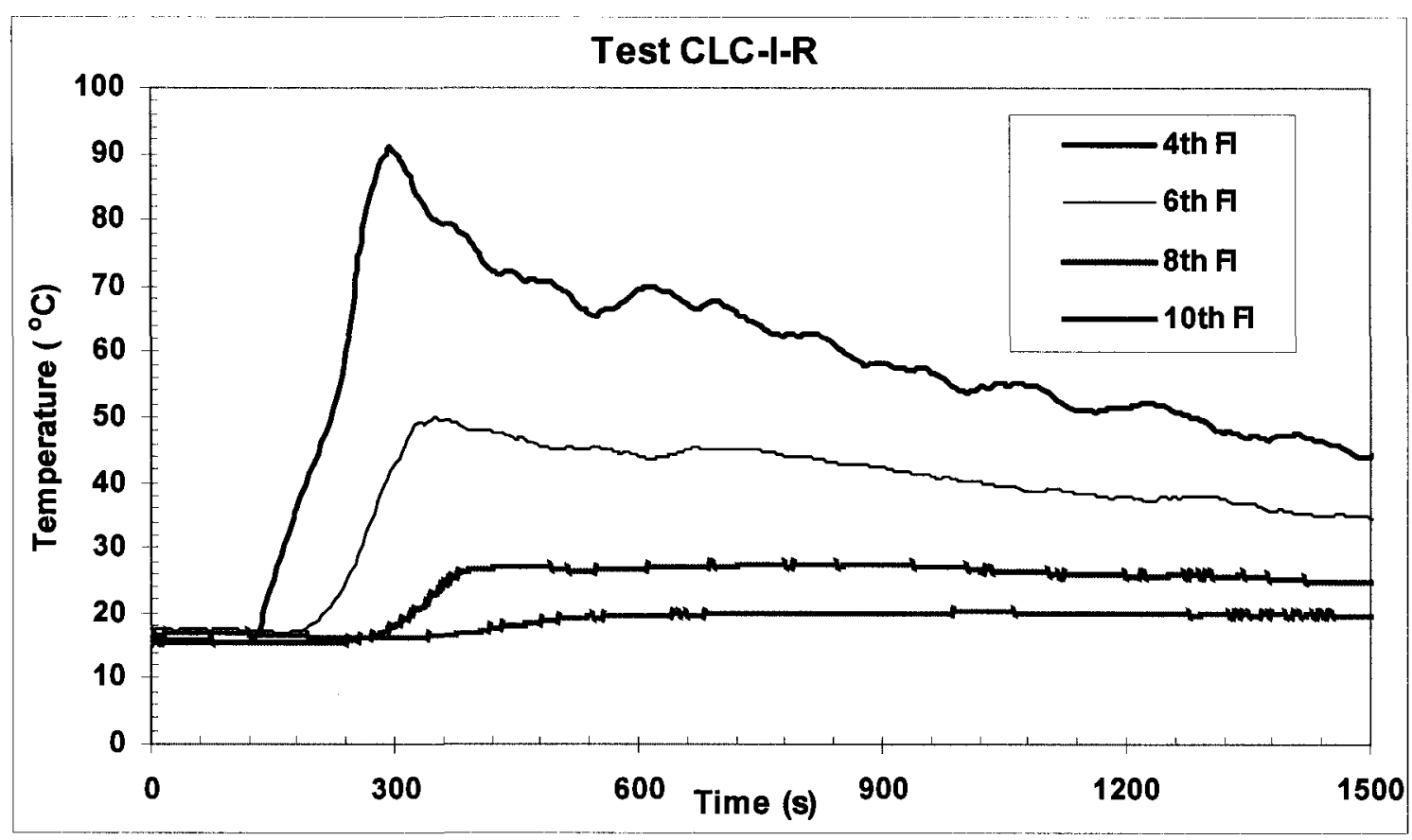

Figure 4-50: Gas temperature histories in the vestibules of the floors with open doors (Test CLC-I-R)

Table 4-18: The maximum gas temperatures in the vestibules of the floors with open doors for Test CLC-I-R

\begin{tabular}{|c|c|c|c|c|c|}
\hline Test ID & Floor \# & $4^{\text {th }}$ floor & $6^{\text {th }}$ floor & $8^{\text {th }}$ floor & $10^{\text {th }}$ floor \\
\hline \multirow{4}{*}{ CLC-I-R } & $\mathrm{T}_{\mathrm{i}}\left({ }^{\circ} \mathrm{C}\right)$ & 15.4 & 17.6 & 15.6 & 16.8 \\
\cline { 2 - 6 } & $\mathrm{T}_{\mathrm{p}}\left({ }^{\circ} \mathrm{C}\right)$ & 90.9 & 49.9 & 27.6 & 20.3 \\
\cline { 2 - 6 } & $\Delta \mathrm{T}\left({ }^{\circ} \mathrm{C}\right)$ & 75.5 & 32.3 & 12.0 & 3.5 \\
\cline { 2 - 6 } & $\mathrm{t}_{\mathrm{p}}(\mathrm{s})$ & 295 & 350 & 895 & 1010 \\
\hline
\end{tabular}

Note: $T_{i}$ is the initial gas temperature; $T_{p}$ is the peak gas temperature; $\Delta T$ is the gas temperature difference between $T_{p}$ and $T_{i}$ and $t_{p}$ is the time when the gas reached the peak temperature

Figure 4-51 shows the gas temperature histories in the vestibules of the floors with closed doors for Test CLC-I-R. The test results were similar to the other tests described before. The gas temperatures in the vestibules of the floors with closed doors increased a few 
degrees compared to the initial values. The doors between the stair shaft and the vestibules of the odd floors were fully closed, but not completely sealed.

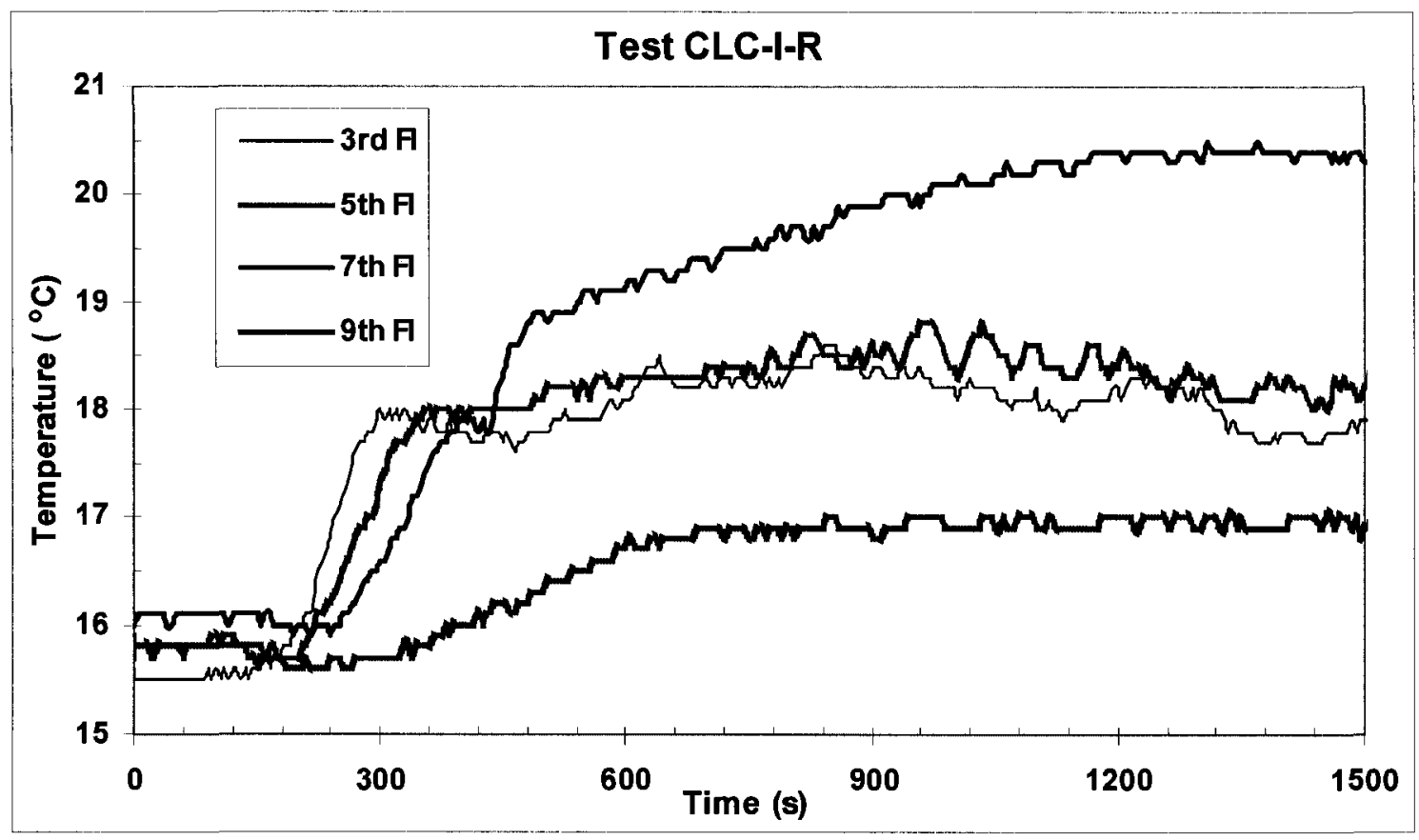

Figure 4-51: Gas temperature histories in the vestibules of the floors with closed doors (Test CLC-I-R)

Figure 4-52 shows the gas temperature histories in the main compartments of the $4^{\text {th }}, 8^{\text {th }}$ and $10^{\text {th }}$ floors for Test CLC-I-R. The maximum values of the gas temperatures in the main compartments of the $4^{\text {th }}, 8^{\text {th }}$ and $10^{\text {th }}$ floors and their corresponding times are listed in Table 4-19. The maximum gas temperatures at the main compartments decreased with the height. These results are similar to the results during Test CLC-I. 


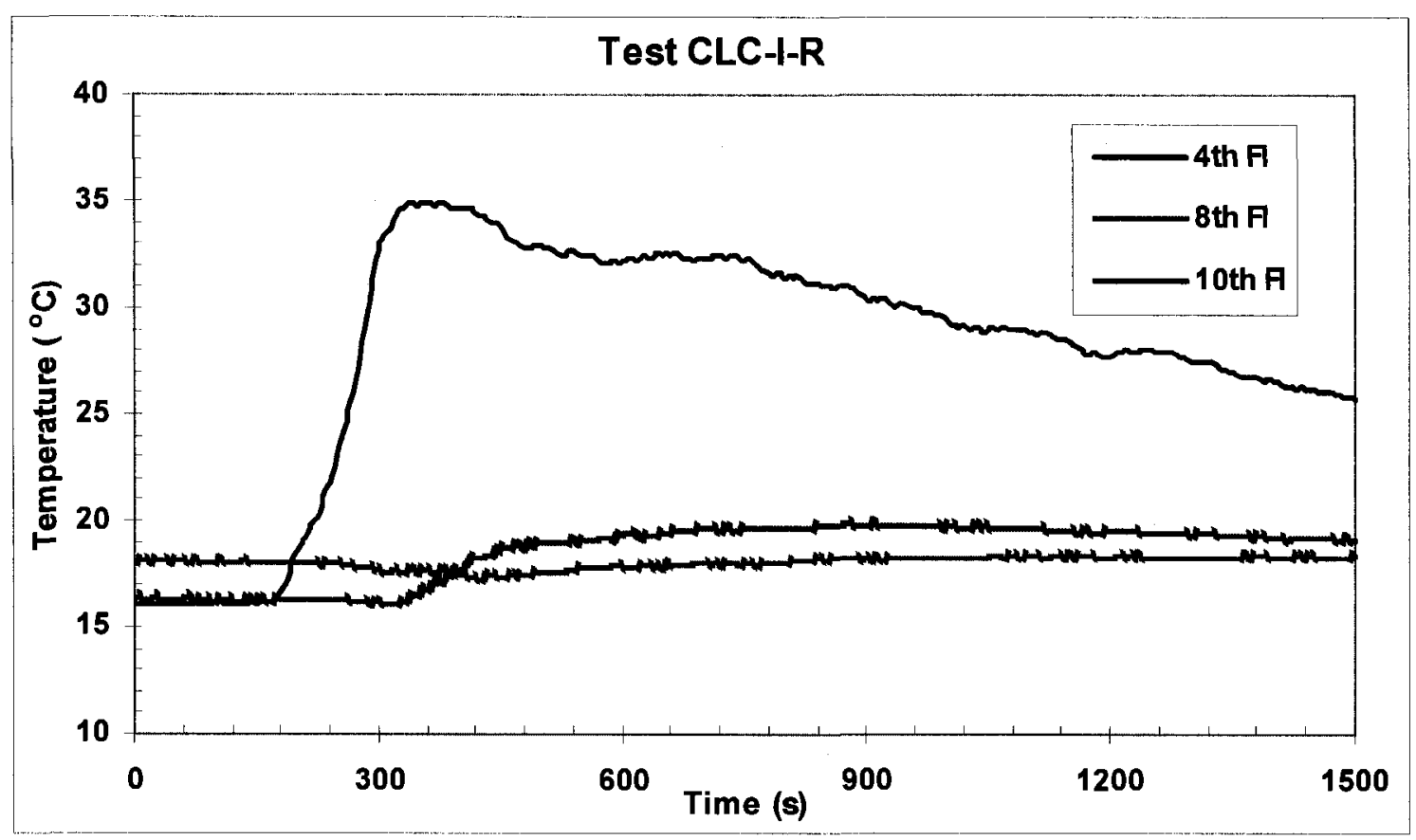

Figure 4-52: Gas temperature histories in the main compartments of the floors of the $4^{\text {th }}, 8^{\text {th }}$ and $10^{\text {th }}$ (Test CLC-I-R)

Table 4-19: The maximum gas temperatures in the main compartments of the floors of the $4^{\text {th }}, 8^{\text {th }}$ and $10^{\text {th }}$ for Test CLC-I-R

\begin{tabular}{|c|c|c|c|c|}
\hline \multirow{2}{*}{ Test ID } & Floor \# & $4^{\text {th }}$ floor & $8^{\text {th }}$ floor & $10^{\text {th }}$ floor \\
\hline \multirow{4}{*}{ CLC-I-R } & $\mathrm{T}_{\mathrm{i}}\left({ }^{\circ} \mathrm{C}\right)$ & 16.0 & 16.4 & 18.0 \\
\cline { 2 - 5 } & $\mathrm{T}_{\mathrm{p}}\left({ }^{\circ} \mathrm{C}\right)$ & 34.9 & 19.9 & 18.4 \\
\cline { 2 - 5 } & $\Delta \mathrm{T}\left({ }^{\circ} \mathrm{C}\right)$ & 18.9 & 3.5 & 0.4 \\
\cline { 2 - 5 } & $\mathrm{t}_{\mathrm{p}}(\mathrm{s})$ & 340 & 910 & 1055 \\
\hline
\end{tabular}

Note: $T_{i}$ is the initial gas temperature; $T_{p}$ is the peak gas temperature; $\Delta T$ is the gas temperature difference between $T_{p}$ and $T_{i}$ and $t_{p}$ is the time when the gas reached the peak temperature

\subsubsection{Propane test for HRR estimation of Test CLC-II (Test CLC-II-R)}

In Test CLC-II-R propane was used as fuel to reproduce the temperature-time curve in the fire compartment of fuel package Test CLC-II.

The temperatures measured by the thermocouple tree located in the corner of the fire compartment are shown in Figure 4-53. The shape of the temperature-time curve in the 
fire compartment for Test CLC-II-R is similar to that during Test CLC-II. The only difference is that during the growth period the new curve is about $80-100 \mathrm{~s}$ behind the fuel package curve. For example, a maximum temperature of $828^{\circ} \mathrm{C}$ at $420 \mathrm{~s}(2.57 \mathrm{~m}$ height) was recorded for Test CLC-II-R, compared to $827^{\circ} \mathrm{C}$ at $335 \mathrm{~s}$ ( $2.57 \mathrm{~m}$ height) for Test CLC-II, showing a delay of $85 \mathrm{~s}$.

Using the upper layer average temperature of $600^{\circ} \mathrm{C}$ as the flashover criterion, the CLC-II-R fire reached the flashover condition at $280 \mathrm{~s}$ and the CLC-II fire at $210 \mathrm{~s}$. The fire entered the decay phase after reaching the peak and the temperature started to decrease steadily until the end of the test at $2100 \mathrm{~s}$. The interface height in the compartment of fire origin determined using Eqn (4-1) was $0.86 \mathrm{~m}$ at 420 s for Test CLC-II-R, whereas $1.11 \mathrm{~m}$ at $335 \mathrm{~s}$ for package Test CLC-II, when the temperatures in the fire compartment reached its maximum value.

The heat release rate of Test CLC-II-R is shown in Figure 4-54. The HRR kept a steady value of $176 \mathrm{~kW}$ for about 2 minutes until $110 \mathrm{~s}$, after which there was a steady increase until a peak value of $3372 \mathrm{~kW}$ was reached at $385 \mathrm{~s}$. Once the peak value was achieved, the HRR dropped at a fast rate until $450 \mathrm{~s}$, then at a slower rate till the end of the test at $2100 \mathrm{~s}$. 


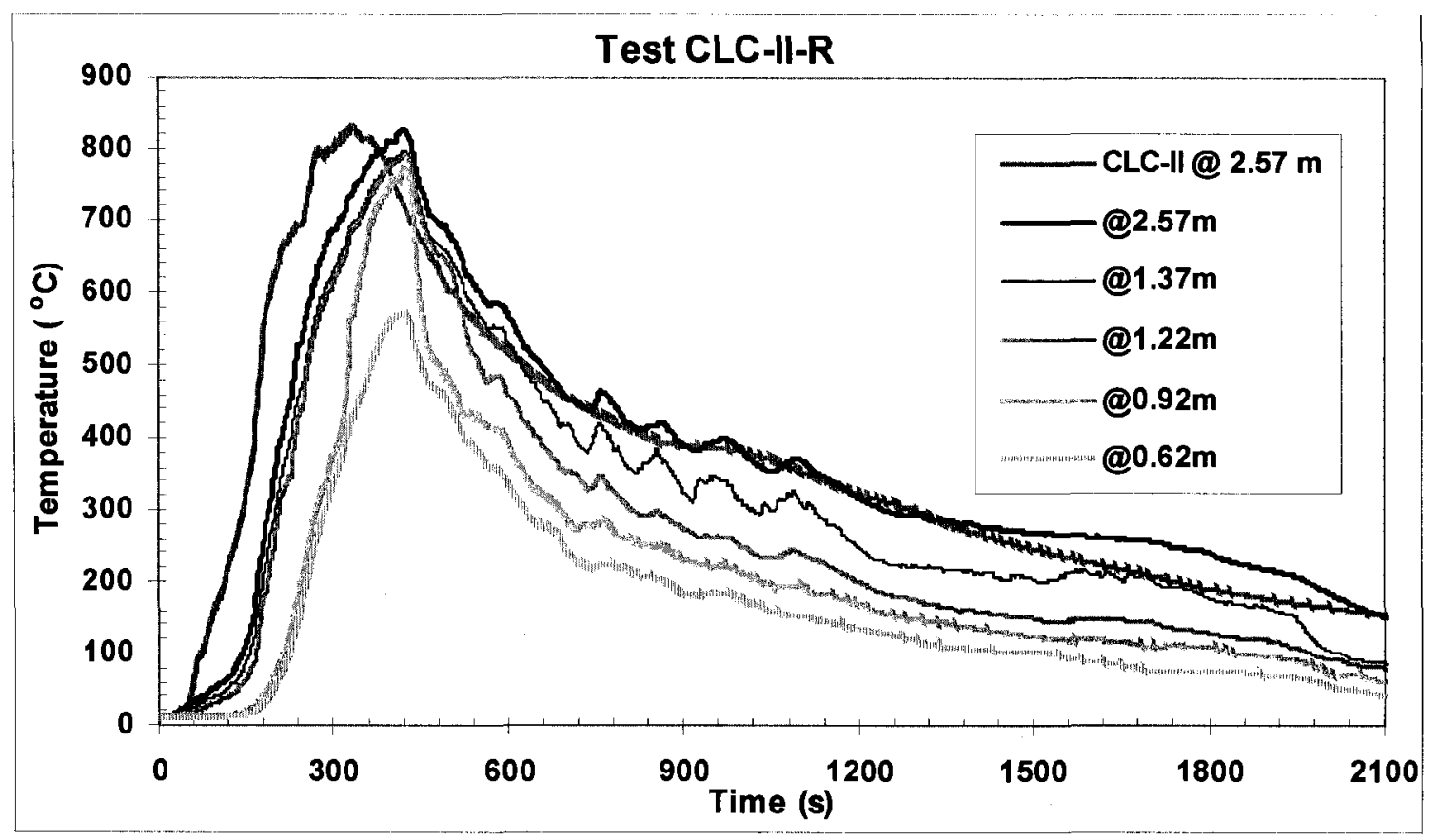

Figure 4-53: Gas temperature histories at different heights in the corner of fire compartment (Test CLC-II-R)

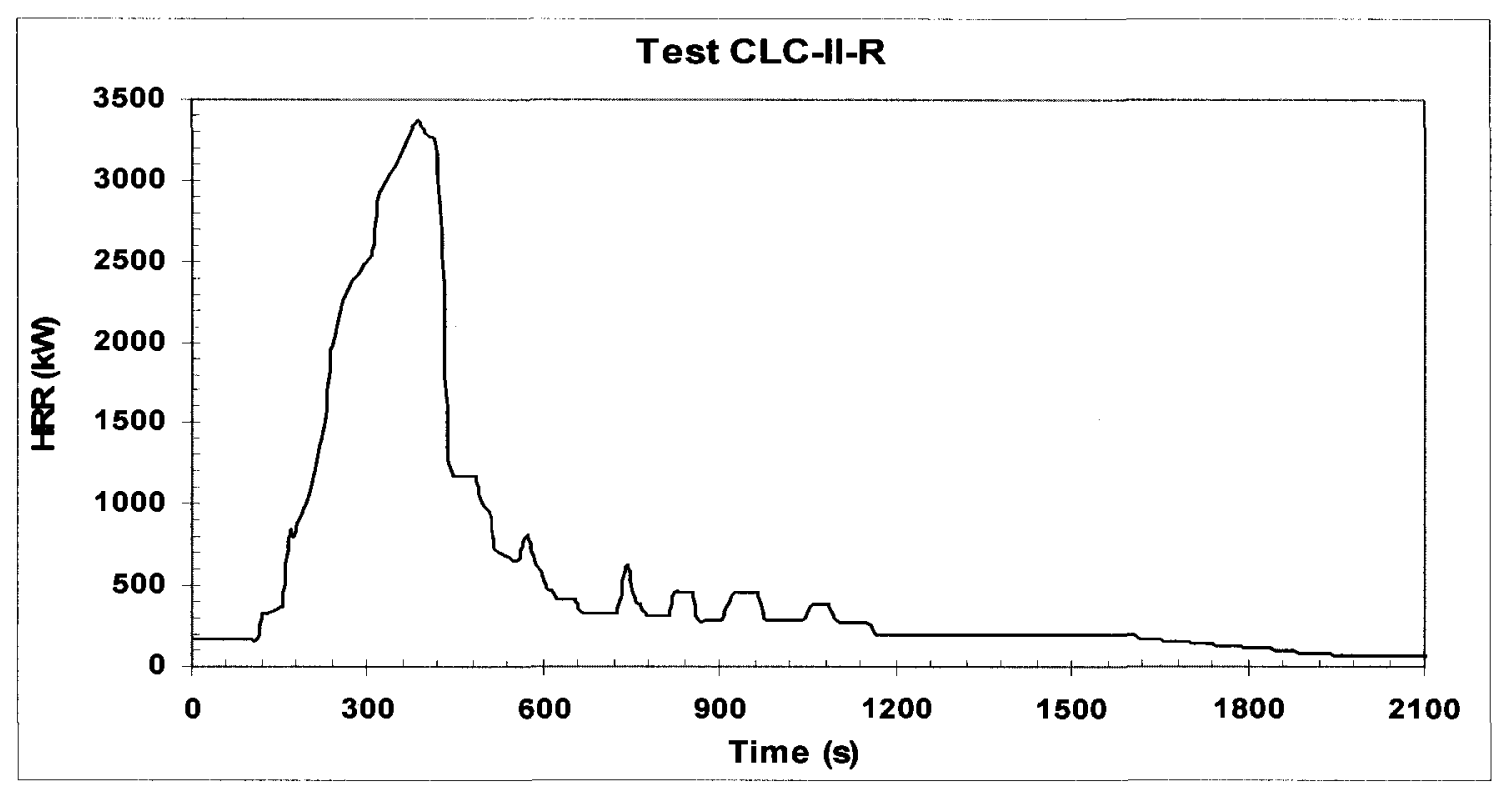

Figure 4-54: Heat release rate (Test CLC-II-R)

Figure 4-55 shows the concentration of $\mathrm{O}_{2}$ and $\mathrm{CO}_{2}$ in the stair shaft at the fire floor during Test CLC-II-R. The figure indicates that the lowest concentration of $\mathrm{O}_{2}$ was $9.53 \%$ 
at $385 \mathrm{~s}$, which is higher than the value of $4.62 \%$ at $255 \mathrm{~s}$ shown in Figure $4-14$ for Test CLC-II. The highest concentration of $\mathrm{CO}_{2}$ was $7.40 \%$ at $410 \mathrm{~s}$, which was lower compared to the value of $14.74 \%$ at 255 s shown in Figure $4-14$ for Test CLC-II. The concentration of $\mathrm{CO}$ in the stair shaft at the fire floor for Test CLC-II-R was very low, and is not shown in the figure. However, the concentration of $\mathrm{CO}$ in the stair shaft at the fire floor for Test CLC-II was as high as $24,917 \mathrm{ppm}$ at $260 \mathrm{~s}$ (Figure 4-15) caused by the similar reason stated in the previous section for Test CLC-I-R. The low oxygen concentration and high $\mathrm{CO}$ concentration indicates that the fuel package Test CLC-II was subjected to oxygen vitiated combustion as opposed to the propane Test CLC-II-R. In Test CLC-II, unburned hydrocarbon burned in the stair shaft at the $2^{\text {nd }}$ floor when meeting sufficient oxygen there, consumed $\mathrm{O}_{2}$ and generated $\mathrm{CO}_{2}$ as well This resulted the concentration of $\mathrm{CO}_{2}$ in the stair shaft at the fire floor was much higher for Test CLC-II.

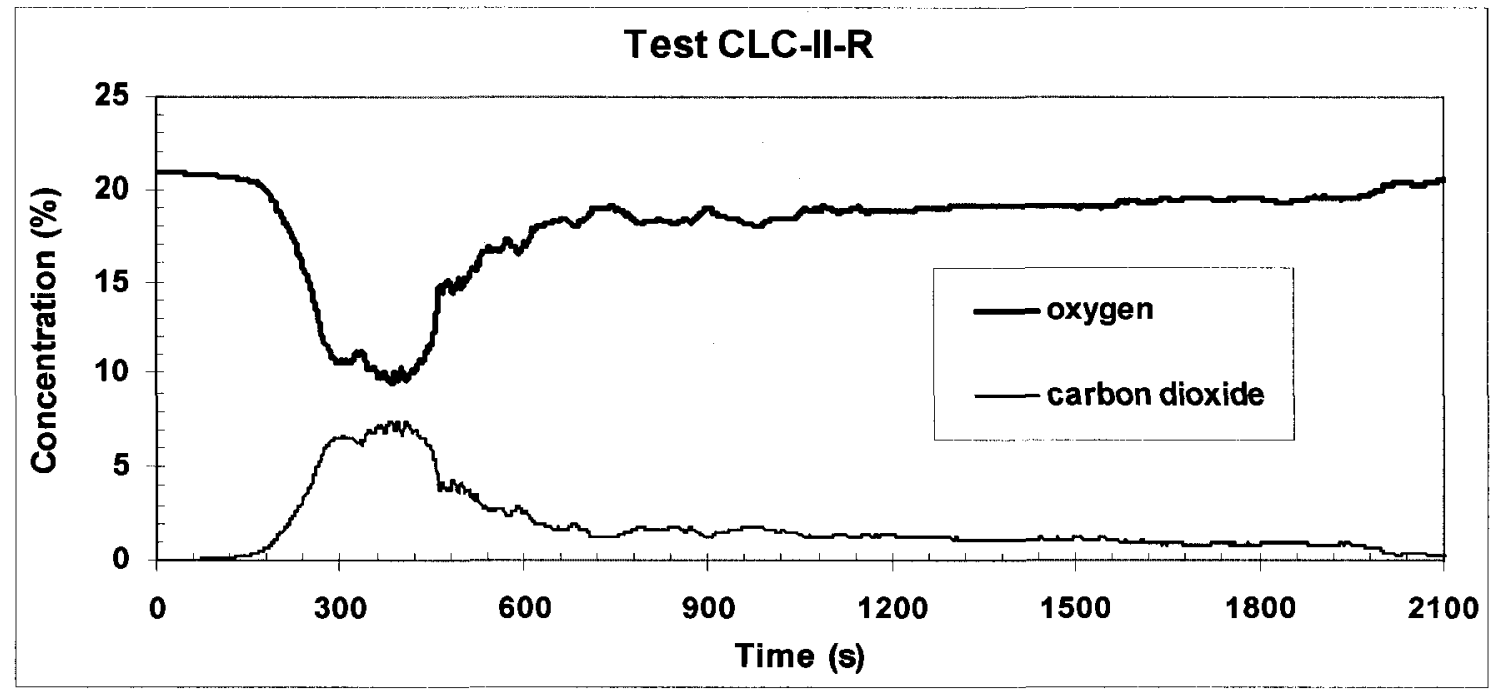

Figure 4-55: Concentration of $\mathrm{O}_{2}$ and $\mathrm{CO}_{2}$ in the stair shaft at the fire floor (Test CLC-II-R) 
Figure 4-56 shows the gas temperature histories at different heights at the doorway during Test CLC-II-R as recorded by the thermocouples placed at the doorway. A maximum temperature of $637^{\circ} \mathrm{C}$ at $420 \mathrm{~s}$ was recorded by the thermocouple at $2.05 \mathrm{~m}$ height, which is lower than the value of $816^{\circ} \mathrm{C}$ at $315 \mathrm{~s}$ at $2.05 \mathrm{~m}$ height measured during Test CLC-II (Figure 4-18). This indicates that during the fuel package Test CLC-II, there was combustion of unburned hydrocarbons in the doorway, but not for the propane Test CLC-II-R. As a result the HRR estimated using the propane method represents only the HRR released within the fire compartment and does not include the heat released outside the fire compartment.

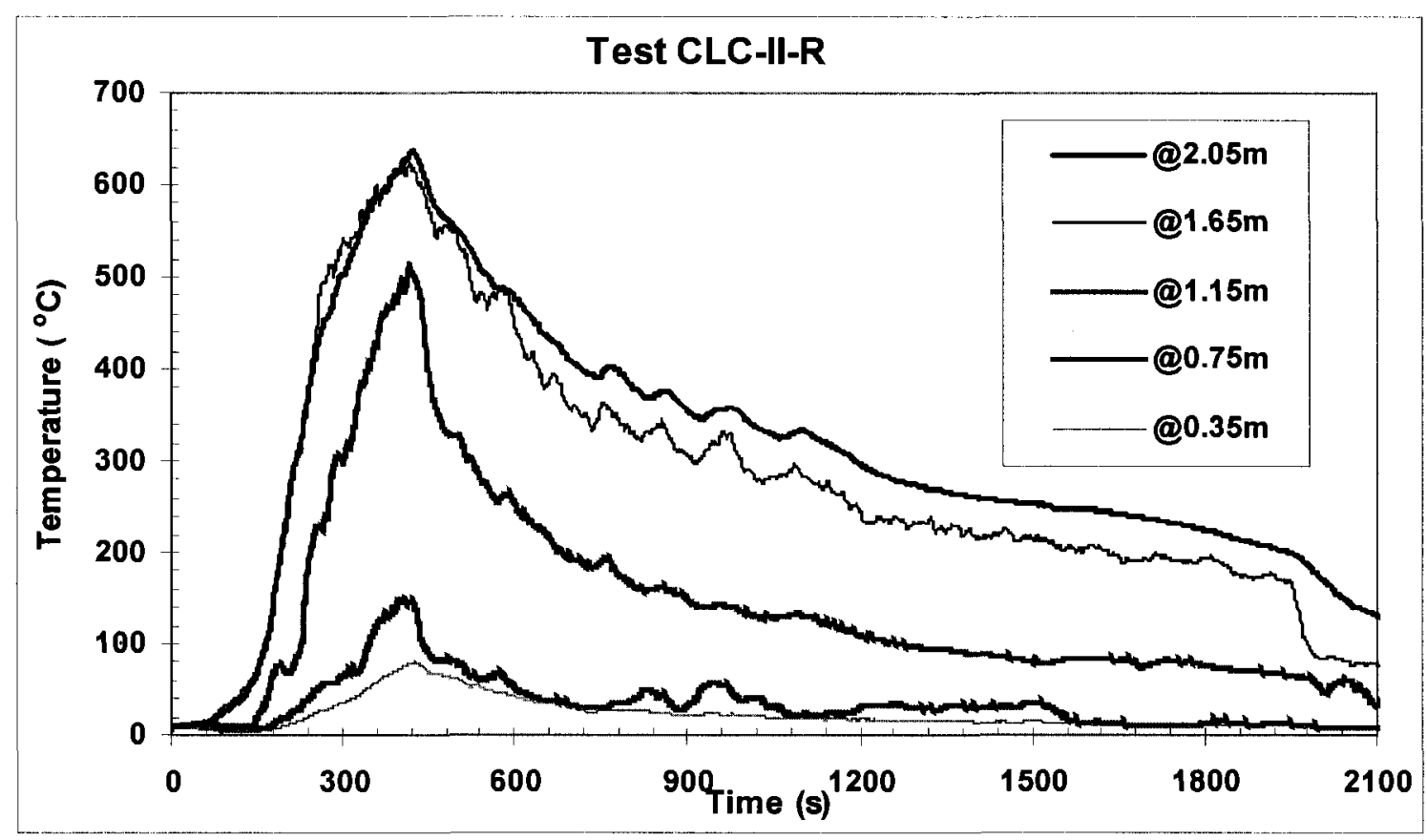

Figure 4-56: Gas temperature histories at different heights at the doorway (Test CLC-II-R)

The gas temperature histories in the stair shaft for Test CLC-II-R recorded by the thermocouples installed in the stair shaft at each floor from the $2^{\text {nd }}$ to the $10^{\text {th }}$ are shown in Figure 4-57. The maximum gas temperature in the stair shaft at the fire floor was 
$286^{\circ} \mathrm{C}$ at $420 \mathrm{~s}$. As mentioned earlier, the maximum gas temperature was $828^{\circ} \mathrm{C}$ at $420 \mathrm{~s}$ in the fire compartment, and $637^{\circ} \mathrm{C}$ at $420 \mathrm{~s}$ at the doorway of the fire floor. The maximum values of the gas temperature and their corresponding times in the stair shaft for floors $2^{\text {nd }}$ to $10^{\text {th }}$ are listed in Table 4-20. As expected, the temperature differences between the maximum and the initial values in the stair shaft were lower than those during Test CLC-II.

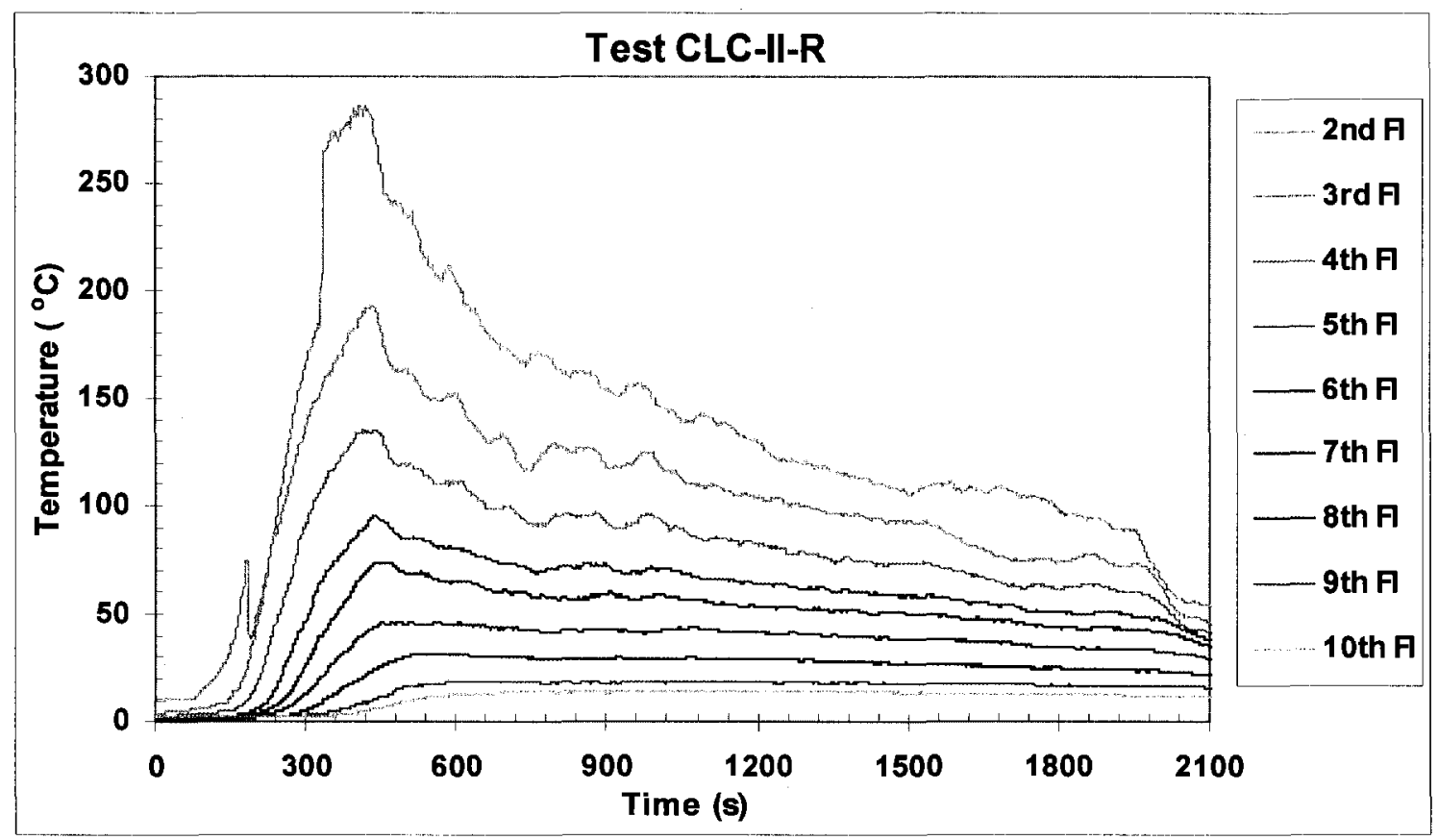

Figure 4-57: Gas temperature histories in the stair shaft (Test CLC-II-R)

Table 4-20: The maximum gas temperatures in the stair shaft of different floors for Test CLC-II-R

\begin{tabular}{|c|c|c|c|c|c|c|c|c|c|c|}
\hline Test ID & Floor \# & $\begin{array}{c}2^{\text {nd }} \\
\text { floor }\end{array}$ & $\begin{array}{c}3^{\text {rd }} \\
\text { floor }\end{array}$ & $\begin{array}{c}4^{\text {th }} \\
\text { floor }\end{array}$ & $\begin{array}{c}5^{\text {th }} \\
\text { floor }\end{array}$ & $\begin{array}{c}6^{\text {th }} \\
\text { floor }\end{array}$ & $\begin{array}{c}7^{\text {th }} \\
\text { floor }\end{array}$ & $\begin{array}{c}8^{\text {th }} \\
\text { floor }\end{array}$ & $\begin{array}{c}9^{\text {th }} \\
\text { floor }\end{array}$ & $\begin{array}{c}10^{\text {th }} \\
\text { floor }\end{array}$ \\
\hline \multirow{4}{*}{ CLC-II-R } & $\mathrm{T}_{\mathrm{i}}\left({ }^{\circ} \mathrm{C}\right)$ & 9.2 & 3.7 & 2.1 & 2.0 & 2.6 & 2.8 & 1.9 & 1.6 & 2.3 \\
\cline { 2 - 12 } & $\mathrm{T}_{\mathrm{p}}\left({ }^{\circ} \mathrm{C}\right)$ & 286.2 & 192.8 & 135.2 & 95.3 & 73.8 & 46.6 & 31.4 & 19.0 & 13.9 \\
\cline { 2 - 12 } & $\left.\mathrm{ST}^{\circ} \mathrm{C}\right)$ & 277.0 & 189.1 & 133.1 & 93.3 & 71.2 & 43.8 & 19.5 & 17.4 & 11.6 \\
\cline { 2 - 11 } & $\mathrm{t}_{\mathrm{p}}(\mathrm{s})$ & 420 & 435 & 440 & 440 & 450 & 455 & 520 & 695 & 1170 \\
\hline
\end{tabular}

Note: $T_{i}$ is the initial gas temperature; $T_{p}$ is the peak gas temperature; $\Delta T$ is the gas temperature difference between $T_{p}$ and $T_{i}$ and $t_{p}$ is the time when the gas reached the peak temperature 
Figure 4-58 shows the gas temperature histories for Test CLC-II-R recorded by the thermocouples in the vestibules of the floors with open doors. The maximum values of the gas temperature and their corresponding times in the vestibules of the floors with open doors are shown in Table 4-21.

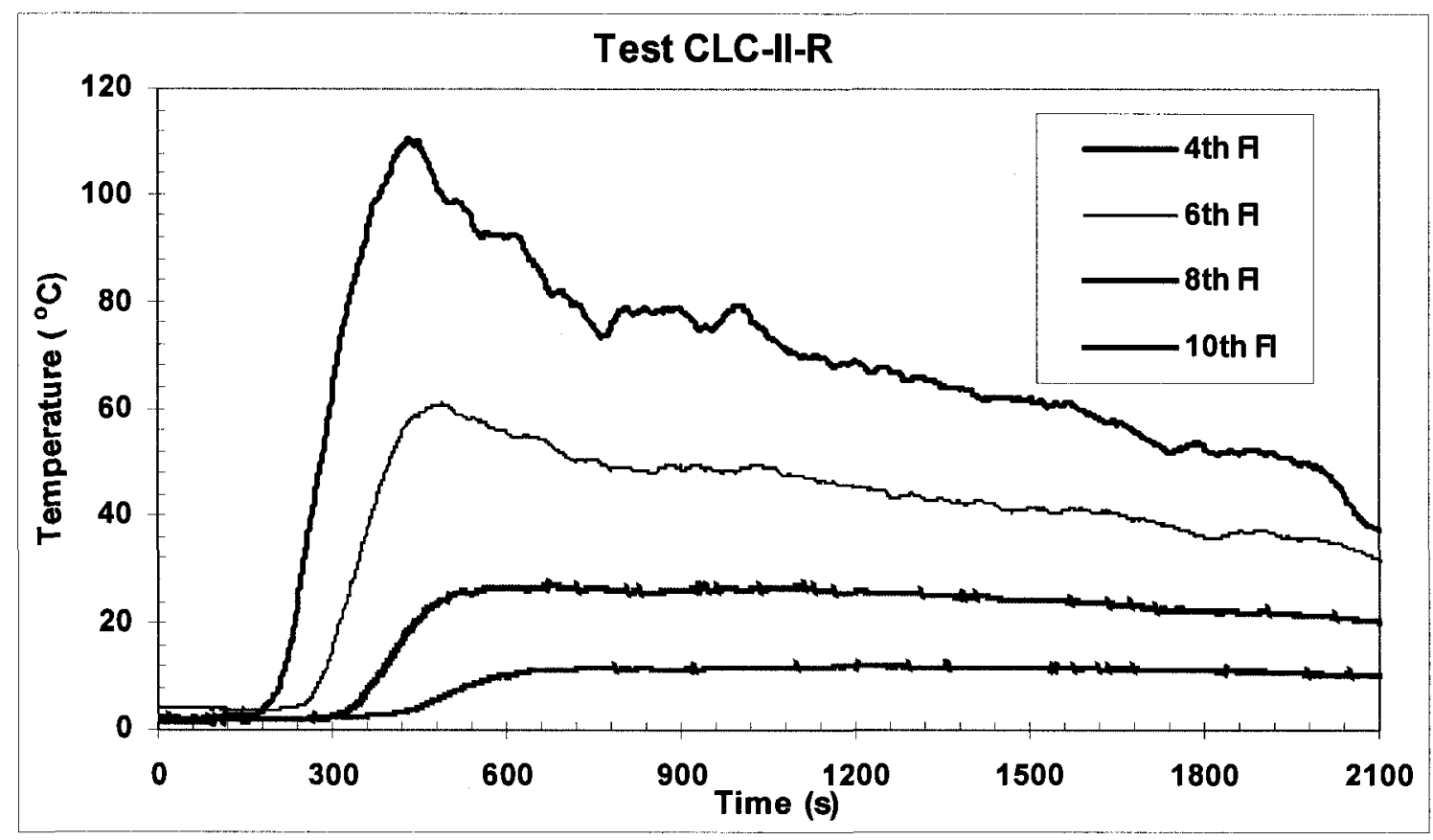

Figure 4-58: Gas temperature histories in the vestibules of the floors with open doors (Test CLC-II-R)

Table 4-21: The maximum gas temperatures in the vestibules of the floors with open doors for Test CLC-II-R

\begin{tabular}{|c|c|c|c|c|c|}
\hline Test ID & Floor \# & $4^{\text {th }}$ floor & $6^{\text {th }}$ floor & $8^{\text {th }}$ floor & $10^{\text {th }}$ floor \\
\hline \multirow{4}{*}{ CLC-II-R } & $\mathrm{T}_{\mathrm{i}}\left({ }^{\circ} \mathrm{C}\right)$ & 1.6 & 4.1 & 1.6 & 2.2 \\
\cline { 2 - 6 } & $\mathrm{T}_{\mathrm{p}}\left({ }^{\circ} \mathrm{C}\right)$ & 110.5 & 61.0 & 27.1 & 12.1 \\
\cline { 2 - 6 } & $\Delta \mathrm{T}\left({ }^{\circ} \mathrm{C}\right)$ & 108.9 & 56.9 & 25.5 & 9.9 \\
\cline { 2 - 6 } & $\mathrm{t}_{\mathrm{p}}(\mathrm{s})$ & 430 & 490 & 675 & 1220 \\
\hline
\end{tabular}

Note: $T_{i}$ is the initial gas temperature; $T_{p}$ is the peak gas temperature; $\Delta T$ is the gas temperature difference between $T_{p}$ and $T_{i}$ and $t_{p}$ is the time when the gas reached the peak temperature

Figure 4-59 shows the gas temperature histories in the vestibules of the floors with closed doors for Test CLC-II-R. The test results are similar to the other tests described before. 
The gas temperatures in the vestibules of the floors with closed doors still increased by few degrees compared to the initial values, which indicate that although the doors between the stair shaft and the vestibules of the odd floors were fully closed, but not completely sealed.

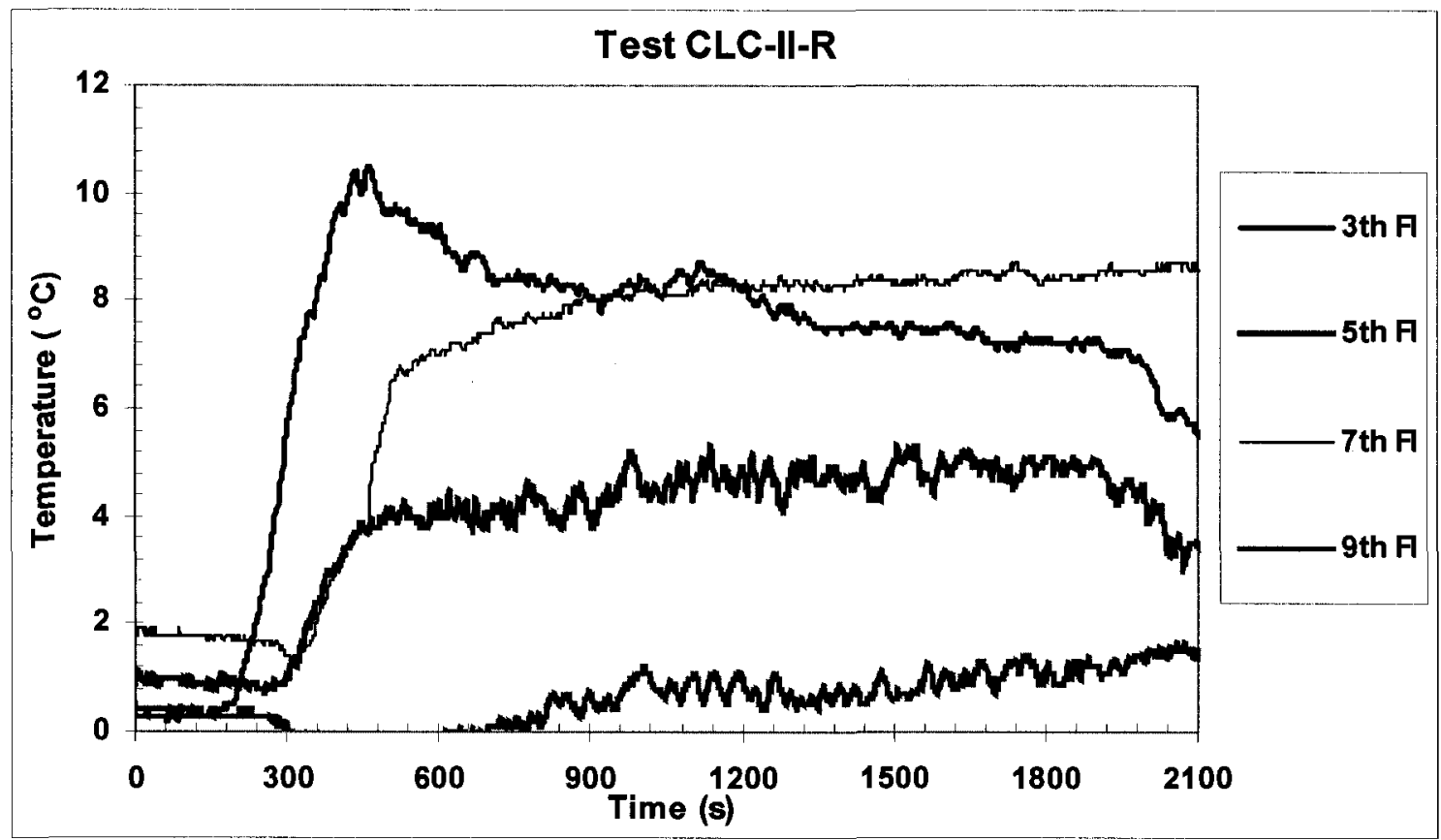

Figure 4-59: Gas temperature histories in the vestibules of the floors with closed doors (Test CLC-II-R)

Figure 4-60 shows the gas temperature histories in the main compartments of the $4^{\text {th }}, 8^{\text {th }}$ and $10^{\text {th }}$ floors for Test CLC-II-R. The maximum values of the gas temperature and their corresponding times at the main compartments of the $4^{\text {th }}, 8^{\text {th }}$ and $10^{\text {th }}$ floors are listed in Table 4-22. 


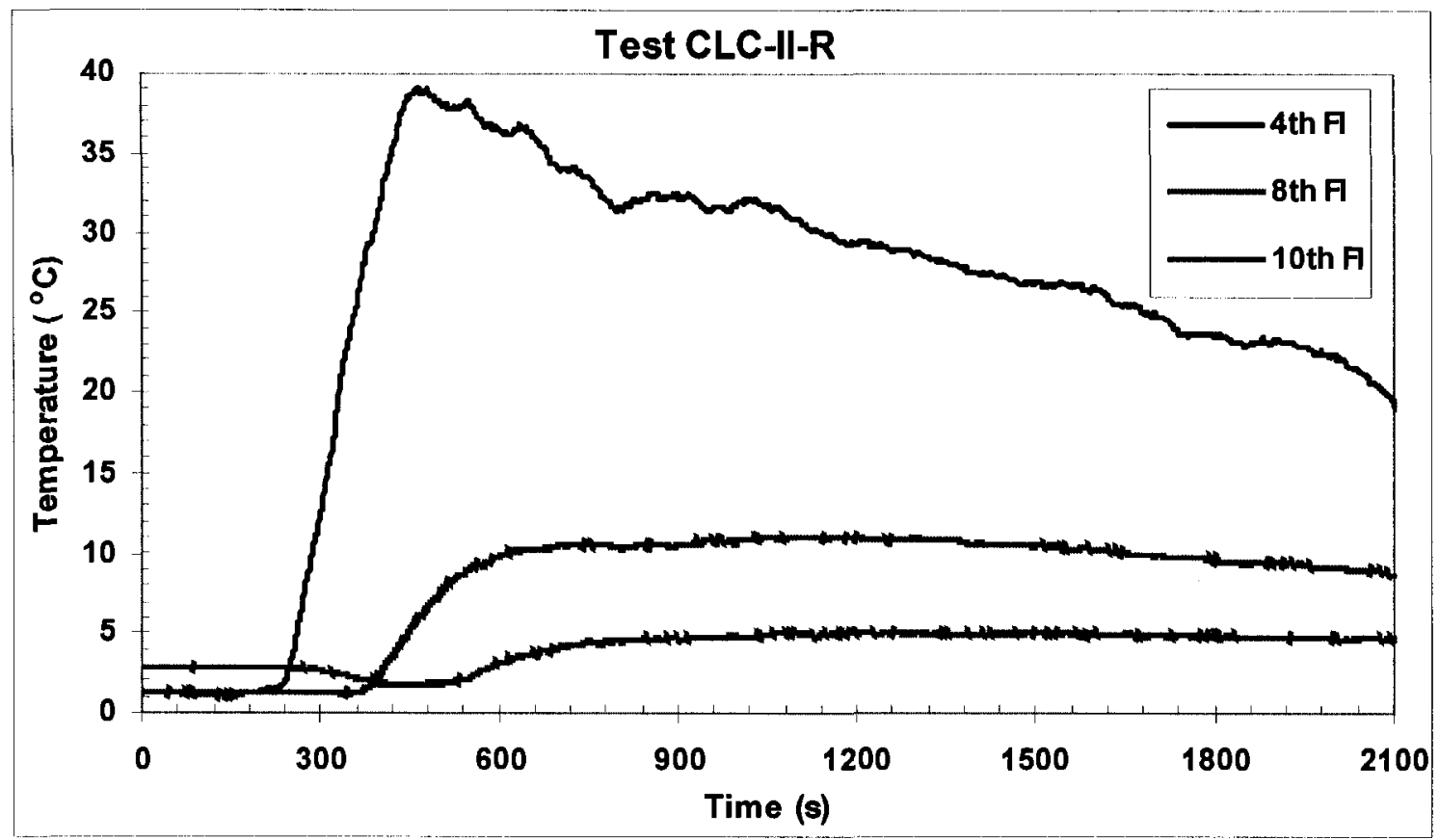

Figure 4-60: Gas temperature histories in the main compartments of the floors of the $4^{\text {th }}, 8^{\text {th }}$ and $10^{\text {th }}$ (Test CLC-II-R)

Table 4-22: The maximum gas temperatures in the main compartments of the floors of the $4^{\text {th }}, 8^{\text {th }}$ and $10^{\text {th }}$ for Test CLC-II-R

\begin{tabular}{|c|c|c|c|c|}
\hline Test ID & Floor \# & $4^{\text {th }}$ floor & $8^{\text {th }}$ floor & $10^{\text {th }}$ floor \\
\hline \multirow{4}{*}{ CLC-II-R } & $\mathrm{T}_{\mathrm{i}}\left({ }^{\circ} \mathrm{C}\right)$ & 1.3 & 1.2 & 2.8 \\
\cline { 2 - 5 } & $\mathrm{T}_{\mathrm{p}}\left({ }^{\circ} \mathrm{C}\right)$ & 39.1 & 11.1 & 5.0 \\
\cline { 2 - 5 } & $\Delta \mathrm{T}\left({ }^{\circ} \mathrm{C}\right)$ & 37.8 & 9.9 & 2.2 \\
\cline { 2 - 5 } & $\mathrm{t}_{\mathrm{p}}(\mathrm{s})$ & 465 & 1040 & 1250 \\
\hline
\end{tabular}

Note: $T_{i}$ is the initial gas temperature; $T_{p}$ is the peak gas temperature; $\Delta T$ is the gas temperature difference between $T_{p}$ and $T_{i}$ and $t_{p}$ is the time when the gas reached the peak temperature

\subsubsection{Propane test for HRR estimation of Test CMP (Test CMP-R)}

Propane was used in Test CMP-R to reproduce the temperature-time curve in the fire compartment of fuel package Test CMP.

The temperatures measured by the thermocouple tree located in the corner of the fire compartment are shown in Figure 4-61. For the first $270 \mathrm{~s}$, the temperature in the fire 
compartment increased at a faster rate in Test CMP-R than in Test CMP. Then the temperature of the propane test was very close to the temperature of the fuel package test. The temperature reached a maximum value of $847^{\circ} \mathrm{C}$ at $710 \mathrm{~s}$, compared to the maximum value of $861^{\circ} \mathrm{C}$ at $680 \mathrm{~s}$ during Test $\mathrm{CMP}$.

Both the propane fire and the fuel package fire reached the flashover condition at about $550 \mathrm{~s}$. Once the temperatures reached their peak values, the fire entered the decay phase during which the temperature started to decrease steadily until the end of the test at 1620 s. The interface height in the fire compartment at the time when the temperature reached its maximum value was $0.86 \mathrm{~m}$ at $710 \mathrm{~s}$; whereas for package Test CMP, the interface height was $0.88 \mathrm{~m}$ at $680 \mathrm{~s}$ when the peak temperatures reached in the fire compartment.

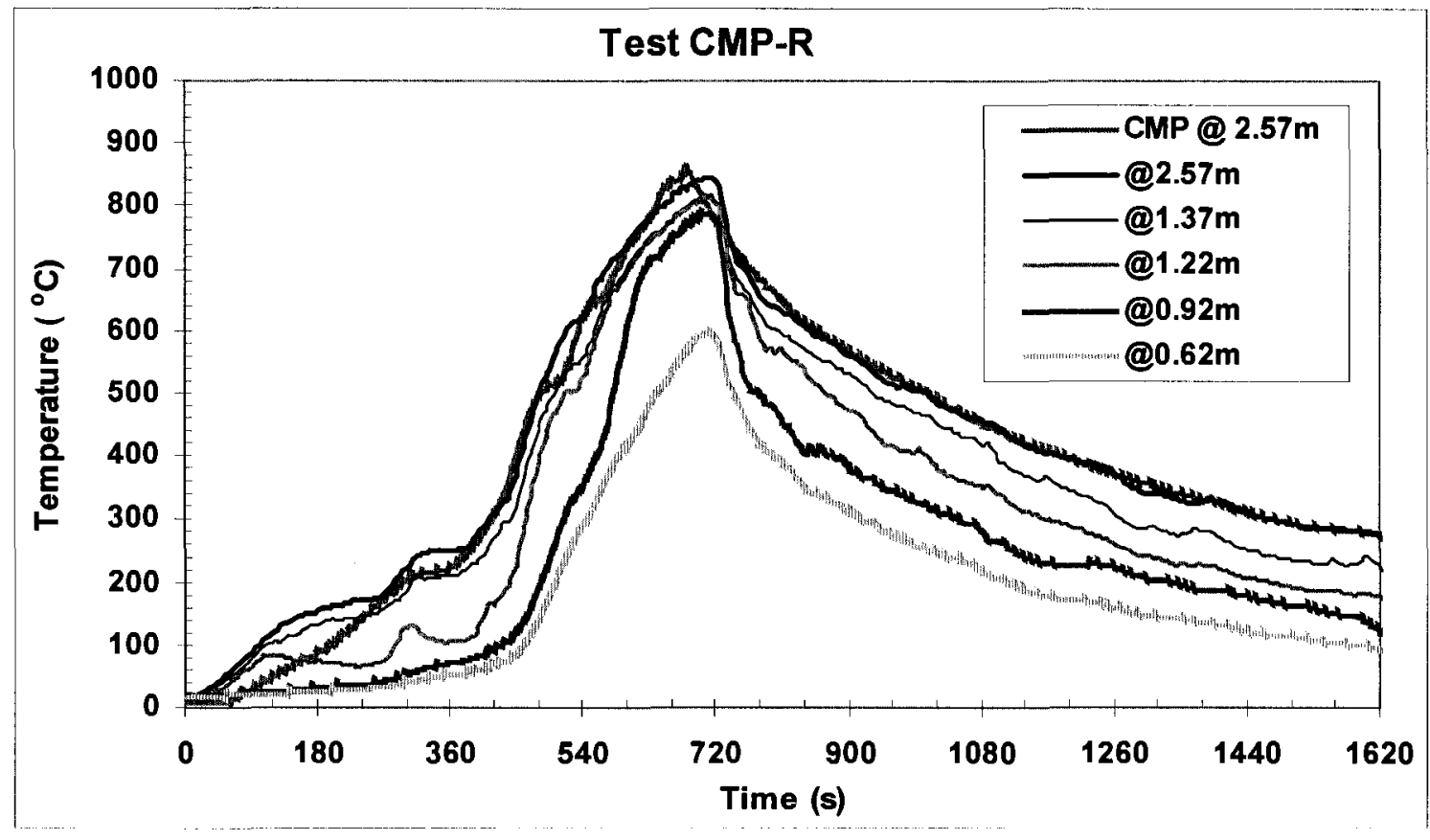

Figure 4-61: Gas temperature histories at different heights in the corner of the fire compartment (Test CMP-R) 
The heat release rate of CMP-R test is shown in Figure 4-62. The HRR stayed at a value of around $160 \mathrm{~kW}$ for $250 \mathrm{~s}$, after which it increased until reaching a peak value of about $3200 \mathrm{~kW}$ at about $650 \mathrm{~s}$. Once the peak was achieved, the HRR dropped at a fast rate until $720 \mathrm{~s}$, followed by a slower rate until the end of the test at $1620 \mathrm{~s}$.

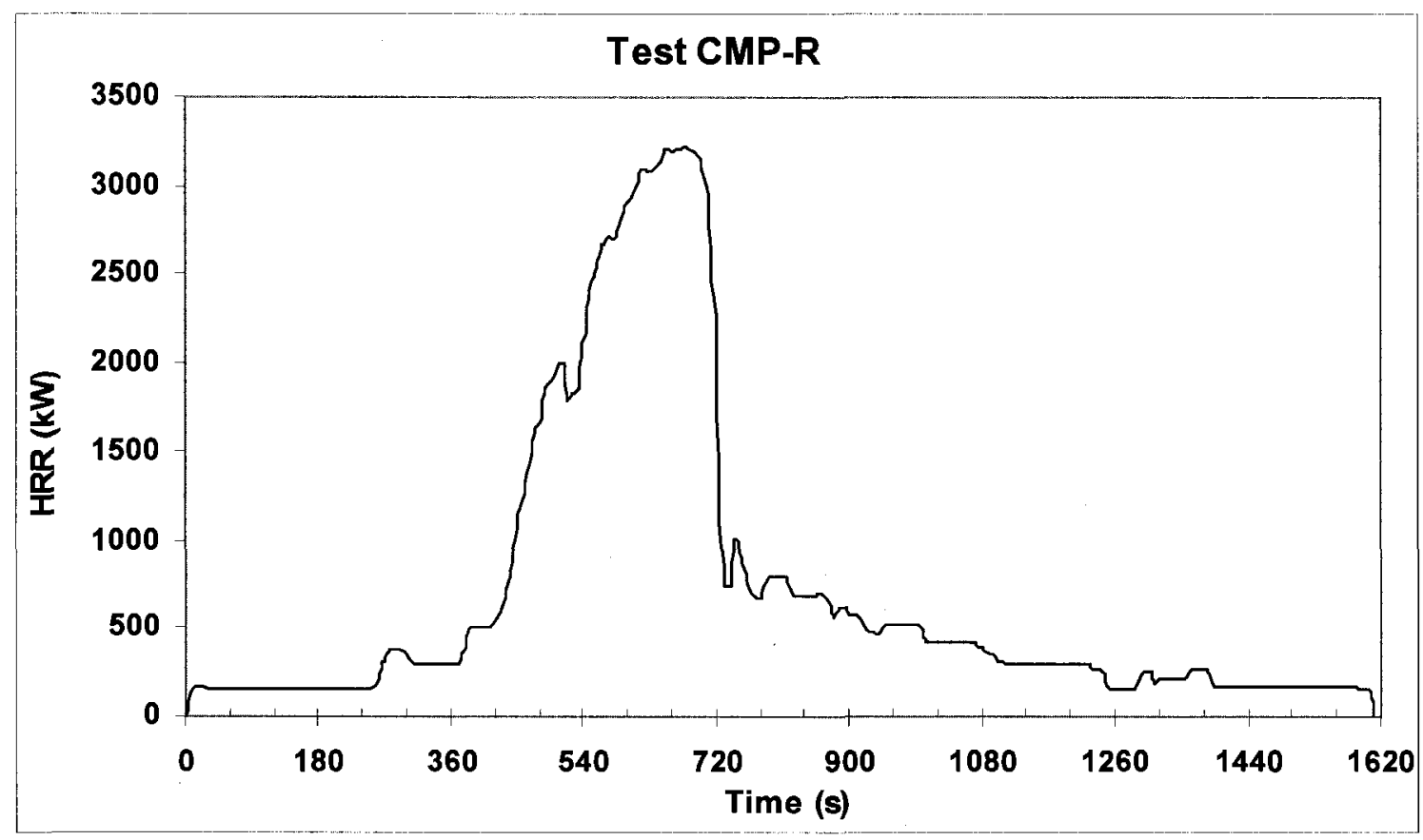

Figure 4-62: Heat release rate (Test CMP-R)

Figure 4-63 shows the concentration of $\mathrm{O}_{2}$ and $\mathrm{CO}_{2}$ in the stair shaft at the fire floor during Test CMP-R. The figure indicates that the lowest concentration of $\mathrm{O}_{2}$ was $10.81 \%$ at $680 \mathrm{~s}$, which is close to the value of $11.32 \%$ at $570 \mathrm{~s}$ measured in Test CMP. The highest concentration of $\mathrm{CO}_{2}$ was $6.40 \%$ at $670 \mathrm{~s}$, which was slightly lower than the value of $7.93 \%$ at $570 \mathrm{~s}$ for Test CMP. The concentration of CO in the stair shaft at the fire floor for Test CMP-R was very low, and is not shown in the figure. However, the concentration of $\mathrm{CO}$ in the stair shaft at the fire floor for Test CMP was 9,366 ppm at 630 s due to not good mixing of oxygen with pyrolysis products for fuel package fire. 


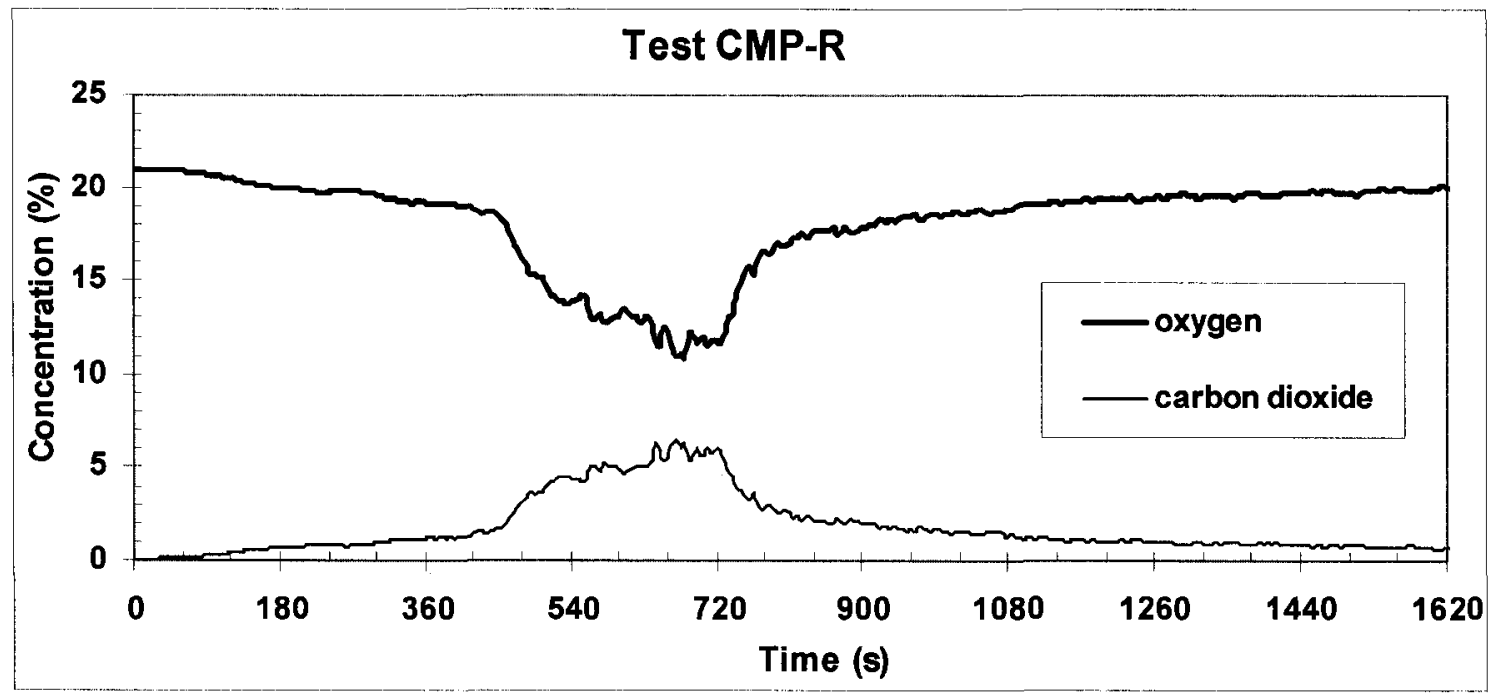

Figure 4-63: Concentration of $\mathrm{O}_{2}$ and $\mathrm{CO}_{2}$ in the stair shaft at the fire floor (Test CMP-R)

Figure 4-64 shows the gas temperature histories at different heights at the doorway during Test CMP-R as recorded by the thermocouples placed at the doorway. A maximum temperature of $653^{\circ} \mathrm{C}$ at $710 \mathrm{~s}$ was recorded by the thermocouple placed at $2.05 \mathrm{~m}$ height, which is close to the value of $635^{\circ} \mathrm{C}$ at $690 \mathrm{~s}$ recorded at that height (Figure 4-28) in Test CMP. The results show that there is a faster decrease in the temperature of the smoke as it leaves the fire compartment in the fuel package test than in the propane test. This is due to the fact that the propane test produced less soot than the fuel package Test CMP and hence its smoke lost less amount of heat due to radiation than the more sooty fuel package smoke.

The gas temperature histories in the stair shaft for Test CMP-R recorded by the thermocouples installed in the stair shaft at each floor from the $2^{\text {nd }}$ to the $10^{\text {th }}$ are shown in Figure 4-65. The maximum gas temperature in the stair shaft at the fire floor was $292^{\circ} \mathrm{C}$ at $710 \mathrm{~s}$. The maximum values of the gas temperature and their corresponding times at the stair shaft for floors $2^{\text {nd }}$ to $10^{\text {th }}$ are listed in Table 4-23. As expected, the temperature differences between the maximum and the initial values in the stair shaft at each floor from 
the $2^{\text {nd }}$ to the $10^{\text {th }}$ for Test CMP-R are slightly higher than those for Test CMP. The sudden drop of the temperature in the stair shaft at the fire floor shown in Figure 4-65 can be explained by the following. As shown in Figure 4-62, at $515 \mathrm{~s}$ there is drop in the heat release rate. This means that the flow rate of propane was reduced at that time in order to follow the temperature-time curve of the corresponding fuel package Test CMP. This reduction of propane reduced the flow rate of hot gases flowing out of the fire compartment to the vestibule and the stair shaft at the fire floor, causing the sudden drop of temperature in the stair shaft.

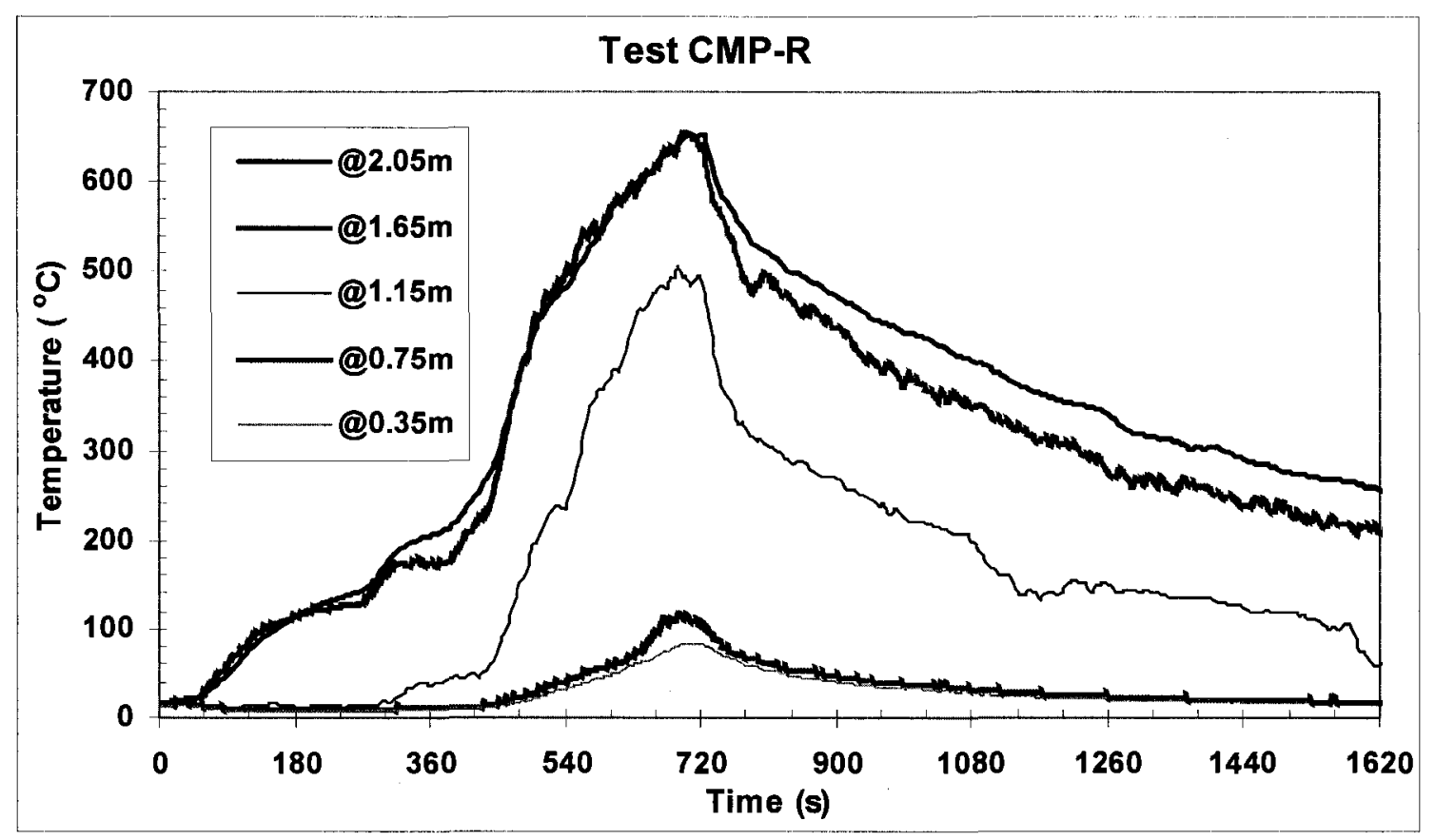

Figure 4-64: Gas temperature histories at different heights at the doorway (Test CMP-R) 


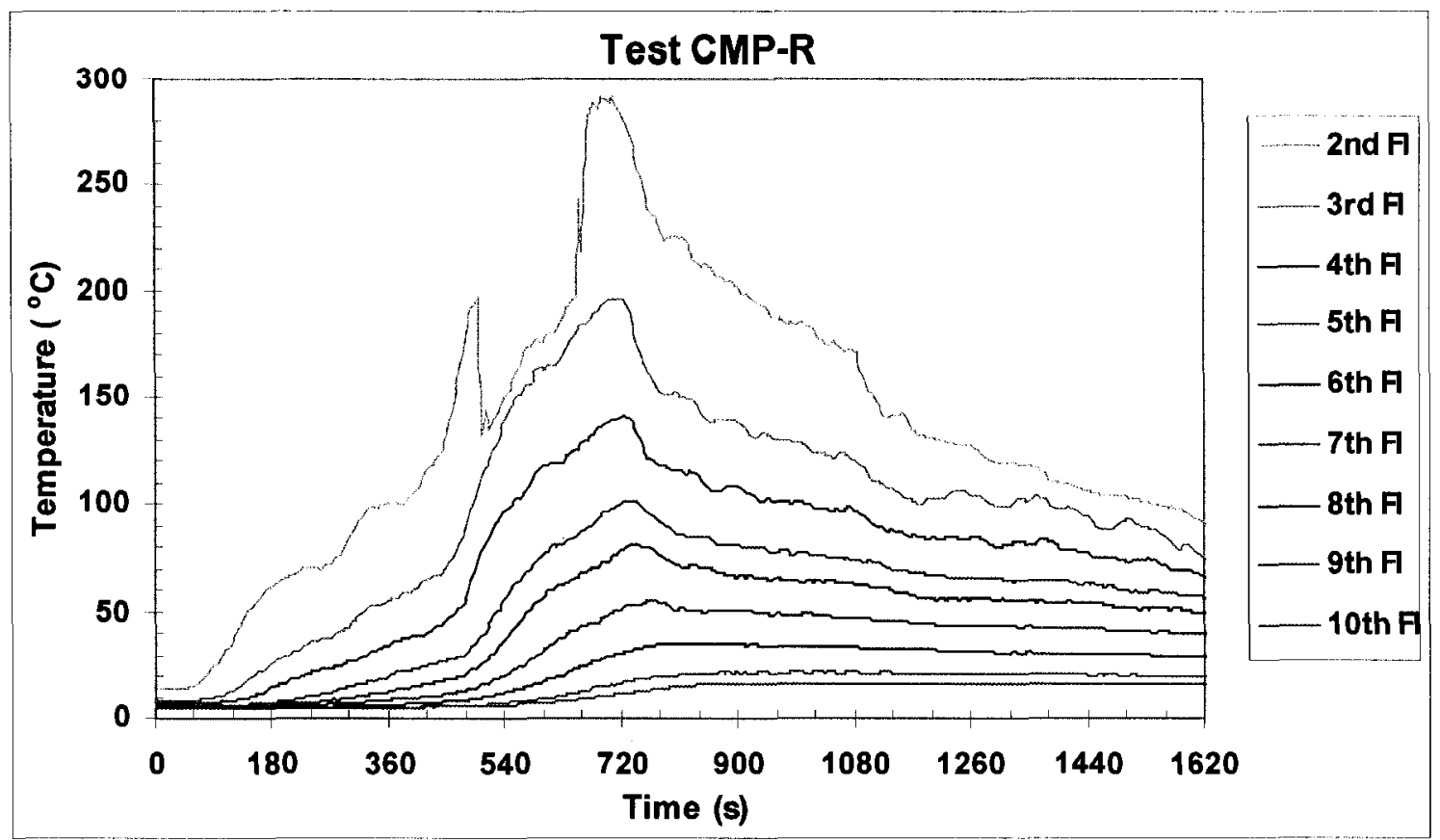

Figure 4-65: Gas temperature histories in the stair shaft (Test CMP-R)

Table 4-23: The maximum gas temperatures in the stair shaft of different floors for Test CMP-R

\begin{tabular}{|c|c|c|c|c|c|c|c|c|c|c|}
\hline Test ID & Floor \# & $\begin{array}{c}2^{\text {nd }} \\
\text { floor }\end{array}$ & $\begin{array}{c}3^{\text {rd }} \\
\text { floor }\end{array}$ & $\begin{array}{c}4^{\text {th }} \\
\text { floor }\end{array}$ & $\begin{array}{c}5^{\text {th }} \\
\text { floor }\end{array}$ & $\begin{array}{c}6^{\text {th }} \\
\text { floor }\end{array}$ & $\begin{array}{c}7^{\text {th }} \\
\text { floor }\end{array}$ & $\begin{array}{c}8^{\text {th }} \\
\text { floor }\end{array}$ & $\begin{array}{c}9^{\text {th }} \\
\text { floor }\end{array}$ & $\begin{array}{c}10^{\text {th }} \\
\text { floor }\end{array}$ \\
\hline \multirow{4}{*}{ CMP-R } & $\mathrm{T}_{\mathrm{i}}\left({ }^{\circ} \mathrm{C}\right)$ & 13.6 & 8.0 & 6.7 & 5.5 & 5.6 & 5.5 & 5.0 & 4.9 & 5.3 \\
\cline { 2 - 12 } & $\mathrm{T}_{\mathrm{p}}\left({ }^{\circ} \mathrm{C}\right)$ & 291.5 & 196.3 & 141.9 & 101.9 & 81.8 & 55.3 & 35.9 & 22.2 & 17.0 \\
\cline { 2 - 12 } & $\Delta \mathrm{T}\left({ }^{\circ} \mathrm{C}\right)$ & 277.9 & 188.3 & 135.2 & 96.4 & 76.2 & 49.8 & 30.9 & 17.3 & 11.7 \\
\cline { 2 - 11 } & $\mathrm{t}_{\mathrm{p}}(\mathrm{s})$ & 710 & 720 & 725 & 735 & 740 & 770 & 795 & 990 & 1005 \\
\hline
\end{tabular}

Note: $T_{i}$ is the initial gas temperature; $T_{p}$ is the peak gas temperature; $\Delta T$ is the gas temperature difference between $T_{p}$ and $T_{i}$ and $t_{p}$ is the time when the gas reached the peak temperature

Figure 4-66 shows the gas temperature histories for Test CMP-R recorded by the thermocouples in the vestibules of the floors with open doors. The maximum values of the gas temperature and their corresponding times in the vestibules of the floors with open doors are listed in Table 4-24. 


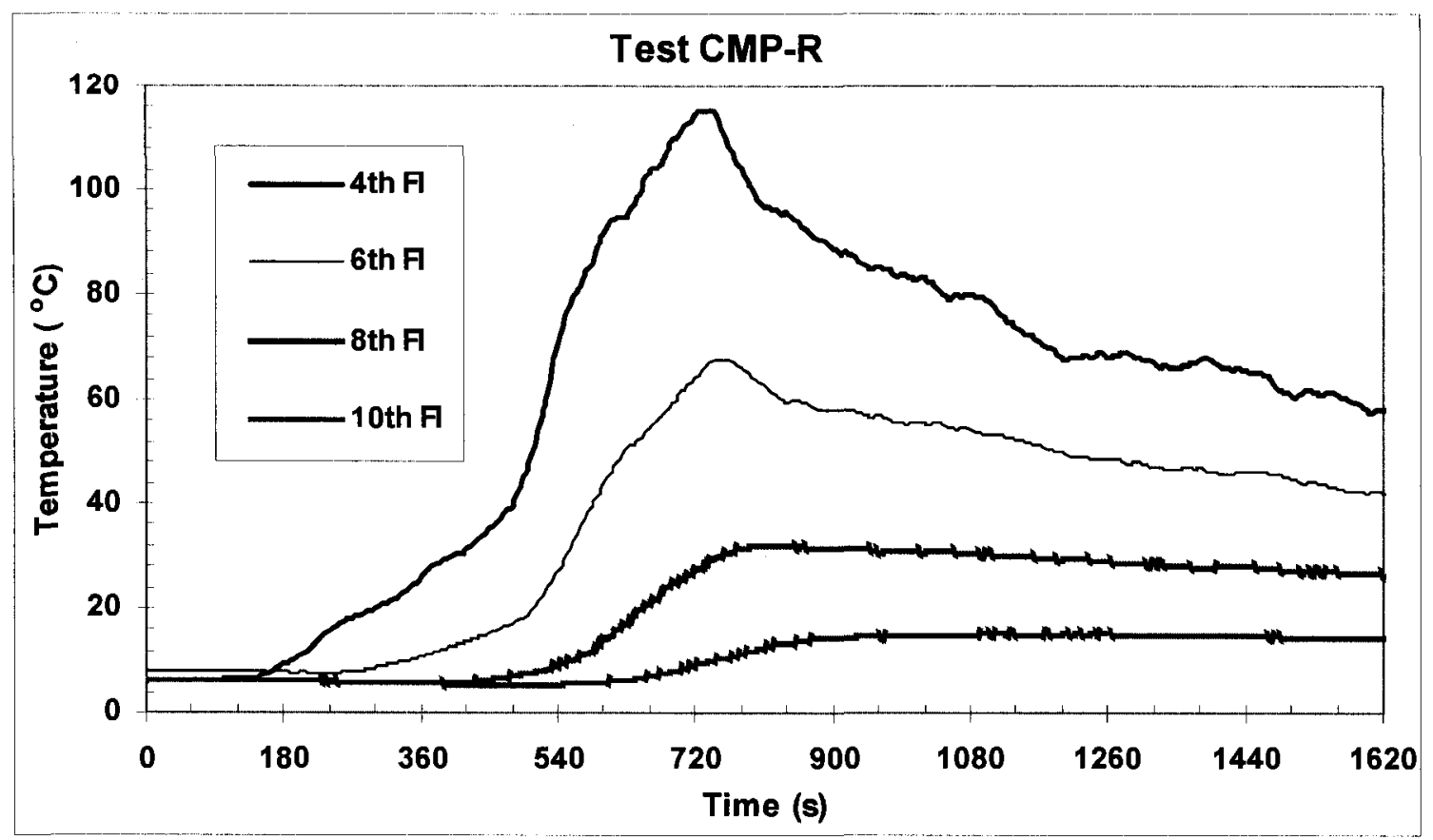

Figure 4-66: Gas temperature histories in the vestibules of the floors with open doors (Test CMP-R)

Table 4-24: The maximum gas temperatures in the vestibules of the floors with open doors for Test CMP-R

\begin{tabular}{|c|c|c|c|c|c|}
\hline Test ID & Floor \# & $4^{\text {th }}$ floor & $6^{\text {th }}$ floor & $8^{\text {th }}$ floor & $10^{\text {th }}$ floor \\
\hline \multirow{4}{*}{ CMP-R } & $\mathrm{T}_{\mathrm{i}}\left({ }^{\circ} \mathrm{C}\right)$ & 6.1 & 7.9 & 6.1 & 6.2 \\
\cline { 2 - 6 } & $\mathrm{T}_{\mathrm{p}}\left({ }^{\circ} \mathrm{C}\right)$ & 115.3 & 67.5 & 32.1 & 15.2 \\
\cline { 2 - 6 } & $\Delta \mathrm{T}\left({ }^{\circ} \mathrm{C}\right)$ & 109.2 & 59.6 & 26.0 & 9.0 \\
\cline { 2 - 6 } & $\mathrm{t}_{\mathrm{p}}(\mathrm{s})$ & 730 & 755 & 815 & 1120 \\
\hline
\end{tabular}

Note: $T_{i}$ is the initial gas temperature; $T_{p}$ is the peak gas temperature; $\Delta T$ is the gas temperature difference between $T_{p}$ and $T_{i}$ and $t_{p}$ is the time when the gas reached the peak temperature

Figure 4-67 shows the gas temperature histories in the vestibules of the floors with closed doors for Test CMP-R. The test results were similar to the other tests described before showing an increase of few degrees. 


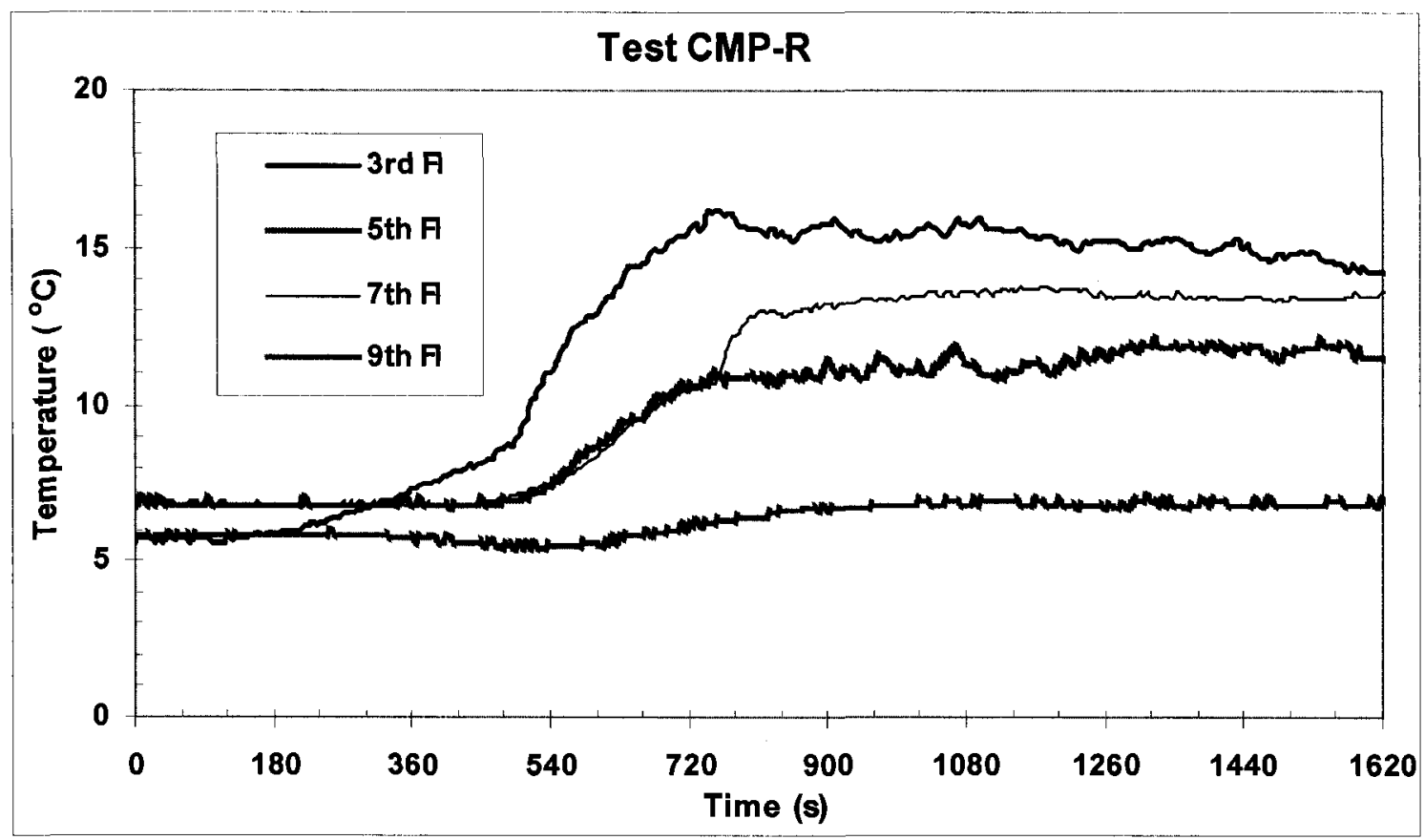

Figure 4-67: Gas temperature histories in the vestibules of the floors with closed doors (Test CMP-R)

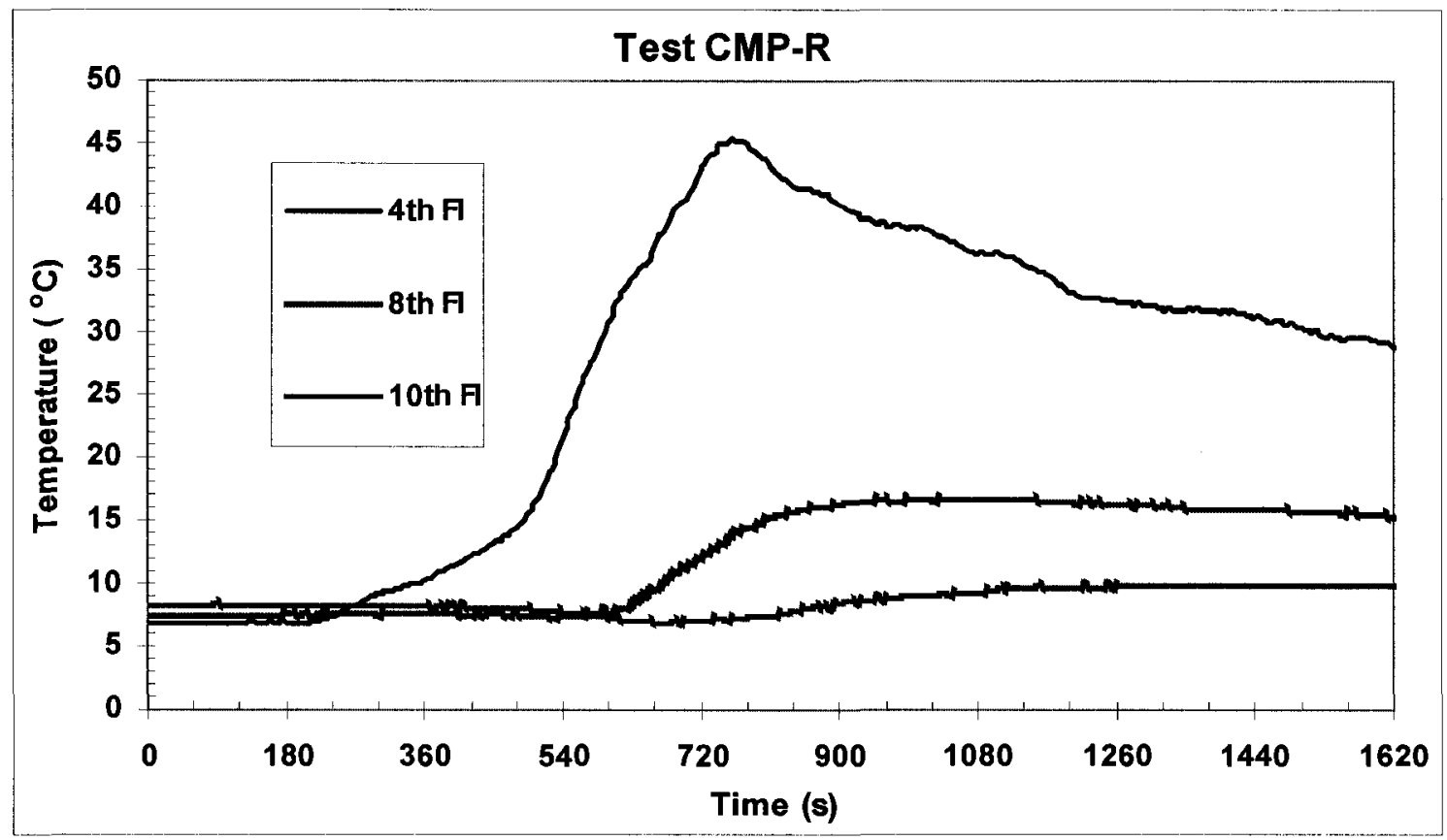

Figure 4-68: Gas temperature histories in the main compartments of the floors of the $4^{\text {th }}, 8^{\text {th }}$ and $10^{\text {th }}$ (Test CMP-R) 
Figure 4-68 shows the gas temperature histories in the main compartments of the $4^{\text {th }}, 8^{\text {th }}$ and $10^{\text {th }}$ floors for Test CMP-R. The maximum values of the gas temperature and their corresponding times at the main compartments of the $4^{\text {th }}, 8^{\text {th }}$ and $10^{\text {th }}$ floors are listed in Table 4-25.

Table 4-25: The maximum gas temperatures in the main compartments of the floors of the $4^{\text {th }}, 8^{\text {th }}$ and $10^{\text {th }}$ for Test CMP-R

\begin{tabular}{|c|c|c|c|c|}
\hline Test ID & Floor \# & $4^{\text {th }}$ floor & $8^{\text {th }}$ floor & $10^{\text {th }}$ floor \\
\hline \multirow{4}{*}{ CMP-R } & $\left.\mathrm{T}_{\mathrm{i}}{ }^{\circ} \mathrm{C}\right)$ & 6.8 & 7.5 & 8.3 \\
\cline { 2 - 5 } & $\left.\mathrm{T}_{\mathrm{p}}{ }^{\circ} \mathrm{C}\right)$ & 45.4 & 16.7 & 9.9 \\
\cline { 2 - 5 } & $\left.\Delta \mathrm{T}{ }^{\circ} \mathrm{C}\right)$ & 38.6 & 9.2 & 1.6 \\
\cline { 2 - 5 } & $\mathrm{t}_{\mathrm{p}}(\mathrm{s})$ & 760 & 1075 & 1285 \\
\hline
\end{tabular}

Note: $T_{i}$ is the initial gas temperature; $T_{p}$ is the peak gas temperature; $\Delta T$ is the gas temperature difference between $T_{p}$ and $T_{i}$ and $t_{p}$ is the time when the gas reached the peak temperature

\subsubsection{Propane test for HRR estimation of Test BK (Test BK-R)}

Propane was used in Test BK-R to reproduce the temperature-time curve in the fire compartment of fuel package Test BK.

The temperatures measured by the thermocouple tree located in the corner of the fire compartment are shown in Figure 4-69. The temperature-time curve in the fire compartment for Test BK-R is similar to the curve produced in Test BK. The maximum temperature could not be obtained because the propane flow rate of the burner used in the test reached is maximum capacity. A maximum temperature of $873^{\circ} \mathrm{C}$ at $1455 \mathrm{~s}(2.57 \mathrm{~m}$ height) was recorded for Test BK-R, which is lower than the value of $952^{\circ} \mathrm{C}$ at $1390 \mathrm{~s}$ (2.57 $\mathrm{m}$ height) reached in Test BK. The propane fire reached flashover condition at $1050 \mathrm{~s}$ and the fuel package fire at $1040 \mathrm{~s}$. The interface height in the fire compartment at $1455 \mathrm{~s}$, when the temperature of the fire compartment reached its maximum value was 
$0.88 \mathrm{~m}$. For package Test $\mathrm{BK}$, the interface height was $0.91 \mathrm{~m}$ at $1390 \mathrm{~s}$ when the temperature reached its maximum in the fire compartment.

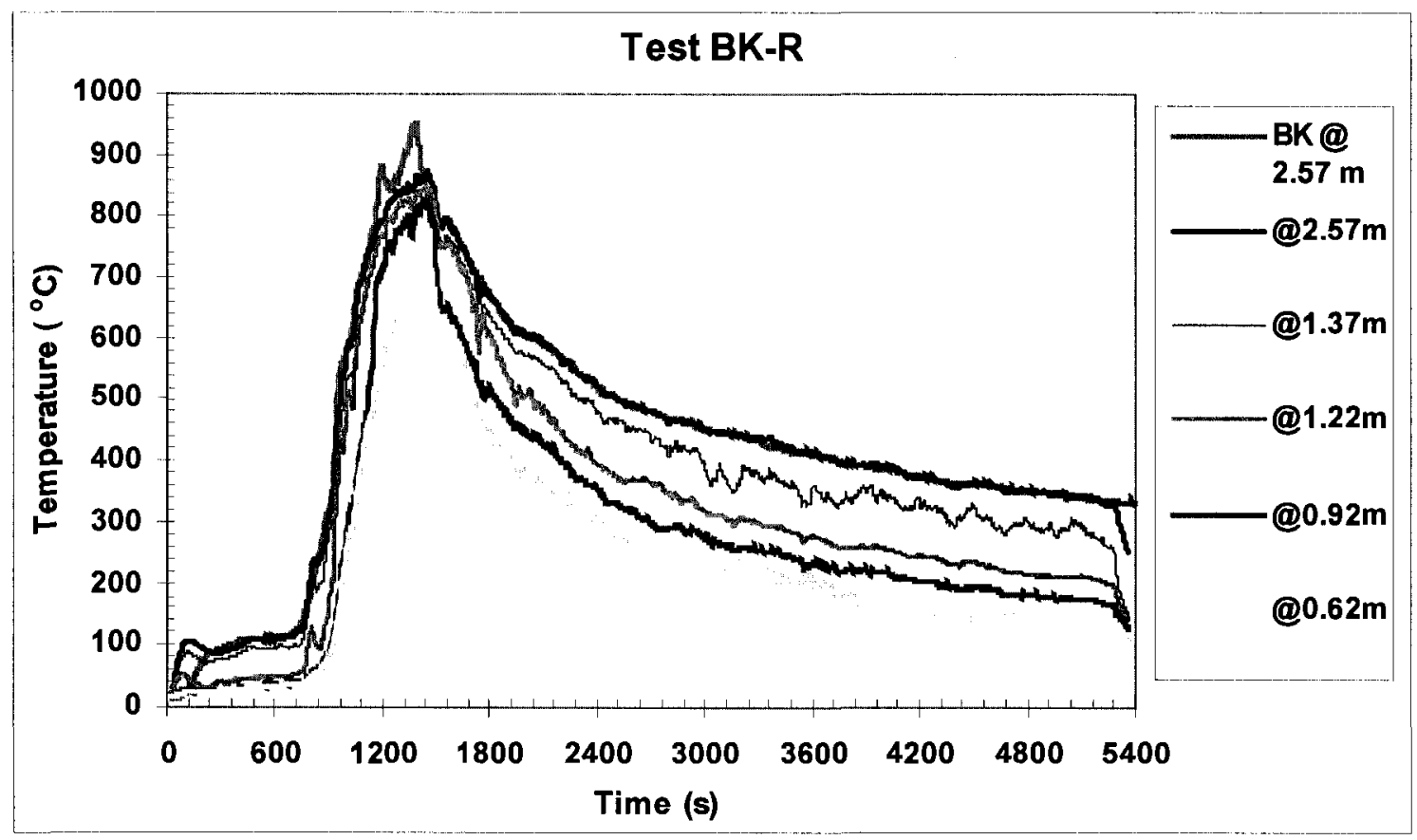

Figure 4-69: Gas temperature histories at different heights in the corner of the fire compartment (Test BK-R)

The heat release rate of the Test BK-R is shown in Figure 4-70. The HRR rose to about $200 \mathrm{~kW}$ within $10 \mathrm{~s}$ after ignition, after which it kept a relatively steady value of around $220 \mathrm{~kW}$ until $55 \mathrm{~s}$. In order to trace the temperature-curve in the fire compartment of Test BK, the heat release rate was adjusted to a lower value of $15 \mathrm{~kW}$ until $710 \mathrm{~s}$. After this time the heat release rate increased steadily until it reached a peak value of $3067 \mathrm{~kW}$ at $1150 \mathrm{~s}$. Once the peak was reached, the HRR dropped at a fast rate until around $1500 \mathrm{~s}$, followed by a slower until the end of test at $5400 \mathrm{~s}$. 


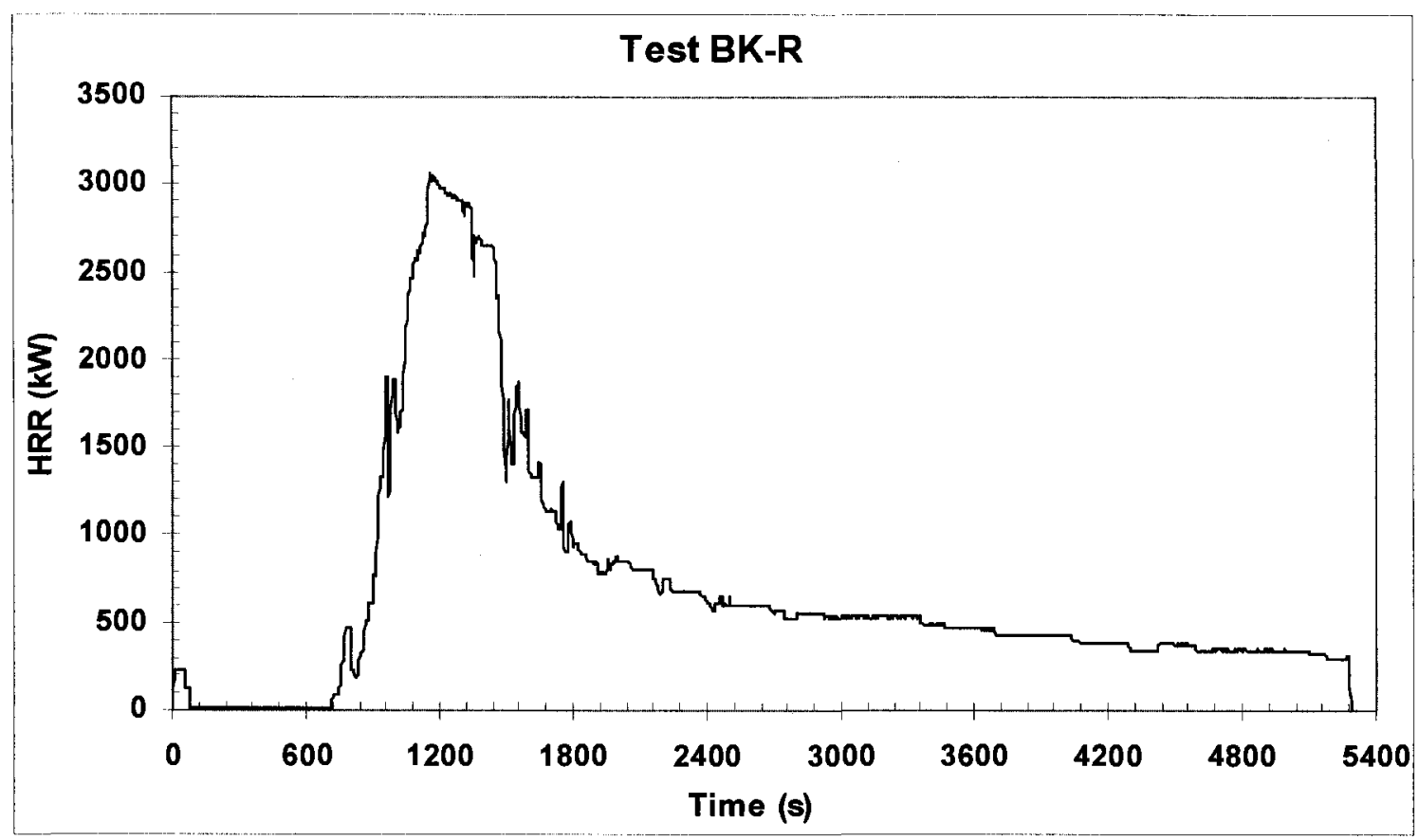

Figure 4-70: Heat release rate (Test BK-R)

Figure 4-71 shows the concentration of $\mathrm{O}_{2}$ and $\mathrm{CO}_{2}$ in the stair shaft at the fire floor of Test BK-R. The figure indicates that the lowest concentration of $\mathrm{O}_{2}$ was $10.76 \%$ at $1265 \mathrm{~s}$, which is much higher than the value of $3.72 \%$ at $1255 \mathrm{~s}$ shown in Figure 4-34 for Test $\mathrm{BK}$. The highest concentration of $\mathrm{CO}_{2}$ was $6.26 \%$ at $1265 \mathrm{~s}$, which is much lower than the value of $16.55 \%$ at $1255 \mathrm{~s}$ for Test BK shown in Figure 4-34. During the fuel package Test BK, there was combustion of unburned hydrocarbons in the stair shaft and doorway area on the fire floor, but not for the propane Test BK-R. During Test BK unburned hydrocarbons burned in the stair shaft at the $2^{\text {nd }}$ floor when meeting sufficient oxygen there, consumed $\mathrm{O}_{2}$ and generated $\mathrm{CO}_{2}$ as well. This resulted the concentration of $\mathrm{CO}_{2}$ in the stair shaft at the fire floor was much higher for Test BK. The concentration of $\mathrm{CO}$ in the stair shaft at the fire floor for Test BK-R was very low, less than $20 \mathrm{ppm}$, which is not shown in the figure. This concentration is much lower than the concentration of $\mathrm{CO}$ at that location for Test $\mathrm{BK}$, which reached values as high as 
28,251 ppm (Figure 4-35). As discussed earlier, the BK test experienced incomplete combustion due to the low oxygen concentration.

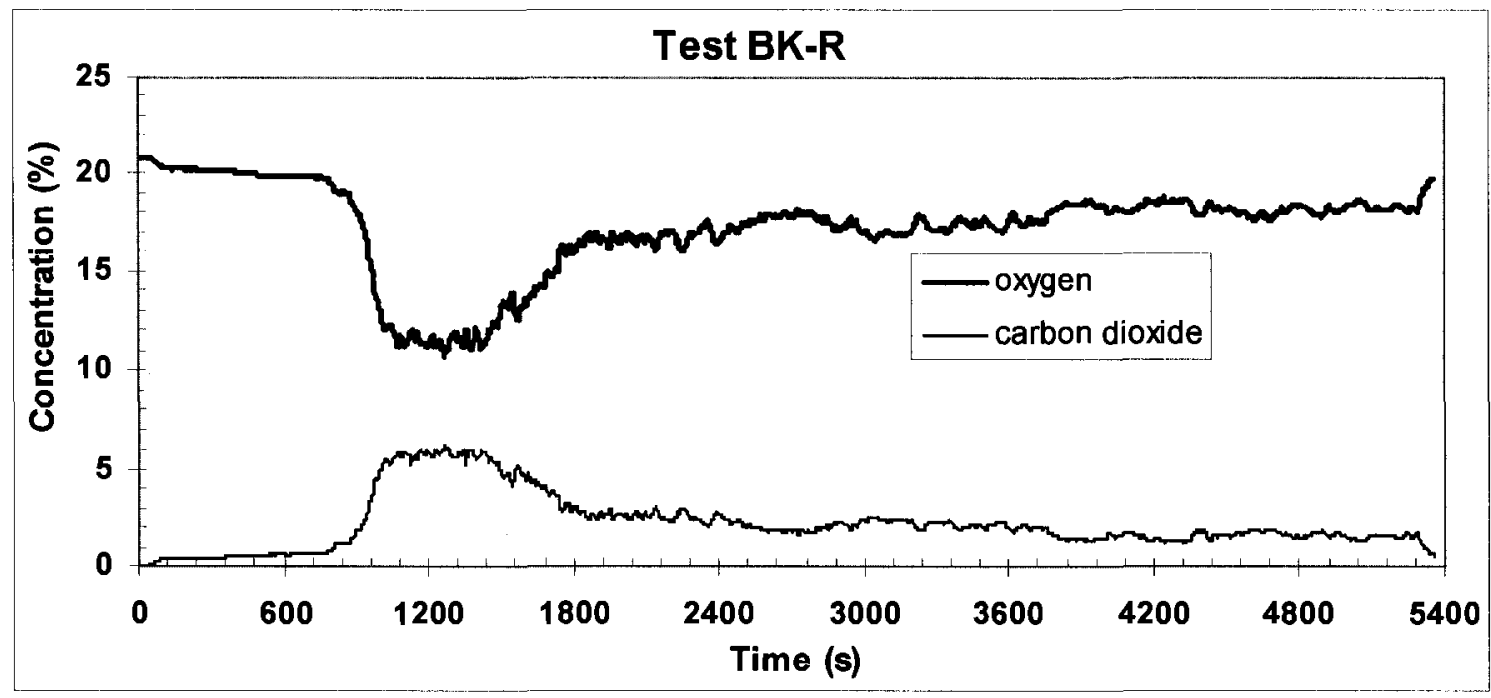

Figure 4-71: Concentration of $\mathrm{O}_{2}$ and $\mathrm{CO}_{2}$ in the stair shaft at the fire floor (Test BK-R)

Figure 4-72 shows the gas temperature histories at different heights at the doorway of Test BK-R as recorded by the thermocouples placed at the doorway. A maximum temperature of $666^{\circ} \mathrm{C}$ at $1405 \mathrm{~s}$ was recorded by the thermocouple at $1.65 \mathrm{~m}$ height compared to $887^{\circ} \mathrm{C}$ at $1260 \mathrm{~s}$ recorded in Test BK (Figure 4-38). The peak temperature at the doorway area in the fuel package test was achieved much earlier compared to the peak temperatures in the fire compartment. For example, peak temperature of $887^{\circ} \mathrm{C}$ at the doorway area was achieved at $1260 \mathrm{~s}$ compared to the peak temperature of $952^{\circ} \mathrm{C}$ in the fire compartment at $1390 \mathrm{~s}$. These temperatures demonstrate that in the fuel package tests there was combustion taking place outside the compartment as opposed to the propane test. 


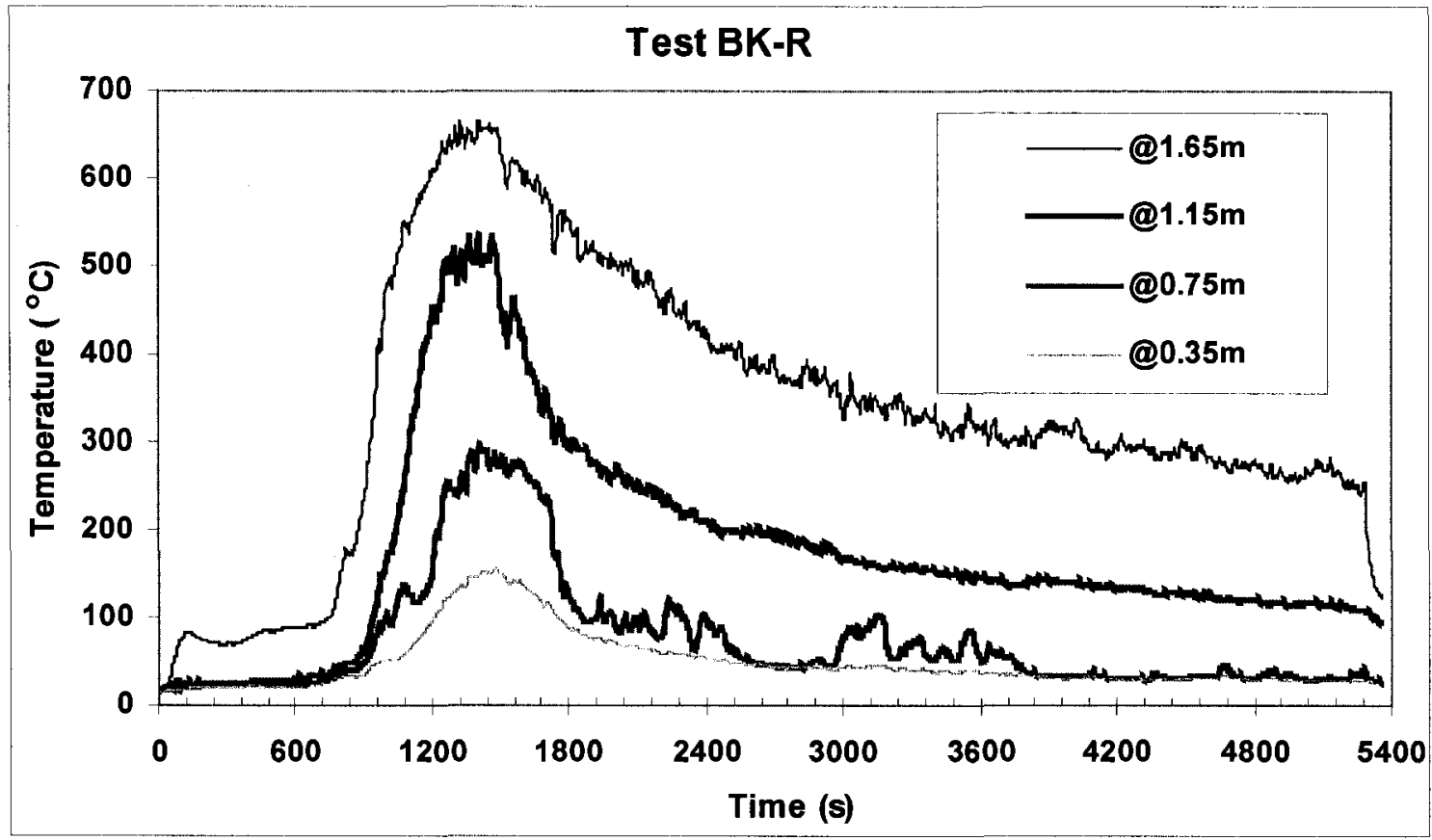

Figure 4-72: Gas temperature histories at different heights at the doorway (Test BK-R)

The gas temperature histories in the stair shaft for Test BK-R recorded by the thermocouples installed in the stair shaft at each floor from the $2^{\text {nd }}$ to the $10^{\text {th }}$ are shown in Figure 4-73. The maximum gas temperature in the stair shaft of the fire floor was $377^{\circ} \mathrm{C}$ at $1365 \mathrm{~s}$, which was earlier than $1405 \mathrm{~s}$ at the doorway and $1455 \mathrm{~s}$ in the fire compartment. This points to the possibility that unburned propane was burned in the stair shaft and the doorway area.

The maximum values of the gas temperature and their corresponding times in the stair shaft at the $2^{\text {nd }}$ to $10^{\text {th }}$ floors are listed in Table $4-26$. 


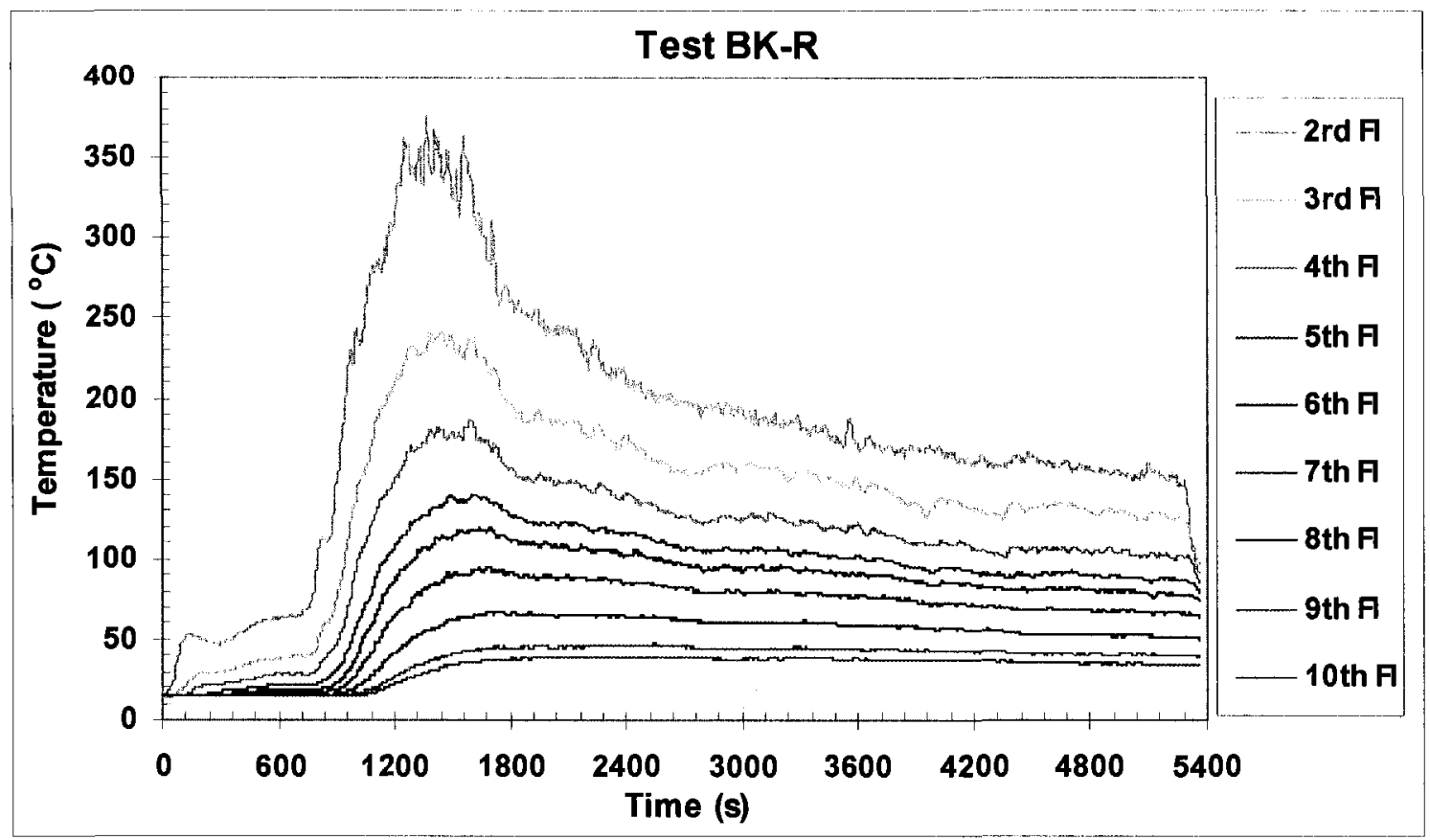

Figure 4-73: Gas temperature histories in the stair shaft (Test BK-R)

Table 4-26: The maximum gas temperatures in the stair shaft of different floors for

\begin{tabular}{|c|c|c|c|c|c|c|c|c|c|c|}
\hline $\begin{array}{c}\text { Test } \\
\text { ID }\end{array}$ & Floor \# & $\begin{array}{c}2^{\text {nd }} \\
\text { floor }\end{array}$ & $\begin{array}{c}3^{\text {rd }} \\
\text { floor }\end{array}$ & $\begin{array}{c}4^{\text {th }} \\
\text { floor }\end{array}$ & $\begin{array}{c}5^{\text {th }} \\
\text { floor }\end{array}$ & $\begin{array}{c}6^{\text {th }} \\
\text { floor }\end{array}$ & $\begin{array}{c}7^{\text {th }} \\
\text { floor }\end{array}$ & $\begin{array}{c}8^{\text {th }} \\
\text { floor }\end{array}$ & $\begin{array}{c}9^{\text {th }} \\
\text { floor }\end{array}$ & $\begin{array}{c}10^{\text {th }} \\
\text { floor }\end{array}$ \\
\hline \multirow{4}{*}{ BK-R } & $\mathrm{T}_{\mathrm{i}}\left({ }^{\circ} \mathrm{C}\right)$ & 16.8 & 14.6 & 14.8 & 15.0 & 15.4 & 15.3 & 15.0 & 14.9 & 15.0 \\
\cline { 2 - 13 } & $\mathrm{T}_{\mathrm{p}}\left({ }^{\circ} \mathrm{C}\right)$ & 376.6 & 241.1 & 186.5 & 139.9 & 119.2 & 94.9 & 67.4 & 47.5 & 39.4 \\
\cline { 2 - 12 } & $\Delta \mathrm{T}\left({ }^{\circ} \mathrm{C}\right)$ & 359.8 & 226.5 & 171.7 & 124.9 & 103.8 & 79.6 & 52.4 & 32.6 & 24.4 \\
\cline { 2 - 11 } & $\mathrm{t}_{\mathrm{p}}(\mathrm{s})$ & 1365 & 1385 & 1600 & 1615 & 1640 & 1685 & 1695 & 2545 & 2560 \\
\hline
\end{tabular}

Note: $T_{i}$ is the initial gas temperature; $T_{p}$ is the peak gas temperature; $\Delta T$ is the gas temperature difference between $T_{p}$ and $T_{i}$ and $t_{p}$ is the time when the gas reached the peak temperature

Figure 4-74 shows the gas temperature histories for Test BK-R recorded by the thermocouples in the vestibules of the floors with open doors. The maximum values of the gas temperature and their corresponding times in the vestibules of the floors with open doors are listed in Table 4-27. 


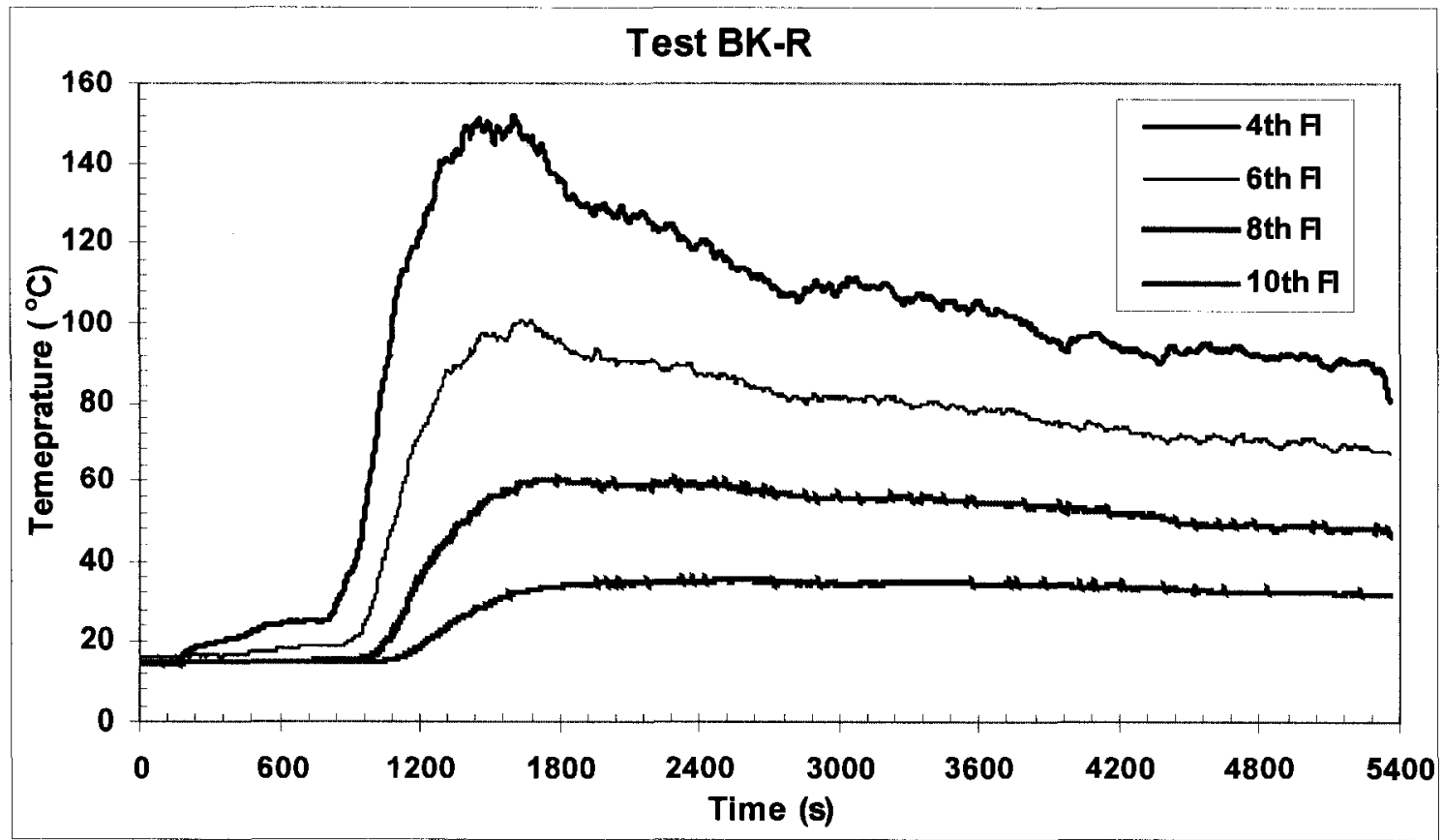

Figure 4-74: Gas temperature histories in the vestibules of the floors with open doors (Test BK-R)

Table 4-27: The maximum gas temperatures in the vestibules of the floors with open doors for Test BK-R

\begin{tabular}{|c|c|c|c|c|c|}
\hline Test ID & Floor \# & $4^{\text {th }}$ floor & $6^{\text {th }}$ floor & $8^{\text {th }}$ floor & $10^{\text {th }}$ floor \\
\hline \multirow{4}{*}{ BK-R } & $\mathrm{T}_{\mathrm{i}}\left({ }^{\circ} \mathrm{C}\right)$ & 14.6 & 16.5 & 14.8 & 15.3 \\
\cline { 2 - 6 } & $\mathrm{T}_{\mathrm{p}}\left({ }^{\circ} \mathrm{C}\right)$ & 151.8 & 100.8 & 60.2 & 35.5 \\
\cline { 2 - 6 } & $\Delta \mathrm{T}\left({ }^{\circ} \mathrm{C}\right)$ & 137.2 & 84.3 & 45.4 & 20.2 \\
\cline { 2 - 6 } & $\mathrm{t}_{\mathrm{p}}(\mathrm{s})$ & 1605 & 1680 & 1745 & 2595 \\
\hline
\end{tabular}

Note: $T_{i}$ is the initial gas temperature; $T_{p}$ is the peak gas temperature; $\Delta T$ is the gas temperature difference between $T_{p}$ and $T_{i}$ and $t_{p}$ is the time when the gas reached the peak temperature

Figure 4-75 shows the gas temperature histories in the vestibules of the floors with closed doors for Test BK-R.

Figure 4-76 shows the gas temperature histories in the main compartments of the $4^{\text {th }}, 8^{\text {th }}$ and $10^{\text {th }}$ floors for Test BK-R. The maximum values of the gas temperature and their corresponding times at the main compartments of the $4^{\text {th }}, 8^{\text {th }}$ and $10^{\text {th }}$ floors are listed in Table 4-28. 


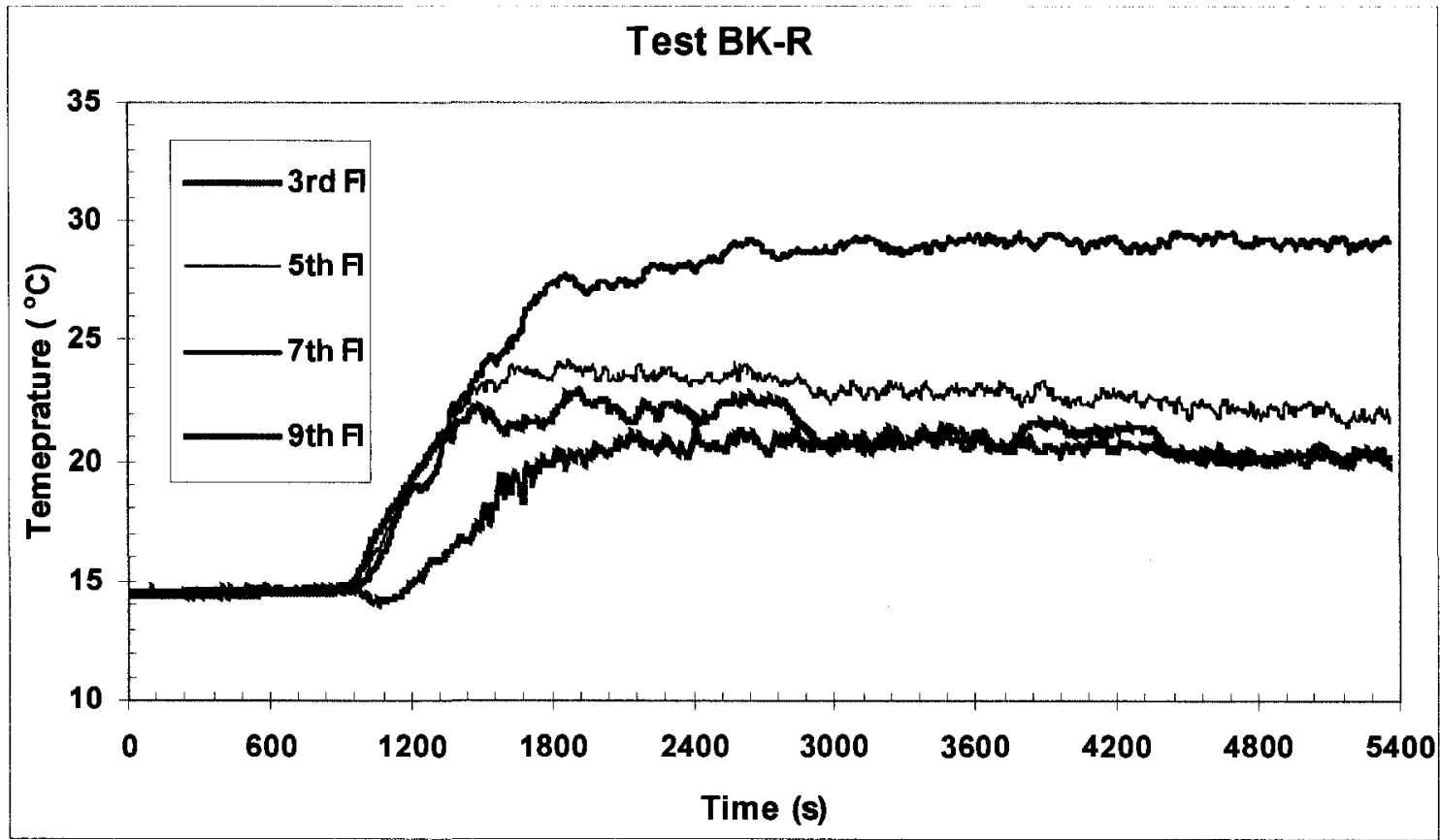

Figure 4-75: Gas temperature histories in the vestibules of the floors with closed doors (Test BK-R)

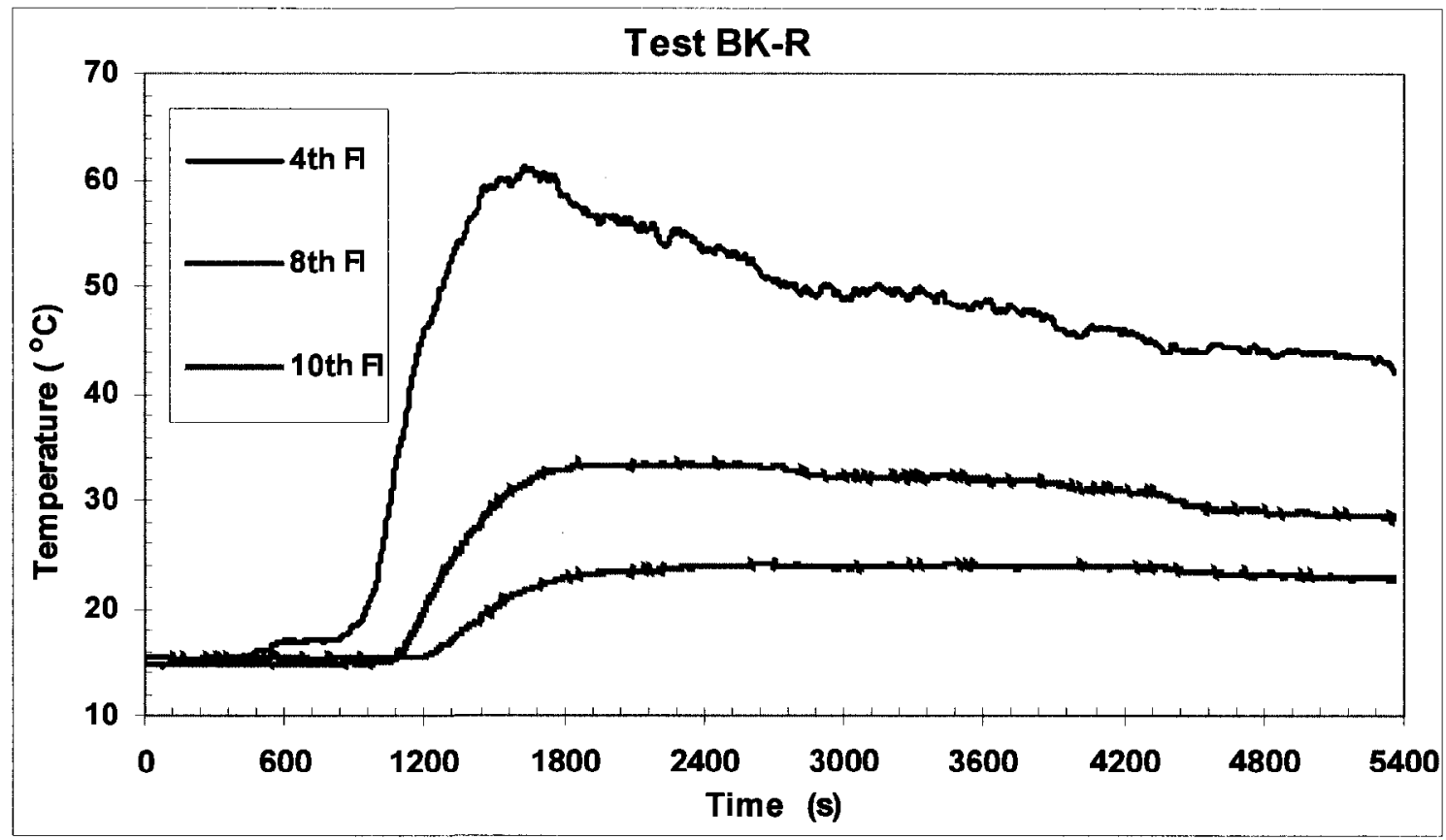

Figure 4-76: Gas temperature histories in the main compartments of the floors of the $4^{\text {th }}, 8^{\text {th }}$ and $10^{\text {th }}$ (Test BK-R) 
Table 4-28: The maximum gas temperatures in the main compartments of the floors of the $4^{\text {th }}, 8^{\text {th }}$ and $10^{\text {th }}$ for Test BK-R

\begin{tabular}{|c|c|c|c|c|}
\hline Test ID & Floor \# & $4^{\text {th }}$ floor & $8^{\text {th }}$ floor & $10^{\text {th }}$ floor \\
\hline \multirow{4}{*}{ BK-R } & $\mathrm{T}_{\mathrm{i}}\left({ }^{\circ} \mathrm{C}\right)$ & 14.7 & 14.8 & 15.3 \\
\cline { 2 - 5 } & $\mathrm{T}_{\mathrm{p}}\left({ }^{\circ} \mathrm{C}\right)$ & 61.2 & 33.5 & 24.2 \\
\cline { 2 - 5 } & $\Delta \mathrm{T}\left({ }^{\circ} \mathrm{C}\right)$ & 46.5 & 18.7 & 8.9 \\
\cline { 2 - 5 } & $\mathrm{t}_{\mathrm{p}}(\mathrm{s})$ & 1625 & 1860 & 2600 \\
\hline
\end{tabular}

Note: $T_{i}$ is the initial gas temperature; $T_{p}$ is the peak gas temperature; $\Delta T$ is the gas temperature difference between $T_{p}$ and $T_{i}$ and $t_{p}$ is the time when the gas reached the peak temperature

\subsubsection{Summary of Group 2 tests}

Four propane tests, CLC-I-R, CLC-II-R, BK-R and CMP-R, were conducted in Group 2 to reproduce the fuel package tests of Group 1. Propane burners were used to reproduce the temperature-time curve in the fire compartment for all these tests. The HRR obtained from the propane fires provides an indication of the HRR released in the fire compartment during the fuel package fires.

For package tests CLC-I, CLC-II and BK, some fuel did not burn in the fire compartment because of insufficient availability of $\mathrm{O}_{2}$ in the fire compartment. These unburned hydrocarbons were carried by the smoke into the stair shaft of the $2^{\text {nd }}$ floor through the vestibule, where they burned. This could not be reproduced in the propane tests CLC-I-R, CLC-II-R and BK-R. Therefore the heat release rate obtained from Test CLC-I-R, CLC-II-R and BK-R show the heat release rate of the packages CLC-I, CLC-II and BK in the fire compartment, excluding the part released in the stair shaft and the doorway area.

The result of Test CMP-R is similar to that of Test CMP. The heat release rate computed for the propane test must be very close to the heat release rate of the corresponding fuel package test. 
All propane fires produced very small amounts of $\mathrm{CO}$ due to the well-ventilated combustion of propane does not produce significant amounts of CO. Since the propane burner was located in the lower layer there was enough oxygen for an efficient combustion producing less CO during propane fires. While, all of fuel package fires produced significant amounts of $\mathrm{CO}$ since the fuel package obstructed the oxygen so there was not good mixing with the pyrolysis products producing more CO. Also the fuel package fires produced more soot, which resulted in higher radiative losses from the smoke causing lower smoke temperatures in the stair shaft.

Table 4-29 summarizes the maximum temperatures in the fire compartment, flashover times, and the interface heights at the time of peak temperature for Group 2 tests. The lowest concentration of $\mathrm{O}_{2}$ and the highest concentration of $\mathrm{CO}_{2}$ are listed in Table 4-30. Table 4-31 provides a summary of the temperature distributions at various locations of the tests in Group 2 and the corresponding tests of Group 1.

Table 4-29: A summary of the maximum temperatures and the lowest interface heights in the fire compartment for Group 2 tests

\begin{tabular}{|c|c|c|c|c|}
\hline Test ID & CLC-I-R & CLC-II-R & CMP-R & BK-R \\
\hline Peak Temp. $\left({ }^{\circ} \mathrm{C}\right)$ & 671 & 828 & 847 & 873 \\
\hline Time of Peak (s) & 260 & 420 & 710 & 1455 \\
\hline $\begin{array}{c}\text { Time of } \\
\text { Flashover (s) }\end{array}$ & 250 & 280 & 550 & 1050 \\
\hline $\begin{array}{c}\text { The Lowest } \\
\text { Interface Height }\end{array}$ & $1.13 \mathrm{~m} @ 260 \mathrm{~s}$ & $0.86 \mathrm{~m} @ 420 \mathrm{~s}$ & $0.86 \mathrm{~m} @ 710 \mathrm{~s}$ & $0.88 \mathrm{~m} @ 1455 \mathrm{~s}$ \\
\hline
\end{tabular}

Table 4-30: The concentration of $\mathrm{O}_{2}$ and $\mathrm{CO}_{2}$ in stair shaft at the fire floor for Group 2 tests

\begin{tabular}{|c|c|c|c|c|}
\hline Test ID & CLC-I-R & CLC-II-R & CMP-R & BK-R \\
\hline \multirow{2}{*}{ Lowest concentration of $\mathrm{O}_{2}(\%)$} & 12.39 & 9.53 & 10.81 & 10.76 \\
& $@ 280 \mathrm{~s}$ & $@ 385 \mathrm{~s}$ & $@ 680 \mathrm{~s}$ & $@ 1265 \mathrm{~s}$ \\
\hline \multirow{2}{*}{ Highest concentration of $\mathrm{CO}_{2}(\%)$} & 5.30 & 7.40 & 6.40 & 6.26 \\
& $@ 270 \mathrm{~s}$ & $@ 410 \mathrm{~s}$ & $@ 670 \mathrm{~s}$ & $@ 1265 \mathrm{~s}$ \\
\hline
\end{tabular}


Table 4-31: Upper layer gas temperature difference between peak value and initial value at various locations for Group 2 tests, and Group 1 tests

\begin{tabular}{|c|c|c|c|c|c|c|c|c|c|c|c|c|}
\hline \multirow[t]{2}{*}{ Floor \# } & \multicolumn{4}{|c|}{ Stair Shaft $\left({ }^{\circ} \mathrm{C}\right)$} & \multicolumn{4}{|c|}{ Vestibule $\left({ }^{\circ} \mathrm{C}\right)$} & \multicolumn{4}{|c|}{$\begin{array}{c}\text { Main Compartment } \\
\text { (fire compartment } \\
\text { at } 2^{\text {nd }} \text { floor) }\left({ }^{\circ} \mathrm{C}\right)\end{array}$} \\
\hline & \begin{tabular}{|c|} 
CLC-I \\
(CLC-I-R)
\end{tabular} & \begin{tabular}{|c|} 
CLC-II \\
(CLC-II-R)
\end{tabular} & $\begin{array}{c}\text { CMP } \\
\text { (CMP-R) }\end{array}$ & \begin{tabular}{|c} 
BK \\
(BK-R)
\end{tabular} & \begin{tabular}{|c} 
CLC-I \\
(CLC-I-R)
\end{tabular} & $\begin{array}{c}\text { CLC-II } \\
\text { (CLC-II-R) }\end{array}$ & \begin{tabular}{|c|} 
CMP \\
(CMP-R)
\end{tabular} & $\begin{array}{c}\text { BK } \\
\text { (BK-R) }\end{array}$ & $\begin{array}{c}\text { CLC-I } \\
\text { (CLC-I-R) }\end{array}$ & \begin{tabular}{|c} 
CLC-II \\
(CLC-II-R)
\end{tabular} & $\begin{array}{c}\text { CMP } \\
\text { (CMP-R) }\end{array}$ & $\begin{array}{c}\text { BK } \\
\text { (BK-R) }\end{array}$ \\
\hline $10^{\text {th }}$ & $\begin{array}{c}4.6 \\
(5.1)\end{array}$ & $\begin{array}{r}16.9 \\
(11.6)\end{array}$ & $\begin{array}{c}9.8 \\
(11.7)\end{array}$ & $\begin{array}{c}24.1 \\
(24.4)\end{array}$ & $\begin{array}{c}2.9 \\
(3.5)\end{array}$ & $\begin{array}{l}10.7 \\
(9.9)\end{array}$ & $\begin{array}{c}7.9 \\
(9.0)\end{array}$ & $\begin{array}{c}20.6 \\
(20.2)\end{array}$ & $\begin{array}{c}0.6 \\
(0.4)\end{array}$ & $\begin{array}{c}5.5 \\
(2.2)\end{array}$ & $\begin{array}{c}3.2 \\
(1.6)\end{array}$ & $\begin{array}{c}7.1 \\
(8.9)\end{array}$ \\
\hline $9^{\text {th }}$ & $\begin{array}{c}8.1 \\
(8.3)\end{array}$ & $\begin{array}{c}23.0 \\
(17.4)\end{array}$ & $\begin{array}{r}15.4 \\
(17.3)\end{array}$ & $\begin{array}{c}32.1 \\
(32.6)\end{array}$ & - & - & - & - & - & - & - & - \\
\hline $8^{\text {th }}$ & $\begin{array}{c}15.0 \\
(14.9)\end{array}$ & $\begin{array}{c}39.7 \\
(29.5)\end{array}$ & $\begin{array}{c}26.6 \\
(30.9)\end{array}$ & $\begin{array}{c}49.4 \\
(52.4)\end{array}$ & $\begin{array}{c}11.8 \\
(12.0)\end{array}$ & $\begin{array}{c}34.4 \\
(25.5)\end{array}$ & $\begin{array}{c}24.2 \\
(26.0)\end{array}$ & \begin{tabular}{|c|}
44.4 \\
$(45.4)$
\end{tabular} & $\begin{array}{c}4.0 \\
(3.5)\end{array}$ & $\begin{array}{l}12.3 \\
(9.9)\end{array}$ & $\begin{array}{c}8.8 \\
(9.2)\end{array}$ & $\begin{array}{c}17.4 \\
(18.7)\end{array}$ \\
\hline $7^{\text {th }}$ & $\begin{array}{r}25.4 \\
(25.1)\end{array}$ & $\begin{array}{r}57.5 \\
(43.8)\end{array}$ & $\begin{array}{r}39.9 \\
(49.8)\end{array}$ & $\begin{array}{c}75.2 \\
(79.6)\end{array}$ & - & - & - & - & - & - & - & - \\
\hline $6^{\text {th }}$ & $\begin{array}{c}38.1 \\
(43.3)\end{array}$ & $\begin{array}{c}74.4 \\
(71.2)\end{array}$ & $\begin{array}{c}53.8 \\
(76.2)\end{array}$ & $\begin{array}{c}101.3 \\
(103.8)\end{array}$ & $\begin{array}{c}33.1 \\
(32.3)\end{array}$ & $\begin{array}{c}62.9 \\
(56.9)\end{array}$ & $\begin{array}{c}47.2 \\
(59.6)\end{array}$ & $\begin{array}{c}80.5 \\
(84.3)\end{array}$ & - & - & - & - \\
\hline $5^{\text {th }}$ & $\begin{array}{c}53.3 \\
(61.4)\end{array}$ & $\begin{array}{c}96.6 \\
(93.3)\end{array}$ & $\begin{array}{c}69.2 \\
(96.4)\end{array}$ & $\begin{array}{c}129.2 \\
(124.9)\end{array}$ & - & - & - & - & - & - & - & - \\
\hline $4^{\text {th }}$ & $\begin{array}{c}83.5 \\
(94.6)\end{array}$ & $\begin{array}{r}141.5 \\
(133.1)\end{array}$ & $\begin{array}{c}98.6 \\
(135.2)\end{array}$ & $\begin{array}{l}192.3 \\
(171.7)\end{array}$ & $\begin{array}{c}69.1 \\
(75.5)\end{array}$ & $\begin{array}{c}114.2 \\
(108.9)\end{array}$ & $\begin{array}{c}83.9 \\
(109.2)\end{array}$ & $\begin{array}{c}148.3 \\
(137.2)\end{array}$ & $\begin{array}{c}21.1 \\
(18.9)\end{array}$ & $\begin{array}{c}37.6 \\
(37.8)\end{array}$ & \begin{tabular}{c|}
27.8 \\
$(38.6)$
\end{tabular} & \begin{tabular}{|c|}
49.0 \\
$(46.5)$
\end{tabular} \\
\hline $3^{\text {rd }}$ & $\begin{array}{c}128.6 \\
(147.1)\end{array}$ & $\begin{array}{c}209.7 \\
(189.1)\end{array}$ & $\begin{array}{c}145.6 \\
(188.3)\end{array}$ & $\begin{array}{c}286.4 \\
(226.5)\end{array}$ & - & - & - & - & - & - & - & - \\
\hline $2^{\text {nd }}$ & $\begin{array}{c}272.3 \\
(237.1)\end{array}$ & $\begin{array}{c}379.7 \\
(277.0)\end{array}$ & $\begin{array}{c}239.7 \\
(277.9)\end{array}$ & $\begin{array}{c}635.6 \\
(359.8)\end{array}$ & $\begin{array}{c}478.0 \\
(522.2)\end{array}$ & $\begin{array}{c}816.9 \\
(636.6)\end{array}$ & $\begin{array}{c}635.0 \\
(653.3)\end{array}$ & $\begin{array}{c}887.2 \\
(665.6)\end{array}$ & $\begin{array}{c}684.0 \\
(670.9)\end{array}$ & $\begin{array}{c}826.8 \\
(827.8)\end{array}$ & $\begin{array}{c}861.2 \\
(847.2)\end{array}$ & $\begin{array}{c}951.9 \\
(872.5)\end{array}$ \\
\hline
\end{tabular}

\subsection{Group 3: Propane Group Tests}

In this group, two propane tests, PP-I and PP-II, were conducted to observe the smoke movement characteristics caused by different HRR histories, as well to produce experimental data for CUsmoke validation. The detailed HRR, temperature distributions 
and concentrations of $\mathrm{O}_{2}, \mathrm{CO}_{2}$, and $\mathrm{CO}$ in the stair shaft of the $2^{\text {nd }}$ floor are discussed in the following sections.

\subsubsection{Propane test I (Test PP-I)}

Propane was used as fuel in Test PP-I.

The mass flow rate of propane consumed was measured and the calculated HRR is shown in Figure 4-77. The peak HRR of $1575 \mathrm{~kW}$ was reached $245 \mathrm{~s}$ after ignition. The fire stayed in a relatively steady phase for $170 \mathrm{~s}$, then entered the decay phase.

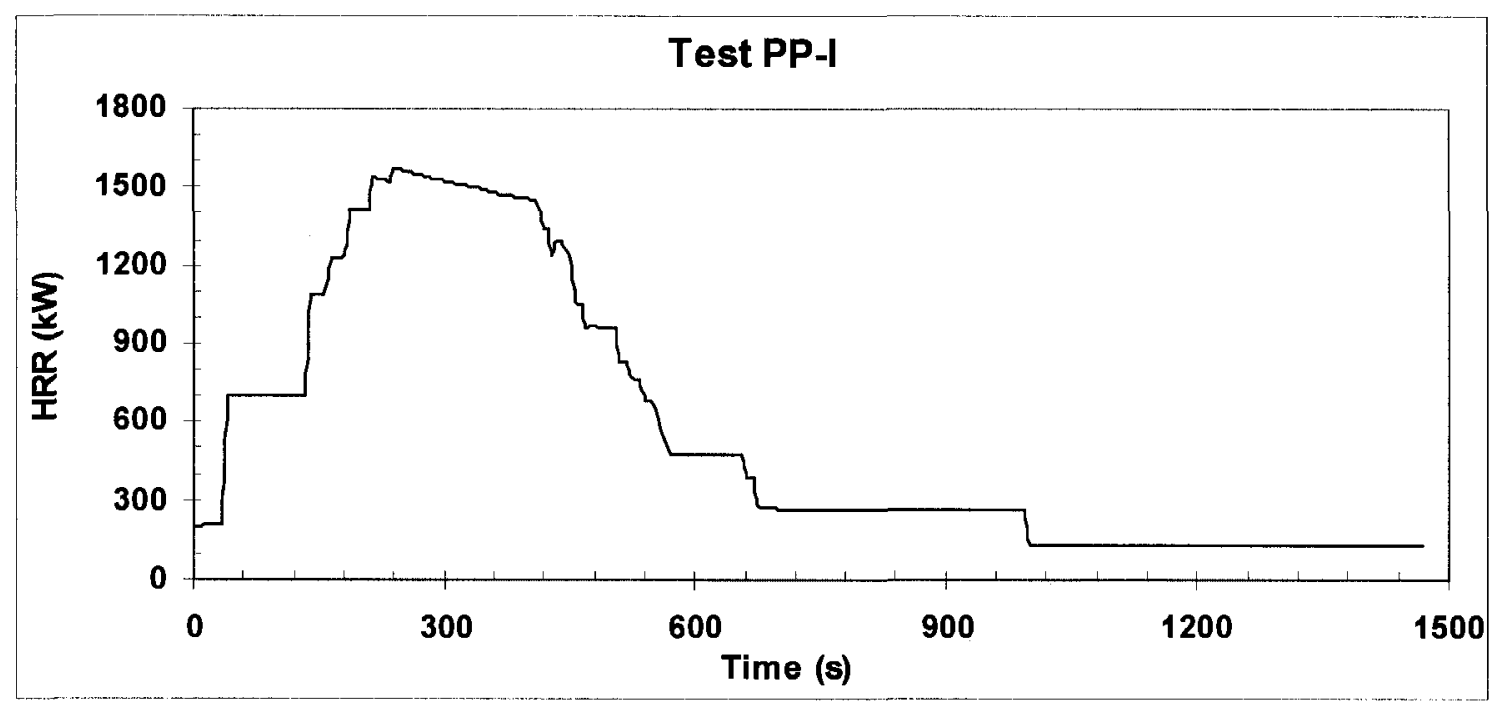

Figure 4-77: Heat release rate (Test PP-1)

Figure 4-78 shows the concentration of $\mathrm{O}_{2}$ and $\mathrm{CO}_{2}$ in the stair shaft at the fire floor. The figure indicates that the lowest concentration of $\mathrm{O}_{2}$ was $13.82 \%$ at $270 \mathrm{~s}$, and the highest concentration of $\mathrm{CO}_{2}$ was $4.56 \%$ at $270 \mathrm{~s}$. 


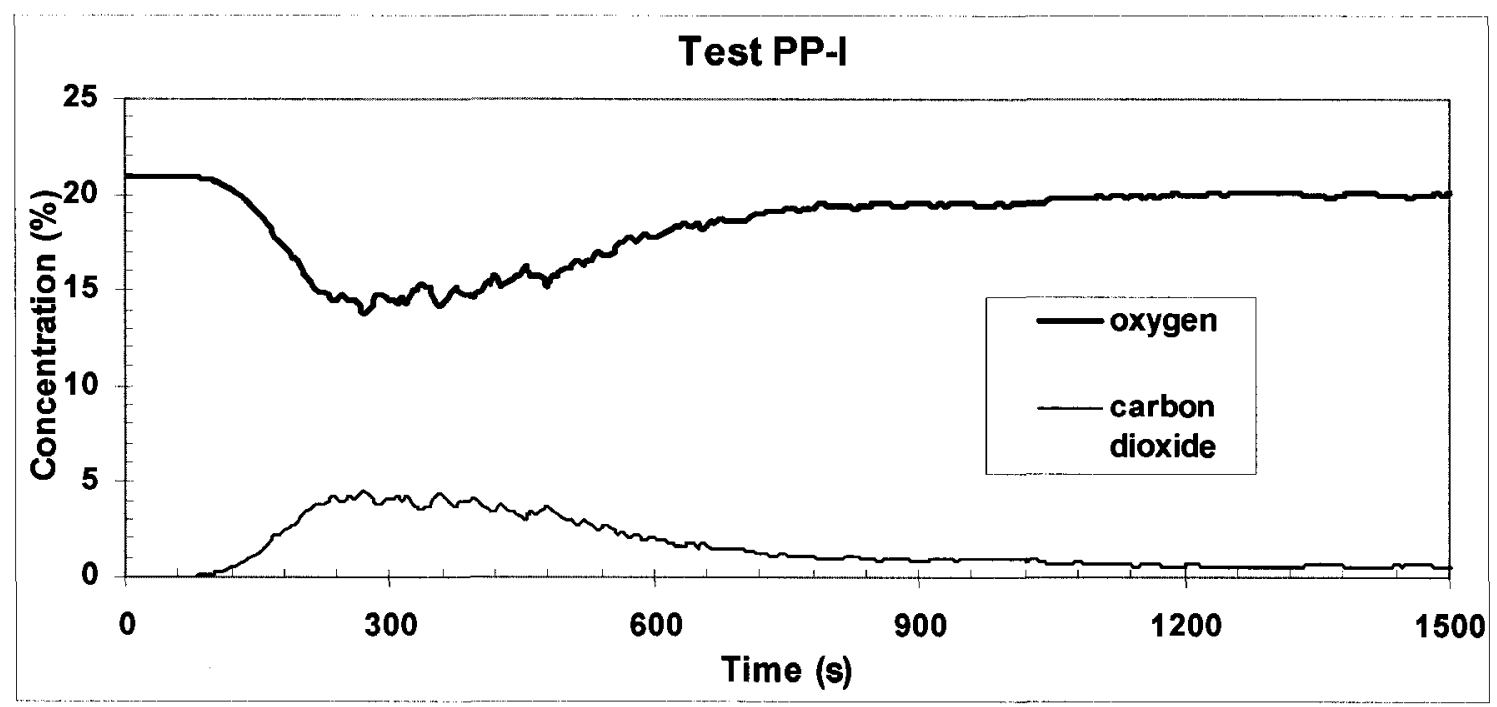

Figure 4-78: Concentration of $\mathrm{O}_{2}$ and $\mathrm{CO}_{2}$ in the stair shaft at the fire floor (Test PP-I)

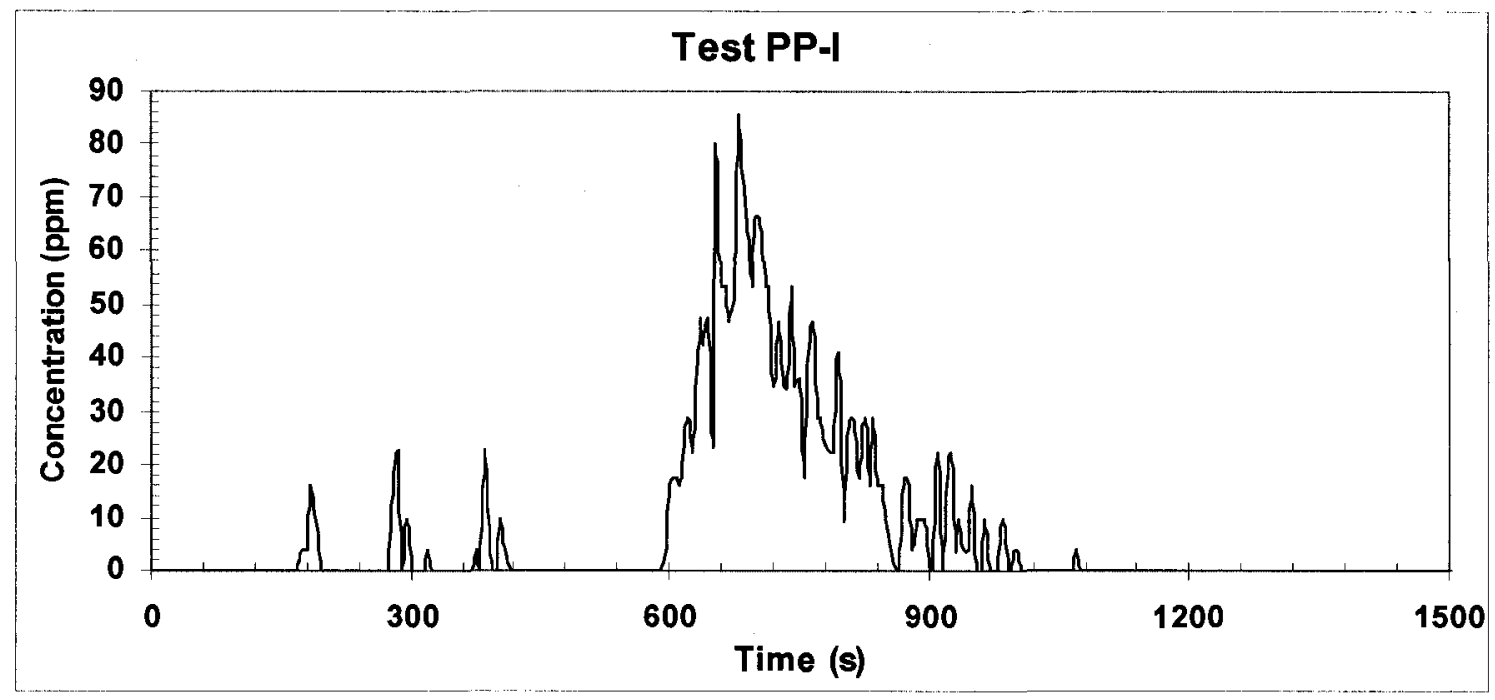

Figure 4-79: Concentration of $\mathrm{CO}$ in the stair shaft at the fire floor (Test PP-I)

The concentration of $\mathrm{CO}$ in the stair shaft at the fire floor is shown in Figure 4-79. The highest concentration of $\mathrm{CO}$ was $84 \mathrm{ppm}$ at $680 \mathrm{~s}$. Although this value is small, it still indicates some incomplete combustion.

The temperatures measured by the thermocouple tree located in the corner of the fire compartment are shown in Figure 4-80. As the figure shows, the temperature in the fire 
compartment increased to a maximum value of $648^{\circ} \mathrm{C}$ at $415 \mathrm{~s}$ after the ignition, with reaching the flashover condition at $350 \mathrm{~s}$. After reaching the peak temperature, the temperature in the fire compartment started to decrease steadily until the end of the test at $1500 \mathrm{~s}$.

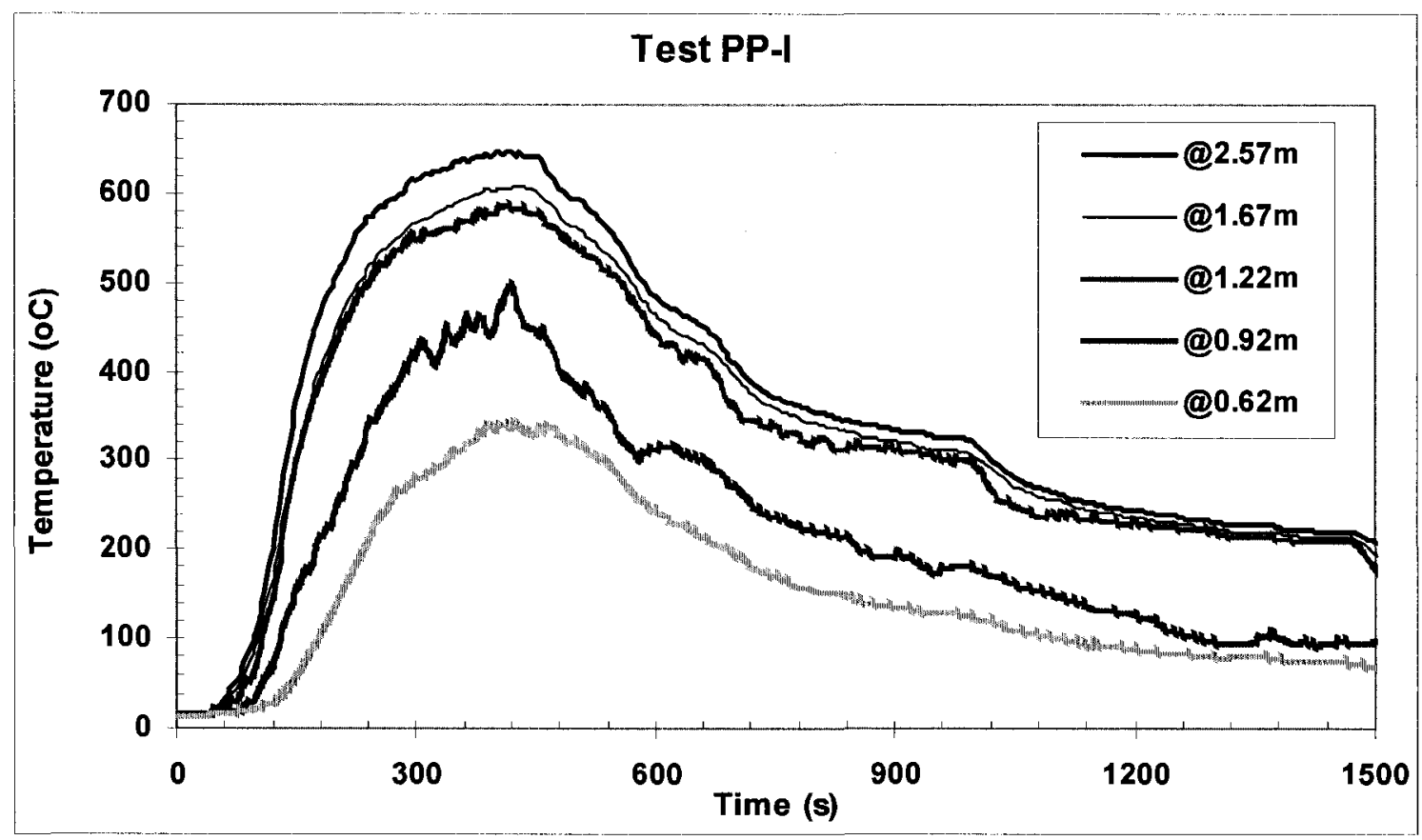

Figure 4-80: Gas temperature histories at different heights in the corner of the fire compartment (Test PP-I)

Figure 4-81 shows gas temperature profiles in the fire compartment at different times. The figure also notes the interface height estimated using Eqn (4-1). At $240 \mathrm{~s}$, the interface height was $1.1 \mathrm{~m}$; however at the time of reaching the flashover condition it dropped to $1.07 \mathrm{~m}$ and continued to drop to $1.03 \mathrm{~m}$ at $415 \mathrm{~s}$ when the peak temperature was reached in the fire compartment. The interface height then increased to $1.1 \mathrm{~m}$ at $540 \mathrm{~s}$. 


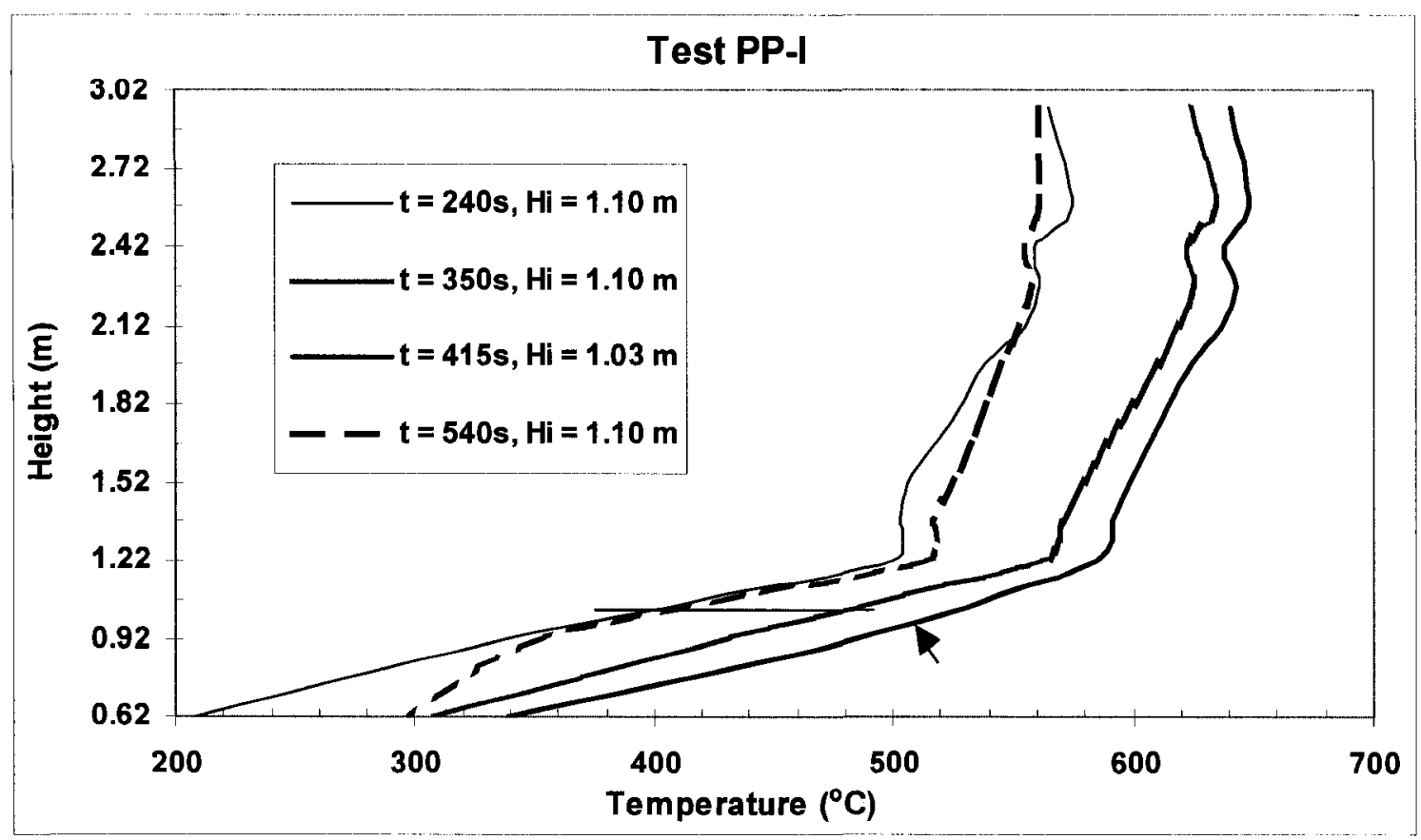

Note: Arrow and line indicate the locations of interface heights.

Figure 4-81: Gas temperature profiles in the fire compartment at different times (Test PP-I)

A short TC tree with 5 TCs was installed at the doorway between the stair shaft and the vestibule of the $2^{\text {nd }}$ floor. During the test, the TC installed at $2.05 \mathrm{~m}$ did not function. The temperature at 2.05 height level is not presented in Figure 4-82. The smoke moved into the stair shaft of the fire floor from the fire compartment via the vestibule. The temperature histories at different heights at the doorway recorded by the thermocouples of the TC tree are shown in Figure 4-82. A maximum temperature of $472^{\circ} \mathrm{C}$ at $415 \mathrm{~s}$ was recorded by the thermocouple at $1.65 \mathrm{~m}$. 


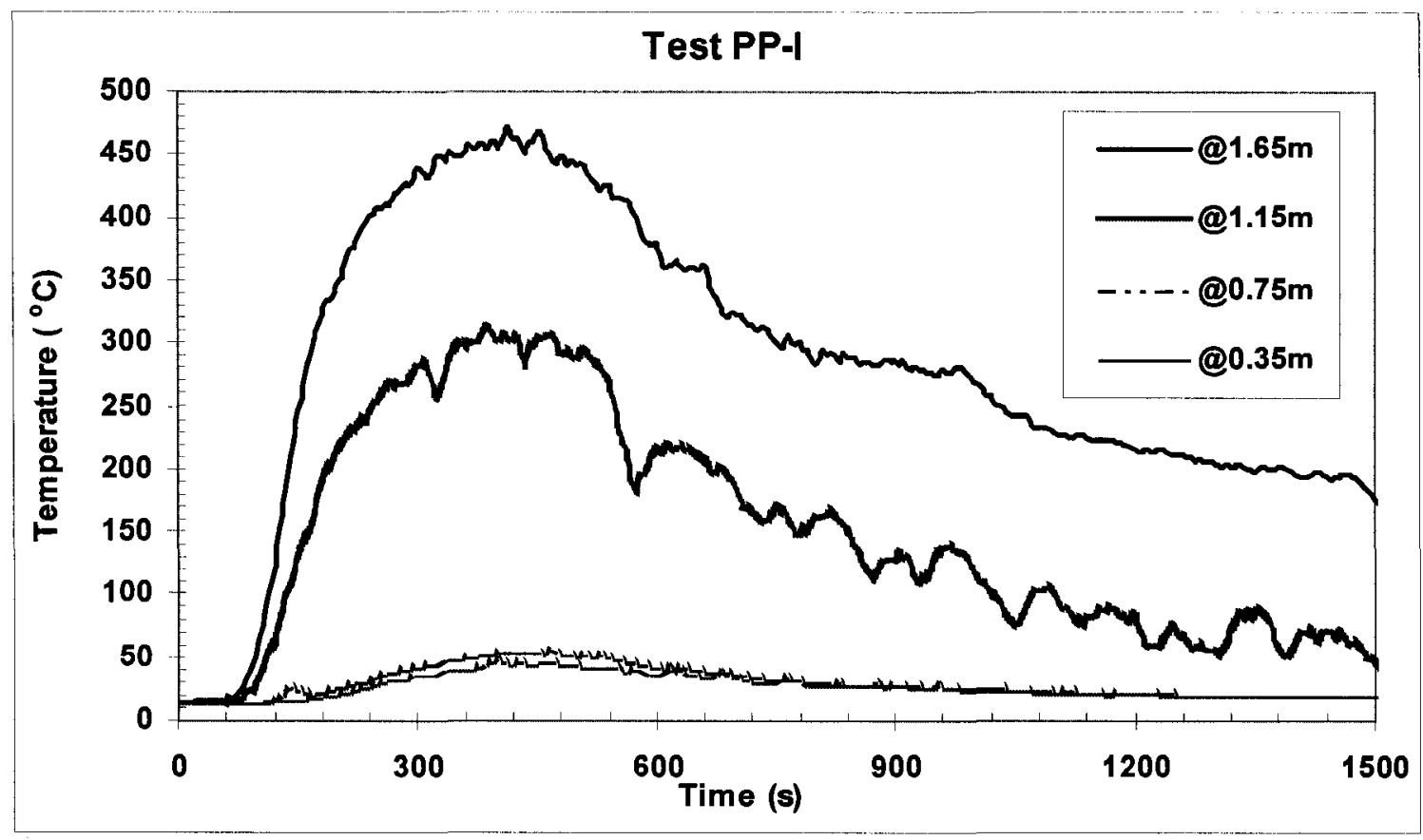

Figure 4-82: Gas temperature histories at different heights at the doorway (Test PP-I)

Three gas temperature profiles at the doorway at different times, before and after reaching the maximum temperature (at $240 \mathrm{~s}$ and $540 \mathrm{~s}$ ), and at the time of reaching the maximum temperature (at $415 \mathrm{~s}$ ) are shown in Figure 4-83.

The gas temperature histories in the stair shaft for Test PP-I as recorded by the thermocouples installed in the stair shaft at each floor from the $2^{\text {nd }}$ to the $10^{\text {th }}$ are shown in Figure 4-84. The figure shows that the maximum gas temperature in the stair shaft at the fire floor was $224^{\circ} \mathrm{C}$ at $380 \mathrm{~s}$. As stated before, the maximum gas temperature was $648^{\circ} \mathrm{C}$ at $415 \mathrm{~s}$ in the compartment of fire, and $472^{\circ} \mathrm{C}$ at $415 \mathrm{~s}$ at the doorway of the fire floor.

Table 4-32 lists the maximum values of the gas temperatures and their corresponding times. The table indicates that the maximum gas temperatures in the stair shaft decreased with the height, due to heat losses to the boundaries and mixing with the cold air. 


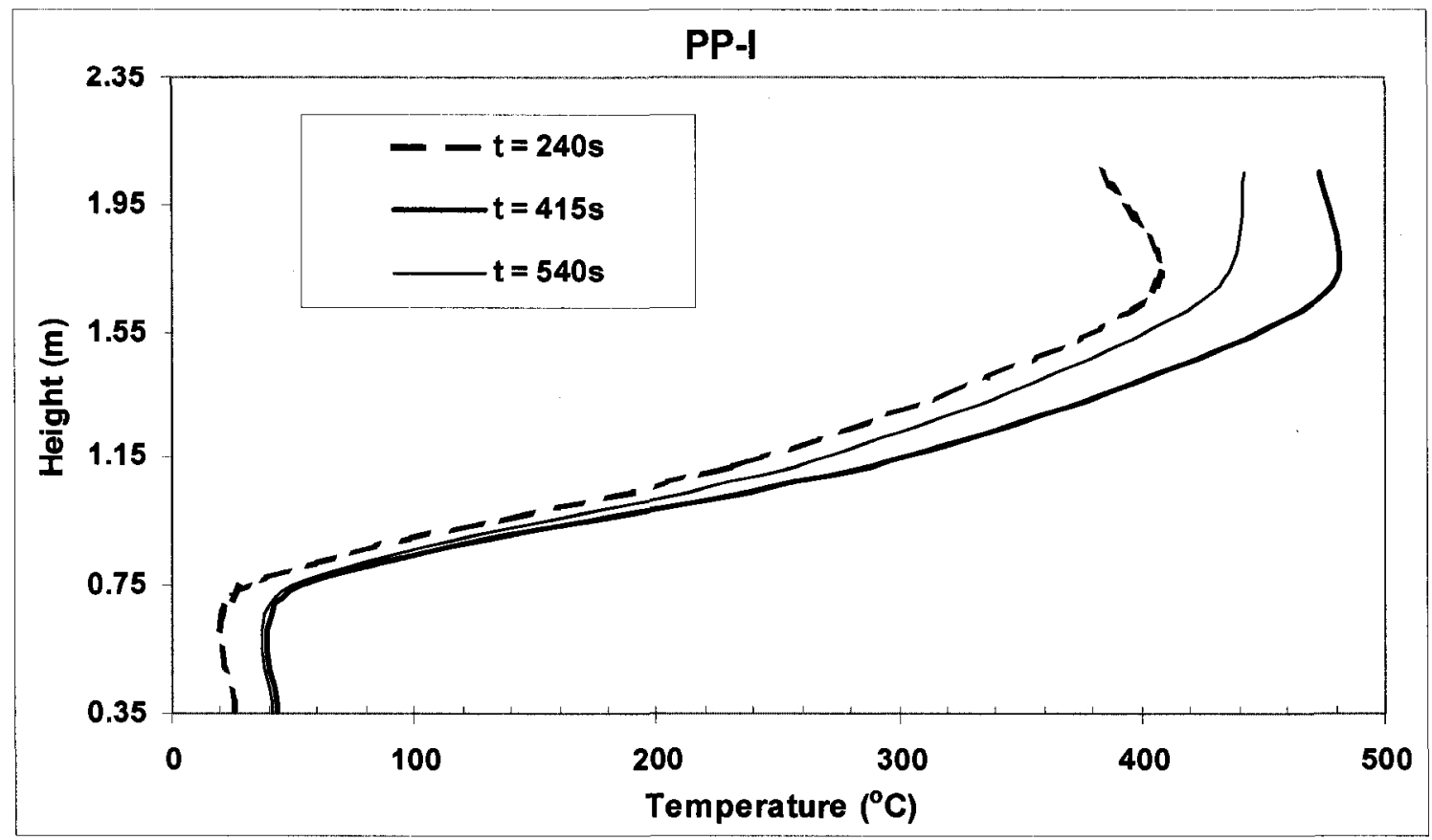

Figure 4-83: Gas temperature profiles at the doorway at different times (Test PP-I)

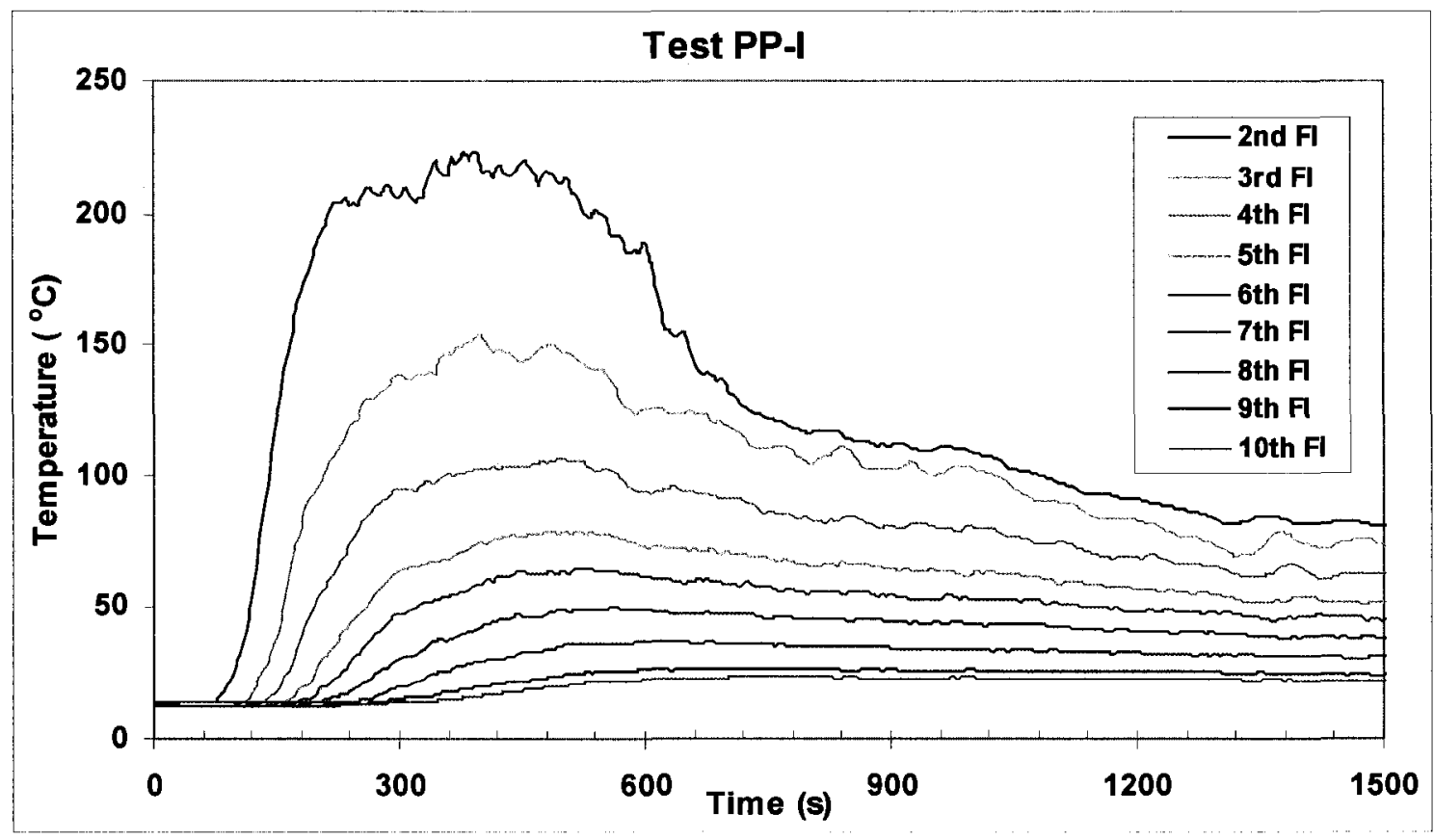

Figure 4-84: Gas temperature histories in the stair shaft (Test PP-I) 
Table 4-32: The maximum gas temperatures in the stair shaft of different floors for Test PP-I

\begin{tabular}{|c|c|c|c|c|c|c|c|c|c|c|}
\hline $\begin{array}{c}\text { Test } \\
\text { ID }\end{array}$ & Floor \# & $\begin{array}{c}2^{\text {nd }} \\
\text { floor }\end{array}$ & $\begin{array}{c}3^{\text {rd }} \\
\text { floor }\end{array}$ & $\begin{array}{c}4^{\text {th }} \\
\text { floor }\end{array}$ & $\begin{array}{c}5^{\text {th }} \\
\text { floor }\end{array}$ & $\begin{array}{c}6^{\text {th }} \\
\text { floor }\end{array}$ & $\begin{array}{c}7^{\text {th }} \\
\text { floor }\end{array}$ & $\begin{array}{c}8^{\text {th }} \\
\text { floor }\end{array}$ & $\begin{array}{c}9^{\text {th }} \\
\text { floor }\end{array}$ & $\begin{array}{c}10^{\text {th }} \\
\text { floor }\end{array}$ \\
\hline \multirow{4}{*}{ PP-I } & $\mathrm{T}_{\mathrm{i}}\left({ }^{\circ} \mathrm{C}\right)$ & 13.4 & 12.4 & 12.2 & 12.2 & 12.2 & 12.4 & 12.4 & 12.7 & 14.1 \\
\cline { 2 - 11 } & $\mathrm{T}_{\mathrm{p}}\left({ }^{\circ} \mathrm{C}\right)$ & 223.6 & 154.3 & 106.4 & 79.0 & 65.1 & 50.1 & 37.2 & 26.4 & 23.4 \\
\cline { 2 - 11 } & $\Delta \mathrm{T}\left({ }^{\circ} \mathrm{C}\right)$ & 210.2 & 141.9 & 94.2 & 66.8 & 52.9 & 37.7 & 24.8 & 13.7 & 9.3 \\
\cline { 2 - 10 } & $\mathrm{t}_{\mathrm{p}}(\mathrm{s})$ & 380 & 400 & 500 & 505 & 525 & 560 & 620 & 880 & 990 \\
\hline
\end{tabular}

Note: $T_{i}$ is the initial gas temperature; $T_{p}$ is the peak gas temperature; $\Delta T$ is the gas temperature difference between $T_{p}$ and $T_{i}$ and $t_{p}$ is the time when the gas reached the peak temperature

The doors between the stair shaft and the vestibules of the $3^{\text {rd }}, 5^{\text {th }}, 7^{\text {th }}$ and $9^{\text {th }}$ floors (odd floors) were fully closed, while the doors of the $4^{\text {th }}, 6^{\text {th }}, 8^{\text {th }}$ and $10^{\text {th }}$ floors (even floors) were fully open. At each vestibule, a thermocouple was installed to measure the gas temperature history. Figure 4-85 shows the gas temperature histories recorded by the thermocouples in the vestibules of the floors with open doors.

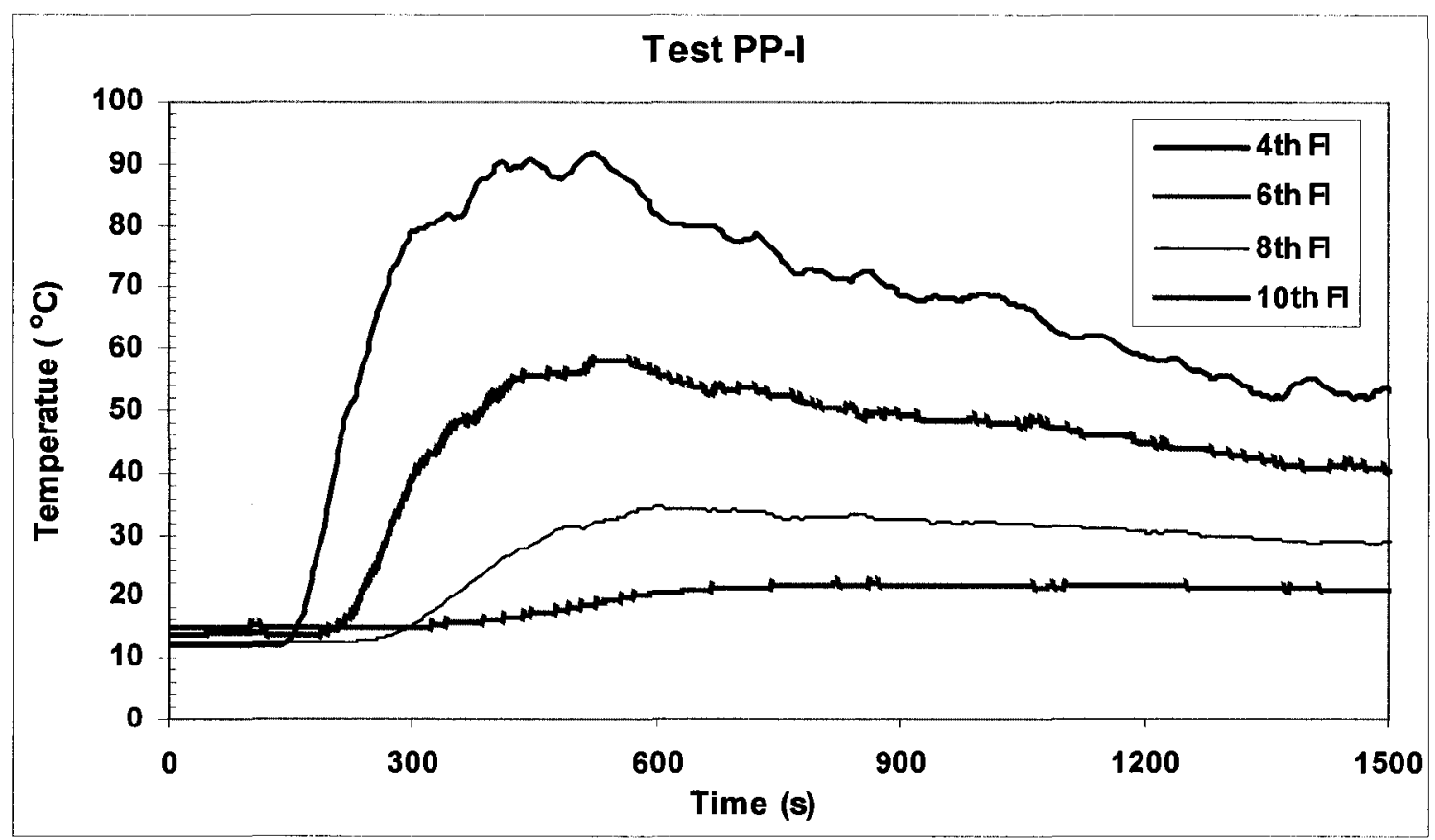

Figure 4-85: Gas temperature histories in the vestibules of the floors with open doors (Test PP-I) 
The maximum values of the gas temperature and their corresponding times in the vestibules of the floors with open doors are listed in Table 4-33.

Table 4-33: The maximum gas temperatures in the vestibules of the floors with open doors for Test PP-I

\begin{tabular}{|c|c|c|c|c|c|}
\hline Test ID & Floor \# & $4^{\text {th }}$ floor & $6^{\text {th }}$ floor & $8^{\text {th }}$ floor & $10^{\text {th }}$ floor \\
\hline \multirow{4}{*}{ PP-I } & $\mathrm{T}_{i}\left({ }^{\circ} \mathrm{C}\right)$ & 12.0 & 13.8 & 12.5 & 15.1 \\
\cline { 2 - 6 } & $\mathrm{T}_{\mathrm{p}}\left({ }^{\circ} \mathrm{C}\right)$ & 91.8 & 58.1 & 34.5 & 22.0 \\
\cline { 2 - 6 } & $\Delta \mathrm{T}\left({ }^{\circ} \mathrm{C}\right)$ & 79.8 & 44.3 & 22.0 & 6.9 \\
\cline { 2 - 6 } & $\mathrm{t}_{\mathrm{p}}(\mathrm{s})$ & 525 & 550 & 600 & 865 \\
\hline
\end{tabular}

Note: $T_{i}$ is the initial gas temperature; $T_{p}$ is the peak gas temperature; $\Delta T$ is the gas temperature difference between $T_{p}$ and $T_{i}$ and $t_{p}$ is the time when the gas reached the peak temperature

Figure 4-86 shows the gas temperature histories in the vestibules of the floors with closed doors. The figure indicates that the gas temperatures in the vestibules of the floors with closed doors increased by few degrees especially for the lower floors demonstrating that the doors were not completely sealed.

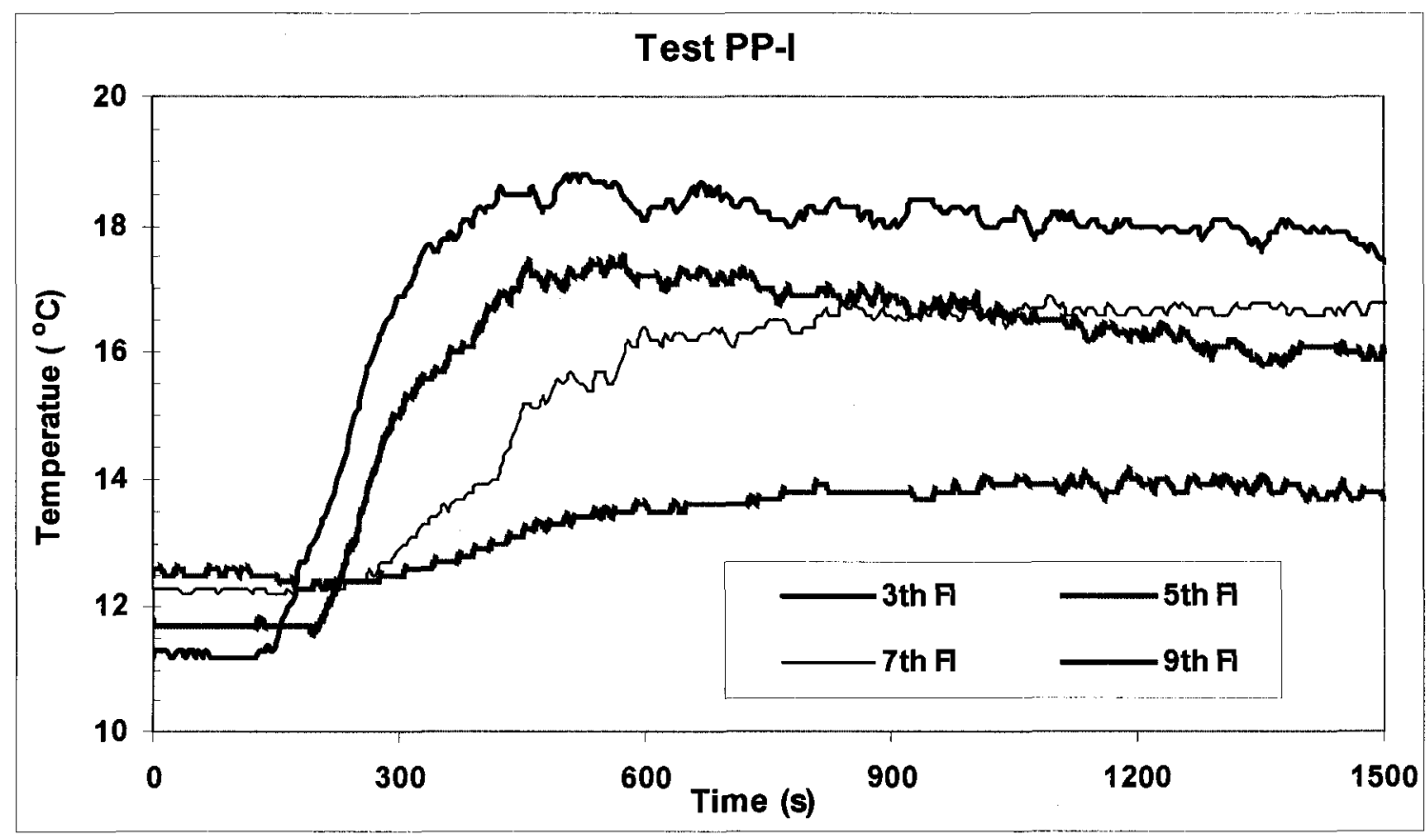

Figure 4-86: Gas temperature histories in the vestibules of the floors with closed doors (Test PP-I) 
On the even floors, the doors between the stair shaft and the vestibules were kept fully open, and the doors between the vestibules and the main compartments were partially open. Smoke from the stair shaft entered the main compartments through the vestibules. The gas temperature histories recorded by the thermocouples located in the main compartments of the $4^{\text {th }}, 8^{\text {th }}$ and $10^{\text {th }}$ floors are shown in Figure 4-87. The maximum values of the gas temperature and their corresponding times are listed in Table 4-34.

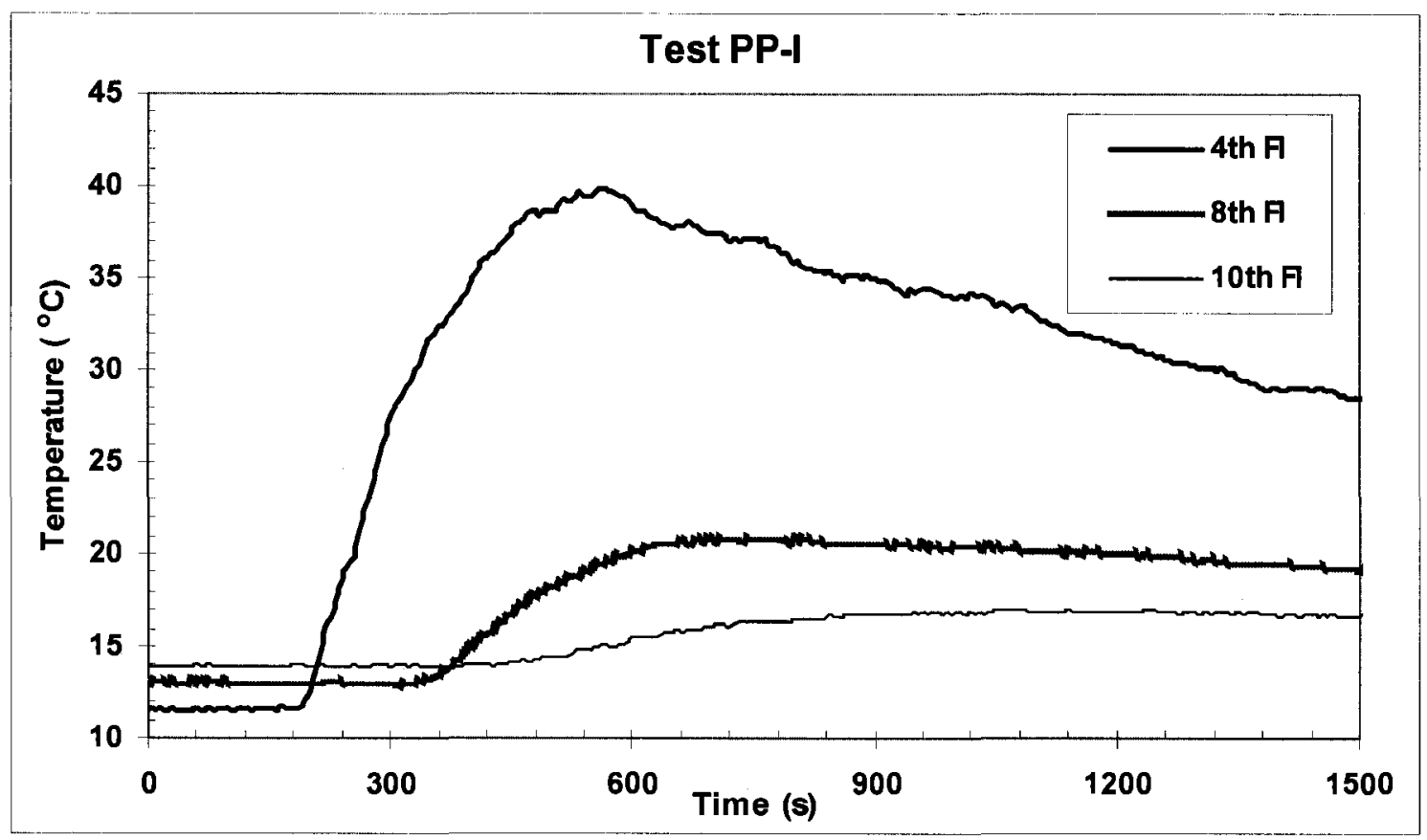

Figure 4-87: Gas temperature histories in the main compartments of the floors of the $4^{\text {th }}, 8^{\text {th }}$ and $10^{\text {th }}$ (Test PP-I)

Table 4-34: The maximum gas temperatures in the main compartments of the floors of the $4^{\text {th }}, 8^{\text {th }}$ and $10^{\text {th }}$ for Test PP-I

\begin{tabular}{|c|c|c|c|c|}
\hline Test ID & Floor \# & $4^{\text {th }}$ floor & $8^{\text {th }}$ floor & $10^{\text {th }}$ floor \\
\hline \multirow{4}{*}{ PP-I } & $\mathrm{T}_{i}\left({ }^{\circ} \mathrm{C}\right)$ & 11.5 & 13.0 & 13.9 \\
\cline { 2 - 5 } & $\mathrm{T}_{\mathrm{p}}\left({ }^{\circ} \mathrm{C}\right)$ & 39.9 & 10.8 & 17.0 \\
\cline { 2 - 5 } & $\Delta \mathrm{T}\left({ }^{\circ} \mathrm{C}\right)$ & 28.4 & 7.8 & 3.1 \\
\cline { 2 - 5 } & $\mathrm{t}_{\mathrm{p}}(\mathrm{s})$ & 565 & 680 & 1060 \\
\hline
\end{tabular}

Note: $T_{i}$ is the initial gas temperature; $T_{p}$ is the peak gas temperature; $\Delta T$ is the gas temperature difference between $T_{p}$ and $T_{i}$ and $t_{p}$ is the time when the gas reached the peak temperature 


\subsubsection{Propane test II (Test PP-II)}

Similar to Test PP-I, propane was used as fuel to conduct Test PP-II. The aim of this test was to produce a more intense fire than that of Test PP-I but with a long incipient phase.

The mass flow rate of propane consumed of Test PP-II was measured and the calculated HRR is shown in Figure 4-88. After ignition, the HRR reached $100 \mathrm{~kW}$ and stayed at that value until $265 \mathrm{~s}$; after which the HRR decreased to about $15 \mathrm{~kW}$ and stayed at that value until $485 \mathrm{~s}$. At $870 \mathrm{~s}$ after ignition, the HRR started to rise faster until it reached the peak value of $2815 \mathrm{~kW}$ at $1170 \mathrm{~s}$ after ignition. The fire remained relatively steady for 4 minutes burning at an average of $2700 \mathrm{~kW}$. Following that, the fire entered the decay phase and the HRR decreased sharply. The HRR profiles of tests PP-I and PP-II have significant differences not only in the peak HRR values but also in the shape of the curve.

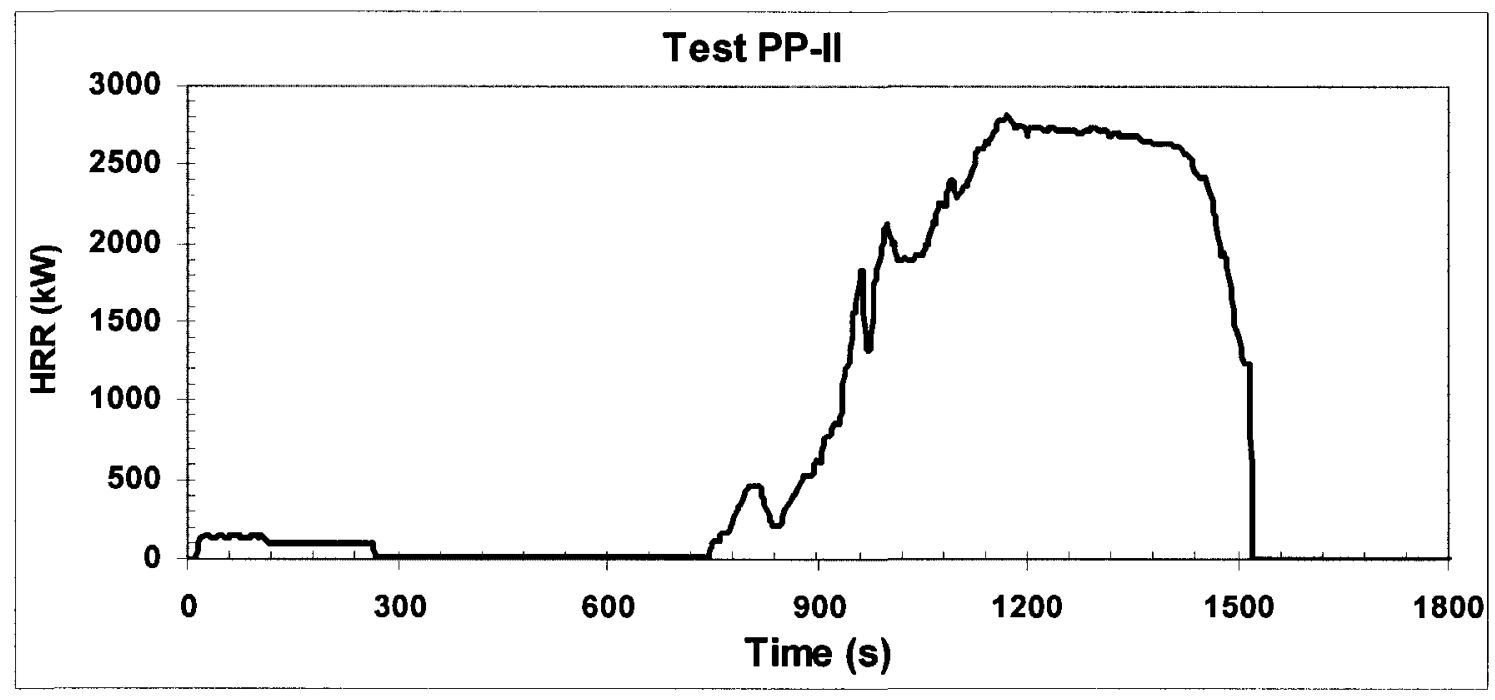

Figure 4-88: Heat release rate (Test PP-II)

Figure 4-89 shows the concentration of $\mathrm{O}_{2}$ and $\mathrm{CO}_{2}$ in the stair shaft at the fire floor. The figure indicates that the lowest concentration of $\mathrm{O}_{2}$ was $12.55 \%$ at $1175 \mathrm{~s}$, and the highest concentration of $\mathrm{CO}_{2}$ was $5.21 \%$ at $1175 \mathrm{~s}$. 


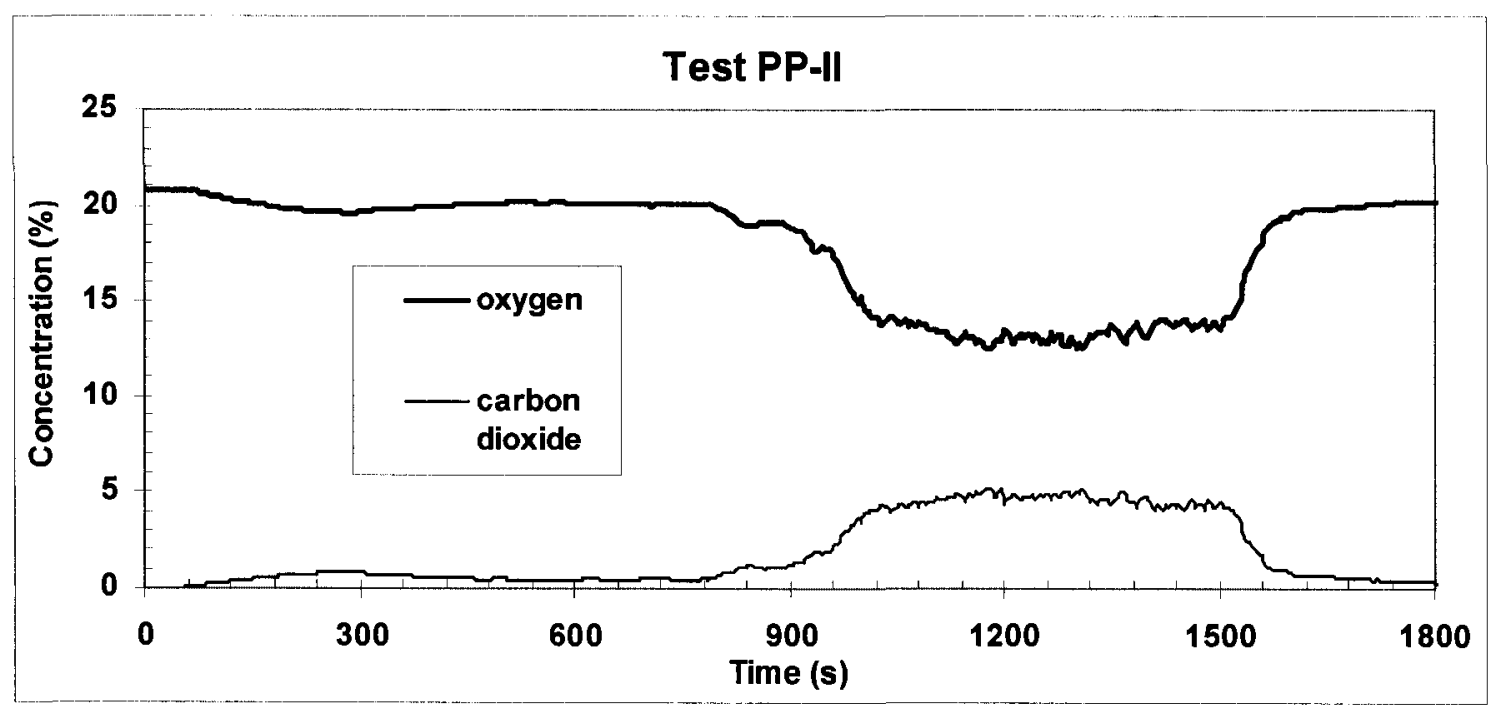

Figure 4-89: Concentration of $\mathrm{O}_{2}$ and $\mathrm{CO}_{2}$ in the stair shaft at the fire floor (Test PP-II)

The concentration of $\mathrm{CO}$ in the stair shaft at the fire floor is shown in Figure 4-90. The highest concentration of $\mathrm{CO}$ was $55 \mathrm{ppm}$ at $1665 \mathrm{~s}$.

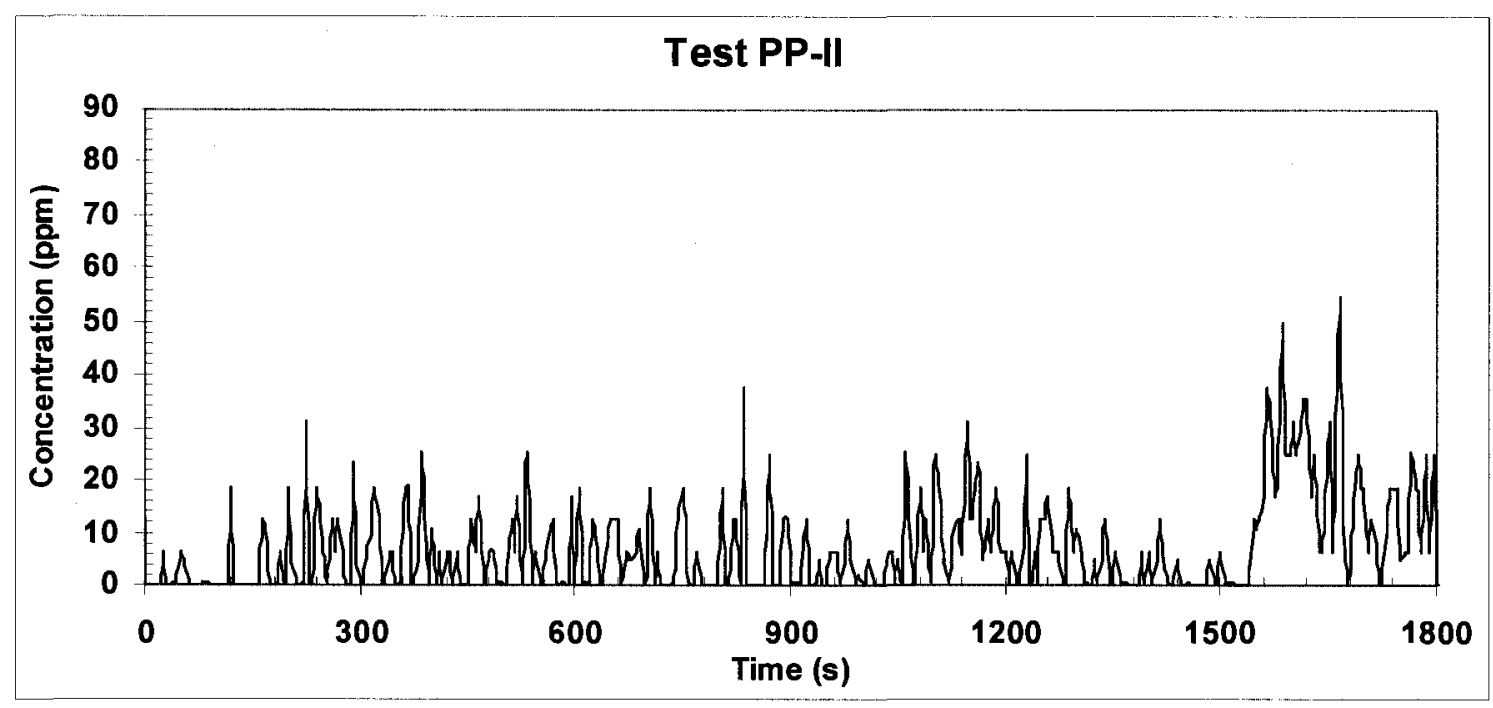

Figure 4-90: Concentration of $\mathrm{CO}$ in the stair shaft at the fire floor (Test PP-II)

The temperatures measured by the thermocouple tree located in the corner of the fire compartment are shown in Figure 4-91. The temperature history follows the same trend as the HRR remaining low during the first $750 \mathrm{~s}$ and the rising to its maximum value of 
$880^{\circ} \mathrm{C}$ at $1415 \mathrm{~s}$. After this time, the temperature in the fire compartment started to decrease steadily until the end of the test at $1800 \mathrm{~s}$. Using the upper layer average temperature of $600^{\circ} \mathrm{C}$ as the flashover criterion, the fire reached flashover condition at $1030 \mathrm{~s}$.

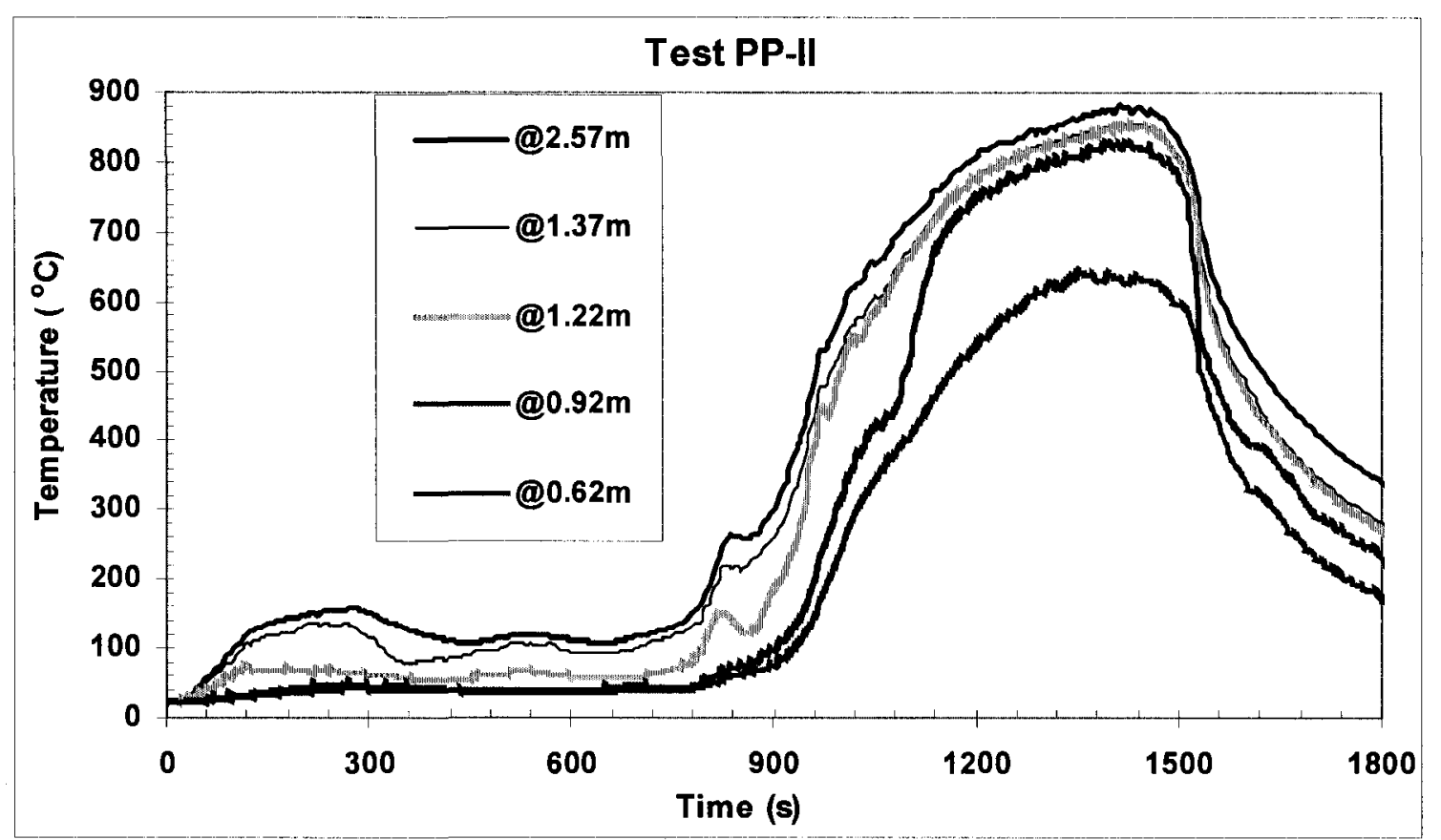

Figure 4-91: Gas temperature histories at different heights in the corner of the fire compartment (PP test-II)

Figure 4-92 shows the gas temperature profiles in the fire compartment at different times and the interface heights estimated using Eqn (4-1). At $750 \mathrm{~s}$, the interface height was $1.3 \mathrm{~m}$, however at the time of reaching the flashover condition it dropped to $1.15 \mathrm{~m}$ and continued to drop reaching $0.86 \mathrm{~m}$ at $1170 \mathrm{~s}$, and remaining at that level until $1415 \mathrm{~s}$. The interface height then increased to $1.2 \mathrm{~m}$ at $1600 \mathrm{~s}$. 


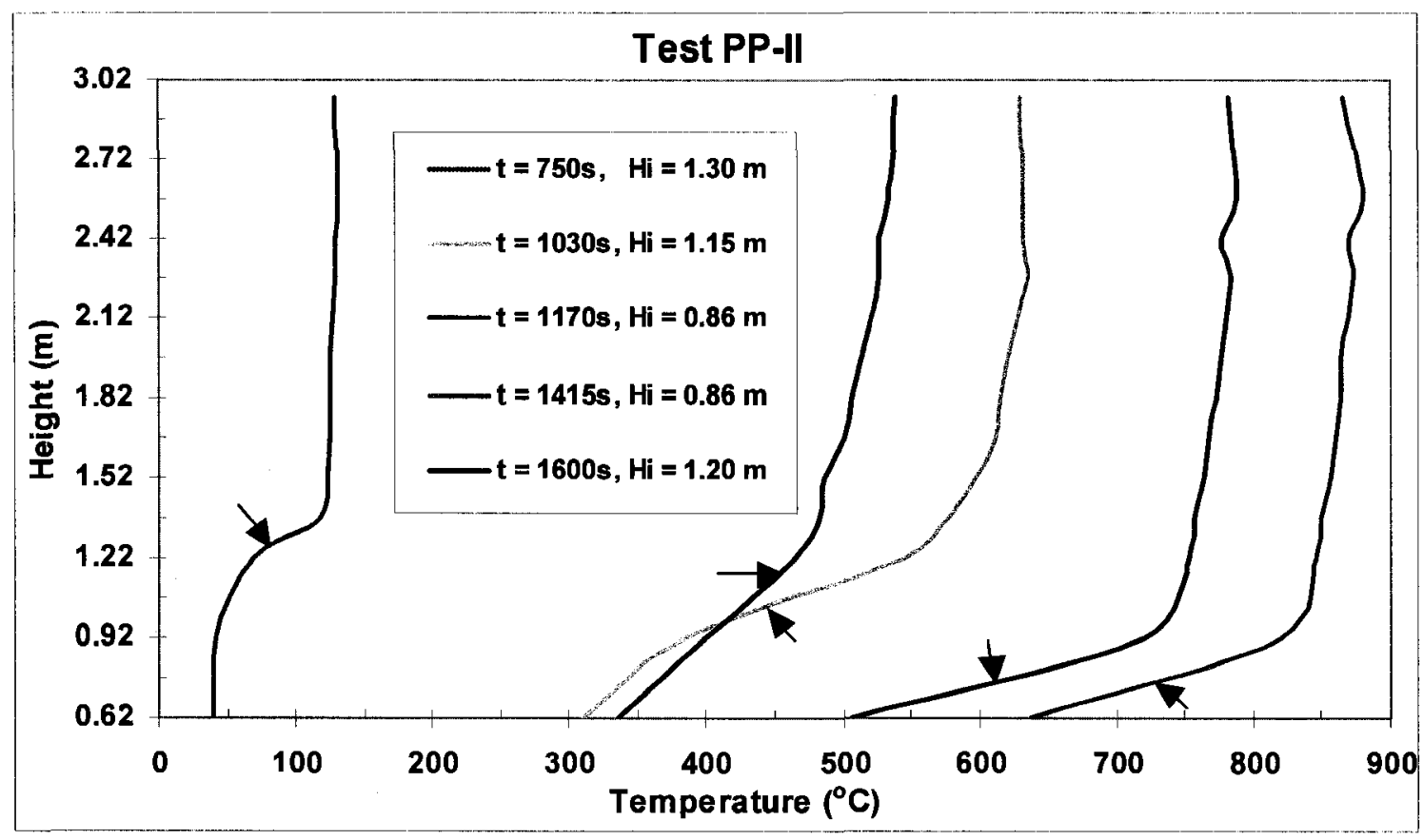

Note: Arrows indicate the locations of interface heights.

Figure 4-92: Gas temperature profiles in the fire compartment at different times (Test PP-II)

A short thermocouple (TC) tree with 5 TCs was installed at the doorway between the stair shaft and the vestibule of the $2^{\text {nd }}$ floor. The smoke moved into the stair shaft at the fire floor from the fire compartment via the vestibule. Figure 4-93 shows the temperature histories at different heights at the doorway recorded by the thermocouples of this TC tree. The thermocouple located at the height of $2.05 \mathrm{~m}$ was not functioning properly, so the value recorded by the TC at $1.65 \mathrm{~m}$ is used to present the peak temperature. A maximum temperature of $646^{\circ} \mathrm{C}$ at $1445 \mathrm{~s}$ was recorded by the thermocouple at $1.65 \mathrm{~m}$ compared to the value of $472^{\circ} \mathrm{C}$ at $415 \mathrm{~s}$ recorded at $1.65 \mathrm{~m}$ for Test PP-I. 


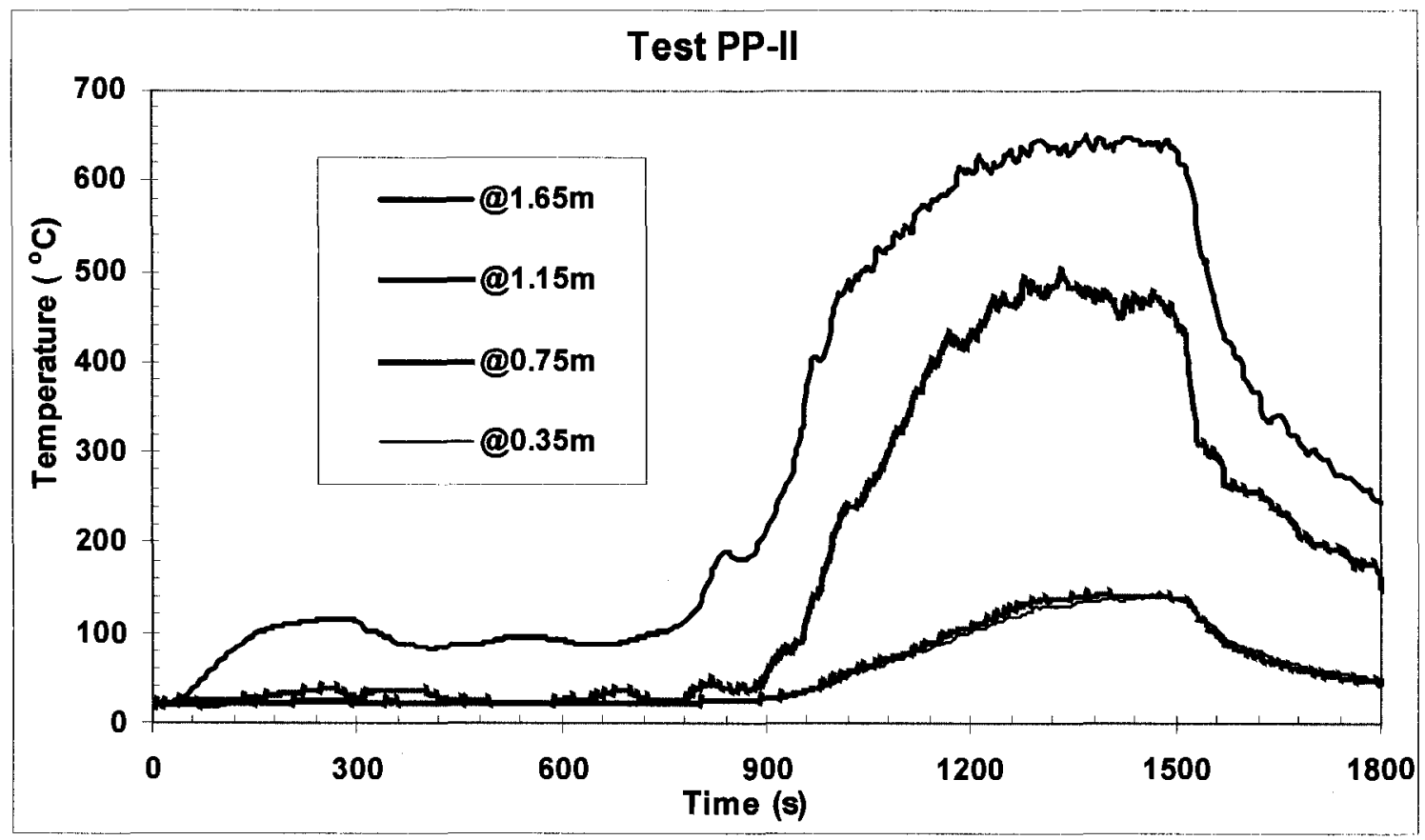

Figure 4-93: Gas temperature histories at different heights at the doorway (Test PP-II)

Figure 4-94 shows the gas temperature profiles at the doorway at different times: (a) before reaching the maximum temperature at $750 \mathrm{~s}$ and $1030 \mathrm{~s}$ (b) after reaching the maximum temperature at $1600 \mathrm{~s}$, (c) at the time of the maximum temperature at $1445 \mathrm{~s}$.

The gas temperature histories in the stair shaft for Test PP-II as recorded by the thermocouples installed in the stair shaft at each floor from the $2^{\text {nd }}$ to the $10^{\text {th }}$ are shown in Figure 4-95. The figure shows that the maximum gas temperature in the stair shaft of the fire floor was $307^{\circ} \mathrm{C}$ at $1480 \mathrm{~s}$. As stated before, the maximum gas temperature was $880^{\circ} \mathrm{C}$ at $1415 \mathrm{~s}$ in the compartment of fire, and $646^{\circ} \mathrm{C}$ at $1445 \mathrm{~s}$ at the doorway of the fire floor. For Test PP-I, the maximum gas temperature in the stair shaft of the fire floor was $224^{\circ} \mathrm{C}$ at $380 \mathrm{~s}$. 


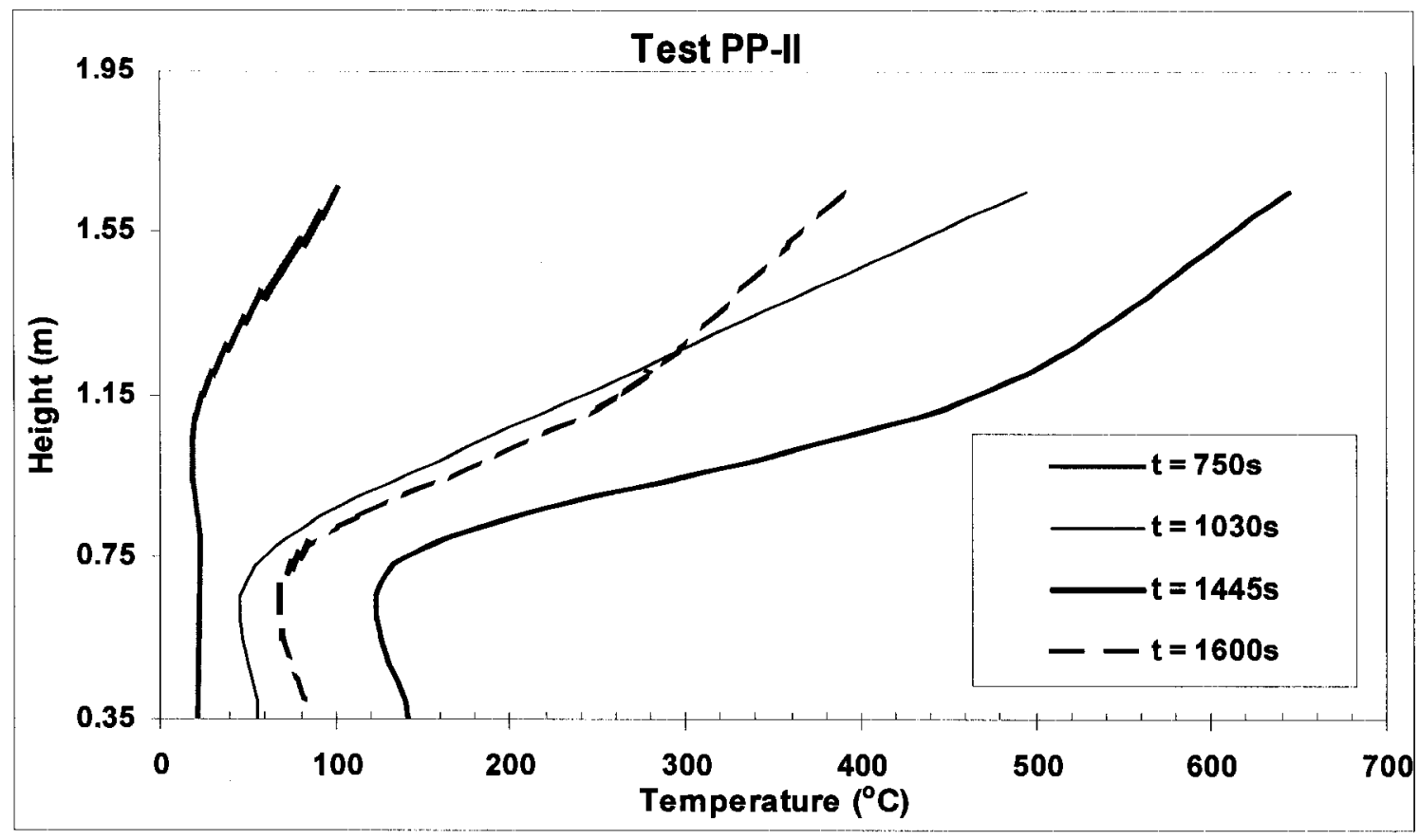

Figure 4-94: Gas temperature profiles at the doorway at different times (Test PP-II)

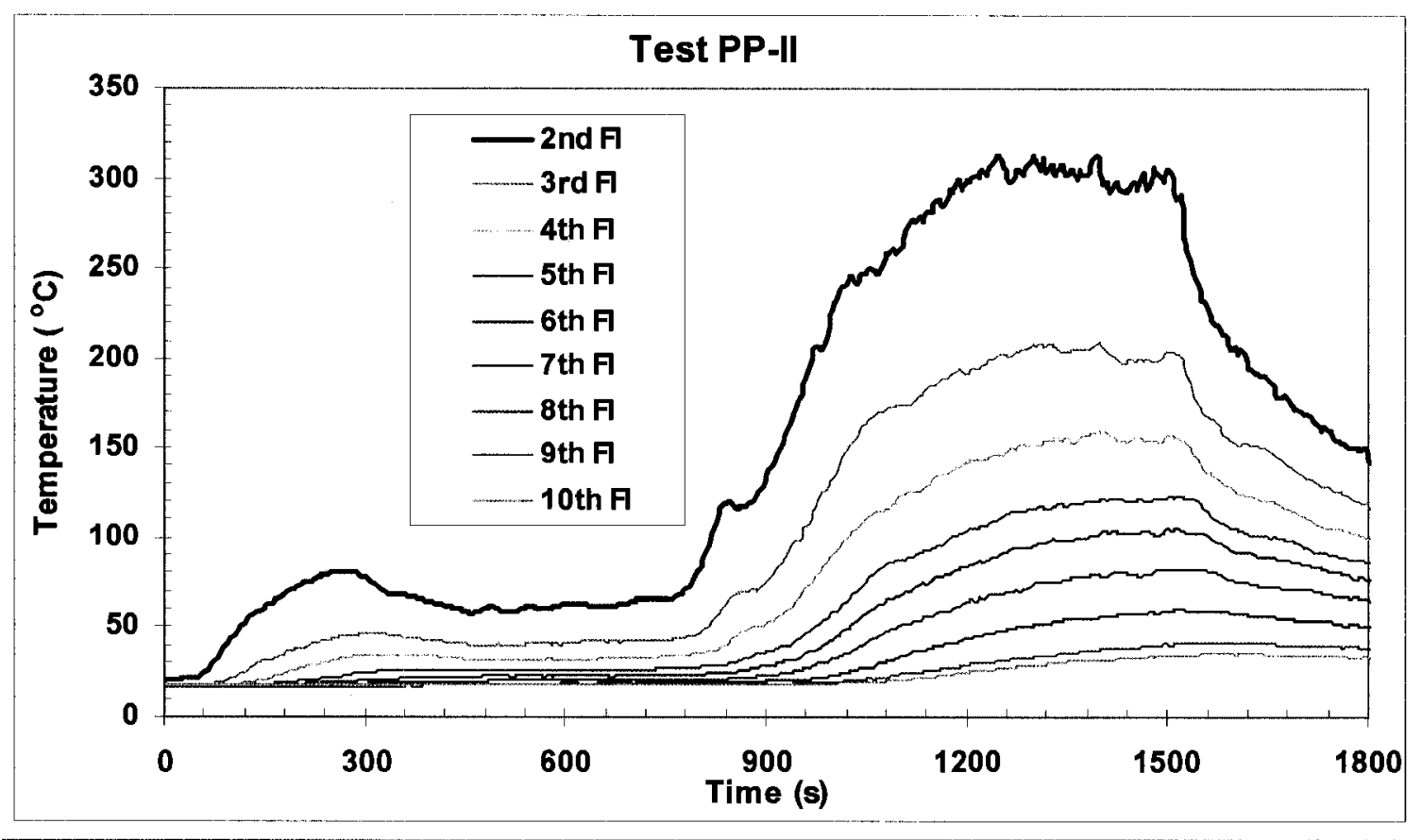

Figure 4-95: Gas temperature histories in the stair shaft (Test PP-II) 
Table 4-35 lists the maximum values of the gas temperatures and their corresponding times. The table indicates that the maximum gas temperatures in the stair shaft decreased with height, due to heat losses to the boundaries and mixing with the cold air.

Table 4-35: The maximum gas temperatures in the stair shaft of different floors for

Test PP-II

\begin{tabular}{|c|c|c|c|c|c|c|c|c|c|c|}
\hline $\begin{array}{c}\text { Test } \\
\text { ID }\end{array}$ & Floor \# & $\begin{array}{c}2^{\text {nd }} \\
\text { floor }\end{array}$ & $\begin{array}{c}3^{\text {rd }} \\
\text { floor }\end{array}$ & $\begin{array}{c}4^{\text {th }} \\
\text { floor }\end{array}$ & $\begin{array}{c}5^{\text {th }} \\
\text { floor }\end{array}$ & $\begin{array}{c}6^{\text {th }} \\
\text { floor }\end{array}$ & $\begin{array}{c}7^{\text {th }} \\
\text { floor }\end{array}$ & $\begin{array}{c}8^{\text {th }} \\
\text { floor }\end{array}$ & $\begin{array}{c}9^{\text {th }} \\
\text { floor }\end{array}$ & $\begin{array}{c}10^{\text {th }} \\
\text { floor }\end{array}$ \\
\hline \multirow{4}{*}{ PP-II } & $\mathrm{T}_{\mathrm{i}}\left({ }^{\circ} \mathrm{C}\right)$ & 18.3 & 17.4 & 17.4 & 17.7 & 17.8 & 17.5 & 17.0 & 17.0 & 18.0 \\
\cline { 2 - 11 } & $\mathrm{T}_{\mathrm{p}}\left({ }^{\circ} \mathrm{C}\right)$ & 307.0 & 204.6 & 156.0 & 122.0 & 104.0 & 82.3 & 59.0 & 41.1 & 35.0 \\
\cline { 2 - 10 } & $\Delta \mathrm{T}\left({ }^{\circ} \mathrm{C}\right)$ & 288.7 & 187.2 & 138.6 & 104.3 & 86.2 & 64.8 & 42.0 & 24.1 & 17.0 \\
\cline { 2 - 9 } & $\mathrm{t}_{\mathrm{p}}(\mathrm{s})$ & 1480 & 1505 & 1510 & 1520 & 1520 & 1540 & 1570 & 1590 & 1630 \\
\hline
\end{tabular}

Note: $T_{i}$ is the initial gas temperature; $T_{p}$ is the peak gas temperature; $\Delta T$ is the gas temperature difference between $T_{p}$ and $T_{i}$ and $t_{p}$ is the time when the gas reached the peak temperature

The doors between the stair shaft and the vestibules of the $3^{\text {rd }}, 5^{\text {th }}, 7^{\text {th }}$ and $9^{\text {th }}$ floors (odd floors) were fully closed, while the doors of the $4^{\text {th }}, 6^{\text {th }}, 8^{\text {th }}$ and $10^{\text {th }}$ floors (even floors) were fully open. At each vestibule, a TC was installed to measure the gas temperature history. Figure 4-96 shows the gas temperature histories recorded by the thermocouples in the vestibules of the floors with open doors. The maximum values of the gas temperature and their corresponding times in the vestibules of the floors with open doors are listed in Table 4-36.

Table 4-36: The maximum gas temperatures in the vestibules of the floors with open doors for Test PP-II

\begin{tabular}{|c|c|c|c|c|c|}
\hline Test ID & Floor \# & $4^{\text {th }}$ floor & $6^{\text {th }}$ floor & $8^{\text {th }}$ floor & $10^{\text {th }}$ floor \\
\hline \multirow{4}{*}{ PP-II } & $\mathrm{T}_{\mathbf{i}}\left({ }^{\circ} \mathrm{C}\right)$ & 18.0 & 19.8 & 17.7 & 18.8 \\
\cline { 2 - 6 } & $\mathrm{T}_{\mathrm{p}}\left({ }^{\circ} \mathrm{C}\right)$ & 132.4 & 88.4 & 53.4 & 31.9 \\
\cline { 2 - 7 } & $\Delta \mathrm{T}\left({ }^{\circ} \mathrm{C}\right)$ & 114.4 & 68.6 & 35.7 & 13.1 \\
\cline { 2 - 7 } & $\mathrm{t}_{\mathrm{p}}(\mathrm{s})$ & 1410 & 1540 & 1590 & 1640 \\
\hline
\end{tabular}

Note: $T_{i}$ was the initial gas temperature; $T_{p}$ was the peak gas temperature; $\Delta T$ was the gas temperature difference between $T_{p}$ and $T_{i}$ and $t_{p}$ was the time when the gas reached the peak temperature 


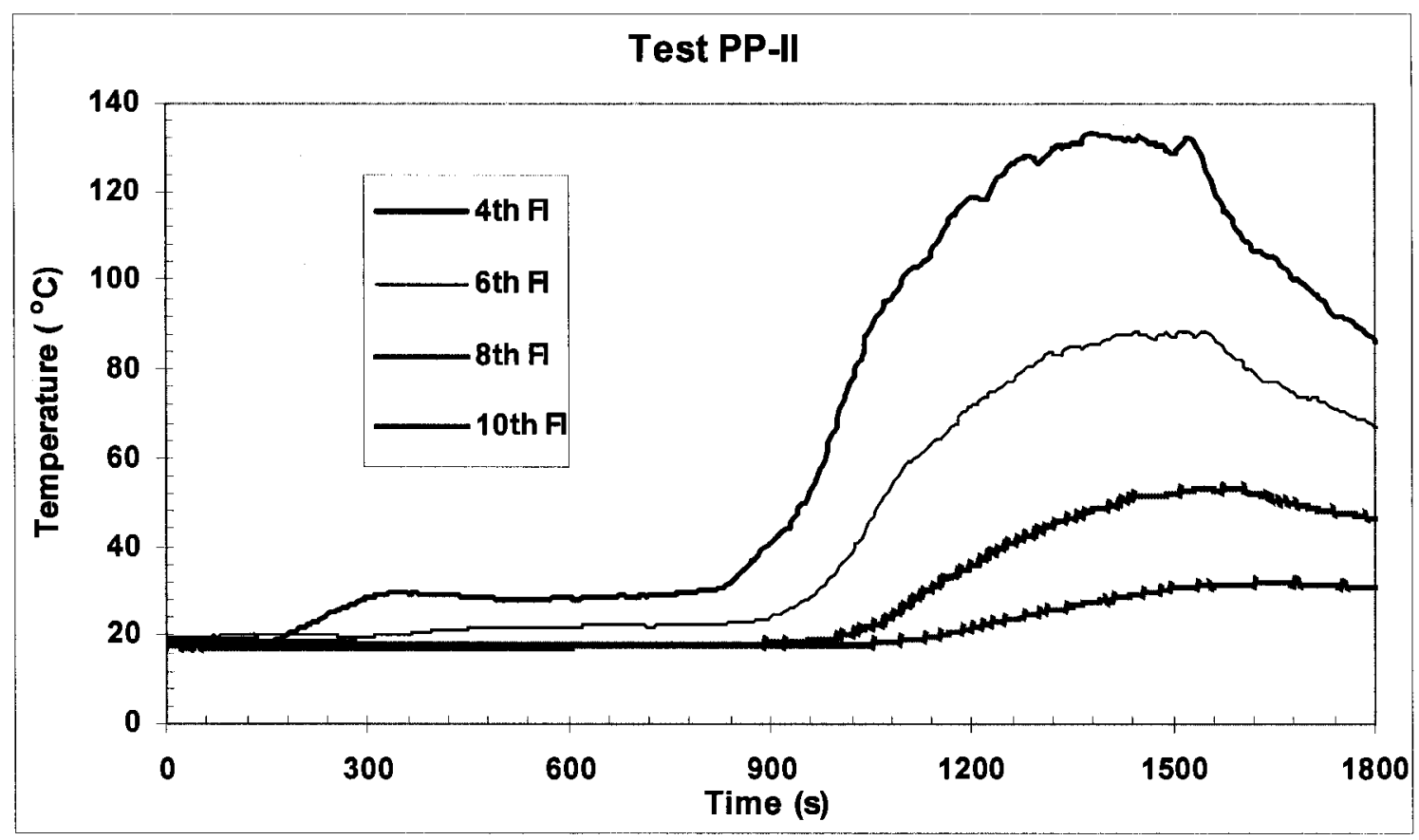

Figure 4-96: Gas temperature histories in the vestibules of the floors with open doors (Test PP-II)

Figure 4-97 shows the gas temperature histories in the vestibules of the floors with closed doors. The figure indicates that the gas temperatures in the vestibules of the floors with closed doors increased by few degrees demonstrating that the doors were not completely sealed.

On the even floors, $4^{\text {th }}, 8^{\text {th }}$, and $10^{\text {th }}$ (PP-II) the doors between the stair shaft and the vestibules were kept fully open, whereas the doors between the vestibules and the main compartments were partially open. Smoke from the stair shaft entered the main compartments through the vestibules. The gas temperature histories recorded by the thermocouples located in the main compartments of the $4^{\text {th }}, 8^{\text {th }}$ and $10^{\text {th }}$ floors are shown in Figure 4-98. The maximum values of the gas temperature and their corresponding times are listed in Table 4-37. 


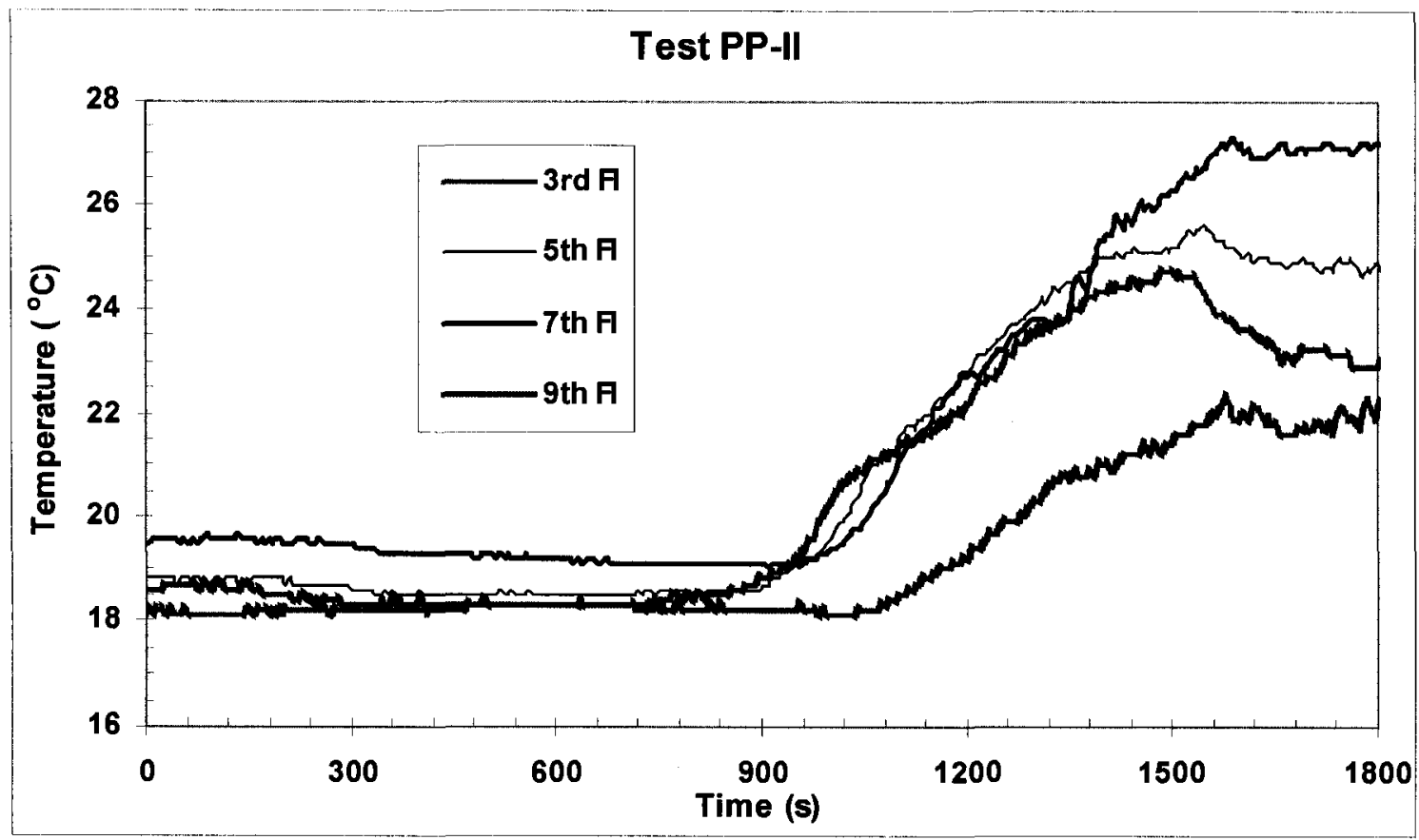

Figure 4-97: Gas temperature histories in the vestibules of the floors with closed doors (Test PP-II)

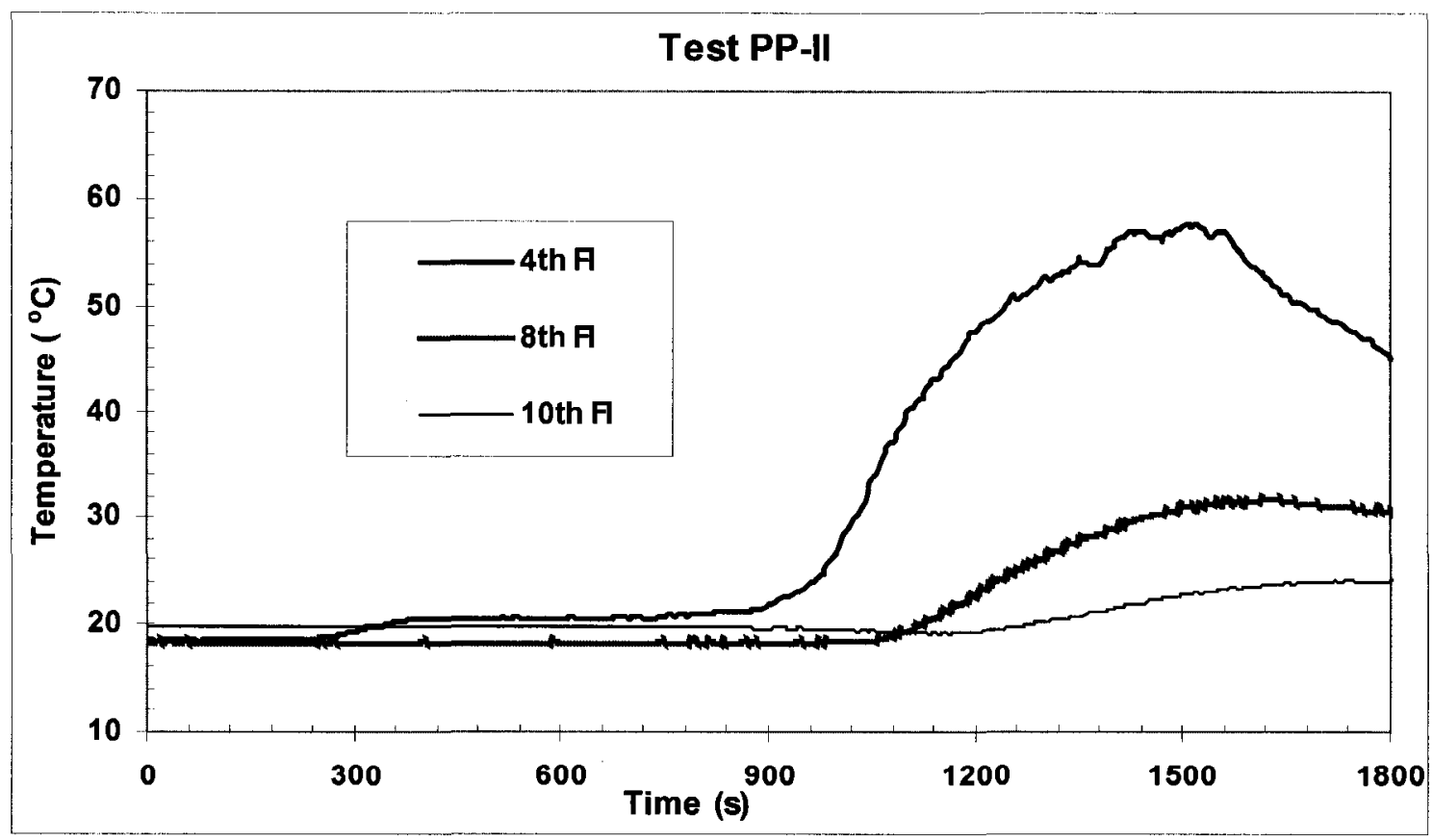

Figure 4-98: Gas temperature histories in the main compartments of the floors of the $4^{\text {th }}, 8^{\text {th }}$ and $10^{\text {th }}$ (Test PP-II) 
Table 4-37: The maximum gas temperatures in the main compartments of the floors of the $4^{\text {th }}, 8^{\text {th }}$ and $10^{\text {th }}$ for Test PP-II

\begin{tabular}{|c|c|c|c|c|}
\hline Test ID & Floor \# & $4^{\text {th }}$ floor & $8^{\text {th }}$ floor & $10^{\text {th }}$ floor \\
\hline \multirow{4}{*}{ PP-II } & $\mathrm{T}_{\mathrm{i}}\left({ }^{\circ} \mathrm{C}\right)$ & 18.5 & 18.2 & 19.7 \\
\cline { 2 - 5 } & $\mathrm{T}_{\mathrm{p}}\left({ }^{\circ} \mathrm{C}\right)$ & 57.7 & 31.6 & 24.2 \\
\cline { 2 - 5 } & $\Delta \mathrm{T}\left({ }^{\circ} \mathrm{C}\right)$ & 39.2 & 13.4 & 4.5 \\
\cline { 2 - 5 } & $\mathrm{t}_{\mathrm{p}}(\mathrm{s})$ & 1510 & 1625 & 1735 \\
\hline
\end{tabular}

Note: $T_{i}$ was the initial gas temperature; $T_{p}$ was the peak gas temperature; $\Delta T$ was the gas temperature difference between $T_{p}$ and $T_{i}$ and $t_{p}$ was the time when the gas reached the peak temperature

\subsubsection{Summary of Group 3 Tests}

Two propane tests, PP-I and PP-II, with different HRR profiles were conducted in this group. Test PP-II had a higher peak heat released rate than Test PP-I. The peak values of the gas temperatures in the fire compartment, doorway, stair shaft, vestibules, and main compartments at floors with open doors for Test PP-II were higher than those recorded in the Test PP-I.

Table 4-38 gives a summary of the maximum temperatures and the lowest interface heights in the fire compartment for the tests of Group 3.

Table 4-39 summarizes the concentration of $\mathrm{O}_{2}, \mathrm{CO}_{2}$ and $\mathrm{CO}$ in the stair shaft at the fire floor for this group, and Table 4-40 gives a summary of gas temperature distributions at various locations in the smoke tower for Test PP-I and PP-II.

Table 4-38: A summary of the maximum temperatures and the lowest interface heights in the fire compartment for Group 3 tests

\begin{tabular}{|c|c|c|}
\hline Test ID & PP-I & PP-II \\
\hline Peak Temp. $\left({ }^{\circ} \mathrm{C}\right)$ & 648 & 880 \\
\hline Time of Peak (s) & 415 & 1415 \\
\hline Time of Flashover (s) & 350 & 1030 \\
\hline The Lowest Interface Height & $1.03 \mathrm{~m} \mathrm{@} 415 \mathrm{~s}$ & $0.86 \mathrm{~m} \mathrm{@} 1415 \mathrm{~s}$ \\
\hline
\end{tabular}


Table 4-39: The concentration of $\mathrm{O}_{2}$ and $\mathrm{CO}_{2}$ in the stair shaft at the fire floor for Group 3 tests

\begin{tabular}{|c|c|c|}
\hline Test ID & PP-I & PP-II \\
\hline Lowest concentration of $\mathrm{O}_{2}(\%)$ & $12.82 @ 270 \mathrm{~s}$ & $12.55 @ 1175 \mathrm{~s}$ \\
\hline Highest concentration of $\mathrm{CO}_{2}(\%)$ & $4.56 @ 270 \mathrm{~s}$ & $5.21 @ 1175 \mathrm{~s}$ \\
\hline
\end{tabular}

Table 4-40: Upper layer gas temperature difference between peak value and initial value at various locations for the tests of Group 3

\begin{tabular}{|c|c|c|c|c|c|c|}
\hline \multirow{2}{*}{ Floor \# } & \multicolumn{2}{|c|}{ Stair shaft $\left({ }^{\circ} \mathrm{C}\right)$} & \multicolumn{2}{c|}{ Vestibule $\left({ }^{\circ} \mathrm{C}\right)$} & \multicolumn{2}{c|}{$\begin{array}{c}\text { Main compartment } \\
\text { (fire compartment } \\
\text { at }{ }^{\text {nd }} \text { floor) }\left({ }^{\circ} \mathrm{C}\right)\end{array}$} \\
\cline { 2 - 7 } & PP-I & PP-II & PP-I & PP-II & PP-I & PP-II \\
\hline $10^{\text {th }}$ & 9.3 & 17.0 & 6.9 & 13.1 & 3.1 & 4.5 \\
\hline $9^{\text {th }}$ & 13.7 & 24.1 & - & - & - & - \\
\hline $8^{\text {th }}$ & 24.8 & 42.0 & 22.0 & 35.7 & 7.8 & 13.4 \\
\hline $7^{\text {th }}$ & 37.7 & 64.8 & - & - & - & - \\
\hline $6^{\text {th }}$ & 52.9 & 86.2 & 44.3 & 68.6 & - & - \\
\hline $5^{\text {th }}$ & 66.8 & 104.3 & - & - & - & - \\
\hline $4^{\text {th }}$ & 94.2 & 138.6 & 79.8 & 114.4 & 28.4 & 39.2 \\
\hline $3^{\text {rd }}$ & 141.9 & 187.2 & - & - & - & - \\
\hline $2^{\text {nd }}$ (fire floor) & 210.2 & 288.7 & 478.2 & 648.1 & 647.8 & 880.5 \\
\hline
\end{tabular}

\subsection{Summary of Experimental Tests}

In all experiments, the fire was started in the main compartment of the $2^{\text {nd }}$ floor. Based on the set-up of the 10-storey smoke tower facility, fresh air entered from outside in the stair shaft and from there into the fire compartment. The hot smoke from the fire compartment passed through the vestibule on the $2^{\text {nd }}$ floor and entered into the stair shaft, where it rose to the upper floors due to buoyancy.

The temperature rise in the stair shaft is related to the heat release rate of the fire. The higher the heat release rate the larger the increase of the temperature. In all tests the 
temperature in the stair shaft and the compartments on different floors decreased with height.

Among the four package tests, package CLC-I and CLC-II had similar fire growth rates, because they contained similar fuel components. The fire growth rates of package CLC-I and CLC-II are faster than which of package CMP and package BK, The CMP package produced a medium fire growth rate, whereas the HRR growth of the BK package was the slowest one. Tests CLC-I, CLC-II, CMP and BK reached the flashover condition as the temperature in the fire compartment for these tests reached values higher than $600^{\circ} \mathrm{C}$, the value used as flashover criterion.

Package CLC-I had the smallest fire load of $661 \mathrm{MJ}$ and peak temperature of $684^{\circ} \mathrm{C}$, whereas package CLC-II (1322 $\mathrm{MJ}$ and $\left.827^{\circ} \mathrm{C}\right)$ and package CMP $\left(1624 \mathrm{MJ}\right.$ and $\left.861^{\circ} \mathrm{C}\right)$ had similar fire loads and closed peak temperature. Package BK had the largest fire load of $10,610 \mathrm{MJ}$ and the highest peak temperature of $952^{\circ} \mathrm{C}$.

The heat released was also affected by the ventilation conditions in the fire compartment. Due to insufficient oxygen in the fire compartment, not all of the fuel was burned completely in the fire compartment for Test CLC-I, CLC-II and BK. Some unburned hydrocarbons moved into the stair shaft at the $2^{\text {nd }}$ floor carried by smoke, and burned on meeting sufficient fresh air, resulting in higher temperatures in the stair shaft and the doorway area of the $2^{\text {nd }}$ floor. Reproduction tests CLC-I-R, CLC-II-R and BK-R did not reproduce this phenomenon; therefore the HRR obtained from Test CLC-I-R, CLC-II-R and BK-R excludes the HRR part released in the stair shaft and the doorway area. 
Package fires CLC-I, CLC-II and BK were more severe than propane fires CLC-I-R, CLC-II-R and BK-R.

The concentration of $\mathrm{CO}$ in the stair shaft at the $2^{\text {nd }}$ floor of the well-ventilated fire was quite different from those of the poorly ventilated fires. Package fires CLC-I, CLC-II and BK experienced poor ventilation conditions around the time of reaching the flashover condition. The durations of undergoing poor ventilation conditions for CLC-II and BK package fires were longer than CLC-I fire. The concentration of CO was higher than $2 \%$ for both CLC-II (2.5\%) and BK (2.8\%) tests. The highest concentration of $\mathrm{CO}_{2}$ was $10.62 \%$ for Test CLC-I, $14.74 \%$ for Test CLC-II and $16.55 \%$ for Test BK. Propane reproduction fires produced almost complete combustion and had less radiative heat loss than their corresponding fuel package fires. 


\section{Modelling}

\subsection{Introduction}

The smoke movement model CUsmoke [3] was used to model fire experiments conducted in three different buildings for which experimental data are available: tests in a single compartment building, tests in a two-compartment building and tests in a multistorey building.

CUsmoke, described in Chapter 2, is a two-zone model developed at Carleton University to model fire growth and smoke movement in multi-storey buildings with stair or elevator shaft, corridors, and variable size compartments. It should be noted that the vents could be vertical or horizontal; as well as, natural or mechanical.

The objective of the study was to test and compare the predictions of CUsmoke against the experimental data for single compartment, two compartments and multi-storey buildings. The rationale behind the testing was to validate the model and see how well it predicts the fire growth and smoke movement in these buildings. To accomplish this, the model was run using the heat release rate (HRR) from the experimental work.

Among the four propane fires in Group 2, the peak HRR of $2565 \mathrm{~kW}$ in Test CLC-I-R was the smallest, whereas the peak HRRs of Test CLC-II-R (3372 kW), CMP-R (3200 $\mathrm{kW})$ and BK-R (3067 kW) were similar. In Group 3, propane Test PP-II with peak HRR 
of $2815 \mathrm{~kW}$ but a long incipient phase was more intense than Test PP-I with peak HRR of $1575 \mathrm{~kW}$. So, the analysis and comparison of modelling and experimental results using tests CLC-I-R, CMP-R, and PP-II, are presented in this chapter. In addition, two more examples using a single-compartment and two-compartment fires were simulated and compared with experimental data to provide additional validation of CUsmoke.

\subsection{Modelling the 10-Storey Smoke Tower}

\subsubsection{Structure of 10-Storey Smoke Tower System: Floor plan, and vertical-vent dimensions and locations}

Figure 5-1 to Figure 5-10 show the modelling plans of the 10-storey smoke tower. The numbers in circle, shown on these figures, represent the compartments, stair shaft, vestibules, and corridors considered in the model. The detailed dimensions of the corridors, stair shaft, and various size compartments are shown in Figure 3-1. The heights of the first and second floor in the smoke tower were $3.3 \mathrm{~m}$; whereas the heights for other floors were $2.4 \mathrm{~m}$. The details such as dimensions, locations, open / closed status of 51 vertical ventilations in 10-storey smoke tower system, which marked as numbers in square at modelling plans, are listed in Table 5-1. 


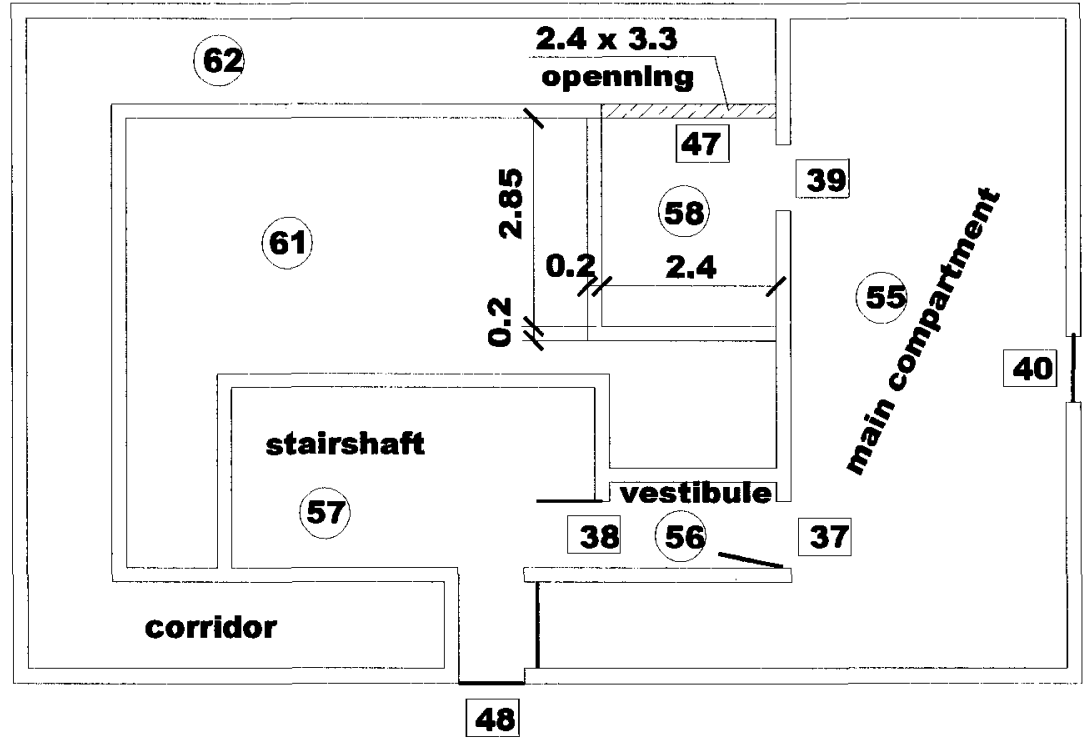

R stands for compartment id. $\mathrm{V}$ stands for vertical-vent id.

Figure 5-1: Plan of the $1^{\text {st }}$ floor used in the model

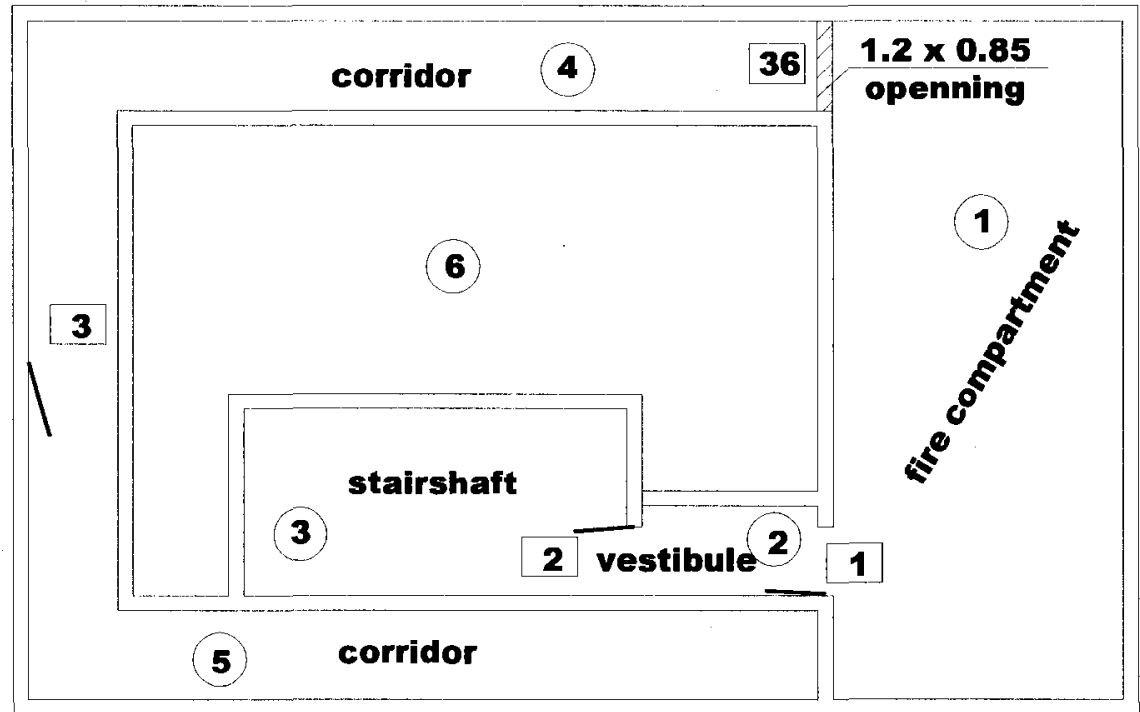

Figure 5-2: Plan of the $2^{\text {nd }}$ floor used in the model 


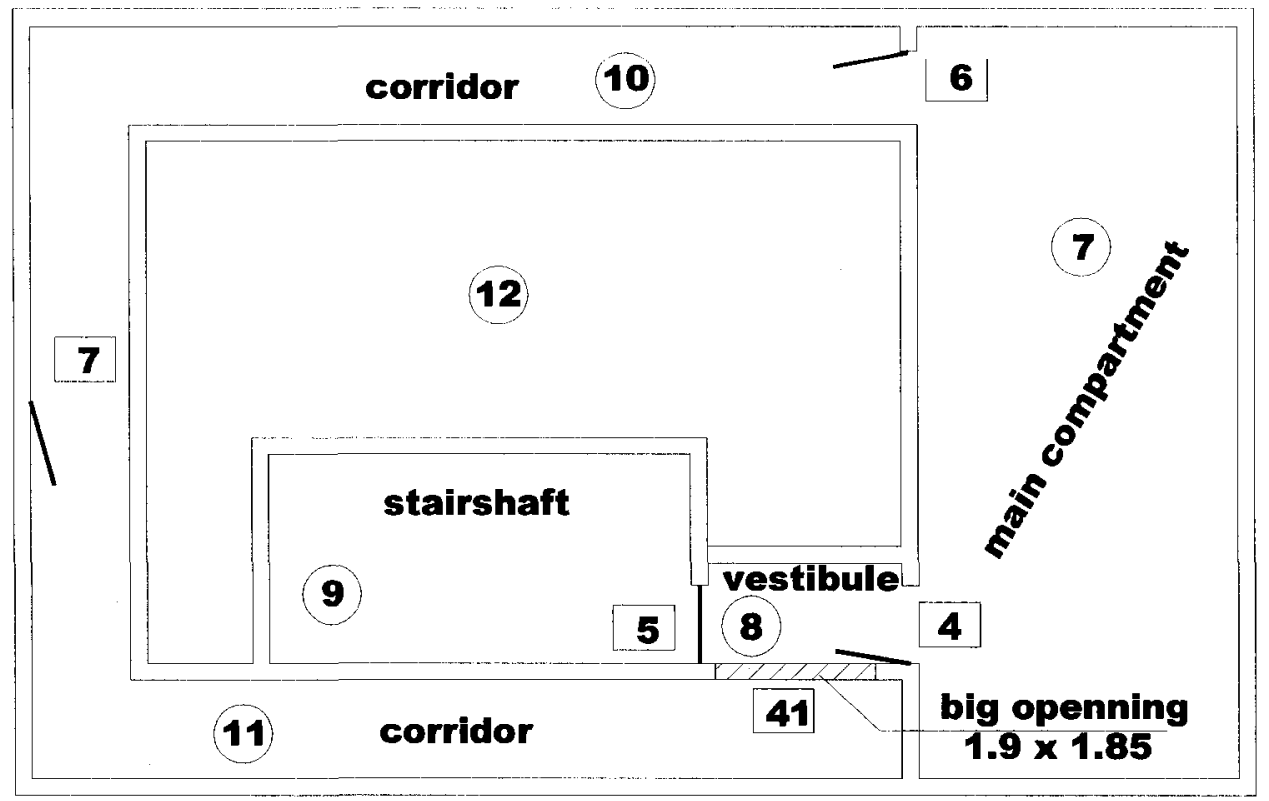

Figure 5-3: Plan of the $3^{\text {rd }}$ floor used in the model

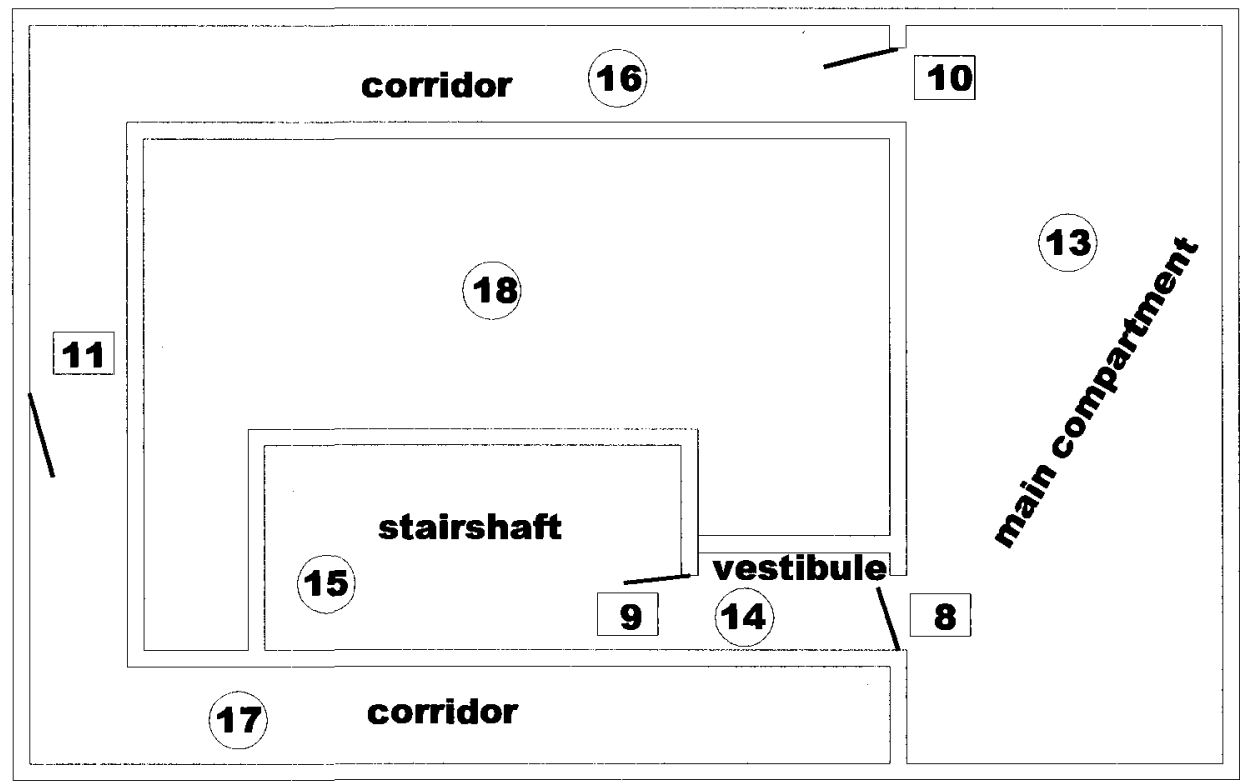

Figure 5-4: Plan of the $4^{\text {th }}$ floor used in the model 


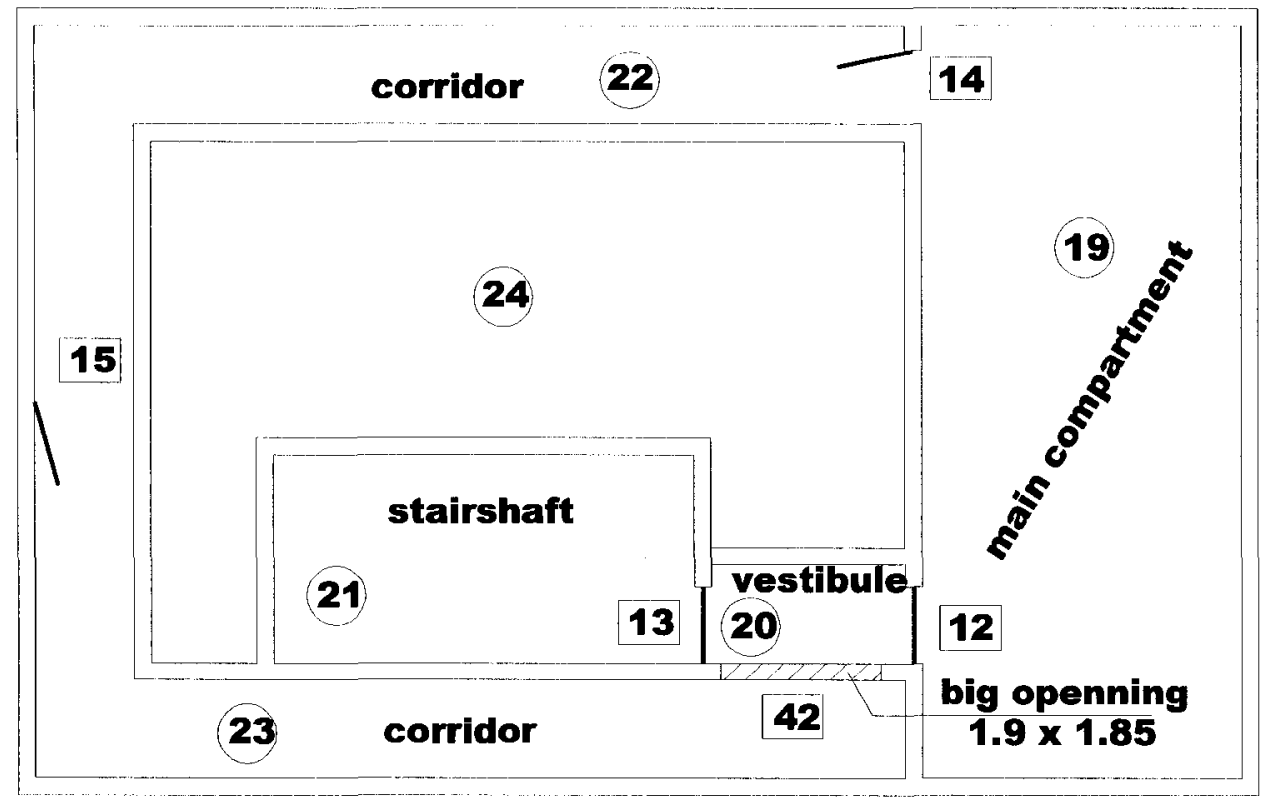

Figure 5-5: Plan of the $5^{\text {th }}$ floor used in the model

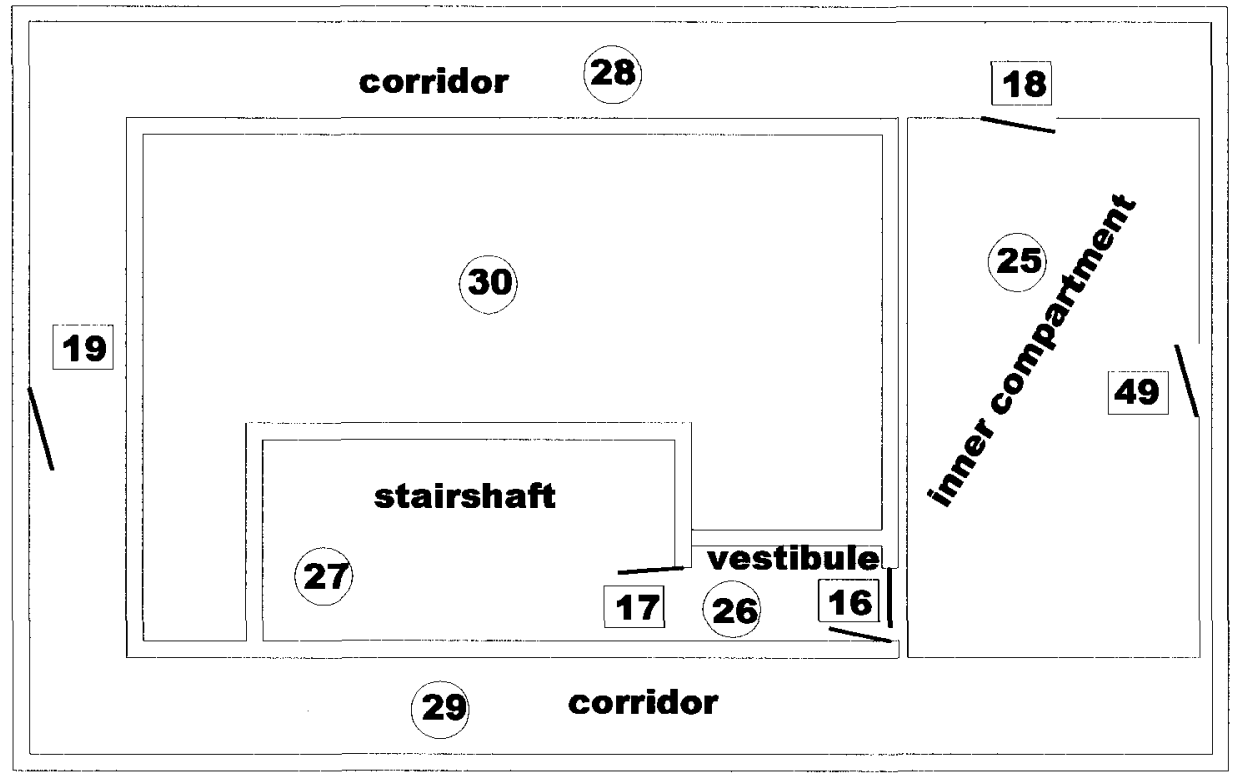

Figure 5-6: Plan of the $6^{\text {th }}$ floor used in the model 


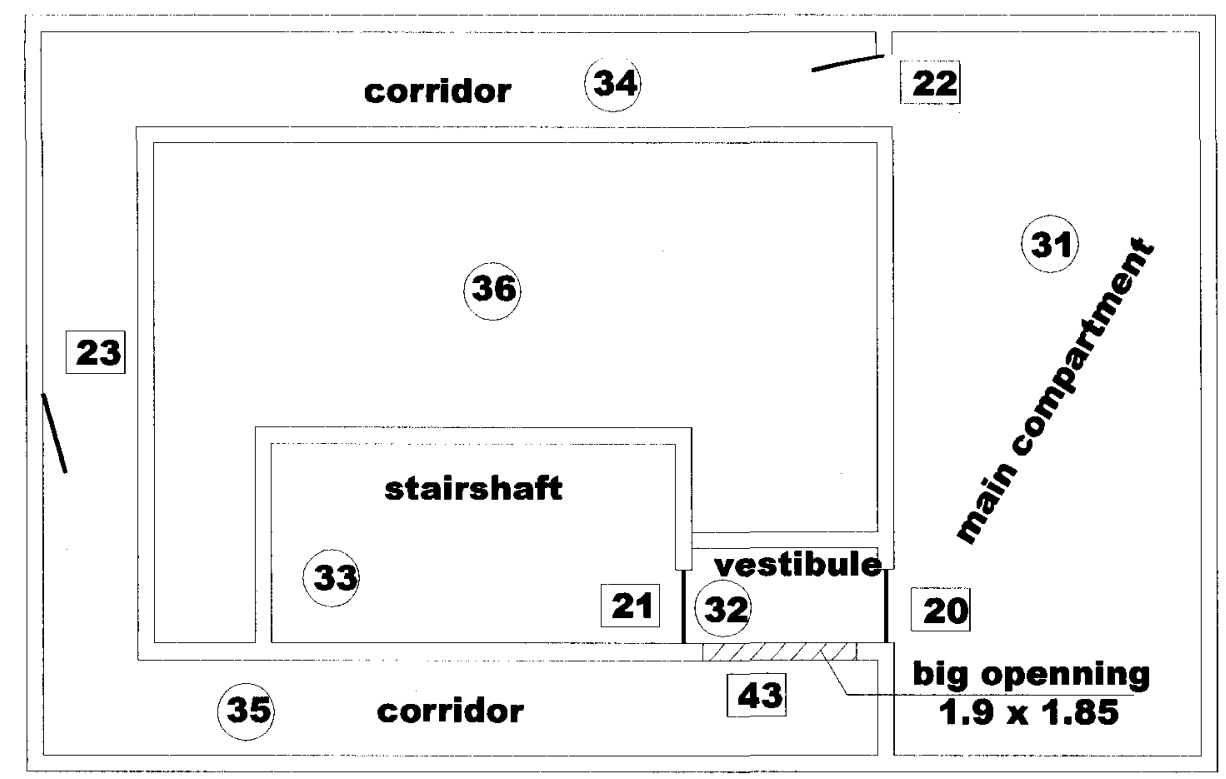

Figure 5-7: Plan of the $7^{\text {th }}$ floor used in the model

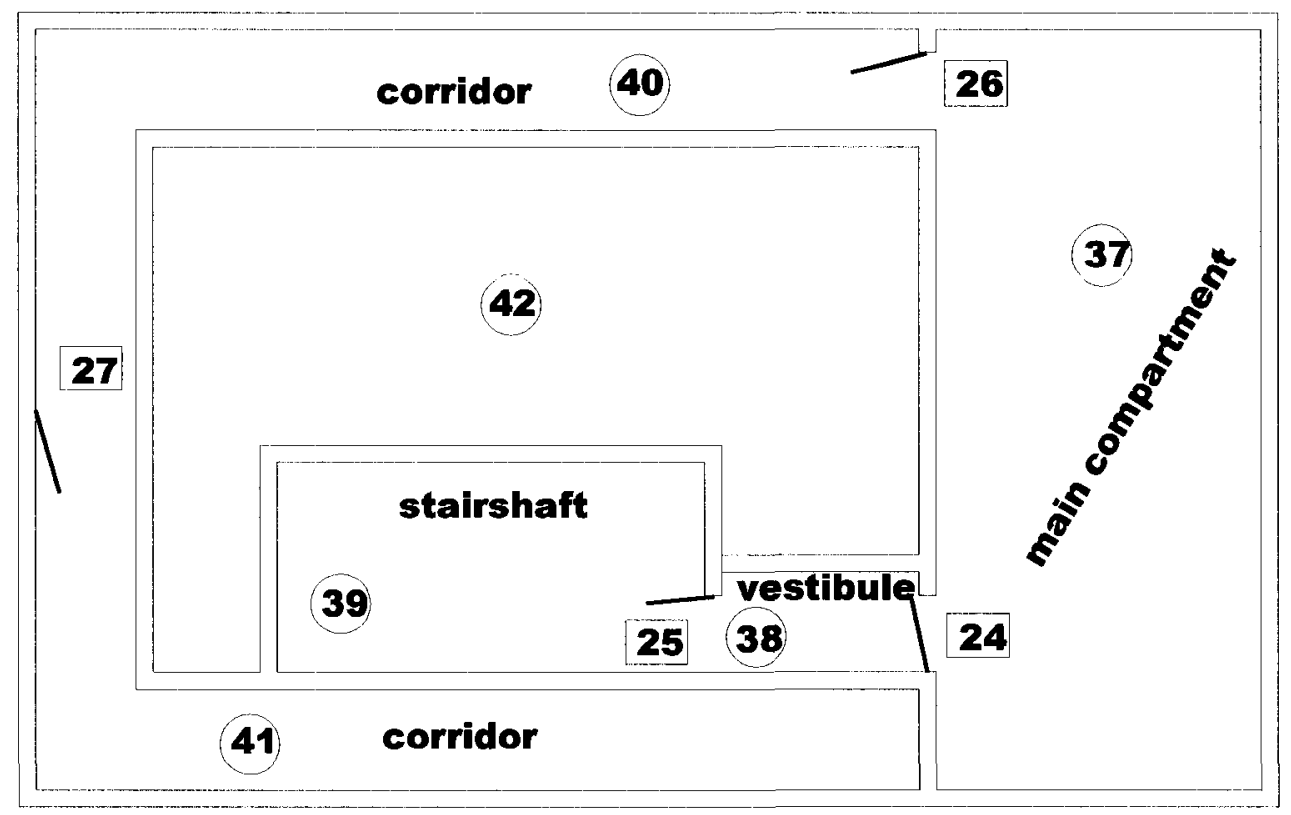

Figure 5-8: Plan of the $8^{\text {th }}$ floor used in the model 


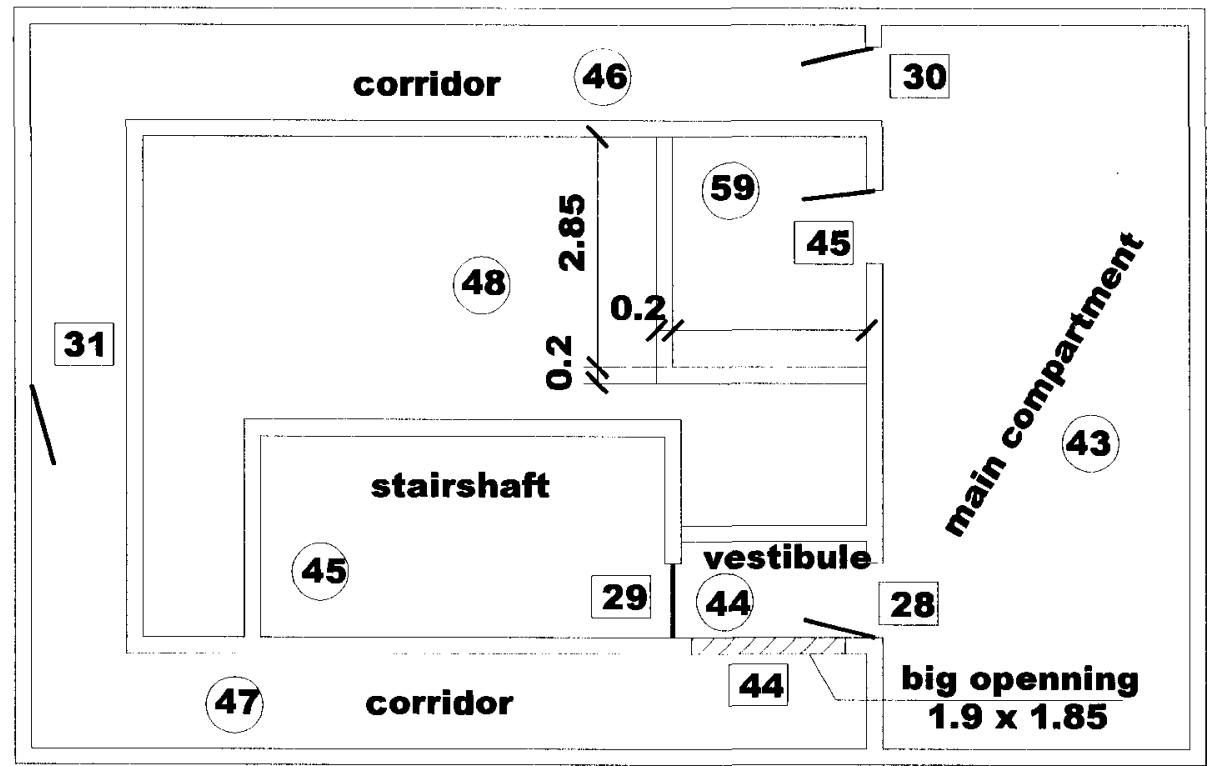

Figure 5-9: Plan of the $9^{\text {th }}$ floor used in the model

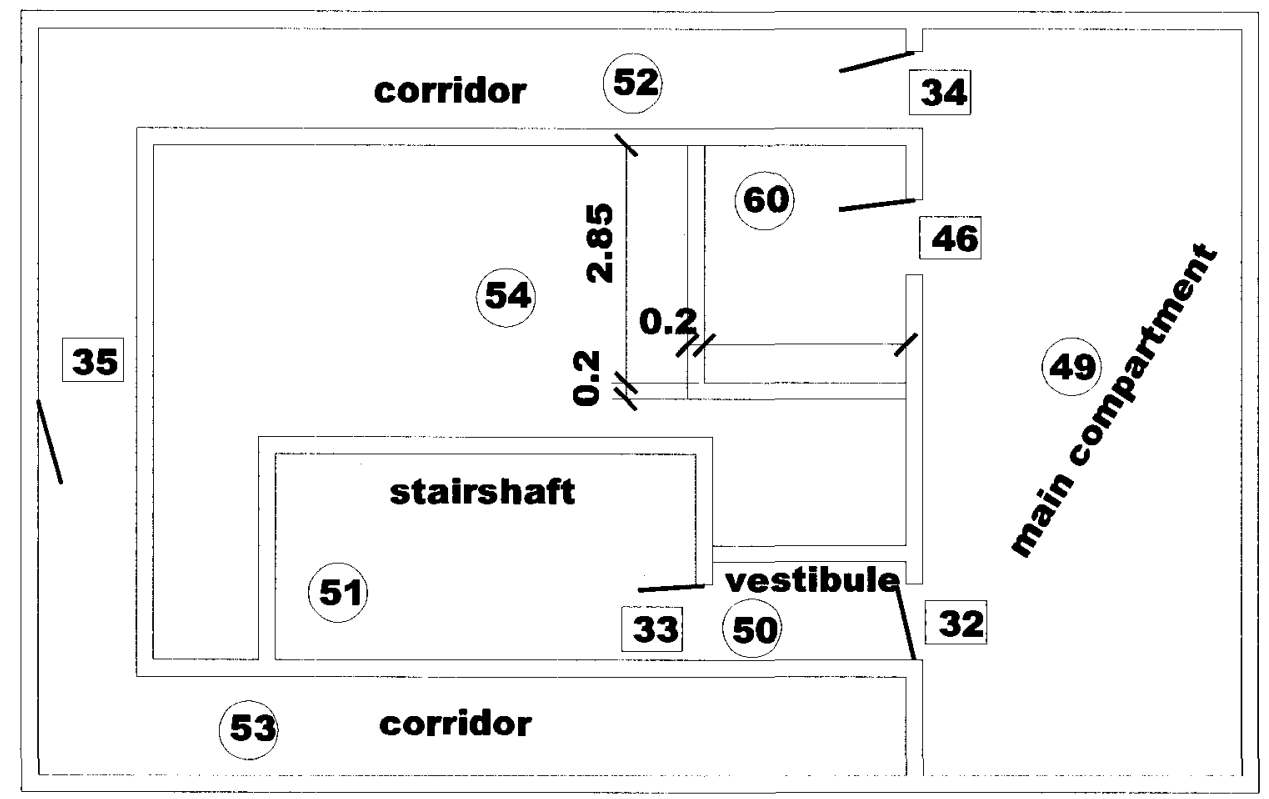

Figure 5-10: Plan of the $10^{\text {th }}$ floor used in the model 
Table 5-1: Dimensions, locations and status of the vertical-vents of the 10-storey tower

\begin{tabular}{|c|c|c|c|c|c|c|c|}
\hline Opening ID & Width (m) & $\begin{array}{l}\text { Soffit } \\
\text { Height } \\
\text { (m) }\end{array}$ & $\begin{array}{c}\text { Sill } \\
\text { Height } \\
\text { (m) }\end{array}$ & $\begin{array}{c}\text { Floor } \\
\text { Number }\end{array}$ & $\begin{array}{r}\mathrm{Cc} \\
\mathrm{Com}\end{array}$ & $\begin{array}{l}\text { ect } \\
\text { tment }\end{array}$ & Open Status \\
\hline 1 & 0.9 & 2.1 & 0 & \multirow{3}{*}{ 2nd } & 1 & 2 & 1 \\
\hline 2 & 0.9 & 2.1 & 0 & & 2 & 3 & 1 \\
\hline 3 & 1.17 & 3.3 & 0 & & 4 & 5 & 1 \\
\hline 4 & 0.9 & 2.1 & 0 & \multirow{4}{*}{$3 \mathrm{rd}$} & 7 & 8 & 1 \\
\hline 5 & 0.9 & 2.1 & $\overline{0}$ & & 8 & 9 & 0 \\
\hline 6 & 0.9 & 2.1 & 0 & & 7 & 10 & 1 \\
\hline 7 & 1.17 & 2.4 & 0 & & 10 & 11 & 1 \\
\hline 8 & 0.9 & 2.1 & 0 & \multirow{4}{*}{4 th } & 13 & 14 & 0.17 \\
\hline 9 & 0.9 & 2.1 & 0 & & 14 & 15 & 1 \\
\hline 10 & 0.9 & 2.1 & 0 & & 13 & 16 & 1 \\
\hline 11 & 1.17 & 2.4 & 0 & & 16 & 17 & 1 \\
\hline 12 & 0.9 & 2.1 & 0 & \multirow{4}{*}{5 th } & 19 & 20 & 0 \\
\hline 13 & 0.9 & 2.1 & 0 & & 20 & 21 & 0 \\
\hline 14 & 0.9 & 2.1 & 0 & & 19 & 22 & 1 \\
\hline 15 & 1.17 & 2.4 & 0 & & 22 & 23 & 1 \\
\hline 16 & 0.9 & 2.1 & 0 & \multirow{4}{*}{ 6th } & 25 & 26 & 0.13 \\
\hline 17 & 0.9 & 2.1 & 0 & & 26 & 27 & 1 \\
\hline 18 & 0.9 & 2.1 & 0 & & 25 & 28 & 0.2 \\
\hline 19 & 1.17 & 2.4 & 0 & & 28 & 29 & 1 \\
\hline 20 & 0.9 & 2.1 & 0 & \multirow{4}{*}{7 th } & 31 & 32 & 0 \\
\hline 21 & 0.9 & 2.1 & 0 & & 32 & 33 & 0 \\
\hline 22 & 0.9 & 2.1 & 0 & & 31 & 34 & 1 \\
\hline 23 & 1.17 & 2.4 & 0 & & 34 & 35 & 1 \\
\hline 24 & 0.9 & 2.1 & 0 & \multirow{4}{*}{ 8th } & 37 & 38 & 0.2 \\
\hline 25 & 0.9 & 2.1 & 0 & & 38 & 39 & 1 \\
\hline 26 & 0.9 & 2.1 & 0 & & 37 & 40 & 1 \\
\hline 27 & 1.17 & 2.4 & 0 & & 40 & 41 & 1 \\
\hline 28 & 0.9 & 2.1 & 0 & \multirow{4}{*}{ 9th } & 43 & 44 & 1 \\
\hline 29 & 0.9 & 2.1 & 0 & & 44 & 45 & 0 \\
\hline 30 & 0.9 & 2.1 & 0 & & 43 & 46 & 1 \\
\hline 31 & 1.17 & 2.4 & 0 & & 46 & 47 & 1 \\
\hline 32 & 0.9 & 2.1 & 0 & \multirow{4}{*}{ 10th } & 49 & 50 & 0.28 \\
\hline 33 & 0.9 & 2.1 & 0 & & 50 & 51 & 1 \\
\hline 34 & 0.9 & 2.1 & 0 & & 49 & 52 & 1 \\
\hline 35 & 1.17 & 2.4 & 0 & & 52 & 53 & 1 \\
\hline 36 & 1.2 & 0.85 & 0 & 2nd & 1 & 4 & 1 \\
\hline
\end{tabular}


Table 5-1: (continued)

\begin{tabular}{|c|c|c|c|c|c|c|c|}
\hline \multirow{3}{*}{$\begin{array}{c}\text { Opening ID } \\
37\end{array}$} & \multirow{3}{*}{$\begin{array}{c}\text { Width (m) } \\
0.9\end{array}$} & \multirow{3}{*}{$\begin{array}{c}\begin{array}{c}\text { Soffit } \\
\text { Height } \\
\text { (m) }\end{array} \\
2.1\end{array}$} & \multirow{3}{*}{$\begin{array}{c}\text { Sill } \\
\begin{array}{c}\text { Height } \\
(\mathrm{m})\end{array} \\
0\end{array}$} & \multirow{3}{*}{$\begin{array}{c}\begin{array}{c}\text { Floor } \\
\text { Number }\end{array} \\
1 \text { st }\end{array}$} & \multicolumn{2}{|c|}{$\begin{array}{c}\text { Connect } \\
\text { Compartment } \\
\text { IDs }\end{array}$} & \multirow{2}{*}{\begin{tabular}{|c|} 
Open Status \\
1 for CLC-I-R, CLC- \\
II-R, PP-I, and PP-II
\end{tabular}} \\
\hline & & & & & & & \\
\hline & & & & & 55 & 56 & $\begin{array}{c}0 \text { for CMP-R, and } \\
\text { BK-R }\end{array}$ \\
\hline \multirow{2}{*}{38} & \multirow{2}{*}{0.9} & \multirow{2}{*}{2.1} & \multirow{2}{*}{0} & \multirow{2}{*}{1 st } & \multirow{2}{*}{56} & \multirow{2}{*}{57} & \begin{tabular}{|l|} 
for CLC-I-R, CLC- \\
II-R, PP-I, and PP-II
\end{tabular} \\
\hline & & & & & & & \begin{tabular}{|c|}
0 for CMP-R, and \\
BK-R
\end{tabular} \\
\hline 39 & 0.9 & 2.1 & 0 & $1 \mathrm{st}$ & 55 & 58 & 1 \\
\hline \multirow{2}{*}{40} & \multirow{2}{*}{0.9} & \multirow{2}{*}{2.1} & \multirow{2}{*}{0} & \multirow{2}{*}{1 st } & \multirow{2}{*}{55} & \multirow{2}{*}{$\frac{y}{0}$} & \begin{tabular}{|l|}
1 for CLC-I-R, CLC- \\
II-R, PP-I, and PP-II
\end{tabular} \\
\hline & & & & & & & $\begin{array}{c}0 \text { for CMP-R, and } \\
\text { BK-R }\end{array}$ \\
\hline 41 & 1.9 & 1.85 & 0 & 3rd & 8 & 11 & 1 \\
\hline 42 & 1.9 & 1.85 & 0 & 5th & 20 & 23 & $\frac{1}{1}$ \\
\hline 43 & 1.9 & 1.85 & 0 & 7 th & 32 & 35 & 1 \\
\hline 44 & 1.9 & 1.85 & 0 & 9th & 44 & 47 & 1 \\
\hline 45 & 0.9 & 2.1 & 0 & 9th & 43 & 59 & 1 \\
\hline 46 & 0.9 & 2.1 & 0 & 10th & 49 & 60 & 1 \\
\hline 47 & 2.4 & 3.3 & 0 & $1 \mathrm{st}$ & 58 & 62 & 1 \\
\hline \multirow[b]{2}{*}{48} & \multirow[b]{2}{*}{0.9} & \multirow[b]{2}{*}{2.1} & \multirow[b]{2}{*}{0} & \multirow[b]{2}{*}{$1 \mathrm{st}$} & \multirow[b]{2}{*}{57} & \multirow{2}{*}{$\begin{array}{l}\frac{0}{0} \\
\frac{0}{0} \\
\frac{5}{0}\end{array}$} & $\begin{array}{l}0 \text { for CLC-I-R, CLC- } \\
\text { II-R, PP-I, and PP-II }\end{array}$ \\
\hline & & & & & & & $\begin{array}{c}1 \text { for CMP-R, and } \\
\text { BK-R }\end{array}$ \\
\hline 49 & 0.15 & 2.1 & 0 & $6^{\text {th }}$ & 26 & 29 & 1 \\
\hline 50 & 0.24 & 2.24 & 2 & $4^{\text {th }}$ & 16 & $\frac{\stackrel{0}{\frac{0}{0}}}{\frac{0}{0}}$ & 1 \\
\hline 51 & 0.1 & 2.1 & 2 & $8^{\text {th }}$ & 40 & $\begin{array}{l}\frac{0}{0} \\
\frac{0}{0}\end{array}$ & 1 \\
\hline
\end{tabular}

Note: For open status, 1 stands for fully open; 0 stands for fully closed; any number in between 0 and 1 stands for partially open. 


\subsubsection{Input Heat Release Rate}

The nominal heat release rate of combustion is the product of effective heat of combustion per unit mass of fuel multiplied by the mass pyrolysis rate. For modelling purposes, the HRR from the experimental work was used as the nominal input HRR in CUsmoke. The nominal input HRR was defined as a series of discrete HRR points at different times as obtained from the experimental work.

\subsubsection{Fuel Properties and Fire Source Location}

Propane was used as the fuel to conduct all the tests used for comparisons. The chemical heat of combustion of propane used in this study is $43.7 \mathrm{MJ} / \mathrm{kg}$ [58] while the radiation fraction used is 0.3 [58]. The mass fraction of carbon for propane is $0.82 \mathrm{~kg} / \mathrm{kg}$; and the mass fraction of hydrogen for propane is $0.18 \mathrm{~kg} / \mathrm{kg}$. The mass ratios of the production of soot and $\mathrm{CO}$ to the carbon related products for propane fire are $0 \mathrm{~kg} / \mathrm{kg}$. The modelling fire source was located almost at the centre of the fire compartment with the dimensions of $1.9 \mathrm{~m}$ width $\times 4.5 \mathrm{~m}$ depth $\times 0.8 \mathrm{~m}$ height.

\subsubsection{Thermal Properties of the Compartment Boundaries}

The 10-storey tower is constructed of reinforced normal-weight concrete. The fire compartment and the vestibule between the fire compartment and the stair shaft at the $2^{\text {nd }}$ floor in this tower were covered with a $25.4 \mathrm{~mm}$ thick layer of ceramic fibre. The conductivity and specific heat value for ceramic fibre are functions of temperature. Values can be obtained using the calculation method provided by the manufacturer (see Appendix A). CUsmoke can only consider unique values of the thermal properties of the boundaries during the simulation process. The representative value of conductivity and 
specific heat of ceramic fibre, normal weight concrete and wood used in the simulation using CUsmoke are listed in Table 5-2.

Table 5-2: Material properties of 10-storey tower boundaries

\begin{tabular}{|c|c|c|c|c|}
\hline Property & Ceramic Fibre & $\begin{array}{c}\text { Normal Weight } \\
\text { Concrete }\end{array}$ & $\begin{array}{c}\text { Normal } \\
\text { Weight } \\
\text { Concrete }\end{array}$ & Wood \\
\hline Location & $\begin{array}{c}\text { Fire compartment } \\
\text { and vestibule at 2nd } \\
\text { floor }\end{array}$ & $\begin{array}{c}\text { Stair shaft at 2nd } \\
\text { and 3rd floors }\end{array}$ & $\begin{array}{c}\text { Other } \\
\text { locations } \\
\text { without } \\
\text { indication }\end{array}$ & Inner room at \\
6th floor \\
\hline Density $\left(\mathrm{kg} \mathrm{m}^{-3}\right)$ & 96 & 2200 & 2200 & 800 \\
\hline $\begin{array}{c}\text { Thermal } \\
\text { Conductivity } \\
\left(\mathrm{W} \mathrm{m}^{-1} \mathrm{~K}^{-1}\right)\end{array}$ & $\begin{array}{c}0.13(\mathrm{CLC}-\mathrm{I}-\mathrm{R}) \\
\text { 0.15 }\end{array}$ & 1.68 & 1.0 & 0.17 \\
\cline { 2 - 5 } (CMP-R and PP-II) & Specific Heat \\
$\left(\mathrm{J} \mathrm{kg}^{-1} \mathrm{~K}^{-1}\right)$ & $\begin{array}{c}992(\mathrm{CLC}-\mathrm{I}-\mathrm{R}) \\
1025(\mathrm{CMP}-\mathrm{R} \text { and } \\
\text { PP-II) }\end{array}$ & 1300 & 880 & 2380 \\
\hline Surface Emissivity & 0.9 & 0.9 & 0.9 & 0.9 \\
\hline
\end{tabular}

\subsection{Comparison of Model Predictions and Experimental Data}

\subsubsection{Single Compartment Tests}

This section presents the comparisons with data from single compartment fires as reported by Dembsey et al. [31]. Dembsey et al. conducted 20 fire experiments suitable for model validation [31]. The experiments were done in a single compartment. The dimensions of the fire compartment were $2.5 \mathrm{~m} \times 3.7 \mathrm{~m} \times 2.5 \mathrm{~m}$ (height). There was a single doorway $0.76 \mathrm{~m}$ wide $\times 2.0 \mathrm{~m}$ high at the centre of one of the shorter sides. A porous propane-fired surface burner supplied heat at a steady rate. In this section, 4 sets of fire tests with steady HRR of $430 \mathrm{~kW}, 680 \mathrm{~kW}, 860 \mathrm{~kW}$ and $980 \mathrm{~kW}$ were simulated and compared with the experimental data. 
The fuel is propane $\left(\mathrm{C}_{3} \mathrm{H}_{8}\right)$. In this simulation, heat of combustion of propane of $44 \mathrm{MJ} / \mathrm{kg}$, and radiation fraction of 0.27 were used to be consistent with the values used by Dembsey et al. [31] in their simulation using CFAST. The mass fraction of carbon for propane is $0.82 \mathrm{~kg} / \mathrm{kg}$; and the mass fraction of hydrogen for propane is $0.18 \mathrm{~kg} / \mathrm{kg}$. The mass ratios of the production of soot and $\mathrm{CO}$ to the carbon related products for propane fire are $0 \mathrm{~kg} / \mathrm{kg}$. Ambient pressure was $1 \mathrm{~atm}$, and ambient temperature was $20^{\circ} \mathrm{C}$.

The burner with dimensions of $1.25 \mathrm{~m}$ depth, $1.85 \mathrm{~m}$ width and $0.61 \mathrm{~m}$ height was located at the centre of the compartment. The pertinent properties of the compartment boundaries are shown in Table 5-3.

Table 5-3: Material properties of single compartment boundaries [31]

\begin{tabular}{|c|c|c|c|}
\hline & Ceiling & Walls & Floor \\
\hline Thickness (m) & 0.066 & 0.054 & 0.044 \\
\hline Density $\left(\mathrm{kg} \mathrm{m}^{-3}\right)$ & 449 & 449 & 770 \\
\hline $\begin{array}{c}\text { Thermal Conductivity } \\
\left(\mathrm{W} \mathrm{m}^{-1} \mathrm{~K}^{-1}\right)\end{array}$ & 0.1 & 0.10 & 0.14 \\
\hline Specific heat $\left(\mathrm{J} \mathrm{kg}^{-1} \mathrm{~K}^{-1}\right)$ & 1090 & 1090 & 900 \\
\hline Surface Emissivity & 0.9 & 0.9 & 0.9 \\
\hline
\end{tabular}

The duration of the 4 tests were $3600 \mathrm{~s}$ for HRR of $430 \mathrm{~kW}, 1800 \mathrm{~s}$ for HRR of $680 \mathrm{~kW}$, $1500 \mathrm{~s}$ for HRR of $860 \mathrm{~kW}$ and $1200 \mathrm{~s}$ for HRR of $980 \mathrm{~kW}$. The upper layer temperatures in the compartment for the 4 tests predicted by CUsmoke are shown in Figure 5-11.

The comparisons of the peak upper layer temperature and interface height between the model predictions and experiments are shown in Table 5-4. 


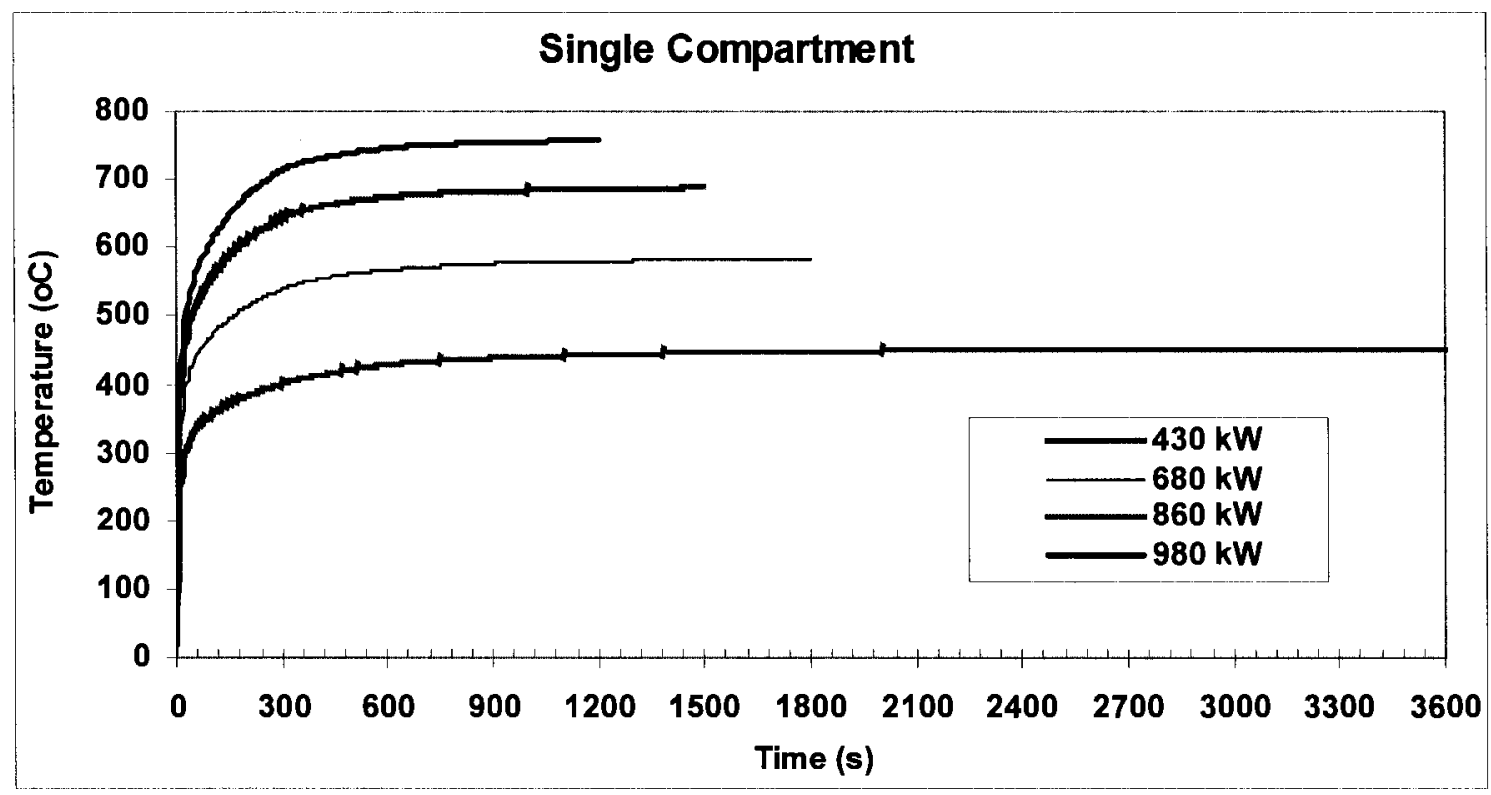

Figure 5-11: Upper layer temperature in the fire compartment (single-compartment example)

Table 5-4: Comparison of upper layer temperature and interface height between model predictions and experimental results

\begin{tabular}{|c|l|c|c|c|}
\hline $\begin{array}{c}\text { HRR } \\
(\mathrm{kW})\end{array}$ & $\begin{array}{c}\text { Upper Layer } \\
\text { Temperature }\left({ }^{\circ} \mathrm{C}\right)\end{array}$ & $\begin{array}{c}\text { Lower Layer } \\
\text { Temperature } \\
\left({ }^{\circ} \mathrm{C}\right)\end{array}$ & $\begin{array}{c}\text { Interface height } \\
(\mathrm{m})\end{array}$ \\
\hline \multirow{2}{*}{430} & Modelling & 453 & 89 & 1.17 \\
\cline { 2 - 5 } & Experiment & 462 & 117 & 1.12 \\
\hline \multirow{2}{*}{680} & Modelling & 582 & 101 & 1.01 \\
\cline { 2 - 5 } & Experiment & 639 & 162 & 0.99 \\
\hline \multirow{2}{*}{860} & Modelling & 687 & 115 & 0.93 \\
\cline { 2 - 5 } & Experiment & 750 & 255 & 0.96 \\
\hline \multirow{2}{*}{980} & Modelling & 758 & 125 & 0.90 \\
\cline { 2 - 5 } & Experiment & 796 & 236 & 0.99 \\
\hline
\end{tabular}

Both the upper layer temperature and interface height predicted by CUsmoke are very close to the experimental values, especially for the smaller HRR fires. However, the predicted lower layer temperatures are lower than experimental results, especially for the larger HRR fires. 


\subsubsection{Two-Compartment Tests}

This section presents comparisons with one of the two-compartment fire tests reported by Cooper et al. [19]. In this section, two two-compartment fires were modelled using CUsmoke and compared with the experimental data reported. The test's setup included a fire compartment with dimensions of $3.3 \mathrm{~m} \times 4.3 \mathrm{~m} \times 2.36 \mathrm{~m}$ (height), and a linked corridor with dimensions of $2.4 \mathrm{~m} \times 11.1 \mathrm{~m} \times 2.36 \mathrm{~m}$ (height). There was a door $1.07 \mathrm{~m}$ wide and $2.0 \mathrm{~m}$ high between the fire compartment and the corridor. In addition, there was a $0.15 \mathrm{~m} \times 0.94 \mathrm{~m}$ hole from the corridor to the outside.

The fuel used was methane $\left(\mathrm{CH}_{4}\right)$. The heat of combustion of methane used in this simulation is $50 \mathrm{MJ} / \mathrm{kg}$ and the radiation fraction is 0.24 [19]. The mass fraction of carbon for methane is $0.75 \mathrm{~kg} / \mathrm{kg}$; and the mass fraction of hydrogen for methane is $0.25 \mathrm{~kg} / \mathrm{kg}$. The mass ratios of the production of soot and $\mathrm{CO}$ to the carbon related products for methane fire are $0 \mathrm{~kg} / \mathrm{kg}$. The ambient pressure was $101300 \mathrm{~Pa}$, and the ambient temperature was $25^{\circ} \mathrm{C}$.

The burner with dimensions of $1.65 \mathrm{~m}$ depth, $2.15 \mathrm{~m}$ width and $0.24 \mathrm{~m}$ height was located at the centre of the compartment. In this section, a fire test with a linearly growing fire $Q=c t, c=30 \mathrm{~kW} / \mathrm{min}$ (t is time in minutes) and a test with a fire with steady HRR of $225 \mathrm{~kW}$ were simulated and compared with the experiment data. The pertinent properties of the compartment boundary are shown in Table 5-5.

The durations of the fires with the linearly growing and steady HRR were $250 \mathrm{~s}$ and $300 \mathrm{~s}$ respectively. 
Table 5-5: Material properties of two-compartment boundaries [34]

\begin{tabular}{|c|c|c|}
\hline & Ceiling/Walls & Floor \\
\hline Thickness $(\mathrm{m})$ & 0.013 & 1.0 \\
\hline Density $\left(\mathrm{kg} \mathrm{m}^{-3}\right)$ & 790 & 1950 \\
\hline $\begin{array}{c}\text { Thermal Conductivity } \\
\left(\mathrm{W} \mathrm{m}^{-1} \mathrm{~K}^{-1}\right)\end{array}$ & 0.2 & 0.8 \\
\hline Specific heat $\left(\mathrm{J} \mathrm{kg}^{-1} \mathrm{~K}^{-1}\right)$ & 900 & 860 \\
\hline Surface Emissivity & 0.9 & 0.9 \\
\hline
\end{tabular}

The predicted and measured upper layer temperatures with time in the fire compartment and the corridor are shown in Figure 5-12 and Figure 5-14, and the interface profiles of the fire compartment and the corridor are shown in Figure 5-13 and Figure 5-15.

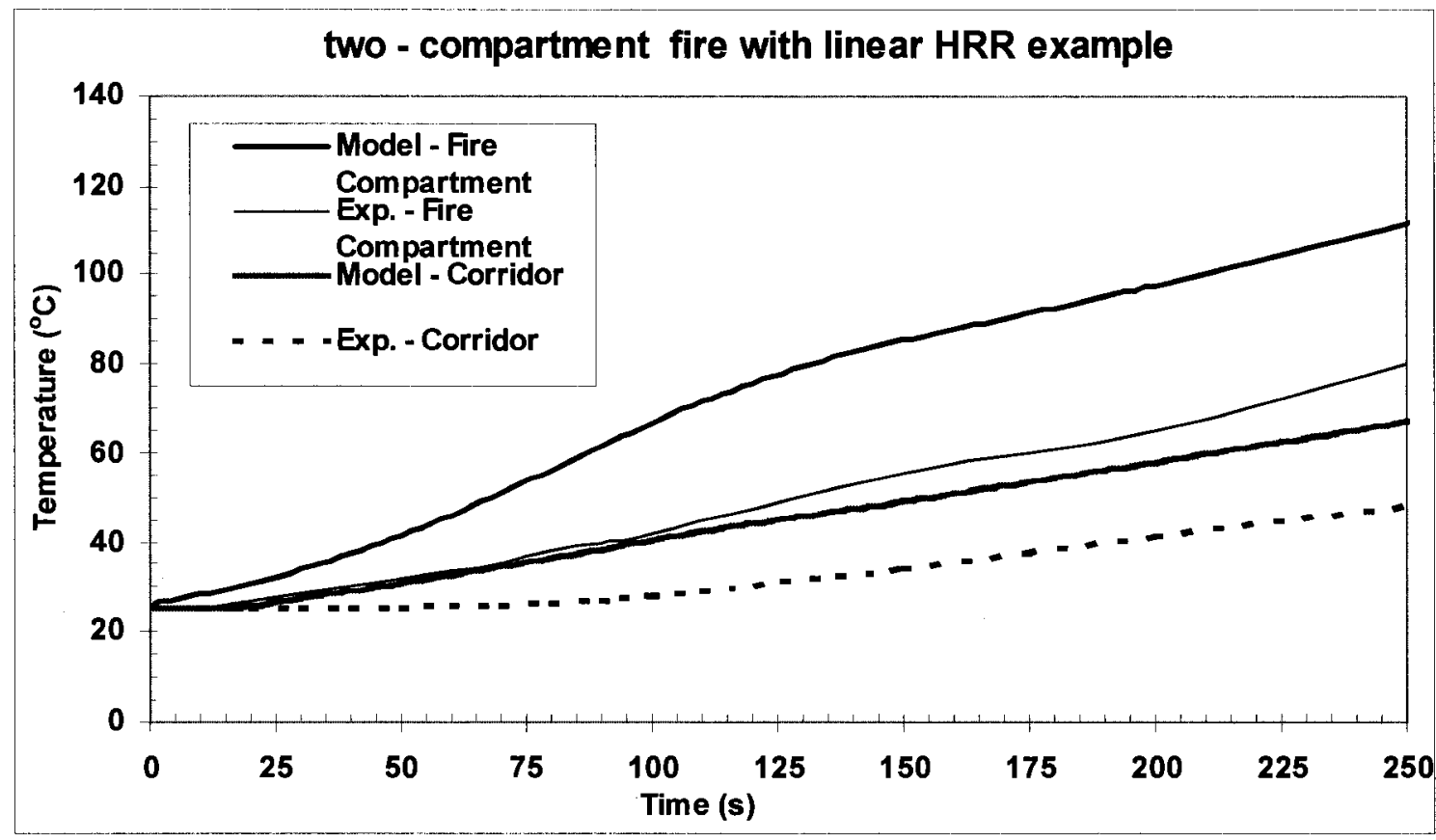

Figure 5-12: Comparison of predicted and experimental upper layer temperatures in the fire compartment and the corridor (linear HRR test) 


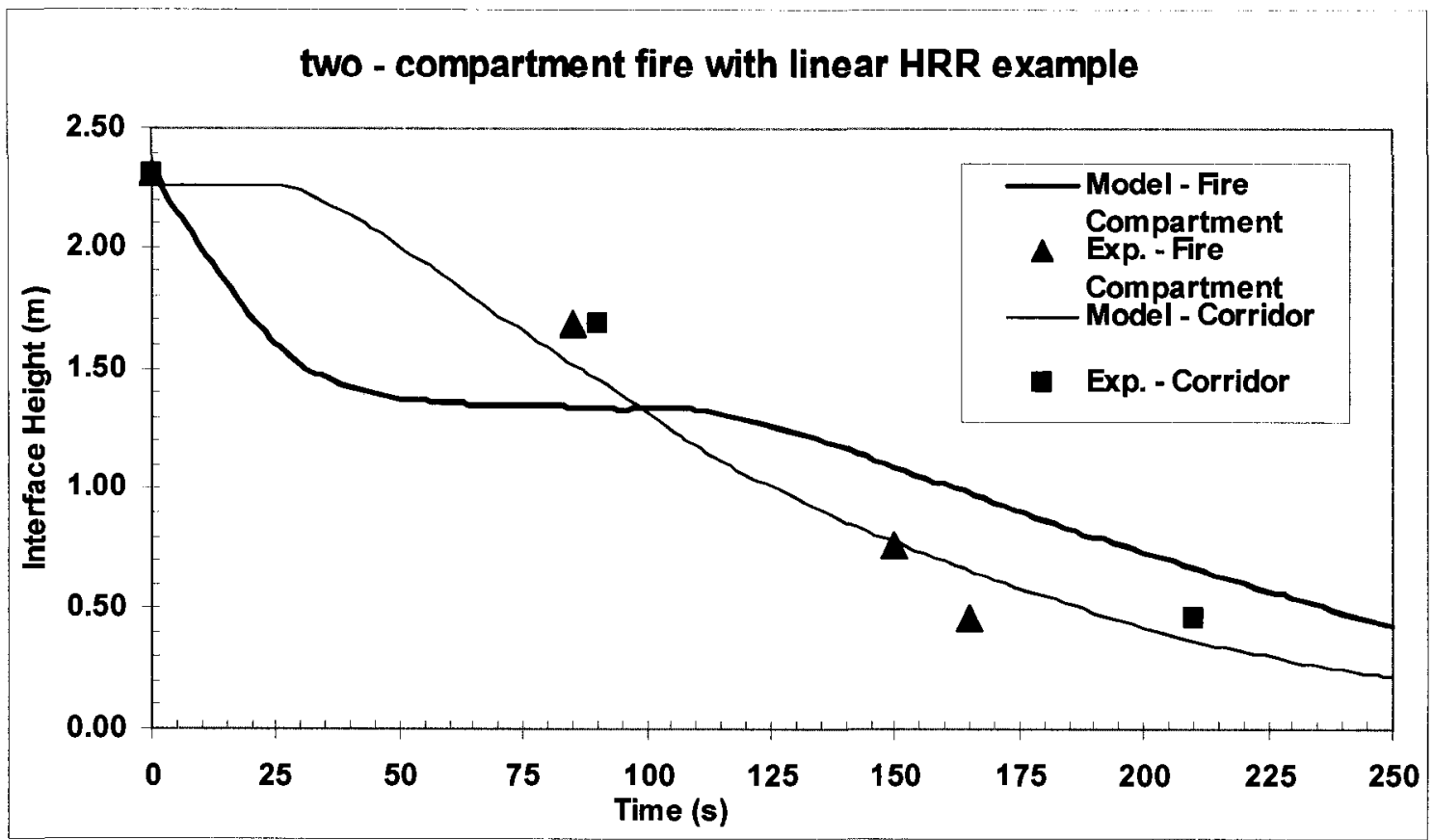

Figure 5-13: Comparison of predicted and experimental interface heights in the fire compartment and the corridor (linear HRR test)

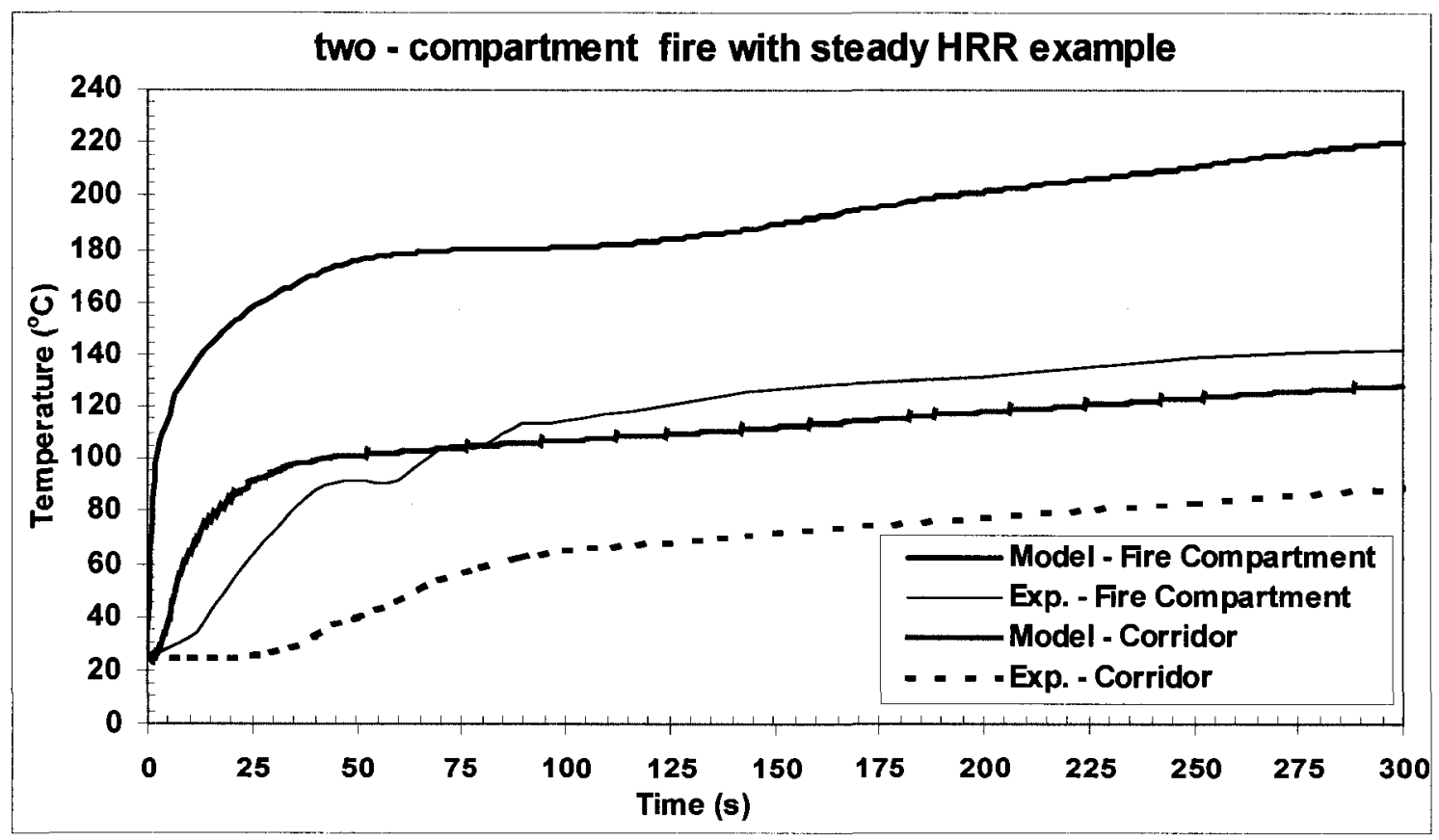

Figure 5-14: Comparison of predicted and experimental upper layer temperature in the fire compartment and the corridor (steady HRR test) 


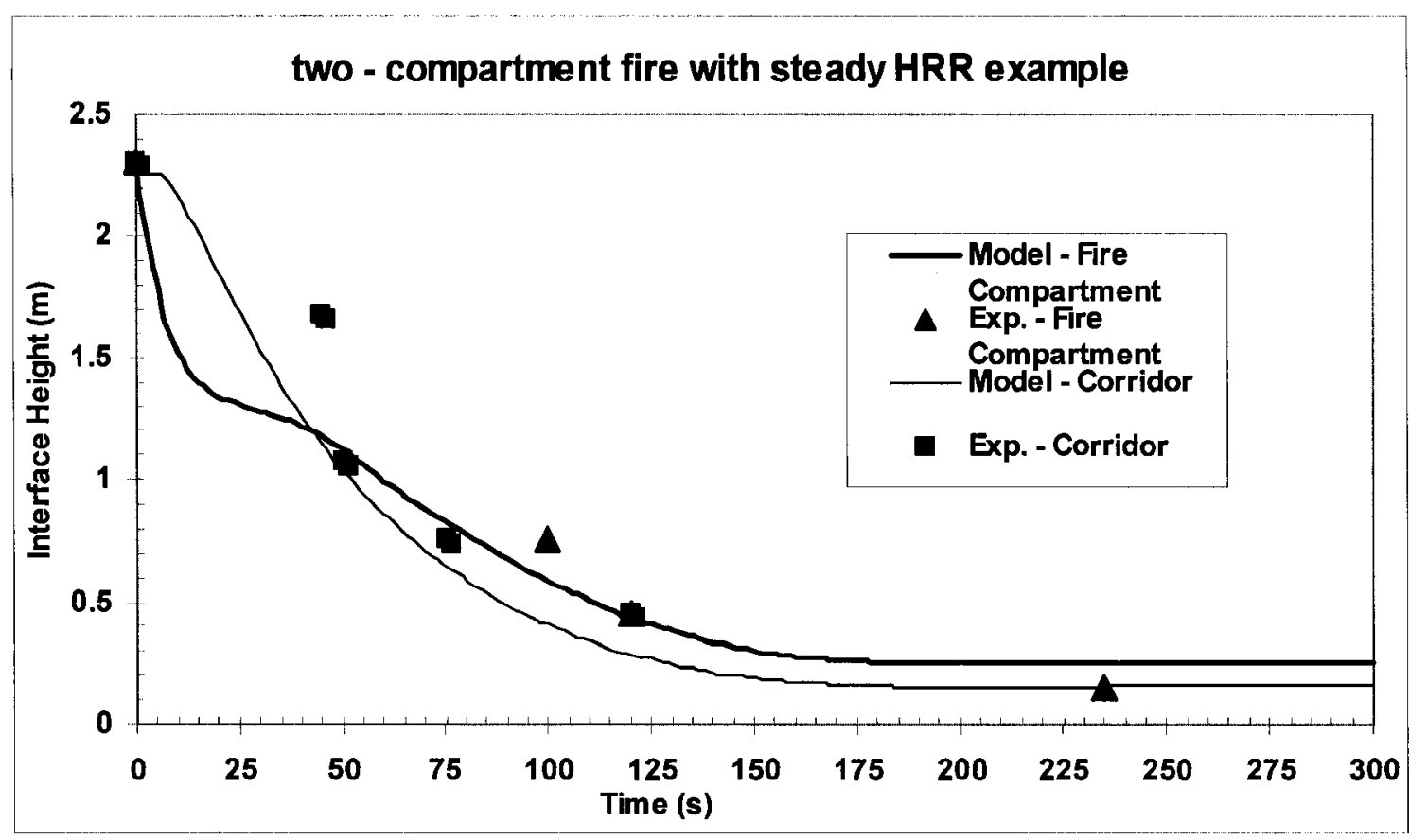

Figure 5-15: Comparison of predicted and experimental interface heights in the fire compartment and the corridor (steady HRR test)

The upper layer temperatures predicted by CUsmoke are higher than the experimental values for both the fire compartment and the corridor. This difference may be attributed to the fact that the interface height for the experiments was determined using $\mathrm{N}$-percent method with $\mathrm{N}=10 \%$. Using such a low $\mathrm{N}$ value will result in low temperatures since the interface height with such value denotes the lower transition point. Using a $60 \%$ for $\mathrm{N}$ will result in higher interface heights and higher temperatures. The predicted interface heights, however, compare very well which means that there are other factors that also contribute to the difference in temperature. This includes radiation and conduction losses to the boundaries as well as convective losses through the openings. 


\subsubsection{Multi-storey Building Tests}

\subsubsection{Test CLC-I-R}

The HRR taken from the experiment was used as input to CUsmoke. This value may be changed by CUsmoke model if not enough oxygen is available in the fire compartment to produce the input rate [3].

The nominal input HRR and modelling output HRR during Test CLC-I-R is shown in Figure 5-16. Despite some minor differences, the simulated results during Test CLC-I-R compared favourably with the experimental data.

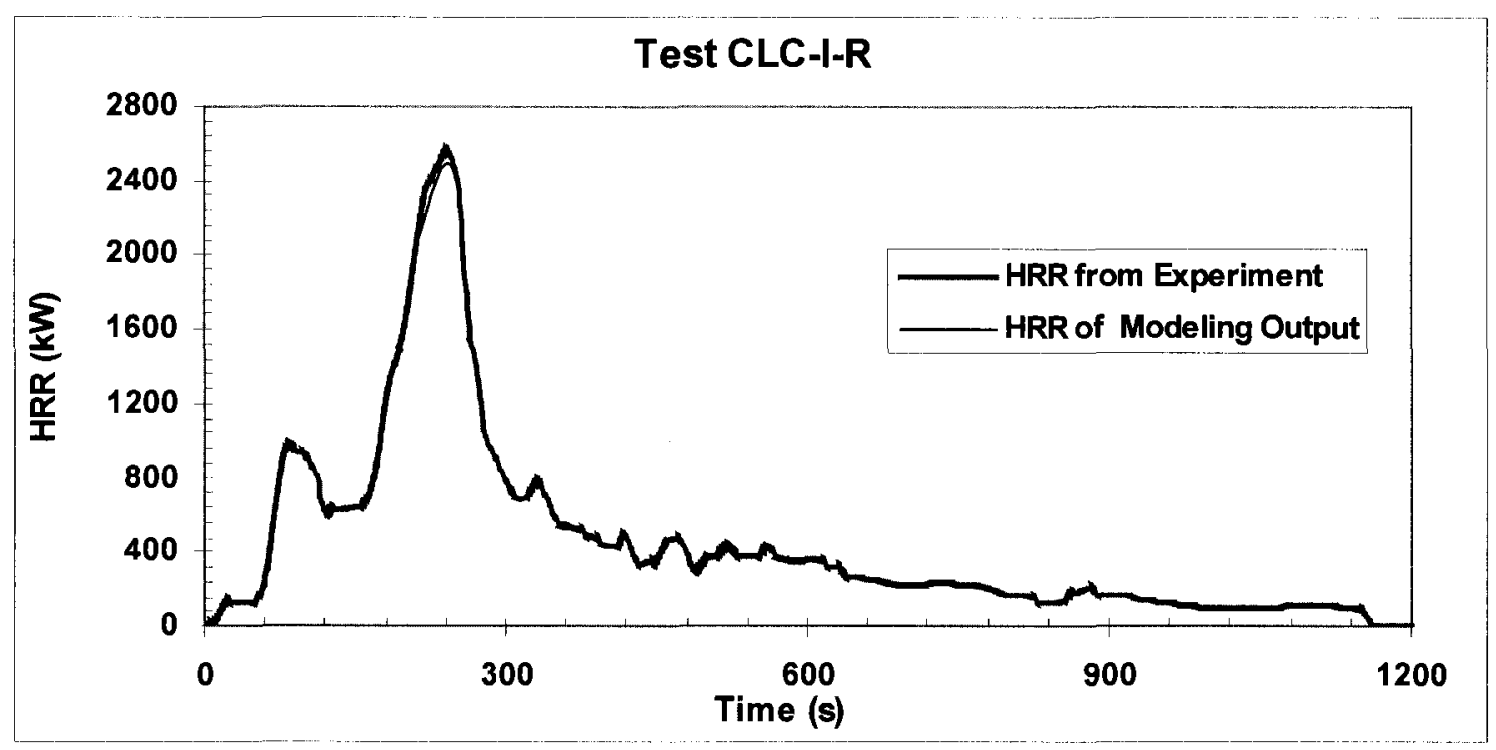

Figure 5-16: Nominal input HRR and model output HRR (Test CLC-I-R)

Figure 5-17 shows both the predicted and experimental concentration of $\mathrm{O}_{2}$ and $\mathrm{CO}_{2}$ in the stair shaft at the fire floor for Test CLC-I-R. Both predicted concentrations follow closely the experimental data during the first $300 \mathrm{~s}$. After that time there is a divergence of the results with the model predicting lower $\mathrm{O}_{2}$ concentrations and higher $\mathrm{CO}_{2}$ concentrations. The reasons for this deviation could not be identified. 


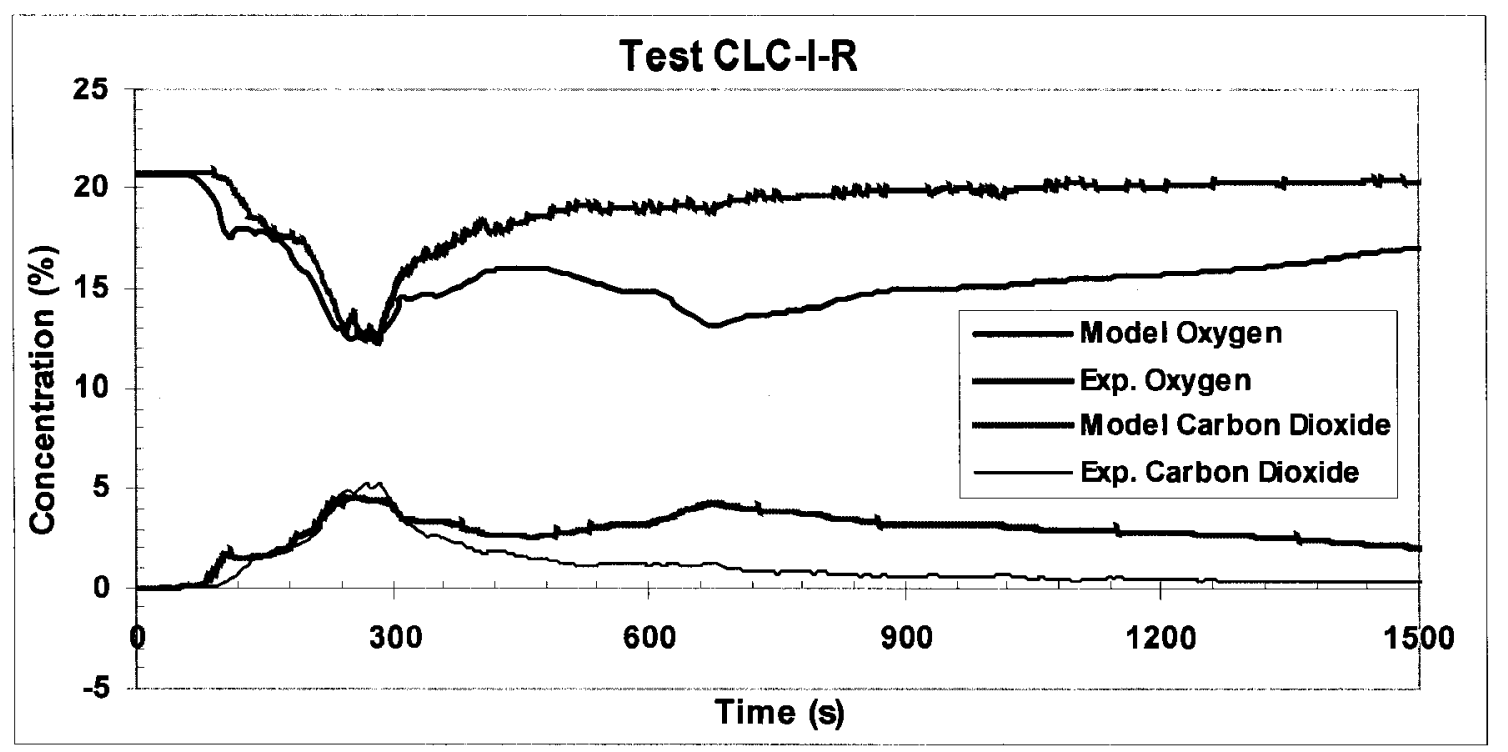

Figure 5-17: Comparison of predicted and experimental upper layer concentration of $\mathrm{O}_{2}$ and $\mathrm{CO}_{2}$ in the stair shaft at the fire floor (Test CLC-I-R)

Figure 5-18 presents a comparison between the predicted and experimental results for the upper layer temperatures in the fire compartment and the vestibule of the fire floor for Test CLC-I-R. The predicted temperatures compare well, especially during the growth phase of the fire with the predicted results been slightly higher than the experimental measurements. The model predicted a much higher peak upper layer temperature in the fire compartment. The predicted temperature peak is $948^{\circ} \mathrm{C}$ at $260 \mathrm{~s}$, whereas the gas temperature for the experiment in the fire compartment at $2.57 \mathrm{~m}$ was $671^{\circ} \mathrm{C}$ at the same time. As expected the predicted peak upper layer temperature in the vestibule of the fire floor was higher than the experiment at $726^{\circ} \mathrm{C}$ at $260 \mathrm{~s}$. The experimental peak temperature in the doorway area at $1.65 \mathrm{~m}$ height was $522^{\circ} \mathrm{C}$ at $260 \mathrm{~s}$. The predicted lower layer temperature is lower than the experimental with peak values of $235^{\circ} \mathrm{C}$ and $350^{\circ} \mathrm{C}$, respectively. Under-predicting heat transfer to the lower layer may be the reason 
why the model computes higher upper-layer temperatures and lower lower-layer temperatures than the experiment.

A sudden jump of the temperature at $620 \mathrm{~s}$ appears in the predicted temperature curve in the vestibule at the fire floor shown in Figure 5-18. This jump can be explained by considering Figure 5-19, which depicts the predicted interface height in the compartment of fire and in the vestibule on the fire floor. As the figure shows, the interface height of the vestibule decreases sharply at $380 \mathrm{~s}$ and becomes much lower than the interface height of the fire compartment. At this time, the upper layer temperature of the vestibule is higher than the lower layer temperature in the fire compartment causing the hot gases of the upper layer of the vestibule to flow into the lower layer of the fire compartment. Figure 5-20 shows a diagram of these conditions. This flow removes heat from the upper layer of the vestibule leading to a rapid decrease of its temperature. At $620 \mathrm{~s}$, this flow stops because the interface height of the vestibule reaches the level of the interface height of the fire compartment. Without hot gases flowing out of the hot layer of the vestibule its upper layer temperature increases suddenly and then it continues to decrease. This may be a numerical effect as such jumps have not been seen it the experimental data.

The predicted interface height in the fire compartment of $0.94 \mathrm{~m}$ at $260 \mathrm{~s}$, is slightly lower than the experimental results of $1.13 \mathrm{~m}$ at $260 \mathrm{~s}$. 


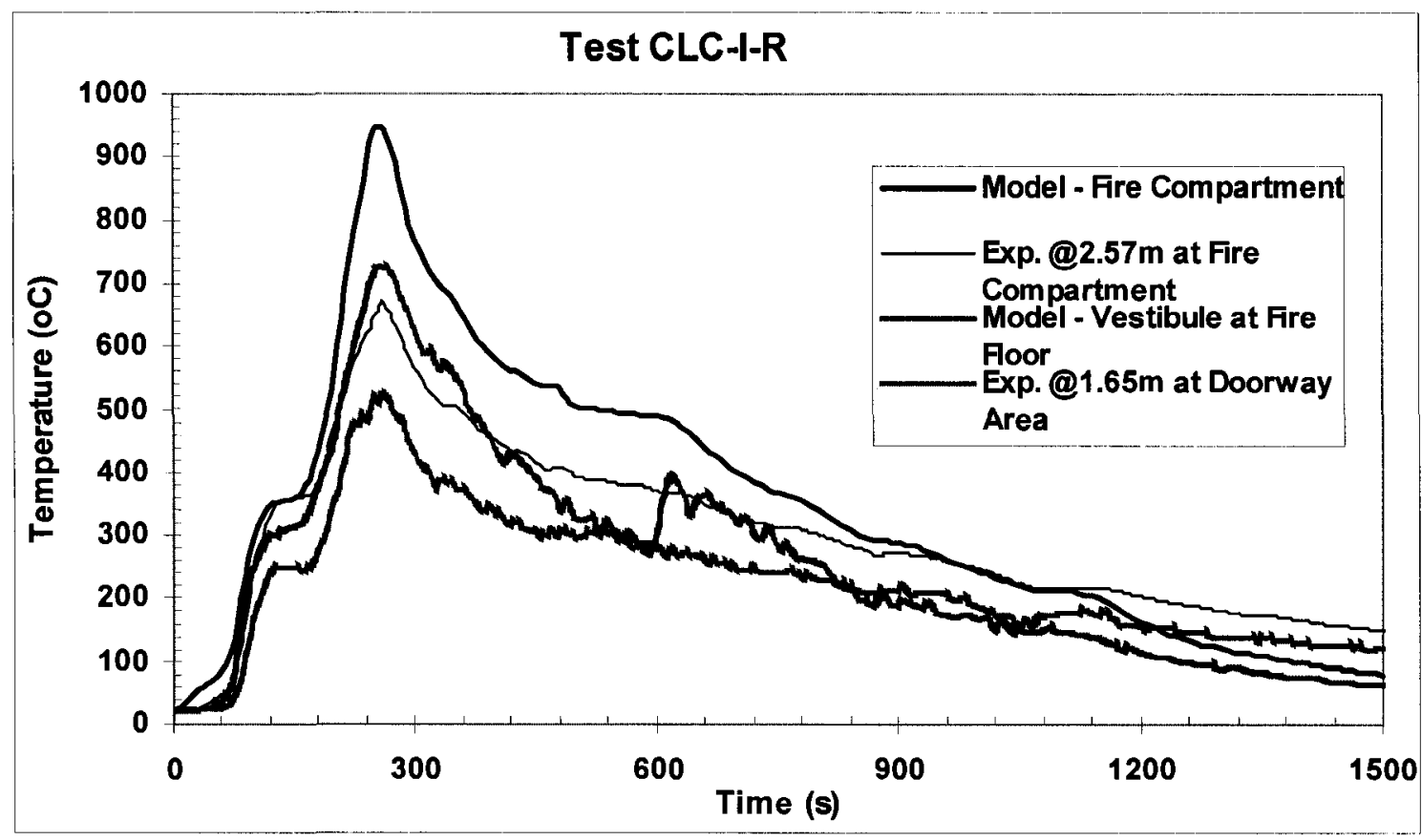

Figure 5-18: Comparison of predicted and experimental upper layer temperatures in the fire compartment and doorway (Test CLC-I-R)

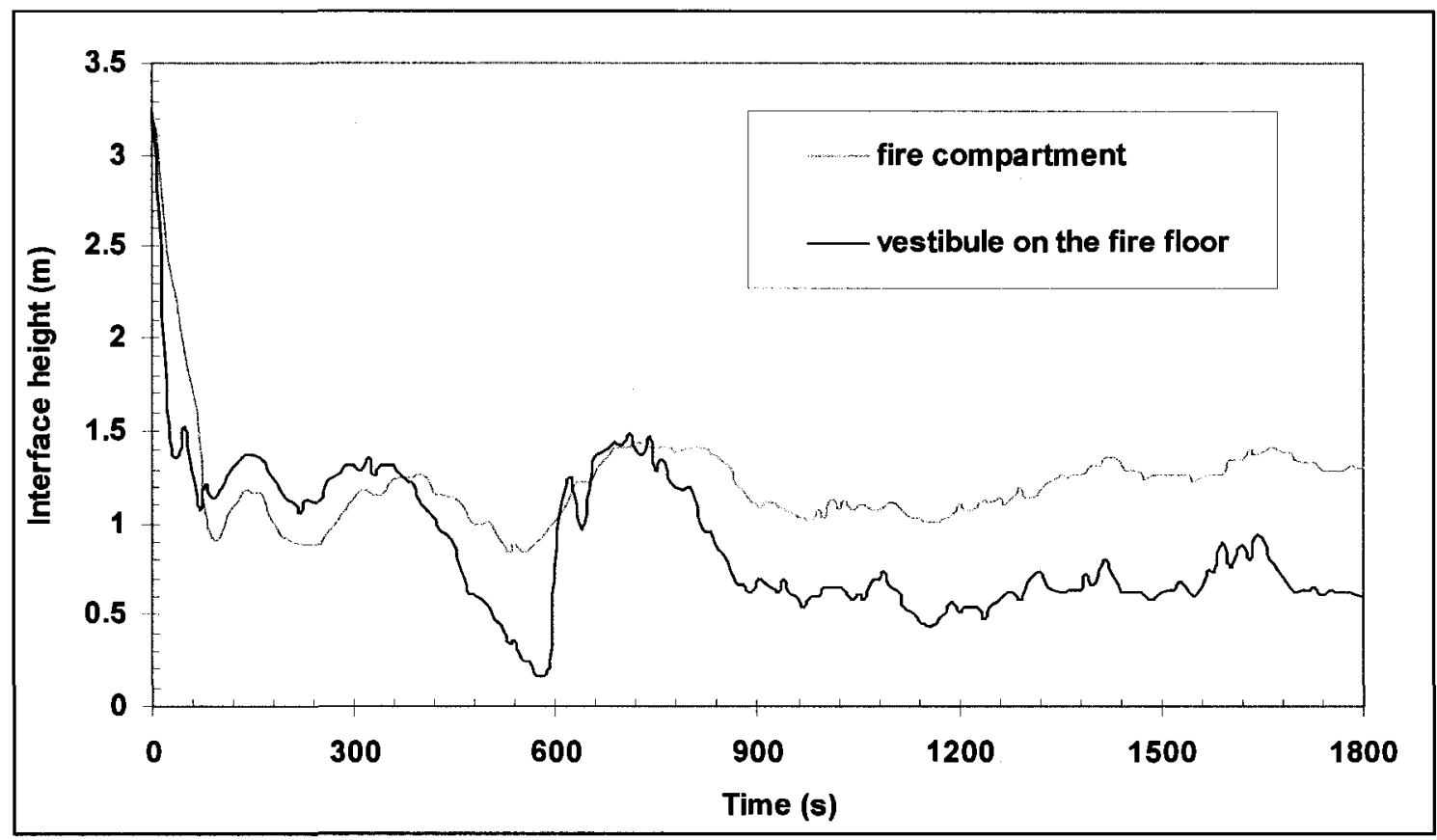

Figure 5-19: predicted interface height in the fire compartment and the vestibule on the fire floor (Test CLC-I-R) 


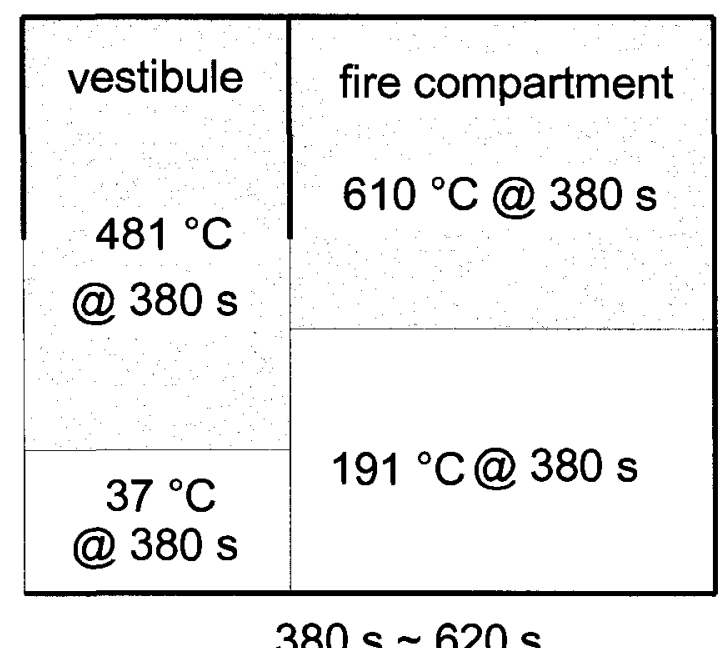

$380 s \sim 620 s$

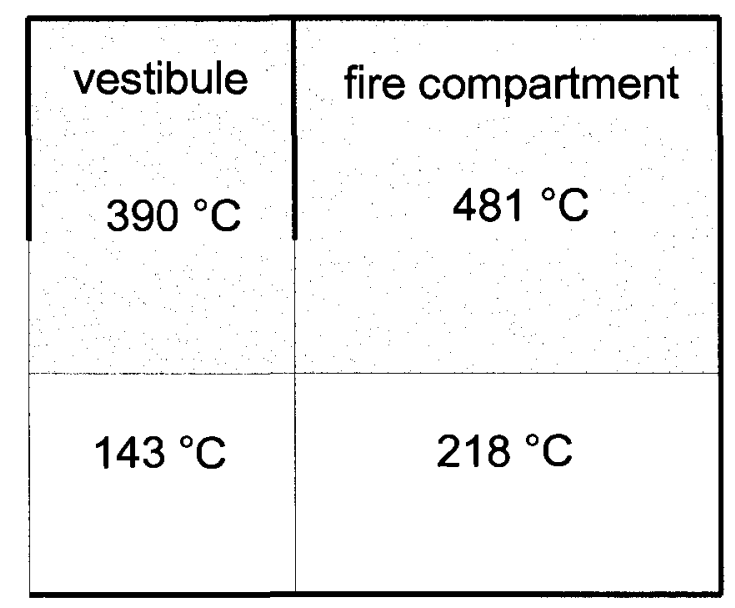

at $620 \mathrm{~s}$

Figure 5-20: schematic upper and lower zones of the fire compartment and the vestibule on the fire floor

Figure 5-21 $\left(2^{\text {nd }} \sim 5^{\text {th }}\right.$ floors $)$ and Figure 5-22 $\left(6^{\text {th }} \sim 10^{\text {th }}\right.$ floors $)$ show a comparison between the predicted and experimental upper layer temperatures in the stair shaft for Test CLC-I-R. The temperatures predicted by the model are higher than the experimental values, a result expected given that the compartment upper layer temperature is higher. Table 5-6 shows the predicted and experimental peak temperatures with time in the stair shaft.

The results indicate that the predicted smoke movement in the stair shaft is faster than the experimental. This is due to the higher buoyancy forces computed by the model due to the higher predicted temperatures. 


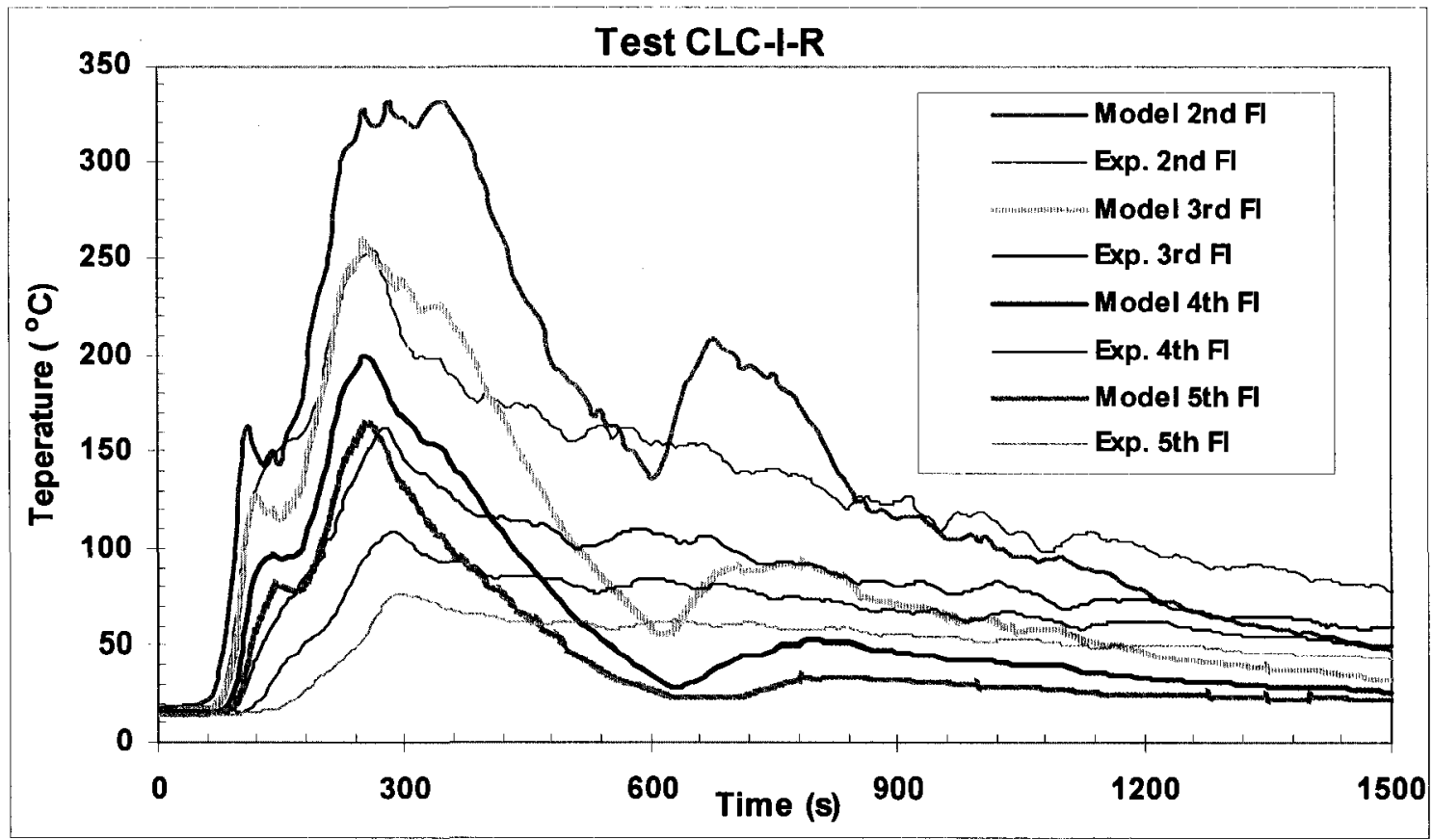

Figure 5-21: Comparison of predicted and experimental upper layer temperatures in the stair shaft at the $2^{\text {nd }}$ to $5^{\text {th }}$ floors (Test CLC-I-R)

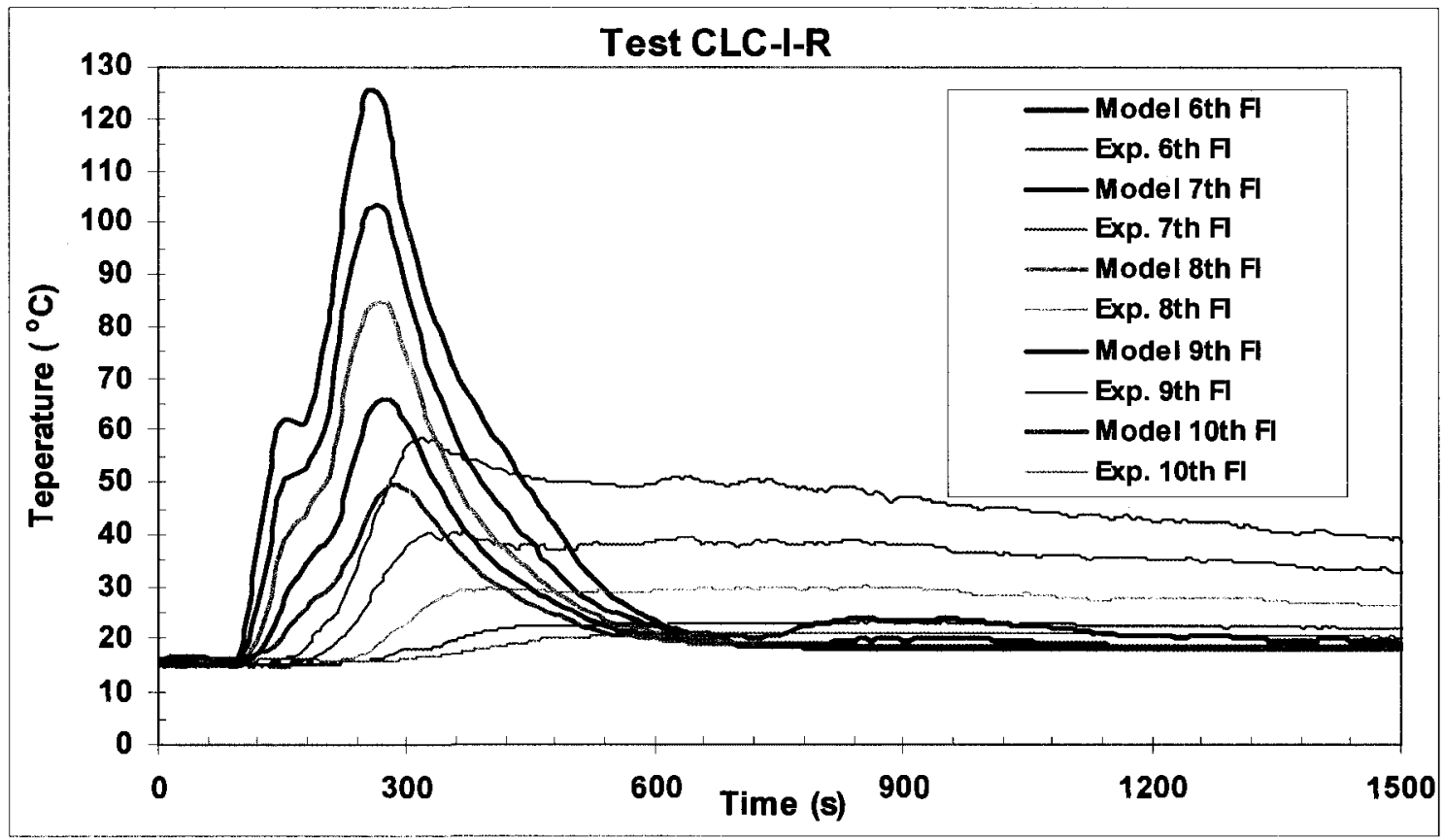

Figure 5-22: Comparison of predicted and experimental temperatures in the stair shaft at the $6^{\text {th }}$ to $10^{\text {th }}$ floors (Test CLC-I-R) 
Table 5-6: Comparison of predicted and experimental peak temperatures in the stair shaft and corresponding times during Test CLC-I-R

\begin{tabular}{|c|c|c|c|c|c|c|c|c|c|c|}
\hline \multicolumn{2}{|c|}{ Floor \# } & $2^{\text {nd }}$ & $3^{\text {rd }}$ & $4^{\text {th }}$ & $5^{\text {th }}$ & $6^{\text {th }}$ & $7^{\text {th }}$ & $8^{\text {th }}$ & 9 th & 10 th \\
\hline \multirow{2}{*}{ Modelling } & $\mathrm{Tp}\left({ }^{\circ} \mathrm{C}\right)$ & 327 & 258 & 200 & 163 & 126 & 103 & 85 & 66 & 50 \\
\cline { 2 - 12 } & $\operatorname{tp}(\mathrm{s})$ & 250 & 250 & 250 & 260 & 260 & 270 & 270 & 270 & 290 \\
\hline \multirow{2}{*}{ Experiment } & $\mathrm{Tp}\left({ }^{\circ} \mathrm{C}\right)$ & 254 & 162 & 109 & 76 & 59 & 41 & 30 & 24 & 21 \\
\cline { 2 - 11 } & $\operatorname{tp}(\mathrm{s})$ & 265 & 265 & 285 & 295 & 320 & 325 & 855 & 885 & 960 \\
\hline
\end{tabular}

Note: $T_{p}$ is the peak gas temperature and $t_{p}$ is the time when the gas reached the peak temperature

A comparison of the predicted and experimental upper layer temperatures in the vestibules of the even floors for Test CLC-I-R is presented in Figure 5-23. CUsmoke predicted higher peak upper layer temperatures in the vestibules on these floors than the experimental results. This is also shown in Table 5-7, which tabulates the predicted and experimental peak temperatures with time in the vestibules of the even floors.

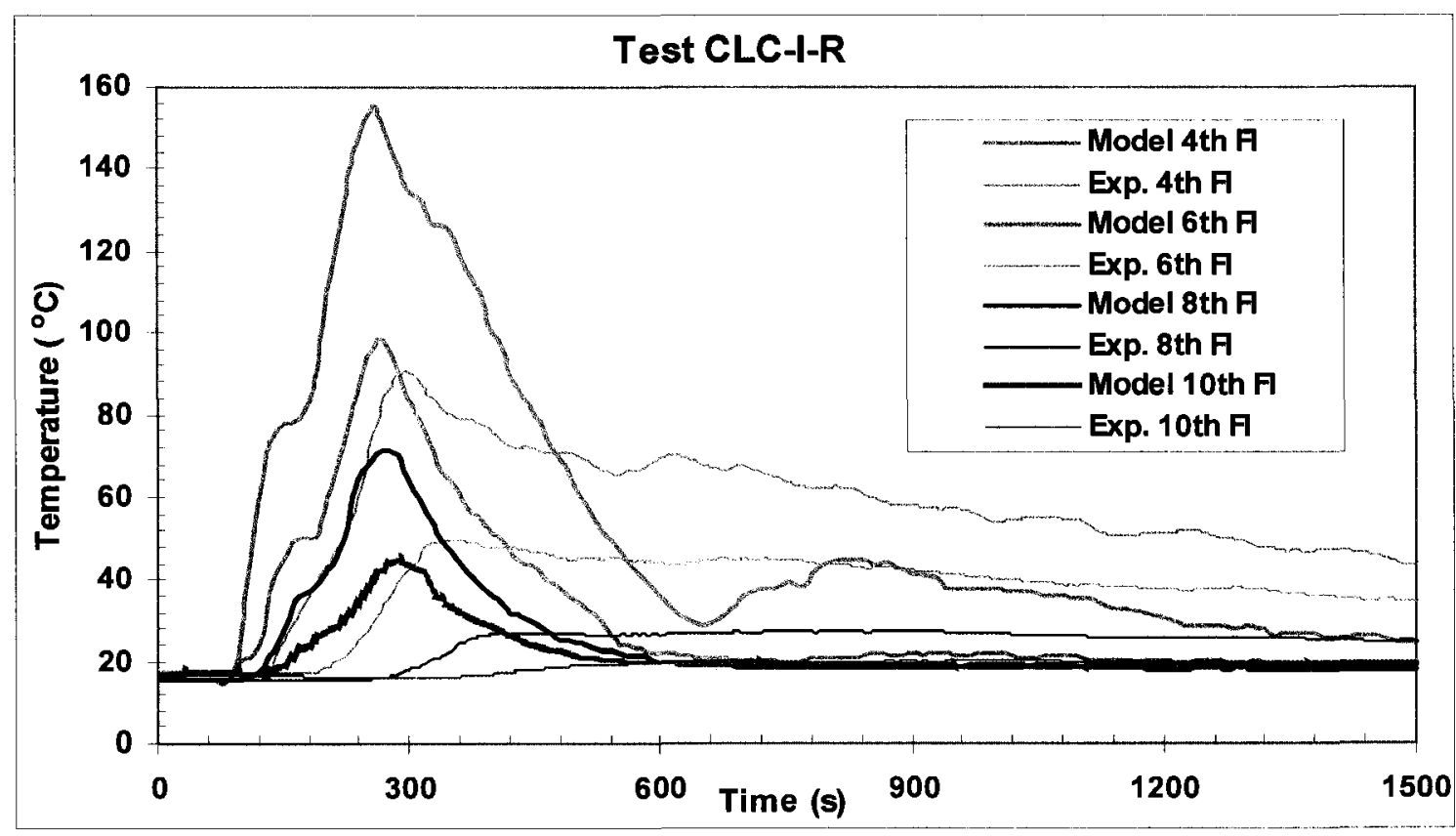

Figure 5-23: Comparison of predicted and experimental upper layer temperatures in the vestibules of even floors (Test CLC-I-R) 
Table 5-7: Comparison of predicted and experimental upper layer peak temperatures in the vestibules of even floors and corresponding times during Test CLC-I-R

\begin{tabular}{|c|c|c|c|c|c|}
\hline \multicolumn{2}{|c|}{ Floor \# } & $4^{\text {th }}$ & $6^{\text {th }}$ & $8^{\text {th }}$ & $10^{\text {th }}$ \\
\hline \multirow{2}{*}{ Modelling } & $\operatorname{Tp}\left({ }^{\circ} \mathrm{C}\right)$ & 155 & 98 & 72 & 45 \\
\cline { 2 - 6 } & $\operatorname{tp~(s)~}$ & 260 & 270 & 270 & 290 \\
\hline \multirow{2}{*}{ Experiment } & $\operatorname{Tp~(~} \mathrm{C})$ & 91 & 50 & 28 & 20 \\
\cline { 2 - 6 } & $\operatorname{tp~(s)}$ & 295 & 350 & 895 & 1010 \\
\hline
\end{tabular}

Note: $T_{p}$ is the peak gas temperature and $t_{p}$ is the time when the gas reached the peak temperature

Figure 5-24 and Table 5-8 compare the predicted and experimental upper layer temperatures in the main compartments of the $4^{\text {th }}, 8^{\text {th }}$ and $10^{\text {th }}$ floors. The predicted peak upper layer temperatures are higher than the experiment results.

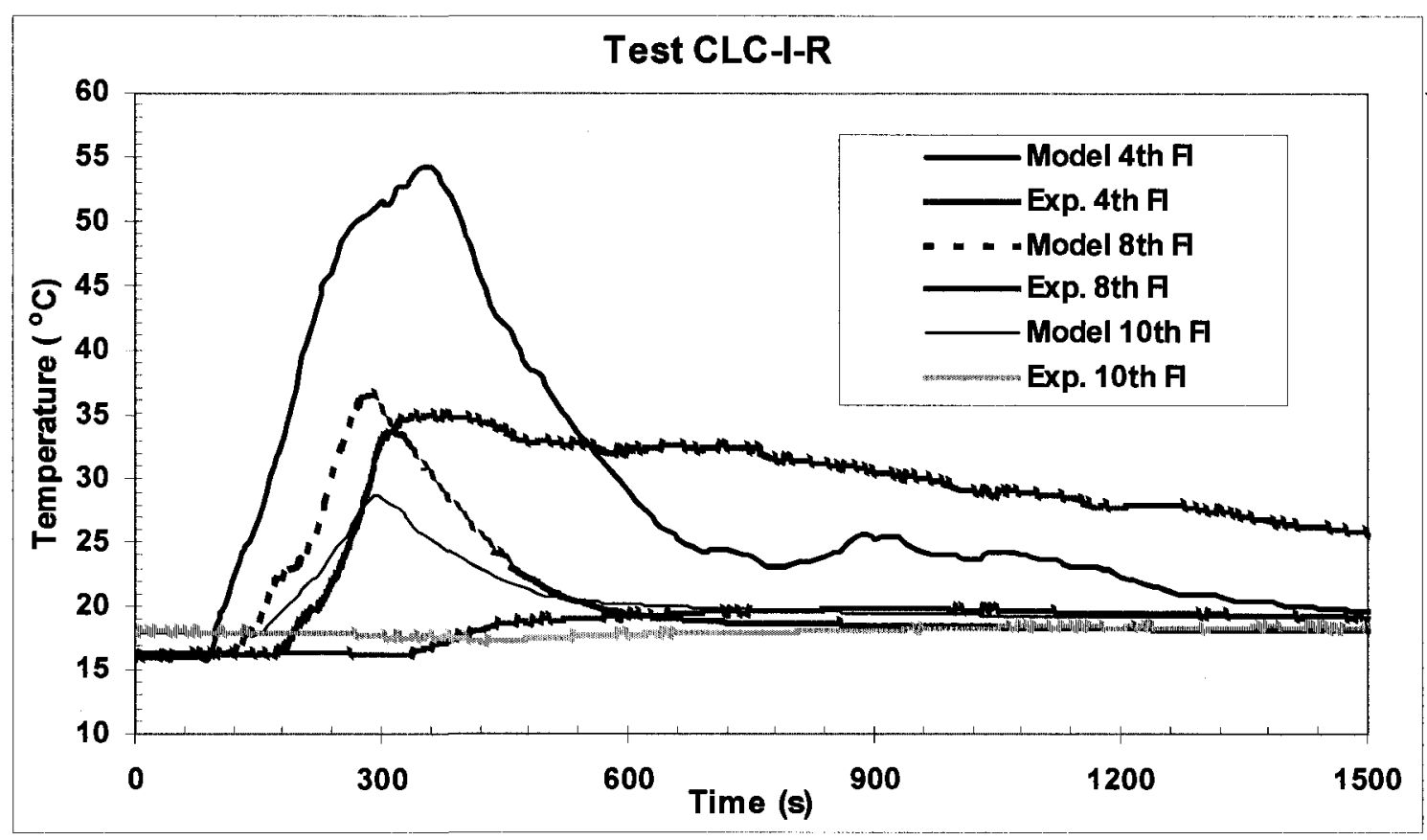

Figure 5-24: Comparison of predicted and experimental upper layer temperatures in the main compartments of the floors of the $4^{\text {th }}, 8^{\text {th }}$ and $10^{\text {th }}$ (Test CLC-I-R) 
Table 5-8: Comparison of predicted and experimental upper layer peak temperatures in the main compartments and corresponding times of the $4^{\text {th }}, 8^{\text {th }}$ and $10^{\text {th }}$ floors during

Test CLC-I-R

\begin{tabular}{|c|c|c|c|c|}
\hline \multicolumn{2}{|c|}{ Floor \# } & $4^{\text {th }}$ & $8^{\text {th }}$ & $10^{\text {th }}$ \\
\hline \multirow{2}{*}{ Modelling } & $\operatorname{Tp}\left({ }^{\circ} \mathrm{C}\right)$ & 54 & 36 & 29 \\
\cline { 2 - 5 } & $\operatorname{tp}(\mathrm{s})$ & 350 & 290 & 290 \\
\hline \multirow{2}{*}{ Experiment } & $\operatorname{Tp}\left({ }^{\circ} \mathrm{C}\right)$ & 35 & 20 & 18 \\
\cline { 2 - 5 } & $\operatorname{tp}(\mathrm{s})$ & 340 & 910 & 1055 \\
\hline
\end{tabular}

Note: $T_{p}$ is the peak gas temperature and $t_{p}$ is the time when the gas reached the peak temperature

\subsubsection{Test CMP-R}

CUsmoke was used to model Test CMP-R. For this the measured HRR during the test was used as input to the model.

Figure 5-25 shows the input HRR and the HRR predicted by the model. As the figure shows the input heat release rate was reduced in the model due to the lack of oxygen in the compartment.

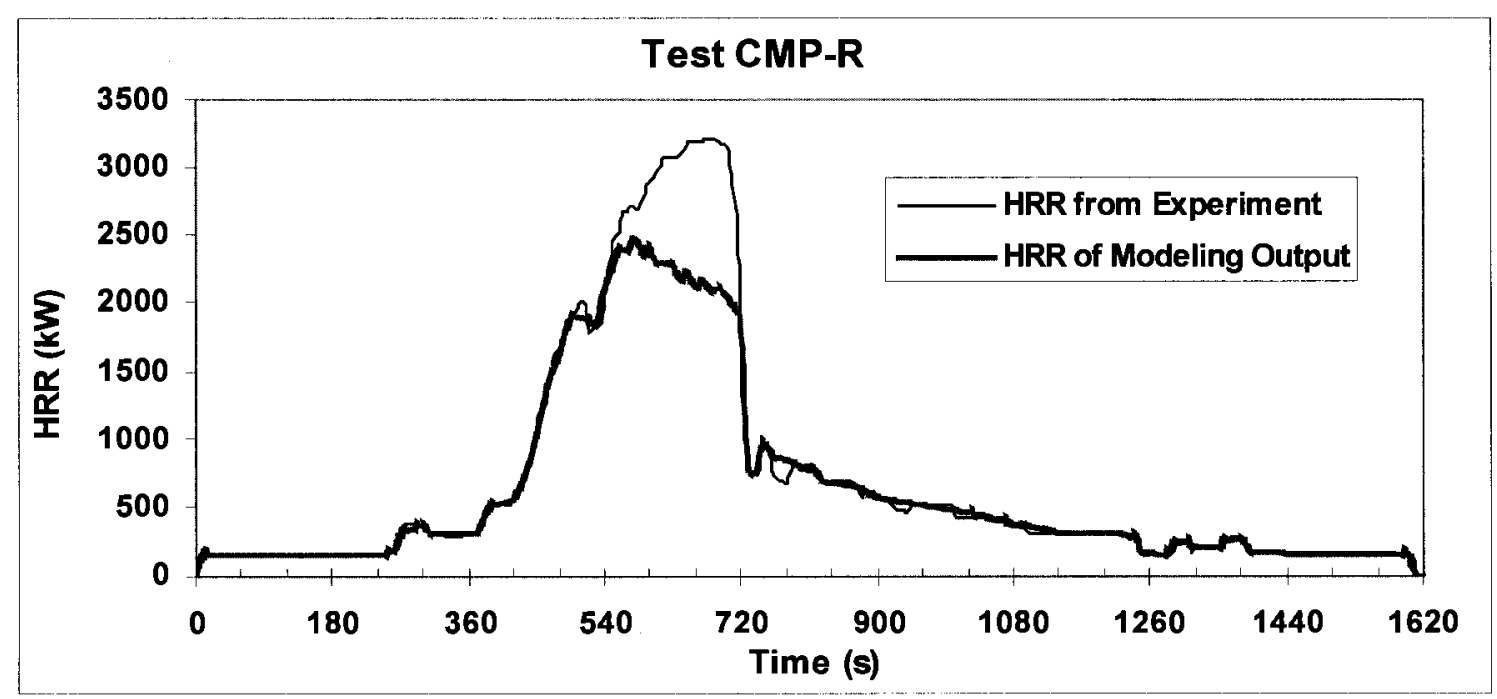

Figure 5-25: Nominal input HRR and model output HRR (Test CMP-R) 
The low oxygen concentration can be seen in Figure 5-26, which shows the predicted and experimental upper layer concentrations of $\mathrm{O}_{2}$ and $\mathrm{CO}_{2}$ in the stair shaft at the fire floor. The predicted HRR is the same as the input HRR until at about $550 \mathrm{~s}$ after the ignition. With the drop of the concentration of oxygen in the stair shaft at the fire floor to as low as $2.22 \%$ at $720 \mathrm{~s}$ the model cannot produce the input HRR resulting in a reduced predicted HRR. After this time, the concentration oxygen started to increase so that it could support the production of the input $H R R$.

A comparison of the predicted and experimental concentrations of oxygen, Figure 5-26 shows that the model initially predicted oxygen concentrations that compare well with the experimental values, however the predicted oxygen concentration continued to decrease reaching $2.22 \%$ at $720 \mathrm{~s}$. The lowest concentration of oxygen in the experiment was $10.81 \%$ at $680 \mathrm{~s}$. This could be due to mixing of fresh air with smoke in that area, a phenomenon that the model does not predict well.

Figure 5-26 also shows the predicted and experimental concentrations of $\mathrm{CO}_{2}$ in the stair shaft at the fire floor. As with the oxygen concentration the model predicts well the concentration of $\mathrm{CO}_{2}$ during the early stages of the fire, however the predicted $\mathrm{CO}_{2}$ concentration continues to rise reaching a peak value of about $10.08 \%$ at $730 \mathrm{~s}$. The experimental peak value was $6.4 \%$ at $670 \mathrm{~s}$. This difference can also be attributed to the mixing of air with smoke that occurs in the stair shaft at that height. 


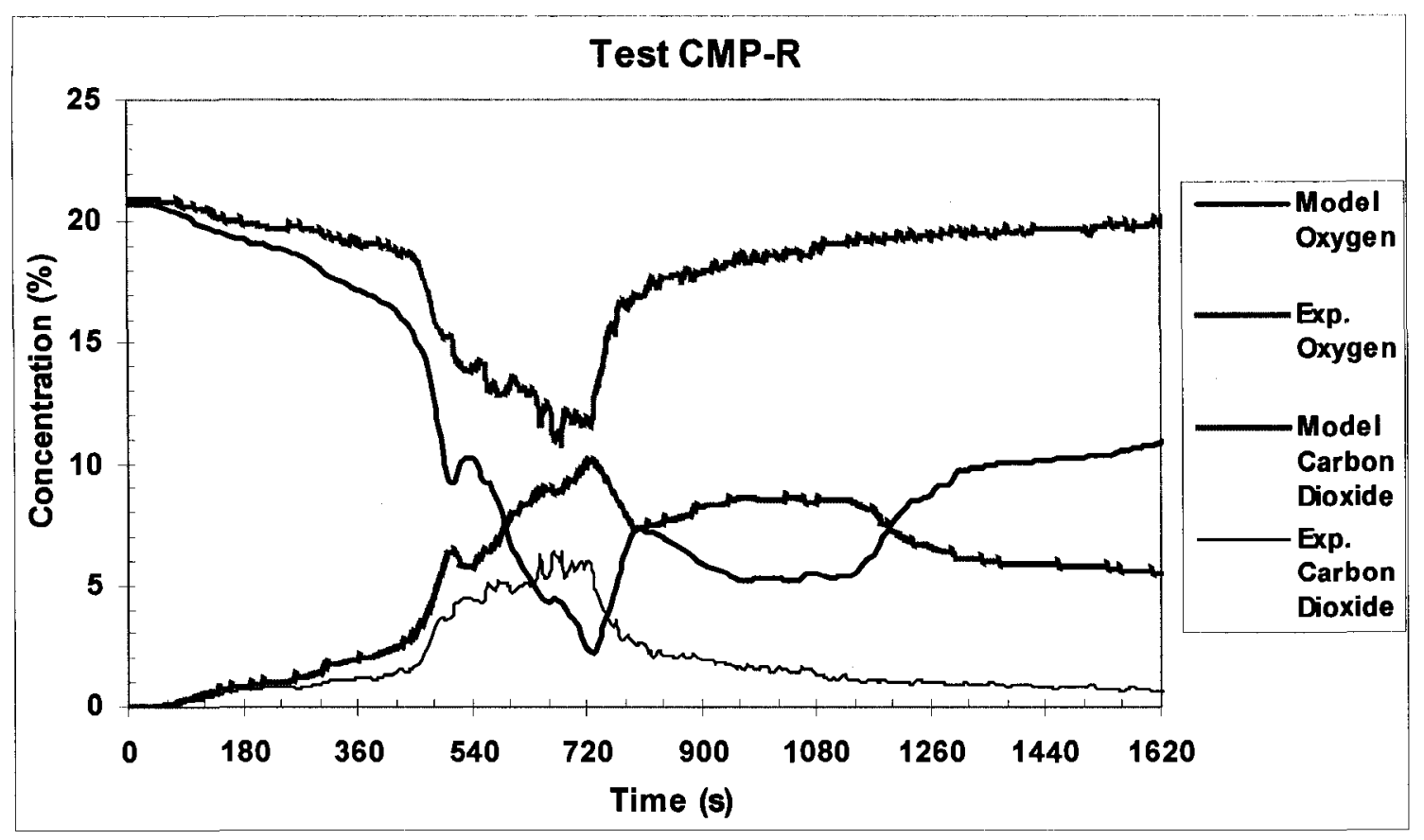

Figure 5-26: Comparison of predicted and experimental upper layer concentration of $\mathrm{O}_{2}$ and $\mathrm{CO}_{2}$ in the stair shaft at the fire floor (Test CMP-R)

Figure 5-27 compares the predicted and the experimental upper layer temperatures in the fire compartment and the doorway for Test CMP-R. The figure shows that the predicted and the experimental results compare very well during the growth phase of the fire. However, after flashover, the model starts to over predict the upper layer temperature reaching a peak value of $1262^{\circ} \mathrm{C}$ at $720 \mathrm{~s}$. The peak experimental upper layer temperature at $2.57 \mathrm{~m}$ high was $847^{\circ} \mathrm{C}$ at $710 \mathrm{~s}$. The predicted peak upper layer temperature in the vestibule on the fire floor was $949^{\circ} \mathrm{C}$ at $720 \mathrm{~s}$, whereas the experimental peak temperature at the doorway area at $2.05 \mathrm{~m}$ height was $653^{\circ} \mathrm{C}$ at $710 \mathrm{~s}$.

The predicted lower layer peak temperature in the fire compartment is $464^{\circ} \mathrm{C}$. However, the experimental average lower layer temperature was about $595^{\circ} \mathrm{C}$, indicating the increased mixing that occurs at flashover between the two layers which is not properly modelled in CUsmoke. The sudden jump of the predicted upper layer temperature of the 
vestibule on the fire floor during the decay phase is similar to for the results of Test CLC-I-R simulation. An explanation of this was given in section 5.3.3.1.

The interface height predicted by CUsmoke in the fire compartment was $0.88 \mathrm{~m}$ at $720 \mathrm{~s}$, a value which is very close to the experiment value of $0.86 \mathrm{~m}$ at $710 \mathrm{~s}$.

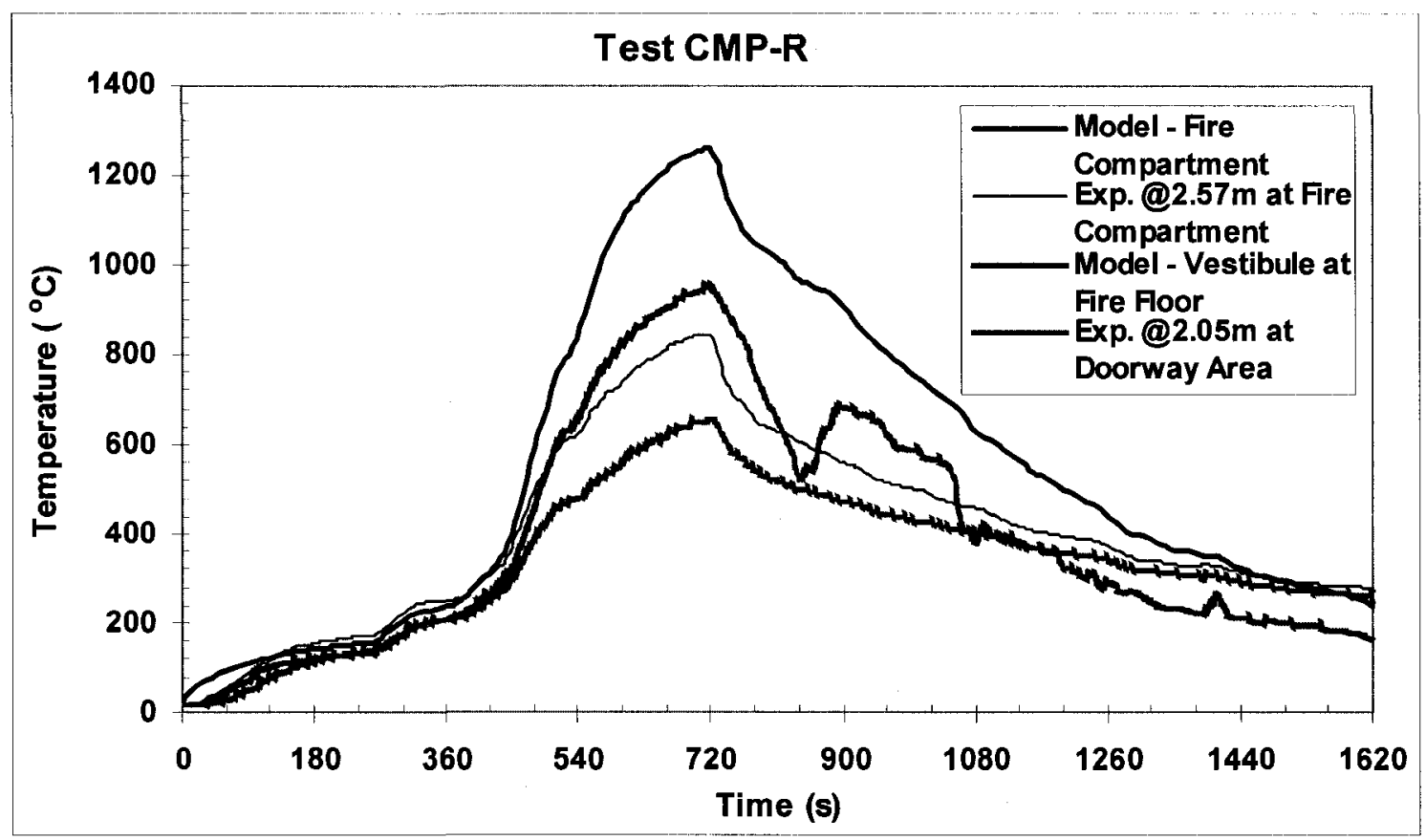

Figure 5-27: Comparison of predicted and experimental upper layer temperatures in the fire compartment and doorway (Test CMP-R)

A comparison of the predicted and the experimental temperatures in the stair shaft is shown in Figure 5-28 (2nd $\sim 5$ th floors) and Figure 5-29 (6th $\sim 10$ th floors) and also tabulated in Table 5-9. The peak temperatures in stair shaft predicted by CUsmoke are higher than the experiment results, as a result of the higher predicted compartment temperatures. 


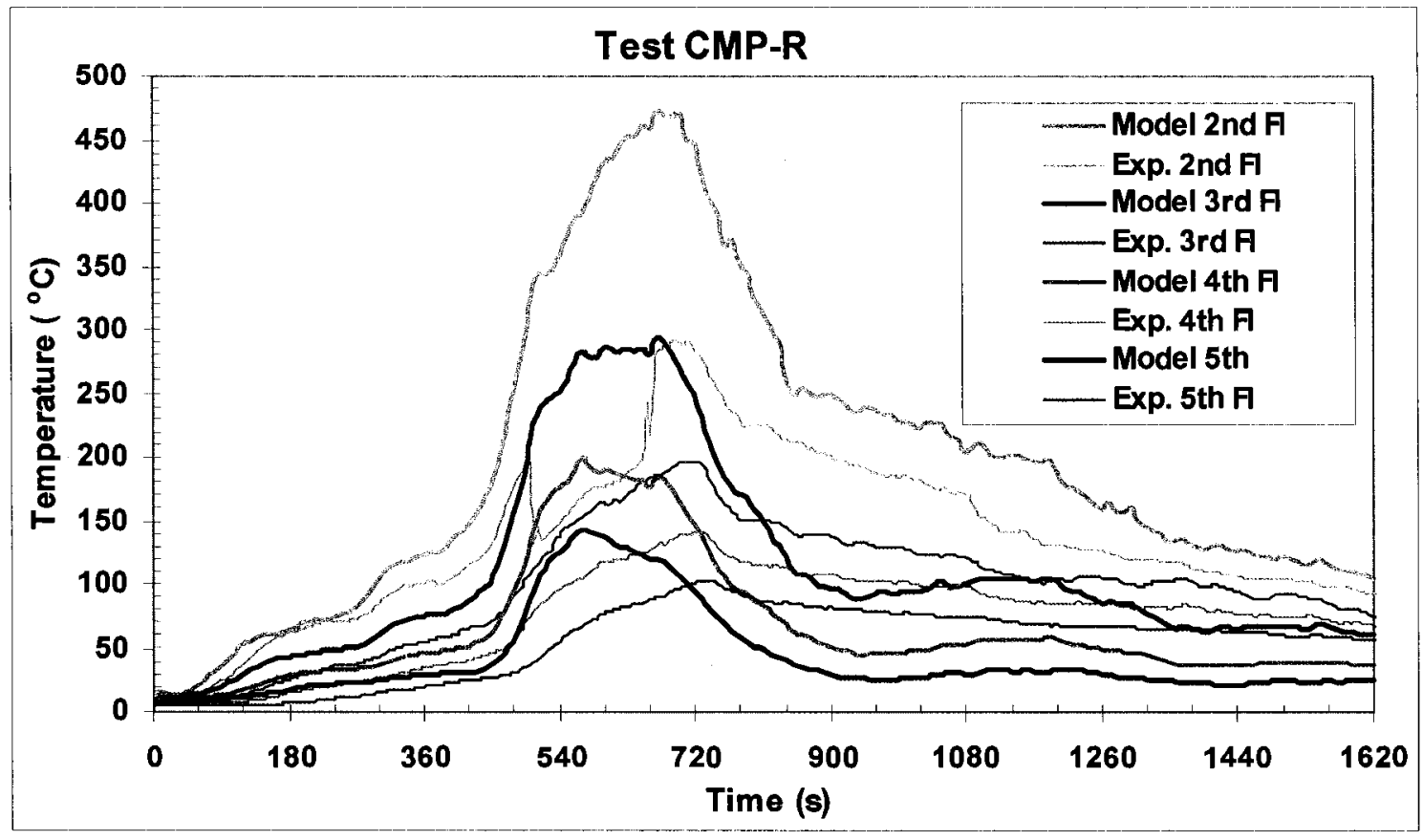

Figure 5-28: Comparison of predicted and experimental upper layer temperatures in the stair shaft at the $2^{\text {nd }}$ to $5^{\text {th }}$ floors (Test CMP-R)

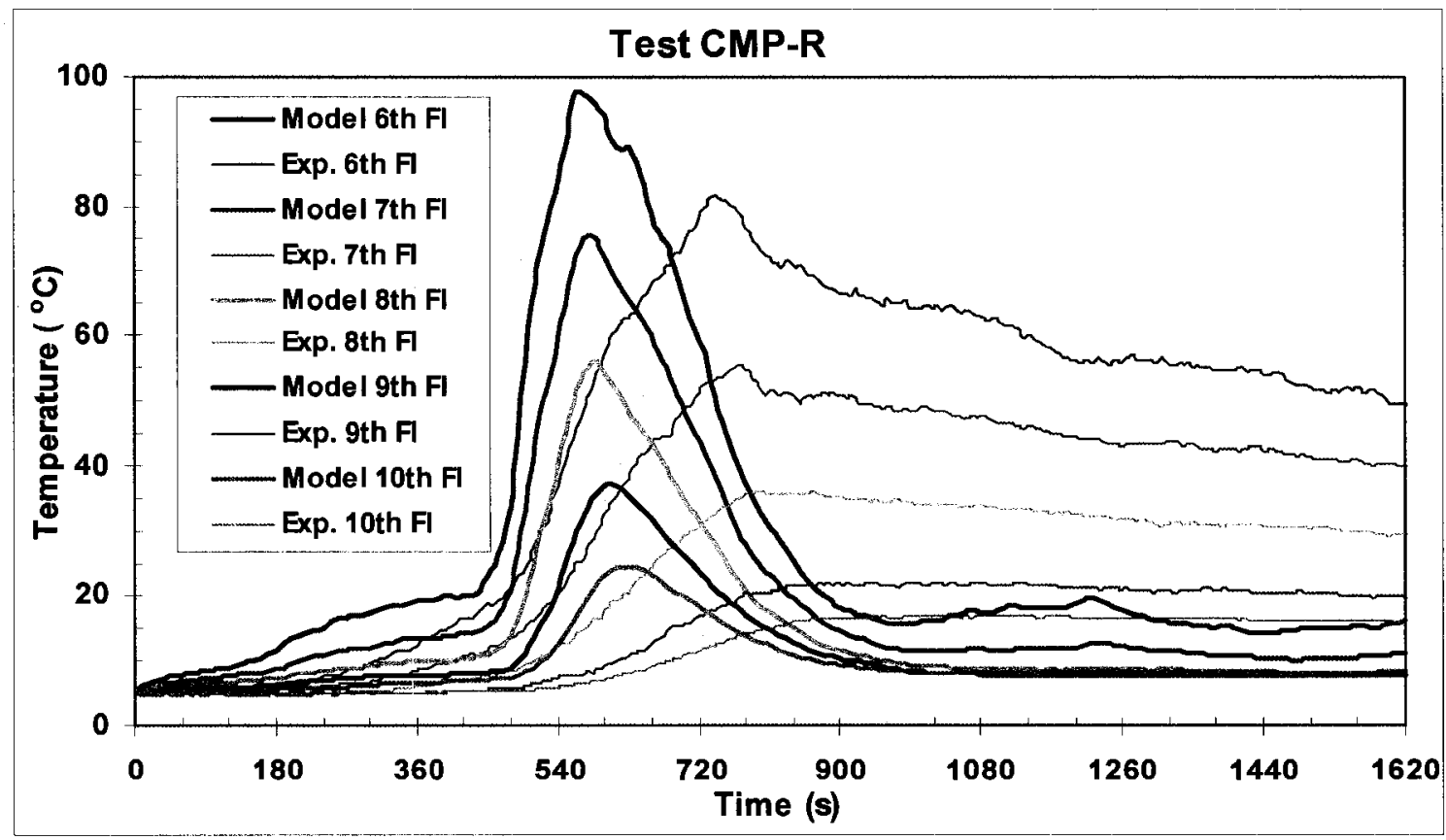

Figure 5-29: Comparison of predicted and experimental temperatures in the stair shaft at the $6^{\text {th }}$ to $10^{\text {th }}$ floors (Test CMP-R) 
Table 5-9: Comparison of predicted and experimental peak temperatures in the stair shaft and corresponding times during Test CMP-R

\begin{tabular}{|c|c|c|c|c|c|c|c|c|c|c|}
\hline \multicolumn{2}{|c|}{ Floor \# } & $2^{\text {nd }}$ & $3^{\text {rd }}$ & $4^{\text {th }}$ & $5^{\text {th }}$ & $6^{\text {th }}$ & $7^{\text {th }}$ & $8^{\text {th }}$ & $9^{\text {th }}$ & $10^{\text {th }}$ \\
\hline \multirow{2}{*}{ Modelling } & $\mathrm{T}_{\mathrm{p}}\left({ }^{0} \mathrm{C}\right)$ & 471 & 293 & 199 & 144 & 98 & 76 & 56 & 37 & 25 \\
\cline { 2 - 12 } & $\mathbf{t}_{\mathrm{p}}(\mathbf{s})$ & 700 & 670 & 570 & 570 & 570 & 580 & 590 & 610 & 620 \\
\hline \multirow{2}{*}{ Experiment } & $\mathrm{T}_{\mathrm{p}}\left({ }^{0} \mathrm{C}\right)$ & 292 & 196 & 142 & 102 & 82 & 55 & 36 & 22 & 17 \\
\cline { 2 - 12 } & $\mathbf{t}_{\mathrm{p}}(\mathbf{s})$ & 710 & 720 & 725 & 735 & 740 & 770 & 795 & 990 & 1005 \\
\hline
\end{tabular}

Note: $T_{p}$ is the peak gas temperature and $t_{p}$ is the time when the gas reached the peak temperature

Figure 5-30 and Table 5-10 compare the predicted and experimental upper layer temperatures in the vestibule of the even floors. The peak upper layer temperatures in the vestibules on even floors predicted by CUsmoke are higher than the experimental results.

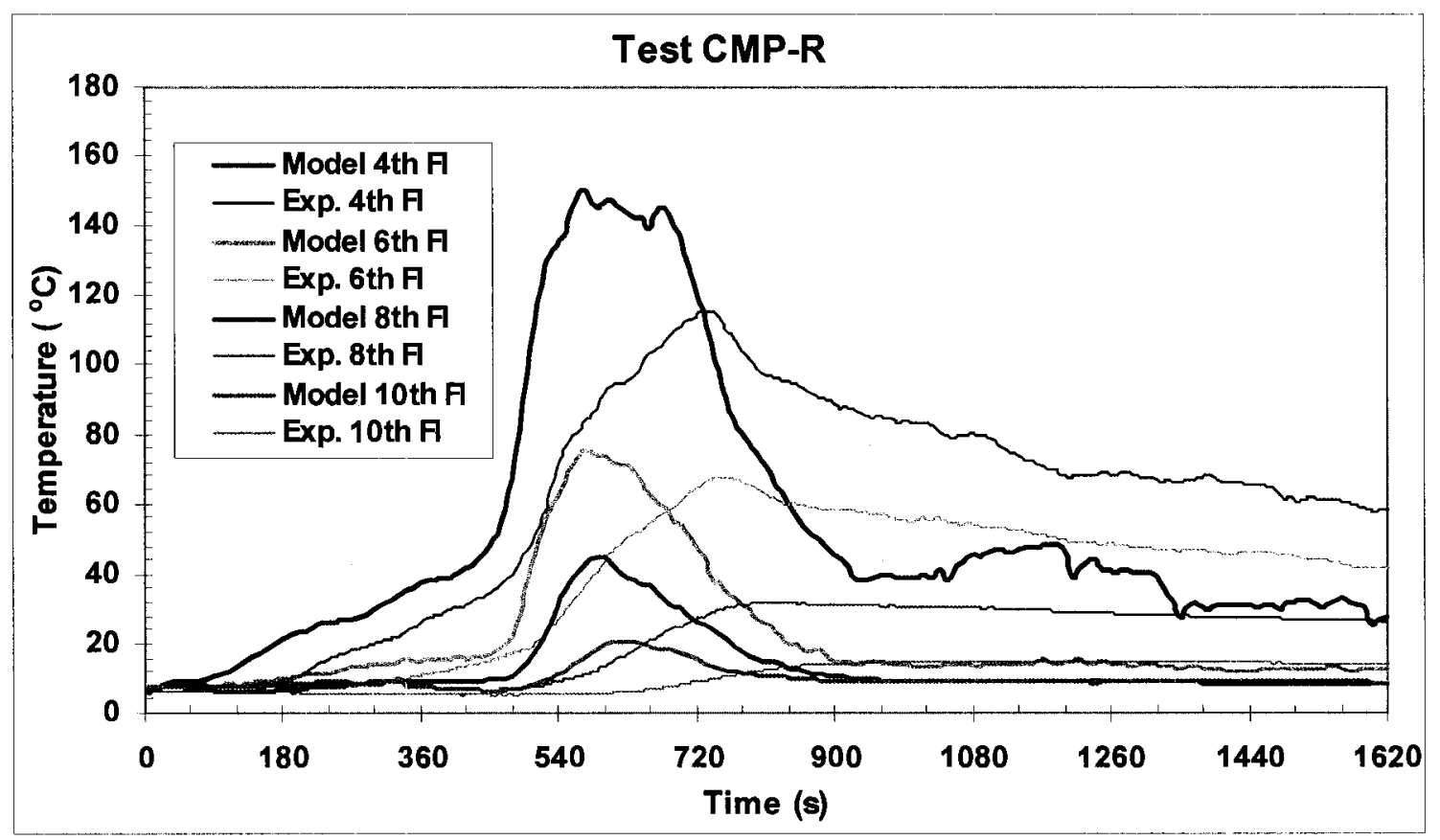

Figure 5-30: Comparison of predicted and experimental upper layer temperatures in the vestibules of even floors (Test CMP-R) 
Table 5-10: Comparison of predicted and experimental upper layer peak temperatures in the vestibules of even floors and corresponding times during Test CMP-R

\begin{tabular}{|c|c|c|c|c|c|}
\hline \multicolumn{2}{|c|}{ Floor \# } & $4^{\text {th }}$ & $6^{\text {th }}$ & $8^{\text {th }}$ & $10^{\text {th }}$ \\
\hline \multirow{2}{*}{ Modelling } & $\operatorname{Tp}\left({ }^{\circ} \mathrm{C}\right)$ & 150 & 76 & 45 & 21 \\
\cline { 2 - 6 } & $\operatorname{tp}(\mathrm{s})$ & 580 & 580 & 600 & 620 \\
\hline \multirow{2}{*}{ Experiment } & $\operatorname{Tp}\left({ }^{\circ} \mathrm{C}\right)$ & 115 & 68 & 32 & 15 \\
\cline { 2 - 6 } & $\operatorname{tp}(\mathrm{s})$ & 730 & 755 & 815 & 1120 \\
\hline
\end{tabular}

Note: $T_{p}$ is the peak gas temperature and $t_{p}$ is the time when the gas reached the peak temperature

Figure 5-31 and Table 5-11 depicts a comparison between the predicted and experimental upper layer temperatures in the main compartments of the $4^{\text {th }}, 8^{\text {th }}$ and $10^{\text {th }}$ floors. The predicted peak upper layer temperatures in these compartments are higher than the experimental results. In addition, the rate of rise during the growth phase and the rate of decease during the decay phase of the predicted temperatures in the stair shaft are higher than the rates of the experimental temperatures. This may be due to the fact that the model does not consider the presence of the steel stairs in the stair shaft. The mass of the stairs acts as a heat sink, during the growth phase, absorbing heat from the gases in the stair shaft and lowering the rate of temperature rise during the growth phase of the experiments. During the decay phase, when the temperature of the steel is higher than the temperature of the gases, the stairs act as a heat source adding heat to the stair shaft gases and slowing its temperature rate of decrease. This also affects the temperatures of the vestibules on the $4^{\text {th }}, 6^{\text {th }}, 8^{\text {th }}$ and $10^{\text {th }}$ floors, and the main compartments on the $4^{\text {th }}, 8^{\text {th }}$ and $10^{\text {th }}$ floors. 


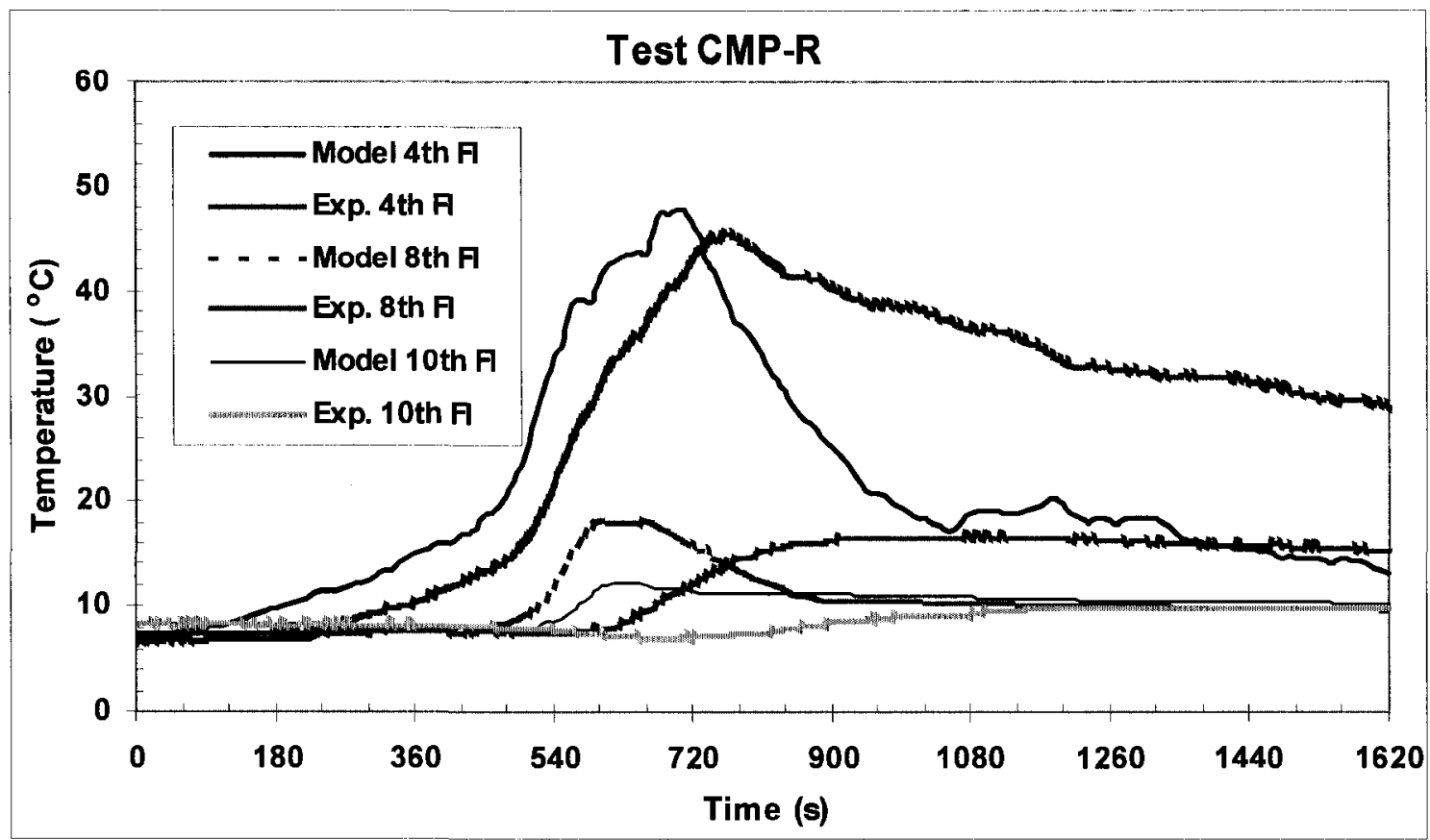

Figure 5-31: Comparison of predicted and experimental upper layer temperatures in the main compartments of the floors of the $4^{\text {th }}, 8^{\text {th }}$ and $10^{\text {th }}$ (Test CMP-R)

Table 5-11: Comparison of predicted and experimental upper layer peak temperatures in the main compartments and corresponding times of the $4^{\text {th }}, 8^{\text {th }}$ and $10^{\text {th }}$ floors during Test CMP-R

\begin{tabular}{|c|c|c|c|c|}
\hline \multicolumn{2}{|c|}{ Floor \# } & $4^{\text {th }}$ & $8^{\text {th }}$ & $10^{\text {th }}$ \\
\hline \multirow{2}{*}{ Modelling } & $\operatorname{Tp}\left({ }^{\circ} \mathrm{C}\right)$ & 48 & 18 & 12 \\
\cline { 2 - 5 } & $\operatorname{tp}(\mathrm{s})$ & 700 & 610 & 630 \\
\hline \multirow{2}{*}{ Experiment } & $\operatorname{Tp}\left({ }^{\circ} \mathrm{C}\right)$ & 45 & 17 & 10 \\
\cline { 2 - 5 } & $\operatorname{tp}(\mathrm{s})$ & 760 & 1075 & 1285 \\
\hline
\end{tabular}

Note: $T_{p}$ is the peak gas temperature and $t_{p}$ is the time when the gas reached the peak temperature

\subsubsection{Test PP-II}

CUsmoke was used to simulate the propane test PP-II. As shown in Figure 5-32, this test had a long incipient phase during which the HRR was low and then the HRR increased rapidly to about $2.8 \mathrm{MW}$. 


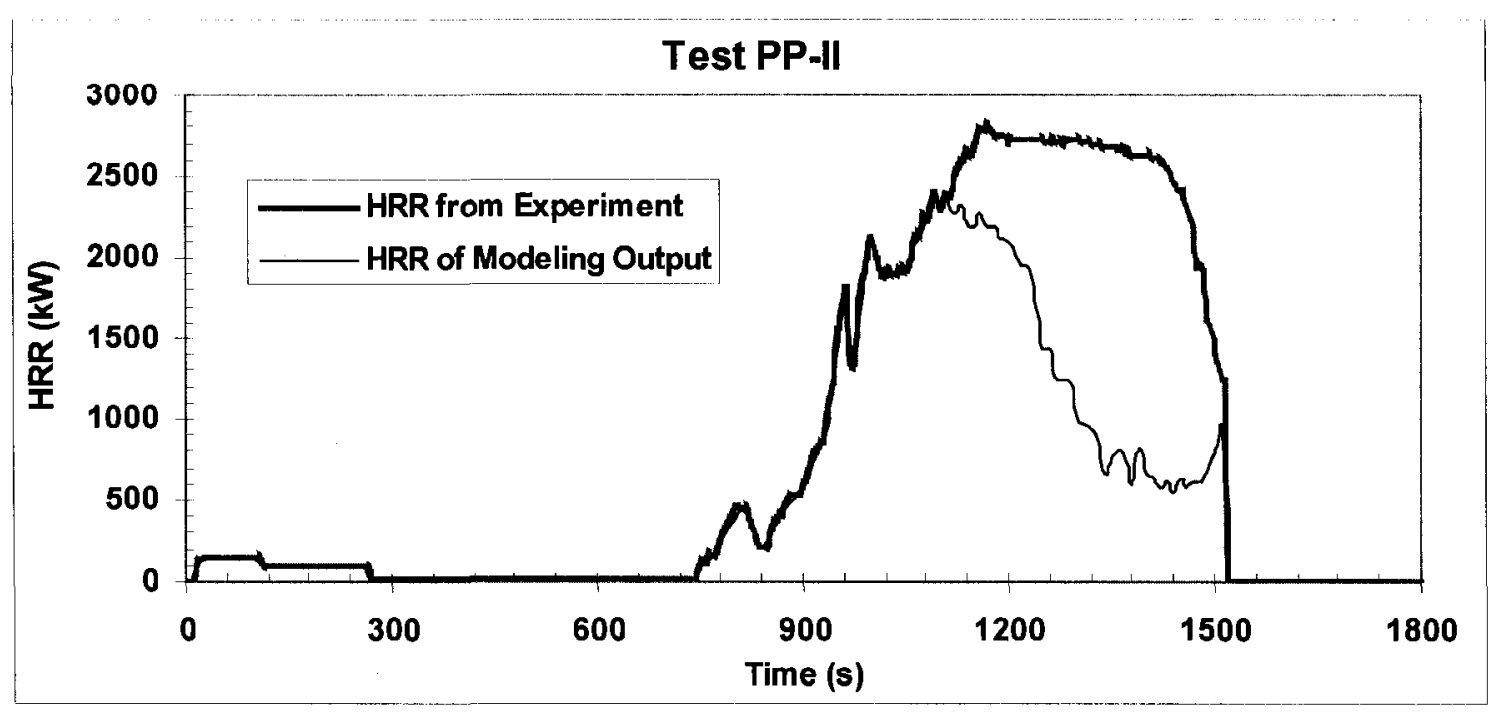

Figure 5-32: Nominal input HRR and model output HRR (Test PP-II)

Figure 5-32 shows that the calculated HRR follows nicely the input curve up to about $1070 \mathrm{~s}$. After this time the calculated HRR is lower than the input HRR indicating that there is not enough oxygen in the compartment to support combustion. This can be seen in Figure 5-33, which depicts concentrations of $\mathrm{O}_{2}$ and $\mathrm{CO}_{2}$ in the stair shaft at the fire floor. After $1070 \mathrm{~s}$ the oxygen concentration starts to decrease reaching about $2 \sim 2.5 \%$ and stays at that level until about $1540 \mathrm{~s}$. The figure shows that the lowest experimental concentration of oxygen was about $12.55 \%$ at $1175 \mathrm{~s}$. In terms of concentration of $\mathrm{CO}_{2}$, the model predicted a high concentration of $10.24 \%$ at $1260 \mathrm{~s}$, whereas the experimental data reached a high of $5.2 \%$ at $1175 \mathrm{~s}$. 


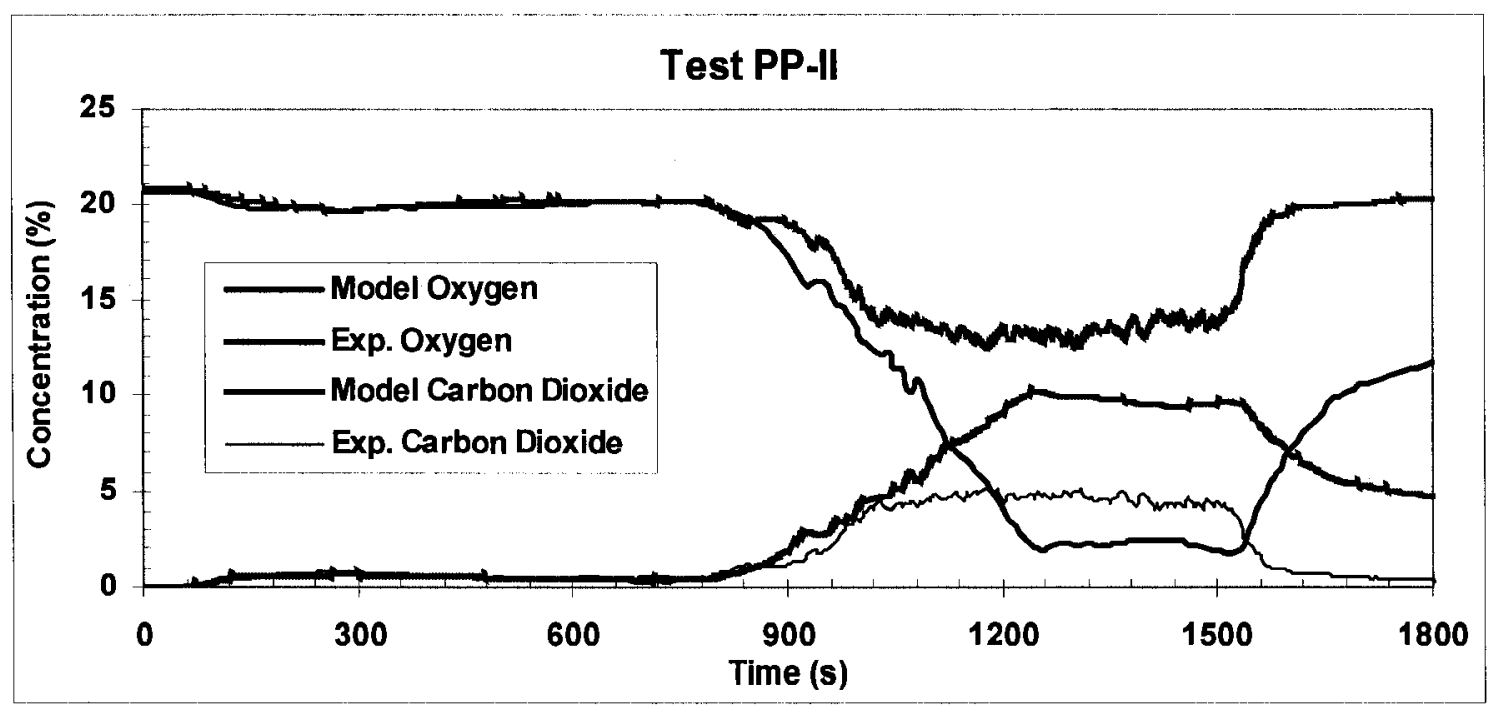

Figure 5-33: Comparison of predicted and experimental upper layer concentration of $\mathrm{O}_{2}$ and $\mathrm{CO}_{2}$ in the stair shaft at the fire floor (Test PP-II)

Figure 5-34 presents a comparison of predicted and experimental upper layer temperatures in the fire compartment and the vestibule on the fire floor. The predicted and experimental temperatures compare well until the temperature reaches $600^{\circ} \mathrm{C}$, flashover criterion. After this time the predicted temperatures are higher than the experimental. The upper layer temperature in the fire compartment reaches $1274^{\circ} \mathrm{C}$ at $1240 \mathrm{~s}$, while the experimental temperature at $2.57 \mathrm{~m}$ height in the fire compartment was $880^{\circ} \mathrm{C}$ at $1415 \mathrm{~s}$. The predicted peak upper layer temperature in the vestibule of the fire floor was $958^{\circ} \mathrm{C}$ at $1230 \mathrm{~s}$ and the experimental gas temperature at $1.65 \mathrm{~m}$ height at the doorway area was $646^{\circ} \mathrm{C}$ at $1445 \mathrm{~s}$. As discussed above this difference is attributed to the fact the model was not developed to handle the flashover phenomenon. This is also supported by the difference in the lower layer temperatures in the fire compartment. The predicted peak lower-layer temperature is $514^{\circ} \mathrm{C}$ and the experimental about $680^{\circ} \mathrm{C}$. 
The predicted interface height in the fire compartment is $0.88 \mathrm{~m}$ at $1240 \mathrm{~s}$, whereas the experimental value was $0.86 \mathrm{~m}$ at $1415 \mathrm{~s}$.

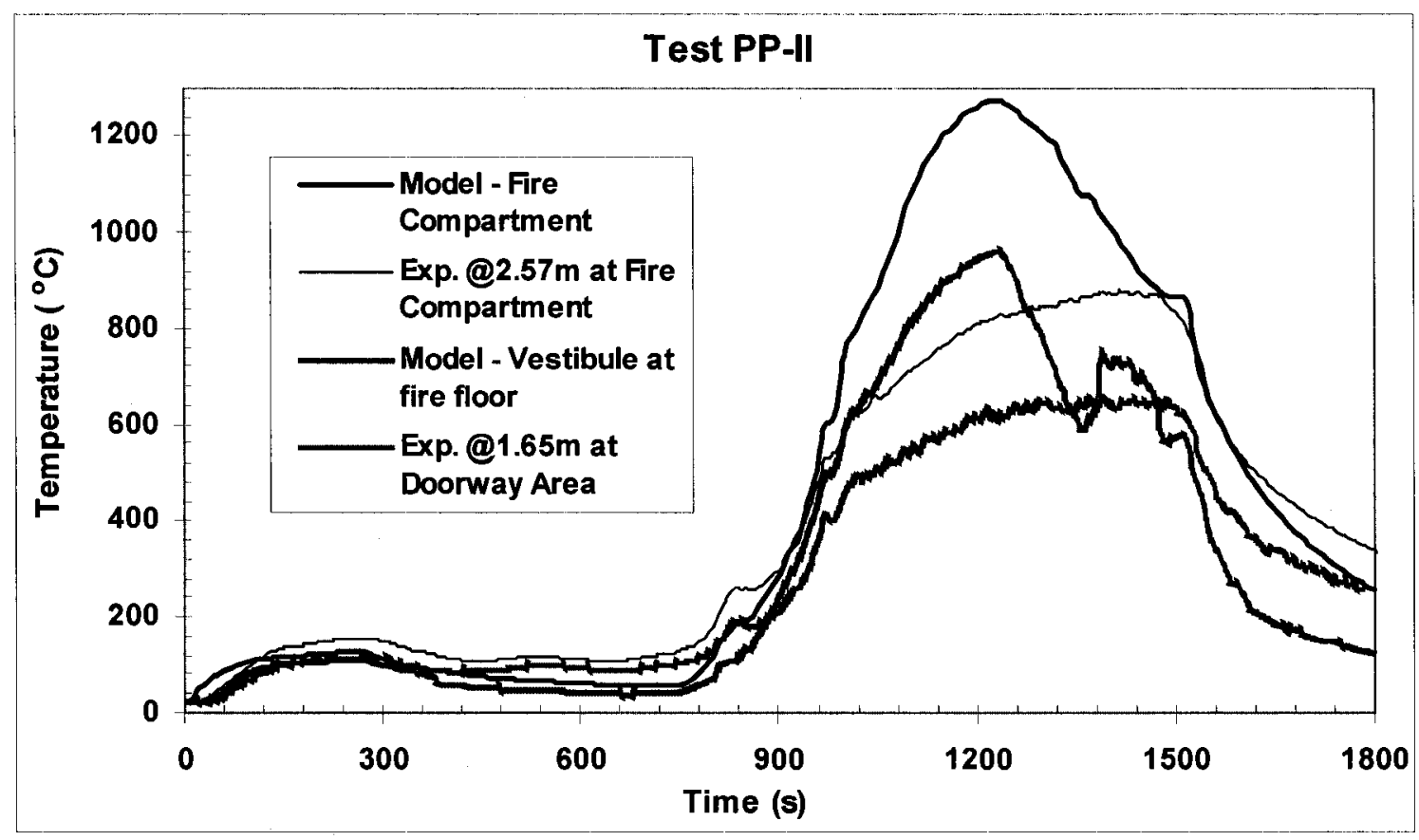

Figure 5-34: Comparison of predicted and experimental upper layer temperatures in the fire compartment and doorway (Test PP-II)

A comparison between the predicted and experimental upper layer temperatures in the stair shaft is shown in Figure 5-35 $\left(2^{\text {nd }} \sim 5^{\text {th }}\right.$ floors $)$ and Figure 5-36 $\left(6^{\text {th }} \sim 10^{\text {th }}\right.$ floors $)$ and also in Table 5-12. The predicted temperatures in the lower floors are in reasonable agreement with the experimental temperatures, however in the upper floors the predictions are quite poor. The predicted temperatures reach much earlier their peak values and then start to decrease rapidly, while the experimental temperatures increase at a much slower rate until they reach their peak values and then decrease slowly. The predictions can be considered as conservative as they show a higher threat to the occupants using the stairs for evacuation at earlier times. 


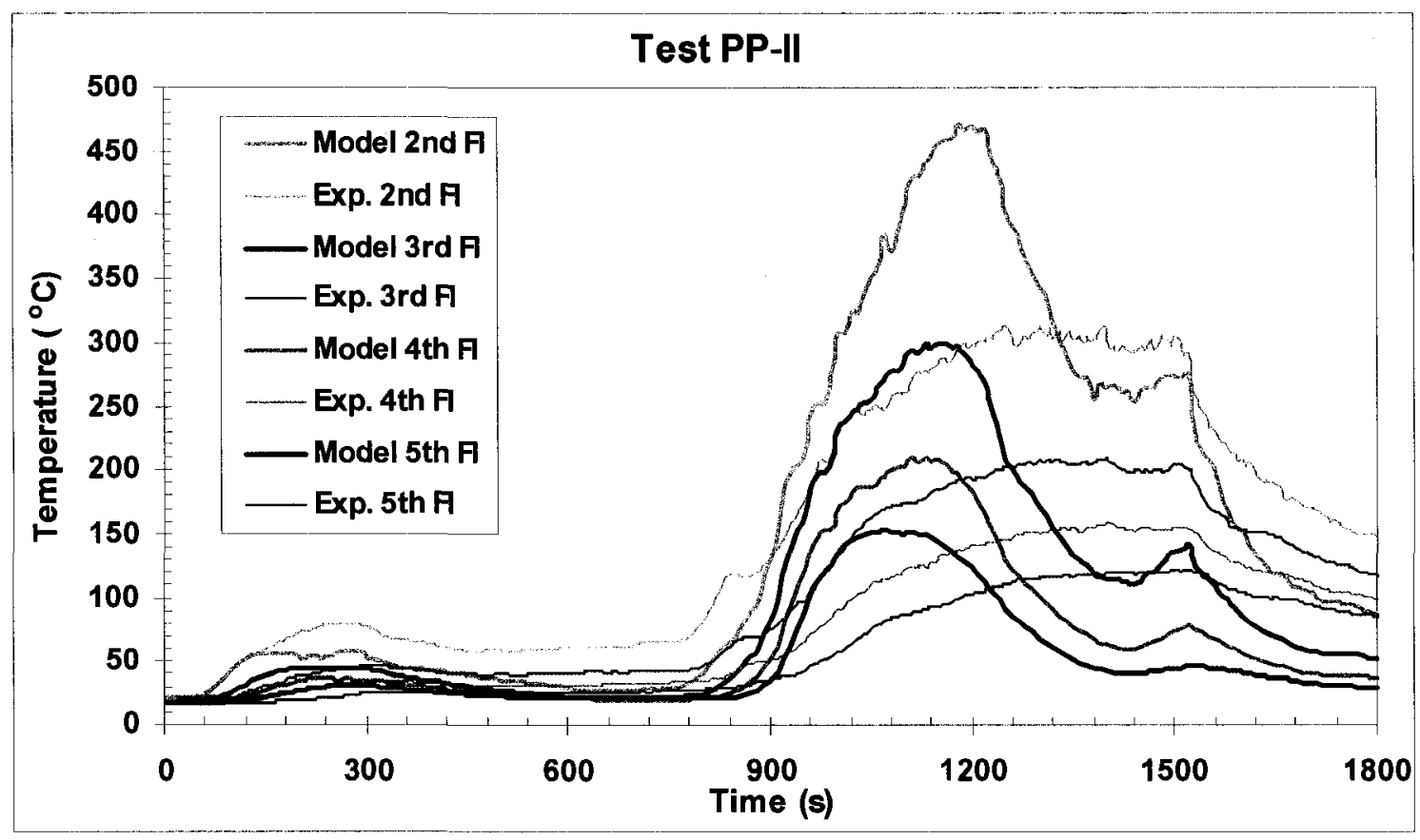

Figure 5-35: Comparison of predicted and experimental upper layer temperatures in the stair shaft at the $2^{\text {nd }}$ to $5^{\text {th }}$ floors (Test PP-II)

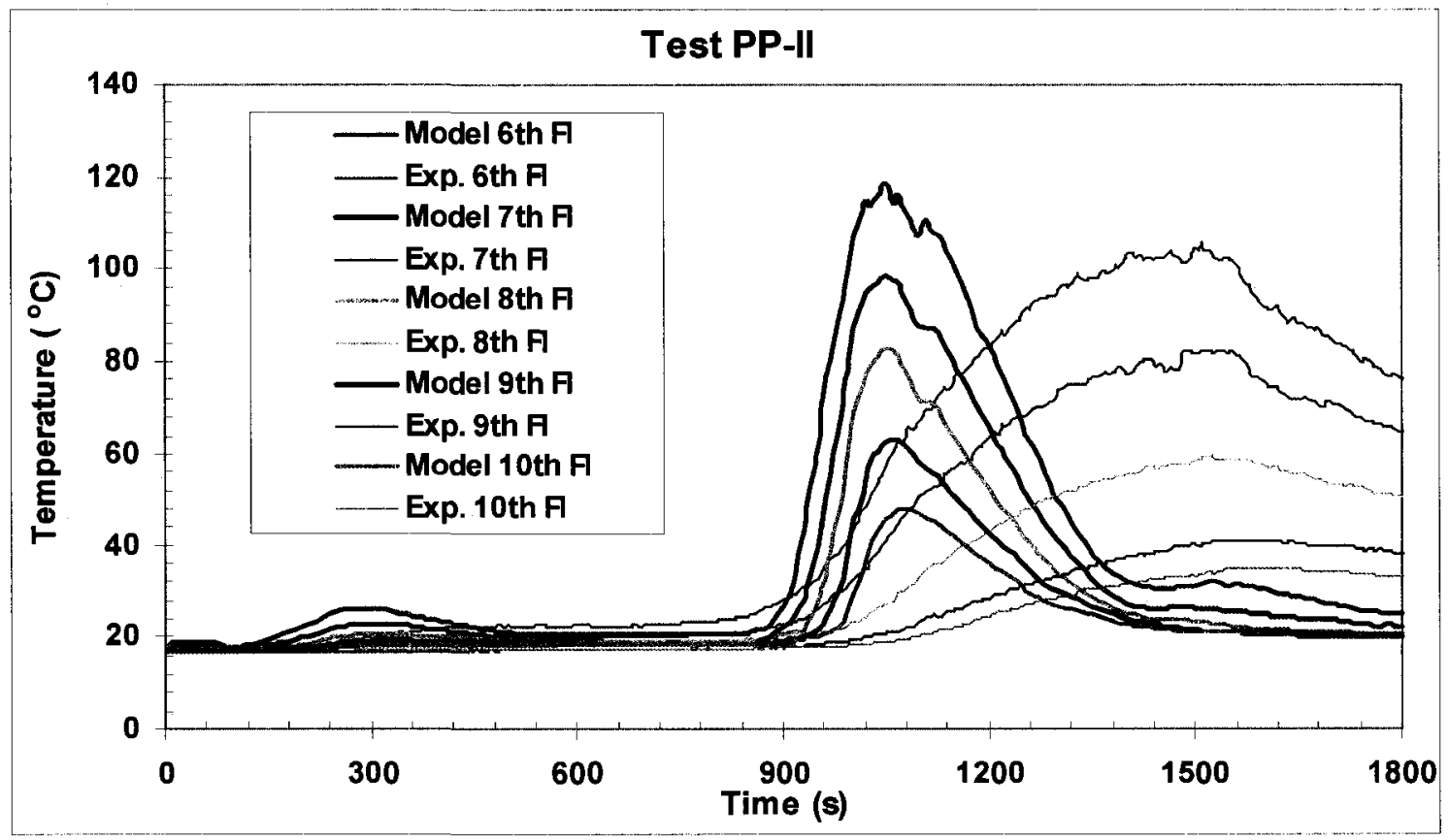

Figure 5-36: Comparison of predicted and experimental temperatures in the stair shaft at the $6^{\text {th }}$ to $10^{\text {th }}$ floors (Test PP-II) 
Table 5-12: Comparison of predicted and experimental peak temperatures in the stair shaft and corresponding times during Test PP-II

\begin{tabular}{|c|c|c|c|c|c|c|c|c|c|c|}
\hline \multicolumn{2}{|c|}{ Floor \# } & $2^{\text {nd }}$ & $3^{\text {rd }}$ & $4^{\text {th }}$ & $5^{\text {th }}$ & $6^{\text {th }}$ & $7^{\text {th }}$ & $8^{\text {th }}$ & $9^{\text {th }}$ & $10^{\text {th }}$ \\
\hline \multirow{2}{*}{ Modelling } & $\operatorname{Tp}\left({ }^{\circ} \mathrm{C}\right)$ & 471 & 300 & 210 & 154 & 119 & 99 & 83 & 63 & 48 \\
\cline { 2 - 12 } & $\operatorname{tp}(\mathrm{s})$ & 1180 & 1150 & 1130 & 1070 & 1050 & 1050 & 1050 & 1060 & 1070 \\
\hline \multirow{2}{*}{ Experiment } & $\mathrm{Tp}\left({ }^{\circ} \mathrm{C}\right)$ & 307 & 205 & 156 & 122 & 104 & 82 & 59 & 41 & 35 \\
\cline { 2 - 11 } & $\mathrm{tp}(\mathrm{s})$ & 1480 & 1505 & 1510 & 1520 & 1520 & 1540 & 1570 & 1590 & 1630 \\
\hline
\end{tabular}

Note: $T_{p}$ is the peak gas temperature and $t_{p}$ is the time when the gas reached the peak temperature

Figure 5-37 and Table 5-13 show a comparison between the predicted and experimental upper layer temperatures in the vestibule of the even floors of Test PP-II. The predicted peak upper layer temperatures show similar trends as seen in the stair shaft, with the predicted temperatures reaching their peak much earlier than the experiment. A similar trend can be seen in Figure 5-38 and Table 5-14, which show upper layer temperatures in the compartments of the $4^{\text {th }}, 8^{\text {th }}$ and $10^{\text {th }}$ floors.

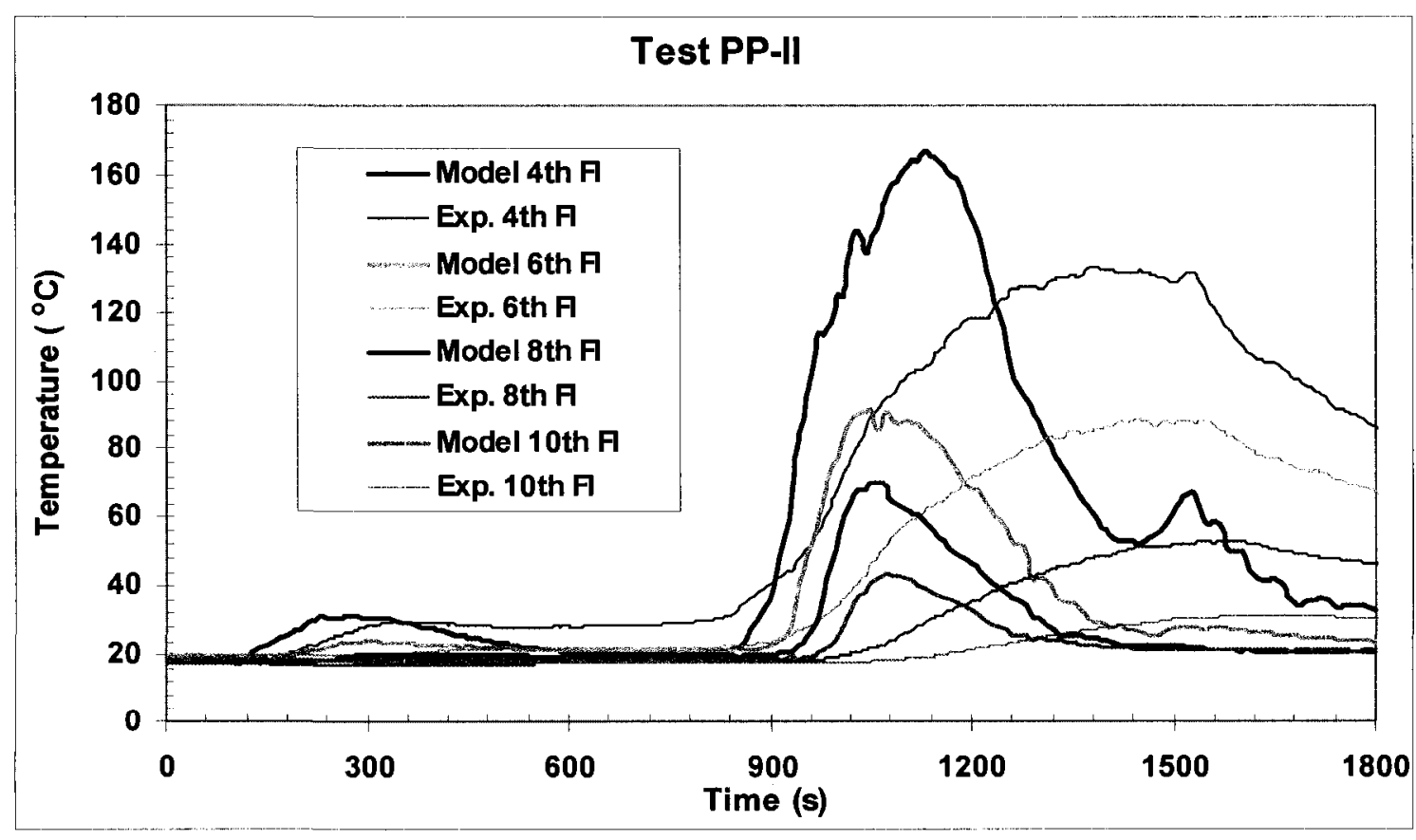

Figure 5-37: Comparison of predicted and experimental upper layer temperature in the vestibules of even floors (Test PP-II) 
Table 5-13: Comparison of predicted and experimental upper layer peak temperatures in the vestibules of even floors and corresponding times during Test PP-II

\begin{tabular}{|c|c|c|c|c|c|}
\hline \multicolumn{2}{|c|}{ Floor \# } & $4^{\text {th }}$ & $6^{\text {th }}$ & $8^{\text {th }}$ & $10^{\text {th }}$ \\
\hline \multirow{2}{*}{ Modelling } & $\operatorname{Tp}\left({ }^{\circ} \mathrm{C}\right)$ & 167 & 92 & 70 & 43 \\
\cline { 2 - 6 } & $\operatorname{tp}(\mathrm{s})$ & 1130 & 1050 & 1050 & 1070 \\
\hline \multirow{2}{*}{ Experiment } & $\operatorname{Tp}\left({ }^{\circ} \mathrm{C}\right)$ & 132 & 88 & 53 & 32 \\
\cline { 2 - 6 } & $\mathrm{tp}(\mathrm{s})$ & 1410 & 1540 & 1590 & 1640 \\
\hline
\end{tabular}

Note: $T_{p}$ is the peak gas temperature and $t_{p}$ is the time when the gas reached the peak temperature

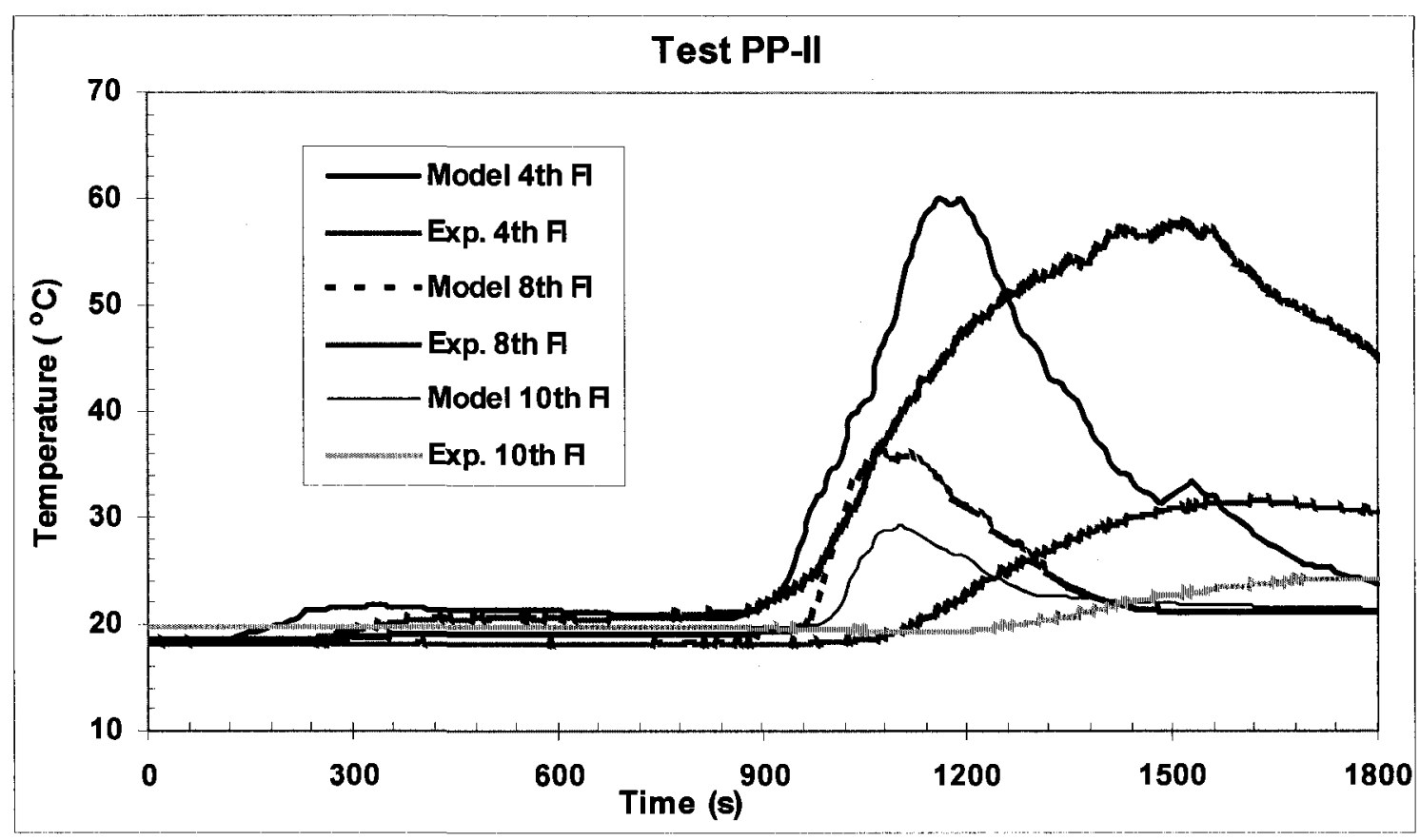

Figure 5-38: Comparison of predicted and experimental upper layer temperature in the main compartments of the floors of the $4^{\text {th }}, 8^{\text {th }}$ and $10^{\text {th }}$ (Test PP-II)

Table 5-14: Comparison of predicted and experimental upper layer peak temperatures in the main compartments and corresponding times of the $4^{\text {th }}, 8^{\text {th }}$ and $10^{\text {th }}$ floors during

Test PP-II

\begin{tabular}{|c|c|c|c|c|}
\hline \multicolumn{2}{|c|}{ Floor \# } & $4^{\text {th }}$ & $8^{\text {th }}$ & $10^{\text {th }}$ \\
\hline \multirow{2}{*}{ Modelling } & $\mathrm{Tp}\left({ }^{\circ} \mathrm{C}\right)$ & 60 & 36 & 29 \\
\cline { 2 - 5 } & $\operatorname{tp}(\mathrm{s})$ & 1190 & 1070 & 1110 \\
\hline \multirow{2}{*}{ Experiment } & $\mathrm{Tp}\left({ }^{\circ} \mathrm{C}\right)$ & 58 & 32 & 24 \\
\cline { 2 - 5 } & $\operatorname{tp}(\mathrm{s})$ & 1510 & 1625 & 1735 \\
\hline
\end{tabular}

Note: $T_{p}$ is the peak gas temperature and $t_{p}$ is the time when the gas reached the peak temperature 


\subsection{Summary and Analysis}

To summarize, CUsmoke was used to model fire tests done in three different buildings. One test in a single-compartment building; one test in a single-storey building with twocompartments and three tests in a multi-storey, multi-compartment building examples. The predicted results were compared with the experimental data to see how well the model can predict smoke movement in different buildings.

In the single-compartment example, four sets of fires were modeled, and the upper layer temperatures predicted by CUsmoke model were found to be close to the experimental values, especially for the smaller HRR fires. For multi-compartment buildings the upper layer temperatures predicted by CUsmoke were higher than the experimental results, especially after the time when the upper layer temperature in the fire compartment reaches $600^{\circ} \mathrm{C}$. This difference can be attributed to the fact that CUsmoke is developed to handle fires in which the two layers remain distinct without much intermixing of the gases. The intense mixing that occurs during and after flashover is not considered in the model. The over-estimated temperatures propagate in the adjacent compartments and stair shaft causing significant differences with the experimental values in these compartments. As a result the predicted lower layer temperatures are lower than the experimental.

The over-prediction by CUsmoke of the upper layer temperature in the fire compartment after flashover produces conservative results, especially in the stair shaft where the conditions deteriorate at earlier times, reducing the time available for occupants to evacuate. 


\section{Conclusions and Recommendations}

The main objectives of this study were the following:

(a) to compare the smoke movement characteristics of different fires using the realistic data generated from full-scale experiments;

(b) to estimate the heat release rate of real fuel package fires; and

(c) to validate the computer model CUsmoke by comparing its predictions with the experimental data.

Below are the conclusions and some recommendations from this study.

\subsection{Conclusions}

(1) The fuel package fires with fire loads containing the same fuel components but different fire load densities have similar fire growth rates but different peak heat release rates.

(2) The temperatures in the stair shaft, vestibules and the main compartments of upper floors during the ventilation controlled fuel package fires were higher than the fuel controlled fuel package fires of similar fire load densities. This is due to combustion of unburned hydrocarbons taking place in the vestibule and stair shaft. 
(3) The gas temperatures in the stair shaft, the vestibules and the main compartments of fuel package fires are lower than the propane fires with the same heat release rate and under the same test conditions. This is due to the production of more soot by the fuel package fires, resulting in increased heat loss by radiation.

(4) The method of estimating heat release rate of the fuel package fires by re-producing the temperature-time curve in the fire compartment of the fuel package fires using propane fires, resulted in good prediction of the heat release rate in the fire compartment. Such a method can be used in cases where the oxygen depletion method cannot be used to measure HRR.

(5) Comparisons between CUsmoke predictions and experimental data showed that CUsmoke is capable of predicting smoke movement in single and multi-compartment and multi-storey buildings with a corridor and stair shaft.In summary:

(a) CUsmoke provides good predictions of the upper layer temperature for non-flashover fires with steady HRR in a single compartment.

(b) CUsmoke overestimates the fire compartment upper layer temperatures and underestimates the lower layer temperature for post flashover-fires.

(c) The interface heights in the fire compartment predicted using CUsmoke compare well with the experimental interface heights estimated using the $\mathrm{N}$-percent method with $\mathrm{N}$ set to $60 \%$ (see Eqn $4-1$ ).

(d) CUsmoke underestimates the maximum heat release rate of the fire. This might be caused by the complex vent conditions of the test facility. For example, there was no 
vertical opening directly to the outside on the fire floor, and fresh air reached the fire compartment through the stair shaft and the vestibule on the fire floor.

(e) CUsmoke predictions of concentration of $\mathrm{O}_{2}$, and $\mathrm{CO}_{2}$ in the growth phase of fires compared well with the experimental measurements. The predictions of these after flashover are poor.

\subsection{Recommendations}

Following are some recommendations for future research work in this area.

(1) Conduct more experiments with steady, linear, and non-linear (for example, $t^{2}$ ) HRR, with more thermocouples and gas analyzers to obtain better data for model validation.

(2) Modify CUsmoke so that it can consider time dependent thermal properties of the building elements.

(3) Modify CUsmoke to simulate the flashover phenomenon and post-flashover condition.

(4) Use a CFD model to simulate the 10-storey tower tests to determine whether these models can be used for such buildings, and compare the results with those of CUsmoke.

(5) Perform a detailed sensitivity analysis of CUsmoke. 


\section{REFERENCES}

[1] Proulx, G., 1996. Critical Factors in High-Rise Evacuation. Fire prevention, $N^{0} 291$, pp.24-27.

[2] Hadjisophocleous, G.; Fu, Zh.; Lougheed, G. 2001. A computational and experimental study of smoke movement in a 10-storey building using a two-zone model. InterFlam 2001: 9th International Fire Science \& Engineering Conference; Edinburgh; Scotland; 17-19 2001. pp. 1047-1058.

[3] Yager, B., 1999, modified by Fu, Z., 2001. FIERAsmoke movement model technical report, National Research Council Canada.

[4] Janssens, M.L., 1991. Measuring rate of heat release by oxygen consumption. Fire Technology. Vol. 27, pp.234-249.

[5] ISO 8421-1:1987. Fire Protection Part 1: General terms and phenomena of fire, International Organization for Standardization, Geneva, Switzerland.

[6] BS4422: Part 1: 1987. Terms associated with fire, British Standard Institution, London, UK.

[7] NFPA 92B, 1991. Guide for smoke management systems in malls, atria and large areas, National Fire Protection, Quincy, Ma, USA.

[8] Klote, J. and Milke, J.; 1992. Design of smoke management systems, ASHRAE Publication 90022 ASHRAE, Atlanta, Georgia, USA.

[9] Hokugo, A.; Yung, D.T.; Hadjisophocleous, G.V. 1994. Experiments to validate the NRC smoke movement model for fire risk-cost assessment. Fourth International Symposium on Fire Safety Science (Ottawa, Ont., Canada, 7/13/94), pp. 805-816.

[10]Luo, M., and Beck, V., 1994. The fire environment in a multi-room buildingcomparison of predicted and experimental results, Fire Safety Journal, Vol. 23, Issue 4, pp. 413-438.

[11] Yamana, T. and Tanaka, T.; 1985. Smoke control in large scale spaces, Part 2: Smoke control experiments in a large scale space, Fire Science and Technology, 5(1): pp. 41-54.

[12] Chow, W.K., Yi, L., Shi, C.L., Li, Y.Z. and Huo, R.; 2005. Experimental studies on mechanical smoke exhaust system in an atrium, Journal of Fire Sciences. Vol. 23, pp. $429-444$.

[13]Lougheed, G. and Hadjisophocleous G.; 1997. Investigation of Atrium Smoke Exhaust Effectiveness, ASHRAE Annual Meeting, Boston. 
[14] Grant, G.B., Jagger, S.F. and Lea, C.J.; 1998. Fires in tunnels, Phil. Trans. R. Soc. Theme Issue on Fire Dynamics, 356(1748): pp. 2873-2906.

[15]Bechtel/parsons Brinckerhoff, November, 2005. Memorial tunnel fire ventilation test program, Comprehensive Test Report, Massachusetts Highway Department.

[16] Hu, L.H.; Huo, R.; Wang, H.B.; Li, Y.Z.; Yang, R.X., November, 2007. Experimental studies on fire-induced buoyant smoke temperature distribution along tunnel ceiling, Building and Environment. Vol: 42, Issue: 11, pp. 3905-3915.

[17] Marshall, N.R.; 1986. Air entrainment into smoke and hot gases in open shaft, Fire Safety Journal, Vol. 10, Issue 1: pp. 37-46.

[18] Mercier, G.P.; Jaluria, Y.; 1999. Fire-induced flow of smoke and hot gases in open vertical enclosures, Experimental Thermal and Fluid Science 19, pp.77-84.

[19] Cooper, L.Y., Harkleroad, M., Quintiere, J.G. \& Rinkinen, W.J., 1982. An experimental study of upper hot layer stratification in full-scale multi-room fire scenarios. ASME Journal of Heat Transfer, Volume: 104, pp. 741-749.

[20] CFAST- Consolidated model of fire growth and smoke transport (Version 6) user's guide, NIST Special Publication 1041.

[21]He, Y. and Beck, V., 1995. A computer model for smoke spread in multi-storey buildings. In proceedings of the Eighth International Symposium on Transport Phenomena in Combustion. Ed. S. H. Chan. Taylor and Francis, San Francisco, 17- 20 July 1995, pp. 713-723.

[22]Zhong, Maohua; Li, Peide; Liu, Tiemin; Wei, Xing; Liao, Guangxuan; 2005. Experimental study on fire smoke movement in a multi-floor and multi-room building. Science in China Ser. E Engineering \& Materials Science. Vol. 48. No. 3. pp. 292-304.

[23] Friedman, R.; 1992. An international survey of computer models for fire and smoke. Journal of Fire Protection Engineering. Vol. 4, No. 2, pp. 81-92.

[24] Olenick, S.M.; Carpenter, D.J.; 2003. An updated international survey of computer models for fire and smoke. Journal of Fire Protection Engineering. Vol. 13, No. 2 , pp. 87-110.

[25]Nakamura, K.; and Tanaka, T.; 1989. 'Predicting capability of a multiroom fire model'. Fire Safety Science -- Proceedings of the Second International Symposium, Hemisphere Publishing Corp., pp. 907-916

[26] Babrauskas, V.; 1979. COMPF2 - A program for calculating post-flashover fire temperatures final report. Tech note 991, National Bureau of Standards (USA). 
[27] Dietenberger, M. A.; 1991. Technical reference and user's guide for FAST/FFM Version 3. NIST-GCR-91-589. National Institute of Standards and Technology (USA).

[28] McGrattan, K. and Forney, G.; 2006. Fire dynamics simulator (version 4) user's guide. NIST special publication 1019. National Institute of Standards and Technology (USA).

[29] Walton, G. N. and Stuard Dols, W; 2005. CONTAM 2.4 User guide and program documentation. NISTIR 7251. National Institute of Standards and Technology (USA).

[30]Remesh, K. and Tan, K.H.; 2007. Performance comparison of zone models with compartment fire tests. Journal of Fire Sciences, Vol. 25, pp. 321-353.

[31]Dembsey, N.A., Pagni, P.J. \& Williamson, R.B., 1995. Compartment fire experiments: comparison with models. Fire Safety Journal, Volume: 25, Issue: 3, pp. 187-227.

[32] Franssen, J.M., 2000. The design fire tool OZone V2.0-theoretical description and validation on experimental fire tests, Civil and Structural Engineering Department, University of Liege, Belgium.

[33] Matsuyama, K.; Wakamatsu,T. and Harada, K., Systematic experiments of room and corridor smoke filling for ise in calibration of zone and CFD fire models. Editor: Bryner, S. L., Fifteenth Meeting of the UJNR Panel on Fire Research and Safety March 1-7, 2000 (Vol. 2). NISTIR 6588, 2000 National Institute of Standards and Technology (USA).

[34] Fu, Z. and Hadjisophocleous, G.; 2000. Two-zone fire growth and smoke movement model for multi-compartment buildings. Fire Safety Journal, Volume: 34, Issue: 3, pp. 257-285.

[35] Mitler, H. E. and Rockett, J. A.; 1987. Users' guide to FIRST, a comprehensive single-room fire model. NBSIR 87-3595, NBS, Gaithersburg, MD.

[36] Achakji, G.Y. and Tamura, G. T.; 1988. Pressure drop characteristics of typical stairshaft in high-rise buildings. ASHRAE Transactions, Vol. 94, Part 1, pp. 1223-1237.

[37] McCaffrey, B.J., 1983. Momentum implications for buoyant diffusion flames. Combustion and Flame. Vol. 52, pp. 149-167.

[38] Heskestad, G., 1995. SFPE Handbook of Fire Protection Engineering, Quincy, Mass.: National Fire Protection Association. 
[39] Lougheed, G. D.; Hadjisophocleous, G. V.; and Cao, S., 1999. Numerical study of the effectiveness of atrium smoke exhaust system. ASHRAE Transactions, Vol. 105, Part 1, pp. 699-715.

[40] Lougheed, G. D.; Hadjisophocleous, G. V.; McCartney, C., and Taber, B.C., 1999. Large-scale physical model studies for an atrium smoke exhaust system. ASHRAE Transactions, Vol. 105, Part 1, pp. 676-698.

[41] Hadjisophocleous, G. and McCartney, C. J. 2005. Guidelines for the use of CFD simulations for fire and smoke modelling. ASHRAE Symposium paper 2005 summer ASHRAE meeting, Denver.

[42] Hadjisophocleous, G.V. and Zhou, J., 2008. Evaluation of Atrium Smoke Exhaust Make-up Air Velocity, ASHRAE Transactions, Volume 114, Part 1.

[43] Walton, W. D. and Thomas, P.H., Third version, 2002. Estimating temperatures in compartment fires. Chapter 6, Section Three. The SFPE Handbook of Fire Protection Engineering, Quincy, MA: National Fire protection Association, pp. 3-171.

[44]Chow, W. K., 1998. Predictability of flashover by zone models. Journal of Fire Sciences. Vol. 16, pp. 335-350.

[45] Thomas, P. H., 1981. Testing products and materials for their contribution to flashover in rooms. Fire and Materials. Vol. 5, Issue 3, pp. 103-111.

[46] Barnett, C. R. 1984. Pilot fire load survey carried out for the New Zealand Fire Protection Association, MacDonald Barnett Partners, Auckland.

[47] Thornton, W. 1917. The relation of oxygen to the heat of combustion of organic compounds. Philosophical Magazine and J. of Science.

[48] Huggett, C.; 1980. Estimation of rate of heat release by means of oxygen consumption. Fire and Materials. Vol. 4, Issue: 2, pp. 61-65.

[49] Parker, W., 1977. An investigation of the fire environment in the ASTM E-84 tunnel test. NBS Technical Note 945, National Bureau of Standards, Gaithersburg, MD, USA.

[50] Quintiere, J. G. and McCaffrey; B. J., 1980. The burning of wood and plastic cribs in an enclosure. Vol. 1. Nat. Bur. Stand. (U.S.), NBSIR 80-2054.

[51] Sensenig, D. L., 1978. New concept for determining rate of heat release by oxygen consumption. Presented at the Fall Technical Meeting, Easten Section of the Combustion Institute, Miani Beach, Florida, USA.

[52] Bwalya, A., Lougheed, G., Su, J., Taker, B., Benichou, N., Kashef, A., 2007. Development of a fuel package for use in the performance of houses project. NRC-45582. NRC, Canada. 
[53]Babrauskas, V., 1983. Upholstered furniture heat release rates: measurements, and estimation. Journal of Fire Sciences, Vol. 1: pp. 9-32.

[54]Parker, W. J., 1982. Calculations of the heat release rate by oxygen consumption for various applications. NBSIR 81-2427. Nat. Bur. Stand. USA.

[55]Chow, W. K., 2002. Assessment on the heat release rate of furniture foam arrangement by a cone calorimeter. Journal of Fire Sciences. Vol. 20, pp. 319-328.

[56] Mowrer, F. W. and Williamson, R. B., 1990. Methods to characterize heat release rate data. Fire safety Journal. Volume: 16, Issue: 5, pp. 367-387.

[57]Zalok, E., 2006. Design fire for commercial premises. $\mathrm{PhD}$ dissertation, Department of Civil and Environmental Engineering, Carleton University, Ottawa.

[58] Tewarson, A., 2002. Generation of heat and chemical compounds in fires. Chapter 4, Section 3, the SFPE Handbook of Fire Protection Engineering, $3^{\text {rd }}$ ED. Quincy, MA: National Fire protection Association.

Additional readings

Chow, W. K. and Yin, R.; 2006. Smoke movement in a compartmental fire. Journal of Fire Sciences. Vol. 24: pp. 445-463.

Hadjisophocleous, G., Fu, Z., Fu, S. and Dutcher, C.; 2007. Prediction of fire growth for compartments of office buildings as part of a fire risk/cost assessment model. Journal of Fire Protection Engineering. Vol. 17, No. 3, pp. 185-209.

Klote, J. H. and Nelson, H. E., 1997. Smoke movement in buildings. Fire Protection Handbook, $18^{\text {th }}$ Edition, NFPA FPH 1897. Section 7, chapter 6. National Fire Protection Association.

Quintiere, J. G., 1989. Fundamentals of enclosure fire "zone" models. Journal of Fire Protection Engineering. Vol. 1, No. 3, pp. 99-119.

Tamura, G.T., and McGuire, J.H., Originally published January, 1971. Smoke movement in high-rise buildings. CBD-133. Canadian Building Digest. 


\section{Appendix A: Calculation method of conductivity and specific heat for ceramic fiber}

The specific heat for refractory ceramic fiber is a function of temperature and governed by the following equation:

Specific heat $=0.1963+0.000043864 \mathrm{~T}\left(\mathrm{BTU} / \mathrm{LB} /{ }^{\circ} \mathrm{F}\right)$

where $\mathrm{T}$ is Temperature $\left({ }^{\mathrm{o}} \mathrm{F}\right)$

Conductivity at a specific temperature

$k=A+B T+C T^{2}$

where $\mathrm{T}$ is Temperature $\left({ }^{\mathrm{O}} \mathrm{F}\right)$ and $\mathrm{k}$ is conductivity (Btu in $/ \mathrm{hr} \mathrm{ft}^{2} \mathrm{~F}$ )

For product 'Durablanket S, 8 pcf '(used in lining the test facility of this study)

$A=0.361178571429$

$B=-0.000068107143$

$C=0.000000684821$ 


\section{Appendix B: Input and output files of CUsmoke (two-compartment single-storey example)}

1. Input file:

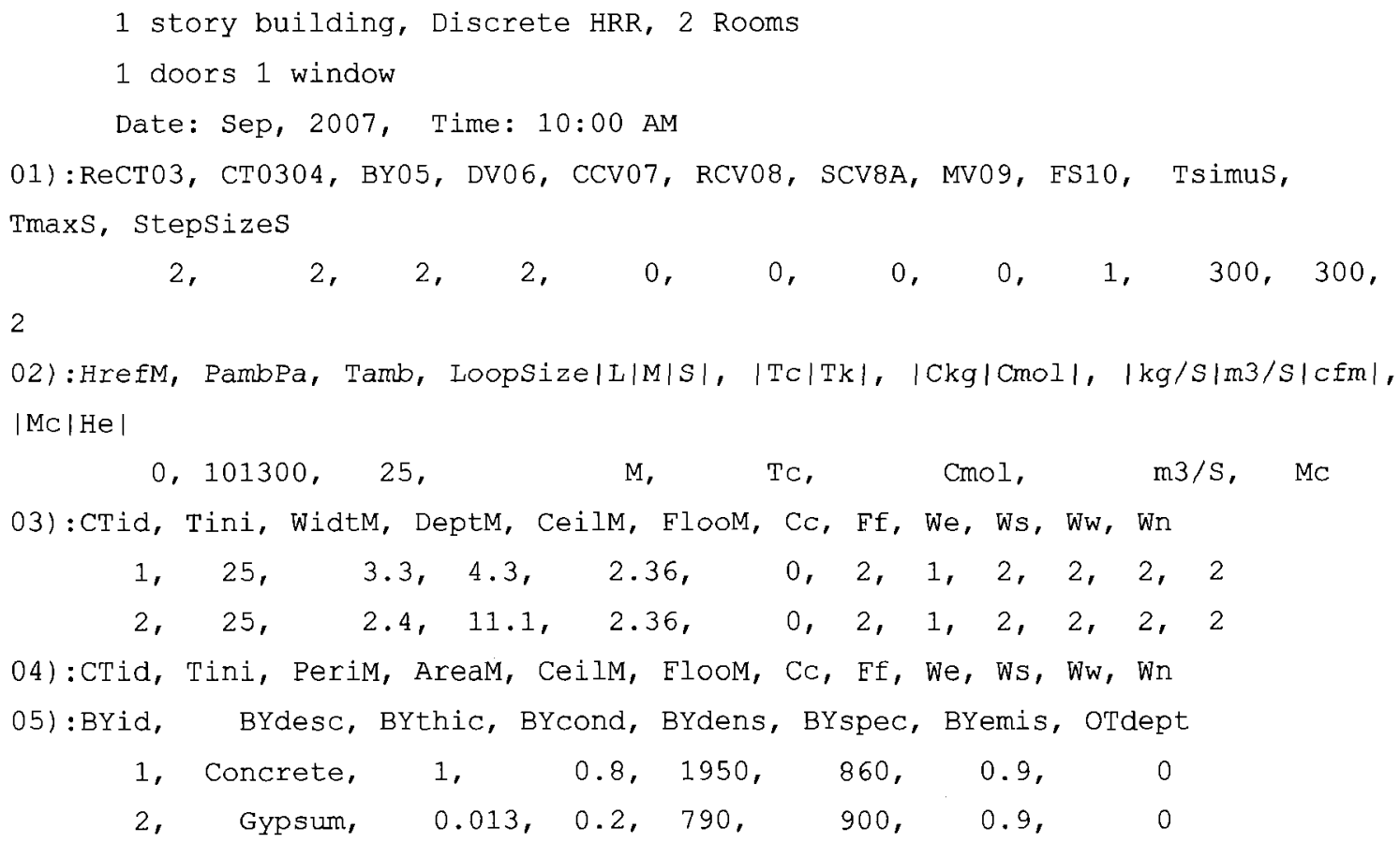
1, 1,
$2,2.0$,
$0.0, \quad 1.07$,
0 ,
10000
2

06B) : DVtime (S)

$0, \quad 250$

06C) : OpeningFactor

1 , 1

06A) : DVid, DVno1, DVno2, DVsoff, DVsill, DVwidt, DVwindV, DVbreakTempC, DVtimePointNo
$2, \quad 2$,
3, 0.94 ,
0.0 ,
0.15 ,
0 ,
10000,
2

06B) : DVtime(S)

$0, \quad 300$

06C) : OpeningFactor

1,1

07):CCVid, Cnotop, CnoBot, Cthic, Cdiam

08): RCVid, RnoTop, RnoBot, Rthic, Rwidt, Rdept 


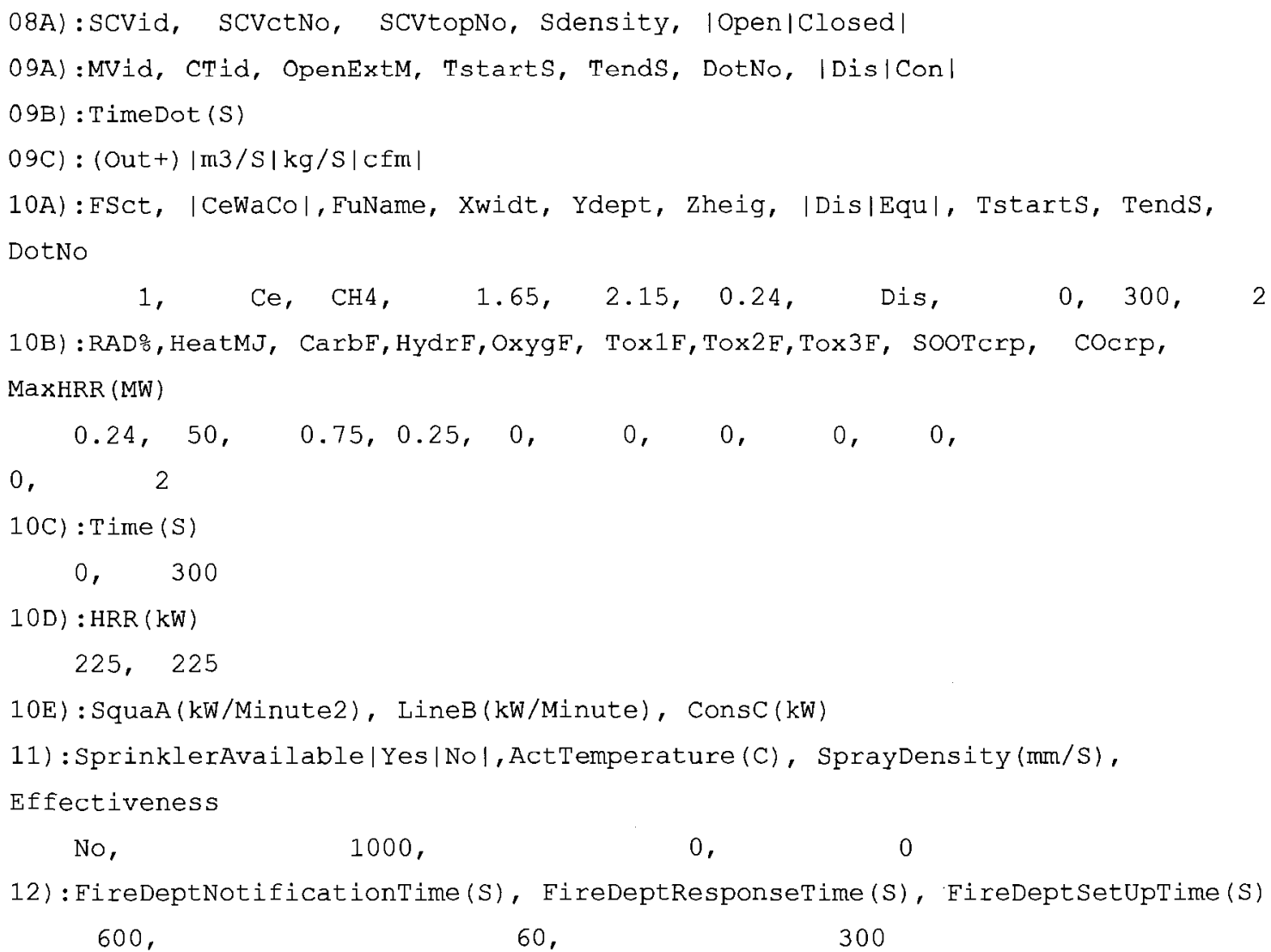

\section{Output file:}

Compartment ID Number

1

Time UppT LowerT UppO2 LowO2 UppCO2 LowCO2 SmokeCO LowerCO SmokeSoot SmokeOD InterH Radiate HRR

(s) $\quad(\mathrm{C}) \quad(\mathrm{C}) \quad(\mathrm{m} 3 \%)(\mathrm{m} 3 \%)(\mathrm{m} 3 \%) \quad(\mathrm{m} 3 \%) \quad(\mathrm{ppm} \mathrm{m} 3)(\mathrm{ppm} \mathrm{m} 3)(\mathrm{ppm} 3) \quad(1 / \mathrm{m}) \quad(\mathrm{m}) \quad(\mathrm{kW} / \mathrm{m} 2)(\mathrm{KW})$ $00000,0025.0,0025.0,20.72,20.72,00.000,00.000,0.00 \mathrm{E}+00,0.00 \mathrm{E}+00,0.00 \mathrm{E}+00,0.00 \mathrm{E}+00,002.31,000.00,2.00 \mathrm{E}+00$ $00002,0097.3,0025.0,19.78,20.68,00.427,00.000,0.00 \mathrm{E}+00,0.00 \mathrm{E}+00,0.00 \mathrm{E}+00,8.75 \mathrm{E}-02,002.07,001.42,2.25 \mathrm{E}+02$ $00004,0111.6,0025.0,19.56,20.67,00.526,00.000,0.00 \mathrm{E}+00,0.00 \mathrm{E}+00,0.00 \mathrm{E}+00,7.51 \mathrm{E}-02,001.87,001.47,2.25 \mathrm{E}+02$ $00006,0121.0,0025.0,19.41,20.67,00.595,00.000,0.00 \mathrm{E}+00,0.00 \mathrm{E}+00,0.00 \mathrm{E}+00,7.00 \mathrm{E}-02,001.72,001.50,2.25 \mathrm{E}+02$ $00008,0127.7,0025.1,19.29,20.66,00.648,00.000,0.00 \mathrm{E}+00,0.00 \mathrm{E}+00,0.00 \mathrm{E}+00,6.77 \mathrm{E}-02,001.61,001.53,2.25 \mathrm{E}+02$ $00010,0133.1,0025.1,19.19,20.66,00.694,00.000,0.00 \mathrm{E}+00,0.00 \mathrm{E}+00,0.00 \mathrm{E}+00,6.67 \mathrm{E}-02,001.52,001.55,2.25 \mathrm{E}+02$ $00012,0137.7,0025.2,19.10,20.65,00.735,00.000,0.00 \mathrm{E}+00,0.00 \mathrm{E}+00,0.00 \mathrm{E}+00,6.63 \mathrm{E}-02,001.46,001.57,2.25 \mathrm{E}+02$ $00014,0141.8,0025.2,19.02,20.65,00.772,00.000,0.00 \mathrm{E}+00,0.00 \mathrm{E}+00,0.00 \mathrm{E}+00,6.61 \mathrm{E}-02,001.42,001.59,2.25 \mathrm{E}+02$ $00016,0145.4,0025.3,18.94,20.65,00.806,00.000,0.00 \mathrm{E}+00,0.00 \mathrm{E}+00,0.00 \mathrm{E}+00,6.66 \mathrm{E}-02,001.39,001.61,2.25 \mathrm{E}+02$ $00018,0148.6,0025.3,18.87,20.64,00.838,00.000,0.00 \mathrm{E}+00,0.00 \mathrm{E}+00,0.00 \mathrm{E}+00,6.66 \mathrm{E}-02,001.36,001.62,2.25 \mathrm{E}+02$ $00020,0151.5,0025.4,18.81,20.64,00.867,00.000,0.00 \mathrm{E}+00,0.00 \mathrm{E}+00,0.00 \mathrm{E}+00,6.70 \mathrm{E}-02,001.34,001.64,2.25 \mathrm{E}+02$ $00022,0154.1,0025.5,18.75,20.64,00.893,00.000,0.00 \mathrm{E}+00,0.00 \mathrm{E}+00,0.00 \mathrm{E}+00,6.74 \mathrm{E}-02,001.33,001.65,2.25 \mathrm{E}+02$ $00024,0156.5,0025.6,18.70,20.63,00.917,00.001,0.00 \mathrm{E}+00,0.00 \mathrm{E}+00,0.00 \mathrm{E}+00,6.77 \mathrm{E}-02,001.32,001.67,2.25 \mathrm{E}+02$ 
$00026,0158.7,0025.7,18.65,20.63,00.939,00.001,0.00 \mathrm{E}+00,0.00 \mathrm{E}+00,0.00 \mathrm{E}+00,6.81 \mathrm{E}-02,001.30,001.68,2.25 \mathrm{E}+02$ $00028,0160.7,0025.7,18.60,20.63,00.960,00.001,0.00 \mathrm{E}+00,0.00 \mathrm{E}+00,0.00 \mathrm{E}+00,6.84 \mathrm{E}-02,001.29,001.69,2.25 \mathrm{E}+02$ $00030,0162.5,0025.8,18.56,20.63,00.978,00.001,0.00 \mathrm{E}+00,0.00 \mathrm{E}+00,0.00 \mathrm{E}+00,6.87 \mathrm{E}-02,001.28,001.71,2.25 \mathrm{E}+02$

\section{Compartment ID Number}

2

Time UppT LowerT UppO2 LowO2 UppCO2 LowCO2 SmokeCO LowerCO SmokeSoot SmokeOD InterH Radiate HRR

(s) (C) (C) $(\mathrm{m} 3 \%)(\mathrm{m} 3 \%)(\mathrm{m} 3 \%)(\mathrm{m} 3 \%) \quad(\mathrm{ppm} \mathrm{m} 3)(\mathrm{ppm} \mathrm{m} 3)(\mathrm{ppm} \mathrm{m} 3)(1 / \mathrm{m}) \quad(\mathrm{m}) \quad(\mathrm{kW} / \mathrm{m} 2)(\mathrm{KW})$ $00000,0025.0,0025.0,20.72,20.72,00.000,00.000,0.00 \mathrm{E}+00,0.00 \mathrm{E}+00,0.00 \mathrm{E}+00,0.00 \mathrm{E}+00,002.31,000.00,0.00 \mathrm{E}+00$ $00002,0025.0,0025.0,20.72,20.72,00.000,00.000,0.00 \mathrm{E}+00,0.00 \mathrm{E}+00,0.00 \mathrm{E}+00,0.00 \mathrm{E}+00,002.26,000.00,0.00 \mathrm{E}+00$ $00004,0032.9,0025.0,20.61,20.72,00.049,00.000,0.00 \mathrm{E}+00,0.00 \mathrm{E}+00,0.00 \mathrm{E}+00,5.13 \mathrm{E}-02,002.26,000.45,0.00 \mathrm{E}+00$ $00006,0045.5,0025.0,20.41,20.71,00.140,00.000,0.00 \mathrm{E}+00,0.00 \mathrm{E}+00,0.00 \mathrm{E}+00,9.62 \mathrm{E}-02,002.26,000.45,0.00 \mathrm{E}+00$ $00008,0056.0,0025.0,20.23,20.70,00.223,00.000,0.00 \mathrm{E}+00,0.00 \mathrm{E}+00,0.00 \mathrm{E}+00,1.05 \mathrm{E}-01,002.23,000.45,0.00 \mathrm{E}+00$ $00010,0063.8,0025.0,20.08,20.69,00.288,00.000,0.00 \mathrm{E}+00,0.00 \mathrm{E}+00,0.00 \mathrm{E}+00,9.55 \mathrm{E}-02,002.17,000.46,0.00 \mathrm{E}+00$ $00012,0069.7,0025.0,19.97,20.69,00.341,00.000,0.00 \mathrm{E}+00,0.00 \mathrm{E}+00,0.00 \mathrm{E}+00,9.00 \mathrm{E}-02,002.11,000.46,0.00 \mathrm{E}+00$ $00014,0074.4,0025.0,19.87,20.69,00.384,00.000,0.00 \mathrm{E}+00,0.00 \mathrm{E}+00,0.00 \mathrm{E}+00,8.45 \mathrm{E}-02,002.05,000.47,0.00 \mathrm{E}+00$ $00016,0078.3,0025.0,19.79,20.68,00.422,00.000,0.00 \mathrm{E}+00,0.00 \mathrm{E}+00,0.00 \mathrm{E}+00,7.91 \mathrm{E}-02,001.98,000.47,0.00 \mathrm{E}+00$ $00018,0081.6,0025.0,19.71,20.68,00.456,00.000,0.00 \mathrm{E}+00,0.00 \mathrm{E}+00,0.00 \mathrm{E}+00,7.64 \mathrm{E}-02,001.91,000.47,0.00 \mathrm{E}+00$ $00020,0084.5,0025.0,19.64,20.68,00.487,00.000,0.00 \mathrm{E}+00,0.00 \mathrm{E}+00,0.00 \mathrm{E}+00,7.36 \mathrm{E}-02,001.85,000.48,0.00 \mathrm{E}+00$ $00022,0087.0,0025.0,19.58,20.67,00.517,00.000,0.00 \mathrm{E}+00,0.00 \mathrm{E}+00,0.00 \mathrm{E}+00,7.15 \mathrm{E}-02,001.78,000.48,0.00 \mathrm{E}+00$ $00024,0089.2,0025.0,19.52,20.67,00.544,00.000,0.00 \mathrm{E}+00,0.00 \mathrm{E}+00,0.00 \mathrm{E}+00,6.98 \mathrm{E}-02,001.72,000.49,0.00 \mathrm{E}+00$ $00026,0091.2,0025.0,19.46,20.67,00.570,00.000,0.00 \mathrm{E}+00,0.00 \mathrm{E}+00,0.00 \mathrm{E}+00,6.81 \mathrm{E}-02,001.65,000.49,0.00 \mathrm{E}+00$ $00028,0093.0,0025.0,19.41,20.67,00.594,00.000,0.00 \mathrm{E}+00,0.00 \mathrm{E}+00,0.00 \mathrm{E}+00,6.73 \mathrm{E}-02,001.59,000.50,0.00 \mathrm{E}+00$ $00030,0094.5,0025.0,19.36,20.66,00.617,00.000,0.00 \mathrm{E}+00,0.00 \mathrm{E}+00,0.00 \mathrm{E}+00,6.61 \mathrm{E}-02,001.53,000.50,0.00 \mathrm{E}+00$ 